Marcel Schmidt

\title{
Eine theoretische Orientierung \\ für die Soziale Arbeit in Zeiten des Klimawandels
} \author{
Von der ökosozialen zur
sozial-ökologischen Transformation \\ Von der ökosozialen zur
sozial-ökologischen Transformation
}

Band 9

Band 9 
Marcel Schmidt

Eine theoretische Orientierung für die Soziale Arbeit in Zeiten des Klimawandels 
Buchreihe

Gesellschaft und Nachhaltigkeit

herausgegeben von

Prof. Dr. Monika Alisch

Prof. Dr. Stefanie Deinert

Dr. Sylvia Pannowitsch

Prof. Dr. Martina Ritter

Prof. Dr. Bettina Stoll

Band 9 
Marcel Schmidt

\section{Eine theoretische Orientierung}

für die Soziale Arbeit in

Zeiten des Klimawandels

Von der ökosozialen zur

sozial-ökologischen Transformation

Verlag Barbara Budrich

Opladen • Berlin • Toronto 2021 
Bibliografische Information der Deutschen Nationalbibliothek

Die Deutsche Nationalbibliothek verzeichnet diese Publikation in der Deutschen Nationalbibliografie; detaillierte bibliografische Daten sind im Internet über http://dnb.d-nb.de abrufbar.

(C) 2021 Dieses Werk ist bei der Verlag Barbara Budrich GmbH erschienen und steht unter der Creative Commons Lizenz Attribution 4.0 International

(CC BY 4.0): https://creativecommons.org/licenses/by/4.0/

Diese Lizenz erlaubt die Verbreitung, Speicherung, Vervielfältigung und Bearbeitung unter Angabe der UrheberInnen, Rechte, Änderungen und verwendeten Lizenz. www.budrich.de

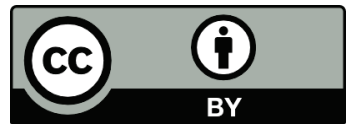

Dieses Buch steht im Open-Access-Bereich der Verlagsseite zum kostenlosen Download bereit (https://doi.org/10.3224/84742504).

Eine kostenpflichtige Druckversion kann über den Verlag bezogen werden. Die Seitenzahlen in der Druck- und Onlineversion sind identisch.

$$
\begin{array}{ll}
\text { ISBN } & 978-3-8474-2504-5 \text { (Paperback) } \\
\text { eISBN } & 978-3-8474-1647-0 \text { (PDF) } \\
\text { DOI } & 10.3224 / 84742504
\end{array}
$$

Umschlaggestaltung: Bettina Lehfeldt, Kleinmachnow - www.lehfeldtgraphic.de Titelbildnachweis: Foto: Bettina Lehfeldt Typografisches Lektorat: Angelika Schulz, Zülpich Druck: docupoint GmbH, Barleben Printed in Europe 


\title{
Soziale Arbeit und die Entfremdung von der Natur: Ein Vorwort
}

\author{
Michael May
}

Am 24.4.2021 wurde im Rahmen der ersten Trinationalen Tagung der Deutschen, Österreichischen und Schweizerischen Gesellschaft für Soziale Arbeit eine Fachgruppe „Sozialökologische Transformation und Klimagerechtigkeit" der Deutschen Gesellschaft (DGSA) gegründet. Marcel Schmidt gehörte zu den Gründungsmitgliedern. 2019 bilanzierte Ulrich Bartosch in seinem Beitrag „Entdecke die Weltrettung als sozialpädagogisches Projekt!“ den Stand des Diskurses in der Sozialen Arbeit noch dahingehend, dass in diesem sozialökologische Ansätze ,insgesamt eher Modelle und Methoden der Ökologie auf soziale Sachverhalte übertragen, als [...] das Verhältnis von Mensch und Mitwelt in den Mittelpunkt des wissenschaftlichen Interesses“" (2019: 21) zu stellen.

Wohl als einer der ersten im deutschen Sprachraum hat Wolf Rainer Wendt im Kontext Sozialer Arbeit auch den Stoffwechsel mit der Natur etwas mehr in den Blick gerückt. So sieht er die von Subjekten zu bewältigenden „Lebensaufgaben und Umweltanforderungen [...] dem Ökosystem einer sich im Raum ihrer Tätigkeit entfaltenden menschlichen (gesellschaftlichen) Natur" (1982: 224) entstammen. Der Sozialen Arbeit käme in diesem Zusammenhang die Aufgabe einer Abstimmung von sich gegenüberstehenden biosozialen Erfordernissen (ebd.: 186) und biosozialen Grundbedürfnissen (ebd.: 187) zu. Von besonderer Bedeutung ist für ihn dabei das Konzept der Nische als ,Summe der die Existenz eines Organismus ermöglichenden Faktoren“ (ebd.: 80). Allerdings akzentuiert er dieses in seiner Anwendung ,im sozialen System menschlichen Lebens" (ebd.: 80) angesichts herrschaftlicher Mechanismen Sozialer Ausschließung (vgl. Anhorn/Stehr 2020) dann doch in beinahe schon zynischer Art klassisch sozialökologisch. Denn er postuliert, dass ein Individuum in seinem ,natürliche[n] Bestreben [...], sich seine besonderen Beziehungen und darin die individuelle Eigenart zu erhalten, $[\ldots]$ je nach kreativer Lebendigkeit (Kompetenz)“ (1982: 80.) solche Nischen „reich oder arm“ (ebd.) einrichte, sowie ,eng oder weit in Konkurrenz zu den anderen, die sie berühren“" (ebd.).

Die ,alte Ökonomik als ein Muster geschlossener lebenspraktischer Orientierungen in ländlichen Verhältnissen" (ebd.: 16) vor Augen, dient Wendt der Begriff oikos (1990: 16ff.), der die Bewältigung des Alltags an die Ver- 
antwortung für die Natur im Haushalt der Schöpfung bindet, zur Begründung einer Fürsorgewissenschaft als Haushaltswissenschaft. Diese verbindet die zur angesprochenen Abstimmung biosozialer Erfordernisse und Grundbedürfnisse erforderlichen Schritte der Planung, Entscheidungsfindung, Organisation, Koordination, Ausführung und Kontrolle in einer Führungslehre und Führungspraxis, die Wendt - abgeleitet vom französischen ménager $=$ haushalten - Management nennt (1986: 70).

Zwar konstatiert auch Oskar Negt, dass „Haus und Haushalt $[\ldots]$ in der Geschichte des europäischen Denkens Bilder, ja Urbilder nicht nur privater Wohlfahrt im Generationenverhältnis“ (2002: 314), sondern auch eines „keineswegs auf wirtschaftliche Fakten reduzierten Wohlstandes des Gemeinwesens" (ebd.) darstellten. Er legt jedoch dar, wie schon im antiken Griechenland Xenophon mit seiner kleinen Schrift Oikonomikos (Der Hausvorsteher), in der er den „Zusammenhang von Haushaltsgegenständen, Arbeitsverrichtungen und Befehls- und Gehorsamsverhältnissen" (ebd.: 310) systematisch entfaltete, darauf reagierte, dass sich im Zuge des Peloponnesischen Krieges „die auf den bäuerlichen Oikos und auf weitgehende Autarkie abgestimmte Haushaltung“ (ebd.) zu einer am expandierenden Markt orientierten Ökonomie weiterentwickelte, in der ,neue und rationellere Formen des Haushaltens erforderlich waren" (ebd.).

Der damit in Gang gesetzte Warentausch hat aber, wie Alfred SohnRethel im Anschluss an Marx zeigt, „die Formen, die er dem reflektierenden Bewußtsein vermittelt“ (2018a: 162), bereits ,,von der der Gesellschaft zugrundeliegenden Naturbasis abstrahiert" (ebd.), indem über die Tauschrationalität, ,als Ergebnis blinder, objektiver Vermittlungen, die abstrakte Natur zur Anwendung auf die konkrete“ (ebd.) gelangte. Deshalb sind dann auch die Begriffe von Wendts Fürsorgewissenschaft als oikos-bezogener Haushaltswissenschaft nicht nur ,ein Vermögen aus Quellen der zweiten Natur, [...] von unserem primären Naturverhältnis geschieden und entfremdet" (Sohn-Rethel 2018b: 810). Als „Reflektionen entsprechender Elemente der Realabstraktion des Austauschs, also der Wechselbeziehung bloßer Aneignung der Arbeitsprodukte" (ebd.), vermögen sie in ihrer gleichermaßen instrumentellen wie paternalistischen Ausrichtung auch nichts zu einer , bewußte[n] gesellschaftliche[n] Bewältigung des primären, eigentlichen Naturverhältnisses " (ebd.) beizutragen. Und erst Recht nicht eröffnen sich dadurch Möglichkeiten zu einer mittlerweils für die Welt überlebensnotwendigen Kompensation jenes ,unheilbaren Riß [...] in dem Zusammenhang des gesellschaftlichen und durch die Naturgesetze des Lebens vorgeschriebnen Stoffwechsels“ (Marx 1978a: 821), auf den schon Marx in seinem Kapital hingewiesen hat und auf den Marcel Schmidt in seiner Arbeit auf der Ebene sowohl theoretischer wie praktischer Dialektik Sozialer Arbeit (vgl. May 2021: 176ff.) eine Antwort sucht. 
Für Marx ist „die entfremdete Arbeit“ (1990: 516) der eigentliche Grund, welcher nicht nur „dem Menschen 1. die Natur entfremdet“ (ebd.), sondern durch die er sich 2. auch von sich selbst entfremdet, weil ihm ,die Arbeit, die Lebenstätigkeit, das produktive Leben selbst nur als ein Mittel zur Befriedigung [...] des Bedürfnisses der Erhaltung der physischen Existenz" (ebd.) erscheint. Damit aber entfremdet sie ihm 3. „seinen eignen Leib, wie die Natur außer ihm, wie sein geistiges Wesen, sein menschliches Wesen" (ebd.: 517) als „das wahre Gemeinwesen der Menschen“ (Marx 1978b: 408). Denn indem ,die entfremdete Arbeit dem Menschen den Gegenstand seiner Produktion entreißt, entreißt sie ihm sein Gattungsleben, seine wirkliche Gattungsgegenständlichkeit und verwandelt seinen Vorzug vor dem Tier in den Nachteil, daß sein unorganischer Leib, die Natur, ihm entzogen wird" (Marx 1990: 517). Als ,unmittelbare Konsequenz davon, daß der Mensch dem Produkt seiner Arbeit, seiner Lebenstätigkeit, seinem Gattungswesen entfremdet ist“ (ebd.: 518) geht dann auch 4. eine „Entfremdung des Menschen von dem Menschen“ (ebd.) einher, wie überhaupt für Marx ,der Satz, daß der Mensch seinem Gattungswesen entfremdet ist, heißt, daß ein Mensch dem andern, wie jeder von ihnen dem menschlichen Wesen entfremdet ist" (ebd.).

Marx' Entfremdungstheorie stellt zugleich auch ein Musterbeispiel seiner Dialektik dar. So hat er zwar ,den Begriff der entäußerten Arbeit (des entäuBerten Lebens) aus der Nationalökonomie als Resultat aus der Bewegung des Privateigentums gewonnen“ (ebd.: 520). In seiner Analyse dieses Begriffs zeigt er jedoch, dass „,wenn das Privateigentum als Grund, als Ursache der entäußerten Arbeit erscheint, es vielmehr eine Konsequenz derselben“" (ebd.) ist: „das Produkt, das Resultat [...] der entäußerten Arbeit, des äußerlichen Verhältnisses des Arbeiters zu der Natur und zu sich selbst" (ebd.).

In jüngster Zeit haben Andreas Schaarschuch und Holger Ziegler vorgeschlagen, das Bezugsproblem bzw. den Gegenstand Sozialer Arbeit als Bearbeitung von Entfremdung zu bestimmen, wobei sie auch an Marx anschließen. Allerdings konzentriert sich Schaarschuch dabei allein auf den Aspekt der „Entfremdung vom Sozialen“ (2019: 256), um in seiner systematischen Begründung dieser Gegenstandsbestimmung ihm ,den Begriff der Vergesellschaftung zur Seite zu stellen und beide aufeinander zu beziehen (ebd.). Vor diesem Hintergrund konstatiert er dann eine gleich ,doppelte[.] Entfremdung vom Sozialen auf Seiten derer [...], die ihre Arbeitskraft zu einer verkäuflichen Ware machen müssen: auf der Seite der gesellschaftlichen Produktion auf Basis des Kapitalverhältnisses und auf der Ebene der privatkapitalistischen Konstitution des Modus bürgerlichen Vergesellschaftung“ (ebd.: 262).

Auch für Ziegler ,besteht die Pointe von Entfremdung darin, dass es um ein radikal soziales (und historisch prozessuales) Phänomen geht, welches zum einen die Nicht-Verfügbarkeit von Autonomie und Kontrolle über die eigene Lebensführung, vor allem aber einen Zustand des Abgeschnitten-Seins "from what is constitutive of, or essential to, one's nature, causal powers or 
wellbeing (Bhaskar, 2008, S. 394) beschreibt" (Ziegler 2021: 105). Dabei bezieht er sich in dieser Weise einerseits auf eine ,an Marx' Arbeiten anschließenden kritisch-realistischen Perspektive“ (ebd.). Vor allem aber stellt für ihn Martha Nussbaums Variante des Capability Approach „ein geeignetes Arsenal bereit[], um das Problem der Entfremdung zu präzisieren und bearbeitbar zu machen" (Ziegler 2021: 100). Zwar beinhaltet deren Zehnerliste auch die ,Fähigkeit, in Verbundenheit mit Tieren, Pflanzen und der ganzen Natur zu leben und pfleglich mit ihnen umzugehen" (Nussbaum 1999: 57f.). Marx Analyse jenes ,unheilbaren Riß [...] in dem Zusammenhang des gesellschaftlichen und durch die Naturgesetze des Lebens vorgeschriebnen Stoffwechsels" (1978a: 821), wird jedoch auch von Ziegler nicht aufgegriffen.

Nun ergänzt dieser ja Nussbaums Liste um die beiden von Elisabeth Anderson (vgl. 1999) vorgeschlagenen Capabilities einer gleichberechtigten Teilnahme sowohl an einem System kooperativer Produktion wie auch an kollektiven Entscheidungen des ,demokratischen Staates [...], die sie selbst betreffen und den Rahmen ihrer Selbstbestimmung mit definieren" (Ziegler 2021: 110). Damit wären zwar Bedingungen der Möglichkeit geschaffen, die von Schaarschuch herausgearbeitete gleich doppelte Entfremdung vom Sozialen aufzuheben. Der von Marx in seiner Entfremdungstheorie dargelegte dialektische Zusammenhang mit der Entfremdung von der Natur und damit auch von sich selbst und vom menschlichen Gemeinwesen bleibt aber bei Schaarschuch wie bei Zieglers Neubestimmungen des Gegenstandes Sozialer Arbeit ausgeblendet.

Es ist der Verdienst von Marcel Schmidt, diesen in seiner Arbeit in den Blick zu rücken, indem er direkt an Marx Begriff eines Stoffwechsels mit der Natur anknüpft und im Anschluss an Lefebvres Begriff von habiter (2016: 46) und seine sich von den klassischen Ansätzen in-, de-, und abduktiven Schließens deutlich abhebende Methodologie der Transduktion (ebd.: 154f.) über diesen hinausgeht in Richtung einer Politisierung der Urbanisierung erdökologischer Zusammenhänge im Rahmen demokratischer Regulierungen gesellschaftlicher Naturverhältnisse durch kollaborative Bildung und Verwaltung nachhaltiger urban und global Commons.

In jüngster Zeit hat Eric Mührel im Hinblick auf eine nachhaltige sozialökologische Transformation mit seiner „Theorie der Willenserziehung auf der Grundlage einer kommenden Weltgemeinschaft" (2019: 171) Natorps am Ende des zweiten Teils seiner ,Sozialpädagogik - Eine Theorie der Willensbildung auf Grundlage der Gemeinschaft" entworfene Vision eines genossenschaftlichen „Aufbau[s] der Menschengemeinschaft in Wirtschaft, Staat und Erziehung“ (Natorp 1974: 145) ,auf dem Grund freier Selbstregulierung, also von unten nach oben“ (ebd.: 146), als „Genossenschaft von Genossenschaften und sofort, bis zum umfassenden Ganzen, dem Sozialstaat" (ebd.: 149), aufgegriffen. In dieser Weise trachtet er das Konzept der Transformationsbil- 
dung des Wissenschaftlichen Beirates der Bundesregierung Globale Umweltveränderungen (vgl. WBGU 2016: 453) weiterzudenken und in neue demokratische „Formen und Netzwerke[.] einer globalen Ordnung“ (Mührel 2019: 171) einzubinden. Zentral bezieht er sich dabei auf Bruno Latours (vgl. 2018) Idee eines Parlaments der Dinge als Erweiterung des Parlaments nicht nur „in einem weltgemeinschaftlichen Zusammenhang. Zudem findet eine zweite Erweiterung statt, die den Lebewesen und Dingen eine Stimme im Parlament verleiht“" (Mührel 2019, S. 170).

All diese Überlegungen, ebenso wie meine zu „Sozialer Arbeit als Arbeit am Gemeinwesen“ (May 2017), werden von Marcel Schmidt in einer Konzeption Sozialer Arbeit als Arbeit am terrestrischen Gemeinwesen synthetisierend weiterentwickelt. Dabei handelt es sich um einen naturethisch informierten, gemeinwesenorientierten Ansatz sozialräumlich gerechter Sozialraumentwicklung und -organisation zur politischen und subjektiven Bildung von lokalen und globalen Transformationsstrategien. Bereits Timm Kunstreich und ich hatten Natorps auf die ,sozialen Bedingungen der Bildung und die Bildungsbedingungen des sozialen Lebens" (Natorp 1974: 86) bezogene Gegenstandbestimmung von Sozialpädagogik im Hinblick auf eine Theoretisierung und Konzeptionierung Sozialer Arbeit als „Bildung des Sozialen und Bildung am Sozialen“" (vgl. Kunstreich und May 1999) weitergedacht. Im Anschluss daran wird ökosoziale Transformation von Marcel Schmidt nun als Bildung des Ökosozialen in Gestalt nachhaltiger urban und global Commons, sowie sozial-ökologische Subjektbildung als damit dialektisch vermittelte emanzipatorische Bildung an diesem Ökosozialen gefasst.

So geht es Marcel Schmidt um nichts weniger als die für Soziale Arbeit zentrale Frage, wie sich im Rahmen einer emanzipatorischen Bildung am Ökosozialen ein gemeinsames Handlungssubjekt der Transformation herausbilden lässt, das nicht nur die Pluralität menschlicher Lebensweisen, sondern darüber hinaus auch die Pluralität nicht-menschlicher Lebensformen und der jeweiligen Beziehungen zu ihren Aktanten repräsentiert, mit denen sich das Leben auf der Erde entwickelt. Sowohl in ihrer theoretischen Begründung wie methodischen Konkretisierung kann diese seine Konzeption Sozialer Arbeit als Arbeit am terrestrischen Gemeinwesen als der wohl gegenwärtig ausgearbeiteste Entwurf im Kontext Sozialer Arbeit gelten, der menschlichen Entfremdung von der Natur und damit auch von sich selbst entgegenzuwirken. 


\section{Literatur}

Anderson, Elizabeth S. (1999): What Is the Point of Equality? In: Ethics 109, 2, S. 287-337.

Anhorn, Roland/Stehr, Johannes (Hrsg.) (2020): Handbuch Soziale Ausschließung und Soziale Arbeit. Perspektiven kritischer Sozialer Arbeit, Band 26. Wiesbaden: Springer Fachmedien Wiesbaden GmbH; Springer VS.

Bartosch, Ulrich (2019): Entdecke die Weltrettung als sozialpädagogisches Projekt! In: Birgmeier, B./Mührel, E./Winkler, M. (Hrsg.): Sozialpädagogische SeitenSprünge. Einsichten von außen, Aussichten von innen: Befunde und Visionen zur Sozialpädagogik. Weinheim: Juventa Verlag ein Imprint der Julius Beltz GmbH \& Co. KG, S. 19-32.

Bhaskar, Roy (2008): Dialectic. The pulse of freedom. Classical texts in critical realism. London, New York: Routledge.

Latour, Bruno (2018): Das Parlament der Dinge. Für eine politische Ökologie. 4. Auflage. Suhrkamp-Taschenbuch Wissenschaft, Band 1954. Frankfurt am Main: Suhrkamp.

Lefebvre, Henri (2016): Das Recht auf Stadt. Flugschrift. Hamburg: Edition Nautilus.

Marx, Karl (1978a): Das Kapital. Kritik der politischen Ökonomie. Dritter Band. Buch III: Der Gesamtprozeß der kapitalistischen Produktion. 11. Aufl. MEW, Band 25. Berlin: Dietz Verlag.

Marx, Karl (1978b): Kritische Randglossen. In: Marx, K./Engels: Werke, Band 1. 6. Aufl., Berlin: Dietz, S. 392-410.

Marx, Karl (1990): Ökonomisch-philosophische Manuskripte aus dem Jahre 1844. In: Marx, K./Engels, F.: Werke, Band. 40. 2. Aufl. Unveränd. Nachdr. d. 1. Aufl. 1985. Berlin: Dietz, S. 465-588.

May, Michael (2017): Soziale Arbeit als Arbeit am Gemeinwesen. Ein theoretischer Begründungsrahmen. Beiträge zur Sozialraumforschung, Band 14. Leverkusen: Budrich, Barbara.

May, Michael (2021): Auf dem Weg zu einer Materialistisch-Dialektischen Theorie Kritischer Sozialer Arbeit. In: May, M./Schäfer, A. (Hrsg.): Theorien für die Soziale Arbeit. 2. aktualisierte und erweiterte Auflage. Baden-Baden: Nomos, S. $155-182$.

Mührel, Eric (2019): Sozialpädagogik - eine Reformulierung. Transgenerative Ethik, das Parlament der Dinge und transformative Bildung als Grundlage für eine humane und nachhaltige Entwicklung. In: Birgmeier, B./Mührel, E./Winkler, M. (Hrsg.): Sozialpädagogische SeitenSprünge. Einsichten von außen, Aussichten von innen: Befunde und Visionen zur Sozialpädagogik. Weinheim: Juventa Verlag ein Imprint der Julius Beltz GmbH \& Co. KG, 166-173.

Natorp, Paul (1974): Sozialpädagogik. Eine Theorie der Willensbildung auf Grundlage der Gemeinschaft. 7. Aufl. Paderborn: F. Schöningh.

Negt, Oskar (2002): Arbeit und menschliche Würde. 2. Aufl. Göttingen: Steidl.

Nussbaum, Martha Craven (1999): Gerechtigkeit oder Das gute Leben. Gender studies. Frankfurt am Main: Suhrkamp.

Schaarschuch, Andreas (2019): Entfremdung vom Sozialen: Elemente zu einer Gegenstandsbestimmung der Sozialpädagogik. In: Zeitschrift für Sozialpädagogik 17, 3, S. 249-263. 
Sohn-Rethel, Alfred (2018a): Grundzüge einer materialistischen Erkenntnistheorie. In: ders.: Geistige und körperliche Arbeit. Theoretische Schriften 1947-1990 Schriften IV. Frieburg: ça ira, S. 135-166.

Sohn-Rethel, Alfred (2018b): Materialistische Erkenntnistheorie? In: ders.: Geistige und körperliche Arbeit. Theoretische Schriften 1947-1990 Schriften IV. Frieburg: ça ira, S. 799-812.

WBGU (2016): Der Umzug der Menschheit. Die transformative Kraft der Städte; Hauptgutachten. Berlin: Wissenschaftlicher Beirat der Bundesregierung Globale Umweltveränderungen.

Wendt, Wolf Rainer (1982): Ökologie und soziale Arbeit. Enke Sozialwissenschaften. Stuttgart: F. Enke.

Wendt, Wolf Rainer (1986): Das breite Feld der sozialen Arbeit: Historische Beweggründe und ökologische Perspektiven. In: Oppl, H./Tomaschek, A. (Hrsg.): Soziale Arbeit 2000. Band 1: Soziale Probleme und Handlungsflexibilität. Freiburg im Breisgau: Lambertus, S. 43-79.

Wendt, Wolf Rainer (1990): Ökosozial denken und handeln. Grundlagen und Anwendungen in der Sozialarbeit. Freiburg im Breisgau: Lambertus.

Ziegler, Holger (2021): Der Capabilities Ansatz (und andere Elemente einer materialistisch-emanzipatorischen Theorie Sozialer Arbeit). In: May, M./Schäfer, A. (Hrsg.): Theorien für die Soziale Arbeit. 2. aktualisierte und erweiterte Auflage. Baden-Baden: Nomos, S. 99-113. 



\section{Inhalt}

\section{Einleitung}

1 Zur ,sozialwissenschaftlichen Unterbestimmtheit“ der

Klimadebatten und erster Umriss des Vorhabens.

2 Näheres zum methodologischen Zugang

Teil A

Der Klimawandel und seine gesellschaftliche Bedeutung im Allgemeinen und für Soziale Arbeit im Besonderen

3 Problembefund Kapitalozän: der Klimawandel aus einer Urbanisierungsperspektive 39

3.1 Von der Sesshaftwerdung zur Handelsware Stadt ....................... 40

3.2 „Urbanisierung des Kapitals“ und „imperiale Lebensweise“ 45

4 Soziale Arbeit als Urbanisierungskritik und subjektorientierte Arbeit am Sozialen mit globalgesellschaftlich-planetarischer Reichweite? Ein Problemaufriss......................................................... 52

4.1 Soziale Arbeit als Urbanisierungskritik ....................................... 52

4.2 Subjektorientierung Sozialer Arbeit............................................ 54

4.3 Soziale Arbeit als Agitatorin subjektorientierter Kulturrevolution mit sozial-ökologischem Anspruch? 66

4.4 Auf dem Weg zum Anthropozän - Soziale Arbeit als Agitatorin subjektorientierter Kulturrevolution mit sozialökologischem Anspruch auf globaler Ebene mit planetarischer Reichweite 
5 Anthropozän als Kulturrevolution sozialer Nachhaltigkeit - ein transdisziplinäres Projekt

6 Ökosozial - sozial-ökologisch? Versuch einer weiteren

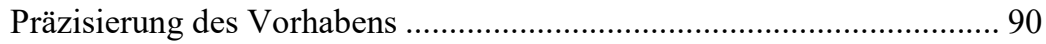

6.1 Ökosoziale Transformation(en) ............................................... 90

6.2 Mit einer terrestrischen Nachhaltigkeitswissenschaft sozialökologischer Transformation über ökosoziale Transformationen hinaus.

7 Fazit. 116

\section{Teil B}

Mit Lefebvres „Recht auf Stadt“" zur ökosozialen und sozialökologischen Transformation?

8 Weiterführende Zusammenfassung von Teil A 121

9 Kollaboration als Arbeitsprinzip Sozialer Arbeit 123

10 Kollaborative Stadtentwicklung im Transformationskonzept des WBGU

10.1 Problemaufriss des WBGU: plutokratische Gesellschaftsverhältnisse als Hindernis von klimaorientierter Armutsbekämpfung

10.2 Kritische Betrachtung der Transformationsvorschläge des WBGU

11 Der „normative Kompass“ des WBGU zum Ersten: Partizipation und Eigenart

11.1 Partizipation als kollaborative Stadtentwicklung? Zur Kritik des WBGU aus sozialarbeiterischer Perspektive

11.2 Kollaborative Stadtentwicklung als (eigensinnige)

Produktion transformativer Eigenarten der Städte - und die

Ergänzung des emanzipatorischen Eigensinns 
12 „Recht auf Stadt“ im Werk Lefebvres

12.1 Von der „Kritik des Alltagslebens“ zum „Recht auf Stadt“

- Lefebvres praxisphilosophische Soziologie als

„strategische Hypothese“

12.1.1 Lefebvres „Metaphilosophie“ als praxisphilosophischer Begründungsrahmen ökosozialer Transformation .....

12.1.2 Lefebvres „Metaphilosophie“ als praxisphilosophischer Begründungsrahmen sozialökologischer Transformation?

12.1.3 Recht auf Stadt als kollaboratives

Transformationskonzept.

12.2 Vom „Recht auf Stadt“ zur „Revolution des Urbanen“

- Lefebvres soziologische Praxisphilosophie.

12.2.1 Nietzsche und Heidegger als Protagonisten des metaphilosophischen Begriffs des Wohnens

12.2.2 Habiter als zentraler Begriff ökosozialer Transformationen

12.2.3 Politische Konsequenzen Lefebvres und nochmal zur Frage von Lefebvres „Metaphilosophie“ als praxisphilosophischer Begründungsrahmen sozialökologischer Transformation 175

12.2.4 (Zwischen-)Fazit 187

\section{Teil C}

Von der „Revolution des Urbanen“ zum Transformationsprojekt Soziale Ökologie? Ein kommunalistisches Gedankenexperiment im Anschluss an Lefebvres „Recht auf Stadt“"

13 Weiterführende Zusammenfassung von Teil A und B 193

14 Der „normative Kompass“ des WBGU zum Zweiten: polyzentrische Verantwortungsarchitektur....

15 Kommunalismus - von der sozial-ökologischen Revolutionierung des Urbanen zum Anthropozän?

15.1 Libertärer Kommunalismus 204 
15.2 Kommunalistische Infrastrukturpolitik

15.3 Zum Begriff der Transformation: symbiotische Freiraumstrategien statt libertärer Bruch.

15.4 Genossenschaftliche Organisierung sozialer Infrastrukturpolitiken als Bedingung der Herausbildung einer übergreifenden Politik des Sozialen

15.5 (Sozial-)Räumliche (Klima-)Gerechtigkeit - Versuch des Umrisses eines strategisch-hypothetischen Begriffs

15.5.1 (Sozial-)Räumliche Gerechtigkeit - zur Reichweite eines ungewöhnlichen Begriffs

15.5.2 „Just City“ - ein räumlicher Ansatz sozialer Klimagerechtigkeit mit globaler Reichweite und kulturrevolutionärem Anspruch

\section{Teil D}

Umriss einer möglichen terrestrischen

Nachhaltigkeitswissenschaft sozial-ökologischer Transformation

- zum Verhältnis ökosozialer Transformationen und sozialökologischer Subjektbildung

16 Weiterführende Zusammenfassung von Teil A, B und C

17 Zur Kritik der emergenzmaterialistischen Verkürzung dialektischmaterialistischer Kritik und die Notwendigkeit komplementärer Transdiszplinarität für eine sozial-ökologische Subjektbildung. 255

18 Mimetische Subjektbildung Sozialer Ökologie durch solidarische Kritik

19 Fotografie als künstlerisch-wissenschaftliche Ermöglichung mimetischer sozial-ökologischer Subjekt- und Theoriebildung zur Erfahrbarmachung, Kritik und Bearbeitung des „Streites zwischen Erde und Welt“ 
20 Professionalität Sozialer Arbeit - kommunalisierende

Praxisphilosophie zwischen Reallaboren und transformativer

Hochschule 286

\section{Teil E}

Zusammenfassende Einordnung des Entwurfs einer terrestrischen Nachhaltigkeitswissenschaft sozial-ökologischer Transformation in die Diskussionen um eine Kritische Theorie gesellschaftlicher Naturverhältnisse

21 Einordnung der vorliegenden Argumentation in Marx“ „Kritik der Erde“

22 Das Verlieren des Marxschen Erdbezugs in der Soziologie 298

23 Zwischen Beschreiben und Fordern: Zur aktuellen Diskussion um eine Kritische Theorie gesellschaftlicher Naturverhältnisse in vier Varianten

24 Vom Fordern zum Fördern: Zur Positionierung in der Diskussion 312

Literaturverzeichnis 321 

Einleitung 



\section{Zur ,Sozialwissenschaftlichen Unterbestimmtheit““ der Klimadebatten und erster Umriss des Vorhabens}

Dass ,seit Mitte des 19. Jahrhunderts [...] eine fortschreitende Erwärmung der Erde“ empirisch zu ermitteln und ,die durch natürliche Ursachen nicht erklärbar ist“, wie es der „Monitoringbericht 2019 zur Deutschen Anpassungsstrategie an den Klimawandel" des Umweltbundesamtes (UBA 2019: 18) einleitend konstatiert, ist weltweit von einer sehr großen Mehrheit - die Untersuchungen schwanken zwischen $90 \%$ und $100 \%$ - der zur Klimaforschung zugehörigen WissenschaftlerInnen anerkannt (Cook et al. 2019). Als schon gegenwärtig zu beobachtende Folgen konstatiert das UBA erhöhte Gesundheitsrisiken und Todesraten durch Hitze- und Dürreperioden bei gleichzeitiger Erwärmung der Meere und Seen sowie das Ansteigen der Meeresspiegel und das dadurch bedingte erhöhte Risiko von Sturmfluten und Hochwasserereignissen, bei wiederum gleichzeitiger Intensivierung niederschlagsbildender Prozesse und Starkregen (UBA 2019; zum Überblick auch: IPCC 2008, 2019). Angesichts dieser sich weiter verschärfenden Bedrohung wurde im Rahmen der UN-Klimakonferenz 2015 in Paris im Anschluss an die Empfehlungen des IPCC ${ }^{1}$ beschlossen, bis 2050 den „Anstieg der globalen Durchschnittstemperatur deutlich unter $2^{\circ} \mathrm{C}$ über dem vorindustriellen Niveau ${ }^{2}$ [zu halten] und Anstrengungen [zu unternehmen], um den Temperaturanstieg auf $1,5^{\circ} \mathrm{C}$ über dem vorindustriellen Niveau zu begrenzen" (Vereinte Nationen 2015b, Art. 2, Abs. 1a). Hinsichtlich der Erforschung zur Reduktion der Erderwärmung stellt das IPCC „,zwei Hauptpfade“ heraus, „die eine globale Erwärmung um $1,5^{\circ} \mathrm{C}$ untersuchen.

„Beim ersten Pfad stabilisiert sich die globale Temperatur bei oder knapp unter $1,5^{\circ} \mathrm{C}$ über vorindustriellem Niveau. Beim zweiten Pfad überschreitet die Erwärmung die $1,5^{\circ} \mathrm{C}$-Marke ungefähr Mitte des Jahrhunderts, verbleibt für maximal ein paar Jahrzehnte über $1,5^{\circ} \mathrm{C}$ und sinkt noch vor dem Jahr 2100 wieder auf unter $1,5^{\circ} \mathrm{C}$. Letzteres wird oft als ,Überschreitungspfad“ (overshoot pathway) bezeichnet. Alle anderen Verläufe, in denen die globale Temperatur weiter ansteigt und $1,5^{\circ} \mathrm{C}$ bis zum Ende des 21 . Jahrhundert dauerhaft überschreitet, werden nicht als 1,5C-Pfade betrachtet.“ (IPCC 2019: 10)

1 Intergovernmental Panel for Climate Change

2 Welches Jahr bzw. welche Zeitspanne als Bezugspunkt des vorindustriellen Niveaus gesetzt wird, variiert nicht nur innerhalb der Untersuchungen des IPCC (IPCC 2008: 91, 2019: 8), sondern auch zwischen den verschiedenen Forschungseinrichtungen (etwa: Hawkins et al. 2017). Oder aber es wird gleich ganz auf eine Konkretisierung des Begriffs des vorindustriellen Niveaus verzichtet. Etwa im Bericht 2019 über die „Ziele für nachhaltige Entwicklung“ der UN (Vereinte Nationen 2019). An der jeweiligen Prognose des immer schneller stattfindenden Klimawandels ändert das allerdings nichts. 
Zugleich weist das Potsdam-Institut für Klimafolgenforschung (PIK) aber auf die nicht zu unterschätzende Gefahr sogenannter Kippelemente der Erdökologie hin. Als Kippelemente werden „Bestandteile des Erdsystems von überregionaler Größe" bezeichnet,

„die ein Schwellenverhalten in Bezug auf das Hintergrundklima aufweisen. Das bedeutet, dass sie, sofern sie schon nahe an einem Schwellenwert operieren, bereits durch kleine externe Störungen in einen qualitativ neuen Zustand versetzt werden können. Beim Vergleich mit dem menschlichen Körper könnten Organe als Kippelemente beschrieben werden. Diese verändern ihre gewohnte Funktionsweise drastisch oder stellen die gar ein, sobald bestimmte Voraussetzungen $[\ldots]$ nicht mehr in ausreichendem Maße erfüllt sind." (PIK o. J.)

Die Kippelemente stellen bei einer Erderwärmung von über $1,5^{\circ} \mathrm{C}$ also insofern ein erhöhtes Risiko dar, da sie, ,vergleichbar mit einer Reihe von Dominosteinen $[\ldots]$ ab einem gewissen Grenzwert in einen neuen Zustand kippen“" (Kornhuber 2019: 29). Das heißt, dass sie, „einmal angestoßen, auch ohne weiteren externen Einfluss weiterlaufen“ und „es passieren kann,

dass der neue Zustand eines Kippelementes erhalten bleibt, selbst wenn das Hintergrundklima wieder hinter den Schwellenwert zurückfällt. Der Übergang nach dem Überschreiten eines systemspezifischen Kipppunktes kann dabei sprunghaft, aber auch kriechend erfolgen. Seine Umweltauswirkungen sind weitreichend und könnten die Lebensgrundlagen vieler Millionen Menschen gefährden.“ (PIK o. J.)

Wie Kornhuber herausstellt, ist „,[n]eueren Studien zufolge [...] der westantarktische Eisschild mit großer Wahrscheinlichkeit bereits gekippt“, was bedeutet, „dass dieser Prozess, der einen Anstieg des Meeresspiegels bedeuten würde, nicht mehr aufzuhalten wäre" (Kornhuber 2019: 29). Ein weiteres offensichtlich bereits gekipptes (King et al. 2020) Klimaelement ist der grönländische Eisschild, was den Prozess und die Konsequenzen des Meeresspiegelanstiegs weiter beschleunigt. Damit ist zugleich die Dringlichkeit betont, Ausmaß und Dauer einer möglichen Überschreitung, durch die weitere klimastabilisierende Elemente zum Kippen gebracht werden und weitere Kettenreaktionen ausgelöst werden können, weitest möglich gering zu halten, um weitere Beschleunigungen des Klimawandels zu verhindern. Dass die globale Mitteltemperatur seit der vorindustriellen Zeit bereits um $1^{\circ} \mathrm{C}$ (Vereinte Nationen 2019: 16, 48) und in Deutschland die Jahresmitteltemperatur im Flächendurchschnitt von 1881 bis 2018 bereits um $1,5^{\circ} \mathrm{C}$ gestiegen ist (UBA 2019: 19), unterstreicht die Dringlichkeit nur noch mehr.

Dies sind nun die Ausgangspunkte der Diskussion um die radikale ${ }^{3}$ Eindämmung problematischer Treibhausgasemissionen und der ebenso radikalen Abkehr von der problematischen fossilen Energieversorgung sowie der konsequenten und nicht minder radikalen Abkehr von individuellen Lebensweisen mit großem globalökologischem »Fußabdruck«. Aber obwohl die Rede

3 Wenn in der vorliegenden Arbeit von radikal die Rede ist dann bezieht sich dieses Wort stets auf die Bedeutung des lateinischen Wortes radix, die Wurzel, und meint daher stets eine Problembekämpfung von der Wurzel des Problems her. 
vom menschengemachten Klimawandel seit Jahren zum festen Bestandteil der Alltagskommunikation gehört, kommt die nicht minder deutlich benannte Ursache des anthropogenen Klimawandels dabei nur erstaunlich blass zum Ausdruck. Auf die Frage, was die weltweite Klimaerwärmung samt dessen Folgen bedingt, stellt der Wissenschaftliche Beirat der Bundesregierung Globale Umweltveränderung (WBGU) „Städte und Stadtgesellschaften“ als „für den überwiegenden Teil aller weltweiten Ressourcenverbräuche und Treibhausgasemissionen [verantwortlich]" heraus und benennt als Grund den historischen Umzug der Menschheit in die Städte (WBGU 2016b: 2).

Gab es 1800 nur 4 Städte mit einer Million EinwohnerInnen (Peking, Tokio, Delhi, London), so waren im Jahr 2000 schon 200 Städte mit einer Million EinwohnerInnen, 100 Städte mit 10 Millionen EinwohnerInnen und 20 Städte mit mehr als 10 Millionen EinwohnerInnen, den sog. Megacities (Girardet 2007: 175f.), von denen ,einige [...] in Bezug auf die Dimensionen und Auswirkungen etwa ihrer $\mathrm{CO}_{2}$-Bilanzen oder ihres Ressourcenverbrauchs mit Nationalstaaten vergleichbar" sind (WBGU 2016b: 43). Wurde im Jahr 2007 von Girardet für Jahr 2020 noch 27 solcher Megacities prognostiziert, so zeigt eine 2020 veröffentliche Statistik (Rudnicka 2020), dass es bereits 201833 solcher Megacities gab. Als Verhältnis formuliert heißt das, dass Mitte des 20. Jahrhunderts noch 30 Prozent der Weltbevölkerung in den urbanen Zentren der Welt lebten, während es heute hingegen über 50 Prozent sind, mit steigender Tendenz (BMZ o. J.). Damit leben seit „2007 [...] weltweit erstmals mehr Menschen in Städten als im ländlichen Raum" (WBGU 2016b: 43). 2030 werden 60 \% der Erdbevölkerung in städtischen Regionen leben und damit mehr als dreimal so viel wie 1900 (Girardet 2007: 187). Bis 2050 werden voraussichtlich 80 Prozent der Weltbevölkerung in Städten leben (BMZ o. J.), d.h. die „Stadtbevölkerung könnte sich bis 2050 weltweit von heute knapp 4,5 Mrd. auf dann 6,5 Mrd. Menschen vergrößern - und mit ihr die urbanen Infrastrukturen“ (WBGU 2016b: 1). Und während sich in den Metropolen der Industriestaaten zwar ein ,verlangsamtes Wachstum oder [...] sogar einen Bevölkerungsrückgang auf[weisen]“ lässt, liegt die Verstädterungsrate in Lateinamerika ,bereits heute bei über 80 Prozent, in Asien und Afrika wird sie bis 2030 auf über 50 Prozent ansteigen“ (BMZ o. J.). Die für Agrarwirtschaft zur Verfügung stehenden Flächen außerhalb der Städte werden durch die (nach)verdichtende Bebauung innerstädtischer Nutzflächen absehbar durch permanente Überbeanspruchung (Überweidung, Düngung) zunehmend unbrauchbar, was zugleich mit der steigenden Nachfrage in den Städten nach Agrarprodukten kollidiert. Zugleich steigt mit den Einwohnerzahlen der Flächenverbrauch der Städte ungleich stärker an (Girardet 2007: 183). Der WBGU fasst die Entwicklung zusammen:

„Durch die derzeitigen Urbanisierungs-, Suburbanisierungs- und Periurbanisierungsprozesse [...] werden zum einen in den Stadtrandgebieten fortlaufend Acker- oder Naturboden in urbane Flächen umgewandelt und versiegelt - der sogenannte Flächenverbrauch. Hierbei handelt es sich 
regelmäßig um irreversible Eingriffe in Natur und Landschaft (Seto et al., 2011: 1). Zum anderen erhöht sich der Druck auf grüne Innenstadtflächen, die aufgrund ihrer Zentralität begehrte Wohnund Bürolagen sind. Es wird prognostiziert, dass der zukünftige Flächenverbrauch von Städten überproportional zum Bevölkerungswachstum steigen wird - in Entwicklungsländern wird bei einer Verdopplung der Bevölkerung bis 2030 sogar mit einer Verdreifachung des Flächenzuwachses gerechnet (Angel et al., 2011). Großer Bedarf an Flächen besteht vor allem in den stark wachsenden Städten Asiens und Afrikas.“(WBGU 2016b: 170)

Unter der vorherrschenden politischen Ökonomie der Kapital(re)produktion heißt das, dass mit der erhöhten Flächennachfrage und deren Bewirtschaftungen die Boden- und (nicht subventionierten) Nahrungspreise steigen und sich damit entlang von Lohn- und Wohnverhältnissen die Zugangsschwellen zu lebenswichtigen Ressourcen erhöhen (ebd.: 174).

Die ,globale Urbanisierung“ in diesem verhältnismäßig neuen Ausmaß ,[löst] mit ihren Ausbreitungs- und Diffusionsprozessen städtischer Lebensformen irreversible Veränderungen der gesellschaftlichen Ordnung von Staaten aus" (ebd.: 43). Eine umfangreiche Literaturrecherche im Auftrag des Umweltbundesamtes zeigt, ,dass zahlreiche Studien den Beweis erbringen, dass langsame Umweltveränderungen (Durchschnittstemperatur, Niederschlag, Niederschlagsvariabilität) einer der treibenden Faktoren der Binnenmigration sind“ (Flavell et al. 2020a: 15), während ,[h]insichtlich der Migrationsbewegungen im Zusammenhang mit plötzlich auftretenden Ereignissen [...] die Literaturrecherche fest[stellte], dass es sich oft um komplexe, mehrstufige Prozesse handelt, die von einer Reihe von Faktoren auf Mikro-, Meso- und Makroebene bestimmt werden“ (ebd.), so dass „globale Prognosen über das Ausmaß der zukünftigen Umweltmigration großen Unwägbarkeiten [unterliegen] und [...] von begrenztem Wert [sind]“" (Flavell et al. 2020b: 12). „Dennoch dürften Umweltveränderungen - durch ihre Auswirkungen auf plötzliche und langsam eintretende Ereignisse - eine Reihe potenzieller Konflikttreiber weiter verschärfen" (ebd.: 13f.), die mit dem oben beschriebenen „globalen Megatrend“ (WBGU 2011b) des „Umzugs der Menschheit“ in die Städte (WBGU 2016b) einhergehen und die ,irreversiblen Veränderungen der gesellschaftlichen Ordnung von Staaten“ (ebd.: 43) potenzieren. Während „eine wachsende Zahl von Menschen in Gebieten“ zurückgelassen werden, ,in denen sie sehr anfällig für Umweltstressfaktoren sind“ (Flavell et al. 2020b: 14), ist eine ebenso wachsende Zahl in den Städten unter Subsistenz verunmöglichenden Bedingungen einem unersättlichen Konsumismus und einem erhöhten Konfliktpotenzial um marktwirtschaftlich verknappte Güter zum Bewerkstelligen des eigenen Alltags ausgesetzt.

Um dem 21. Jahrhundert als dem „Jahrhundert der Städte“ (WBGU 2016b: 1) zu begegnen, müssen sich die Städte ,im Grunde neu erfinden, um selbst mit den Herausforderungen eines abgeschwächten Klimawandels zurechtzukommen“ (Rahmstorf/Schellnhuber 2007: 130). Aber gleichwohl dieser für Sozialwissenschaften im Allgemeinen und Sozialer Arbeit im Besonderen relevanten Implikationen des Klimawandels wird die fachliche 
Diskussion fast ausschließlich naturwissenschaftlich geführt. Ein (Coronabedingtes Online-) Symposium der Scientists For Future bestätigt auch 2020 noch die von Leggewie 2015 kritisierte ,sozialwissenschaftliche Unterbestimmtheit" (Leggewie 2015: 66) der Debatten, die im Zuge der Diskussionen um einen menschengemachten Klimawandel aufgekommen sind. In einer aktuellen „Topografie der Klimaforschung“ in der Zusammenarbeit des Berliner Forschungsinstitut Mercator Research Institute on Global Commons an Climate Change (MCC) mit dem Priestley International Centre for Climate an der Universität Leeds stellt sich zwar heraus, dass Klimathemen ,von den Sozialwissenschaften wenig beachtet" werden, allerdings zeigen sie sich ,in den jüngsten Sachstandsberichten des Weltklimarates keineswegs unterrepräsentiert“ (MCC 2020). Wenn John Bellamy Foster in einem Interview aber provokant zusammenfasst, dass

„der Mainstream der Sozialwissenschaften, wie wir ihn heute vorfinden, [...] die kapitalistische Ideologie fast vollständig verinnerlicht [hat]; so sehr, dass der Mainstream der Sozialwissenschaften unfähig ist, das Problem in seiner Reichweite anzugehen, und zwar auf eine Weise, die den herrschenden historischen Bedingungen angemessen ist" (Foster 2017)

dann stellt sich die Frage, welche Theorietradition ,,in den jüngsten Sachstandsberichten des Weltklimarates" (MCC 2020) repräsentiert sind und welche nicht. Wenn Foster im besagten Interview weiterhin kritisiert, dass „[j]ene Mainstream-Sozialwissenschaftler*innen, die ökologischen Probleme thematisieren, [...] dies so [tun], als ob wir es mit recht gewöhnlichen Bedingungen zu tun hätten und nicht mit einem planetarischen Notfall, einer nie dagewesenen Situation“, dann „kann [es] keine gradualistische, öko-modernistische Antwort geben auf die schrecklichen ökologischen Probleme, mit denen wir es zu tun haben“ (Foster 2017). Doch die Umweltbewegungen seit den 1980er Jahren - zu denen in ihrer gegenwärtigen Ausdrucksform explizit auch soziale Bewegungen wie Friday For Future (FFF.) und sie unterstützende Gruppen wie Scientists For Future (SFF.) gezählt werden müssen -, tendiert - nicht zuletzt auch wegen einem alltäglich gewordenen Systemverständnis der Welt in Alltag und Wissenschaft, das schon in den 1980er Jahren als die Problemursache und ihre Lösungsansätze depolitisierend zurückgewiesen wurde (Becker 2016f) - zur ,ökologischen Modernisierung“ (Foster et. al 2011: 239). D.h. zur „Ökologisierung der Wirtschaft“ und „Ökonomisierung der Ökologie“ (ebd.: 241) und damit zum Greenwashing kapitalistischer Vergesellschaftung von Naturverhältnissen.

Vor diesem Hintergrund - so das hier vertretene Plädoyer - braucht es eine Kritische Theorie gesellschaftlicher Naturverhältnisse. Für eine solche Kritische Theorie ist es durch die Entwicklung der Kritischen Theorie in den letzten 50-60 Jahren allerdings schlecht bestellt. Mit Görg lassen sich ,zwei gegenläufige Tendenzen" der Kritischen Theorie zusammenfassen: Zum einen ,eine Ignoranz gegenüber dem Potential, das in den Schriften der älteren Kritischen Theorie angelegt war und das dazu geeignet gewesen wäre, 
der Vernachlässigung ökologischer Probleme und der Ausblendung der Naturverhältnisse in den Sozialwissenschaften entgegenzuwirken“" (Görg 2003: 41). Und zum anderen ,wurde dieses Potential der älteren Kritischen Theorie [...] wenigstens teilweise auf völlig anderem Wege“, nämlich ,,von der poststrukturalistisch orientierten feministischen Wissenschafts- und Technikkritik bis zur Regulationstheorie“, ,in die Diskussion eingebracht", während hingegen sich ein ,einheitlicher Theorierahmen zur Diskussion der Naturverhältnisse [...] noch nicht herausgebildet [hat]“", so dass, wie Görg bereits 2003 kritisiert, eine kritische Theorie gesellschaftlicher Naturverhältnisse ein „Desiderat" ist (ebd.). Daran hat sich bis heute nicht viel verändert. In seiner „Theorie für das Anthropozän“ endet McKenzie Wark daher mit einer herben Kritik am westlichen Marxismus samt der Kritischen Theorie:

„Mit der Vereinnahmung durch die professionelle akademische Praxis fiel der Marxismus einer Verschiebung seiner Agenda zum Opfer. [...] Mit der Zeit wurde dies so schlimm, dass man im frühen einundzwanzigsten Jahrhundert bei der Lektüre führender Erben der Tradition des Westlichen Marxismus vergeblich nach dem Hinweis sucht, dass das Schicksal der ,Moderne“ sich der Kohlenstoffbefreiung zugewendet hat.“(Wark 2017: 319)

Die Kritische Theorie, so Wark, ist dadurch ,zur hypokritischen Theorie verkommen“ (ebd.: 321) und „verstrickte[] sich in der Sprache des Kulturellen, des Politischen oder sogar des alten theologischen Überbaus“ (ebd.: 320). Warks Kritik: Mit ihrem Interesse an „Nichtidentität, Supplementen, Inkommensurabilität, daran, wie unsere Subjektivität innerlich gespalten ist und wie Antagonismen die Politik strukturieren“ (ebd.: 323), verlor die „hypokritische Theorie“ die Kritik am metabolischen oder ökologischen Bruch der westlichen Gesellschaftspraxis aus den Augen.

Als diesen Stoffwechsel stellte bereits Marx den „Prozeß zwischen Mensch und Natur“ dar, einem „Prozeß, worin der Mensch seinen Stoffwechsel mit der Natur durch seine eigne Tat vermittelt, regelt und kontrolliert" (Marx 1962a: 192) und dessen „Arbeitsmittel“" ihm für diesen Prozess die Erde ist (ebd.: 194). Der Naturprozess des Stoffwechsels von Mensch und Erde ist für Marx nicht nur die existenzielle Grundlage jeglicher Gesellschaftsformationen, sondern die ontologische Substanz der Existenz selbst. Nämlich das Zeitlose der Arbeit schlechthin ${ }^{4}$, das Alfred Schmidt als „,negativ zu fassende Ontologie" (Schmidt 2016: 103) begreifbar zu machen sucht. ${ }^{5}$ Es ist eine von Marx“ Leistungen im „Kapital“", dass er herausstellt, wie die-

4 Für Marx vollzieht sich der ,[ursprüngliche] Arbeitsprozess [...] nur zwischen dem Menschen und der ohne sein Zutun vorhandnen Erde“ und ,,ist zweckmäßige Tätigkeit zur Herstellung von Gebrauchswerten, Aneignung des Natürlichen für menschliche Bedürfnisse, allgemeine Bedingung des Stoffwechsels zwischen Mensch und Natur, ewige Naturbedingung des menschlichen Lebens und daher unabhängig von jeder Form dieses Lebens, vielmehr allen seinen Gesellschaftsformen gleich gemeinsam“ (Marx 1962a: 198).

5 Das Negative der negativ zu fassenden Ontologie meint, dass nur das Dass des Stoffwechsels unhintergehbar gegeben ist, nicht aber dessen Wie, Womit und Wozu bzw. zu was kurz: nicht seine Geschichte. 
ser Stoffwechsel durch das merkantile bzw. kapitalistische Wertgesetz (Marx 1968b: 532) zur Kommerzialisierung des Bodens und dessen Vernutzung drängt (Marx 1962a: 527ff.) und damit die private Eigentumsordnung der einstigen Feudalherren monopolisiert (Marx 1964: 821), was unweigerlich „die Springquellen alles Reichtums untergräbt: die Erde und den Arbeiter“ (Marx 1962a: 530). Die privatwirtschaftlich organisierten Eigentumsverhältnisse an Grund und Boden, so Marx am Ende des dritten Bandes des „Kapitals", erzeugen

„Bedingungen, die einen unheilbaren Riß hervorrufen in dem Zusammenhang des gesellschaftlichen und durch die Naturgesetze des Lebens vorgeschriebnen Stoffwechsels, infolge wovon die Bodenkraft verschleudert und diese Verschleuderung durch den Handel weit über die Grenzen des eignen Landes hinausgetragen wird.“ (Marx 1964: 821)

Auch ohne die Kenntnis von Erderwärmung, klimatologischen Kippelementen und planetarischen Quantifizierungen des Stoffwechsels zwischen Erde und Erdbewohnerschaft drängte schon Marx aufgrund der seinerzeit deutlich sichtbaren und absehbaren Schäden und Folgeschäden - für die insbesondere auch Engels (Engels 1975: 425f.) sensibel war - auf die Notwendigkeit einer konsequenten Politisierung der Vergesellschaftung der Erde bzw. der (Erd-)Naturverhältnisse, durch die die Erde als Gemeineigentum hervorgebracht wird und durch die eine transgenerative Ethik des Erhalts der Bewohnbarkeit der Erde überhaupt erst ermöglicht werden kann:

„Vom Standpunkt einer höhern ökonomischen Gesellschaftsformation wird das Privateigentum einzelner Individuen am Erdball ganz so abgeschmackt erscheinen, wie das Privateigentum eines Menschen an einem andern Menschen. Selbst eine ganze Gesellschaft, eine Nation, ja alle gleichzeitigen Gesellschaften zusammengenommen, sind nicht Eigentümer der Erde. Sie sind nur ihre Besitzer, ihre Nutznießer, und haben sie [...] den nachfolgenden Generationen verbessert zu hinterlassen." (Marx 1964: 784)

Auch wenn Marx den Begriff Ökologie nicht kannte, oder ihn wenigstens nicht benutzte, so ist er bei Marx dennoch omnipräsent. Als Ökologie wurde von Haeckel in etwa zeitgleich zu Marx in der Biologie „die Physiologie der Wechselbeziehungen der Organismen zur Aussenwelt und zu einander“ (Haeckel 1866b: 236) bezeichnet. Genauer: „die gesammte Wissenschaft von den Beziehungen des Organismus zur umgebenden Aussenwelt, wohin wir im weiteren Sinne alle ,Existenz-Bedingungen' rechnen können. Diese sind theils organischer, theils anorganischer Natur; [...]" (ebd.: 286). Während Haeckel aber im Anschluss an die Entwicklungs- bzw. „Descendenz-Theorie“ Darwins „die Haushalts-Verhältnisse der Organismen mechanisch“ versteht, nämlich ,als die nothwendigen Folgen wirkender Ursachen[.] und [...] somit die monistische Grundlage der Oecologie [bildet]“ (ebd.: 287), versucht der Marxsche Naturbegriff diese - wie Haeckel sagt - physiologischen „Haushalts-Verhältnisse“ "theils organischer, theils anorganischer Natur" (ebd.: 286) als dialektisch-materialistische Wechselwirkung zu verstehen. Die Haushalts-Verhältnisse (ebd.) zwischen Organismen und Erde sind für Marx 
vor allem ökonomisch, d.h. durch die Praxis im Spannungsfeld von Bedürfnis und Bedürfnisbefriedigung der lebendigen Leibnaturverhältnisse und allen daraus hervorgehenden sozialen Organisations- und Machtstrukturen von Produktion und Produktionsweisen geprägt, wobei erst die strukturellen Manifestationen der bürgerlichen Herrschaft den physiologischen Haushaltsverhältnissen der Erde ihr kapitalisiertes Gesicht aufdrücken. So schreibt Marx: „Bürgerliche Industrie und bürgerlicher Handel schaffen diese materiellen Bedingungen einer neuen Welt in der gleichen Weise, wie geologische Revolutionen die Oberfläche der Erde geschaffen haben“ (Marx 1960b: 226). Der die Erde vergesellschaftende Stoffwechsel zwischen Mensch und Erde durch die Herrschaft der bürgerlichen Industrie erschafft für Marx zugleich die Bedingungen, mit denen sich die Menschen die (resp. ihre) Welt aneignen müssen und dadurch letztendlich ein reduktionistisch-ökonomistisches Verständnis von Natur hervorbringen, das das Verhältnis äußerer und innerleiblicher Naturverhältnisse nicht länger als sich selbst genügsamen dialektischmaterialistischen Metabolismus in Erscheinung treten lassen, sondern als Mensch-Natur-Dualismus, bei dem Mensch und Natur zudem als an sich wertlos erscheinen und erst durch Kommodifizierungen einen (monetären) Wert erhalten. Erst dieses bürgerliche Naturverständnis lässt die Fortentwicklung der bürgerlichen Gesellschaft überhaupt als im ökonomischen wie ethischen Sinn wertschöpfend und daher erstrebenswert erscheinen. Das bedeutet aber letztlich, dass die maximale Inwertsetzung von Naturverhältnissen zwar die maximale ökonomische Wertschöpfung verheißt, zugleich aber auch die maximale Parzellierung der Erde und ihrer Bewohnerschaft in tauschbare Einheiten der Kapital(re)produktion. Dies wiederum bedeutet - konsequent zu Ende gedacht - den maximalen Bruch des ökologischen Metabolismus, die maximale Entsolidarisierung durch die maximale Vereinzelung der Menschen im Namen einer nur scheinbar erstrebenswerten Autonomie, die in Wahrheit die Menschen auf sich selbst zurückwirft und sie für die Sicherung ihres eigenen Überlebens dazu bringt, die menschliche wie nicht-menschliche Mitwelt zu unterdrücken und sie zur Sicherung des eigenen Überlebens maximal zu instrumentalisieren. Mit anderen Worten: Sie werden dazu gebracht jegliche Eigentätigkeit natürlicher Entwicklung unter technische Kontrolle zu bringen und sie entlang von kapitalogenen Sachzwängen optimieren zu müssen, wodurch ihnen Natur als Fremdes und widerspenstiges Gegenüber in Erscheinung tritt, das es »ohne Wenn und Aber« zu beherrschen gilt. Kurz: die maximale Inwertsetzung menschlicher wie nicht-menschlicher Naturverhältnisse der Erde mündet in einer maximalen Entfremdung zwischen den Menschen und zwischen den Menschen und ihrer Erde (samt ihrer nichtmenschlichen Mitbewohnerschaft).

Vor diesem Hintergrund gesellschaftlicher Alltagspraxis versucht Marx, dessen „Entwicklungsbegriff [...] nicht nur an Hegel, sondern auch an Darwin geschult [ist]“ (Schmidt 2018c: 109), diesen in der alltäglichen Wahr- 
nehmung verloren gegangenen Gesamtzusammenhang von Gesellschaft und Natur resp. Erde in die Philosophie zurück zu holen und betont hierfür die (Erd-)Natur als „de[n] unorganische[n] Leib des Menschen“ (Marx 1968b: 516). Und weiter:

„Die Natur ist sein Leib, mit dem er in beständigem Prozeß bleiben muß, um nicht zu sterben. Daß das physische und geistige Leben des Menschen mit der Natur zusammenhängt, hat keinen andren Sinn, als daß die Natur mit sich selbst zusammenhängt, denn der Mensch ist ein Teil der Natur" (ebd.).

In seinen „Grundrissen der Kritik der politischen Ökonomie“ präzisiert Marx dieses leibliche Mensch-Natur-Postulat als leibliches Mensch-ErdePostulat und konkretisiert die Natur als Erde und formuliert die „Erde als [...] unorganischen Leib“ und ihre „unorganische Natur als Subjekt" des Menschen (Marx 1983: 396), als ihr subjektives Gemeinwesen, das sich ,in der menschlichen Geschichte - dem Entstehungsakt der menschlichen Gesellschaft -“, als seine „werdende“ und „,wirkliche Natur“ (Marx 1968b: 543) zu verwirklichen sucht, weil die menschliche Natur zum Überleben zur Vergesellschaftung des Naturstoffwechsels gezwungen ist und sich dadurch mit seiner vergesellschafteten resp. urbanisierten Erde (fort-)entwickelt und damit einen phylogenetisch unabgeschlossenen Menschen hervorbringt.

Aus dieser dialektischen Perspektive muss die Rede der Erde als Umwelt des Menschen im Hinblick auf den darin implizierten Begriff der Erde als terrestrisches Gemeinwesen zurückgewiesen werden und stattdessen als physisch unmittelbare Mitwelt, eben als ,unorganischer Leib“ (Marx 1983: 396) des Menschen, begriffen werden. Doch damit die Erde wieder als unmittelbare Mitwelt und allen menschlichen Handlungen zugrundeliegendes Subjekt bzw. subjektives Gemeinwesen subjektiv bewusst werden kann - vor allem nachdem es durch kapitalistische Inwertsetzungsstrategien fragmentiert und die Fragmente des ursprünglichen Zusammenhangs unter der Ägide der Naturbeherrschung nur funktional und als einander fremde (d.h. entfremdete) Fragmente wieder zusammengesetzt wurde -, braucht es grundlegende politische Transformationen des Gesellschaftlichen und mithin der gesellschaftlichen Naturverhältnisse. Sah Marx (Marx 1981b: 408f.) die Arbeiterkämpfe seiner Zeit noch als Versuche, durch die sich die als Menschen politisch bewusst werdende Erdnatur gegen ihre Entfremdungen vom subjektiven Gemeinwesen zu wehren gesucht wurde, so müssen aus dieser Perspektive neben den weltweiten Recht-auf-Stadt-Bewegungen auch die weltweiten Klimaproteste von Fridays For Future und die sie unterstützenden Gruppen (Scientists For Future, Parnets For Future etc.) ebenso als solche emanzipatorischen Versuche erblickt werden. Dass Marx davon ausgeht, dass sich die als Menschen politisch bewusst werdende Erdnatur ihrer Entfremdung vom subjektiven Gemeinwesen Erde bewusst wird und versucht, das ursprüngliche Gemeinwesen des Gesamtzusammenhanges der Erdnatur wieder herzustellen und dadurch politisch erst zu verwirklichen, erweist ihn als dialekti- 
schen Ökologen aristotelischer Prägung. So resümiert Blöhbaum die „Dialektik des Ökologiebegriffs unter Berücksichtigung des Physisbegriffs bei Aristoteles":

„Die Dialektik des Ökologiebegriffs besteht eben darin, dass nach einer Phase des Übergangs in der die Natur in ihre Einzelteile zerlegt und die Naturvorgänge und Naturdinge in bestimmte Klassen gesondert werden, die Kenntnis in Bezug auf die Einzeldinge zwar wesentlich erhöht ist, aber in Bezug auf das Ganze immer unlebendiger wird - eine Phase des erneuten Zusammenwachsens einsetzt, in der unsere Begriffe und unser Denken wieder konkreter auf das Ganze der Natur ausgerichtet werden [...].“ (Blöhbaum 1992: 182)

Genau dieses Verständnis dialektischer Ökologie verlangt nach einer umfassenden Kritischen Theorie gesellschaftlicher Naturverhältnisse, die die Ökound Klimaproblematik als Problem der Vergesellschaftung der natürlichen Mitwelt resp. der Urbanisierung der Erde als Entfremdung vom terrestrischen Gemeinwesen, d.h. der Erde als Subjekt des Menschen (Marx 1983: 396) in den Blick nehmen kann und die politischen Versuche, sich dem Naturbeherrschungsimperativ kapitalistischer Inwertsetzungsstrategien menschlicher wie nicht-menschlicher Naturverhältnisse zugunsten einer gemeinwesenorientierten „Naturallianz“ (Bloch 1975: 251) zu erwehren, theoretisierend und strategisch begleitet. In diesem Zusammenhang öffnet sich der Begriff sozialökologischer Transformation. Aber was heißt das genau? Was heißt sozialökologische Transformation und wie lässt sie sich begrifflich als Analysekategorie formulieren, die diesen Zusammenhang kritisch und strategisch in den Blick nehmen kann? Aus der Beantwortung lässt sich zur Kernfrage der Untersuchung vordringen: Worüber muss in der Klimafrage ins Gespräch gekommen werden? Es sind vor allem diese beiden Fragen, die die Teile A-E der Studie zusammenhalten. An sie schließen sich eine Reihe weiterer Fragen an, die in den Teilen A-E weiter entfaltet werden. Fragen nach kommunaler und subjektiver Bildung im Zusammenhang mit Stadtentwicklungsprozessen, die die Politisierung der Klimafrage ins Zentrum künftiger urbaner Lebensweisen rücken. Darin enthalten die Frage nach dem Verhältnis des Ansatzes sozial-ökologischer Transformation zum Ansatz ökosozialer Transformation, der in der Sozialen Arbeit bereits diskutiert wird (Elsen 2013, 2017, 2018). Darin auch enthalten die Frage, wie sich ein Ansatz gesellschaftlicher Transformation subjekt- und gemeinwesenorientiert zu Wege bringen ließe, so dass die Transformationsprozesse nicht nur im technisch-ressourcenschonenden Sinne auf Nachhaltigkeit aus sind, sondern vor allem auch im emanzipatorisch-sozialen Sinne.

Da das Klimaproblem als gesamtökologisches Problem weder rein naturwissenschaftlich noch rein sozialwissenschaftlich angegangen werden kann, sondern neue Wege der professionellen und disziplinären Zusammenarbeit sowie der gemeinsamen Theoriebildung verlangt, muss diese soziale Nachhaltigkeit weder nur im alltäglichen gesellschaftlichen Kontext noch nur im alltäglichen wissenschaftlichen Kontext zu Wege gebracht werden. Viel- 
mehr müsste eine transdisziplinäre Zusammenarbeit zwischen wissenschaftlichen AkteurInnen sowie zwischen wissenschaftlichen und nicht-wissenschaftlichen AkteurInnen im Kontext gesellschaftlicher Alltagspraxis entwickelt und verwirklicht werden. Eine solche theoretische wie praktische Transdisziplinarität (Mittelstraß 2005) muss die Vergesellschaftung resp. Urbanisierung menschlicher wie nicht-menschlicher Naturverhältnisse der Erde kritisch in den Blick nehmen und den gesellschaftlichen AkteurInnen neue und andere Wege der Urbanisierung ihrer Sozialbeziehungen zu sich selbst und zu anderen sowie zur Erde eröffnen, mit denen sie sich zugleich politisch emanzipieren, d.h. mit denen sie ihre spezifische Menschlichkeit und damit sich selbst als Menschen weiter herausbilden können.

Vor dem Hintergrund dieses Anspruchs wird in der vorliegenden Studie der Umriss einer terrestrischen Nachhaltigkeitswissenschaft sozial-ökologischer Transformation entwickelt, die sich vor allem als gesellschaftliche Naturverhältnisse politisierende Arbeit am terrestrischen Gemeinwesen begreift. Um sie zu verwirklichen, müsste sie in den Klima- und Anthropozändebatten daher vor allem von professionellen und wissenschaftlichen AkteurInnen Sozialer Arbeit eingefordert werden, da Soziale Arbeit „einen Blick auf das Soziale einbring[t], den keine andere Wissenschaft ersetzen kann" und entsprechend ,als Profession für die Entwicklung der nachhaltigen Gesellschaft konkret wirken [kann], wie keine andere" (Bartosch 2020: 20). „Eine Praxisforschung, die in ihr Feld verändernd eingreift und dabei die Beteiligung der Betroffenen vorsieht, ist uns geläufig." (ebd.: 22) Dass zwar weder die öffentlichen noch die akademischen Klimadiskurse, dass weder soziale Bewegungen wie Fridays For Future noch die sie unterstützenden Scientists For Future davon Kenntnis nehmen, ist die eine Sache. Dass sich aber zugleich auch Soziale Arbeit weder als Disziplin und noch als Profession von der Klimaproblematik bislang noch kaum angesprochen sieht (von wenigen jüngeren Anrufen von Mührel 2020; Bartosch 2020; Böhnisch 2020; Liedholz 2021; Stamm $2021^{6}$ einmal abgesehen), ist eines der großen Forschungsdesiderate der Gegenwart und trägt letztlich zur ,sozialwissenschaftliche[n] Unterbestimmtheit" (Leggewie 2015: 67) der gesamten Klimadebatte bei. Diese Lücke zu schließen muss daher zentraler Bestandteil künftiger Diskussionen um die Theoriebildung und Professionalität sozialraum- und gemeinwesenorientierter Sozialer Arbeit sein, von wo aus der Transformationsbegriff in der Klima- und Anthropozändebatte neue Impulse erhalten kann. Damit diese Debatten aber überhaupt solche Impulse erhalten, muss sich Soziale Arbeit dort selbst zu Wort melden. Anders: Entweder bringt sich Soziale Arbeit proaktiv und mit einem eigenen Standpunkt in die Debatten ein, oder sie verpasst auf ihrem eigenen professionellen und disziplinären Terrain die Antwortsuche auf die gegenwärtige soziale Frage (Mührel 2020):

6 Die Arbeiten von Böhnisch, Liedholz und Stamm sind nicht mehr in die vorliegende Arbeit eingeflossen. 
Nämlich einen gesellschafts-emanzipatorischen Umgang mit dem drohenden Klimakollaps zu finden. Einen solchen eigenen fachlichen Standpunkt Sozialer Arbeit zu entwickeln - darin ist der ganze Grund dieser Studie zu erblicken.

Hierfür wird im Folgenden in Teil $A$ mit einer Begründung begonnen, sich auch unabhängig vom Autoritätsargument eines weltweiten Konsenses zwischen KlimawissenschaftlerInnen (Cook et al. 2019) mit dem Klimawandel beschäftigen zu müssen, indem dem Klimawandel aus einer Vergesellschaftungs- bzw. Urbanisierungsperspektive auf den Grund gegangen wird. Von dorther wird versucht, die Anschlussfähigkeit Sozialer Arbeit an die Problemlage und die Notwenigkeit Sozialer Arbeit im sozial-ökologischen Transformationsprozess aufzuweisen. Im Anschluss wird der Begriff der sozial-ökologischen Transformation noch einmal näher betrachtet und die Anschlussstelle an bestehende Diskussionen in der Sozialen Arbeit zu Nachhaltigkeit und ökosozialer Transformation herausgestellt, woran das Untersuchungsvorhaben noch weiter konkretisiert wird. In Teil B wird ein aktuelles Gutachten des Wissenschaftlichen Beirats Globale Umweltveränderung (WBGU) möglicher Transformationsentwicklungen näher untersucht. Kernelement ist ein kollaborativ-transdisziplinäres Teilhabekonzept transformativer Stadtentwicklung, das dem „Arbeitsprinzip Partizipation“ Sozialer Arbeit (Kunstreich 2014: 27f.) erstaunlich nah zu sein scheint, letztlich aber den Aspekt der Subjektbildung, der für eine Soziale Arbeit, die sich als emanzipatorisch-transformative Partizipationsprofession versteht, unerlässlich ist, völlig ungeachtet lässt. Von dieser Differenz ausgehend wird der gemeinsame Bezugspunkt des WBGU und einer sich als subjekt- und gemeinwesenorientierte verstehenden Sozialen Arbeit herausgestellt. Dieser gemeinsame Bezugspunkt konzentriert sich in Henri Lefebvres „Recht auf Stadt“, das im Kontext seines Werkes systematisch erschlossen wird. Im Mittelpunkt steht dabei immer wieder die Frage, inwiefern die Überlegungen Lefebvres dem in Teil A herausgestellten Begriffsduo ökosozialer und sozialökologischer Transformation gerecht werden bzw. wo und wie Lefebvre weitergedacht werden muss. Teil $C$ und $D$ stellen ein solches Weiterdenken dar. Zum einen mit einem kommunalistischen Begriff des Politischen (Teil C) und zum anderen mit einer ikonografischen Methode sozial-ökologischer Subjektbildung (Teil D). Es geht dabei nicht um eine konkrete Handlungsempfehlung für die Praxis Sozialer Arbeit, sondern darum, eine Denk- und Praxisrichtung künftiger Professionalität Sozialer Arbeit zu begründen, mit der Soziale Arbeit einen disziplinären und professionellen Zugang zu der zentralen sozialen Frage des 21. Jahrhunderts finden kann: Wie lassen sich die notwendigen ökosozialen und sozial-ökologischen Transformationsprozesse wissenschaftlich-strategisch begleiten und subjektorientiert gerecht gestalten? Abschließend werden in Teil E die erarbeiteten Überlegungen in 
die gegenwärtige Diskussion um eine Kritische Theorie gesellschaftlicher Naturverhältnisse eingeordnet.

Der vorliegenden Studie kommt es dabei vor allem darauf an, eine Argumentation zu Wege zu bringen, die sich dabei in der Tradition der Kritischen Theorie versteht, ohne ihr zugleich minuziös zu folgen, sondern eher lose anzuhängen. Zudem soll mit der vorliegenden Studie nicht nur die „,sozialwissenschaftliche Unterbestimmtheit" (Leggewie 2015: 66) der Klimadiskurse jenseits des kapitalistischen Mainstreams sozialwissenschaftlicher Befassung mit dem Problembereich Klimawandel behoben werden, sondern auch das Desiderat des ganzen Themenkomplexes in den theoretischen und praktischen Diskursen Sozialer Arbeit.

\section{Näheres zum methodologischen Zugang}

Sich überhaupt mit dem Themenkomplex Klima, Klimawandel und den Folgen des Klimawandels zu beschäftigen, bedarf nicht nur vor dem hoch problematischen Hintergrund, dass die Klimathematik durch ihre Verwobenheit mit Staatspolitik (Walkenhorst 2008; Krauß 2016) und Medienberichterstattung (Uekötter 2019; Bojanowski 2019) durchaus vorsichtig zu betrachten ist - was ebenfalls die Zurückhaltung kritischer SozialwissenschaftlerInnen in den Klimadebatten erklären könnte -, eine besondere Rechtfertigung. Sondern auch vor dem Hintergrund des spätestens mit David Hume's (Hume o. A.: 50) skeptizistischer Kritik am Empirismus aufgeworfenen Induktionsproblem (zum Überblick des Induktionsproblems: Popper 1973: $11 \mathrm{ff}$.; Körner 1976: 330f.). Auf den Klimawandel übertragen lässt es sich formulieren: Aus der vergangenen Klimaentwicklung bis in die Gegenwart lässt sich auf der Grundlage logischer Regeln des Schlussfolgerns die künftige Klimaentwicklung nicht zwingend schlussfolgern und prognostizieren. Auch nicht, wenn vergangene Klimaentwicklungsmodelle bereits an der Gegenwart überprüft und bestätigt werden konnten. Eine induktive Prognose einer jeden künftigen Entwicklung verbleibt stets im Rahmen nomologisch deduktiver Ableitungen aus bereits gemachten Erfahrungen bzw. empirischen Daten und ihrer linearen Projektion in die Zukunft. Aus ihnen lässt sich aber kein sicheres, sondern nur ein wahrscheinliches Zukunftswissen ableiten. Nämlich entlang der Wahrscheinlichkeit, dass sich die Ausgangsbedingungen des Modells nicht verändern, oder aber nur so verändern, wie nomologisch-deduktiv ermittelte und in die Zukunft induzierte Annahmen über ihre Veränderungen nahelegen, wie sie sich verändern könnten. Entsprechend vorsichtig müsste das Klimaproblem formuliert werden. Doch gerade diese Vorsicht wird in den öffentli- 
chen Diskursen geradezu diskursiv marginalisiert (Bojanowski 2019), gar in die reaktionäre Ecke des Rechtspopulismus gestellt.

Vor diesem Hintergrund und vor allem vor dem Hintergrund des mit dem Klimawandel zugleich prognostizierten Leid der weltweit vom Klimawandel betroffenen Menschen sowie dem weiteren Aussterben nicht-menschlicher Lebensformen, stellt sich die Frage des philosophierenden Abwägens der Klimaprognosen. Gemeint ist, ob ein philosophisches Problem mehr zu Gewichten ist, als das - möglicherweise falsch hergeleitete, gar übertrieben dargestellte - Leid unzähliger menschlicher und nicht-menschlicher Akteure dieser Erde.

Ausgehend von der Einsicht, dass in der Klimathematik die historische Möglichkeit der emanzipatorischen Politisierung der Existenzbedingungen auf und mit der Erde - d.h. nicht nur des Erdbodens, sondern des ökologischen Gesamtkomplex Erde als dem existenziellen Produktionsmittel der Entwicklung menschlicher wie nicht-menschlicher Lebensformen - schlummert, muss - so das Plädoyer dieser Studie - die Höhergewichtung des Induktionsproblems abgelehnt werden. Der Präferenz für die politische Bekämpfung absehbaren Leids gegenüber philosophischen Problemen liegt die Präferenz für die leibliche Leidensfähigkeit des (nicht nur) menschlichen Leibes zugrunde, mit der bereits Feuerbach ${ }^{7}$ den Grundstein für die Praxisphilosophie gelegt hatte und sie von Anfang an als sensualistisches LeibErde-Verhältnis formuliert hatte. ${ }^{8}$ Gemeint ist eine Philosophie, die sich nicht mehr nur um theoría und um sich selbst dreht, sondern bei der es vor allem um pragma, um Praxis geht. ${ }^{9}$ Ausgehend von Feuerbachs Diktum, womit er

7 Zwar hatte bereits Schopenhauer (vor allem in seinem Werk „Die Welt als Wille und Vorstellung“, Schopenhauer 1998) die menschliche Leiblichkeit und ihre Leidensfähigkeit fokussiert und damit (s)eine Mitleidsethik begründet (zum Überblick: Schmidt 1988b, Niemann 2010), allerdings suchte er hierfür noch nach metaphysischen Begründungen, nicht nach physischen resp. sensualistischen, wie etwa zur gleichen Zeit Feuerbach.

8 Schmidt resümiert Feuerbachs sensualistisch-erdverbundene Leibphilosophie: „Nochmals sei betont, dass das ,sensualistische Prinzip“ keine begriffslose Bestandsaufnahme dürrer Fakten sein kann; denn selbst von ihnen wäre ohne Denkarbeit nicht zu reden. [...] Die Sinnlichkeit als , wahre, nicht gedachte und gemachte, sondern existierende Einheit des Materiellen und Geistigen': ein radikal ,vom Denken unterschiedenes Element" bildet Alpha und Omega jedes Erkenntnisprozesses. Sie ist das auf ,Geist" schlechthin Irreduktible, untilgbarer Erdenrest." (Schmidt 1988a: 84f.) Diesen „untilgbaren Erdenrest“ (ebd.) des sensualistischen Leib-Erde-Verhältnisses, das ja auch das ganze Marxsche Werk durchzieht (Schmidt 2016), hebt Feuerbach wohl am deutlichsten in seinen „Vorlesungen zum Wesen der Religion“" hervor (Feuerbach 1908: 115f., 160).

9 Während im griechischen Wort theoría eine „Kontemplation“ zum Ausdruck kommt, „für die ja auch charakteristisch ist, dass der Mensch nicht als geistig Bohrender dabei tätig ist, sondern sich nur öffnet gegenüber einem Gegenstand, der ein heiliger und umfassender ist"“ (Schadewaldt 1978: 182), kommt im griechischen Wort pragma zum Ausdruck, ,worin man in der Praxis des Lebens verwickelt ist, was also nicht gegenübersteht und entgegensteht $[\ldots]$, sondern worin man sich bewegt und womit man es zu tun hat" (Gadamer 2012: 155f.). 
eine „Reformation der Philosophie“ (1842) zu begründen versuchte und wonach die „Philosophie [...] nicht mit sich, sondern mit ihrer Antithese, mit der Nichtphilosophie zu beginnen“ (Feuerbach 1969: 181) habe und das zugleich als Theorem der marxschen Praxisphilosophie angesehen werden kann, liegt der vorliegenden Studie daher die Entscheidung zugrunde, das möglicherweise auch nicht oder weniger drastisch eintretende Leid der Prognosen der Klimaforschung mehr zu gewichten, als das philosophische Problem der Induktion.

Aber auch schon kurz vor Feuerbachs materialistischen Begründungsversuchen einer „Reformation der Philosophie“ (1842) stellte bereits Marx (1840/41) in seinen Anmerkungen zu seiner Dissertation die Forderung auf, die Welt müsse philosophisch und die Philosophie müsse weltlich werden (Marx 1968a: 328, 329). Eine leibphysiologische Wendung bekam das Marxsche Diktum allerdings erst mit Feuerbach und ihre konsequent dialektischmaterialistische, d.h. praxisphilosophische Vollendung bekam sie wiederum erst in Marx späteren „Pariser Manuskripten“ (zum Überblick: Schmidt 2016). Mehr als 100 Jahre später schließt Henri Lefebvre hier an und präzisiert die ganze Entscheidungskaskade, an der entlang sich eine Wendung der Philosophie zur Praxisphilosophie vollziehen müsse. In einer verkürzten Form lässt sie sich zusammenfassen (ausführlicher siehe Kap. 12.1.1, Teil B):

„Entweder läßt der Philosoph das politische Handeln, den Staat und die Politik außerhalb seines Denkens [...]. [...] Oder der Philosoph tritt mitten ins politische Leben ein, d. h. er läßt die Politik und den Staat in seine Philosophie eintreten: Dann muß er sofort die peinliche Wahl zwischen verschiedenen Wegen treffen, von denen keiner als philosophisch befriedigend angesehen werden kann.“(Lefebvre 1975c: 71)

Die Entscheidung, meine Dissertation, die im Folgenden als Studie oder Untersuchung bezeichnet wird, der aktuellen Klimaproblematik zu widmen und sie so auszuformulieren, wie es hier getan wird, ist eine solche ,peinliche Wahl zwischen verschiedenen Wegen [...], von denen keiner als philosophisch befriedigend angesehen werden kann" (ebd.). ABER: Soll Philosophie tatsächlich Praxisphilosophie sein, so meine Begründung, muss sich aus ethischen Gründen auf das Wagnis der Induktion einlassen, da auf sie, wie Körner Hume zusammenfasst, ,nur ein ,Narr oder ein Wahnsinniger' verzichten könnte“ (Körner 1976: 330, zum Überblick der aktuellen Diskussion des Induktionsproblems sowie dessen vermeintlicher Lösung bei Popper 1973: Albert 2010b, 2010a, 2011; Hoerster 2010a, 2010b, 2011; Schramm 1998). Entsprechend muss Praxisphilosophie, das ist nun der ethische Ausgangspunkt der vorliegenden Studie, dem leiblichem Leiden auf und mit der Erde mehr Aufmerksamkeit schenken als den Regeln der Philosophie. Andernfalls würde nicht nur Philosophie Philosophismus hervorgebracht, sondern auch die Erdvergessenheit der Moderne (re)produziert, die die subjektive Erdverbundenheit des Leibes aus den Augen verloren hat. Damit wird nun letztlich auch der Dialektische Materialismus als Erkenntniszugang zur Welt fokus- 
siert. Da „bis heute keine historisch-philologisch gesicherte und anerkannte Rekonstruktion des Marxschen Begriffs von Dialektik erbracht" (Arndt 2012: 216) wurde, wird an dieser Stelle unter materialistischer Dialektik bzw. dialektischem Materialismus eine „theoretische Anstrengung“ verstanden, „die darauf abzielt, daß kein Mensch auf der Welt mehr materielle und intellektuelle Not leidet“ und „den Menschen aus dem selbstgeschmiedeten Käfig undurchschauter ökonomischer Determination heraushelfen [will]" (Schmidt 2016: 52f.). Damit erweist sich der Dialektische Materialismus bei Marx als ethisch motivierte Kritik der „bloß empirische[n] Bestandsaufnahme der Fakten“, weil sie „das Erkenntnisinteresse an der Reflexion des sozialen Ganzen und seiner geschichtlichen Möglichkeiten abschneidet" und stattdessen ,im Bann des Bestehenden [verharrt]“" (Schmidt 2018a: 69f.).

Die hier betonte Vergessenheit der physischen Natur resp. Erde unterscheidet sich von der Fundamentalontologie der Heideggerschen „Seinsvergessenheit“ (Heidegger 2000c), insistiert aber zugleich auf eine ähnliche Kritik der Moderne, die bis zur Abwertung der Natur bei Platons Sokrates zurückreicht, wonach ihm ,[d]ie Felder und die Bäume [...] nichts lehren [wollen], wohl aber die Menschen in der Stadt" (Platon 1940: 415). Mit dieser Zurückweisung der Natur reduzierte Platon letztlich das Politische auf das In-der-Stadt, statt es, wie noch in der ionischen Naturphilosophie, im Kontext und der Entwicklung der gesamten Physis zu erblicken (zum Überblick: Schadewaldt 1978: 201ff.), die durch die Politik und politische Erziehung überhaupt erst ihre Ausformulierung bekommt (insbesondre bei Heraklit, zum Überblick: Bremer/Dilcher 2013). Während Heideggers Philosophie hieran aber nichts zu verändern vermochte, ist es inhärenter Auftrag von Praxisphilosophie seit Marx, das Verhältnis von Erde/Natur und Gesellschaft wieder zu politisieren. Dieses Verhältnis hat seinen Ort in der bürgerlichkapitalisierten Praxis der Urbanisierung und den damit verschränkten urbanen Lebensweisen, von wo aus es seinen Weg zum Klimawandel nimmt (Kap. 1). Zur Frage steht, welche Urbanisierungsform wie und womit den Klimawandel hervorruft. Entsprechend soll sich im folgenden Teil A dem Klimawandel aus einer Urbanisierungsperspektive näher zugewandt werden. 


\section{Teil A}

\section{Der Klimawandel und}

seine gesellschaftliche Bedeutung im Allgemeinen und für Soziale Arbeit im Besonderen 



\section{Problembefund Kapitalozän: der Klimawandel aus einer Urbanisierungsperspektive}

Wenn der WBGU die ,Städte und Stadtgesellschaften als [...] für den überwiegenden Teil aller weltweiten Ressourcenverbräuche und Treibhausgasemissionen [verantwortlich]“ herausstellt (WBGU 2016b: 2), die sich mit den absehbaren Urbanisierungsentwicklungen noch dramatisch erhöhen werden, dann ist damit aber allenfalls der Anlass des anthropogenen Klimawandels benannt. Denn die Ursachen sind ,tief in die Produktions- und Konsumtionsweise der Industrieländer eingelassen [sind]" (Walkenhorst 2008: 1042) und bringen dadurch erst den Menschen als homo geo-destructor hervor. Entsprechend betont Altvater, dass es

„nicht die Menschen schlechthin [sind], sondern die Menschen in der kapitalistischen Produktionsweise, die die grandiosen Veränderungen aller Erdsysteme seit der industriellen Revolution bewirkt haben. Ihre Vorfahren in nicht- und vorkapitalistischen Gesellschaftsformationen haben zwar große Veränderungen in der Kultur, in der Agrikultur und Politik, in der Ökonomie und in der Architektur zustande gebracht. Sie waren also kreativ, häufig auch innovativ. Doch die räumliche und zeitliche Reichweite wurde erst unter kapitalistischen Verhältnissen so über alle menschlichen, gesellschaftlichen und natürlichen Maße gedehnt, dass auch Erdsysteme umgewälzt worden sind und der Mensch selbst zum biotisch-technischen Avatar-Hybrid mutieren konnte (Hörz und Hörz 2013). Der moderne Kapitalismus ist heute also mehr als eine Gesellschaftsformation. Er usurpiert und verändert die menschliche Existenz und ist inzwischen eine erdsystemische Formation. Er ist in den Gesteinsschichten der Erde nachweisbar und zum Kapitalozän geworden. Als solches ist der moderne Kapitalismus die zeitgemäße Form des dialektischen Mensch-Gesellschaft-Natur-Zusammenhangs.“ (Altvater 2015: 62f.)

Im Folgenden soll sich die Entwicklung der kapitalogenen Ursachen des Kapitalozäns, d.h. der den Klimawandel forcierenden bürgerlichen Form der Urbanisierung der Naturverhältnisse der Erde etwas näher angeschaut werden. Die Bezeichnung kapitalogen dient dabei der Beschreibung eines Effekts, etwa des Urbanisierungseffekts, der sich entlang der Kapital(re)produktion vollzieht. Als Kapitalozän oder kapitalozäner Prozess wird hingegen der geologische Veränderungsprozess der Erdökologie, wie etwa der Klimawandel, bezeichnet, der sich entlang des Kapital(re)produktionsprozesses vollzieht. Die Endung -zän insistiert hierbei auf den in der Geologie typisch anzutreffenden Begriffspartikel zur Beschreibung bestimmter Erdepochen, wie das Miozän, Pliozän, Pleistozän, Holozän etc. 


\subsection{Von der Sesshaftwerdung zur Handelsware Stadt}

Während in der vorherrschenden Diskussion für den menschengemachten Klimawandel der Begriff des Anthropozäns ${ }^{10}$ (zum Überblick: Dürbeck 2018a, 2018b; Lesch/Kamphausen 2016) aufgebracht wird, erscheint dieser vor dem Hintergrund der als Kapitalozän beschriebenen Entwicklung als zu unkritisch und ist unter kapitalogenen Vorzeichen entsprechend kritisch aufzubereiten. Dazu gehört nicht nur, das damit Begriffene in seiner Entwicklung nachzuzeichnen, sondern auch, statt nach empiristisch genauen geologischen und/oder chemischen Markern des Beginns des Anthropozäns zu suchen (zum Überblick der Diskussion um den golden spike des menschengemachten Klimawandels, des Anthropozäns: Leinfelder 2015), das gesamte Holozän als einen zusammenhängenden sozialen Handlungskomplex zu begreifen, der sukzessive einen menschengemachten Klimawandel hervorgebracht hat und ihn weiterhin hervorbringt.

Die Entstehungsgeschichte des Klimawandels als holozänen Handlungskomplex lässt sich mit Altvater (2017) und Wulf (2020) als mehrphasige Entwicklung darstellen: Beide sehen in der globalen Erwärmung nach dem Ende der letzten Eiszeit eine erste Phase einsetzen, die im allgemeinen als neolithische Revolution bezeichnet wird und gekennzeichnet ist durch das Sesshaftwerden der Menschen, ihrer Entwicklung von Landwirtschaft und des Handels sowie der ,wachsende[n] Ausbreitung des Menschen über die Erde“" (ebd.: 192). Genauer: Die erste Phase des Anthropozäns setzt mit dem Durchsetzen der Lebensweise ein, Mittel zum Leben „unter Nutzung der Sonnenenergie und des Feuers selbst zu produzieren" und der damit aufkommenden Arbeitsteilung, die ,immer auch Herrschaftsteilung war und ist": etwa ,von Männern über Frauen, der geistigen über die körperliche Arbeit, der Stadt über das Land, [...] die des Menschen über die Natur" (Altvater 2017: 109). Während Wulf historisch vom Ende der letzten Eiszeit gleich zur „Industrialisierung um 1800“ (Wulf 2020: 192) springt, sieht Altvater in der altertümlichen Institutionalisierung der Arbeits- und Herrschaftsteilung, die entlang der Mythologien und Religionen der alltäglichen Praxis jeweils narrative Rahmen gaben (Altvater 2017: 109), eine zweite Phase einsetzen. Eine dritte beginnt für ihn mit der Einmündung der arbeitsteiligen Rationalität in das „Projekt der Welteroberung, das seit dem 11. Jahrhundert von WestEuropa seinen Ausgang nahm und dabei die christliche Religion als missionarisches Versprechen der ökonomischen und politischen Kolonialisierung

10 Der Begriff Anthropozän geht auf Paul Crutzen und Eugene Stoermer (Crutzen/Stoermer 2000; Crutzen 2011) zurück, steht aber erst am Ende einer Reihe begrifflicher Formulierungen, die das geologische Wirken des Menschen auf die Erde fassen sollen und bis in die Mitte des 19. Jahrhunderts zurückreichen (zum Überblick: Ali-Zade/Aliev 1985: 70; Leinfelder 2015: 8, 2017: 260; Kersten 2014: 379). 
nutzte" (ebd.). Die vierte Phase, die ins Wulfs Phasenmodell als zweite Phase gezählt wird, kann als „Zeitalter der großen Maschinen“ bezeichnet werden (Wulf 2020: 192) und setzt dieselbe Rationalität zwischen dem 18. bis zur Mitte des 20. Jahrhunderts mit ,mächtigeren Mitteln“, d.h. mit ,geeignete[n] Maschinen“ fort, die die ,in Arbeitsenergie umgewandelte Primärenergie [...] nicht mehr von der Sonne, sondern aus terrestrischen Bordmitteln, die aus der Erdkruste extrahiert werden müssen“, beziehen (Altvater 2017: 109):

„Erst jetzt kann sich die kapitalistische Produktionsweise der systematischen Produktion einer ungeheuren Warensammlung durchsetzen. Mehrwert zu produzieren und dessen Produktion maximal zu steigern, wird zum vorrangigen Ziel. Der gesamte Globus wird in ein Ressourcenlager, ein Arbeitskräftereservoir und eine Deponie für alle möglichen Abfälle verwandelt. Die Ausbeutung von Menschen durch andere Menschen wird ebenso wie der Stoffwechsel zwischen Mensch und Natur globalisiert. Allerdings funktionieren die Treiber der vielfältigen metabolischen Kreisläufe höchst einfältig kapitalistisch. Der Überschuss wird als Mehrwert ins Verhältnis zum Ursprungswert gesetzt und als Profitrate bestimmt. Das kapitalistische A und O ist es, diese zu optimieren. Natürliche Grenzen sind da unerheblich, weil sie als solche gar nicht erkannt und beachtet oder umgedeutet werden, indem die Natur als Naturkapital interpretiert wird, in der Naturgrenzen durch Verwertungsgrenzen des Kapitals ersetzt werden.“(ebd.: 109f.)

In der Nachkriegszeit seit 1945 und bis 2015 erwächst aus dieser Entwicklung eine fünfte Phase, die mit der Nuklearenergie ,[a]uf die Spitze [...] getrieben" wird (ebd.: 111). Sie beginnt mit dem Abwurf der ersten Atombombe und ist ,durch die gewaltige Beschleunigung des Lebens, die damit verbundene wirtschaftliche Expansion sowie die Erfindung und globale Verbreitung der neuen Medien“" gekennzeichnet (Wulf 2020: 192). Aber erst im Jahr 2015 setzt mit dem „Beschluss der UNO-Vollversammlung über die Ziele nachhaltiger Entwicklung“ (ebd.; vgl. Vereinte Nationen 2015a) eine sechste, politische Phase ein, die „zu umfangreichen, von Sorge getriebenen Korrekturen menschlichen Verhaltens auf dem Planeten führt" (Wulf 2020: 192).

Ein solches Phasenmodell erdgestalterischer Menschheitsgeschichte kann mit Lefebvre (Lefebvre 2014) als Urbanisierungsprozess auf den Begriff gebracht werden, wobei damit bei ihm aber nicht nur dieser menschheitsgeschichtliche Ausschnitt, sondern darüber hinaus die ganze Erdgeschichte als Urbanisierungsprozess begriffen wird. Dieser terrestrische Urbanisierungsprozess impliziert, wenn auch nicht von Lefebvre expliziert, immer auch eine Klimagestaltung. In dieser Entwicklung tritt der Mensch in Erscheinung und übernimmt sie im zunehmenden Maße. Erdgeschichte und Menschheitsgeschichte sind damit von Anfang an untrennbar miteinander verflochten und entwickeln sich miteinander, d.h. aneinander und durch einander fort. Urbanisierung lässt sich mit Lefebvre daher verstehen als Prozess „,von der ,reinen Natur', der den Elementen ausgelieferten Erde [.] bis zur gänzlichen Vollendung des Prozesses“, der noch ausstehenden vollständigen Urbanisierung der Erde, d.h. der vollständigen Zurichtung der Erde für das städtische Leben auf der Erde. Unter kapitalistischen Bedingungen wird dieser Prozess nun zu- 
nehmend zum Problem und zerstört sukzessive die Bewohnbarkeit der Erde (ebd.: 13, 158). Anders formuliert: Ging aus dem geologischen Urbanisierungsprozess der Erde die Entwicklung der Menschen hervor, und ging der Urbanisierungsprozess der Erde durch die holozäne Menschheitsentwicklung dazu über, das Von-Selbst der natura naturans einzuhegen und landwirtschaftlich bzw. agrilogistisch zu kultivieren, so hat er entlang der arbeitsteiligen Rationalität seine eigenen menschengemachten Sachzwänge produziert und begonnen sich zu verselbstständigen. Dementsprechend ,[haben] wir [...] es inzwischen mit einer zweiten Natur zu tun, welcher der ersten an Macht und Gewalt in keiner Weise nachsteht: Die kultivierte Natur, die natura culturata, wirkt mit der unkontrollierbaren Kraft der natura naturans zurück auf die Kultur" (Becker-Lindenthal 2017: 169). Mit Lefebvre (Lefebvre 1974: 18) lässt sich diese zweite Natur als „Stadtkultur“ bzw. „'automatisierte" Natur" konkretisieren, deren Genese im Folgenden näher betrachtet werden soll.

Maßgeblich beteiligt an der Autonomisierung des menschengemachten Urbanisierungsprozesses war die Einführung der Münzwährung in der griechischen Antike, durch die die arbeitsteilige Rationalität um die rationale Arbeitsteilung von Handarbeit und Kopfarbeit erweitert wurde und sich so zum einen das konflikthaften Klassenverhältnis von Grundbesitzern und Besitzlosen bis hin zum Krieg der gesamten antiken Welt verschärfte (Heuss 1962; Meier 1983; Holz 2011). Zum anderen brachte die Einführung der Münzwährung die Mathematisierung der Tauschabstraktion hervor und mit ihr die Übertragung der Rationalität des Geldkreislaufs und der Sachzwänge der Kapital(re)produktion auf das städtische Alltagsleben. Mithin wurde die Rationalität des Geldkreislaufs und der Sachzwänge der Kapital(re)produktion auch auf die erkenntnistheoretische und philosophische Begriffsbildung der Realabstraktion übertragen (Sohn-Rethel 1989, 1990), wo sie regional unterschiedlich aufgenommen wurde (Sommer 2012, 2013; Reden 2015) und die verschiedenen Erkenntnistheorien sowie philosophischen Begriffsbildungen der sog. Vorsokratiker hervorbrachte (zum Überblick: Diels 1906; Capelle 2008; Flashar et al. 2013; Schadewaldt 1978).

Von einem Kapitalismus im modernen Sinne kann allerdings noch keine Rede sein, weil zum einen die urbane Subsistenz der Haushalte noch nicht systematisch verunmöglicht und ein entsolidarisierter Individualismus entsprechend noch nicht notwendig wurde (Stein-Hölkeskamp 2015: 178ff., 213ff.). Zum anderen wurde der Wirtschaftskreislauf noch zu keiner Zeit als eigenständiges und von menschlichen Handlungen losgelöstes System von ökonomischen Gesetzen und Rationalisierungen verstanden (zum Überblick der Unterschiede vom antiken zum modernen Kapitalismus: Reden 2015: 2, 86; Sommer 2013: 61), was ja erst die gegenwärtig empfundene Ohnmacht gegen die zerstörerische Wachstumsökonomie begründet und zugleich zum Kern der Kritik am kapitalistischen Ökonomiebegriff vordringt. Was die Al- 
ten noch wussten, ist den Modernen aus dem Blick geraten: Ökonomie ist ein Begriff menschengemachter Praxis, nicht menschenunabhängiger Gesetze.

Die Scharnierstelle zum modernen Kapitalismus (und damit zum Kapitalozän) lässt sich indes erst im Städtebau des 12./13. Jahrhundert ausfindig machen (Mathis 1992: 118; Ganshof 1963: 405ff.). Ausgehend von zahlreichen Kirchenreformen seit dem 9. Jahrhundert und ausgehend von den daraus resultierenden Zuspitzungen des Konflikts zwischen Papsttum und Kaiser bei dem der politische Triumph zu dieser Zeit noch bei der Kirche lag (Russell 2009: 419ff., 440ff.) - wurden Bestrebungen zur Gemeindebildung nach italienischem und französischem Vorbild durch Klosterreformen zur politischen Tagesordnung erhoben und stießen ,im europaweiten Vergleich“ insbesondere die lombardischen Städte über die Jahrhunderte - nicht zuletzt durch die kaiserlich-politischen Gegenbewegungen durch die Förderung der „nichtkirchlichen Kultur“ in den Städten, wie Literatur, Kunst und Wissenschaft (ebd.) - zu einem „bisher nicht gekannten sehr hohen Urbanisierungsgrad im Reich" an (Hirschmann 2012: 1358). Mit der durch die päpstlichen Reformen und den kaiserlichen Gegenbewegungen einhergehende feudale Neuordnung des Land-Stadt-Verhältnisses und der daraus resultierenden Bevölkerungszunahme in den Städten wurde es zunehmend schwieriger, „die wachsende Bevölkerung mit landwirtschaftlich nutzbarem Boden zu versorgen“, so dass „,sich immer mehr Menschen veranlasst [sahen], ihren Lebensunterhalt aus gemischten Einkommen landwirtschaftlicher und gewerblicher Natur zu bestreiten“" (Mathis 1992: 119f.). Den Städten kam dadurch die „Funktion als Zentren von Handel und Gewerbe“ zu, welche das städtische Handwerk vor die Herausforderung stellte, ,den Großteil der in den Handel gelangenden gewerblichen Produkte" zu liefern (ebd.). Die Städte indes begannen sich dadurch als „Nervenzentren der sich weiter entfaltenden Binnenwirtschaft" herauszustellen (ebd.). Dies konnte aber nur erfolgen,

„wenn die Landwirtschaft in der Lage war, so viel zu produzieren, dass neben der Deckung des Eigenbedarfs auch die städtische Bevölkerung ernährt werden konnte. [...] Neben der schieren Notwendigkeit, Mittel und Wege zu finden, die wachsende Bevölkerung zu ernähren, waren es insbesondere die im Verhältnis zu anderen Preisen und zu den Löhnen rascher steigenden Getreidepreise, die die Bauern veranlassten, sich um eine Produktionssteigerung zu bemühen.“ (ebd.: 120)

Dies war allerdings „nur ein[em] Teil der Bauern, nämlich [der] rechtlich bessergestellten und die mit größeren Bodeneinheiten ausgestatteten“" möglich, während hingegen ,die Mehrzahl von ihnen [...] - insbesondere in Zeiten schlechterer Ernten - Mühe hatten, die Selbstversorgung sicher zu stellen“, und daher gezwungen waren, ihr (Über-)Leben in den Städten gewerblich zu bestreiten (ebd.). Mit dem Funktionswandel der Städte vom politischen zum marktwirtschaftlichen Raum gingen erhebliche städtebauliche Veränderungen einher (Lefebvre 2014: 16f.), die sehr viel - seit dem 13. Jahrhundert systematisch kreditfinanziertes (Ganshof 1963: 411) - Geld 
benötigten und damit Sachzwänge schufen, den städtischen Raum die investierten Kosten amortisierend und gewinnbringend $\mathrm{zu}$ organisieren und $\mathrm{zu}$ vermarkten. Diese allmähliche Herausbildung des städtischen Raums als kapitalbildende Handelsware (Lefebvre 2016: 30f., 2014: 16f.) war zugleich die Geburtsstunde der bürgerlichen Gesellschaft und ihrer sukzessive die Nationalstaaten bildenden Organisierung der Reproduktion der Vormachtstellung ihrer eigenen Handelsklasse entlang der Bedarfsdeckung des steigenden Rohstoffbedarfs in den Städten (Getreide, Holz, zunehmend Metalle/Erze, Sand) und vor allem entlang des weiter zunehmenden banken- und kreditfinanzierten Städtebaus. In ihrem Zusammenwirken schufen sie die Bedingungen, den marktwirtschaftlichen Raum systematisch auszubauen und die räumlichen Möglichkeiten zur urbanen Subsistenzwirtschaft systematisch abzubauen, indem entsprechend benötigte Agrarflächen und -böden zunehmend mehr gegen Geld und zunehmend weniger gegen Dienste und Naturalien zur Nutzung überlassen wurden (Engel 1993: 270ff.). Auf diese Weise wurden zwei gesellschaftliche Erscheinungen zu einer bürgerlich-adligen Allianz zusammengeführt: Der ,,aus Handelsgeschäften gespeisten, auf Anlage drängende[] Geldbesitz auf bürgerlicher Seite" verband sich mit dem „Geldbedarf von Fürsten und Adel, die Land, Schlösser, Bauernhöfe, Eigenwirtschaften, bäuerliche Geld- und Naturalabgaben veräußerten", so dass die „Eigenversorgung mit Lebensmitteln und Rohstoffen“ der Städte und Fürstentümer, sowie die „Produktion von Getreide als Handelsware“ durch Kontrolle der Handelswege und ihrer Nutzung gegen Raub zwar sichergestellt werden konnte, letztlich aber den Mittellosen jegliche Möglichkeit nahm, sich jenseits der Marktwirtschaft zu versorgen (ebd.: 273ff.). „Landbesitz und vor allem Rentenkauf waren ferner eine risikoarme, gewinnbringende Kapitalanlage - eine Art Bank“ (ebd.) - und, nicht zu vergessen: eine profitable Privatisierung der Erde, die den Mittellosen epochemachend den Boden unter Füßen entzog. Damit wird eine bis zum Klimawandel reichende Inwertsetzung menschlicher wie nicht-menschlicher (Erd-)Naturverhältnisse in Gang gesetzt, die durch die marktwirtschaftliche Logik der Mehrwertproduktion seinerzeit zur Steigerung der Agrarpreise und Grund- bzw. Bodenrenten führte und durch die dadurch erzeugten weiteren massenhaften Entlassungen Leibeigener Bauern in die Heerscharen der Tagelöhner in den Städten zugleich bis zur „Verarmung der Mehrheit der deutschen Bevölkerung im 16. Jahrhundert“" (Mathis 1992: 121) fortentwickelte. 


\section{2 „Urbanisierung des Kapitals“ und „,imperiale Lebensweise"}

Mit der marktwirtschaftlich bedingten Vergrößerung der städtischen Bevölkerung wuchs unter der politischen Ökonomie des Bodens in den Städten zugleich der Bedarf an konsumistischer Versorgung mit Mitteln des alltäglichen Lebens, woraus die Notwendigkeit neuer Technologien und Techniken der effizienteren und effektiveren landwirtschaftlichen Produktion und Distribution der Waren hervorging. Diese Notwendigkeit machte wiederum eine industrielle Infrastruktur der Städte und der städtischen Versorgung notwendig, bei der sich der Städtebau und der städtische Alltag zunehmend um diese zu organisieren begann. Dieser Prozess gesellschaftlicher Entwicklung macht wiederum eine die Inwertsetzung menschlicher und nicht-menschlicher Naturverhältnisse notwendig. In dieser dreifach verschränkten und sich bedingenden Entwicklung gerieten die alltäglichen sozialen und ökologischen Voraussetzungen der städtischen Alltags(re)produktion aus dem Blick. Industrialisierung meint daher nicht ,lediglich die Ansiedlung eines oder mehrerer industrieller Betriebe auf der Gemarkung einer Stadt" seit den letzten zwei bis drei Jahrhunderten, sondern die „funktional-räumliche[] Transformation der europäischen Stadt" und die für das Gelingen dieser Transformation notwendige Organisation von Natur, die ,grundlegend die Art und Weise veränderte, wie Stadt als Gesamtsystem funktionierte“ (Schott 2014: 280) und vor allem: wie Städte terrestrisch eingebettet waren. Diese Urbanisierungstrialektik setzt um das 12. Jahrhundert ein und entwickelt sich seither zur zweiten Natur der Menschen fort, der sie ebenso ausgeliefert ist, wie einst den Naturzwängen. Allerdings mit dem Unterschied, dass diese zweite, technologisch vernetzte Natur durch den Bau von Straßen, Trassen, Gebäuden, Fabriken und Röhren- bzw. Leitungssystemen zugleich eine ,gigantische Kapitalinvestitionen“" verkörpern und dadurch die ,raumstrukturelle[n] Weichenstellungen“ für „das kommunale und planerische Handeln“ (ebd.: 303) der folgenden Generationen vorprägen. Industrialisierung hat damit also nicht nur allmählich die ,städtische Alltagswirklichkeit“ revolutioniert, etwa durch die „Abkopplung städtischen Lebens von natürlichen Lichtverhältnissen“, die Neudefinition der „Bedeutung räumlicher Distanzen“ durch die sich entwickelnden Nahverkehrssysteme, die mit der industriellen Zersiedelung der Städte notwendig wurden und an die in der zweiten Hälfte des 20. Jahrhundert das städtebauliche Konzept der autogerechten Stadt nahtlos anknüpfen konnte (Schott 2014: 282; Bernhardt 2017). Sondern hat auch die politischen Strukturen der Stadtentwicklung von den demokratischen (Kinder-)Füßen der frühen griechischen Antike auf den plutokratischen Kopf des modernen Kapitalismus gestellt. Industrialisierung bedeutet vor diesem Hintergrund also vor allem das Agieren und Fortagieren in technologischen wie finanziellen, d.h. 
investitions-amortisierend-administrativen, kurz: urbanisierten polit-ökonomischen Pfadabhängigkeiten, die sich „,bis heute noch vielfach hindernd und erschwerend bemerkbar [machen], wenn etwa städtische Infrastrukturen im Sinne nachhaltiger Stadtentwicklung umgestaltet und modernisiert werden sollen“ (Schott 2014: 303).

Das Problem des ansteigenden Ressourcenverbrauchs zur alltäglichen städtischen Versorgung unter marktwirtschaftlichen Bedingungen machte den Ausbau der seit der (vor allem römischen) Antike bestehenden kolonialen Landnahme von Asien, Afrika sowie Nord- und Südamerikas notwendig. Mit der Vergrößerung der europäischen Welt durch die Kolonialisierung ging seit dem 11./12. Jahrhundert die „Beschleunigung aller Prozesse in der Produktion, Kommunikation, Zirkulation, einschließlich des Transportwesens, und der Konsumtion“ einher, die „letztlich [...] auch die Evolution des Lebens [erfasst]" (Altvater 2015: 60). Dadurch war es entlang der Kolonialisierung der neuen Welt nun möglich, neue Rohstoffe zu gewinnen, etwa Holz, Metalle und Erze, mit denen „Apparaturen zur Steigerung der Produktiv- und Destruktivkräfte" konstruiert und eingesetzt werden konnten, welche bis hin zu fossilen Antriebsarten fortentwickelt wurden (ebd.: 61) und kontinuierlich die Produktion ,billiger Arbeitskraft, billiger Nahrung, billiger Energie und billige[r] mineralische[r] und agrarische[r] Ressourcen" begünstigten (ebd.: 62). „Diese ,four cheaps““, so Altvater in Bezug auf Moore, „waren im Rahmen einer gesellschaftlichen Formation bedeutsam, deren handelnde Subjekte es verstanden, sie zu ihrem und der Gesellschaft Vorteil zu nutzen und alles, was dem Nutzen im Wege stand, zu eliminieren oder zu externalisieren“ (ebd.). Die nicht nur in Europa, sondern auch in Asien, Afrika sowie Nordund Südamerika zum Arbeiten gebrachten menschlichen wie nicht-menschlichen Naturverhältnisse erfuhren zunächst mit den Warenbörsen (Gründung 1409 in Brügge) und später Aktienbörsen (Gründung 1639 in Amsterdam), und der damit einhergehenden vergrößerten und beschleunigten Möglichkeiten Kapital zu generieren, weitere Verbilligungen und ein schier grenzenloses Wirtschaftswachstums, das ,zu einer noch nie dagewesenen revolutionären Umgestaltung von Landschaft [führte]“ (Moore 2016: 607). D.h. zu einer kapital(re)produzierenden privatwirtschaftlich organisierten Urbanisierung der Erde, die sich geradezu sachzwanghaft die Fortentwicklung von (Geld)Märkten, der (Geld-)Marktabhängigkeit (ebd.: 605ff.) sowie die staatliche Regulierung und Verwaltung beider Entwicklungen einfordert. Ein Prozess, der Erdgeschichte schreibt (Altvater 2015: 62f.) und mit Harvey im Anschluss an Lefebvre als „Urbanisierung des Kapitals“ bezeichnet werden kann:

„Die Reproduktion des Kapitals durchläuft auf verschiedensten Wegen Prozesse der Urbanisierung. Doch die Urbanisierung des Kapitals setzt voraus, dass kapitalistische Klassenmächte in der Lage sind, den urbanen Prozess zu bestimmen. Dies wiederum impliziert nicht nur die Herrschaft der kapitalistischen Klasse über den Staatsapparat (insbesondere über die Aspekte staatlicher Macht, die die sozialen Bedingungen und die Infrastruktur innerhalb territorialer Strukturen 
verwalten und lenken), sondern auch die gesamte Bevölkerung - über ihren Lebensstil und ihre Arbeitskraft, ihre kulturellen und politischen Werte sowie ihre Vorstellungen von der Welt. Ein solches Ausmaß an Kontrolle ist, wenn überhaupt nicht leicht zu erreichen." (vgl. Harvey 2014: 126)

Um die Bindung der Macht des Kapitals bzw. der Macht der KapitaleignerInnen über die Lebensweise der Menschen an die gebaute Umwelt binden zu können, müssen daher bestimmte Voraussetzungen erfüllt sein, die die kapitalogene Urbanisierung in die urbane Subjektivierung der Menschen hineinverlegt. Dazu gehört sicher eine fast 1000jährige kapitalogene Urbanisierungsgeschichte, die schon aus historischer Gewohnheit im Alltag kaum in Frage gestellt wird. Damit geraten aber zugleich auch die dazugehörigen juristisch-administrativen Staatsapparaturen aus dem Blick, die durch ihre „Bürokratie und ihre Organisationsmethoden“ „sich (ihren) Raum an[ordnen]", der das zulässige Dasein der Menschen, d.h. ihre zulässige alltägliche Lebensweise absteckt, Abweichungen sanktioniert und damit kapitalogene Formen urbaner Subjektivität herausbildet (Lefebvre 1972: 215, 219). Fraser spricht diesbezüglich von einem ,juristisch-administrativ-therapeutischen Staatsapparat“ (Fraser 1994: 237ff.). Dergestalt impliziert die „Urbanisierung des Kapitals“ (Harvey 2014: 126) die Herausbildung einer politisch-ökonomischen Ordnung des urbanen Alltagslebens, die die innere Natur des Menschen, seine leibliche Bedürftigkeit und Sinnlichkeit entlang des (Re-)Produktionskreislaufs des Kapitals, innerhalb derer die Städte seit dem ausgehenden Mittelalter ihre Entwicklung vollziehen (müssen), urbanisiert. Nämlich dadurch, dass sie die Menschen in ihrer bedürftigen und sinnlichen Leiblichkeit in die Räumlichkeit und Zeitlichkeit, d.h. in die innere Kapitallogik des Städtebaus einpflegt. Diese juristisch-administrativ-therapeutische Herrschaft erfolgt - wie sich mit Gronemeyer zusammenfassen lässt durch die „Brechung der Eigenmächtigkeit“, die „Austreibung des Eigensinns“ des Menschen, die „Umlenkung des Eigennutzes“ sowie die „Bezwingung der Eigenart“ der leiblichen Natur des Menschen (Gronemeyer 2014: 45ff.). Kurz: durch herrschaftliche Eingriffe in die konviviale Autonomie der Menschen und herrschaftliche Eingriffe in ihre Subjektbildung zur Herausbildung konsumistischer Bedürfnisse (Gronemeyer 1988). Anders: Durch die politisch-ökonomisch systematische Verunmöglichung urbaner Subsistenz zugunsten der Hervorbringung marktwirtschaftlicher Abhängigkeiten für das eigene (Über-)Leben wird der urbanisierte Mensch als homo geo-destructor hervorgebracht.

Damit aber auch die erdökologischen Folgeprobleme, wie etwa der Klimawandel, mit in die Kritik der Praxis der "Urbanisierung des Kapitals“ (Harvey 2014: 126), die im Begriff Kapitalozän kumuliert, einbezogen werden kann, genügt es weder dessen Subjektivierungseffekte zu kritisieren noch nur die Stadt als unorganischen Leib des Menschen zum Politikum zu machen. Stattdessen muss die gesamte Erde als unorganischer Leib des Men- 
schen (Marx 1968b: 516, 1983: 396) in den Blick genommen und letztlich zum Politikum gemacht werden (vgl. Kap. 2). Nur dadurch lässt es sich vermeiden, die Natur der Erde als bloße Umwelt der Stadt zu verkennen, die den einen als romantische Kulisse für Sonntagsausflüge und den anderen als Quelle der Kapitalbildung gereicht. Der Begriff Kapitalozän zwingt die „Historiografie des Kapitalismus“ (Moore 2016: 602) als Stadtentwicklungsgeschichte und die daraus systematisch resultierenden Notwendigkeiten zur stetig steigenden Ausbeutung menschlicher wie nicht-menschlicher Naturverhältnisse in den Blick der Kritik zu nehmen. Der Anthropozänbegriff in den vorherrschenden Debatten der Klima- und Klimapolitikdiskursen unterschlägt diese Kritik in unzulässiger Weise (Moore 2013, 2016; Altvater 2013, 2014, 2015, 2017) und lässt damit ungeachtet, dass sich innerhalb von 300 Jahren (1450-1750) durch und für die weltweite Urbanisierung der ruralen Erde eine Industrialisierung herausgebildet hat, die ihr Kapital zwischen „1700 und 2008 [...] - trotz vieler zerstörerischer Kriege - um den Faktor 134“ vergrößert hat, währenddessen sich ,die Bevölkerung nur um den Faktor 10" vermehrt hat (Bonneuil 2015). (Hierin wird noch einmal ersichtlich, dass es „der Prozess der Kapitalakkumulation“ ist, der stetig mehr fossile Energie verbrauchen muss, um noch Wirtschaftswachstum generieren zu können und der dadurch ,für die Dynamik der Erdtransformation [...] verantwortlich ist" (ebd.), nicht die Menschheit als solches, wie es ein unkritischer Begriff des Anthropozäns voreilig nahelegt.)

Mit der Unterschlagung der „Historiografie des Kapitalismus“ (Moore 2016: 602) unterschlägt ein unkritischer Anthropozänbegriff den grundsätzlichen Widerspruch der kapitalistischen Produktionsweise: nämlich den Widerspruch zwischen Kapital(re)produktion und Arbeit, der im geologischen Maßstab ausgreift in den Widerspruch von begrenzten Erdressourcen sowie der Langsamkeit ihrer natürlichen Regenerationskreisläufe auf der einen Seite und dem unbegrenzten Kapitalwachstum sowie der Schnelligkeit ihrer (derweil digitalen) Regenerationskreisläufe auf der anderen. Der Grundwiderspruch offenbart sich dadurch zwischen den ökologischen Entwicklungsgrenzen der Erdnatur und den Verwertungsgrenzen der Kapital(re)produktion. Indem „Naturgrenzen durch Verwertungsgrenzen des Kapitals ersetzt“ (Altvater 2017: Hervorhebung MS) und damit gesellschaftlich gesetzt werden, werden zwei inkompatible Eigenlogiken zusammengebracht. Nämlich einerseits die „soziale Logik von Reversibilität und Zirkularität“ des Kapitals (Kapitalkreislauf.) und andererseits die ,natürliche[] Logik der Irreversibilität und Entropiesteigerung" der Erdökologie (Naturkreislauf.) (Altvater 2013: 85). Während durch den Menschen erzeugte Waren auf dem Markt verhandelt werden, erzeugen sie (gesellschaftlich gesetzte) Mehrwerte, brauchen sich aber mit ihrem alltäglichen Gebrauch auf. D.h. sie werden verwertet und gehen dadurch ihrem irreversiblen Ende entgegen. Demgegenüber aber fließt das in Arbeitskraft, Produktionsmittel, Ressourcen und Rohstoffe investierte 
und um ihrem (Mehr)Wert gestiegene Kapital zurück in den Kapitalkreislauf und braucht sich nicht auf. Im Gegenteil: Es wird vermehrt, d.h. aufgewertet und wiederverwertet. Während also ausgegebenes Geld verhältnismäßig schnell wieder dem Kapitalkreislauf zugeführt, sich dort regenerieren und wieder ausgegeben werden kann, kann verbrauchtes Erdöl, abgeschlagenes Holz, abgebaute Metalle, abgepumptes Grundwasser etc. bei weiten nicht so schnell wieder dem ökologischen Kreislauf zur Regeneration zugeführt und wieder verbraucht werden. Durch Spekulationen kann ein und dasselbe Geld sogar gleichzeitig mehrfach ausgegeben und investiert werden, während das im Reich der tatsächlichen physischen Welt nicht möglich ist. Dadurch entsteht ein Wachstumsdurst nach Kapital(re)produktion, der letztlich mehr Planeten beansprucht, als unsere eine physisch-reale Erde nicht nur nicht und niemals stillen kann, sondern schon in dem Versuch, ihn zu stillen, die Bewohnbarkeit der Erde für zunehmend viele Lebensarten, auch die des Menschen, zerstört. Hat die bisherige kapitalogene Urbanisierungsgeschichte allein der westeuropäischen und nordamerikanischen Produktions- und Konsumtionsweisen schon existenziell zerstörerische Spuren in der Erdgeschichte hinterlassen, so zeichnet sich ein noch größeres Ausmaß an existenzieller Zerstörung ab, der mit dem „Run auf fossile Brennstoffe“ in China und den sog. Schwellenländern sowie mit dem Run auf die für die „Digitaltechnik und 'grüne' Technologien“ rund um die Welt benötigten Ressourcen entsteht (Bonneuil 2015). Zumindest wenn die Inkommensurabilität der Tempi von Kapitalkreislauf und Erdkreislauf nicht radikal durchbrochen wird. Das muss aber im Hinblick auf die soziale Ungleichheit zwischen den Gesellschaften im global-räumlichen Maßstab, wie sie etwa im Nord-Süd-Gefälle Ausdruck findet, aber auch innerhalb der Gesellschaften, bedeuten, ein räumliches Verständnis sozialer Gerechtigkeit zu entwickeln, an dem entlang die Veränderungen bewusst vollzogen werden.

Daraus, dass der ökologische Fußabdruck der unbeschränkt wachstumsorientierten Globalisierung den physischen Globus übersteigt (Altvater 2014; Latour 2018), folgt, was schon Marx die „Vernichtung des Raums durch die Zeit"“11 (Marx 1983: 445) genannt hat und die, wie Lefebvre daran anschließend aufgezeigt hat, durch die Produktion des kapitalistischen Raums kompensiert wird:

„Die Natur, die als solche zerstört wurde, muss neu geschaffen werden und wird bereits neu geschaffen auf einer anderen Ebene, der Ebene einer zweiten Natur: der Stadt und der Stadtkultur. [...] Die Stadt, Anti-Natur oder Nicht-Natur und zugleich doch auch zweite Natur, kündigt die künftige Welt an, die Welt einer allgemeinen Stadtkultur. Als Summe im Raum verstreuter

11 Marx schreibt in seinen „Grundrissen zur Kritik der politischen Ökonomie“ von 1857/58: „Je entwickelter das Kapital, je ausgedehnter daher der Markt, auf dem es zirkuliert, der die räumliche Bahn seiner Zirkulation bildet, desto mehr strebt es zugleich nach größrer räumlicher Ausdehnung des Markts und nach größrer Vernichtung des Raums durch die Zeit.“ (Marx 1983: 445) 
Einzelheiten, die einander äußerlich sind, stirbt die Natur. An ihre Stelle tritt der produzierte Raum: Stadtkultur [...].“(Lefebvre 1974: 17)

Und weiter:

„Und dieser Raum [der Stadtkultur, MS] ist es, der die Reproduktion [der Produktionsverhältnisse, ebd.] produziert, indem er vielfältige Widersprüche in sie einbringt, die teils aus der historischen Zeit stammen und teilweise nicht. Im Verlauf eines Prozesses von gewaltigen Ausmaßen hat der Kapitalismus sich der historischen Stadt bemächtigt, sie zerbrochen und einen gesellschaftlichen Raum geschaffen, den er nun einnimmt; seine materielle Basis bleibt dabei das Unternehmen und die Technik der Arbeitsteilung innerhalb des Unternehmens.“ (ebd.: 22)

Lefebvre nimmt hierin vor knapp 50 Jahren den Jetzt-Zustand der globalen Verstädterung bzw. der oben beschriebenen Gegenwart des „Umzugs der Menschheit" in die Städte (WBGU 2016b) vorweg und beschreibt mit dem Begriff der ,allgemeinen Stadtkultur“ (Lefebvre 1974: 17) die unternehmerischen Bedingungen des städtischen Lebens. D.h. den Prozess der Verlagerung der ökonomischen Wettbewerbs- und Wachstumspolitik in den Raum der sozialen (Nah-)Beziehungen der Menschen, wodurch eine Subjektivität unternehmerischen urbanen Alltagslebens eingefordert und hervorgebracht wird. Ohne schon an dieser Stelle näher auf das Wie dieses Subjektbildungsprozesses einzugehen (vgl. Teil B) lässt sich dieses unternehmerische urbane Alltagsleben, das subjektbildende urbane Alltagspraxis und Kapitalozän zusammenbringt, mit Brand/Wissen (2017) als ,imperiale Lebensweise“ auf den Begriff bringen, auf den in der vorliegenden Studie immer wieder Bezug genommen wird:

„Der von uns vorgeschlagene Begriff der imperialen Lebensweise verweist auf die Produktions-, Distributions- und Konsumnormen, die tief in die politischen, ökonomischen und kulturellen Alltagsstrukturen und -praxen der Bevölkerung im globalen Norden und zunehmend auch in den Schwellenländern des globalen Südens eingelassen sind. Gemeint sind nicht nur die materiellen Praxen, sondern insbesondere die sie ermöglichenden strukturellen Bedingungen und die damit verbundenen gesellschaftlichen Leitbilder und Diskurse. Zugespitzt formuliert: Die Standards des ,guten' und ,richtigen' Lebens, das ja vielfach aus der imperialen Lebensweise besteht, werden im Alltag geprägt, auch wenn sie dabei Teil umfassender gesellschaftlicher Verhältnisse und insbesondere von materiellen und sozialen Infrastrukturen sind. [...] Sie [die imperiale Lebensweise, MS] ist den Subjekten nicht äußerlich. Vielmehr bringt sie die Subjekte in ihrem Alltagsverstand hervor, normiert sie und macht sie gleichzeitig handlungsfähig: als Frauen und Männer, als nutzenmaximierende und sich anderen überlegen fühlende Individuen, als nach bestimmten Formen des guten Lebens Strebende.“ (ebd.: 44f.).

\section{Und weiter:}

„Der Begriff der imperialen Lebensweise verbindet den Alltag der Menschen mit den gesellschaftlichen Strukturen. Er beansprucht, die sozialen und ökologischen Voraussetzungen der vorherrschenden Produktions- und Konsumnormen sowie die Herrschaftsverhältnisse, die in diese Voraussetzungen eingelassen sind, sichtbar zu machen. Und er will erklären, wie Herrschaft im neokolonialen Nord-Süd-Verhältnis, in den Klassen- und Geschlechterverhältnissen sowie durch rassisierte Verhältnisse in den Praxen des Konsums und der Produktion normalisiert wird, sodass sie nicht länger als solche wahrgenommen wird. Insofern beinhaltet der Begriff der Lebensweise auch jenen der Produktionsweise, er nimmt die technischen Bedingungen der 
Produktion sowie die Formen der Unternehmens- und Arbeitsorganisation in ihrem Verhältnis zu den vorherrschenden Konsumnormen in den Blick." (ebd.: 46)

Brand/Wissen stellen heraus, dass die ,imperiale Lebensweise“ überhaupt erst ,entlang vielfältiger gesellschaftlicher Spaltungslinien - zwischen Ländern und Regionen, Stadt und Land, Klassen, Geschlechtern, race sowie zwischen Gesellschaft und Natur" (ebd.: 62), die die Menschen einander entfremden und entsolidarisieren und sie letztlich zum Konsumismus zwingen - notwendig wird. Folglich werfen sie als Gegenmodell den Begriff der „solidarischen Lebensweise“ auf, die „die grundlegende Verletzlichkeit des menschlichen und außermenschlichen Lebens anerkennen und Formen des Zusammenlebens schaffen [muss], die nicht auf der Prekarisierung vieler oder auch nur einiger Menschen und der gesellschaftlichen Naturverhältnisse beruhen“ (ebd.: 179). Zugleich ist darin eine kritische Einstellung ,gegenüber den kapitalistischen Verwertungs- und Akkumulationsimperativen“ (ebd.) enthalten, worin sich eine degrowth- oder Postwachstumsperspektive abzeichnet, der es

„,nicht um eine pauschale Ablehnung von ,Mehr', etwa im Bildungs- und Gesundheitssystem, an öffentlichen Dienstleistungen oder guten Lebensmitteln [geht], sondern darum, Lernprozesse zu ermöglichen und demokratisch darüber zu entscheiden, wo ein Zuwachs an je konkreten Konsumgütern, Produktionsmitteln und Dienstleistungen gesellschaftlich erwünscht und sozialökologisch zu verantworten ist"“ (ebd.: 179f.).

\section{Mit anderen Worten:}

„Es geht um andere politische Regeln sowie gesellschaftliche Selbstverständlichkeiten und Leitbilder, welche kapitalistische Expansion und Landnahme zurückdrängen und eine solidarische Lebensweise ermöglichen. Wichtig sind zudem die Veränderung von Subjektivitäten, die für Menschen erfahrbare Verringerung von Ungerechtigkeit und die Verschiebung von Kräfteverhältnissen. Es geht um die konkreten Dimensionen des Lebens - von Ernährung, Wohnen, Kleidung, Gesundheit u. a. - jenseits disziplinierender, die kapitalistische Expansion und Landnahme stützender und die Gesellschaft hierarchisierender Praxen.“ (ebd.: 169)

Damit ist nun aber nicht nur die Ursache des Klimaproblems, sondern auch die mögliche Lösungsperspektive eine Frage gesellschaftlicher Stadtentwicklungsprobleme und ihrer Lösungsansätze, mithin eine Problemstellung Sozialer Arbeit als Disziplin professioneller Urbanisierungskritik und subjektorientierter Arbeit am Sozialen. Im folgenden Kapitel soll es darum gehen, diesen Anspruch Sozialer Arbeit theoretisch zu begründen und zugleich das Vorhaben der vorliegenden Studie noch weiter zu präzisieren. 


\section{Soziale Arbeit als Urbanisierungskritik und subjektorientierte Arbeit am Sozialen mit globalgesellschaftlich-planetarischer Reichweite? Ein Problemaufriss}

\subsection{Soziale Arbeit als Urbanisierungskritik}

Mit der Behauptung, dass die Klimaprobleme dieser Erde vorrangig Probleme gesellschaftlicher Stadtentwicklung und, als Frage nach dem Zusammenhang von urbaner Praxis und Praxis der Urbanisierung, eine Frage bzw. Problemstellung für Disziplin und Praxis Sozialer Arbeit ist, ist die These impliziert, „dass die Stadt als analytische Kategorie einen systematischen Ort in der Theorie und Geschichte der Sozialen Arbeit einnimmt" (Baum 2018: 20). Das aber bestreitet Detlev Baum. Baum konstatiert, dass sich mit dem spatial turn zwar das Raumverständnis in der Sozialen Arbeit verändert habe, dies aber nicht dazu geführt habe, Raum als einen „urban geprägte[n] Raum“ zu thematisieren (ebd.: 21).

Eine genauere Betrachtung, woran zu erkennen sei, dass das Thema Stadt für Baum in Disziplin und Profession Sozialer Arbeit zentral verortet sei, offenbart aber einen Widerspruch. So fasst Baum zusammen, dass Soziale Arbeit dann das Thema Stadt zentral thematisiert, wenn sie sich mit Fragen „,der wachsenden kulturellen Vielfalt und ethnischen Diversität in den Städten und die damit verbundenen Spannungen und Konflikte" auseinandersetzt (ebd.: 25). Zudem, wenn sie in Theoriebildung und Praxis zur Kenntnis nimmt, dass ,sich die Prozesse sozialer Ungleichheit nicht nur verstärkt in der sozialräumlichen Verteilung der Bevölkerung in der Stadt widerspiegeln, sondern auch zu sozialen Verwerfungen in benachteiligten Quartieren führen und zu einer verstärkten sozialen Spaltung der Städte beitragen“ (ebd.). Ebenso, wenn sich „eine sozialraumorientierte Soziale Arbeit" der Herausforderung stellt, dass ,in sozial benachteiligten Quartieren Menschen wohnen, deren sozialräumliche Ausgrenzung [...] mit der Frage verbunden ist, ob sie noch zur Gesellschaft gehören oder nicht" (ebd.). Ferner, wenn sie in Theoriebildung und Praxis zur Kenntnis nimmt, dass „Fragen des Zugangs zum Wohnungsmarkt für sozial bedürftige Bevölkerungsgruppen sowie Fragen prekärer Wohnverhältnisse und der Wohnungslosigkeit verstärkt auf der stadtpolitischen Agenda stehen“ (ebd.). Und wenn sie auch „alle anderen psychosozialen Problemlagen wie Armut, Sucht und Krankheit, Umgang mit Arbeitslosigkeit etc., die sich gerade in den Großstädten verstärkt zeigen“, sowie deren „Verfestigung und ständige[] Perpetuierung“ im Kontext „,sol- 
cher sozialer Problemlagen in der Stadt und durch die städtische Dynamik" in den Blick nehmen (ebd.). „Gerade deshalb“, so Baum weiter, „muss Soziale Arbeit diese [genannten sozialen Problemlagen in der Stadt, MS] zukünftig besser mit den strukturellen Prozessen städtischen Lebens und der städtischen Logik von Integration und Ausgrenzung verbinden, um zu besseren Erkenntnissen über die Ursachen und Folgen zu kommen“ (ebd.).

Der Widerspruch zeigt sich nun vor allem darin, dass Baums stadtbezogenes Verständnis Sozialer Arbeit letztlich wieder auf sozialraumbezogene Fragestellungen und Antwortversuche Sozialer Arbeit zurückführt, die er aber als nicht explizit stadtfokussiert gerade in Frage stellt. Zugleich stellt sich aber auch die Frage, warum er die stadtbezogenen Entwicklungen der sozialraumorientierten Theoriebildung und Praxis der Sozialen Arbeit in den letzten mehr als 15 Jahren nicht zur Kenntnis nimmt? Angefangen vom „Handbuch Sozialraum“ (Kessl et al. 2005), über die von Alisch/May seit 2008 herausgegebene Reihe „Beiträge zur Sozialraumforschung“, bis hin zu den Sammelbänden von Oehler/Drilling (2016), Oehler et al. (2016) oder Oehler et al. (2017), die mitunter schon seit Baums vorangegangenem „Handbuch für soziale und planende Berufe“ (Baum 2007a), in dem er bereits dieselbe Kritik anstellte, erschienen waren? Dass nämlich ,[i]n der Sozialen Arbeit [...] die Bedeutung der Stadt als Lebensraum noch keinen systematischen Ort [hat]“, obwohl ,die Geschichte der Sozialen Arbeit ihre Anfänge mit den sozialen Problemen genommen [hat], die sich aus der Entwicklung der modernen Stadt als Industriestadt ergeben“ (Baum 2007b: 13).

Sicher ist Baums Kritik dennoch insofern zutreffend, als dass im problemprivatisierenden und medikalisierend-therapeutisierenden Mainstream in Theoriebildung und Praxisausübung Sozialer Arbeit derlei Zusammenhänge in der Tat kaum anzutreffen sind (zum Überblick und zur Kritik: Anhorn/Balzereit 2016). Deswegen aber den sich dagegenstellenden, wenn auch marginalisierend kleiner werdenden Teil in Theoriebildung und Praxisausübung, auszublenden, heißt diesen Bestrebungen und auch Baums eigenes Anliegen einen Bärendienst zu erweisen. Die Blindstelle Baums bläst letztlich Wind auf die Mühlen medikalisierend-therapeutisierender Ausrichtungen Sozialer Arbeit, gegen die sich bereits Jane Addams' Settlement-Bewegung als frühe Form urbanisierungskritischer Sozialer Arbeit in den letzten Jahrzehnten des 19. Jahrhunderts gerichtet hat (zum Überblick: Anhorn 2012, Staub-Bernasconi 2013). Ebenso daran anschließend Saul Alinskys Community Organizing (zum Überblick: Stövesand 2013), sowie im deutschsprachigen Raum seit dem aus und mit dem Arbeitskreis Kritische Soziale Arbeit sich herausbildenden Arbeitsprinzips Gemeinwesenarbeit (zum Überblick: Oelschlägel 2013b), das 1980 mit Boulet et al. eine konzeptionelle „Grundlegung“ und Ende der 1980er Jahre mit Winkler (1988) und Sünker (1989) sowie in den 1990er Jahren mit Richter $(1998,2001)$ auch eine theoretische Fundierung erfährt, die seither weiterverarbeitet und fortentwickelt wird. 
Dabei geht es nicht nur darum, eine alternative Sozialpolitik, sondern - und das gilt als bislang unabgegoltenes Erbe der Gemeinwesenarbeit (May/Stock 2019) - eine gemeinwesenorientierte Alternative zur (post)wohlfahrtsstaatlichen Sozialpolitik zu Wege zu bringen (etwa bei May 2017b). Diese gemeinwesenorientierte Entwicklungslinie Sozialer Arbeit muss als urbanisierungskritischer Antwortversuch auf die sich über die Jahrhunderte anbahnende und im 19. Jahrhundert sich bis ins Unerträgliche zuspitzende Verelendungsurbanisierung (zum Überblick: Engels 1962; Benevolo 1971) verstanden werden, aus der sich im 20. Jahrhundert eine subjektorientierte Theorietradition Sozialer Arbeit herauskristallisiert und dabei ihre urbanisierungskritischen Wurzeln nicht vergessen hat.

\subsection{Subjektorientierung Sozialer Arbeit}

Wie Winkler herausstellt, kumuliert die „Vorstellung von Geschichte als sozialer und kultureller Veränderung" in der Mitte des 18. Jhd. im Begriff Sozialpädagogik kumulierte, worin zugleich der Antwortversuch auf die Urbanisierungsprobleme und -fragen erblickt wurde, die „um 1800 virulent geworden sind" (Winkler 2018: 39). Aus diesen im vorangegangenen Kapitel geschilderten Entwicklungen entlang der „Urbanisierung des Kapitals“ (Harvey 2014: 126) entwickelten sich mehrere neue Herausforderungen für das Verständnis von Bildung. Zum einen hieß Bildung weiterhin Traditionen zu wahren, während sie entlang der sich im beruflichen und privaten Alltag verändernden Anforderungen zugleich Veränderungen tradierter urbaner Alltagsroutinen der StadtbewohnerInnen zulassen und ermöglichen musste. Zum anderen musste Bildung Gesellschaft begrifflich fassen bzw. sichtbar machen, womit der „Pädagogik [...] eine neue, ungeheure Aufgabe zu[kam], nämlich das Zeigen des eigentlich nicht Sichtbaren“" (Winkler 2018: 39). Damit avancierte die Frage nach der Gesellschaft zur pädagogischen Frage (ebd.: 41), wobei sich in der pädagogischen Bearbeitung dieser Probleme das Problem offenbarte, dass das Versprechen der bürgerlichen Gesellschaft von Freiheit, Gleichheit und Brüderlichkeit nicht nur nicht eingelöst werden konnte und bis heute nicht eingelöst werden kann, sondern vor dem Hintergrund der industriellen und heute postindustriellen Gesellschafts- und Arbeitsbedingungen mitunter gar ,als brutaler Hohn“ erscheint (ebd.: 39). Statt das gute Leben bedeutet(e) das Leben in den Städte für die meisten Leute das bloße Überleben (ebd.), da sich die kapitalistisch organisierten (post)industriellen Gesellschafts- und Lebensverhältnisse nach wie vor häufig als Erniedrigung erweisen und die Handlungsfähigkeit der Menschen zerstören, ,weil die Menschen eben aus dem Zusammenhang mit dem menschlichen Gattungswesen ausgeschlossen werden, das - so Marx (1845/1990) in seinen berühmten 
Thesen über Feuerbach - als Ensemble der gesellschaftlichen Verhältnisse zu beschreiben ist“ (ebd.: 40). Mit anderen Worten: „Menschen werden unter dem Niveau der menschlichen Möglichkeiten gehalten, demoralisiert und das heißt auch: von jeglicher Möglichkeit eines freien Willens und Handelns ausgeschlossen." (ebd.) Und weiter:

„Die moderne Gesellschaft erscheint geradezu paradox, weil sie als Gesellschaft die Vergesellschaftung ihrer Mitglieder tendenziell verhindert und gesellschaftlich geradezu systematisch Sozialpathologie erzeugt - die Diagnose klingt seltsam vertraut: Sie verweigert den Unvermögenden die Chance zur Bildung und richtet sie zugleich für sich ab. Gesellschaftliche Erziehung erzeugt eine Bestialität des Sozialen, weil sie den Menschen die Subjektivität verweigert, der moralisch begründetes Handeln erst entspringen kann.“(ebd.: 44)

Wenn Winkler hier die menschlichen Möglichkeiten in den Mittelpunkt rückt, die in der modernen Gesellschaft nicht nur nicht gefördert und verwirklicht werden, sondern abgerichtet und damit unterdrückt werden, dann ist in diesen menschlichen Möglichkeiten das Subjekt der pädagogischen Bildung ausgesprochen. Das dahinterstehende bis in die griechische Antike (Meister 2010: 58ff.) zurück verfolgbare Auffassung des Menschen bzw. der menschlichen Natur findet sich - wenn auch noch in metaphysischem Gewandt, das erst bei Marx versucht wurde vollständig zu durchbrechen und auf physische resp. materialistische Füße zu stellen - neuzeitlich vor allem seit Humboldt wieder im Bildungsbegriff kumuliert. Mit Wulf lässt sich das Subjekt der Bildung in Anlehnung an Humboldt wie folgt zusammenfassen:

„Als Sinn menschlichen Lebens wird die Bildung der Kräfte angesehen. [...] Sie sind es, die der Bildung bedürfen und die zugleich die Bildsamkeit ausmachen. [...] Bildungsprozesse sind energetisch. Sie werden dadurch gestaltet, dass sich die menschliche Energie auf ein Außen richtet. [...] Die innere Natur des Menschen bedarf also eines Außen, um sich zu bilden. Menschliches Denken und Handeln kann sich nur mit Hilfe der Bearbeitung eines Außen, eines Nicht-Menschlichen, entwickeln. [...] Bildung heißt, Verknüpfung unseres Ichs mit der Welt zu der allgemeinsten, regesten und freiesten Wechselwirkung ${ }^{6}$. [...] So begriffene Bildungsprozesse sind mimetisch. [...] Mit Hilfe mimetischer Prozesse findet eine Ausweitung des Individuums auf die Außenwelt hin und eine Anähnlichung an diese statt. Diese Anähnlichung an Welten außerhalb des Individuums führt zur Gestaltung der nach außen gerichteten, für das menschliche Leben charakteristischen Energie. In Humboldts Verständnis ist diese Gestaltung des Außen zugleich eine Gestaltung des Innen, also Bildung. Insofern Bildung nicht auf Herrschaft, sondern auf die Formung der Kräfte des Individuums in einer herrschaftsfreien Begegnung mit äußeren Welten zielt, ist sie mimetisch.“(Wulf 2020: 56f.)

Damit ist zum einen eine Priorisierung der Gestaltung der äußeren Natur herausgestellt, an der entlang die innere sich bilden und entwickeln kann, was dann zugleich bedeutet: Wenn ,imperiale Lebensweisen“ (Brand/Wissen 2017) überwunden werden müssen, um die Bewohnbarkeit der Erde nicht weiter $\mathrm{zu}$ gefährden, damit sich menschliche Lebensweisen und nichtmenschliche Lebensformen auf und mit ihr entwickeln können, müssen zugleich gesellschaftliche Verhältnisse gestaltet werden, in der diese Überwindung nicht nur möglich ist, sondern so möglich ist, dass sich Menschen zugleich daran bilden können. Die Überwindung der ,imperialen Lebensweise“ 
(ebd.) durch gesellschaftliche Transformationen muss hernach als ihre Überwindung entlang ihrer Biografien als ihre Subjektbildung ermöglicht werden. Mit Humboldt tritt zum anderen aber auch die grundlegende Frage subjektorientierter Bildung in Erscheinung:

„Wie ist es möglich, selbst unter Bedingungen sozialer Ungleichheit und Ungerechtigkeit, kultureller Undeutlichkeit und Ambivalenz Menschen zu befähigen, dass sie zu autonom und moralisch handlungsfähigen Subjekten werden?" (Winkler 2018: 41)

Die urbanisierungskritischen gemeinwesenorientierten Antwortversuche seit dem Ende des 19. Jahrhunderts lauten: durch Wiederherstellung der ,vertraute[n] Erfahrung von Sozialität" (ebd.: 42), die in der modernen Massengesellschaft des urbanisierten Industrialismus und der zugleich industrialisierten Urbanität verloren gegangen sind. Bildung heißt in dieser Hinsicht Herausbilden veränderter gesellschaftlicher Möglichkeiten des Zusammenkommens. Praktisch wurde dieser Bildungsanspruch schon in den sozialistischen Siedlungsprojekten - etwa Owens „Harmony“ (Owen 1988, 2016), Fouriers „Phalanstère“ (Fourier 1988, 2016) und im Anschluss daran Godins „Familistère“ (Heigl 2008: 398; Benevolo 2007: 807) - versucht umzusetzen, scheiterten aber einerseits allesamt auf verschiedene Weisen, andererseits und darin waren sie sich ähnlich - in der naiven Hoffnung, dass aus einer theoretisch gut geplanten und durchdachten Stadtplanung eine neue Sozialität veränderter Lebensweisen entstehen kann (Bach 2016; Töppner 2016). Mit anderen Worten: sie verpassten die notwendige Subjektbildung resp. die notwendige Bildung der inneren Natur der Menschen, die sie zwar theoretisch andachten, aber nicht zu verwirklichen vermochten, weil sie unterschätzten, dass für eine wirklich veränderte gesellschaftliche Praxis auch die ErzieherInnen erzogen werden müssen, woran sich u.a. Marx' und Engels' (Marx/Engels 1978; Marx 1978a) Kritik entzündete. ${ }^{12}$ Damit unterschätzten sie in geradezu naiver Weise, dass gesellschaftliche Verhältnisse zu verändern nicht nur bedeuten muss, eine Stadt anders zu organisieren, sondern auch, dass das Erziehungsverhältnis anders zu organisieren ist. Erst darin

12 Insbesondere in der von Engels bearbeiteten Fassung der Marxschen Feuerbachthesen heißt es in der dritten These: „Die materialistische Lehre, daß die Menschen Produkte der Umstände und der Erziehung, veränderte Menschen also Produkte anderer Umstände und geänderter Erziehung sind, vergißt, daß die Umstände eben von den Menschen verändert werden und daß der Erzieher selbst erzogen werden muß. Sie kommt daher mit Notwendigkeit dahin, die Gesellschaft in zwei Teile zu sondern, von denen der eine über der Gesellschaft erhaben ist. (Z. B. bei Robert Owen.) Das Zusammenfallen des Anderns der Umstände und der menschlichen Tätigkeit kann nur als umwälzende Praxis gefaßt und rationell verstanden werden.“ (Marx 1978a: 533f.) Fourier hingegen wird von Marx/Engels in der „Deutschen Ideologie" zwar immer wieder lobend herausgestellt, ändert aber nichts an ihrem Gesamturteil, ,,[d]aß die Fouriersche Teilung zwischen Kapital, Talent und Arbeit einen prächtigen Stoff zu breiter Klugtuerei bietet“ und schließlich verpasst, ,die Unmöglichkeit und Ungerechtigkeit der Teilung [...], diese Teilung aus dem wirklichen Verhältnis von Arbeit und Kapital zu kritisieren“"(Marx/Engels 1978: 499). 
ließe von einer transformativen Bildung mit gesellschaftlicher Reichweite auf historischem Niveau sprechen.

Dennoch waren gerade auch die Ansätze Owens ein maßgeblicher Ausgangspunkt der Siedlungsbewegung rund um Jane Addams (Staub-Bernasconi 2013: 39), die auch in Deutschland ihre Nachahmer fand und denen mit dem 1889 erlassenen Genossenschaftsgesetz neue Möglichkeiten eröffnet wurden. So etwa das in den Geschichtsbüchern Sozialer Arbeit kaum erwähnte, 1893 gegründete und bis heute noch existierende bodenreformistische Siedlungsprojekt „Eden“ in Oranienburg (Baumgartner 2005) oder aber die mit dem Nazi-Regime zugrunde gegangene Soziale Arbeitsgemeinschaft Berlin-Ost (Oelschlägel 2013a).

All diesen Bemühungen war das Erarbeiten eines anderen, nicht mehr kapitalistisch-industriell funktionalisierten Sozialen gemeinsam. D.h. die Erarbeitung resp. Bildung eines anderen Sozialen zur Ermöglichung eines anderen Sozialverhaltens (Subjektbildung), die zugleich eine Bildung am Sozialen zur Erarbeitung anderer gesellschaftlicher Verhältnisse (kommunale Gesellschaftsbildung) ermöglicht. Das darin zum Ausdruck kommende „Arbeitsprinzip Partizipation“ (Kunstreich 2014: 272f.) wurde später bei Alinsky als Community Organizing (Stövesand 2013) und in der deutschen Rezeption - stärker als bei Addams und Alinsky - unter dem Marxschen Begriff menschlicher Emanzipation (Marx 1981c: 370) ${ }^{13}$ weiter konzeptioniert (Oelschlägel 2013b). Allerdings stand es hier wie da der historischen Entwicklung des Zusammengehens von Urbanisierung und staatlicher Verwaltung (Schott 2014; Benevolo 1971, 2007) nahezu diametral entgegen und führte bereits Mitte des 19. Jahrhunderts nicht nur dazu, die Stadtentwicklungsfrage, sondern seit Ende 19./Anfang 20. Jahrhundert auch die soziale Bildungsfrage kapitalogen-industriell urbanisierter Subjekte in den Bannkreis staatlicher Behörden zu überführen (Winkler 2018: 46), die beide (spätestens) seither nicht losgelöst voneinander und nicht losgelöst vom Kapitalbildungsprozess verstanden werden können.

Damit wohnt Sozialer Arbeit in Profession wie Disziplin - zunächst in ihren Spezialisierungsversuchen als Sozialpädagogik (zum Überblick: Mührel/Birgmeier 2009), dann in ihren Spezialisierungsversuchen als Sozialarbeitswissenschaft (zum Überblick: Birgmeier/Mührel 2009), sowie in ihren

13 Marx schreibt: ,Alle Emanzipation ist Zurückführung der menschlichen Welt, der Verhältnisse, auf den Menschen selbst. Die politische Emanzipation ist die Reduktion des Menschen, einerseits auf das Mitglied der bürgerlichen Gesellschaft, auf das egoistische unabhängige Individuum, andrerseits auf den Staatsbürger, auf die moralische Person. Erst wenn der wirkliche individuelle Mensch den abstrakten Staatsbürger in sich zurücknimmt und als individueller Mensch in seinem empirischen Leben, in seiner individuellen Arbeit, in seinen individuellen Verhältnissen, Gattungswesen geworden ist, erst wenn der Mensch seine ,forces propres' als gesellschaftliche Kräfte erkannt und organisiert hat und daher die gesellschaftliche Kraft nicht mehr in der Gestalt der politischen Kraft von sich trennt, erst dann ist die menschliche Emanzipation vollbracht.“ (Marx 1981c: 370) 
theoriebildenden Konversionsversuchen als Soziale Arbeit (zum Überblick: Mührel/Birgmeier 2011; Birgmeier 2012; May 2010) - von Anfang ein behördlich-strukturelles An-Gefangensein inne, das sich seither durch die Professions- wie Disziplinentwicklung zieht: Nämlich, dass sie vorstrukturiert und angefangen, d.h. in den Fängen der Behörden sich bewegt, darin aber nicht gefangen ist. Damit durchzieht Soziale Arbeit in Profession wie Disziplin von Anfang an ein Konfliktverhältnis im Umgang damit, staatlich verankert und gesetzlich verbrieft zu sein. Der Konflikt entzündet sich an der Frage, sich diesem behördlich-strukturellen An-Gefangensein zu ergeben und damit die Rolle des Staates bei der systematischen Verunmöglichung der sozialen Vergesellschaftung der Menschen entlang von (vor-)herrschenden kapitalogen-industrialisierten Urbanisierungspraxen einerseits zu unterschätzen und andererseits zu unterstützen. Oder aber sich von diesem strukturellen An-Gefangensein mit allen Mitteln der professionellen und disziplinären Kunst zu emanzipieren (zum Überblick: Anhorn 2012; Oelschlägel 2013b).

Dabei steht im Zentrum aber zugleich die Frage nach dem Verständnis von Wissenschaft, d.h. ob sich der Prozess der Herausbildung Sozialer Arbeit als wissenschaftliche Disziplin also „unmittelbar an den Professionalisierungsprozess koppeln und eine Kongruenz im Verhältnis zwischen Disziplin und Profession favorisieren“ muss, „mit der der Grad der Disziplinierung stets vom Grad der Professionalisierung abhängig gemacht wird (vgl. Engelke 2010; Staub-Bernasconi 2010b)“ (Birgmeier 2012: 167). Oder aber „ob sie Disziplinbildungsprozesse von Professionsbildungsprozessen trennen und somit auch von einer Divergenz zwischen Disziplin und Profession und damit ebenso: zwischen wissenschaftlichem Wissen und praktischem Können, zwischen Disziplinwissen und Professionswissen ausgehen möchten (vgl. Höllmüller 2011a, b; Birgmeier/Mührel 2011)“ (ebd.). In Anbetracht der historischen Überführung der Bildungs- und Entwicklungsfrage urbaner Subjektivität in die Staatsapparaturen, was die dergestalt strukturell angefangene Mandatierung der Profession Sozialer Arbeit (Olk 1986) sowie das darin sich herausgebildete Professions- und Methodenwissen in den Dienst herrschaftlicher Hilfe und Kontrolle gestellt wird, scheint der einzige Wege des Aufbrechens der Reproduktion der gesellschaftlichen Verunmöglichung sozialer Vergesellschaftung menschlicher und - angesichts der ökologischen Problemlage - auch nicht-menschlicher Verhältnisse im Aufbrechen der Kopplung disziplinärer Theoriebildung von vorherrschenden Professionspraktiken zu liegen. Mehr noch: Nur in dieser Abkoppelung scheint sich eine theoriegestützte Subjektorientierung Sozialer Arbeit erst ermöglichen und verwirklichen zu lassen.

Das heißt nun aber nicht, dass sich Theoriebildung parallel zur Profession entwickeln soll. Aber es heißt, dass die Priorisierung verschoben werden muss. Die disziplinäre Entwicklung kann nicht einfach der vorherrschenden professionellen Praxis abgelesen werden. Mit Winkler bedeutet „Theorie [...] 
Nach-Denken. Sie kommt hinterher, folgt dem Geschehen“ (Winkler 2018: 32), d.h. sie folgt ihr zeitlich, aber nicht zwingend auch strukturell. ,Theorie zeigt auf, welcher Handlungssinn [in den vorherrschenden Professionspraktiken, MS] möglich ist, welche Aufgaben sich stellen, wie das Handlungsfeld $\mathrm{zu}$ gestalten ist. So gesehen hat Theorie eine nachgehend-vorgängige Funktion." (ebd.) Mit anderen Worten: Theorie ahmt die wirkliche Praxis nach und geht über die Praxis ins Mögliche hinaus. Dadurch macht sie transformative Möglichkeiten der Praxis, sowohl der Praxis der Professionellen als auch der Praxis ihrer Adressaten und NutzerInnen, sichtbar. Theoriebildung trägt dabei zur Professionsentwicklung insofern bei, als dass die den Diskurs um die Professionalität Sozialer Arbeit eröffnet. D.h., dass Profession und Disziplin Sozialer Arbeit dazu beitragen, ,den Spielraum menschlicher Praxis in seiner je besonderen Vermitteltheit mit dem historisch-konkreten Bedingungsgefüge herauszuarbeiten“ (Sünker 1989: 24) und mit einem „Plädoyer für die Auflösung verdinglichter Strukturen und Inhalte des Alltagslebens“" (ebd.: 48) zu verbinden und dabei das Ziel der „Entfaltung emanzipatorischer menschlicher Bedürfnisse“ im urbanen Alltagsleben verfolgen (ebd.: 49).

Stellt Sünker heraus, dass die Bildungsfrage als Frage nach der gesellschaftlichen Subjektkonstitution eine Frage ist, die in den konkreten Orten des städtischen Alltags anzusiedeln ist, so ergründet Winkler ergänzend das konkrete fachliche Handeln an diesen Orten, das er als „,sozialpädagogische[s] ,Ortshandeln“" (Winkler 1988: 323) bezeichnet. In diesem Begriff setzt er Fragen der Gestaltung eines konkreten Ortes des urbanen Raums mit Fragen der Bildung von Subjektivität zueinander ins Verhältnis. Der Subjektbegriff umfasst hierbei nicht nur die Anerkennung dessen, was ein Mensch bereits geworden ist, sondern vor allem auch die Anerkennung des noch Möglichen seines Werdens. D.h. er umfasst die Anerkennung der noch unabgegoltenen bzw. noch unverwirklichten Möglichkeiten von menschlichen Entwicklungen. Was geworden ist und was noch nicht geworden ist, kann also nicht losgelöst von den Orten verstanden werden, mit denen sich das subjektive Menschsein bislang hat interaktiv herausbilden können. Die Strukturierungen eines Ortes stellen die Lebensbedingungen der Menschen dar, mit denen sie sich subjektivieren, d.h. mit denen sie sich gewahr werden, was ihnen als Möglichkeiten der eigenen Entwicklung offen steht und was nicht.

Als Subjekt wird damit das den Menschen gemeinsam Zugrundeliegende des Handelns bezeichnet. Genauer: als Subjekt wird der gemeinsame Raum handelnder Menschen bezeichnet, der als pädagogisch-dritte Instanz die je inneren und äußeren Naturverhältnisse resp. die je innere und äußere Mitwelt der Menschen in ein gemeinsames Verhältnis (Subjekt) setzt und ihnen dadurch ihre Selbstbezüglichkeit, d.h. ihr jeweiliges Selbst-Bewusstsein (Subjektivität) räumlich und zeitlich ermöglicht: Selbstbewusstsein, d.h. sich selbst bewusst zu sein, heißt, sich an einem bestimmten Ort zu einer bestimmten Zeit der eigenen Entwicklung(smöglichkeiten) bewusst zu sein 
bzw. zu werden. Erst dadurch werden sich Menschen als konkrete AkteurInnen einer konkreten Wirklichkeit mit konkreten und verwirkten Möglichkeiten bewusst. Subjektivität ist also verwoben mit dem Ort, an dem und durch den sie sich als gesellschaftshistorisches Produkt bewusst wird. Je nach dem, wie ein Ort gestaltet ist, können sich die Menschen ihre Möglichkeiten ihres Werdens selbst regulieren und sich dadurch als selbstbestimmt werdende AkteurInnen bewusst werden - oder eben auch nicht. Entsprechend fordert der Subjektbegriff für Winkler dazu auf, „Orte zu schaffen, an welchen sich die Subjekte nicht nur selbst aushalten können, sondern [...] angemessene Lebensmöglichkeiten finden“, und zugleich, so Winkler weiter, ,wirkt er [...] als ein Instrument zur Kritik dieses Ansinnens" (ebd.: 268).

Subjektorientierung Sozialer Arbeit besagt also, „dass Sozialarbeit und Sozialpädagogik als Instanzen der öffentlichen Kontrollpolitik glückende Aneignungsprozesse aus einer negativen Bewertung der Lebenswelten für defizitär erklären und diese systematisch umzugestalten suchen" (ebd.: 156f.). Und weiter:

„Einmal fragt man mit ihr danach, ob bestimmte Lebenswelten überhaupt angeeignet werden können, bzw. eine Entwicklung des Subjekts erlauben. Zum anderen bleibt man sich in ihr der Gesellschaftlichkeit des Subjektes bewußt: Führen Lebenswelten und Lebensstile in die Isolation, führen sie dazu, daß das Subjekt gesellschaftlich ohnmächtig, bloßer Adressat der Verfügung andrer wird, dann liegt darin keine Berechtigung, die ursprünglichen Aneignungsprozesse zu negieren [...], legitimiert aber wohl zu einem pädagogischen Handeln. In der Tat zeigt sich hier nämlich ein Aneignungsproblem, welches durch Anstöße zur Selbsttätigkeit gelöst werden kann. Insofern führt die sozialpädagogische Problembestimmung zur Gesellschaft hin - wenngleich Sozialpädagogik selbst nur den Weg dazu eröffnen kann.“(ebd.)

Mit dem Begriff des Subjekts wird es also möglich zu entdecken, wie Orte „Subjektivität schädigen und Möglichkeiten der Subjekte einschränken“ (ebd.: 268). Sozialpädagogisches Ortshandeln nimmt dabei die jeweils örtlich vorfindbare Subjektivität der AkteurInnen zum Ausgangs- und Bezugspunkt fachlichen Handelns, mit dem Ziel, den AkteurInnen ein Bewusstsein für ihr noch mögliches Werden zu eröffnen, indem es ihnen zu ermöglichen sucht, sich die räumlichen Bedingungen des Ortes gemeinsam, d.h. politisch selbst zu gestalten. Dabei hat das fachliche Handeln zu berücksichtigen, „dass das Subjekt sich auf seine eigene Weise bildend veränder[n]“ und „seiner individuellen Entwicklungslogik gehorch[en]“ kann, so dass „das pädagogische Handeln die Integrität und Autonomie des Zöglings [oder allgemeiner: die des Adressaten und der NutzerInnen fachlichen Handelns, MS] wahr[t]“ (ebd.: 271). Die subjektive Eigenlogik des Bildens gilt sowohl der Fachkraft als auch dem Adressaten als ,eine Art ,Naturgrenze“" (ebd.). Nicht das Subjekt soll für eine Gesellschaft sich bilden können, sondern eine soziale Gesellschaft muss gebildet werden, in der und mit der sich ein emanzipatorisches (Handlungs-)Subjekt herausbilden kann. Entsprechend sind „realistische Lebensbedingungen zu schaffen, die zugleich zukünftige Möglichkeiten eröffnen, welche das Subjekt ausgestalten kann. Kurz: das sozial- 
pädagogische Handeln muss die Gegenwart des Subjekts so strukturieren, dass in ihr eine offene Zukunft für dieses entsteht" (ebd.: 275). Daher beginnt für Winkler pädagogisches Handeln „mit der Frage nach dem Ort, seiner Bedeutung für den Menschen, den diesem durch ihn gegebenen Möglichkeiten und Grenzen", d.h.

„wie ein Ort beschaffen sein muss, damit ein Subjekt als Subjekt an ihm leben und sich entwickeln kann, damit er auch als Lebensbedingung vom Subjekt kontrolliert wird. Sozialpädagogisches Handeln stellt somit Räume zur Verfügung, in welchen sich die Individuen wieder bewegen und miteinander als Subjekte verkehren, zugleich auch sich selbst bilden können.“ (ebd.: 278f.)

Daraus ergibt sich für Winkler als „Grundaufgabe“ fachlichen Handelns, dass „Plätze, Trassen und Räume zur Verfügung gestellt werden, an welchen die Subjekte selbst die Gleise legen, auf welchen sie sich bewegen wollen“ (ebd.: 279). Ergänzend lässt sich mit Sünker das sozialpädagogische Ortsverhältnis von „Bildung, Alltag und Subjektivität“ zusammenfassen:

„Wenn ,Individuen Bewußtseinsstrukturen ausbilden können, die auf einer höheren Stufe liegen als die, die bereits in den Institutionen ihrer Gesellschaft verkörpert sind“ (Habermas 1985a), also das Alltagsleben , die geheime Hilfe der Geschichte' ist (Heller 1978) und es dessen virtuellen Reichtum zu entdecken gilt (Lefebvre 1972), wenn die Bildung aller auf der Tagesordnung steht (Heydorn 1979), dann besteht auch die Chance, mit Hilfe sozialpädagogischen Handelns gesellschaftliche Bedingungen zu verändern, substantielle - und nicht allein technische - Entwicklungen im Gesellschaftsleben zu befördern.“ (Sünker 1989: 164)

Subjektorientierte Soziale Arbeit bedeutet also „Bildungsarbeit an gesellschaftlichen Strukturen und mit Individuen [zu] arbeite[n], um eine Beförderung der Demokratie, eine Überwindung gesellschaftlicher Ungleichheit sowie eine Unterstützung individueller Handlungs- und Bewusstseinsfähigkeit zu erreichen (vgl. Sünker 1989, S. 133-159)“, wie Sünker seinen Ansatz später selbst zusammenfasst (Sünker 2012: 264). Soziale Arbeit muss entsprechend „Initiierung und Beförderung von Bildungsprozessen“ (ebd.: 263) heißen, die Bildung als Subjektbildung über das Soziale, d.h. entlang der Bildung sozialpädagogischer Orte und ihrer Verknüpfung zu sozialpädagogischen Räumen begreift und dabei die (Subjekt-)Bildungstätigkeit bei den AkteurInnen belässt. Eben darin lässt sich Subjektbildung als „Frage nach freiheitsverbürgenden Möglichkeiten menschlicher Geschichte" fassen, bei der sich ein Mensch unter Menschen als „'eigener Täter“ ([Heydorn] 1980: 164)" selbst herausbilden kann, was Subjektbildung als soziale Aktualisierung individueller Potenzialität verstehen lässt (Sünker 2014: 335).

Bildung dergestalt ,als ,Mittel der Befreiung' ([Heydorn] 1979: 45, 324)“ (ebd.) von der aus der „Urbanisierung des Kapitals“ (Harvey 2014: 126) erwachsenen Zerschneidung räumlicher und zeitlicher Zusammenhänge in Berufsarbeit, Freizeit und Privatleben und dessen funktionalistischer Wiederzusammenführung entlang einer Subjektivität, die diese Wiederzusammenführung ermöglicht bzw. zu ermöglichen verheißt (Stichwort „imperiale 
Lebensweise“, Brand/Wissen 2017), heißt aber zugleich, zunächst auf eine auf diese oktroyierten Bedürfnisse zugerichtete Subjektivität zu treffen, aus der heraus eine emanzipatorische Subjektivität erst herausgebildet werden muss. Vor allem aber heißt es, sich mit den darin gesellschaftlich vermittelten und entfremdeten Perspektiven auf Gesellschaft, Staat, sowie menschliche und nicht-menschliche Naturverhältnisse auseinanderzusetzen. Wie May (May 2017b) im Anschluss an Lefebvre und Freire herausstellt, kann eine solche emanzipatorische Bildung nur gelingen, wenn die Subjektbildung an die in der imperial zugerichteten Subjektivität zurückgelassenen Bedürfnisse und Wünsche Anschluss findet. Erst an den brachliegenden Bedürfnissen und Wünschen, Lefebvre spricht von Residuen (Lefebvre 1975c: 322ff., 1987: $311 \mathrm{ff}$.), können die AkteurInnen ein Bewusstsein davon herausbilden, dass sie entlang der sie dominierenden Alltagspraxis in ihrer Entwicklung begrenzt werden, von wo aus erst der Fokus auf die gesellschaftlichen Bedingungen der Alltagspraxis sowie den schon vorhandenen oder noch zu erarbeitenden politischen Möglichkeiten, sie zu verändern, gelenkt werden kann.

Erst durch diese Vorbedingungen ließe sich die „Urbanisierung des Kapitals" (Harvey 2014: 126) und ihre imperialen Subjektivierungseffekte politisieren und vielleicht zu einem transformativen Prozess gesellschaftlicher wie subjektiver Bildung ausgestaltet werden. Bedingungen hierfür wären,

1. dass es durch die sozialpädagogische Gestaltung von Orten gelingt, die verschiedenen AkteurInnen eines Ortes und auch verschiedener Orte zu problembezogenen Interessensgemeinschaften zusammenfinden zu lassen,

2. dass der so gebildete urbane Handlungsraum sie zugleich darin befähigt, ihre Probleme und (brachliegenden bzw. blockierten) Bedürfnisse (Residuen) artikulieren zu können,

3. dass sie sich residuenorientiert politisch so organisieren können, dass sie ihre problematisierten Angelegenheiten (handlungs-)subjektorientiert zu regulieren lernen,

4. so dass sie sich dadurch eine urbane Sozialität bzw. ein Handlungssubjekt herausbilden, das ihnen real erscheinen lässt, die ,imperiale Lebensweise" (Brand/Wissen 2017) hinter sich lassen zu können.

5. Nämlich dadurch, dass sich die AkteurInnen allmählich als wirkliche, d.h. wirkende und wirkmächtige AkteurInnen bewusst werden, die über ihre urbane Praxis eine Wirkung auf die Praxis der Urbanisierung erfahren, durch die sie sich zugleich den Spielraum ihrer alternativen urbanen Praxis vergrößern, was ihnen zugleich den Spielraum vergrößert, die Praxis der Urbanisierung weiter mitzugestalten.

Dass dies nur mit der Unterstützung kommunaler und staatlicher Behörden und ihren strukturellen Möglichkeiten und Reichweiten verwirklicht werden 
kann, bedarf keiner tieferen Analyse, wohl aber die Analyse strukturellen und subjektiven Blockaden eines solch umfassenden sozialpädagogischen Ortshandelns auf der Ebene einer kommunalen Pädagogik des Sozialen mit praxisphilosophisch resp. emanzipatorisch forschendem Anspruch.

Bildung kann daher ,nur in Verbindung ,mit der gesamten geschichtlichen Bewegung““ ein ,"revolutionäres Movens“" sein, wie Sünker im Anschluss an Heydorn (1980: 100) hevorhebt (Sünker 2014: 335), was zum einen „den Zugang aller zu den gesellschaftlich verfügbaren Ressourcen“ impliziert und was zum anderen „Konsequenzen für das Verständnis von Staat, Gesellschaft und Individuum", mithin eine urbane Kulturrevolution bedeutet (Sünker 2012: 263). Es geht letztlich hierbei nicht nur um eine gerechtere Verteilung der gesellschaftlichen Ressourcen, bei der die Zugangsverhältnisse zu den zu verteilenden Ressourcen unangetastet bleiben, sondern es geht um eine veränderte kulturelle Hervorbringung ebenjener Zugangsverhältnisse, mithin um eine revolutionäre Erneuerung der gesellschaftlichen Produktionsverhältnisse der zu verteilenden gesellschaftlichen Ressourcen auf kultureller Ebene, die alltäglich, d.h. zur urbanen Alltagspraxis und Alltagskultur werden soll und was hier als revolutionär-transformative Bildung - oder aber im Anschluss an Hirschs Begriff des „radikalen Reformismus“ (Hirsch 2007) auch als radikal-reformerische Bildung - bezeichnet werden soll. Es geht „wesentlich darum zu erkennen, dass Bildung, einen eigenen verändernden Beitrag (leistet), der unauswechselbar ist. Dieser Beitrag darf nicht aus der Institution zurückgezogen werden, er kann auf gleiche Weise an keiner anderer Stelle geleistet werden` (1980: 167)“ (Sünker 2014: 335).

Konkret heißt das, dass Soziale Arbeit die revolutionäre Transformation der städtischen Alltagspraxis in ihrem behördlich-strukturellen AnGefangensein vollziehen muss, da sie nur so zu einer forschen Bildungspraxis gelangen kann, die den AkteurInnen zur Emanzipation gereicht, weil sie $\mathrm{zu}$ einer revolutionären Transformation des Staates von innen vordringt und ihn als Apparatur eines top-down-orientierten Bedürfnismanagements (Fraser 1994: 237ff.) hinter sich lässt. Das bedeutet zugleich, dass eine revolutionärtransformative Bildung eine von den AkteurInnen nicht nur in, sondern von der Kommune ausgehende dialogisch-konfliktorientierte Bedürfnispolitik anstrebt, die als „reflexive Institution “14 (Ritsert 2005: 11, 2007: 63, 69) das pädagogische Verhältnis von „Bildung des Sozialen und Bildung am Sozialen“ (Kunstreich/May 1999) politisch herauszubilden unterstützt, was zugleich immer auch bedeutet, das reflexiv-institutionelle Verhältnis von „Bildung des Sozialen und Bildung am Sozialen“ (ebd.) immer wieder sozial-

14 In seinem Aufsatz „Dimensionen des Vernunftbegriffs in der ,Dialektik der Aufklärung““ schreibt Ritsert: „Reflexive Institutionen entlasten die Menschen nicht nur vom Willen zur Macht in der Bürokratie bzw. der , verwalteten Welt" (Adorno), sie sind vor allem so verfasst, dass sie die Autonomie des Subjekts fördern, nicht untergraben. Sie ,entlasten ' die Individuen allerdings nicht von ihrer Autonomie!“(Ritsert 2005: 11) 
pädagogisch herausbilden zu müssen. Darin muss letztlich die Alltagspraxis einer politischen Stadt erblickt werden, die sich als Kommune versteht und die sich zugleich die Bedingungen ihrer Ermöglichung sowie ihrer alltäglichen Reproduktion selbst zu erschaffen beansprucht. Die politische Stadtkommune als „reflexive Institution“ (Ritsert) ist alltägliche Arbeit am Sozialen, die durch professionelle wie nicht-professionelle Produktivkräfte hervorhervorgebracht wird und die sich ihrer unterschiedlichen Arbeits/Produktionsweisen sowie ihrer daraus resultierenden Statusunterschiede bewusst sind, sie sich zugleich aber auch gemeinsam politisch darüber verständigen und nach strategischen Mitteln und Wegen suchen, die Statusunterschiede für den gegenseitigen Erziehungsprozess produktiv zu wenden und sie darin auszubalancieren. Darin besteht die Revolution politischen Alltagskultur: „Die Revolution verändert das Leben, nicht nur den Staat oder die Eigentumsverhältnisse.“ (Lefebvre 1972: 275)

Die institutionelle Möglichkeit eines solchen politischen Bildungsprojekts mit revolutionär-transformativem Charakter, d.h. einer solchen Arbeit am Sozialen entlang der Arbeit des Sozialen hatte schon Marx in kommunalen Assoziationen erblickt, die dann kurz nach Marx ‘ Tod mit dem Genossenschaftsgesetz einen juristisch anerkannten Rahmen erhielt und den Natorp dann (wieder) - zumindest auf theoretisierender Ebene - aus der Reichweite der Siedlungsprojekte holte und in die revolutionär gesellschaftstransformative, d.h. staatsbildende Reichweite rückte, in der sie bereits Marx erblickte: Nämlich als „Verein freier Menschen, die sich wechselseitig erziehen“ (Marx 1981a: 95) und „mit gemeinschaftlichen Produktionsmitteln arbeiten und ihre vielen individuellen Arbeitskräfte selbstbewußt als eine gesellschaftliche Arbeitskraft verausgaben“ (Marx 1962a: 92f.), um dadurch zu einer ,wahre[n] ,öffentliche[n]“" Erziehung des Staates“ vorzudringen (Marx 1981a: 95), die die Verwirklichung des menschlichen Gemeinwesens, d.h. die menschliche Subjektbildung institutionell unterstützt. Ganz analog schwebt Natorp eine „Vergenossenschaftung von Erziehung“ vor, bei der

,[a]lle gemeinsamen Einrichtungen für gediegene Unterhaltung, körperliche Übungen, Spiele der Kinder und Jugendlichen, wie für Bildungs- und Kunstpflege der Erwachsenen, [...] dieselben Verbände anzuschließen sein [würden]. Ich denke mir also eine zentrale, ganz auf Selbstregierung und Selbstkontrolle gegründete Organisation auf dem Grunde der Wirtschaftsgemeinschaft, welche alle Seiten der Volksstruktur umfasst. Durch die Einordnung in die Wirtschaftsgemeinschaft würde erreicht, dass die gedachte Erziehungsorganisation ganz von selbst, ohne irgend welcher äußeren Zwangsmittel zu bedürfen, etwas vom obligatorischen Charakter annähme. [...] Voraussetzung müsste sein, dass jede freie Genossenschaft, um als vollgültiges Organ der sozialen Gesamtordnung anerkannt zu werden, die gedachten Erziehungs- und (Selbsterziehungs)Einrichtungen in ihren Organisationsplan aufnähme und nach allgemeinen Normen beständig zu erhalten und $\mathrm{zu}$ bessern bemüht wäre. Das aber fördert wiederum die Einheitsordnung eines durchaus autonomen Erziehungswesens, nicht als eines Staates im Staat, sondern der Seele des Staates überhaupt.“(Natorp 1922: 112)

Doch ein solch politisch-pädagogisch ausgerichtetes Bildungsmandat muss Soziale Arbeit - gerade wenn sie im gesellschaftstransformativen Entwick- 
lungsprozess im Kontext der Klimafrage als emanzipatorische Profession und Disziplin mitwirken will - vor dem Hintergrund ihrer vielfach nicht nur behördlich-strukturell an-gefangenen, sondern auch bis ins Selbstverständnis ihrer fachlichen AkteurInnen hinein durchwalteten Professionsentwicklung, vieler Orts erst wiederentdecken. Wiederentdeckt werden muss, dass sich die Fachkräfte Sozialer Arbeit dieses Mandat selbst geben müssen (CremerSchäfer 2001), da es ihnen im behördlich-strukturellen An-Gefangensein der Profession häufig weder zugestanden, noch gebilligt wird. Aber erst im alltäglichen Kampf um die Deutungshoheit der Mandatierung Sozialer Arbeit beginnt nicht nur die Emanzipation Sozialer Arbeit vom Beruf zur Profession $^{15}$, sondern beginnt auch eine praxisphilosophisch-emanzipatorische Professionalität Sozialer Arbeit sich herauszubilden und an Kontur zu gewinnen, die die Trennung von emanzipatorischer Disziplin- und pragmatischer Professionsentwicklung aufzuheben vermag. Wenn Birgmeier ein solche gemeinsame Disziplin- und Professionsentwicklung nur dann gelingen sieht, wenn

,[v]or allem aus der Perspektive der Adressaten (um die es ja in allen Denk- und Handlungslogiken der Sozialen Arbeit zu gehen hat) [...] gemeinsam (und jenseits aller Abgrenzungstendenzen) sämtliche relevanten Themen der Sozialen Arbeit erforscht und die vielen drängenden Probleme, die die gesellschaftlichen Entwicklungen mit sich bringen, gelöst werden“ (Birgmeier 2012: 168),

dann ist die Klimafrage hierfür eine historische Chance. Somit erweist sich die „Frage nach der disziplinären Identität der Sozialen Arbeit [...] nach wie vor als bedeutsam“ (Sünker/Braches-Chyrek 2010: 71), da deren Beantwortung grundsätzliche Auswirkungen hat auf das Verständnis von der Aufgabengenerierung und die Arbeitsweise ihrer Erledigung. Also darauf, ob die Professionalität Sozialer Arbeit in der Klimafrage in einem Case- und/oder Quartiersmanagement oder aber in einer „mondialen Mäeutik“ (Lefebvre 1978: 23) erblickt wird, zu der auch Case-/Quartiersmanagement gehören kann. Anders: Ob fachliches Handeln Sozialer Arbeit in der Klimafrage im oder am Sozialen arbeitet (zur Diskussion v.a. zwischen May und Hinte: Kessl et al. 2005: 529). Oder nochmal anders: Ob Soziale Arbeit in der Klimafrage in der ,sozialraumorientierten Verwaltungsmodernisierung“ ihr Ziel erblickt (zum Überblick: Stoik 2013), oder aber in der „Geburtshilfe für die Zukunft einer Gesellschaft“ (Sünker 1989: 147), die mit einem „umfassenden Umformungsprozess[] des Raums“" (ebd.: 120) einhergehen muss, so dass die „Stadt (wieder) zum Werk [...] sogar zum Widerständigen gegenüber dem Alltäglichen werden“ (ebd.: 128f.) kann. Das verlangt dann aber nicht nur

15 An dieser Stelle wird allerdings nur an die strukturelle Unterscheidung Staub-Bernasconis (2007) zwischen Beruf und Profession angeschlossen, nicht an ihre deduktive Begründung Sozialer Arbeit als Menschenrechts-profession vor dem Hintergrund Obrechts (2005) „Biopsychosoziokultureller Theorie menschlicher Bedürfnisse“ (zur Kritik: Kappeler 2008; Cremer-Schäfer 2008; May 2017b: 137ff.). 
eine Verwaltungsmodernisierung, sondern die Ermöglichung einer umfassenden Politisierung aller öffentlichen, d.h. aller sozialen, ökonomischen und ökologischen Angelegenheiten der AkteurInnen der (Stadt-)Kommune, die auch eine Verwaltungsmodernisierung beinhaltet. Und zwar dergestalt, dass diese drei Bereiche nicht versäult, also losgelöst voneinander und gegeneinander ausspielend bearbeitet werden. ${ }^{16}$ Vielmehr müssen die Bereiche miteinander und durcheinander als politisch-kulturelle Bildungsaufgabe der Zukunft bearbeitet werden! Was das genau für die bevorstehenden klimawandelbedingten sozial-ökologischen Transformationsprozesse der Städte bedeutet, soll in der vorliegenden Arbeit näher untersucht werden.

\subsection{Soziale Arbeit als Agitatorin subjektorientierter Kulturrevolution mit sozial-ökologischem Anspruch?}

Der dem revolutionär-transformativen bzw. radikal-reformerischen Bildungsansatz Sozialer Arbeit innwohnende Ansatz einer urbanen Kulturrevolution muss, das sollte deutlich geworden sein, auch der eigenen Professions- und Disziplinentwicklung zu Leibe rücken. Urbane Kulturrevolution bedeutet damit also nicht bloß eine grundlegende Veränderung der städtischen Alltagskultur und der imperialen Kultur der Verstädterung, bedeutet also nicht bloß eine grundlegende Veränderung der urbanen Praxis und der Praxis der Urbanisierung, sondern bedeutet vor allem auch eine grundlegende Veränderung der politischen Alltagskultur Sozialer Arbeit auf professioneller und disziplinärer Ebene. Das bedeutet für die Alltagspraxis Sozialer Arbeit, dass durch „mäeutisch geförderte[] Kreativität“ im gesellschaftlichen Alltagsleben der NutzerInnen soziale Situationen erzeugt werden müssten, ,in der die Alltäglichkeit nicht mehr gelebt werden kann (vgl. Lefebvre 1972, S. 51)“ (Sünker 2012: 263). Im Anschluss an Lefebvre (Lefebvre 1972) plädiert Sünker daher dafür,

„um der Subjektperspektive Willen für eine kulturrevolutionär begründete Änderung der gegenwärtigen Gesellschaft, d. h. für eine Auflösung der verdinglichten und verdinglichenden Strukturen des Alltagslebens. Verbunden wird so die den westlichen Marxismus auszeichnende praxisphilosophische Position (vgl. exemplarisch Schmied-Kowarzik 1981; Sünker 1989) mit der These von der historisch-gesellschaftlichen Notwendigkeit einer Entfaltung emanzipatorischer Bedürfnisse und Fähigkeiten, um des Überlebens der Gattung und der konkreten Einzelnen Willen (vgl. Heller 1976; Castells 1998, S. 336-360)“ (Sünker 2012: 259).

16 Es gehört sicher zur Tragik des vorherrschenden Nachhaltigkeitsdiskurses im Bereich der offiziellen Politik, dass der Begriff Nachhaltigkeit gemeinhin als Säulenmodell versinnbildlicht wird, was zwar die Gleichrangigkeit der drei Säulen Soziales, Ökonomie und Ökologie unter dem Dach der Nachhaltigkeit verdeutlichen soll, zugleich aber auch die Isolierung der drei Bereiche darstellt. 
In Anbetracht der gegenwärtigen Klimaproblematik und der sich als gefährlich zäh erweisenden notwendigen Umkehr historisch gewachsener und miteinander verflochtenen Praxen der „Urbanisierung des Kapitals“ (Harvey 2014: 126) mit urbanen Praxen des Kapitalismus zu einer „imperialen Lebensweise" (Brand/Wissen 2017), steht damit wohl historisch erstmals seit der letzten Eiszeit das Überleben nicht nur nicht-menschlicher Gattungen, sondern auch das der menschlichen Gattung auf dem Spiel. Darin wird nun die ganze Notwendigkeit einer durch Soziale Arbeit mäeutisch erzeugten Kulturrevolution bezeugt, worin sich zugleich der in der Studie vertretene sozial-ökologische Anspruch kulturrevolutionär-subjektorientierter Sozialer Arbeit zeigt. Eine Kulturrevolution erfordert daher, „'eine demokratische Gesellschaftsordnung aufzubauen und die zentralen Institutionen kapitalistischer Ökonomie zu eliminieren“", da, wie Sünker Bowles/Gintis (1987, 3) weiter zitiert, „'keine kapitalistische Gesellschaft heute vernünftigerweise demokratisch genannt werden kann“", da sie es verhindere, die ,'Vorstellung der Sicherung persönlicher Freiheit"“ mit ,"einer gesellschaftlich verantwortlichen Ausübung von Macht zu vermitteln““ (1987: 3)“ (Sünker 2017: 446). Eine unter kapitalistischen Bedingungen hervorgebrachte Demokratie ist daher ,ihres sozialen Gehalts entleert“ und ermöglicht nur „'eine Form von Demokratie, in der die formale Gleichheit politischer Rechte nur geringe Auswirkungen auf Ungleichheiten oder Herrschaftsbeziehungen und Ausbeutungsverhältnisse in anderen Bereichen hat" ([Meiksins Wood] 1995: 224)“" (ebd.: 446, Hervorh. MS). Als ein solch ,anderer Bereich“, auf dem eine kapitalistisch organisierte Demokratie einflusslos bleiben muss, ist vor allem auch das imperiale Ausbeutungsverhältnis der (Erd-)Naturverhältnisse, da sie allenfalls einen grünen Kapitalismus erzeugt (was in Kap. 1 bereits problematisiert wurde).

Um diese imperialen Ausbeutungsverhältnisse menschlicher wie nichtmenschlicher Naturverhältnisse durch demokratische Regulierungen überwinden zu können, so kann mit Sünker fortgefahren werden, bedürfe es einen „kommunale[n] Leben[s]“, worunter Sünker mit Theunissen versteht, „dass die ,Realisierung von Allgemeinheit' daran gebunden wird, ,daß das menschliche Individuum sein Leben an in sich vernünftigen Sachen ausrichtet und an der Allheit gleicher Subjekte orientiert ist' ([Theunissen] 1982: 27)“ (ebd.: 453). Erst so ließen sich die durch den Klimawandel verschärften sozialen Ungleichheiten (Liedholz 2021: Kap. 4) überhaupt dort bearbeiten und überwinden, wo sie produziert werden: in den urbanen Praxen kapitalisierter Praxen der Urbanisierung. Sünker sieht hierfür die Notwendigkeit „einer sozialen Bewegung“, die „die Vernunft und eine solidarisch agierende Mehrheit verkörpert, um den bislang üblichen Beendigungen von Befreiungskämpfen zu entkommen“ (Sünker 2017: 453), nämlich „'im Mülleimer der Verwertungsprozesse [...] ([Heydorn] 1979: 8)“ (Sünker 1989: 15). Mit Heydorn geht es Sünker darum, dass die subjektiven Ansprüche der „'befrei- 
ten Gattung universell werden können“ (Heydorn IV,S. 293)“, indem „Vorstellungen über radikale Änderungen im Verhältnis von Kultur und Ökonomie“ zum alltäglichen kommunalen Handlungssubjekt werden können, mit dem ,Ziel [...] der Entwicklung einer radikalen Demokratie, die auf Selbstverwaltung und Beteiligung aller aufruht (vgl. Sünker/Farnen/Széll 2003)“ (Sünker 2012: 258). Nur durch eine kommunal organisierte Demokratie, so schon Lefebvre, auf den sich Sünker bezieht, wird Selbstverwaltung - die nicht nur „zur Kulturrevolution [gehört]“ (Lefebvre 1972: 276), sondern vielmehr deren Voraussetzung und zugleich notwendiges Ziel ist - zum politischen Instrument einer ,permanenten kulturellen Revolution“ (ebd.: 236), bei der das „Leben, und nicht nur de[r] Staat oder die Eigentumsverhältnisse [verändert]" (ebd.: 275) werden, weil endlich die gesamten zur Verfügung stehenden gesellschaftlichen Ressourcen in den Dienst dieser Veränderungen des Alltäglichen gestellt werden können.

Von einer grundlegenden Transformation gesellschaftlicher Verhältnisse lässt sich also nur dann sprechen, wenn sie nicht nur mit demokratischem und partizipatorischem Mitteln realisiert wird, sondern wenn sie zudem zum emanzipatorischen Selbstzweck erhoben wird. Und das heißt, dass der Erhalt der Bewohnbarkeit Erde nicht um der Bewohnbarkeit der Erde Willen angestrebt werden muss, sondern damit sich Menschen resp. menschliche Entwicklung auf und mit der Erde so verwirklichen kann, dass sie über ihre individuellen Lebensweisen beginnen, ihre menschlichen Belange und dessen Auswirkungen auf nicht-menschlicher Akteure und ökologische Aktanten ${ }^{17}$ des Planeten (anorganische Gebilde wie Gewässer, Gebirge, Atmosphäre, bzw. das Klima im allgemeinen) politisch zu regulieren. Erst von diesem Augenblick an ließe sich aus einer Subjektperspektive von einem Anthropozän in Sinne eines Erdzeitalters sprechen, in dem sich die Menschen (wieder) ihrer erdökologischen Einbettung bewusst werden, d.h. sich als AkteurInnen dieser Erde und sich der Erde als ihr gemeinsames Subjekt (wieder) gewahr werden können. Nämlich als ontisches Existenzial menschlicher wie nichtmenschlicher Existenzweisen, als allen gemeinsames Wesen resp. Gemeinwesen terrestrischer Existenz, als pädagogisch zu gestaltender Ort, auf und mit dem sich die Menschen ihre gedeihliche Entwicklung ermöglichen müssen.

17 In Anlehnung an Latours Begriff der Aktanten als ,,aktive Bestandteile jeder Praxis“ (Hillebrandt 2015: 15), genauer: als ,,beobachtbare Kraftübertragungen, bei denen noch nicht geklärt ist, wer für diese Impulse eigentlich verantwortlich ist“ (Laux 2014: 271), werden unter Aktanten hier vor allem erdökologische Komponenten wie Gewässer, Gebirge, Landschaften, Atmosphäre bzw. das Klima als Aktanten gefasst, die eine beobachtbare (ebd.) Wirkung auf handelnde Akteure zeitigen (etwa in politischen Auseinandersetzungen hinsichtlich des Umgangs mit dem Klimawandel, der Versauerung der Meere, der Zerstörung von Biotopen und der Ozonschicht) und damit „aktive Bestandteile“ (Hillebrandt 2015: 15) der Praxis sind. 
In dieser Hinsicht spricht ja auch schon Marx von der „Erde [...] als Subjekt" (Marx 1983: 396), beschränkt dieses Subjekt aber immer wieder nur auf den Menschen, da er offensichtlich nicht im Blick hat, dass die Erde auch allen Tieren und Pflanzen das für ihre gedeihliche gemeinsame Zugrundeliegende ist. Anders Nietzsches Figur des ,Zarathustra'. Auch sie greift die Erde als Subjekt des Menschen auf, geht aber zugleich den Schritt über Marx hinaus, indem sie den philosophischen Anthropozentrismus zu öffnen sucht (Joisten 1994). Doch sowenig wie Marx'/Engels' Praxisphilosophie von ihren Zeitgenossen Gehör fanden, sowenig fand auch Nietzsches Zarathustra bei seinen Zeitgenossen Gehör (sowohl auf dem Papier als auch in der realen Welt), so dass sowohl die Marxsche und Engels'sche als auch die Nietzscheanische philosophische Figur der Erde als Subjekt nach wie vor nach wie vor als unabgegoltenes Transformationsnarrativ betrachtet werden muss.

Mit anderen Worten: Der Subjektbegriff ist zwar einerseits seit Marx/Engels und Nietzsche ökologisch aufgeladen, andererseits war diese Aufladung bis zum Ende des 20. Jahrhunderts in der sozialpädagogischen bzw. sozialarbeiterischen Theoriebildung weitestgehend übersehen oder ignoriert worden. Entsprechend ist es geradezu als revolutionär anzusehen, dass Winkler diese ökologische Latenz des Subjektbegriffs in die „Theorie der Sozialpädagogik" (Winkler 1988) einzuarbeiten sucht, um so dem ontischen Zusammenhang von Mensch und Erde gerecht zu werden. Dies macht er über einen Bezug zu Nietzsches Betrachtung des Menschen als „das noch nicht festgestellte Tier“ aus „Jenseits von Gut und Böse“ (Nietzsche 1954c: 623; Winkler 1988: 105). Damit nimmt der Subjektbegriff für Winkler seine Berechtigung vor allem dort auf, wo Menschen nicht bloß als Instinktwesen anerkannt werden, sondern als sich aus bloßen Instinktwesen herausbildende Wesen, die sich als nicht nur bloße Instinktwesen $\mathrm{zu}$ begreifen beginnen. Wenn Winklers Subjektbezug in Nietzsches „Jenseits von Gut und Böse“ aber nicht aus dessen Kontext zur Argumentation seines zuvor erschienenen „Zarathustra“ gerissen werden soll, wo der Mensch als „Seil, geknüpft zwischen Tier und Übermensch" (Nietzsche 1954a: 281), und der Übermensch als „Sinn der Erde“ herausgestellt wurde (ebd.: 280$)^{18}$, dann muss der Ökolo-

18 Nietzsche führt an anderer Stelle im „Zarathustra“ weiter aus: „Führt, gleich mir, die verflogene Tugend zur Erde zurück - ja, zurück zu Leib und Leben: daß sie der Erde ihren Sinn gebe, einen Menschen-Sinn! [...] Tausend Pfade gibt es, die noch nie gegangen sind, tausend Gesundheiten und verborgene Eilande des Lebens. Unerschöpft und unentdeckt ist immer noch Mensch und Menschen-Erde. [...] Wahrlich, eine Stätte der Genesung soll noch die Erde werden! Und schon liegt ein neuer Geruch um sie, ein Heil bringender - und eine neue Hoffnung!“ (Nietzsche 1954a: 338f.) Karen Joisten interpretiert diese Stellen so: „Die Erde bedarf, um Erde in der vollen Bedeutung des Wortes zu sein, eines Sinns, der ihr allerdings nicht äußerlich ist, sondern den sie selbst birgt. Anders gesagt: Der Mensch muss sich als ÜBER in Richtung auf den Sinn, den Übermenschen, entwerfen, und dergestalt in der Erde verwurzelt sein, um die Chance der Realisierung des Übermenschen zu haben. Er muss sich willentlich auf den Übermenschen ausrichten und der Erde seinen Sinn und ihren Sinn geben [...].“(Joisten 1994: 215f.) (Näheres dazu auch in Kap. 12.2.1.) 
gie-Bezug, den Winkler über Nietzsche in die sozialpädagogische/ sozialarbeiterische Theoriebildung einnäht, deutlich weiter gefasst werden, als es Winkler tut. Winkler schreibt:

„Zwar teilt die menschliche Gattung mit allen anderen Lebewesen die Grundmechanismen des Biologischen und lebt daher in einem ihr als Bedingung vorgegebenen Naturzusammenhang, doch ist sie durch diesen in ihrer Existenz nicht determiniert. Menschen sind abhängig vom Gesamtzusammenhang der Natur und doch als ,nicht festgestellte Tiere' aus ihm entlassen, daher auch weltoffen. Biologisch verwaist stehen sie ihren eigenen Naturbedingungen gegenüber, die sie doch wieder aneignen müssen: Um die Kontinuität ihres Gattungslebens zu sichern, sind sie auf sich selbst verwiesen; sie müssen den verlorenen Zusammenhang mit der Natur wieder herstellen, sich ökologisch verhalten. Die eigenen Naturbedingungen sind der menschlichen Gattung nicht gegeben, sondern aufgegeben.“(Winkler 1988: 105)

„Subjektorientierung“, so Winkler weiter, „begreift also menschliche Subjektivität ökologisch“ (ebd.: 156). Das meint bei Winkler, dass menschliche Subjektivitätsbildung entlang der „Strukturen des alltäglichen Lebens im Sinne ökologischer Nahbeziehungen" (ebd.: 77) verstanden werden muss. Ökologisch heißt bei Winkler daher eine Bezugnahme ,auf die Gesamtheit der menschlichen Lebenspraxis als eines kulturellen Selbstschöpfungsprozesses, der jegliche Lebenstätigkeit umfasst" (ebd.: 127). Winkler lässt es im Ungefähren, ob sich ,die Gesamtheit der menschlichen Lebenspraxis“ (ebd.) nur auf das Soziale beschränkt, oder auf die ganze Erde, die die ökologische Gesamtheit des Sozialen erst vervollständigen würde.

Gleichwohl ist in Winklers Verschränkung der analytischen Kategorie der Subjektbildung und dem damit verknüpften anthropologischen Begriff des sich als Mensch bewusst werdendem biologisch „verwaisten Tier“" (ebd.: 105) mit der Kategorie des Ortes ein Erdbezug inhärent. Der Ort als das „Haus“ der ökologischen Zusammenhänge ist für ihn die „Grundlage [...] auf welcher Aneignungs- und Entwicklungsprozesse stattfinden können“ (ebd.: 258) und „eine Betrachtung und Beurteilung von ,ökologischen“ Lebensverhältnissen [erlaubt]“ (ebd.: 259). Allerdings lokalisiert Winkler den Ort nicht weiter, so dass Winkler hier mit Lefebvre und Sünker weiter gedacht werden kann, die den pädagogischen Ort Winklers in der Räumlichkeit des städtischen Alltags lokalisieren. Zugleich ist der Begriff des städtischen Alltags bei Lefebvre noch deutlich weiter gefasst, als er von Sünker später fortgeführt wird. Für Lefebvre ist nämlich der städtische Alltag das Haus des Seins, „die Wohnung des Menschen als menschliches Sein, erbaut in der Praxis und auf der Erde“ (Lefebvre 1975c: 351, Hervorh. MS). Nämlich eingebettet in die ökologischen Naturverhältnisse dieser Erde. Doch diese subjektive Wahrnehmung der eigenen erdökologischen Verwurzelung ist unter kapitalistisch Lebensbedingungen weitestgehend entfremdet, gar der Wahrnehmung ganz entschwunden. Darauf machten ja in je verschiedener Weise bereits Marx/Engels und Nietzsche aufmerksam. Um sie wieder zu ermöglichen, müssen - so die trotz aller Unterschiede dennoch recht ähnliche Kernaussage ihrer Argumentationsfiguren - die Möglichkeiten hierfür im kommunalen 
Leben des urbanen Alltags geschaffen werden. Erst von dort aus lassen sie sich politisieren und könnten dadurch erst in einen gesellschaftlichen Transformationsprozess resp. eine subjektorientierte Kulturrevolution mit planetarischer Reichweite aufgehen. Dieser Möglichkeit im kommunalen urbanen Alltagsleben den Weg zur Wirklichkeit zu ermöglichen, darin lässt sich Soziale Arbeit als subjektorientierte Arbeit am Sozialen mit sozial-ökologischem Anspruch auf den Begriff bringen.

\section{Exkurs zum Begriff sozialer Ökologie bei Marx und dessen Bedeutung für Soziale Arbeit}

Die Leistung von Marx/Engels war es, vor dem Hintergrund erdzerstörerischer Problemlagen - die aus bürgerlichen bzw. imperialen Lebensweisen entstehen, genauer: aus dem kapitalistischen Zwang der Bodenverwertung und -vernutzung, für die sich später der Begriff Extraktivismus herausgebildet hat (Acosta/Brand 2018) - Fragestellungen politischer und sozialer Revolutionierung mit Fragen kommunaler Bildung - wie sie im Begriff der Kulturrevolution ihr Korrelat finden - zusammenzubringen und zum nahezu durchgängigen Ausgangs- und Bezugspunkt ihrer Untersuchungen zu machen (zum Überblick zu Marx: Schmied-Kowarzik 2018; zum Überblick zu Engels: Altvater 2015). Insbesondere bei Marx kommt zum Ausdruck, dass das Verständnis von Natur bzw. Erde, das wird bei Marx synonym verwendet (Schmidt 2016: 39), nicht losgelöst betrachtet werden kann von der alltäglichen urbanen Art und Weise der Vergesellschaftung von und äußeren (Erd)Naturverhältnissen des Menschen. Das bislang betonte Verhältnis von urbaner Praxis und der Praxis der Urbanisierung erdökologischer Naturverhältnisse hatte bei Marx sowohl ein philosophisches wie soziologisches Fundament. War das Mensch-Erde-Verhältnis seinerzeit noch weitgehend idealistisch versucht worden herauszustellen, arbeitete es Feuerbach als leiblichsinnliches Verhältnis heraus, das für Marx allerdings noch zu sehr in einem Mensch-Natur-Dualismus verhaftet war, bei dem der Mensch „der Natur als toter Objektivität passiv-anschauend, nicht praktisch-tätig gegenüber“ steht (ebd.: 37):

„Was Feuerbach als Einheit von Mensch und Natur bezeichnet, bezieht sich nur auf das von ihm romantisch verklärte Faktum der Naturentsprungenheit des Menschen, nicht aber auf seine geschichtlich-gesellschaftlich vermittelte Einheit mit der Natur in der Industrie, eine Einheit, die auf allen Stufen ebenso Verschiedenheit, Aneignung eines Fremden, Auseinandersetzung ist. Feuerbachs Mensch tritt nicht als eigenständige Produktivkraft auf, sondern bleibt an vormenschliche Natur gefesselt." (ebd.)

Für Marx ist demgegenüber „Natur [...] Moment menschlicher Praxis wie zugleich Totalität dessen, was ist" (ebd.). Diese Totalität der Natur meint bei Marx eine „genetische Priorität gegenüber den Menschen“ (ebd.: 39), sein 
ontisches Existenzial, das „das Leben von seiner allgemeinsten Notwendigkeit, dem Stoffwechsel von Mensch und Natur bestimmt" (ebd.: 103). Naturverhältnisse bedingen menschliche Praxis. Sie fangen die Gesellschaftsverhältnisse und die alltägliche gesellschaftliche Praxis ontisch an. Naturverhältnisse und Gesellschaftsverhältnisse - beide stehen als gesellschaftliche Naturverhältnisse in einem unaufkündbaren Stoffwechselverhältnis. Auch wenn, wie in Kap. 1. erwähnt, Marx der Begriff Ökologie noch nicht zur Verfügung stand, kommt in Marx Begriff des Naturstoffwechsels aber nicht nur schon zum Ausdruck, was Haeckel (Haeckel 1866a, 1866b) dann darunter verstehen sollte, sondern geht zugleich auch schon über dessen mechanische Anpassungsphysiologie hinaus, die Haeckel von Anfang an in diesen Begriff hineingelegt hatte. Während Haeckels Ökologiebegriff noch ganz im Feuerbachschen Materialismus steht, wonach der Mensch „der Natur als toter Objektivität passiv-anschauend, nicht praktisch-tätig gegenüber“ steht (Schmidt 2016: 37) und, darin geht Haeckel über Feuerbach hinaus, sich ihr anpasst, ist dieses ökologische Verhältnis von Natur bzw. Erde und Mensch für Marx ein gesellschaftliches bzw. soziales, das sich gegenseitig herausbildet und fortentwickelt. In der menschlichen Praxis, so Marx, verstoffwechselt sich die Erde/Natur und kreiert sich darin fort. Philosophiehistorisch gesprochen: Natur wird bei Marx verstanden als natura naturans, worin Marx“ Praxisphilosophie den Anschluss an die antike Physis-Konzeption sucht (Kap. 2). ${ }^{19}$ Dabei geht er mit seiner Fokussierung auf die ,geschichtlichgesellschaftlich vermittelte Einheit mit der Natur in der Industrie“ (ebd.) und ihrer Bedeutung für die Vergesellschaftung/ Urbanisierung von Mensch und Erde zugleich weit über die antike Physis-Konzeption hinaus. Während Haeckel also einen mechanischen Ökologiebegriff als, wenn man so will, »ErdeMensch-Einbahnstraße« zu Wege bringt, bringt Marx einen Begriff Sozialer Ökologie zu Wege, der Erde und Mensch in ein dialektisches Stoffwechselverhältnis setzt, das sich gegenseitig zur Weiterentwicklung affiziert. Entsprechend konnte Marx eine sozial-ökologische Kritik entwickeln, dass der Mensch die physiologische Erdökologie, in die der Mensch eingebettet ist, solange ruinieren muss, bis er die Erde als Gemeingut der Menschen aus dem Reich des Ökomischen in das Reich des Politischen, d.h. der politischen Regulierung überführt hat.

Wenn in der vorliegenden Studie von sozial-ökologisch oder Sozialer Ökologie die Rede ist, findet sie, soweit die jeweilige Bedeutung nicht anders gekennzeichnet ist, immer in dieser Marxschen Bedeutung als gegenseitige

19 Das Marxsche Postulat, dass der Mensch seine eigene, innere Natur durch die Gestaltung der äußeren Natur gestaltet (Marx 1962a: 192), findet sich geradezu analog bei Demokrit, dem wohl letzten antiken Vertreter der ionischen Naturphilosophie schon vorweggenommen: „Die Natur und die Erziehung sind etwas Ähnliches. Denn die Erziehung formt zwar den Menschen um, aber durch diese Umformung schafft sie Natur“ (B33 = Clem. Alex strom. IV 151. Stob II 31,65 zit. und übersetzt in Meister 2010: 59f.) 
Entwicklung bedingende Verflochtenheit von Gesellschaftsverhältnissen und Naturverhältnissen Verwendung. Sie ist zugleich immer mit dem Imperativ versehen, dieses Verhältnis von Grund auf zu politisieren. Damit avanciert der Begriff zum Begriff einer sich als Arbeit am terrestrischen Gemeinwesen verstehenden Sozialen Arbeit, die sich in ihrer Arbeit am zu bildenden emanzipatorisch-menschlichen Subjekt an den Residuen der Subjektivität ,imperialer Lebensweisen“ (Brand/Wissen 2017) zu orientieren sucht und die zu bildende menschliche Subjektivität nicht losgelöst von ihrer existenzialen Verflochtenheit mit der Erde betrachtet. Das menschliche Gemeinwesen kann damit niemals losgelöst betrachtet werden vom ihm ontisch zugrundliegenden und ihm zeitlich vorausgehenden planetarischen Gemeinwesen, das es hervorgebracht hat und in das es ökologisch eingewoben ist und von dem es von Anfang an an-gefangen ist. Politisch verwirklicht werden kann es allerdings erst durch ein politisches Gemeinwesen, das ihm eine gesellschaftliche Form gibt und es inhaltlich ausgestaltet, indem es nicht nur die Gedeihlichkeit des Menschen, sondern der ganzen Erdökologie ins Zentrum des Politischen rückt. D.h. das Politische muss letztlich so verfasst sein, dass sich das politische Gemeinwesen mit der Entwicklung des erdökologischen Gemeinwesens historisch mitentwickeln kann. Nur dadurch - so die hier vertretene docta spes ${ }^{20}$ - kann die Erde als globales Gemeingut hervorgebracht werden, das ihre Akteure und Aktanten als Nutzungsberechtigte mit eigener politischer Stimme und Gewicht konstituiert. Die vorliegende Studie knüpft damit an meine Lesart von May's theoretischen Begründungsrahmen „Sozialer Arbeit als Arbeit am Gemeinwesen" an, wie ich sie in einem Rezensionsaufsatz zum besagten Buch nur angerissen habe (Schmidt 2017) und sie hier nun auszuformulieren suche: Nämlich als Versuch einer Begründung Sozialer Arbeit im und am politischen Gemeinwesen Erde.

Zur Frage steht nun aber, wie der Mensch bzw. das menschliche Subjekt im Zentrum dieser sozialen resp. politischen Ökologie zu verorten ist, so dass sein vergesellschaftetes und stets weiter sich vergesellschaftendes Verhältnis zur Erde Gegenstand subjektorientierter Sozialer Arbeit sein kann, die das menschliche Subjekt nicht nur als pädagogisch bildbares annimmt, sondern durch das auch eine revolutionär-transformative Bildung in Erwägung gezogen werden kann, zu der Soziale Arbeit auch hinsichtlich der gegenwärtigen Öko- und Klimaproblematik einen Beitrag leisten kann und muss. - Exkurs Ende

20 Als docta spes bezeichnet Bloch (2013a: 8) die ,dialektisch-materialistisch begriffene Hoffnung“, die ,noch ungewordene, noch ungelungene Heimat, wie sie im dialektischmaterialistischen Kampf des Neuen mit dem Alten sich herausbildet, heraufbildet“. Für Bloch ist damit zugleich das „Grundthema der Philosophie, die bleibt und ist, indem sie wird", ausgesprochen. (ebd.) 
Zusammengefasst: Auch wenn sich Sünkers bildungstheoretischer Ansatz recht mühelos in einen Begriff sozial-ökologisch revolutionärer Transformation überführen lässt, weil kommunale Selbstverwaltung Voraussetzung und zugleich notwendiges Ziel einer kulturellen Revolution ist, die nicht nur am „Überleben[] der Gattung [Mensch, MS] der konkreten Einzelnen“ (Sünker 2012: 259), sondern auch an der Emanzipation der bloß biologischen Gattung zur politisch-ökologischen Gattung - und hier wäre Sünker um einen sozialökologischen Sinngehalt zu präzisieren: auf und mit der Erde - interessiert ist. Dann bleibt hierin dennoch die Frage nach der Begründung einer solchen Bildungsthese offen. Diese Begründung lässt sich nach den bisherigen Ausführungen zusammengefasst darlegen in der Parallele von Winklers existenzial-historischer Mensch-Ort-Dialektik und Marxens existenzial-historischer Mensch-Erde-Dialektik. Beiden ist damit ein unaufkündbares ökologisches Verhältnis von Mensch und Ort bzw. Mensch und Erde gemeinsam, das sich gegenseitig bedingt und hervorbringt und in dieser Dialektik das Subjekt sozial-ökologischer Transformation bildet. Dass Marx allerdings die gesellschaftliche Vermittlung dieser Ökologie auf der Makroebene stärker betont, während es bei Winkler einerseits unausgesprochen impliziert wird, andererseits bewusst ausgelassen wird, um so die Analyse der Subjektbildung auf eine Mikroebene zu bringen und dort möglichst scharf zu konturieren, ist hier nur ein Nebenschauplatz. ${ }^{21}$ Für Soziale Arbeit in der Mesoebene bedeutet dies in beiden Fällen die Notwendigkeit „sozialpädagogischen Ortshandelns“ (Winkler 1988: 278ff.), wobei dieser Ort mit Sünker (Sünker 1989) im städtischen Alltag erblickt wurde und der städtische Alltag zugleich in einem sozial-ökologischen Kontext verortet werden muss. Nämlich als städtischer Alltag auf und mit der Erde. Mit anderen Worten: Soll sich etwas an der Zerstörung der Bewohnbarkeit der Erde ändern, muss sich das alltägliche städtische Wohnen so verändern können, dass es ein anderes urbanes Wohnen auf und mit der Erde möglich würde. Im Anschluss an Lefebvre betont Sünker hierfür die Notwendigkeit einer kulturellen Revolutionierung des urbanen Alltagslebens, in und mit der sich die subjektive Bildung der inneren Natur zur Überwindung ,imperialer Lebensweisen“ (Brand/Wissen 2017) vollziehen kann.

21 So Winkler in einem Doktorandenkolleg an der Hochschule RheinMain 06.03.2020. 


\subsection{Auf dem Weg zum Anthropozän - Soziale Arbeit als Agitatorin subjektorientierter Kulturrevolution mit sozial-ökologischem Anspruch auf globaler Ebene mit planetarischer Reichweite}

Es sollte deutlich geworden sein, dass die hier verwendeten Implikationen im Begriff Ökologie bzw. im Attribut ökologisch nichts mit „grüner Sozialer Arbeit" (Limbrunner/van Elsen 2013) zu tun hat, obschon in sog. grünen Projekten Sozialer Arbeit, d.h. in „Einrichtungen, die Landbau und Sozialarbeit kombinieren" (Limbrunner 2013: 26), alternative Wirtschaftsweisen zum Ausdruck kommen, die für die Überwindung imperialer Lebensweisen (Brand/Wissen 2017: 165ff.) von zentraler Bedeutung sein können. So „versteht sich [der ökologisch bewirtschaftete Hof] als ganzheitlicher Betriebsorganismus, als ein Mikrokosmos, der Erde, Pflanzen, Tiere und Menschen in sichtbaren Kreisläufen verbindet"“ (Limbrunner 2013: 26) und

,auch unter dem Blickwinkel der Subsistenzperspektive gesehen werden kann. Dieser Ansatz erfordert eine Haltung, in der sich Menschen als Individuen in ihrer Souveränität angesprochen fühlen. Mit Subsistenz ist ein alternativer Arbeits- und Produktivitätsbegriff gemeint, bei dem nicht die Arbeit an sich viel wert ist, die möglichst viel weiteres Geld hervorbringt, sondern die Arbeit, die Leben erhält und Lebensfreude hervorbringt. Hier wird nicht nur wegen des Geldes gearbeitet, sondern der Sinnhaftigkeit, Freude und Notwendigkeit wegen. Subsistenz meint zudem die konkrete Hinwendung zum näheren Lebensumfeld. Produziert wird demnach, aber nicht nur, für den unmittelbaren Umkreis, für die eigene Einrichtung, für das regionale Umfeld.“ (ebd.: 27)

Damit sind sicher postwachstumsökonomische Implikationen ausgesprochen (zum Überblick der Bandbreite der Debatte: Brand 2014; Schmelzer/Vetter 2019; D'Alisa et al. 2016; Eversberg/Muraca 2019; Schoppek 2019). Zugleich steht aber die Frage im Raum, wie die Reichweite kleiner lokaler Projekte als notwendige Ausgangspunkte gesellschaftlicher Transformationen in die Reichweite gesamtgesellschaftlicher Transformationen überstiegen werden können, ohne dass die alltäglichen Schwierigkeiten, den alltäglichen Reproduktionszwängen der ,imperialen Lebensweise“ (Brand/Wissen 2017) als privates Problem zu verklären und ihre Bearbeitung den Individuen zu überlassen. Vor diesem Hintergrund ergibt sich für eine subjektorientierte Professionalität Sozialer Arbeit mit sozial-ökologischem Anspruch der Arbeit am terrestrischen Gemeinwesen ein ganzer Fragenkomplex:

- Mit welchen Problemen müssen sich Menschen im Alltag auseinandersetzen, um die ,imperiale Lebensweise“ (ebd.) überwinden zu können und welche gesellschaftlichen Blockierungen bzw. Widersprüche offenbaren sich ihnen dabei? 
- Wie (würden) sie diese bearbeiten, was fehlt ihnen hierzu (noch), was bleibt ihnen dabei dennoch als unverwirklichte Subjektivität zurück, steht diese möglicherweise im Widerspruch zur Überwindung imperialer Lebensweisen und wie lassen sich diese politisieren?

Diese Fragen sind gewiss zentrale Fragen. Aber mit dem Anspruch einer praxisphilosophischen Arbeit an einer sozial-ökologischen Transformation des gesellschaftlichen Alltags (Kap. 1 und 2) müssen sie zusammengeführt und zugleich auch weiter gefasst werden:

- Wie können die Menschen ihre Probleme bei der Überwindung der ,imperialen Lebensweise" (ebd.) öffentlich politisieren und wie kann diese Politisierung zu einer Bildung verbindlicher politischer Strukturen führen, die ein demokratisches Gemeinwesen eröffnen, in den und an dem sich eine sozial-ökologisch bewusste menschliche Subjektivität (heraus-)bilden kann, die sich zwar der Menschen als zentrale AkteurInnen ihrer Politischen Ökologie bewusst ist, zugleich aber auch der nur dezentralen Positionierung des Menschen in der sozialen Produktion resp. Bildung der Erdökologie?

Daran schließen weitere Fragen an:

- Wie können Menschen fachlich unterstützt werden, ihren Alltag und ihre Alltagsbedingungen so zu politisieren, dass sie über die Machtmittel verfügen, alltägliche Blockierungszusammenhänge in der Überwindung der „imperialen Lebensweise“ (ebd.) politisch selbst zu bearbeiten?

- Wie lassen sich die Ergebnisse in eine verbindliche Alltagspraxis umsetzen?

- Wie lässt sich urbane Subsistenz unter demokratischen Dissensbedingungen bewerkstelligen?

- Wie lassen sich diejenigen Subjekte erreichen, die sich das Klimaproblem bislang nicht haben aneignen können?

Praxisphilosophisch subjektorientierte Soziale Arbeit fokussiert als Arbeit am terrestrischen Gemeinwesen, wie in den vorangegangenen Kapiteln herausgestellt wurde, die Herausbildung eines emanzipatorischen menschlichen Subjekts, das, wie May/Kunstreich (1999) im Anschluss an Freire herausstellen, nur dadurch ermöglicht werden kann, wenn die „Bildung des Sozialen“ zugleich auch eine „Bildung am Sozialen“ ermöglicht. Entsprechend „[wird] [e]chte Bildungsarbeit [...] nicht von A für B oder A über B vollzogen, sondern vielmehr von A mit B, vermittelt durch die Welt - eine Welt, die beide Seiten beeindruckt und herausfordert und Ansichten oder Meinungen darüber hervorruft" (Freire 1975: 76f.). Eine solche praxisphilosophisch subjektorien- 
tierte Pädagogik des Sozialen findet sich bereits bei Marx in der revidierten Fassung der dritten Feuerbachthese von 1888 angelegt (Marx 1978a: 533f.). Sie wird in seinem Gesamtwerk sogleich in einen kommunalistischstaatserzieherischen Kontext gerückt (zusammenfassender Überblick: May 2016, 2001), der in der Sozialen Arbeit - nicht zuletzt in Fortführung von Winklers Ansatz ,sozialpädagogischen Ortshandeln[s]“ (Winkler 1988: 278ff.) - vor allem in Richters Ansatz einer kommunalen Pädagogik des Sozialen (Richter 1998, 2019b) ihre Fortsetzung findet. Wir bei Marx wird auch bei Richter dabei auf eine gesellschaftliche Transformation mit sozialökologischem Bezugspunkt insistiert. In der vorliegenden Studie wird dafür an Marx“ Anspruch Anschluss gesucht, den „unheilbaren Riß [...] in dem Zusammenhang des gesellschaftlichen und durch die Naturgesetze des Lebens vorgeschriebnen Stoffwechsels“ (Marx 1964: 821) zu überwinden, so dass der kommunalistische Gedanke der „Assoziation, auf Grund und Boden angewandt, [...] die gemütliche Beziehung des Menschen zur Erde herstellt, indem die Erde aufhört, ein Gegenstand des Schachers zu sein, und durch die freie Arbeit und den freien Genuß wieder ein wahres, persönliches Eigentum des Menschen wird" (Marx 1968b: 508). Zugleich wird in der vorliegenden Studie dieser anthropozentrische Anspruch Marx' dahingehend zu übersteigen versucht, dass die Erde nicht als ,persönliches Eigentum des Menschen“ (ebd.) hervorgebracht wird, sondern als kollektives Eigentum aller Erdbewohner. Darin erfährt der Begriff Praxisphilosophie zugleich seine politische Kontur und gesellschafts-transformative Reichweite, die sich in zwei für die vorliegende Studie wegweisenden Punkten zusammenfassen lassen:

1. Die Überführung der Nutzung des Gemeinguts Erde aus dem Reich der ökonomistischen Verwertung in das Reich der politischen Regulierung der gesellschaftlichen Ver- und Erarbeitung der Erde als „Laboratorium“ (Marx 1983: 400) und ,ursprüngliche Proviantkammer“ sowie „ursprüngliches Arsenal von Arbeitsmitteln“ zur „Herstellung von Gebrauchswerten, Aneignung des Natürlichen für menschliche Bedürfnisse" (Marx 1962a: 194, 198), was bei Marx immer im Kontext der Urbanisierung begriffen werden muss (Lefebvre 1975b). Die politische Regulierung der Urbanisierung der Erde, so die Essenz der vorangegangenen Kapitel, muss dabei von den Kommunen ausgehen und muss im Kontext einer radikalen Politisierung der Stadtentwicklung erst ermöglicht werden. Im Kontext Sozialer Arbeit wird diese „Notwendigkeit der Rückgewinnung des Territorialen in Form der Kommune“ insbesondere von Richter betont, der hierin den „Ansatzpunkt" sieht, „die Pädagogik, die seit der Herrschaft der bürgerlichen Gesellschaft implizit immer als Nationalpädagogik konzipiert worden ist, unter expliziter Nennung des territorialen Momentes als Kommunalpädagogik zu fassen“" (Richter 2001: 144). 
2. Zugleich - und hierin wird über Richters kommunalpädagogischen Ansatz sogleich hinaus gegangen ${ }^{22}$ - muss der Prozess der Politisierung der Praxis der Urbanisierung mit einer Politisierung der urbanen Praxis einhergehen, um so die vielfältigen gesellschaftlichen Ausschließungen, herrschaftlichen und Residuen erzeugenden Unterdrückungszusammenhänge sowie sozialen Ungleichheiten, die der ,imperialen Lebensweise“ innewohnen (Brand/Wissen 2017: 43ff.), ins Verhältnis zur Urbanisierungspraxis zu setzen, die, wie in Kap. 3.2 gezeigt werden konnte, spätestens seit der Seßhaftwerdung institutionell arbeitsteilig durchzogen ist und soziale Herrschaftsverhältnisse hervorgebracht hat, die seither die innere wie äußere Natur des Menschen urbanisieren und die entlang des kapitalogenen Städtebaus wortwörtlich zementiert werden. Die in diesem historischen Prozess einsetzende „Urbanisierung des Kapitals“ (Harvey 2014: 126) bringt essentiell letztlich nichts allzu Neues in die Welt, treibt aber die vorhandenen Entwicklungstendenzen der Urbanisierung im ungeheuren Tempo auf die Spitze der Ausbeutung menschlicher und nichtmenschlicher Naturverhältnisse und hebt sie auf ein planetarisches Ausmaß, während sie zugleich die Bedingungen einer Lebensweise produziert, die die zerstörerischen Entfremdungen zur inneren und äußeren Natur des Menschen aus den Augen verlieren lässt. Mit Lefebvre lässt sich diesbezüglich von „Entfremdungen zweiten Grades“ sprechen, ,der Entfremdungen nicht mehr nur durch die Sache, sondern durch den Blick auf die Sache, nicht mehr allein durch das Reale, sondern durch das Bildnis des Realen, nicht mehr nur durch die subjektiven Illusionen über die Objektivität, sondern durch die Subjektivität selbst" (Lefebvre 1975c: 68). Es ist dieser Schleier entfremdeter Subjektivierung, den eine praxisphilosophische Gesellschaftstransformation mit emanzipatori-

22 Richters durchgängige Betonung der kommunalpädagogischen Herausbildung der Argumentationsfähigkeit der Akteure ist durchaus zuzustimmen, aber den Ausgangspunkt bei Habermas‘ Begriff der Universalpragmatik zu nehmen (etwa: Richter 1998: 61, Richter 2016: 50, Richter 2019a: 349ff.), erscheint eher mutwillig denn stringent rekonstruierbar. Statt das Argumentieren sowohl innerhalb als auch zwischen den Kommunen als universal, d.h. als bereits allgegenwärtig seiend anzunehmen, wäre Richter an dieser Stelle zu erwidern, dass die universalpragmatische Annahme des Argumentierenkönnens nicht der Ausgangspunkt Sozialer Arbeit sein kann, sondern dass die Arbeit ihren Ausgangspunkt bei den subalternen Subjekten (Gramsci 1994b: 1325) bzw. den Residuen (Lefebvre 1975c: 332, 1987: 311) nehmen muss. D.h. bei AkteurInnen, denen durch herrschaftliche Unterdrückungsprozesse nicht nur erst das Argumentieren, sondern schon deren Grundlage, das ZurSprache-bringen-können, abhandengekommen ist (Spivak 2008a, 2008b) und die durch gesellschaftliche und politische Arbeit erst mühsam und pädagogisch begleitet wieder ermöglicht werden muss (May 2017a). An diesem Punkt entzündet sich auch Winklers Revidierung seiner Theorie von 1988 (Winkler 2006), während Richter diesen Punkt weiterhin übergeht. Kurz: Richter setzt ein Können als gegeben voraus, das aber erst im Zuge einer kommunalen Pädagogik des Sozialen hergestellt werden muss - zumindest, wenn (s)ein Gemeinwesenbegriff alle Menschen umfasst und nicht nur diejenigen, die ihre Bedürfnisse und Interessen bereits artikulieren und vertreten können. 
schem Bildungsanspruch entlang des Prozesses sozial-ökologischer Stadtentwicklung zerschneiden muss.

Soziale Arbeit, die dieses dialektische Verhältnis von urbaner Praxis und der Praxis der Urbanisierung praxisphilosophisch zu politisieren sucht, muss also zugleich auch das politische Vermögen der Subjekte umwälzend transformieren, indem sie es der Entwicklung menschlicher Subjektivität politisch ermöglicht, das Verhältnis von innerer und äußerer Natur nicht länger in der Naturbeherrschung, sondern in der Naturallianz zu erblicken. Eine in einer kommunalen Pädagogik des Sozialen auf Naturallianz ausgerichtete hervorgebrachte kommunale Politik Sozialer Ökologie ${ }^{23}$ lässt sich im Anschluss an Marx mit Bloch wie folgt zusammenfassen,

dass ,[d] erartige Praxis [...] sich nicht darauf beschränken [kann], das Verhältnis des Menschen zum Menschen in einer klassenlosen Gesellschaft von Entfremdung zu befreien; sie geht weiter verändernd in das Verhältnis des Menschen zur Natur hinein. So daß der Mensch in der Natur nicht mehr zu stehen braucht wie in Feindesland, mit dem technischen Unfall als ständiger Drohung, wie er ja im noch abstrakten Ausbeutungsverhältnis zu den Naturkräften der Krise zu entsprechen vermag, die aus dem Ausbeutungsverhältnis der Menschen folgt. Ein anderes nicht ausbeutendes Verhalten zur Natur wurde schon der objektiv-realen Möglichkeit nach bedeutet als befreundete, konkrete Allianztechnik, die sich in Einklang zu bringen versucht mit dem hypothetischen Natursubjekt. Das wird um so notwendiger, als sich der Unfall ja längst ausgewachsen hat zu drohender Selbstausrottung des Menschen, gründlicher Zerstörung seiner natürlichen Existenzbedingungen durch Mißachtung der Ökologie. Letzteres eben ist nicht die Praxis als solidester Beweis konkreter Theorie, sondern umgekehrt der schrecklichst solide Beweis für die Falschheit einer die Klassengesellschaft verewigenden Theorie. Die dagegen sich wendende Allianztechnik nun betrifft jenen Rayon der Natur, der uns unmittelbar umgibt, unsere Umgebungsnatur, in die wir eingreifen können und mit der wir in ständigem Stoffwechsel stehen.“ (Bloch 1975: 251)

Bloch sieht für eine solche Praxis den Sozialismus als notwendige Bedingung an (ebd.), so dass für eine dergestalt praxisphilosophische Professionalität subjektorientierter Sozialer Arbeit nicht nur gelten muss, durch eine „mäeutisch geförderte[] Kreativität“" soziale Situationen zu erzeugen, ,in der die Alltäglichkeit nicht mehr gelebt werden kann (vgl. Lefebvre 1972, S. 51)“ (Sünker 2012: 263), sondern hierfür zugleich gelten muss:

„Lasst uns alle unsere Ressourcen, Ämter und Mandate gemeinsam dafür nutzen, aufzuklären und alles dafür zu tun, dass eine mächtige betriebs- und ortsübergreifende und internationale Bewegung entsteht, die die bestehenden Verhältnisse umstößt zugunsten einer globalen ökosozialistischen Demokratie!“ (Ökosozialistisches Netzwerk 2017: 17)

Neben diesen sozialwissenschaftlichen Fragen, stellen sich angesichts der Klimaproblematik aber vor allem auch naturwissenschaftliche Fragen, etwa

23 Der Begriff Soziale Ökologie wird hier von Bookchin (Bookchin 1992a: 204) übernommen. Allerdings, und darauf wird in Kap. $15 \mathrm{ff}$. noch dezidiert eingegangen, wird in der vorliegenden Arbeit hieran kein libertärer, sondern im Sinne des hier verwendeten Begriffs revolutionär-transformativer Bildung ein radikal-reformerischer Kommunalismusbegriff angeschlossen. 
nach urbanen $\mathrm{CO}_{2}$-Reduktionsmöglichkeiten und alternativer Energieversorgung, die ebenso praxisphilosophisch im sozial-ökologischen Transformationsprozess der Städte aufgefangen und angegangen werden müssen und ebenso Anschluss an die kommunalen Subjekte suchen müssen sowie in der Subjektbildungsfrage einer Kritischen Theorie gesellschaftlicher Naturverhältnisse aufgehen müssen. Die Frage transformativer Bildung, wie sie der WBGU (WBGU 2016b) zu beantworten sucht, aber auch wie sie in der vorliegenden Studie zu beantworten gesucht wird, ist im elementaren Maße eine theoretisch wie praktisch transdisziplinär (Mittelstraß 2005) zu beantwortende Frage. Sie verlangt sowohl die Zusammenarbeit verschiedener Disziplinen als auch die Zusammenarbeit mit außerwissenschaftlichen PraxisakteurInnen. Nicht nur um die vorherrschende Alltagspraxis aller, auch der wissenschaftlich beteiligten AkteurInnen, forscherisch in den Blick zu nehmen, sondern vor allem deswegen, um daran die objektiv-realen sozial-ökologischen Entwicklungsmöglichkeiten der Praxis wissenschaftlicher wie nicht-wissenschaftlicher AkteurInnen in den Blick zu nehmen, zu theoretisieren und die Praxis mit Hilfe der Theoriebildung revolutionär bzw. radikal zu transformieren.

Mit dem Bezug auf Blochs Kategorie des „objektiv-real Möglichen“ (Bloch 2013a: 271ff.), d.h. des tendenziell Möglichen der Praxis jenseits herrschaftlicher Beschränkungen/Blockierungen, kündigt sich eine solche „Aussichts-Erforschung des In-Möglichkeit-Seienden“, d.h. die Erforschung der „Aussicht aufs [...] gesamthistorisch-utopische[] Totum“ (ebd.: 240) als strategische Erforschung revolutionär-transformativer Bildungsperspektiven an. Dessen ermittelte Möglichkeiten lassen sich aber erst dadurch verwirklichen, wenn sich das transformative Wissen derart in politisches Können mit gesellschaftlicher Reichweite übersetzen lässt, dass es „die im Geschichtsprozess anhängige Sache“ (ebd.: 285) zur Praxis zu verhelfen vermag, indem „die Revolution [...] das Urbane machen [wird], nicht das Urbane die Revolution" (Lefebvre 1972: 277). Und zwar in einem Ausmaß, das dem anzugehenden weltweiten Problem der „Urbanisierung des Kapitals“ (Harvey 2014: 126), der daraus resultierenden ,imperialen Lebensweise“ (Brand/Wissen 2017) sowie dem daraus resultierenden Klimaproblem weltweit und auf gesellschaftshistorischem Niveau gerecht geworden werden kann. Gesellschaftliche Reichweite heißt für Soziale Arbeit also die politische Herausbildung eines planetarisch-subjektiven Gemeinwesens auf globaler Ebene. Damit ist der Begriff sozial-ökologische Transformation im Sinne einer sozialökologischen Kulturrevolution auf die Ebene eines gesamthistorischen Gesellschaftsprojekts gehoben, das als Projekt der Politisierung der gesamtökologischen Existenzbedingung auf und mit dieser Erde, kurz: als Anthropozän bezeichnet werden kann. 
Die „,im Geschichtsprozess anhängige Sache“ (Bloch 2013a: 285) ist für Bloch (ebd.: 241) im Anschluss an Marx ${ }^{24}$ (Marx 1968b: 536, 538) in der Natur bereits angelegt als Naturalisierung des Menschen, die zugleich eine Humanisierung der Natur bedeutet und findet sich auch in Nietzsches Argumentationsfigur des „homo natura“ (Nietzsche 1954c: 696), in der „Zarathustras" Argumentationsfigur des Übermenschen als „Sinn der Erde“ (Nietzsche 1954a: 280) aufgegangen ist, wieder. Vor dem Hintergrund Marxens (und auch Nietzsches) synonymer Verwendung von Natur und Erde (Schmidt 2016: 39) ließe sich hierbei auch von einem Planetarisieren oder Reterrestrialisieren (Latour 2017: 377) des Menschen sprechen, das zugleich eine Humanisierung des Planeten - modern gesprochen: die erdgeschichtliche Hervorbringung menschlichen Daseins als Anthropozän - bedeutet. Stärker als bei Nietzsche werden bei Marx, Bloch und auch Lefebvre aber die gesellschaftlichen Bedingungen der Verwirklichung des Naturmöglichen, d.h. des „hypothetischen Natursubjekt[s]“ (Bloch 1975: 251), betont, woran sich die Notwendigkeit Sozialer Arbeit anschließt. Winkler (1988), Sünker (1989), Richter (1998) und May (2017b) schließen, wie herausgestellt wurde, an diese geschichtsphilosophische Argumentationsfigur mit je unterschiedlichen Konkretisierungen an und machen die innere Natur des Menschen, d.h. dem der menschlichen Natur innewohnenden Drang zur sozialen Vergesellschaftung zum Hauptgegenstand Sozialer Arbeit, indem durch die pädagogische Gestaltung der verstädterten äußeren Natur das politische Können der Subjekte zu bilden und - insbesondere bei Richter und May - sozialräumlich $\mathrm{zu}$ organisieren gesucht wird. Diese theoretischen Begründungsrahmen Sozialer Arbeit gilt es in der vorliegenden Studie von der speziezistisch-menschlichen Ebene auf eine terrestrische Ebene des Gemeinwesens zu heben, ohne dabei die Bedeutung des menschlichen Gemeinwesens für eine solche Soziale Ökologie zu schmälern.

Was politisch gekonnt wird, um transformatives Wissen in einer transformativen Praxis aufgehen zu lassen, lässt sich der Praxis weder empirisch ablesen, noch lässt es sich ihr normativ vorschreiben. Die Frage nach den Möglichkeiten sozial-ökologischer Transformation ist damit weder eine Frage quantifizierender Wissenschaften noch eine philosophische Frage im Sinne der klassischen Sollensdeduktion. Die Frage was politisch also gekonnt wird, ist eine ganz genuin praxisphilosophische Frage praxisforscherischer

24 Ein solches zur Sozialität drängendes Subjekt menschlicher Natur findet sich mit je unterschiedlichen Begründungsversuchen bereits bei Humboldt (Bildung zum Menschen - zum Überblick: Menze 1965, Wulf 2020: 30ff.), Hegel (Hegel 1970a, 1970b), Schopenhauer (der Wille als Befähigung zum Mitleid - Schopenhauer 1998, 1989: 296ff.; zum Überblick: Schmidt 1988b) und Feuerbach (emanzipatorischer Sensualismus - zum Überblick: Schmidt 1988a) und wird philosophisch offenbar erst dort notwendig, wo der Riss zwischen Mensch und Natur zwar im Denken selbstverständlich geworden ist, sich in der alltäglichen Praxis der Mensch-Natur-Dualismus aber nicht bestätigt findet und bei genauerem Besehen auch nicht bestätigt finden kann. 
Subjektbildung und damit eine Frage der Könnenstransduktion. Was politisch gekonnt wird, liegt in der Könnerschaft der Subjekte, die sich mit dem Sozialen und am Sozialen herausbilden muss. Das verlangt ein Verständnis von „Bildung als Lebensform“ (Winkler 2014) und von Demokratie als (urbaner) Lebensweise (Richter 2015, 2016, 2019a), das beides erst durch eine subjektorientierte Sozialraumentwicklung und Sozialraumorganisation (Alisch/May 2013, 2015; May 2017b) aus den entfremdenden Formen alltäglicher Interaktionsweisen kapitalistisch-industrialisierter Vergesellschaftungspraxen der AkteurInnen herausgebildet werden muss. Darin gründet Gemeinwesenarbeit seit ihren Anfängen am Ende des 19. Jahrhunderts ihr politisches und pädagogisches Mandat (Müller 2013), das in der Klimafrage dringender denn je von Disziplin und Profession Sozialer Arbeit betont werden muss.

Subjektorientierte Soziale Arbeit, die sich von ihrem staatlich-strukturellen An-Gefangensein praxisphilosophisch zu emanzipieren sucht, adressiert damit nicht länger Menschen bzw. bestimmte Personenkreise, sondern und darin besteht das emanzipatorische Element - adressiert objektiv-real mögliche gesellschaftliche Verhältnisse und fokussiert dabei die politische Verwirklichung eines terrestrischen Gemeinwesens. Ein solches Gemeinwesen umfasst nicht nur alle Menschen rund um den Globus, sondern - und hierin liegt eine wichtige Erweiterung des Marx'schen Gemeinwesenbegriffs $^{25}$ - begreift die menschliche Gattung als gleichrangige Gattung unter nicht-menschlichen Gattungen dieser Erde. Einer Arbeit am terrestrischen Gemeinwesen geht es also darum, die Erdökologie als Wohnung des irdischen Seins und die Städte, d.h. die alltäglichen urbanen Lebensweisen als sozialpädagogische Orte sozial-ökologischer Kulturrevolution(en) hervorzubringen. Erst darin ließe sich ein Anthropozänbegriff begründen, der sich nicht nur technisch definiert, sondern der politisch ermöglicht wird und sich subjektiv herausbildet. Der Anthropozänbegriff würde damit zu einem politischen Begriff menschlicher Subjektivität avancieren, die sich ihrer Erdverbundenheit und speziezistischen Relationalität (wieder) bewusst werden kann, indem sie ihren ,gesunden Tierverstand“ (Nietzsche 1954b: 152) wiederentdeckt und damit die anthropozentrischen Engführungen der Marxschen Naturphilosophie politisch öffnen kann für die Politisierung der Gesamtökologie Erde als sympoietischen Komplex (Haraway 2018), der entlang der

25 Der bei Winkler, Sünker und May zugrundeliegende Gemeinwesenbegriff gründet auf einer speziezistischen Einengung, die Marx schon über seinen Naturbegriff hinein gewoben hat. Sie lässt sich mit Kirchhoff als ,nicht-instrumenteller“ Anthropozentrismus bezeichnen, der den Naturverhältnissen und Naturphänomenen einen relativen Eigenwert zuspricht, die ,nicht als Mittel [ = instrumenteller Anthropozentrismus, ebd.], sondern unmittelbar als solche wertgeschätzt werden, dies jedoch nur relativ zu menschlichen Interessen, Sinnsystemen und Wertvorstellungen“ (Kirchhoff 2020: 39). Die Erde als Arbeitsmittel (Marx 1962a: 194) auch für nicht-menschliche Lebensformen kommt in Marx' Gemeinwesenbegriff (etwa Marx 1981b: 408f.) und in ihm darin folgenden Theorieansansätzen daher nicht in Betracht. 
Historiografie des Kapitalismus (Moore 2016) seine qualitativen Entwicklungspotenziale einbüßt.

Der Begriff der Sympoiesis ist maßgeblich von Donna Haraway geprägt und ,heißt ,mit-machen'. [...] Es ist ein Wort für Mit-Verweltlichung mit GenossInnen. Sympoiesis umfasst Autopoiesis, erlaubt ihre Entfaltung und erweitert sie." (Haraway 2018: 86) Die Erweiterung, auf die es in der Studie besonders ankommt, ist die Erweiterung des Akteurskreises der mitweltlichen GenossInnen, den Haraway nicht nur auf (menschliche) Artgenossen einschränkt, sondern auch auf nicht-menschliche Akteure dieser Erde ausweitet. Da menschliche wie nicht-menschliche Akteure ein erdökologisches Klima brauchen, um sich miteinander gedeihlich entwickeln zu können, zielt die Verwendung des Sympoiesisbegriff in der vorliegenden Studie auch auf die Politisierung klimatologischer Aktanten. Diese beiden Erweiterungen der Marxschen Naturphilosophie werden hier als terrestrische Öffnung des Anthropozentrismus bezeichnet, mit der überhaupt erst ein Anthropozän zu denken ist, das nicht in einer weiteren Aufblähung des menschlichen Chauvinismus gegenüber allem Nicht-menschlichen mündet. - Es kann indes nur von einer Öffnung, nicht von einer Überwindung des Anthropozentrismus gesprochen werden, weil alle Begriffe und Formen der Reflexion der Politisierung nicht-menschlicher Akteure und Aktanten von Menschen vollzogen werden (zum Überblick: Krebs 2016b, 2017). Streng genommen kann also nicht der Anthropozentrismus überwunden werden, sondern nur der Speziezismus menschlicher Urbanisierungspolitik, wodurch sich der Anthropozentrismus terrestrisch öffnen ließe, ohne ihn je wirklich verlassen zu können. Am Begriff Anthropozän ist einzig und allein aus dem Grund festzuhalten, weil er wie kein anderer diese zentrale Bedeutung der Menschen und ihrer Politik für einen Erdepoche machenden Prozess zum Ausdruck bringt, der, obschon mit weniger Pathos, auch mit einem Begriff Sozialer Ökologie zum Ausdruck gebracht werden kann. Zumindest wenn damit nicht bloß auf die Beschreibung des Wechselwirkungsverhältnisses von Natur/Erde und Gesellschaft abgestellt wird und auf jegliche Normativität verzichtet, den Anthropozentrismus politisch antispeziezistisch resp. terrestrisch öffnen zu müssen.

Im Folgenden soll es daher um einen ersten Aufriss bildungstheoretischer Aspekte gehen, die ein Begriff sozial-ökologischer Transformation umfassen müsste, um beanspruchen zu können, vom Hier und Jetzt der ,imperialen Lebensweise" (Brand/Wissen 2017) zu einer ein emanzipatorisches Anthropozän eröffnenden Politik Sozialer Ökologie gelangen zu können. Was die bildungstheoretischen Aspekte gesellschafts-transformatorisch genau bedeuten und wie sie konkret von Sozialer Arbeit bearbeitet werden können, wird dann in den Teilen B, C und D weiter entfaltet und in Teil E ins Verhältnis zur gängigen Diskussion um eine Kritische Theorie gesellschaftlicher Naturverhältnisse gesetzt. 


\section{Anthropozän als Kulturrevolution sozialer Nachhaltigkeit - ein transdisziplinäres Projekt}

Wenn Winkler die Theorieentwicklung Sozialer Arbeit trotz aller Divergenzen „als Zukunftswissenschaft“ (Winkler 2018: 50) herausstellt, da es der Profession nur theoriegeleitet gelingen kann, „die Gegenwart des Subjekts so [zu] strukturieren, dass in ihr eine offene Zukunft für dieses entsteht" (Winkler 1988: 275), so lässt sich, wie mit Wulf Winklers Gedanke fortgeführt werden kann, um so größer der Zeitraum der antizipierten Zukunft wird, nur umso ungenauer angeben, ,was zu einer zukunftsfähigen Bildung gehört“ (Wulf 2020: 204). Dennoch besteht für Wulf „kein Zweifel darüber, dass Frieden, Umgang mit kultureller Diversität und Nachhaltigkeit zu den Bedingungen zukunftsfähiger Bildung in der globalen Moderne gehören“" (ebd.). Nicht nur entlang des ökonomischen Zusammenhangs aller Regionen der Erde, sondern vor allem auch entlang des ökologischen Zusammenhangs aller Regionen der Erde kann Bildung nur ökumenisch, d.h. die ganze Erde umfassend begriffen werden. Für eine gemeinwesenorientierte pädagogischpolitische Bildung eines künftigen Erdzeitalters als Anthropozän sieht Wulf als Aufgabe für eine solche Subjektbildung an, weltweit „eine Kultur des Friedens, der kulturellen Vielfalt und der Nachhaltigkeit zu entwickeln“ (ebd.), worin sich zugleich Sünkers (Sünker 1989) Begriff der politischen Kulturrevolution weiter ausdifferenzieren lässt.

Eine Kultur des Friedens muss damit beginnen, „eine kritische Perspektive gegenüber der eigenen Gesellschaft, der ihr inhärenten Gewalt und ihrer Rolle im internationalen System" zu entwickeln und neben der Fokussierung direkter kriegerischer Gewaltakte vor allem auch einen kritischen Blick für die westliche ,'organisierte Friedlosigkeit' (Senghaas) und ,strukturelle Gewalt" (Galtung)“ zu gewinnen (Wulf 2020: 210f.). Dies ist umso schwieriger als dass diese beiden Formen indirekter Gewalt nicht nur seit knapp 12.000 Jahren in die leibliche Subjektivität des menschlichen Körpers eingewachsen ist (Theweleit 1982a, 1982b) und die Theweleit mit dem Begriff des ,muskulären Körper-Ichs“ (Theweleit 1982b: 368) zum Ausdruck bringt, sondern auch im Städtebau sich fortgeschrieben haben und sich damit nicht nur muskulär, sondern auch infrastrukturell verhärtet haben. Dadurch kann es den AkteurInnen nur unter größtmöglichen theoriegeleiteten strategischem Aufwand ermöglicht werden, sich jenseits der innerlich und äußerlich inkorporierten „,imperialen Lebensweise“ (Brand/Wissen 2017) völlig neu, nämlich friedlich zu verräumlichen. $\mathrm{Zu}$ einer solchen friedlichen Verräumlichung menschlicher Subjektivität entlang der Klimafrage gehört substanziell die politische Herstellung sozialer Gerechtigkeit und ihre begriffliche wie praktische Ausweitung auf räumlich-ökologische und kulturelle Aspekte. Das wird in aktuellen Diskursen als Klimaethik oder Klimagerechtigkeit zwar disku- 
tiert (zum Überblick: Gesang 2011; Ekardt 2012; Christ/Gellrich/Ide 2012), diskutiert werden dort aber vor allem quantitative bzw. quantifizierbare Gerechtigkeitsaspekte der Klimafrage, während eine qualitativ-sozialräumliche bzw. urbane Perspektive sozialer Gerechtigkeit in der Klimafrage weitgehend ausbleibt (zur Kritik: Brunnengräber/Dietz 2016; zu einem Ansatz räumlicher sozialer Gerechtigkeit: Davoudi/Bell 2016; siehe auch in Teil C).

In der Kritik an den beiden Formen indirekter Gewalt kommt zwar zum Ausdruck, dass derweil Egozentrismus und Ethnozentrismus in den Blick sozialwissenschaftlicher Kritik geraten ist. In der vorrangig quantitativmethodologisch und rationalistisch diskutierten Klimafrage hingegen kommt aber zugleich auch zum Ausdruck, dass der westliche Logozentrismus weiterhin imperial im Vormarsch ist und als weltweite Vernaturwissenschaftlichung der Klima- und Ökoproblematik sich dadurch - mehr oder weniger offensichtlich - gewaltförmig eine rationalistische Vereinheitlichung von Lebensweisen einfordert (zur Kritik an der rationalistischen Gewalt: Gronemeyer 2012, 2014; Feyerabend 1980, 2018; zur weiteren Ausformulierung dieses Gedankens: Schmidt 2021a [i.E.]), die den Klimawandel evidenzbasiert in den Griff zu bekommen verheißt. Die Ausbreitung und Hegemonie des westlichen Logozentrismus aber erschwert es zunehmend, an anderen Lebensweisen und Kulturen noch wahrzunehmen, was „nicht vernunftfähig und vernunftförmig“" ist, ohne dies mit der Wahrnehmung zugleich abzuwerten und/oder auszuschließen (Wulf 2020: 218).

Demgegenüber kann es für Wulf nur um eine mimetische Annäherung an das Fremde gehen, sei es nun menschlicher oder nicht-menschlicher Art: „In mimetischen Prozessen wird das Fremde in die Logik und Dynamik der eigenen imaginären Welt eingefügt" und ,,in eine Repräsentation transformiert", d.h. zu einer Figuration verbildlicht, ,in der sich Fremdes und eigenes mischen, zu einer Figuration des Dazwischen“ (ebd.: 224). Über dieses Dazwischen muss eine Verständigung ihren Weg suchen, auf dem das Ergebnis „offen und abhängig vom Spiel der Phantasie und dem symbolischen und sozialen Kontext" bleiben muss (ebd.: 225). Die Verständigung lässt sich dabei als substanzieller Bestandteil einer Bildung am Sozialen auffassen, der es entlang dialogischer Verständigungspraxen über das eigene und fremde Anderssein gelingen kann menschliche Subjektivität zu bilden, die nicht nur kulturelle, sondern auch individuelle Vielfalt subjektiver Vermögen und Fähigkeiten (an)erkennt. $\mathrm{Ob}$ und vor allem wie es gelingen kann, muss dabei konkret und vor Ort, d.h. im ,sozialpädagogischen Ortshandeln“ (Winkler 1988: 278ff.) ermittelt werden, das solche Verständigungsräume nicht nur zu ermöglichen sich zur Aufgabe macht, sondern auch die Subjekte zur gemeinsamen Aufgabenbewältigung (etwa des Klimaproblems) befähigt.

Derlei fachliches Handeln Sozialer Arbeit tritt damit zugleich als Herstellen einer Kultur der Nachhaltigkeit in Erscheinung, die kulturelle Vielfalt beibehält und/oder wieder ermöglicht und vergrößert und damit grundlegend 
an einer Kultur des Friedens arbeitet. Nachhaltigkeit meint, wenn damit nicht nur ein quantitativer Begriff langfristigen Wirtschaftens mit knappen bzw. verknappten Gütern, sondern vor allem ein qualitativer Begriff verbunden wird, eine ,regulative Idee“ zur „Herstellung sozialer Gerechtigkeit zwischen den Nationen, Kulturen und Weltregionen und den Generationen“, die ,[n]eben der Förderung und Umgestaltung des Sozialen, der Ökologie und Ökonomie [...] auch die globale Verantwortung und die politische Partizipation“ (Wulf 2020: 229) bedeutet. Um allerdings „Nachhaltigkeit als Zentrum einer Kultur des Friedens“ (ebd.: 232) zu positionieren, muss die politische Partizipation an den jeweiligen kulturellen Eigenheiten der AkteurInnen ausgerichtet werden bzw. über diese in Verständigung kommen, wobei (Interessens-)Divergenzen politisch in Ausgleich zu bringen sind. Darin erst lässt sich die noch offene Stelle eines sozialräumlich-qualitativen Begriffs sozialer Gerechtigkeit füllen, wie er für eine revolutionär-transformative Bildung von Nöten ist und der in der Diskussion um Klimagerechtigkeit derweil noch fehlt. Damit bedeutet Nachhaltigkeit zugleich eine subjektbildende Politik, d.h. eine politische Produktivität, die über eine verlässliche Verständigungskultur eine verbindliche politische Struktur herauszubilden vermag, in der die Akteure ihre Auseinandersetzungen und Ergebnisse wiederfinden, weil es die von ihnen verlegten Gleise sind, ,auf welchen sie sich bewegen wollen“ (Winkler 1988: 279).

In dieser Hinsicht muss Partizipation letztlich politische Selbstverwaltung bedeuten, die vor dem Hintergrund der notwendigen globalen Problembearbeitung des gemeinsamen globalen Klimaproblems planetarischen Ausmaßes auf kommunaler und globaler Ebene zur Praxis werden müsste. Darin sind nun zugleich auch die ,grundlegende[n] gesellschaftliche[n] Veränderungen" (Wulf 2020: 204) ausgesprochen, von denen Wulf zwar spricht, aber letztlich unausgesprochen lässt, worin sie bestehen. Dadurch lässt er aber auch offen, dass es für die Abkehr von „'organisierte[r] Friedlosigkeit (Senghaas) und ,strukturelle[r] Gewalt" (Galtung)" (ebd.: 211) auf kommunaler gesellschaftlicher Ebene darauf ankäme, eine Bildung des Sozialen zur Bildung am Sozialen (Kunstreich/May 1999) zu ermöglichen. Denn dadurch erst ließe sich eine lokal wie global sozial nachhaltige Kultur der kulturellen Vielfalt als Element einer politisch organisierten weltweiten Kultur des Friedens verwirklichen, die Wulf im Begriff des Anthropozäns normativ angelegt sieht.

Das Bisherige zusammengenommen: Woran lässt sich das Anthropozän als sozial nachhaltige politische Verwirklichung eines subjektiven Gemeinwesens im globalen Maßstab mit planetarischer Reichweite erkennen? Sie lässt sich erkennen im Rückgang der zerstörerischen Knechtung und Umgestaltung der Erdnatur bei gleichzeitigem Anstieg der Vielfalt menschlicher Lebensweisen und nicht-menschlicher oder hybrider Lebens- und Seinsformen, bei wiederum gleichzeitigem Anstieg der Rückgewinnung der Erde als 
politisches Gemeingut und der gemeinsamen demokratischen Regulierung ihrer Ökologie, wodurch die Radikalität des erderwärmenden Klimawandels ausgebremst und dessen gesellschaftlichen Effekte sozial aufgefangen würden. Über die Qualität dieses politischen Gemeinwesens ist entlang dieser Erkenntniskaskade freilich noch nichts gesagt. Das spricht einmal mehr dafür, die Klimadebatte nicht nur wissenschaftlich quantifizierend - sei es nun im Bereich naturwissenschaftlicher Disziplinen oder im Bereich sozialwissenschaftlicher Disziplinen - zu bearbeiten, sondern vor allem auch durch qualifizierende Wissenschaften zu ergänzen. Das wiederum spricht einmal mehr dafür, für das Klimaproblem und für den daran gekoppelten Begriff sozial-ökologischer Transformation ein theoretisch wie praktisch transdisziplinäres (Mittelstraß 2005) Problem- und Transformationsverständnis zu entwickeln, das sich nicht im Logozentrismus erschöpft, sondern ihre transformative Produktivität in Theorie- und Praxisentwicklung stattdessen in der Anerkennung der kulturellen Vielfalt und ihren Arten und Weisen, Wissen zu schaffen, zu erblicken.

Doch auch dieses Verständnis muss entwickelt und aus dem hegemonialen Selbstverständnis der logozentrischen Vernaturwissenschaftlichung des Klimaproblems sowie ihrer Bearbeitungs- und Lösungsstrategien herausgebildet werden. Das ist insbesondere vor dem Hintergrund der numerischen Dominanz naturwissenschaftlicher AkteurInnen im Klimadiskurs (MCC 2020) ein nicht zu unterschätzendes Problem. Das grundsätzliche Problem des Logozentrismus, das bei genauem Besehen in einem (nomologischen) Deduktivismus besteht, besteht darin, dass deduktiv erschlossene Transformationsstrategien zwar im Rahmen ihrer eigenen Annahmen, wie sie etwa in der Formulierung planetarischer Leitplanken ${ }^{26}$ der Urbanisierung bzw. der Vergesellschaftung von Naturverhältnissen erarbeitet wurden, sinnvolle Ziele herleiten können. Problematisch sind aber ihr global undifferenzierter objektiver Gültigkeitsanspruch, der neben regionalen Unterschieden gesellschaftlicher Produktionsweisen und ihrer klimatologischen Effekte auch ihre ,diskursiven Implikationen“ (Görg 2016: 240) unberücksichtigt lässt. Denn wie selbstverständlich wird expertokratisch impliziert, dass die gesellschaftlichen PraxisakterInnen an der Entwicklung von Leitplanken und darin(!) sich bewegenden Transformationsstrategien keinerlei Mitsprache- und Mitgestaltungsmöglichkeiten haben, so dass ihnen letztlich bloß die Rolle zukommt, „sich in ein funktionsfähig konzipiertes Modell einzufügen und es zu verwirklichen“ (Demirović 2011: 41), was dann berechtigterweise „als Korrup-

26 Die Bezeichnung geht auf den WBGU (2014b) zurück, der darin quantitativ definierte begrenzte Leitlinien berechnet, durch deren globale Einhaltung die Erderwärmung und Ozeanversauerung begrenzt, der Verlust der Biodiversität, die Land- und Bodendegradation sowie die Gefährdung durch langlebige anthropogene Schadstoffe also auch den Verlust von Phosphor gestoppt werden können. Sie sind auch Ausgangspunkt des Konzept zur Transformation der Städte (WBGU 2016b). 
tion der eigenen Selbstbestimmungsinteressen wahrgenommen" (Kaindl 2011: 73) wird und letztlich nicht selten zur Ablehnung des notwendigen Transformationsdiskurses führt. Zudem können deduktivistische Transformationsprojekte immer nur sehr kleinschrittige Projekte mit wenig umwälzender Innovationskraft sein, weil die Projekte immer nur soweit gehen können, wie die BürgerInnen geradeso bereit sind sie mitzugehen bzw. sie entlang der Zirkelzwänge der „,imperialen Lebensweise“ (Brand/Wissen 2017) tatsächlich mitgehen können. Solange weder die konkreten Transformationsmaßnahmen und Strategien ihrer Umsetzung, noch die deduktiven Prüfkriterien nicht mit den konkreten AkteurInnen vor Ort zusammen entwickelt werden, sondern sie ihnen a priori und von außen, d.h. von ExpertInnen auferlegt werden, solange sind gesellschaftliche Transformationsprojekte latent herrschaftlich aufgeladen und drohen daran zu scheitern. Oder aber sie verlangen - gerade bei der sich zuspitzenden Klimaproblematik - sukzessive nach mehr herrschaftlichen bzw. obrigkeitsstaatlichen Zwang ihrer Umsetzung (Stichwort Ökodiktatur).

Beide Konsequenzen der logozentrischen Handhabung des Klimaproblems sowie ihrer Bearbeitungs- und Lösungsstrategien legen ein grundlegendes Umdenken nahe, das das Anthropozän als transdisziplinäres Projekt sozialer Nachhaltigkeit begreifen lässt. Ein solch transdisziplinärer Transformationsbegriff bedarf zur Theorie- und Praxisentwicklung die komplementäre Ergänzung verschiedener disziplinärer Perspektiven und Methodologien seitens der verschiedenen wissenschaftlichen AkteurInnen untereinander, aber auch zwischen wissenschaftlichen und nicht-wissenschaftlichen AkteurInnen. Zwingende Voraussetzung ist hierfür das (An)Erkennen des mimetischen Verhältnisses zur Welt, wie es seit Humboldt zwar in den Bildungsbegriff eingeschrieben ist (zum Überblick: Wulf 2020: 49ff.), das aber entlang des hegemonial vorherrschenden Logozentrismus und eines perzipierenden Erkenntnismodells, bei dem der Mensch als passiv bloß aufnehmender $\mathrm{Zu}-$ schauer der Welt in Erscheinung tritt, noch immer nicht das alltägliche Verständnis des Menschen kennzeichnet. Für eine revolutionäre Produktivität sozial-ökologisch-transformativer Theorie- und Subjektbildung muss daher Nicht-Identität zur zentralen Kategorie des Bildungsprozesses erhoben werden, wonach es nicht länger darauf ankommen kann, alle Erkenntnis unter ein Wissenschaftsparadigma zu subsumieren, und schon gar nicht, die PraxisakteurInnen der Städte nach einer Theorie oder der deduktiven Herleitung aus einer Theorie zuzurichten. Auch wenn die Klimafrage die wohl drängendste Soziale Frage der Gegenwart darstellt, darf sie nicht dazu verführen, die Knechtung inner-menschlicher Naturverhältnisse gegen die Rettung der Erde utilitaristisch abzuwägen und fortzuführen.

So etwa im „,(bio-)technologischen Narrativ“ des Anthropozäns, einem „fortschrittsoptimistische[n] Narrativ“, das zwar „ein gutes, wenn nicht sogar großartiges Anthropozän' mit Wohlstand für alle Menschen bei hoher 
Energieverfügbarkeit durch hocheffiziente Solar-, aber auch Kernenergie, niedrigem Ressourceneinsatz und verbessertem Naturschutz [verspricht]", zugleich aber ,die vorhersehbare Machtkonzentration der technischen und ökonomischen Eliten [normalisiert] und [...] nicht beabsichtigte Nebenwirkungen herunter[spielt]" sowie ,die technologischen Eliten als die neuen „Helden“ [präsentiert], die allein die Probleme lösen könnten“ (Dürbeck 2018a: 16). Stattdessen müsste es vielmehr darauf ankommen theoretische, kulturelle und individuelle Differenzen in der alltäglichen wissenschaftlichen wie nicht-wissenschaftlichen Praxis der AkteurInnen anzuerkennen und zu politisieren, statt sie mit struktureller Gewalt, zu der auch der Logozentrismus gezählt werden muss, zum Schweigen zu bringen. Etwa dadurch, dass der dem Logozentrismus innewohnende Utilitarismus, d.h. der deduktiv bewertenden und begutachtenden Abwägung von Partikular- und Gesamtinteressen, im Kontext der Klimafrage nahezu jede Kritik mundtot zu machen droht, da sie letztlich immer nur als partikulare Marginalie gegenüber einer zu rettenden Erde in Erscheinung treten kann. Damit ist im Namen der Erdrettung jedweder öko-diktatorischen Tyrannei Tür und Tor geöffnet.

Gerade vor dem Hintergrund dieses sich ankündigenden Szenarios muss Bildung heißen, individuelle Aneignungsprozesse und kritische Reflexionen zu ermöglichen, statt flächendeckende kritiklose Anpassungsleistungen (Mimikry) an objektiv-verfertigte Lösungsstrategien entlang eines Expertenkonsenes zu verlangen, wie es im vorschnellen Abwerten von sogenannten KlimaskeptikerInnen und KlimaleugnerInnen bereits heute alltäglich zum Vorschein kommt. Bildung muss also auch heißen, sich hinsichtlich der alltäglichen Sachzwänge der „,imperialen Lebensweise“ (Brand/Wissen 2017) zu fragen, warum sich die einen die Klimathematik aneignen (können) und warum andere dies nicht tun (können). Bildung im Anthropozän muss entsprechend darauf aus sein, allen Menschen zu ermöglichen, die Erde als sympoietisches Ökologiegefüge zu erkennen und anzuerkennen und letztlich solche politischen Konsequenzen pädagogisch zu erarbeiten, die die Spezies Mensch nicht länger allein ins Zentrum der Welt setzen. - Ob aus der ,exzentrischen Positionalität" des Menschen der Schluss gezogen werden kann, dass das ,ganze sogenannte Anthropozän [...] tendenziell nämlich durch ein Kosmozän vermittelt [ist], in dem sich bereits ein weiteres - nun durch den Menschen vermitteltes kosmisches Zeitalter anbahnt", weil mit der Raumfahrt nicht nur eine ,exzentrische Positionialität“ auf der Erde, sondern auch im Kosmos erfahrbar wird (Fischer 2018: 131ff., Hervorhebung im Original), sei einmal dahin gestellt. In der vorliegenden Arbeit geht es allein darum, die bevorstehenden Aufgaben und Probleme dieser Erde grundlegend in den Griff zu bekommen, nicht darum, mit der Zerstörung der Bewohnbarkeit dieses Planeten die Flucht zum nächsten zu legitimieren. 


\section{6 Ökosozial - sozial-ökologisch? Versuch einer weiteren Präzisierung des Vorhabens}

Bislang ist die Rede von sozial-ökologischer Transformation, während zugleich ein Plädoyer für eine globale ökosozialistische Demokratie (Ökosozialistisches Netzwerk 2017: 17) ausgesprochen wird. Vor diesem bislang begrifflich verwirrenden Hintergrund ist es notwendig noch einmal näher hinzuschauen.

Es sollte deutlich geworden sein, dass der Begriff sozial-ökologisch weder als conterainerisierender Begriff im Sinne der Chicago-Schule (Park et al. 1967 [1925]) verwendet wird, noch im Sinne Bronfenbrenners, der darunter das Verhältnis von ,der in Entwicklung begriffenen Person und ihrer Umwelt, insbesondere der allmählich entstehenden Wechselwirkung zwischen beiden“ und unter Umwelt „dritte Personen“ sowie „den unmittelbaren Lebensbereich, der die sich entwickelnde Person umgibt" (Bronfenbrenner 1981: 19), versteht. Bronfenbrenners Sozialökologie verbleibt damit ganz im Kontext menschlicher Sozialitäten, für die er im Sinne der Entwicklung einer Person plädiert, sie als Haushalt resp. ökologisch zu betrachten. In dieser Hinsicht hat auch Wendt ein ökosoziales Prinzip Sozialer Arbeit formuliert, bei dem ,die natürliche Umwelt als Objektbereich weitgehend außen vor [bleibt]“ (Wendt 2018: 39) und das sich auf ein „soziales Wirtschaften“ beschränkt (ebd.: 29). Während Bronfenbrenner Wendt gegenüber zwar auch die natürliche Umwelt, besser: Mitwelt mit einzubeziehen sucht, bleibt sein Begriff von Sozialökologie allerdings weitgehend frei von einer Perspektive, die es auch vermag, soziale Herrschaftsverhältnisse und daraus resultierende Machtverhältnisse in den Blick zu nehmen und zu kritisieren. Für die Problemstellung der vorliegenden Arbeit sind beide Autoren daher kaum geeignet, näher in Betracht gezogen zu werden.

Gleichwohl ist die Bandbreite der Diskussion um den transformativen Gehalt der Begriffsattribute ökosozial und sozial-ökologisch mit den beiden Autoren längst nicht umrissen und erschöpft. Im Folgenden soll resümierend der Stand der Diskussion in der Sozialen Arbeit um eine ökosoziale Transformation zusammengefasst und der Unterschied zum hier fokussierten Begriff sozial-ökologischer Transformation hervorgehoben werden.

\section{1 Ökosoziale Transformation(en)}

Als ökosoziale Transformation wird von Susanne Elsen im „Handbuch Soziale Arbeit" im Anschluss an Karl Polanyis Kritik an der industriekapitalisti- 
schen Moderne von 1944 die „Umkehrung“ der „Entbettung des wirtschaftlichen Systems aus seinen gesellschaftlichen und natürlichen Einbindungen“" verstanden (Elsen 2018: 1058). Genauer: „die sukzessive Umkehr [...] der Herausbildung eines Wirtschaftssystems, welches Natur und Gesellschaft vollständig seiner Verwertungslogik unterwirft" (ebd.: 1058f.). Eine solche Umkehr bedarf, wie bereits mit Sünkers (Sünker 1989, 2012) Begriff der Kulturrevolution herausgestellt, der kulturellen Herausbildung emanzipatorischer Subjekte, die es vermögen, die Alltagspraxis der (mittlerweile post)industriekapitalistischen Moderne revolutionär zu reformieren resp. zu transformieren. Ebenso wurde mit Winkler (Winkler 1988, 2006, 2018) und Richter (Richter 2001, 2019b) bereits herausgestellt, dass dies allenfalls nur durch den Prozess einer Subjektbildung entlang eines kommunalisierend raumbildenden sozialpädagogischen Ortshandelns zu bewerkstelligen ist, der es zugleich vermag, eine die Produzierendensozialpolitiken übergreifende Politik des Sozialen (May 1997b; Kunstreich/May 1999; May 2017b; Kunstreich 2014; Kunstreich/May 2020) hervorzubringen. Da der Begriff einer die Produzierendensozialpolitiken übergreifenden Politik des Sozialen keineswegs geläufig ist, ist er folgend kurz näher zu bestimmen.

\section{Exkurs zum Begriffsverhältnis der die Produzierendensozialpolitiken übergreifenden Politik des Sozialen}

Der Begriff der Politik des Sozialen ist in den 1980er Jahren von der Redaktion der Zeitschrift Widersprüche aus der Perspektive eines linken Korrektivs der „ökologischen Sozialpolitik der Grünen“ entstanden, bei der damals und heute nun auch jenseits der Grünen inmitten der fachlichen Diskussionen rund um die Klimafrage - ,"strategisch' oder vorschnell ,realpolitisch ' auf eine alternative Staatlichkeit gesprungen wird“ und/oder „soziale Prozesse und Bewegungen übersprungen werden“, woraus sich nach wie vor ,Tendenzen einer ,ökologischen Technokratie“" abzeichnen (Widersprüche Redaktion 1983). Seither wird von der Redaktion - als ,,roter Faden auf grünem Grund“ (ebd.) - an einer Alternative gearbeitet, „die hilfreich, aber nicht beherrschend [...], individuell zureichend, aber nicht parzellierend; Lebenszusammenhänge stützend, aber nicht kompensatorisch; und wirkungsvoll, aber nicht herrschaftlich funktional [...] ist" (Widersprüche Redaktion 1984: 131).

Der Begriff der Politik des Sozialen wird dabei als „Arbeitstitel für eine Strategie" verstanden, bei der die betroffenen Akteure selbst bestimmen, was ein bzw. ihr Problem ist,

,und die eingreift in die Bedingungen im Bereich der Verursachung selbst. [...] Statt durch Statusdifferenzierung und herrschaftliche Hierarchie in die bürgerliche Hegemonie eingebunden, sind hier die ExpertInnen in einen lebendigen Diskussionszusammenhang einbezogen, der, von unten' kontrolliert, der vor Vereinzelung, Machtanhäufung und unausgewiesenen Normalitätskriterien schützt.“(ebd.) 
Ziel der Strategie einer Politik des Sozialen ist es, ,eine unabhängige sozialistische Position zu formulieren“ (Widersprüche Redaktion 1983), mit der beansprucht werden kann, bereits erreichte sozialpolitische Errungenschaften zu verteidigen, ihnen entgegen-, gar rückläufige Tendenzen zu kritisieren und zugleich überwinden zu können (Widersprüche Redaktion 1984). Dieser Anspruch wird von der Redaktion seither weiter ausformuliert und weiterentwickelt (zum Überblick der Entwicklung: Widersprüche Redaktion 1997, 2005, 2006, 2012; May 2013b). So formuliert May (May 1997b) den ,zentrale[n] Gedanke[n] der Politik des Sozialen als Produzenten-Sozialpolitik“, wonach ,es die Gesellschaftsmitglieder selbst sind, die als Produzenten ihrer Gesellschaftlichkeit agieren, und [...] sich das Soziale erst durch ihre Aktionen konstituiert" (ebd.: 231f.). Das Soziale, so ergänzt Kunstreich, wird dabei verstanden ,als die spezifischen, aktuellen, historisch einmaligen Beziehungen real existierender Subjekte untereinander" (Kunstreich 2014: 365). Mit Negts Diktum auf den Punkt gebracht: „Nicht nach Köpfen, sondern nach Interessen organisieren!“ (Negt 1977). Vor dem Hintergrund dieses Verständnisses des Sozialen wird Politik im Anschluss an Negt verstanden „'als einen auf Lebensinteressen bezogenen Produktionsprozess““, der „,im überschaubaren Umkreis der eigenen Erfahrungen überprüfbar"“ gemacht wird, "worin der Befreiungsgehalt politischen Handelns und demokratischer Selbstorganisation besteht' [...]" (Negt 1995: 162 zit. in May 1997b: 231f.). War von der Redaktion bislang „Politik des Sozialen noch als ProduzentenSozialpolitik“ (Kunstreich 2014: 365, Hervorhebung MS) eher undifferenziert in eins gesetzt, wird mit Politik des Sozialen - vor allem durch Mays Weiterentwicklung - nun eine übergreifende Politik verschiedener Produzierendensozialpolitiken bzw. Sozialpolitiken der Produzierenden bezeichnet. Zunächst im Anschluss an „Lefebvres Theorie der Bedürfnisse“ (May 1997b: 238f.; Lefebvre 1987: 258ff.), dann auch an dessen Begriff der Residuen (Lefebvre 1975c: 332ff.), die den AkteurInnen in den gruppen- bzw. milieuspezifischen Widersprüchen und Konflikten durch gesellschaftliche Machtund Herrschaftsverhältnisse hindurch als unabgegoltene Möglichkeiten subjektiver Wirklichkeiten in ihrem gesellschaftlichen Alltagsleben zurückgelassen werden, formuliert die Widersprüche-Redaktion nun auch den Begriff der Produzenten-Sozialpolitik konkreter aus und setzt ihn zugleich ins gegenderte Plural (Produzierenden- bzw. ProduzentInnensozialpolitiken, oder auch Sozialpolitiken der Produzierenden):

\footnotetext{
„Damit behaupten wir eine Realität, die ausgelassen wird, wenn diese Eigenschaften und Vermögen nur unter dem Aspekt ihrer tatsächlichen Funktion in der Geschichte gesehen werden. Zugleich halten wir an der Möglichkeit einer anderen, nicht kapitalistischen Akkumulation fest“", weshalb ,solche Vermögen nicht bloß als Mittel zur Selbstentfremdung, sondern in der Perspektive ihrer Verwirklichung und Kooperationsfähigkeit in den Blick zu nehmen [sind]. Denn gerade die gegen das Verwertungsinteresse stehenden Anteile sind es, die auf der Stufe der gesellschaftlichen Entwicklung den Beginn der Herausbildung dessen markieren, was wir als ,Produzierendensozialpolitik[en]` bezeichnen.“ (Widersprüche Redaktion 2012: 6f.).
} 
Eine „übergreifende Politik des Sozialen“ wird in der Redaktion damit als „Polyphonie von Sozialpolitiken der Produzierenden“ (ebd.: 7) verstanden, die sich aus „elementaren Situationen zusammensetzt, , in denen eine Praxis miteinander verknüpfter Subjekt-Objekt-Beziehungen die unterdrückte und im Kapitalverhältnis verdrehte menschliche Sinnlichkeit als ProduzentInnensozialpolitik zu sich selbst kommt' (May 1997: 233)“"((Widersprüche Redaktion 2012: 6)). Beide Begriffe - Produzierendensozialpolitiken und Politik des Sozialen - werden in Anlehnung und in materialistischer Wendung von Hegels Begriffsdialektik (Hegel 1970c: 273ff.) als dialektisches Verhältnis „emphatische[r] Kategorien“ verstanden, die sich erst über eine „mit diesen Kategorien anvisierte politische Öffentlichkeit“ mit konkreten Inhalten füllen können (May 1997b: 234) und sich dadurch jeglicher vorabDefinition einer richtigen Politikform entziehen. Zugleich werden sie „,von der Redaktion als praktisches Programm“ Sozialer Arbeit begriffen, mit dem sich die tatsächlichen, aber herrschaftlich blockierten bzw. residualisierten gesellschaftlichen Möglichkeiten des subjektiven Gemeinwesens als gesellschaftliche Praxis politisch verwirklichen können sollen (Widersprüche Redaktion 2012: 6).

In dieser doppelten Bedeutung als praxisphilosophische Begriffe und transdisziplinäres Programm revolutionärer Praxis wird das Konzept einer die verschiedenen Produzierendensozialpolitiken übergreifenden Politik des Sozialen mit Lefebvre (Lefebvre 1987: 372) als "strategische Hypothese“ betont (May 1997b: 234), das sich nicht nur, wie erwähnt, jeglicher Vorbestimmung einer richtigen Politikform des Sozialen entzieht. Sondern mit dem vor allem öffentliche urbane Räume eingefordert werden, an und mit denen sich die Residuen versammeln und politisch organisieren können, wodurch sich erst mit den sich versammelnden und organisierenden Produzierendensozialpolitiken der verschiedenen AkteurInnen und Gruppen eine übergreifende Politik des Sozialen herausbilden kann. In dieser real-experimentellen Hinsicht wird das strategisch-programmatische Konzept der die Produzierendensozialpolitiken übergreifenden Politik des Sozialen von der Redaktion mit Richard Saage denn auch verstanden als ,reflexive Utopie, in der 'die individuelle Vernunft der Einzelnen ihr notwendiges Korrektiv in der kollektiven Vernunft einer solidarischen Gesellschaft und ihrer Institutionen hat und umgekehrt' (Saage 1990:24)“(Widersprüche Redaktion 2012: 7).

Letztlich weiß sich eine Politik des Sozialen aber dennoch wenigstens darin als richtige Politikform, als dass sie sich jederzeit zukunftsoffen halten und gestalten, mit anderen Worten: dass sie sich durch die konkrete Arbeit des subjektiven Sozialen mitentwickeln können muss, damit sie auch tatsächlich die Verwirklichung des subjektiven Gemeinwesens auf der jeweils historischen Höhe gesellschaftlicher Entwicklung politisch ermöglichen kann. Und genau darin entzündet sich die praxisphilosophische Notwendigkeit eines kollaborativen Partizipationsverständnisses jedweder gesellschaftlicher 
Transformationsprozesse. Ein solches kollaboratives Partizipationsverständnis einer die Produzierendensozialpolitiken übergreifenden Politik des Sozialen ist damit als elementarer Baustein auch jedweder ökosozialen und sozialökologischen Transformation städtischer Lebensweisen besonders zu betonen. Zumindest wenn sie mit demokratischem und emanzipatorischem Anspruch in Erscheinung treten wollen. (Mehr dazu in Teil B, C, D.) $-E x$ kurs Ende

Hinsichtlich ökosozialer Transformationen im Kontext Sozialer Arbeit - da waren wir vor dem Exkurs stehen geblieben - führt Elsen nun aus, wie eine solche transformative „Bildungsarbeit auf allen Ebenen“ als eine solch partizipatorisch-emanzipatorische resp. kollaborative „Arbeit am Sozialen“ aussehen kann,

„die den ökosozialen Kulturwandel der Gesellschaft fördert und ermöglicht [...]. [...] Es geht um die Sicherung des Ressourcenzugangs und der Handlungsoptionen insbesondere für Benachteiligte, um Organisationsformen und Regeln der Gestaltung von Lebensprozessen und der nachhaltigen Bewirtschaftung der Lebensgrundlagen durch die betroffenen Menschen selber, um eine Reduktion der Versorgungsabhängigkeit vom Markt, um neue soziale Arrangements, in denen zivile Selbstorganisation möglich wird, sowie um wirksame politische Steuerung. Dies aber erfordert eine Ausweitung von Handlungsoptionen und einen Paradigmenwandel von einer reaktiven und individualisierenden hin zu einer gestaltenden und kooperativen Sozialpolitik und Sozialen Arbeit, die gesellschaftliche Erfordernisse und veränderte Normalitätsvorstellungen zum Ausgangspunkt nimmt.“ (Elsen 2018: 1059f.)

Wenn, wie Elsen weiter schreibt, ,sich der Diskurs um Ansätze ökosozialer Sozialarbeit und Sozialpolitik in internationalen Kongressen, Publikationen, Lehrveranstaltungen und Forschungsprojekten (Elsen 2011; Matthies/Närhi 2016) [langsam bewegt]“ (ebd.: 1061), dann stellt sich die Frage - wie es ja auch Bartosch (Bartosch 2020) und Mührel (Mührel 2020) monieren -, warum Soziale Arbeit in der gegenwärtigen Klimafrage bislang so leise ist und die Diskussionen fast ausschließlich naturwissenschaftlichen AkteurInnen überlässt und damit letztlich im nicht unerheblichen Maß an der vorherrschenden „sozialwissenschaftliche[n] Unterbestimmtheit des AnthropozänBegriffs“ (Leggewie 2015: 67) beiträgt. Aber um diese Frage, die vor allem eine empirische Frage ist, soll es hier nicht gehen, sondern vielmehr um die Frage, wie und mit welcher theoretischen Argumentationsfigur Soziale Arbeit dieser Diskussion beitreten kann.

In dieser Hinsicht stellt Elsen dann im Weiteren heraus, dass für eine kulturrevolutionäre Arbeit an einer ökosozialen Transformation „Überlegungen $\mathrm{zu}$ einer bedingungslosen Grundsicherung“ zwar „notwendig, aber nicht ausreichend [sind]“" (Elsen 2018: 1061). Zudem bedarf es „der Erschließung von sozialproduktiven Handlungsoptionen und der demokratischen Organisation der Gemeingüter“, die „nicht nur die natürlichen Lebensgrundlagen“, wie „Wasser, Boden, Wälder, Fischgründe, Luft, Artenvielfalt etc.“ umfassen, „sondern auch soziale Organisationsformen wie öffentliche Räume, 
Daseinsvorsorge, Sozialversicherungssysteme, Gesetze und vieles mehr“ (ebd.). Diese wiederum verlangen ,[d]ezentralisierte demokratische Organisationsformen und Entscheidungsverfahren sowie neue institutionelle Arrangements auf lokaler Ebene“, die „Reziprozität, Vertrauen und Verantwortungsübernahme für gemeinsame Belange" ermöglichen (ebd.). Elsen betont zudem, dass die „Stärkung der lokal-regionalen Ebene [...] in einem Modell der politischen Steuerung und Verteilung auf mehreren Niveaus zu denken [ist] - bis hin zur globalen Ebene" (ebd.).

Das Potenzial einer solchen „Bildungsarbeit auf allen Ebenen“ (ebd.: 1059), die zugleich die Bildung einer Gemeinwesenökonomie von urban und global commons, die „Subsistenzwirtschaft, Familienökonomie, Tauschwirtschaft, Formen der Gemeinschaftsnutzung, Kooperativen, sozialökonomische Netzwerke und eingebundene Marktunternehmen [umfassen]" (ebd.: 1063) und auch ,die Einbettung wirtschaftlichen Handelns in ökologische und gesellschaftliche Zusammenhänge (Elsen 1998, 2007)“ (ebd.: 1061) ermöglichen könnte, sieht Elsen in der Organisationsform der Genossenschaften angelegt. Als „Schulen der Demokratie“ stellen Genossenschaften einen Rahmen dar, der eine kollaborative Bewirtschaftung von Gemeingütern („Gemeineigentumsregime“) ermöglicht und entlang der „Mitbesitzerbeziehung [...] zugleich eine Mitverantwortungsbeziehung und Mitnutzerbeziehung“" (ebd.: 1064) bedeutet und durch diese gemeinsame Aufgabenbewältigung eine Bildung des Sozialen wie auch eine (Subjekt-)Bildung am Sozialen verwirklichen könnte (Kunstreich 2018; Kunstreich/May 1999, 2020). Zu fokussieren sind dabei „Ansätze neuer Subsistenz“, worunter „alle neuen Formen des freien Engagement zur eigenen und gemeinsamen Lebenssicherung und generell Formen marktunabhängiger sozialer Produktivität", wie etwa „[u]rbane Landwirtschaft“, gefasst werden kann, bei der „Parks und Grünflächen [...] von Anwohnerinnen und Anwohnern übernommen und in Eigenregie betrieben oder von den städtischen Verwaltungen zur Nutzung an BürgerInnen und Bürger übertragen [werden]" (Elsen 2018: 1064).

Vor dem Hintergrund des globalen Runs sowohl auf den städtischen als auch den noch nicht verstädterten Erdboden entlang der durch neoliberale Depolitisierungsstrategien möglich gewordenen gewinnträchtigen „Urbanisierung des Kapitals“" (Harvey 2014: 126) - die seit den 1970er Jahren und spätestens seit der Finanzkrise 2008/09 noch einmal als Rasanz zugenommen und an gesellschaftlicher Anerkennung zugewonnen hat (zum Überblick: ebd.) - stellt sich eine ökosoziale Transformation zwar programmatisch den herrschenden Eigentumsverhältnissen an den genannten Gemeingütern radikal entgegen. Steht aber zugleich vor dem massiven Problem, kaum noch Boden und andere Gemeingüter zur Verfügung zu haben, die frei von kapitalbildenden Verwertungszwängen sind (zum Überblick: Tricarico/Löschmann 2012). Entsprechend schreibt Elsen: 
„Die Wiederentdeckung und Verteidigung der Commons ist also eine Kampfansage gegen den Privatisierungswahn und die bizarren Formen der Plünderung und Enteignung von Menschen und Gemeinwesen durch internationale Großkonzerne und deren Lobby. Gemeingüter basieren auf öffentlichen oder gemeinschaftsbasierten Formen des Nutzungseigentums, die nicht ausschließen, sondern Zugang und nachhaltige Nutzungsmöglichkeiten sichern. Das Recht auf Zugang zu den grundlegenden Gemeingütern folgt der Prämisse sozialer Teilhaberechte am Erbe der Natur und der sozialkulturellen Evolution und ist ein grundlegendes Menschenrecht." (Elsen 2018: 1062)

Eine dergestalt postwachstumsorientierte Gemeinwesenökonomie muss also nicht nur das politische Gemeinwesen erst herstellen, das sie zu ihrer Realisierung braucht, sondern muss zugleich auch - aufgrund der einfachen Tatsache, dass für alles, "'[w]as ein Mensch auch immer tut oder zu tun wünscht, er [...] etwas ,Boden“ unter den Füßen haben [muß]' (LEWIN 1968, S. 205)“ (Richter 2001: 86) - auf allen Ebenen mit „der Rückgewinnung des Territorialen in Form der Kommune“ (ebd.: 144) einhergehen vom lokalen Boden und dessen urbaner Mehrwertproduktion (urban commons) bis zur gesamten planetaren Ökosphäre (global commons). Der zugrundeliegende politische Gemeinwesenbegriff muss also als „Gegenentwurf zum Menschen- und Gesellschaftsbild der orthodoxen Marktwirtschaft, deren Rationalitätskriterien und Koordinationsprinzipien" in Erscheinung treten und ,,auch zu einem Staatsverständnis“ vordringen, das sich von ,Wettbewerbs- und Wachstumsförderung sowie Kontrolle und Verwaltung der Bürgerbelange“ verabschiedet (Elsen 2018: 1062). Darin wäre der Begriff ökosozialer Transformation umrissen, in dem Elsen gemeinwesenorientierte Soziale Arbeit verortet:

„Professionelle Arbeit am Gemeinwesen müsste die ökosozialen Entwicklungserfordernisse einerseits und die Förderung der grundlegenden Fähigkeiten (Capabilities) und Tätigkeiten von Menschen andererseits zum Ausgangspunkt nehmen. Von zentraler Bedeutung ist die Stärkung der Organisations- und Bewältigungsfähigkeiten von Menschen und die Schaffung von Ermöglichungsstrukturen für ökosoziale Aktivitäten. Dies beinhaltet auch eine existenzielle Grundsicherung. Gestaltender Sozialpolitik und Sozialer Arbeit kämen die Aufgaben zu, Optionen sozialproduktiver Nutzungen insbesondere für benachteiligte und verwundbare Gruppierungen zu erschließen. Soziale Experimente sind angesichts einer höchst unsicheren Zukunft Labore für die Erprobung von Politiken der Möglichkeiten (Elsen 2013).“ (ebd.: 1063)

Eine solche praxisphilosophische, d.h. reell-experimentelle Professionalität Sozialer Arbeit impliziert vor allem eine Nachhaltigkeitsforschung, die die „,disziplinären Grenzen zwischen Sozial- und Naturwissenschaften transzen$\operatorname{dier}[\mathrm{t}]$ “" und stattdessen eine transdisziplinär und ,in vernetzten und heterogenen Formen organisiert[e]“ Wissenschaft zu begründen sucht, die ,integrativ und partizipativ anzulegen" ist (ebd.: 1059):

„Getrenntes muss dabei in Beziehung gesetzt werden, um Interdependenzen zu erkennen und bearbeitbar zu machen (Spangenberg 2003, 575). [...] Sozialarbeit verfügt über die Tradition der multidisziplinären und partizipativen Forschung und Entwicklung sowie über die Kultur der sozialwissenschaftlichen Aktionsforschung im Kontext des Community Development. Während im deutschsprachigen Raum jedoch Sozialarbeit diese Methoden ebenso wie die der emanzipato- 
rischen Gemeinwesenarbeit seit Mitte der 1990er Jahre zugunsten des therapeutischen und managementorientierten Zugangs aufgegeben zu haben scheint, ist das Methodenrepertoire des Community work (Rubin / Rubin 2008) die wichtigste Basis der Ansätze transformativer Entwicklung (Elsen/Schicklinski 2016, 221-238).“(ebd.)

Mit der Betonung der ökosozialen Bildung des politischen Gemeinwesens durch Soziale Arbeit übersieht Elsen aber zugleich die Notwendigkeit der Bildung des subjektiven Gemeinwesens, das die kulturelle Vielfalt der subjektiven Produzierendensozialpolitiken dergestalt anerkennend $\mathrm{zu}$ einem gesellschaftlichen Transformationssubjekt zusammenbringt, durch das die kulturelle Vielfalt der subjektiven Produzierendensozialpolitiken erhalten bleiben und die Differenzen und Konflikte über eine gemeinsame Politik des Sozialen reguliert werden kann. Erst durch eine solche übergreifende Politik des Sozialen wäre das von Elsen favorisierte politische Gemeinwesen nicht nur ein technischer Verband, sondern auch ein subjektiver Verbund, der nicht nur auf eine „soziale Revolution mit einer politischen Seele“, sondern eine „politische Revolution mit einer sozialen Seele“ (Marx 1981b: 409) insistiert und das Leben selbst verändert, ,nicht nur den Staat oder die Eigentumsverhältnisse“ (Lefebvre 1972: 275).

Dass für eine sozial-ökologische Transformation nicht nur sozialwissenschaftliche, sondern auch naturwissenschaftliche Expertisen von höchster Relevanz sind, wurde bereits herausgestellt und resultiert allein schon aus dem Umstand, dass die Städte neben allen sozialen Transformationen auch technisch zu transformieren sind, obschon dabei nicht das Gesellschaftliche auf den jeweiligen Stand der Technik, sondern die Technik auf den jeweiligen Stand des Gesellschaftlichen gehoben werden muss. Offen ist bislang noch die Frage, wie dies erfolgen kann.

\subsection{Mit einer terrestrischen Nachhaltigkeitswissenschaft sozial-ökologischer Transformation über ökosoziale Transformationen hinaus}

Mit dem Anspruch einer integrativen und partizipativ angelegten transdisziplinären Nachhaltigkeitswissenschaft, muss, wenn die Bedeutung des Wortes integrativ als das Herstellen eines neuen gemeinsamen Ganzen ernstgenommen werden soll, die nur menschenzentrierte ökosoziale Perspektive um eine nicht mehr nur menschenzentrierte sozial-ökologische Perspektive erweitert werden. Mehr noch: sie muss notwendigerweise um eine sozial-ökologische Perspektive ergänzt werden. Nämlich um eine Perspektive, die es vermag, das subjektive Gemeinwesen Erde, inmitten der Subjektivität der ,imperialen Lebensweise“" (Brand/Wissen 2017) subjektiv wieder oder überhaupt bewusst werden zu lassen. Eine sich an der Arbeit am terrestrischen Gemeinwesen 
orientierende sozial-ökologische Soziale Arbeit muss den beteiligten AkteurInnen durch praxisforscherische (Subjekt-)Bildungsprozesse also ermöglichen versuchen, sich die verschiedenen wissenschaftlichen, politischen, ökonomischen und administrativen Problembereiche der Klimafrage individuell aneignen zu können. Zudem muss sie neben diesem Aspekt emanzipatorischer Sozialraumentwicklung auch auf die kollaborative Einbeziehung von behördlichen und staatstragenden AkteurInnen in den transformativen (Subjekt-)Bildungsprozess insistieren, so dass durch eine solche Sozialraumentwicklung und -organisation (zusammenfassend: May 2017b) letztlich möglichst vielen beteiligen AkteurInnen einer Kommune resp. einer Stadt das Nutzen und das Fortentwickeln von urbanen Ressourcen und politischen Infrastrukturen ermöglicht wäre, die sie für ihren gemeinsamen Bildungsprozess im und am Sozialen brauchen, um sich darin und daran als emanzipierte Wesen zu entwickeln. Erst dadurch wären die Bedingungen günstig, den städtischen AkteurInnen zu ermöglichen, ihre individuell emanzipatorischen Beiträge zum Transformationsprozess des städtischen Alltagslebens zu entwickeln und auch tatsächlich verwirklichen zu können.

Durch die genossenschaftliche Organisierung eines solchen gesamtstädtischen Realexperiments, das mit Elsen als ökosoziale Transformation bezeichnet werden könnte, wäre es zumindest objektiv möglich, dass auch alltägliche PraxisakteurInnen für ihre subjektiven Zusammenhänge wissenschaftliche und/oder professionelle Institutionen - etwa Soziale Arbeit, aber auch andere Disziplinen und Professionen - aber auch staatliche Behörden nutzen könnten, um sich in ihren transformativen Angelegenheiten und Vorhaben unterstützen zu lassen. Und zwar ohne, dass sich ihren Anfragen und Bedürfnisse sich hierfür in die juristischen und administrativen Logiken der jeweiligen Institutionen einpflegen lassen müssen.

Solche kommunalisierenden Transformations- und (Subjekt-)Bildungsprozesse ließen sich dann nicht mehr nur als ökosoziale, sondern als sozialökologische Transformationen bezeichnen, wenn so organisiert wären, dass den AkteurInnen subjektiv bewusst werden würde, dass wir Menschen nicht nur in den Städten und auf der Erde leben, sondern als städtische Kommune und mit der Erde, d.h. in ihren ökologischen Verhältnissen, die sie durch ihre vielfältigen urbanen Lebensweisen mitentwickeln. Dass dieses terrestrische Bewusstsein entlang der ,imperialen Lebensweise“ (Brand/Wissen 2017) und ihrer sie bedingenden entfremdenden Herrschaftsverhältnisse zwischen den Menschen sowie zwischen den Menschen und ihrer Erde entfremdet ist - was schon Marx als „Riss“27 bezeichnet hat, der nur durch die Überwindung kapi-

27 Marx schreibt im dritten Band seines postum erschienen „Kapitals“: ,[D]as große Grundeigentum [...] erzeugt dadurch Bedingungen, die einen unheilbaren Riß hervorrufen in dem Zusammenhang des gesellschaftlichen und durch die Naturgesetze des Lebens vorgeschriebnen Stoffwechsels, infolge wovon die Bodenkraft verschleudert und diese Verschleude- 
talistischer Herrschaftsverhältnisse wieder zu kitten sei - impliziert nun zugleich den sozial-ökologischen Imperativ, dass eine terrestrische Nachhaltigkeitswissenschaft herauszubilden wäre, die empirisch gesicherte Strategien entwickelt, durch die es möglich würde, entlang von gesellschaftlichen Transformationen ein ebensolches menschliches Gemeinwesen zu bilden, das sich zum einen bewusst ist, nur als menschliche Gattung unter nichtmenschlichen Gattungen diese Erde zu bewohnen und zu verstoffwechseln. Und das sich zum anderen seiner Existenzbedingungen mit dieser Erde und ihren nicht-menschlichen Akteuren und ökologischen Aktanten bewusst ist.

Die menschliche Gattung ist zwar unter den Gattungen dieser Erde offenbar als einzige zur Begriffs- und Realabstraktion befähigt, wodurch es uns ganz offensichtlich möglich ist, die Bewohnbarkeit der Erde zu ruinieren. In der Klimafrage kommt es nun aber darauf an, uns selbst unter Beweis zu stellen, dass wir es auch vermögen, dies zu verhindern und das Wohnen auf und mit der Erde begriffs- und realabstrahierend radikal neu zu erfinden. Solche emanzipatorischen Subjektbildungsprozesse brauchen vor allem dort, wo die Menschen entlang von urbanen Lebensbedingungen einander fremd und unsolidarisch geworden sind, die Praxis gemeinsamer Aufgabenbewältigung. Und das heißt zum einen, dass sie die Praxis gemeinsamen Forschens brauchen, um zu ermitteln, welche Aufgaben wie gemeinsam bewältigt werden können bzw. müssen. Und das heißt zum anderen, sie brauchen die Praxis der gemeinsamen Hervorbringung politischer Strukturen und Institutionen, um die Ergebnisse dieser gemeinsamen Aufgabenermittlung und -bewältigung auch verbindlich und langfristig und damit nachhaltig verwirklichen zu können. Eine solche sozial nachhaltige Politik bedarf zu ihrer Ermöglichung und Verwirklichung aber vor allem auch eine praxisforscherische Begleitung, damit sich die AkteurInnen von den alltäglichen Verführungen, den vorherrschenden und subjektiv verinnerlichten Handlungs- und Denklogiken verhaftet zu bleiben und/oder nach kurzer Zeit wieder in sie zurück zu verfallen, emanzipieren und sich dadurch überhaupt erst subjektiv (fort)bilden können.

Mit Latour lässt sich eine solche Nachhaltigkeitswissenschaft sozialökologischer Transformation dahingehend umreißen, dass es durch sie möglich werden muss, die Erde nicht länger nur als von außen, d.h. vom Universum her erkanntes ,galileisches Objekt“ zu betrachten (Latour 2018: 81), sondern von innen heraus, aus dem sozialen Gefüge bzw. dem gesellschaftlichen Prozess, aus dem heraus die Erkenntnis letztlich tatsächlich stattfindet. Aus der Universumsperspektive ergibt sich für Latour nur allzu leicht ein teilnahmsloser Blick auf den Klimawandel, aus der heraus sich immer sagen lässt, das Klima habe sich schon immer verändert. Sie verleitet daher dazu, ihn ,als bedeutungslose Schwankung hinzunehmen“ (ebd.: 87). Eine terrest-

rung durch den Handel weit über die Grenzen des eignen Lan- des hinausgetragen wird.“ (Marx 1964: 821) 
rische Perspektive hingegen kennt eine solche Teilnahmslosigkeit nicht. Eine solche terrestrische Nachhaltigkeitswissenschaft sozial-ökologischer Transformation könne es für Latour aber nur geben, wenn hinsichtlich des Naturbegriffs

„sorgsam unterschieden wird zwischen jenen [WissenschaftlerInnen, MS], die sich dem Universum widmen, und jenen, die sich der prozesshaften Natur (natura oder physis) zuwenden. Während Erste vom Planeten als einem Körper unter anderen ausgehen, erscheint Letzteren die Erde als vollkommen einzigartig." (ebd.: 89)

An dieser Unterscheidung Latours, die die bisherige Unterscheidung in Sozial- und Naturwissenschaften hinfällig werden lässt bzw. neu sortiert, soll in der vorliegenden Studie festgehalten werden. Während Latour aber letztlich in zwei Naturwissenschaften unterscheidet, bei der die eine die Erde als sich entwickelnde Prozessnatur ${ }^{28}$ und die andere die Erde als ablaufenden Naturprozess untersucht, soll Latours Unterscheidung dahingehend präzisiert und erweitert werden, dass eine die Erde als sich entwickelnde Prozessnatur untersuchende Wissenschaft zugleich die soziale resp. gesellschaftliche Praxis der Menschen untersuchen muss, die entlang der ,imperialen Lebensweise“ (Brand/Wissen 2017) die Prozessnatur dergestalt manipuliert hat, dass sie zwar die Natur zu beherrschen beansprucht, aber eben doch bloß nur eine Katastrophe ausgelöst hat.

Mit dieser ideologiekritischen Erweiterung kann unter dem Begriff der Sozialwissenschaften nicht länger nur die Untersuchung gesellschaftlicher Praxis und/oder Struktu(ierung)en auf der Erde gefasst werden, sondern muss ihre Forschungspraxis ausweiten auf die kritische Untersuchung gesellschaftlicher Praxis und/oder Struktu(ierung)en der Erde (Stichwort Kapitalozän), bei der die Eigentätigkeit der Erdnatur nicht länger als Umwelt des sozialwissenschaftlichen Untersuchungsgegenstandes ausklammert wird. Gerade diese Erdvergessenheit der Sozialwissenschaften hat ja geradewegs dazu geführt, die erdökologischen Auswirkungen der „imperialen Lebensweise“ (ebd.) zu übersehen, die Wark (Wark 2017) an der Kritischen Theorie bemängelt (Kap. 1). Zugleich müssen sich aber auch naturwissenschaftliche Zugänge nicht nur der gesellschaftlichen Einbettung ihrer vermeintlich objektiven Erkenntnisapparaturen vergewissern, sondern auch das Stoffwechselverhältnis von gesellschaftlicher Praxis und Erdökologie stärker fokussieren. Aus der Kritik an diesen jeweiligen Blindstellen wurde im Anschluss an Goethes und Marxens ganzheitlichen Naturbegriff bereits in den 1980er Jahren eine ,soziale Naturwissenschaft“" (Böhme/Schramm 1985) bzw. Wissenschaft Sozialer Ökologie (Becker 2016f, 2016a) eingefordert, die „die sozial organisierte Natur

28 Mit Bloch lässt sich diesbezüglich von ,unabgeschlossener Prozessmaterie“ (Bloch 2013a: 273) sprechen, wonach „, die große Werkstatt der Mensch- und Weltmaterie [...] noch nicht geschlossen [ist].“ (Bloch 1972: 478) Mit anderen Worten: Was die Welt wird, entscheidet sich im Prozess der Praxis des Wirklichkeitsvollzugs der Erdnatur. 
und die Selbstorganisation der Natur miteinander verhandelbar und verbindbar machen möchte" (Altner 1987: 171).

Während eine soziale Naturwissenschaft bislang weitegehend ausgeblieben ist, hat sich eine naturalisierende Sozialwissenschaft weitgehend durchgesetzt. Der Unterschied verläuft nun genau an der Demarkationslinie Latours: Während naturalisierende Sozialwissenschaften die untersuchten Phänomene, von Klimaphänomenen bis zu sozialen Phänomenen in den kleinesten Mikrobeziehungen, als mechanistisch-zusammenhängende Systeme zu begreifen suchen, die als natürlich ablaufende Prozesse beschrieben und dargestellt werden können. Gehen sozial-ökologische Naturwissenschaften nicht von (Öko-)Systemen, sondern von (Öko-)Gefügen (ebd.: 170) aus, die einerseits die gesellschaftliche Zusammensetzung der verschiedenen Phänomene zu einem zusammenhängenden Bild der Wirklichkeit fokussieren und andererseits auf klein- und großräumiger (mikro- und makroskaliger) Ebene diejenigen Bereiche der Natur ausfindig zu machen suchen, die zur gelingenden biophysikalischen Reproduktion unverzichtbar sind. $\mathrm{Zu}$ ergänzen wäre dieser sozial-ökologische Ansatz um den Aspekt der gelingenden subjektiven (Re)Produktion im Kontext der gelingenden biophysikalischen Reproduktion sowie der Politisierung resp. Demokratisierung dieses immer schon gesellschaftlichen Verhältnisses. Darin erst öffnet sich ein subjektorientierter politischer Begriff gesellschaftlicher Naturverhältnisse bzw. ein subjektorientierter Politikbegriff Sozialer Ökologie, wie er in der vorliegenden Studie ausformuliert wird und der zu seiner Verwirklichung eine, wie sie hier bezeichnet wird, terrestrische Nachhaltigkeitswissenschaft sozial-ökologischer Transformation bedarf.

Dies passiert aber wohl nicht von Heute auf Morgen und vor allem nicht einfach so, d.h. nicht ohne die subjektive Entwicklung der wissenschaftlichen AkteurInnen, die letztlich selbst wissenschaftlich resp. praxisforscherisch zu ermöglichen und $\mathrm{zu}$ begleiten wäre. Die Demarkationslinie verläuft also zwischen einem naturalisierenden Zugang zur Erde bzw. zur Welt als (emergenz-)mechanistisch ablaufendes (Öko)System, das in Sozial- und Naturwissenschaften anzutreffen ist, und einem sozialen Zugang zur Erde bzw. der Welt als wechselwirkend-produzierend, d.h. dialektisch-arbeitendes (Öko-)Gefüge, das ebenfalls, wenn auch je marginalisiert, in Sozial- und Naturwissenschaften anzutreffen ist. Entsprechend müsste das Verhältnis von Sozialund Naturwissenschaften neu aufgespannt werden. So etwa ließen sich alle methodologischen Zugänge zusammenfassen, die die Erde von innen heraus, d.h. ,von Nahem“ (Latour 2018: 87), entlang der menschlichen wie nichtmenschlichen Akteure und Aktanten der Erde und ihren jeweiligen verflochtenen Entwicklungen auf und mit ihr als sympoietisch sich entwickelnde Prozessnatur zu beschreiben versuchen. Und es ließen sich alle methodologischen Zugänge zusammenfassen, die die Erde von außen her betrachten und ihre Entwicklung entlang mechanistisch ablaufender Naturprozesse zu be- 
schreiben versuchen und sich dabei ,auf ferne, nur mittels technischer Geräte, Modelle und Berechnungen erkennbare Phänomene [konzentrieren]“ (ebd.: 93).

Hierin findet sich mit einigem Wohlwollen die wissenschaftstheoretische Unterscheidung in induktive und deduktive Methodologien wieder (Seiffert 1980; Kutschera 1972a, 1972b; Losee 1977), entlang derer die hier als (Sozial- und Natur-)Wissenschaften der Prozessnatur zusammengefassten Zugänge induktiv von jeweils konkreten Praxen zum Allgemeinen (etwa einer Kritischen Theorie gesellschaftlicher Naturverhältnisse der Erde) und die hier als (Sozial- und Natur-)Wissenschaften der Naturprozesse zusammengefassten Zugänge deduktiv vom Allgemeinen (der allgemeinen Annahme einer mechanistischen Natur) zur Beschreibung konkreter Phänomene verfahren.

Viel offensichtlicher liegt in dieser Unterscheidung aber das jeweilige Annehmen oder Ablehnen der Vorstellung der Welt bzw. Natur als mechanistische Maschine. Diese sich bis in die griechische Antike zurück verfolgen lassende Vorstellung ist von Anfang an „mit dem Systemgedanken“ verbunden, der sich von der Vorstellung eines idealen Weltsystems als „die formale Seite des zusammengesetzten Körpers“" entwickelt hat zur Vorstellung einer Weltmaschine, mit der zudem „die materielle, reale Seite“ des Systemgedankens zum Ausdruck gebracht wurde (Gloy 1995: 158f.). Insbesondere diese sogenannte reale Seite des Systemgedankens findet seit der Renaissance breiten Zuspruch und findet als „mechanistische Erklärungsprinzip“ seither „nicht nur in der Physik Anwendung [...], sondern auch in den Human- und Geisteswissenschaften“ (ebd.: 171). Damit wird nun aber nicht nur die Natur als dem Menschen gegenüberstehender Mechanismus begriffen (etwa bei Descartes 1870), sondern auch der Mensch wird als leiblicher und die Gesellschaft als politischer Teil der mechanistischen Naturmaschine begriffen (etwa bei Hobbes 2005). ${ }^{29}$ Aber das erkenntnistheoretisch-neuzeitliche Paradigma der machina mundi ist von Anfang an von einem ,spezifisch instrumentale[n] Charakter" der Naturbeherrschung resp. der Beherrschung „der nur fabrizierten und von außen betriebenen Maschine" durchzogen (Gloy 1995: 162). Es steht daher ebenfalls seit der griechischen Antike in Konkurrenz zur Auffassung einer "sich selbsttätig erhaltenden Natur als eines Beweggrundes“ (ebd.), der gesellschaftlich nicht entgegen zu arbeiten (Naturbeherrschung), sondern mit der eine Allianz einzugehen ist, indem das gesellschaftliche Verhältnis zur Erdnatur politisiert und politisch reguliert wird (Naturallianz, Soziale Ökologie).

29 Hatte Descartes noch einigen Zweifel bestehen lassen, auch den Menschen als Maschine zu beschreiben, weil ,wir kein Mittel haben würden, sie [die Menschen, MS] ihrer Natur nach von den Thieren zu unterscheiden“ (Descartes 1870: 64ff.), gibt Hobbes „Leviathan“ diese Vorsicht wegweisend auf und beschreibt nicht nur den Menschen als Maschine, sondern ihn zugleich auch als Teil einer Staatsmaschine, die ,jenes vernunftbegabte und höchst vortreffliche Werk der Natur, den Menschen, nachahmt" (Hobbes 2005: 5). 
Dadurch, dass mit dem machina mundi-Paradigma nun auch die holozäne Entwicklung gesellschaftlicher Herrschafts- und Naturbeherrschungsverhältnisse bis hin zur „Urbanisierung des Kapitals“ (Harvey 2014: 126) (vgl. Kap. 3) ihren vermeintlich objektiven Erklärungs- und Legitimationsrahmen erhalten hatte, blieb die ganzheitliche Perspektive einer Naturallianz und ihre politischen Implikationen für eine von Grund auf andere Vergesellschaftung von Naturverhältnissen bis heute als unabgegoltene historische Möglichkeit gesellschaftlicher resp. urbaner Praxis zurück. Dabei würde aber erst durch eine solche ganzheitliche Perspektive die immer schon sozial, d.h. symbolisch vermittelte Bedeutung von Natur und Erde überhaupt erst selbst zum Politikum gemacht werden können.

Eine terrestrische Nachhaltigkeitswissenschaft sozial-ökologischer Transformation braucht nun aber letztlich beide Zugänge, um die sozialökologische Entwicklung der Erde als sympoietischen Gesamtkomplex vollumfänglich beschreiben zu können. So können bspw. Prognosen zum Verlauf und Ablauf des Kippens klimatologischer Kippelemente (Kap. 1) nicht von der Untersuchung konkreter gesellschaftlicher Praxen hergleitet werden. Gleichwohl lassen sich Untersuchungen zur gesellschaftlichen Erzeugung subjektiver Residuen (Kap. 4.2ff.) nicht mechanistisch angehen. Entsprechend haben in der Klimafrage beide Zugänge zum Problemkomplex ihre Berechtigung. Eine terrestrische Wissenschaft ist daher „mit konkurrierenden Erkenntnissen konfrontiert, die sie a priori nicht disqualifizieren [kann]", sondern „sich mit den Konflikten auseinandersetzen [muss]“ (Latour 2018: 93). Sie kann sich also nicht mit der Postulierung eines methodologischen Widerspruchs beider Herangehensweisen zufrieden geben, sondern muss transversal dazu einen dritten, den Widerspruch aufhebenden ${ }^{30}$ Zugang ermöglichen, der zudem die forschenden und beforschten menschlichen AkteurInnen mit ihren gesellschaftlich erzeugten subjektiven Residuen in den Blick nimmt und mit ihnen und ihren jeweiligen wissenschaftlichen und nichtwissenschaftlichen Expertisen nach unabgegoltenen (blockierten bzw. residualisierten) Möglichkeiten des urbanen Lebens Ausschau hält, durch das die Alltäglichkeit des urbanen Bewohnens der Erde eine andere werden könnte.

Ein solch dritter methodologischer Zugang lässt sich mit Lefebvre (Lefebvre 1987: 373f.) als transduktiv verfahrend bezeichnen. Transduktion heißt, dass mit den AkteurInnen theoretisch wie praktisch transdisziplinär (Mittelstraß 2005) vom Hier und Jetzt zum objektiv Möglichen vorgedrungen und von dorther nach Möglichkeiten und Strategien für das Hier und Jetzt Ausschau gehalten wird, um das bislang noch residualisierte und unabgegoltene objektiv Mögliche ihrer Lebensweisen zu verwirklichen. Eine solch transduk-

30 Aufheben meint hier im Sinne Hegels (Hegel 1970b: 94f.) ein Doppeltes: Nämlich Aufheben als Beenden eines bisherigen Zustandes durch dessen Aufheben auf eine andere Ebene der Bearbeitung, um ihn damit fortzuentwickeln und einer qualitativ veränderten Produktivität zuzuführen. 
tiver Wissenschaftsansatz lässt sich einerseits, wie bereits mit Lefebvre herausgestellt, als „strategische Hypothese“ (Lefebvre 1987: 372) und andererseits mit Bloch als „Aussichtserforschung des [objektiv-real, ebd. $271 \mathrm{ff}$.] InMöglichkeit-Seienden“ (Bloch 2013a: 240) bezeichnen. In der vorliegenden Studie wird er als terrestrische Nachhaltigkeitswissenschaft sozial-ökologischer Transformation auszuformulieren versucht. Beansprucht wird damit der von Bloch (Bloch 1975: 251, 2013b: 82ff.) im Anschluss an Marx formulierte Versuch, den historischen und (erd-)epochemachenden Schritt von der bürgerlich-instrumentellen Vernunft der Naturbeherrschung zur demokratisch-reflexiven Vernunft sozial-ökologischer Naturallianz zu vollziehen, welcher sich als Anthropozän bezeichnen ließe.

Was also „nottut“", so Latour weiter, ,ist, so kaltblütig und nüchtern wie möglich die erhitze Aktivität einer endlich von Nahem erfassten Erde zu erkennen“ (Latour 2018: 86). Eine terrestrische Wissenschaft der Nähe muss „die Lebewesen auf der Erde wie Agentien bzw. Akteure betrachte[n] [...], die an den Entstehungsprozessen der chemischen und teilweise sogar geologischen Bedingungen des Planeten voll beteiligt sind“ (ebd.: 89). Aus dieser Perspektive ,gibt [es] nicht auf der einen Seite Organismen und auf der anderen eine Umwelt, sondern es besteht eine Überlagerung wechselseitiger Konstellationen" (ebd.: 90), was - wie bereits in Kap. 1 erwähnt - am ehesten mit dem Begriff Mitwelt zum Ausdruck gebracht werden kann. Zumindest wenn dieser aus seiner bisherigen philosophischen Diskussion befreit wird (zum Überblick: Dabag 1980).

Diese „Überlagerung wechselseitiger Konstellationen“ (Latour 2018: 90), die im „sozialen Kode ,Mit““ (Kunstreich/May 2020: 49f.) des Begriffs Mitwelt zum Ausdruck kommt, lässt sich - wie ebenfalls bereits in Kap. 4.4 erwähnt - mit Haraway (Haraway 2018) als Sympoiesis bezeichnen. Eine solche mutualistische Perspektive auf den Evolutionsbegriff, die nicht nur die Entwicklung des Lebens auf der Erde, sondern die Entwicklung des Lebens mit der Erde, gar die Entwicklung mit der Erde als sich selbstverwirklichenden Entwicklung der Erde in den Blick nimmt, fasst zuvor schon Lovelock unter dem Begriff Gaia zusammen. Darunter subsumiert er

„das Lebenssystem der ganzen Erde, zu dem alles gehört, was von der Gesamtheit von Flora und Fauna (Biota) beeinflußt wird oder sie beeinflußt. Das Gaia-System hat mit allen lebendigen Organismen die Fähigkeit zur Homöostase gemein, das heißt, zur Stabilisierung der physikalischen und chemischen Umwelt auf einem das Leben begünstigenden Niveau." (Lovelock 1992: 56)

\section{Und weiter:}

„Wenn ich von Gaia als einem Superorganismus spreche, habe ich keinen Augenblick eine Göttin oder irgendein denkbegabtes Wesen im Sinn. Ich kleide meine Eingebung in Worte, dass die Erde sich wie ein selbstregulierendes System verhält und die zu ihrer Erforschung geeignete Wissenschaft daher die Physiologie ist.“ (ebd.: 57) 
Die Erde wird im Gaia-Konzept nicht als handelnde, sondern als sich verhaltende angenommen, nämlich dass sie sich ,verhält, indem sie auf das reagiert, was wir ihr antun“(Latour 2017: 126). Damit wird nicht gesagt,

„dass sie lebendig ist, sondern bloß, dass sie nicht tot ist. [...] Zur Unbelebtheit der materiellen Welt gelangt man, wenn man die Wirkungsmächte zwischen Ursachen und Folgen dergestalt aufteilt, dass alles auf die Ursachen und nichts auf die Folgen entfällt, außer dass eine Wirkung sie durchdringt, ohne ihnen etwas hinzuzufügen. [...] Durch den kausalistischen Bericht erhält man diesen Entseelungseffekt, aber stets nachträglich, nachdem man eine ganze Reihe der Folgen ausgeheckt, aufgebaut, zusammenmontiert und die Reihenfolge, in der diese Serie durchlaufen wird, umgekehrt hat.“(ebd.: 126f.)

Und weiter:

„Für Lovelock entwickelt sich jeder Organismus - versteht man ihn als Ausgangspunkt einer biochemischen Reaktion - nicht ,in“ einer Umgebung, er wickelt sie, wenn man so sagen darf, zum Behuf der eigenen Entwicklung um sich. In diesem Sinn manipuliert jeder Organismus absichtlich das, was ihn umgibt, ,in seinem eigenen Interesse“ [...].“(ebd.: 172)

Interesse wird dabei von Latour wörtlich verstanden als „'zwischen zwei Entitäten“" (ebd.). Die Erde besteht somit nicht aus getrennten Teilen oder Aggregaten, sondern als sympoietisches Netzwerken gemeinsamer Teile eines Organismus (ebd.: 128). Damit ist ebenfalls nicht animistisch gesagt,

„dass GAIA[sic!] über eine Art ,große empfindsame Seele“ verfügt, sondern dass der Begriff GAIA die Intentionalität in sich auffängt, die an alle Akteure verteilt ist, von denen jeder seine Umgebung so modifiziert, wie es ihm passt. [...] Wenn A um seines Überlebens willen B, C, D, und $\mathrm{X}$ modifiziert, dann modifizieren $\mathrm{B}, \mathrm{C}, \mathrm{D}$ und $\mathrm{X}$ rückwirkend $\mathrm{A}$. Alsbald breitet Leben sich an allen Punkten aus.“(ebd.: 173f.)

Der Zweck des irdischen Seins steht damit „nicht mehr am Ende [...], sondern an jedem Punkt durch das Eingreifen [...] kräftiger Intentionen und Interessen anderer Organismen" (ebd.: 174f.). Jedes Interesse von Organismen ist Selbstzweck und damit Endzweck zugleich. „Aus einer solchen Verteilung von Endzwecken geht kein oberster Endzweck hervor, sondern schlicht ein wüstes Gewirr. Dieses Gewirr ist Gaia.“ (ebd.: 176)

Im Anschluss an die Gaia-Hypothese lässt sich die Erde also als dialektisch-physiologischer resp. dialektisch-materialistischer Bildungsprozess, mithin die Erde als Soziales im Sinne ,spezifische[r], aktuelle[r], historisch einmalige[r] Beziehungen real existierender Subjekte untereinander" (Kunstreich 2014: 365) verstehen. Entsprechend muss eine terrestrische Nachhaltigkeitswissenschaft sozial-ökologischer Transformation den Blick zum einen auf die dialektischen Verflechtungen nicht-menschlicher (geologischer, botanischer und zoologischer) und menschlicher (gesellschaftlicher) Entwicklungsprozesse der Erde lenken. Und zum anderen auf die Art und Weise, wie im urbanen bzw. gesellschaftlichen Alltag menschliche und nicht-menschliche (Erd)Naturverhältnisse vergesellschaftet werden. Und zudem auf dessen Konsequenzen für die Erde als ganzheitlicher „Superorganismus“ (Lovelock 1992: 57). Erst in dieser Gesamtschau lässt sich ein Überblick gewinnen, was 
dieses „wüste[] Gewirr“ (Latour 2017: 176) umfasst, das letztlich als demokratisch regulierbares politisches Gemeinwesen hervorzubringen wäre., mit dem sich das menschliche Gemeinwesen als Gattung von Erdbewohnern unter Gattungen von Erdbewohnern verwirklichen kann.

An dieser Stelle ist ein weiterer Exkurs angebracht, der den philosophisch-normativen Leitgedanken einer solchen terrestrischen Nachhaltigkeitswissenschaft sozial-ökologischer Transformation entlang des ,wüste[n] Gewirr[s]" (ebd.) Gaia strukturiert und es als terrestrisches Gemeinwesen begrifflich fasst.

\section{Exkurs zum philosophisch-normativen Fundament des Begriffs des Sozial- Ökologischen}

Um einer terrestrischen Nachhaltigkeitswissenschaft sozialer Ökologie über den Begriff des Sozial-Ökologischen einen kritischen Impetus einzupflanzen, der zum einen an Latours Unterscheidung von Naturprozesswissenschaften und Prozessnaturwissenschaften anknüpft und sie zum anderen zugleich aufhebt $\mathrm{zu}$ einer strategischen Aussichtserforschung eines objektiv-möglichen sozial-ökologischen Gemeinwesen menschlicher und nicht-menschlicher Akteure und Aktanten, kann sich nicht mit Latours Begriff der Komposition zufrieden gegeben werden. In seinem „Versuch, das 'Kompositionistische Manifest" zu schreiben“, schreibt Latour:

„Obwohl das Wort ,Komposition“ ein bisschen lang und aufgeblasen ist, ist schön daran, dass es betont, dass Dinge zusammengesetzt wurden (lat. componere), während sie ihre Heterogenität beibehalten. Außerdem ist es mit dem Komponieren verbunden; es hat seine Wurzeln in Kunst, Malerei, Musik, Theater, Tanz, und ist daher assoziiert mit Choreographie und Szenographie; es ist nicht allzu weit von ,Kompromiss' entfernt, und so hat es einen gewissen diplomatischen, vernünftigen Beigeschmack. Vor allem kann eine Komposition scheitern und so beibehalten, was im Gedanken des Konstruktivismus am wichtigsten ist (eine Bezeichnung, die ich auch hätte verwenden können, wenn sie nicht bereits von der Kunstgeschichte eingenommen wäre). Sie lenkt so die Aufmerksamkeit weg vom irrelevanten Unterschied zwischen dem Konstruierten und dem nicht Konstruierten, zwischen dem Komponierten und nicht Komponierten, und stattdessen hin zum wichtigen Unterschied zwischen dem gut oder schlecht Konstruierten, gut oder schlecht Komponierten. Was komponiert wurde, kann jederzeit auch kompostiert werden." (Latour 2010b)

Einerseits geht es einer terrestrischen Nachhaltigkeitswissenschaft sozialer Ökologie zwar im Anschluss an Latour darum, verschiedene Disziplinen der Prozessnatur und der Naturprozesse zusammenzubringen und gesellschaftliche (Erd-)Naturverhältnisse politisch zu komponieren. Andererseits bedarf es aber zur Kritik an der bisherigen Vergesellschaftung der (Erd-)Naturverhältnisse einen philosophisch-normativen Bezugspunkt, an dem entlang sozialökologische Transformationsstrategien entwickelt und, wie Latour es vorschlägt, als gute oder schlechte sozial-ökologische Kompositionen beurteilt werden können. 
Latours Vorschlag fehlt hierfür aber nicht nur jegliche Subjektebene. Auch sein vorgeschlagener philosophisch-normativer Bezugspunkt für die Politisierung der Erde als wüstes Gaia-Gewirr kann nicht halten, was er verspricht. Denn er schlägt vor Natur als „Vielfalt von Determinierungsebenen zu bestimmen, die vom Atom bis zum Gesellschaftssystem reichen" (Latour 2010a: 78), mit dem Ziel, die Determinierungsebenen nicht gegeneinander auszuspielen bzw. in eine systematisch-fixe Hierarchie zu bringen, sondern sie zu integrieren und zu komponieren, d.h. ihre Hierarchie und Verhältnisse zu politisieren: „Anstatt von einem feststehendem Inventar natürlicher Bestandteile auszugehen, aus denen sich die Gesamtheit zusammensetzen soll“" plädiert Latour für eine „Metawissenschaft“, eine „Wissenschaft der Totalität, die als einzige die Komplexität der Lebewesen“" bzw. das ,energetische[], überströmende[], fruchtbare[] Ganze“ der Natur, „das nicht auf die kalte Kausalität der klassischen Wissenschaften reduzierbar ist" (ebd.: 79f.), zu erfassen und wissenschaftlich, politisch, ökonomisch, moralisch und administrativ (neu) zu komponieren vermag (ebd.: Kap. 4). ${ }^{31}$ Diese „Übernatur“ bzw. „Globalität“ (resp. Totalität) des „energetischen, überströmenden, fruchtbaren Ganze“ der Natur ist sogleich „,von der menschlichen Geschichte her zu denken, indem alles, auch die nicht-soziale Natur, in den Begriff der menschlichen Konstruktion oder Geschichte eingeschlossen wird" (ebd.: 80). Latour geht es nun darum den „Rest“ ausfindig zu machen, ,der sich nicht einschließen lässt“", um daran den Begriff der Natur zu füllen: Natur ist das, was sich seiner menschlichen Vergesellschaftung ,verweigert“ (ebd.: 80f.).

Es findet sich hier durchaus eine Parallele zu Lefebvres Begriff des Residuums, das als blockierter Rest leiblich-lebendiger Arbeit natürlicher resp. „unabgeschlossener Prozessmaterie“ (Bloch 2013a: 273) begriffen werden kann, die sich zu entwickeln, d.h. in ihrem Zusammenhang als globales (totales) Verhältnis zu individuieren sucht. ${ }^{32}$ Aber anstatt an diesem sich jeder Vergesellschaftung sperrenden Residuum eine gesellschaftstheoretische Kritik vorherrschender gesellschaftlicher Naturverhältnisse und/oder sozialökologischer Transformationsstrategien zu entzünden, geht es Latour in seinem „Parlament der Dinge“ (Latour 2010) letztlich bloß um eine wissen-

31 Latour schreibt: „Kompositionismus stellt sich der Aufgabe, Universalität zu suchen, ohne zu glauben, dass Universalität schon da sei und darauf warte, enthüllt und entdeckt zu werden. Es ist somit so weit vom Relativismus im banalen Sinn entfernt wie vom Universalismus in der modernistischen Bedeutung des Wortes [...]. Vom Universalismus nimmt sie die Aufgabe an, eine gemeinsame Welt aufzubauen; vom Relativismus die Gewissheit, dass diese gemeinsame Welt aus absolut heterogenen Teilen aufgebaut werden muss, die nie ein Ganzes ergeben werden, sondern bestenfalls eine zerbrechliche, korrigierbare und vielfältige Komposition." (Latour 2010b)

32 Gemeinsamer Bezugspunkt von Blochs und Lefebvres Begriffen ist die Marxsche materialistische Wendung von Hegels Begriff menschlicher Verwirklichung (zum Überblick des Begriffs menschlicher Verwirklichung bei Hegel und dessen materialistische Wendung bei Marx: May 2009: 51ff.) 
schaftliche, politische, ökonomische und moralische Bestandsaufnahme sowie der administrativen Sicherstellung der iterativen Wiederholung dieser Bestandsaufnahme, um so das „Parlament der Dinge“ (ebd.) permanent offen zu halten und sich entwickeln zu lassen. Mit Latour lässt sich damit also eine Transformationsstrategie begründen, die permanent Ausschau danach hält, mit welchen nicht-menschlichen Akteuren und Aktanten es Menschen für ihr gesellschaftliches Alltagsleben $\mathrm{zu}$ tun haben bzw. von welchen nichtmenschlichen Akteuren und Aktanten ihr gesellschaftliches Alltagsleben abhängt. Aber es bleibt offen, wie und mit welchen Mitteln dies als konkrete urbane Praxis, d.h. wie dies vor dem Hintergrund der technologischen und strukturellen Pfadabhängigkeiten der vorherrschenden (kapitalisierten) Praxis der Urbanisierung realisiert werden kann.

Hierfür soll in Teil B Lefebvres Vorschlag eines Rechts auf Stadt im Hinblick auf die Möglichkeiten sozial-ökologischer Stadtentwicklung näher untersucht werden. An dieser Stelle ist es zuvor aber noch wichtig, einen elementaren Unterschied zwischen Lefebvre und Latour zu markieren, weshalb es im Weiteren auch plausibel erscheint, nicht weiter auf Latour einzugehen, sondern seine Studien letztlich nur als Steigbügelhalter zu benutzen und sie mit Lefebvres Studien weiter zu entwickeln.

Der fundamentale Unterschied besteht vor allem darin, dass Latour den „Unterschied zwischen dem Konstruierten und dem nicht Konstruierten, zwischen dem Komponierten und nicht Komponierten“ als ,irrelevant[]“ erklärt und stattdessen nur auf den ,wichtigen Unterschied zwischen dem gut oder schlecht Konstruierten, gut oder schlecht Komponierten“" insistiert (Latour 2010b). Wenn aber der „Unterschied zwischen dem Konstruierten und dem nicht Konstruierten, zwischen dem Komponierten und nicht Komponierten" verwischt wird, Latour also das dünne Eis des Konstruktivismus betritt, dann öffnet sich die Frage, wie denn bzw. von welchem normativen Bezugspunkt aus zwischen ,gut oder schlecht Konstruierten, gut oder schlecht Komponierten" (ebd.) unterschieden werden soll? Als offene Frage bleibt bei Latour also zurück, wie es durch die konstruktivistische Auflösung der Relata (Natur und Gesellschaft bzw. Ökologie und Politik) in ihre Relationalität als globale bzw. totale „Übernatur" (Latour 2010a) des „Kompositionismus“ (Latour 2010b) noch möglich sein soll, einerseits die je eigenständigen Produktionsweisen des Klimawandels durch gesellschaftliche Produktionsweisen und durch klimatologische Kippelemente zu untersuchen. Und andererseits in den gesellschaftlichen Produktionsweisen nach residuen- resp. subjektorientierten Strategien gesellschaftlicher Transformationen $\mathrm{zu}$ suchen, die den klimatologischen Naturprozessen gerecht werden. Sobald dies versucht würde, müssten die Relata zwar in ihrer Verflochtenheit untersucht werden, um aber ihrer Eigentätigkeit, d.h. der Sache ihrer jeweiligen Logik auf die Spur zu kommen, müssten sie zugleich auch wieder entflochten werden, was in einer konsequenten Auflösung der Relata in den Relationen nicht mehr mög- 
lich wäre, weil es nur noch Netzwerke, aber keine NetzwerkakteurInnen mehr geben würde. Es sei denn, die Relata würden durch die Hintertür doch wieder eingeführt, oder aber gar nicht erst konsequent überwunden. Um es deutlicher zu sagen: Latours philosophisch-normativer Bezugspunkt scheint auf Sand gebaut, auf dem eine Kritik gesellschaftlicher Naturverhältnisse und eine Kritik an gesellschaftskritischen sozial-ökologischen Transformationsstrategien fest fußen könnte. Seine wissenschafts- und erkenntnistheoretischen Überlegungen spielen für die weitere Untersuchung einer emanzipatorischen Politik Sozialer Ökologie daher keine zentrale Rolle.

Stattdessen, so die hier vertretene Position, bedarf eine terrestrische Nachhaltigkeitswissenschaft sozial-ökologischer Transformation ein philosophisch-normatives Fundament, das die Eigentätigkeit der Relata des Klimawandels anerkennt und sie zugleich in ein sich gegenseitig bedingendes Entwicklungsverhältnis setzt, das die Erde einerseits als „,wüstes Gewirr“ (Latour 2017: 176), sie zugleich aber auch als sich sozial entwickelndes bzw. sozial selbst strukturierendes und regulierendes, d.h. sympoietisches Ökogefüge (Gaia) zu fassen ermöglicht. Mit anderen Worten: es braucht einen Naturbegriff, der Gaia als soziale Ökologie eines „wüste[n] Gewirr[s]“ (ebd.) anerkennt und mit dem sich eine Strategie der Kritik sowie die Kritik von Strategien begründen lässt und mit der sich das „wüste[] Gewirr“ (ebd.) politisch regulieren ließe. Ein solch philosophisch-normativer Naturbegriff lässt sich aus der von Hegel eingeführten Dialektik des ,allgemeine[n] Begriffs“, der „die drei Momente: Allgemeinheit, Besonderheit und Einzelheit [enthält] “33 (Hegel 1970c: 273), herleiten. Aber nur, wenn sie - in Anlehnung an Engels (Engels 1989: 48) Kritik an Hegels Dialektik - zugleich vom idealistischen Kopf auf materialistische Füße gestellt wird.

Moog erblickt in Hegels Begriff der Allgemeinheit ein ,unvollkommenes Moment des Begriffes“, das „,keine Wahrheit hat" (Moog 1930: 263). Als „'schöpferische Macht“" (ebd.) ohne eigene Wahrheit resp. Definition bestimmt sich das Allgemeine eigenständig und selbstregulierend über das eigenständige und sich selbst regulierende Verhältnis von Besonderheit und Einzelheit, das es in sich trägt. Im Zusammenhang mit dem in Kap. 6.1 aus-

33 Der ganze Passus in Hegels zweiten Teil seiner „Wissenschaft der Logik“ lautet: „Zuerst ist er reiner Begriff oder die Bestimmung der Allgemeinheit. Der reine oder allgemeine Begriff ist aber auch nur ein bestimmter oder besonderer Begriff, der sich auf die Seite neben die anderen stellt. Weil der Begriff die Totalität ist, also in seiner Allgemeinheit oder rein identischen Beziehung auf sich selbst wesentlich das Bestimmen und Unterscheiden ist, so hat er in ihm selbst den Maßstab, wodurch diese Form seiner Identität mit sich, indem sie alle Momente durchdringt und in sich faßt, ebenso unmittelbar sich bestimmt, nur das Allgemeine gegen die Unterschiedenheit der Momente $\mathrm{zu}$ sein. Zweitens ist der Begriff dadurch als dieser besondere oder als [der] bestimmte Begriff, welcher als gegen andere unterschieden gesetzt ist. Drittens, die Einzelheit ist der aus dem Unterschiede in die absolute Negativität sich reflektierende Begriff. Dies ist zugleich das Moment, worin er aus seiner Identität in sein Anderssein übergetreten ist und zum Urteil wird.“(Hegel 1970c: 273f.) 
geführten Begriff der die Produzierendenensozialpolitiken übergreifenden Politik des Sozialen, lässt sich eine übergreifende Politik des Sozialen in einer materialistisch gewendeten Fassung von Hegels Begriffsdialektik begreifen als allgemeines Gesellschaftliches, das die je besonderen (milieuspezifischen/ lebensweltlichen) Produzierendensozialpolitiken umfasst. Diese wiederum umfassen die einzelnen AkteurInnen und die jeweils leiblichsensualistischen Aneignungen ihrer inneren wie äußeren Naturverhältnisse sowie den sozialen Umgang mit ihren je gesellschaftlich blockierten subjektiven Vermögen sozialer Interaktion (Residuen), durch den sie sich entlang aller gesellschaftlichen Blockierungen als Individuen hervorzubringen suchen. Entlang dieser Residuen und den Weisen ihrer Aneignungen durch die AkteurInnen (Einzelheiten) konstituieren und unterscheiden sich die verschiedenen Produzierendensozialpolitiken (Besonderheiten) und mit ihnen entwickelt sich das Gesellschaftliche (Allgemeinheit), das durch eine übergreifende Politik des Sozialen im tatsächlichen Fluss der Entwicklung des Verhältnisses der Einzelnen zu ihren jeweiligen Produzierendensozialpolitiken als Gruppe sowie des Verhältnisses der Gruppenmitglieder zu Gruppenmitgliedern anderer Produzierendensozialpolitiken, d.h. der Gruppen zueinander, gehalten und gestaltet werden soll.

Analog dazu lässt sich nun auch der Begriff des Sozial-Ökologischen als dialektischer Naturbegriff erfassen. Ist im Begriff der Politik des Sozialen der Begriff des Gesellschaftlichen als allgemeiner Begriff mit „'schöpferische[r] Macht"“" ohne Definition (ebd.) angelegt, so ist auch im Begriff des SozialÖkologischen die Erde als allgemeiner Begriff „'schöpferische[r] Macht““ ohne Definition (ebd.) angelegt. Die Erde wird damit verstanden als Allgemeines ohne eigene Wahrheit/Definition da das, was das Allgemeine resp. die Erde ist, sich eigentätig und selbstregulierend über das Verhältnis der einzelnen menschlichen und nicht-menschlichen Akteure und Aktanten und ihrer jeweiligen gattungsbedingten Besonderheit(en), das sie in sich trägt, bestimmt. Ohne eigene Wahrheit heißt also nicht ohne Anerkennung der Eigentätigkeit der Erde, sondern heißt, dass diese Eigentätigkeit nicht ohne die sie konstituierenden Komponenten (Akteure und Aktanten) begriffen werden kann. Diese ihr eigentümliche Eigentätigkeit ist nicht einfach als innere Natur der Erde vorhanden, sondern sie entwickelt sich in Wechselwirkung mit der äußeren Natur der Erde. Anders: Dass die Erde ihre Eigentätigkeit besitzt, bestimmt sich zwar aus den Naturprozessen der Prozessnatur des Universums. Aber die konkrete Eigentätigkeit der Erde entwickelt sich mit den Akteuren und Aktanten, die die Erde in der Wechselwirkung mit ihrer Universumsmitwelt hervorbringt. Nochmal anders: Durch Wechselwirkungen mit Sonne und anderen Planeten, durch Kollisionen mit Kometen und Planeten entwickelten sich die Entstehungsbedingungen der konkreten Eigentätigkeit dieser Erde, die die Herausbildung der ersten Aktantengattungen wie Meere (Hadaikum) und Gesteine sowie organische Moleküle und Einzeller 
(Archaikum) hervorbrachten und die durch ihre Wechselwirkungen eine Sauerstoffatmosphäre, erbfähige Zellen, Chloroplasten, und die ersten vielzelligen Lebensformen (Proterozoikum) entstehen ließen. Aus den Wechselwirkungen der sich vergrößernden Vielzahl der Gattungen terrestrischer Aktanten und noch mikroskopischer Lebensformen gingen letztlich vielfältigere und differenziertere makroskopische Lebensformen und Wälder hervor, die wiederum die Sauerstoffatmosphäre und die Böden veränderten, auf sie zurück wirkten und die konkrete Eigentätigkeit der Erde sich weiter entwickeln ließen sowie die Bedingungen schufen, mit denen sich die ersten Formen der Gattung Mensch herausbilden konnten (Phanerozoikum) (stark gekürzte und vergröbernd zusammenfassende Darstellung von Kasang o. J; Kückens/Anthropocene Learning Lab o. J; Oschmann 2003). Mit all diesen erdhistorischen Entwicklungen der Besonderheiten resp. den je besonderen Akteuren und Aktanten und ihren je gattungsbedingten Wechselwirkungen entwickelte sich das besondere ökologische Gefüge der Erde und damit die allen gemeinsame (allgemeine) terrestrische Eigentätigkeit der Erde.

Das Allgemeine der Erde lässt sich damit also verstehen als „'schöpferische Macht"“ (Moog 1930: 263) ohne eigene Wahrheit resp. Definition, allerdings nicht ohne Eigentätigkeit, wobei die Eigentätigkeit als sich selbstregulierendes Verhältnis von Besonderheiten (Aktanten- und Akteursgattungen) und Einzelheiten (die konkreten Akteure und Aktanten) begriffen werden muss. Die Erde (Allgemeines) als je historisch-konkretes Verhältnisverhältnis ist nicht von vornherein und allgemein gegeben, sondern entwickelt sich aus der Arbeit, d.h. der Dialektik von Allgemeinen, Besonderen und Einzelnen, nämlich durch die gattungsbedingten Produktionsweisen der Auseinandersetzung resp. Arbeit der Akteure und Aktanten mit Akteuren und Aktanten anderer Gattungen - gar außererdigen Aktantengattungen - und ihren je gattungsbedingten Produktionsweisen. Die Entwicklung der Erde entwickelt sich damit demnach im Fluss der Entwicklung der Wechselwirkungen der Akteure und Aktanten, die sie hervorbringt, und den außererdigen Aktanten, denen sie ausgesetzt ist.

Dieser quasi-soziale - dialektische - Entwicklungsprozess der Eigentätigkeit der allgemeinen Erdökologie kommt im Begriff Sozialer Ökologie zum Ausdruck. Zugleich bleibt er dabei aber nicht stehen, sondern versammelt zugleich den Beitrag menschlicher Produktionsweisen und ihre Effekte auf das erdökologische Gefüge, mit der sie über ihre Produktionsweisen des Sozialen und ihrer Vergesellschaftung/Urbanisierung menschlicher wie nichtmenschlicher Akteure und Aktanten die allgemeine Eigentätigkeit der Erde mitgestalten. $\mathrm{Ob}$ und wie dabei der Erhalt der Lebensgrundlagen welcher Gattungen gefördert oder untergraben wird, lässt sich aber erst dadurch bewerten, wenn die Erde nicht mehr nur als das ermittelt wird, was sich der menschlichen Vergesellschaftung sperrt (Latour), sondern auch als das, was eine emanzipatorische Kritik an der Vergesellschaftung begründet. In den 
Blick der Kritik geraten muss damit also nicht nur dass die Erde sich sozialökologisch entwickelt, sondern auch wie. Und das heißt aus einer dialektischen Perspektive, sie entwickelt sich durch die Arbeit bzw. in der Auseinandersetzung ...

1. ... der menschlichen Gattung und ihrer AkteurInnen untereinander mit dem jeweils Allgemeinen der Erde im urbanen/gesellschaftlichen Zusammenleben. Was ein/e AkteurIn der Gattung Mensch konkret wird, wird er entlang der Vergesellschaftung bzw. Urbanisierung seiner gattungsbedingten menschlichen Besonderheit, d.h. seiner menschlich-leiblichen Eigentätigkeit, Widerständigkeit und der körperlichen Ausstattung. Nämlich dadurch, dass die konkreten Menschen dieses Erde-StadtMensch-Verhältnis (mehr oder weniger bewusst und kritisch) reflektieren, es sich aneignen und ausgestalten.

2. ... der AkteurInnen menschlicher Gattung mit Akteuren und Aktanten nicht-menschlicher Gattungen im urbanen/gesellschaftlichen Zusammenleben inmitten der allgemeinen Erdnatur, aus der sich das urbane/ gesellschaftliche Zusammenleben herausarbeitet. Was die konkreten Menschen werden können, werden sie nicht nur entlang der Vergesellschaftung/ Urbanisierung ihrer je gattungsbedingten menschlichen Besonderheit (siehe 1), sondern vor allem auch durch die Vergesellschaftung/Urbanisierung ihrer je gattungsbedingten menschlichen Besonderheit inmitten einer Mitwelt (außer)terrestrischer Aktanten und nicht-menschlicher Akteure. Dadurch kann die Vergesellschaftung/Urbanisierung der Erde an einem bestimmten Ort zu einer bestimmten Zeit nur so stattfinden, wie es die (außer)terrestrische Mitwelt ermöglicht. In diesem mitweltlichen Angefangensein wird eine Vergesellschaftung von menschlichen wie nichtmenschlichen Akteurs- und Aktantengattungen vollzogen, wodurch das Allgemeine der historisch je konkreten Erde als Allgemeines fortentwickelt wird.

Eine nicht nur anthropozentrische, sondern terrestrisch geöffnete Perspektive Sozialer Ökologie kann aber hierbei nicht stehen bleiben, sondern muss die Entwicklung der Erde als Allgemeines auch erblicken in der Arbeit bzw. der Auseinandersetzung...

3. ...der Akteure nicht-menschlicher Gattungen mit menschlichen AkteurInnen und ihren gesellschaftlichen Aktanten im gattungsbedingten $\mathrm{Zu}-$ sammenleben der Tier-, Pflanzengattungen entlang der menschlichen Vergesellschaftung ihrer gattungsbedingten Eigentätigkeiten und Widerständigkeiten (durch Domestizierung, Einhegen/Kontrolle ihrer Population, industrielle Verwertung). Dadurch können sich die nicht-menschlichen Akteure jeweils nur so entwickeln, wie es ihnen ihre gattungsfremde 
Vergesellschaftung entlang ihrer je gattungsbedingten Eigentätigkeiten und Widerständigkeiten erlaubt.

4. ...der erdökologischen Aktanten (Gewässer, Gebirge, Gletscher etc.) in der Auseinandersetzung mit menschlichen und nicht-menschlichen Akteuren und ihren jeweils hervorgebrachten $A_{k t a n t e n}{ }^{34}$, d.h. der Reaktion erdökologischer Aktanten auf ihre vor allem menschliche Benutzung bzw. Aneignung und Ausgestaltung (durch industrielle Verwertung zur Nahrungsmittelproduktion von Landschaften, Gewässern, Bio- und Ökotopen). Ein Gletscher, ein Gebirge, Gewässer ist das, was er/es entlang seiner/ihrer Eigentätigkeit und Widerständigkeit sowie der Auseinandersetzung bzw. Bearbeitung (Benutzung/Vernutzung) mit nicht-menschlichen und vor allem menschlichen AkteurInnen werden kann. Aktanten entwickeln sich so, wie sie sich vor allem entlang von menschlichen Urbanisierungsprozessen, die auf sie einwirken, entwickeln können. Ihre Naturprozesse müssen damit im Kontext einer sich entwickelnden Erde als Prozessnatur begriffen werden. Die Eigentätigkeit von Aktanten resp. ihre Naturprozesse zeigen sich vor allem auch darin, dass sie sich eigentätig weiter entwickeln, auch wenn sich die Weise ihrer Vergesellschaftung ändert (Stichwort Kippelemente, Kap. 1), was letztlich weitere tech$\mathrm{n}(\mathrm{olog})$ ische Aktanten notwendig werden lässt, um die Effekte der Eigentätigkeit von Aktanten auf das Verhältnis von Erde (Allgemeinen), Gattungen (Besonderen) und Akteuren (Einzelnen) in Grenzen zu halten, die den Lebensbedingungen der gedeihlichen Entwicklung der Akteure der Gattungen gerecht werden können.

Aus einer dialektischen bzw. sozial-ökologischen Perspektive lässt sich die Entwicklung der Erde also als vier-dimensionales Verhältnisverhältnis darstellen, in dem sich die Erde als Allgemeinheit entwickelt, die zugleich das Moment der Weiterentwicklung des die Erde konstituierenden vierdimensionalen Verhältnisverhältnisses von Einzelheiten und Besonderheiten bildet. Eine durch eine terrestrische Nachhaltigkeitswissenschaft sozial-ökologischer Transformation entwickelte Kritik müsste also dieses vierdimensionale Verhältnisverhältnis im Blick haben und zugleich nach Möglichkeiten suchen, dieses dialektische Verhältnisverhältnis nicht nur zur Sprache zu bringen und zu politisieren. Sondern sie müsste es so politisieren, dass eine Politik Sozialer Ökologie nicht nur die Gedeihlichkeit menschlicher AkteurInnen und ihrer dafür notwendigen Aktanten, sondern auch die Gedeihlichkeit nichtmenschlicher Akteure und ihrer hierfür benötigten Aktanten im Blick hat.

34 Aktanten nicht-menschlicher Akteure sind bspw. Biberdämme, die analog zu menschlichen Staudämmen ökologische Aktanten (Flüsse) beeinflussen - obschon empirisch mit stark ungleichen und nur im Theoretisch-Abstrakten vergleichbaren Auswirkungen. Aktanten nicht-menschlicher Akteure sind aber Landschaften, Gewässer, Gebirge, Atmosphäre, die sie ebenfalls zum Leben benötigen. 
Erst darin ließe sich ein dialektischer Naturbegriff formulieren, der es vermag, eine Kritik bzw. einen kritischen Gaia-Begriff zu entzünden, der zwischen „gut oder schlecht Konstruierten, gut oder schlecht Komponierten“ (Latour 2010b) zu unterscheiden vermag, indem er die Dialektik des gedeihlichen Miteinander (Sympoiesis) zum philosophisch-normativen Bezugspunkt nimmt. Und erst von dort aus ließe sich ein sozial-ökologisches Transformationssubjekt formulieren, das sich über die Auseinandersetzung von menschlichen AkteurInnen mit Akteuren und Aktanten nicht-menschlicher Gattungen konkretisiert und dadurch das menschliche (Gattungs-)Subjekt konkret erfahrbar machen könnte, das entlang dieser sozial-ökologischen Subjektbildung ein politisches Gemeinwesen zu begründen vermag, das das dialektische Abhängigkeits- resp. Entwicklungsverhältnis von Allgemeinen, Besonderen und Einzelnen, d.h. von Erde, Gattungen und menschlichen wie nicht-menschlichen Akteuren ins Zentrum des Politischen rückt (und nicht nur menschliche, gar nur privat-menschliche Einzelinteressen). Dies tun zu können ist eine genuin menschliche Gattungsbesonderheit, die es den menschlichen AkteurInnen erlaubt, nicht nur auf sich selbst, d.h. nicht nur das Subjekt ihrer eigenen Gattung zu reflektieren, sondern die Erde als allgemeines Subjekt aller Gattungen - ohne dabei festzulegen, was die Erde ist, sondern immer wieder neu zu beschreiben, was sie unter der Berücksichtigung der Entwicklung aller besonderer Einzelnen als Allgemeines, d.h. als allen gemeinsames Subjekt sein könnte. - Exkurs Ende

Zusammenfassend: Ein dergestalt dialektisch fundierter praxisphilosophischer Begriff sozial-ökologischer Transformation ermöglicht einen Kritikbegriff, der sich einerseits auf Marx' (Marx 1981c: 371) gattungsgeschichtlichen (bzw. materialistisch geschichtsphilosophischen) Emanzipationsbegriff berufen kann und der es zugleich aber auch vermag, den darin enthaltenen nicht-instrumentellen Anthropozentrismus (Kirchhoff 2020; Schmidt 2018b: 175; Kropp 2002: 152ff.) zu durchbrechen und terrestrisch zu weiten. Während, wie mit Elsen dargestellt, ökosoziale Transformationen darauf insistieren, das Soziale wieder ökologisch einzubetten, insistieren sozial-ökologische Transformationen zwar auch darauf, das Soziale wieder ökologisch einzubetten, versuchen aber zugleich der Versuchung zu entgehen, die Erde als Werkzeug bzw. Arbeitsmittel nur für den Menschen bzw. menschliche Entwicklung zu urbanisieren. Entsprechend bräuchte es eine menschliche Politik Sozialer Ökologie, die den Menschen dezentral positioniert, auch wenn er weiterhin der zentrale Initiator und Akteur seiner Politik bleibt, worin der Schritt von der ökosozialen zur sozial-ökologischen Transformation gegangen würde.

Der dialektisch fundierte praxisphilosophische Begriff sozial-ökologischer Transformation offenbart zugleich aber noch einen weiteren elementaren Aspekt einer terrestrischen Nachhaltigkeitswissenschaft sozial- 
ökologischer Transformation, den Marx und Engels in kaum zu schlagender Kürze auf den Punkt bringen: „[n]icht das Bewußtsein bestimmt das Leben, sondern das Leben bestimmt das Bewußtsein“ (Marx/Engels 1978: 27). ${ }^{33}$ Nicht das Bewusstsein sozial-ökologischer Prozesse der Erdökologie bestimmt das gesellschaftliche Leben und sozial-ökologische Transformationsprozesse, sondern erst bestimmte gesellschaftliche Verhältnisse können ein Bewusstsein sozial-ökologischer Prozesse der Erdökologie ermöglichen, von dem aus sozial-ökologische Transformationsprozesse zu Wege gebracht werden können. Mit anderen Worten: ökosoziale Transformationen sind die zwingende Voraussetzung für ein sozial-ökologisches Verständnis der Erde, während betont werden muss, dass erst die begrifflich-normative Aussicht auf ein sozial-ökologisches Verständnis der Erde die subjektive Voraussetzung dafür bildet, die Notwendigkeit von ökosozialen Transformationen zu erkennen und anzuerkennen (subjektive Bildung).

Der hypothetische Begriff eines sozial-ökologischen Natursubjekts, der die Erde als allen - nicht nur der Menschen - gemeinsamer unorganischer Leib und allgemeines Wesenssubjekt (Marx 1983: 396) darzustellen sucht, ist die zwingende Voraussetzung und das normative Fundament eines möglichen sozial-ökologischen Verständnisses der Erde. Sozial-ökologische Transformationen, die eine praxisphilosophische Alltagspraxis der Gesellschaft ermöglichen wollen, dürfen daher nicht bei theoretischen Postulaten und/oder philosophischen Problemen anfangen, sondern im praktischen Alltag der gesellschaftlichen AkteurInnen und ihren darin erzeugten Residuen. Zugleich aber brauchen sie einen normativen Begriff, von dem aus eine Alltagspraxis als problematisch bewertet und verändert werden kann. Der Wahrheitsgehalt der philosophischen und theoretischen Untersuchen zur Erde als Allgemeines und allen gemeinsames Wesensubjekt muss sich daher in der Praxis erweisen können (Lefebvre 1987: 372; Bloch 1978: 250ff.), nicht zwingend in ihrer apriori-logischen und/oder empiristischen, d.h. postitivistisch-empirischen Plausibilität. Der hierin enthaltene Wahrheitsbegriff lässt sich mit Hörisch als ,apothekarische[n] Wahrheitsbegriff“ fassen, wonach Theorien und Theoreme als wahr gelten, wenn sie ,auf Heilsversprechen verzichten, aber uns zu helfen und zu heilen vermögen" (Hörisch 2010: 27). Heilen heißt im hier vorliegenden Kontext, ob und wie sie dazu beitragen, die gesellschaftliche Alltagspraxis auf kultureller Ebene sozial-ökologisch zu transformieren und

35 Kurze Zeit später schreiben Marx/Engels auch in der „Heiligen Familie“: „Wenn der Mensch aus der Sinnenwelt und der Erfahrung in der Sinnenwelt alle Kenntnis, Empfindung etc. sich bildet, so kommt es also darauf an, die empirische Welt so einzurichten, daß er das wahrhaft Menschliche in ihr erfährt, sich angewöhnt, daß er sich als Mensch erfährt. [...] Wenn der Mensch von den Umständen gebildet wird, so muß man die Umstände menschlich bilden. Wenn der Mensch von Natur gesellschaftlich ist, so entwickelt er seine wahre Natur erst in der Gesellschaft, und man muß die Macht seiner Natur nicht an der Macht des einzelnen Individuums, sondern an der Macht der Gesellschaft messen.“ (Marx/Engels 1962: 138) 
nicht nur das gesellschaftliche Leben, sondern das ganze Menschsein auf und mit der Erde zu erneuern helfen.

Der Begriff sozial-ökologischer Transformation umfasst dabei ökosoziale Transformationsprozesse (Kap. 6.1), geht ihnen aber durch die implizierte Praxis subjektiver Bildung zum einen voraus und zugleich auch einen notwendigen Schritt über sie hinaus und gelangt so überhaupt erst zu einem Umriss eines möglichen Anthropozäns, mit dem die gesellschaftlichen Ursachen des Klimawandels als Frage veränderter Stadtentwicklung bearbeitet werden kann und dabei den Menschen subjektiv exzentrisch positioniert, ohne dadurch zugleich den Sprung ins All zu vollziehen (Stichwort Kosmozän, Fischer 2018: 131ff.). Soziale Arbeit als sozial-ökologisch transformative Arbeit am terrestrischen Gemeinwesen (Gaia) muss damit zwar prioritär auf die politische Bildung des Ökosozialen fokussieren, darf zugleich aber auch die Ermöglichung der subjektiven Bildung am Ökosozialen niemals aus den Augen verlieren, da sie - wie sich mit May/Kunstreich (1999) zusammen fassen lässt - weder zwingend aus der politischen Bildung des Ökosozialen hervorgeht, noch eine politische Bildung des Ökosozialen je ohne subjektive Bildung am Ökosozialen zu verwirklichen ist.

Damit lässt sich die Frage sozial-ökologischer Transformation in zwei Kategorien aufspalten, ohne ihre innere Dialektik für ihre Verwirklichung dabei aus den Augen zu verlieren:

1. Politische Bildung des Ökosozialen: Was meint ökosoziale Transformation und wie ließ sie sich ermöglichen? (Teil B und $C$ )

2. Subjektive Bildung am Ökosozialen: Was meint sozial-ökologische Transformation und wie ließ sie sich ermöglichen? (Teil D)

Zielen die folgenden Teile B und C (1.) zuvörderst auf die politische Bildung von Strukturen ökosozialer Transformationen und der kollaborativen Bewirtschaftung des Ökosozialen, so zielt Teil D (2.) zuvörderst auf die subjektive Bildung zur politischen Hervorbringung eines nicht nur den Menschen umfassenden städtischen Gemeinwesens auf und mit der Erde.

\section{$7 \quad$ Fazit}

Der Begriff Anthropozän als Begriff eines Erdzeitalters, in dem die gesellschaftlichen Ursachen des Klimawandels bearbeitet werden, tritt auf theoretischer wie praktischer Ebene in mehrfacher Hinsicht als Gemeinwesenbegriff sozialer Nachhaltigkeit in Erscheinung, für die es zur Verwirklichung eine transformative Bildung auf historisch-revolutionärem Niveau bedarf. Dass „Soziale Arbeit sowohl thematisch wie forschungsmethodisch im Transfor- 
mationsdiskurs eine Rolle spielen könnte und müsste“ (Bartosch 2020: 23), dies aber nicht tut, ist daher ein Skandal historischen Ausmaßes!

Dass „Soziale Arbeit [...] als Profession für die Entwicklung der nachhaltigen Gesellschaft konkret wirken [kann], wie keine andere" (ebd.: 20), liegt in ihrer subjektorientierten Tradition begründet, der weder ein politischökologischer Bezug (Boulet et al. 1980: 293ff.), noch ein transformativmaterialistischer Bildungs- und Pädagogikbegriff (Sünker 1989, 2012; Winkler 1988, 2017, 2014; Richter 2001, 2015, 2019a, 2019b; May 2017b; Kunstreich 2005, 2006a, 2006b, 2018), noch die Forderung der „Notwendigkeit der Rückgewinnung des Territorialen in Form der Kommune" (Richter 2001: 144) fremd sind. Dennoch sind die fachlichen Positionen, die Soziale Arbeit ausdrücklich in der ,heutige[n] Soziale[n] Frage“, nämlich den „großen Transformationsprozesse[n]" der Klimaproblematik (Mührel 2020: 167) verorten, verschwindend gering.

Mührel benennt in diesem Kontext ,[z]wei zentrale sozialpädagogische Aufgaben“: ,zum einen die Sicherung sozialer Teilhabe und gesellschaftlicher Partizipation aller Menschen und gesellschaftlicher Gruppen", worin er eine „transgenerative Ethik“ angelegt sieht (ebd.: 168). Und „zum anderen die Erziehung und Bildung der Menschen zur Reflexion der Transformationsprozesse und ihrer innovativen Mitgestaltung" (ebd.: 168). Den Beitrag Sozialer Arbeit für die Antworten auf die großen Herausforderungen der Gegenwart sieht Mührel mit Natorp (Natorp 1922) in der „Konzeption eines politischen Programms einer Demokratie als Lebensform mit den Paradigmen Soziale Erziehung, Soziale Wirtschaft und Soziale Politik", mithin in einer ,genossenschaftlich organisierte[n] Gemeinschaft, die eine gleichberechtigte und solidarische Mitbestimmung der jeweiligen Akteure in den Bereichen der Erziehung und Bildung, der Wirtschaft und der politischen Willensbildung vorsieht" (Mührel 2020: 171f.).

Doch der tatsächlich vorfindliche Mainstream professioneller und disziplinärer Sozialer Arbeit ist von einem solchen Anspruch mehr als nur weit entfernt. Damit verpasst sie aber nicht nur theoretisch wie praktisch den Anschluss an die zentrale soziale Frage der Gegenwart, sondern, viel grundlegender, auch die Ursache sozial-ökologischer Problemlagen in Frage zu stellen. Die vorliegende Untersuchung will daher nicht nur versuchen, an das unabgegoltene Erbe der Gemeinwesenarbeit (May/Stock 2019) anzuschließen, sondern auch die marxistische Gesellschafstheorie dort fortzuführen, wo sie begonnen wurde: als Kritische Theorie gesellschaftlicher Naturverhältnisse, d.h. als gesellschaftstheoretische Kritik der kapitalistischen Vergesellschaftung der Erde, die nicht nur die Menschen auf der Erde knechtet und einander entfremdet, sondern auch die Bewohnbarkeit der Erde selbst aufs Spiel setzt. Zudem sucht sie nach möglichen Wegen, den Marxschen Anthropozentrismus sozial-ökologisch zu öffnen, um erst darin den Schritt von ökosozialen zur sozial-ökologischen Transformation zu vollziehen. 
Da mit der technizistischen Bearbeitungsweise der Klimaproblematik, samt aller damit verknüpften Probleme der Stadtentwicklung, nicht nur die biografischen Subjekte, sondern auch die Möglichkeit zur Bildung menschlicher Subjektivität abermals übergangen zu werden droht, muss die Klimafrage und die Frage der Verwirklichung menschlicher Subjektivität zu einer Frage sozial-ökologischer Stadtentwicklung verbunden werden, die die Frage nach ökosozialen Transformationen des Gesellschaftlichen in sich aufhebt. 


\section{Teil B}

Mit Lefebvres „Recht auf Stadt“ zur ökosozialen und sozial-ökologischen Transformation? 



\section{Weiterführende Zusammenfassung von Teil A}

Im Folgenden wird Teil A verdichtend zusammengefasst und zugleich in Teil B eingeführt. Teil A läuft darauf hinaus, dass die Klimafrage mit der Frage nach den Möglichkeiten emanzipatorischer Subjektbildung und der Politisierung der Bedingungen ihrer Verwirklichung in der Frage nach der Verwirklichung menschlicher Subjektivität aufgehoben und zu einer Frage sozialökologischer Stadtentwicklung, die sich ökosozialer Strategien bedient, verdichtet werden muss, um dadurch die Frage beantworten zu können, wie sich ein Anthropozän, d.h. eine weltweit politisch organisierte soziale Nachhaltigkeit im Maßstab eines planetarischen Gemeinwesens zu Wege bringen ließe. Im Anschluss zeigte sich, dass die Frage sozial-ökologischer Stadtentwicklung in zwei Schritte aufgeteilt werden müsste: in ökosoziale gesellschaftliche Transformationen, die auf die politische Aneignung und gemeinwesenorientierte Bewirtschaftung von Gemeingütern zur emanzipatorischen Verwirklichung menschlicher Subjektivität insistiert, und eine darin verschränkte sozial-ökologische gesellschaftliche Transformation, die den Menschen zwar als zentralen Akteur ökosozialer Politik setzt, sich aber dennoch seiner nur dezentralen Position bewusst ist und seine Politik Sozialer Ökologie danach ausrichtet.

Die Ausgangsfrage der vorliegenden Studie und auch von Teil A war die gegenwärtig aktuelle Klimafrage: Was bedeutet der Klimawandel für unsere Lebensweisen auf und mit der Erde? Nähere Nachforschungen haben ergeben, dass der Klimawandel nur insofern anthropogen verursacht ist, als dass es bislang nicht gelungen ist, die Kreisläufe des Kapital(re)produktionsprozesses zu politisieren. Das hat zur Folge, dass das dem Kapitalbildungsprozess inhärente Wachstumsparadigma innerhalb weniger Jahrhunderte zu geologischen und klimatologischen Veränderungen geführt hat, durch die sich in den kommenden Jahrzehnten die Bewohnbarkeit des Planeten der kommenden Epochen der Erdgeschichte in qualitativer (wie) und quantitativer (auf wieviel bewohnbarer Fläche und zu welchen klimatologischen Bedingungen) Hinsicht entscheidend verändern werden. In dieser Hinsicht wird in den vorherrschenden Klimadiskursen oft von einem Anthropozän gesprochen, wonach es der Mensch bzw. die Menschheit sei, die den Klimawandel versursacht habe. Bei genauerer Betrachtung zeigt sich aber, dass es vor allem westlich kapitalisierte bzw. westlich städtische Lebensweisen sind Brand/Wissen 2017 fassen sie als ,imperiale Lebensweise“ zusammen -, die im Kontext einer seit dem ausgehenden Mittelalter durchgesetzten „Urbanisierung des Kapitals“ (Harvey 2014: 126) den rasanten Klimawandel hervorgebracht haben und aufrechterhalten. Statt von einem Anthropozän muss daher stattdessen von einem Kapitalozän gesprochen werden. 
Wenn in Teil A herausgestellt wurde, dass die gegenwärtige Klimafrage maßgeblich durch eine urbane „,imperiale Lebensweise“ (Brand/Wissen 2017), und die wiederum aus den Sachzwängen der „Urbanisierung des Kapitals" (Harvey 2014: 126) hervorgegangen ist, dann lässt sich die Klimafrage maßgeblich als eine Stadtentwicklungsfrage formulieren, die auf die grundlegende gesellschaftliche Transformation des Städtischen, d.h. des städtischen Lebens und dessen sozialen wie ökologischen Voraussetzungen und Folgen, insistieren muss. Mit anderen Worten: Wenn das Klima aber nicht nur um des Menschen Willen (gar nur um der Erde Willen), sondern um der Erde als Wohnraum sympoietischer Entwicklungsdialektik menschlicher Lebensweisen und nicht-menschlicher Lebensformen Willen zum Politikum gemacht werden will, muss die Klimafrage mit der Bildungs- und Politisierungsfrage und mit der Frage nach der Verwirklichung menschlicher Subjektivität als ökosoziale Stadtentwicklungsfrage zu einer sozial-ökologischen Stadtentwicklungsfrage auf und mit der Erde zusammengebracht werden (Kap. 4.4). Darin ließe sich erst die Frage nach dem Anthropozän konkretisieren, das der Klimawandel zwar als allgemeine objektive Möglichkeit in Aussicht stellt, das aber im konkreten urbanen Alltagsleben erst konkretisiert werden muss. Vor allem dadurch, dass es den Menschen in den jeweiligen Städten gelingt, ihre imperiale Alltagspraxis aus ihren je städtisch spezifischen Reproduktionszwängen der global strukturierten und lokal konkretisierten ,imperialen Lebensweise" (Brand/Wissen 2017) zu befreien. Nämlich indem sie als Stadt, d.h. durch ein städtisch-kommunales Lebens je stadt-spezifische Subsistenzformen und ökosoziale Transformationspfade entwickeln können, an und mit denen sie sich als erdbewusste Wesen herausbilden und ihre ökosoziale Stadtentwicklung dahingehend zuspitzen können, dass sie als Menschen zwar nur exzentrisch positionierte Gattungswesen unter exzentrisch positionierten Gattungswesen sind, zugleich aber der politisch elementare Teil des Gemeinwesens Erde, der seine tellurische Macht erkannt und politisch unter Kontrolle gebracht hat. Erst unter diesen Bedingungen ließe von einer sozialökologischen Transformation sprechen, weil sie das Politische nicht mehr nur menschenzentriert organisiert.

Die Teil A eingeführte analytische Auffächerung des Transformationsbegriffs in ökosoziale und sozialökologische Transformation darf also nicht aus dem dialektischen Zusammenhang beider Aspekte gerissen werden. Pointiert zusammengefasst: Als ökosoziale Transformation wird das Herstellen von urban und global commons durch eine (kommunal-)genossenschaftlich verfasste kollaborativ-demokratische Gemeinwesenökonomie bezeichnet, die das Ökonomische nicht länger in den Dienst der Kapital(re)produktion stellt, sondern in den Dienst der emanzipatorischen Entwicklung der Menschen auf und mit der Erde. Ökosoziale Transformationen sind die notwendige durch Stadtentwicklung hervorgebrachte gesellschaftstransformative Voraussetzung sozial-ökologischer Subjekt- und Politikbildung, die den historisch gewach- 
senen und gesellschaftlich verwachsenen Anthropozentrismus zu überwinden suchen. Als sozial-ökologische Transformation wird das Herstellen einer Politik Sozialer Ökologie bezeichnet, bei der nicht mehr nur der Mensch und menschliche Maßstäbe das Zentrum des Politischen resp. der Stadtentwicklung bilden, d.h. der Verwaltung und Nutzungsregulierung von urban und global Commons, sondern auch die nicht-menschliche Mitwelt. Das Herstellen einer solchen Politischen Ökologie muss dabei als politischer Subjektbildungs- und subjektiver Politikbildungsprozess verstanden werden, für den entlang der transformativ-politischen Bildung des Ökosozialen eine transformative (Subjekt-)Bildung am Ökosozialen ermöglicht werden muss. Entsprechend soll in Weiterentwicklung des von May/Kunstreich (1999) formulierten Ansatzes „Sozialer Arbeit als Bildung des Sozialen und Bildung am Sozialen" Soziale Arbeit begriffen werden als politische Bildung des Ökosozialen zur sozial-ökologischen Bildung am Ökosozialen, mithin als sozialökologische Arbeit am terrestrischen Gemeinwesen, Gaia. Ökosoziale Transformationen (Bildung des Ökosozialen) sind dabei die Voraussetzungen für sozial-ökologische Subjekt- und Politikbildung (Bildung am Ökosozialen), zugleich ist eine sozial-ökologische Subjekt- und Politikbildung die Voraussetzung für die Herausbildung eines Anthropozäns. In dieser emanzipatorischen Hinsicht wird mit dem Begriff Anthropozän also die konkrete Utopie einer erdgeschichtlichen Epoche umrissen, die den Versuch einer Politik Sozialer Ökologie unternimmt, bei der die Erde als sympoietischer Komplex begriffen wird, deren zentraler politischer Akteur zwar der Mensch ist, seine Politik aber nicht länger nur die gedeihliche Entwicklung des Menschen, sondern die des gesamten Planeten fokussiert. Was das genau heißt, soll in den folgenden Kapiteln und Teilen auf theoretischer bzw. theoretisierender Ebene umrissen werden, indem zunächst auf das Arbeitsprinzip kollaborativer Partizipation eingegangen wird und daran anschließend entlang eines konkreten Transformationsvorschlages des WBGU eine Kritik entwickelt wird, aus der die weitere Argumentation der vorliegenden Studie erst konkretisiert werden kann.

\section{Kollaboration als Arbeitsprinzip Sozialer Arbeit}

Kunstreich/May unterscheiden die Arbeitsweisen Sozialer Arbeit anhand eines ,sozialen Kode[s] ,Für“", der, indem er ihre Probleme privatisiert, die „Themen und Tendenzen der Herrschaft“ in der Einzelfallarbeit „verschlüsselt“, und eines „,sozialen Kode[s] ,Mit““, der die „Themen und Tendenzen der Befreiung“ fokussiert und die ,wechselseitige[] Anerkennung der in einem Setting Beteiligten als gleichwertig, aber unterschiedlich“, ins Zentrum 
der gemeinsamen Arbeit rückt (Kunstreich/May 2020: 49f.). Dadurch wollen sie das im ,sozialen Kode ,Für“" verschlüsselte Fachkraft-Klienten-Verhältnis aufbrechen (ebd.), um so allen Beteiligten durch die im ,sozialen Kode ,Mit'“" eröffnete kollaborative Bildung des Sozialen eine Subjektbildung am Sozialen zu ermöglichen (Kunstreich/May 1999). Vor dem Hintergrund der in Kap. 4 herausgestellten Subjektorientierung Sozialer Arbeit sollte deutlich geworden sein, dass die als notwendig herausgestellten Stadtentwicklungsprozesse ökosozialer und sozial-ökologischer Transformationen nur kollaborativ entlang eines „sozialen Kode[s] ,Mit““ (Kunstreich/May 2020: 49f.) verwirklicht werden können.

Unter Kollaboration wird mit Rohr ein demokratisches Partizipationsprinzip verstanden, bei dem ,die Menschen die Möglichkeit zur aktiven Mitgestaltung durch ihre konkreten Potentiale erhalten" (Rohr 2012):

„Kollaborative Prozesse setzen bewusst auf die sehr unterschiedlichen Kompetenzen und Potenziale der Menschen, lassen diese zu und fördern sie, Teilhabe und Gestaltungsmacht ist nicht mehr ausschließlich abhängig von der eigenen Artikulationsfähigkeit oder von den kognitiven und intellektuellen Kompetenzen. Kollaborative Prozesse sprechen weitaus stärker als deliberative Prozesse auch die sozialen, praktischen und emotionalen Fähigkeiten der Menschen an. Wenn Aktivitäten wie Bauen, Zeichnen, Erinnern, Handwerken, Geschichtenerzählen, Messe, Reparieren, Träumen und sinnliches Wahrnehmen neben Diskutieren, Analysieren und Schreiben eine starke Rolle im Prozess einnehmen, können mehr Menschen etwas beitragen und aktiven Einfluss auf die Ergebnisse nehmen. Die Ergebnisse werden dadurch vielschichtiger, inklusiver und integrativer, und sie haben stärken Bezug zu den Menschen und Orten, an denen und durch die sie entstehen." (Rohr 2013: 34f.)

Damit geht der Kollaborationsansatz nicht nur über das „Particitainment“ (Selle 2013: 276f.) der üblichen deliberativen Stadtentwicklungsprozesse hinaus, sondern „definiert den politischen Prozess grundsätzlich neu“:

„Meinungsbildung geschieht nicht ausschließlich deliberativ, sondern über eine gemeinsame, methodisch vielfältige Auseinandersetzung mit dem jeweiligen Themenkomplex. Das Ziel dieser Auseinandersetzungen ist jedoch nicht, für eine Partei, ein Milieu oder eine Fachdisziplin eine gemeinsame Meinung zu generieren, die dann gegen andere Meinungen vertreten wird, sondern eine gemeinsame Verständnisbasis über Partei-, Milieu- und Fachgrenzen hinweg zu schaffen, die die Grundlage für die Entwicklung von konkreten Lösungen ist.“ (Rohr 2012)

Mit diesem Anspruch legt der kollaborativ-demokratische Partizipationsbegriff - ganz dem Anspruch einer die Produzierendenpolitiken übergreifenden Politik des Sozialen (Kap. 6.1) - keinen Begriff des Politischen fest, sondern stellt dies der Aushandlung der kollaborierenden AkteurInnen anheim, womit ihnen gerade darin ,ein hohes Maß an gesellschaftlicher Teilhabe und Gestaltungsmacht" ermöglicht wird, ohne die je subjektiven, d.h. milieuspezifischen Interaktionsformen, die gerade in männlich dominierten Milieus, durchaus martialisch und zunächst wenig demokratisch geprägt sein können, von vornherein (herrschaftlich) zu überformen oder durch eine vorbestimmte abverlangte Demokratieform gar auszuschließen. Entsprechend bestimmt ein kollaborativer Demokratiebegriff den Begriff des Politischen über die Kritik 
und den Widerstand am Prozess negativ: „Kollaboration hört dort auf, wo Widerstand anfangen muss" (Rohr 2013: 30). Das, was Kollaboration ist, füllt sich mit ihren AkteurInnen in actu. Durch die anvisierte Subjektorientierung kann überhaupt erst der Anspruch eines Subjektbildungsprozess aller oder wenigstens möglichst vieler - StadtbewohnerInnen realisiert werden. Vor allem auch jenen, die von den eher bürgerlich sozialisierten AkteurInnen und Gruppen geprägten Klimadiskursen nur allzu leicht übergangen werden, weil sich ihre Produzierendensozialpolitik nicht durch Forderungen zur nachhaltigen Lebensweise per Selbsteinsicht, d.h. ohne Förderung der Subjektbildung und ohne Förderung Subjektbildung ermöglichender Transformationen imperialer gesellschaftlicher Verhältnisse in die Klimafrage einpflegen lassen und daher nur allzu leicht als vermeintliche KlimawandelleugnerInnen etikettiert und im Transformationsprozess zurückgelassen werden. Stattdessen versteht sich kollaborative Partizipation als

„,normativer Beitrag zu einer offeneren, transparenteren, solidarischeren und demokratischeren Gesellschaft, in der die Einzelnen ein hohes Maß an gesellschaftlicher Teilhabe und Gestaltungsmacht erhalten, die sich in gemeinsamen gesellschaftlichen Verstehens-, Auseinandersetzungs- und Lernprozessen entfaltet“" (Rohr 2012),

und damit überhaupt erst die Perspektive der Verwirklichung ihrer Residuen im Stadtentwicklungsprozess entlang der Klimafrage eröffnet.

Kollaborative Stadtentwicklungsansätze finden sich seither auch in den Empfehlungen des Umweltbundesamtes, die sie herausstellen als „durch eine aktive Zusammenarbeit aller Teilnehmenden", die

„Arbeitsmethoden beinhalten [können], die [...] über den Austausch von Informationen, Meinungsäußerungen und eine auschließlich[sic!] gesprächsorientierte Auseinandersetzung hinaus[gehen]. Stattdessen führen die Teilnehmenden methodische Arbeitsschritte analog zu den Tätigkeiten professioneller Entwickler und Gestalter durch. Sie analysieren, vermessen, recherchieren, interviewen, entwerfen und entwickeln Maßnahmen, Projekte oder Planungen." (Rohr et al. 2017: 29f.)

Auch der WBGU spricht sich in seinem Hauptgutachten zur „Transformativen Kraft der Städte“ (WBGU 2016b) - unter Bezug auf White (1996), Cornwall (2008) und Herrle (2015) - auch für eine ,transformative Partizipation“ und „Kollaboration“ im Stadtentwicklungsprozess aus, bei der „zivilgesellschaftliche Akteure die Agenda und Prioritäten setzen und auf Augenhöhe mit städtischen Entscheidungsträgern und Unternehmen [...] agieren“" (ebd.: 115).

Als „Arbeitsprinzip Partizipation“ findet sich der kollaborative Partizipationsansatz, der auf die „Praxis gemeinsamer Aufgabenbewältigung“ hinarbeitet (Kunstreich/May 2020), allerdings schon von Anfang an in der Settlement-Bewegung Addams' und seit Jahrzehnten auch in den Theoriediskursen Sozialer Arbeit wieder (Kap. 4). Kunstreich/May fassen es wie folgt zusammen: 
„Das Arbeitsprinzip Partizipation hingegen geht davon aus, daß es Leitlinie jeder/jedes Professionellen in der sozialen Arbeit sein kann, die/der Settings schafft, in denen Verständigung [...] möglich wird, und ihre/seine Handlungsorientierung [...] an den Konfliktregelungskompetenzen der Adressaten gewinnt. Wie die konkrete Ausprägung der Assistenz [...] in der Gestaltung oder Neugewinnung von Sozialitäten aussieht, wird von der ,Federführung ' der Mitglieder in diesen Sozialitäten abhängen und davon, was Partizipation aus der Perspektive der AdressatInnen tatsächlich bedeutet. Nur wenn deren Anliegen oder Themen mit der Problemsetzung (nächster Abschnitt) getroffen wird, werden sich soziale Kategorisierung, soziale Identität ${ }^{36}$ und sozialer Vergleich in Richtung eines egalitären Gerechtigkeitsbildes anreichern. Die Sozialität, in der sich die/der Einzelne sich ihrer/seiner Einmaligkeit versichert, ist aus der Perspektive dieses Arbeitsprinzips die fundamentale Form der Partizipation und damit das reale ,Gemeinwesen'. Erst auf dieser Basis gewinnt die Dimension des Territoriums als sozialer Raum, als Raum der Aneignung (vgl. BÖHNISCH/MÜNCHMEIER 1990), Bedeutung." (Kunstreich 2014: 272f.; vgl. auch Kunstreich/May 2020)

Der darin zum Ausdruck kommende Ansatz ,Sozialer Arbeit als Bildung des Sozialen und Bildung am Sozialen [...], der den gesamten Lebenszusammenhang der Menschen - und damit auch das in den Institutionen und der Privatheit Kasernierte - durchdringt und aufsprengt“ (Kunstreich/May 1999: 50), hebt die schon zuvor in der Sozialen Arbeit diskutierten und praktizierten „spezifischen Formen des Arbeitsprinzips GWA“ (Boulet et al. 1980: 291ff.) auf die Ebene einer übergreifenden kollaborativen Politik des Sozialen (May 1997b, 1997a), die zur Einlösung des noch unabgegoltenen Erbes der Gemeinwesenarbeit (zum Überblick: May/Stock 2019) den Fachkräften Sozialer Arbeit die „Freiheit“ eröffnen soll,

„mit den AdressatInnen Sozialer Arbeit in der Weise an ihren Problemen arbeiten zu können, daß es möglich wird, eine an ihren konkreten Erfahrungszusammenhängen anknüpfende, aber auf kollektiven gesellschaftlichen Ausdruck ihrer individuellen Interessen und Bedürfnisse gerichtete Öffentlichkeit herzustellen, um damit zugleich individuell wie gesellschaftlich in der Problembewältigung voran zu kommen [...].Das von uns skizzierte „Arbeitsprinzip Partizipation" läßt sich in dieser Weise als eine solidarische Professionalität nur im Widerspruch der Institution verwirklichen. Letztendlich muß es - ebenso wie Heydorn (1972: 151) dies für die Bildung eingeklagt hat - darauf zielen, die Institution ,als zerbrochenes Gerät ' hinter sich zu lassen. [...] Nur in einer solchen Politik des Sozialen, in die alle Tätigkeiten der Auseinandersetzung mit innerer und äußerer Natur hineingezogen werden, wird Bildung zur Selbsthilfe, zu Selbsttun und Selbstversuch. Und nur als eine derartige Selbstbildung am Sozialen kann diese sich vermittels

36 Dem Begriff der sozialen Identität ist durchaus kritisch zu begegnen, da der Begriff der Identität andeutet, man könne sich mit etwas identisch machen resp. in-eins setzen. Wie in Kap. 5 mit dem Begriff der Nicht-Identität dargelegt, lässt sich einer Sache aber immer nur mimetisch aneignen, um sich mit ihr symbolisierend subjektiv auszudrücken. Wo eine Subjektbildung durch eine symbolische Repräsentation von den AkteurInnen als gelungen erlebt wird bzw. wo es gelingt, die eigene Subjektivität mit einer Sache symbolisch repräsentierend auszudrücken, lässt sich daher eher von einer Identifikation mit einer Sache sprechen, bei der sich eine Sache dergestalt angeeignet wird, dass es durchaus so erscheinen kann, als ob Sache und Selbst identisch sei. Tatsächlich aber bleibt stets ein Residuum von Nicht-Identischem. Statt von sozialer Identität wäre entsprechend von einer (mimetischen) Identifikation mit einer Sozialität durch eine vom Subjekt so erlebte gelungene gemeinsame Raumproduktion in Form der Kommune zu sprechen. 
transversaler Sozialitäten als Bildung des Sozialen in eine autonome Vergesellschaftung auf historischem Niveau umsetzen.“ (Kunstreich/May 1999: 50)

Die Klimafrage, so ließe sich nachschieben und Teil A weiter ergänzend zusammenfassen, ist eine Frage, die entlang der Aussicht auf die politische Verwirklichung eines menschlichen Gemeinwesens durch Subjektbildung und die Politisierung ihrer Bedürfnisse zu einer Frage kollaborativer ökosozialer- und sozial-ökologischer Stadtentwicklung verdichtet werden muss und die Antworten auf historischem Niveau verlangt, welche eine Politik Sozialer Ökologie ermöglichen und damit die Erdepoche des Anthropozäns eröffnen.

\section{Kollaborative Stadtentwicklung im Transformationskonzept des WBGU}

2016 legte der WBGU als Fortschreibung seines Gutachtens von 2011 zur „Welt im Wandel - Gesellschaftsvertrag für eine Große Transformation“ (WBGU 2011c) ein umfassendes gutachterliches Konzept zum „Umzug der Menschheit in die Städte“ vor und stellt dabei die „transformative Kraft der Städte“ heraus, die es vermögen, entlang einer ,polyzentrische[n] Organisation des Urbanen" soziale Fragen und Klimafragen zu einer Frage revolutionär-transformativer Stadtentwicklung zusammenzuführen, die er zugleich zum „Forschungsthema ersten Ranges“ (WBGU 2016b: 41) erklärt.

\subsection{Problemaufriss des WBGU: plutokratische Gesellschaftsverhältnisse als Hindernis von klimaorientierter Armutsbekämpfung}

Für eine solche Zusammenführung der Klimafrage mit sozialen Fragen sieht es der WBGU als notwendig an, Armutsbekämpfung nicht nur in der ,Überwindung städtischer Armut“, sondern auch in der Bekämpfung ,neu hinzukommende[r] multiple[r] Risiken, wie z. B. Umweltrisiken“" (ebd.: 169; zum aktuellen Überblick der der multiplen Risiken: UBA 2019) zu erblicken. Zur Bekämpfung sozioökonomischer Ungleichheiten wird dabei die Herstellung des ,universellen Zugang[s] zur Grundversorgung mit Infrastrukturen und Dienstleistungen“ hervorgehoben, so etwa „Wohnen [...], Wasser- und Sanitärversorgung, Gesundheitsversorgung, Abfallmanagement, klimaverträgliche Energiedienstleistungen und Transport sowie Kommunikationstechnologien“ (WBGU 2016b: 170). Desgleichen zeigen sich sozioökonomische 
Ungleichheiten aber auch in anderen Bereichen, so etwa - gerade vor dem Hintergrund der weiteren Klimaerwärmung - in klimatisierten Arbeitsplätzen und Wohnungen, die offensichtlich nicht jeder Bevölkerungsgruppe gleichermaßen zugänglich sind. Zugleich öffnet sich hierbei das Problem, dass, wenn jedem Haushalt und Arbeitsplatz eine Klimatisierung ermöglicht wird, sich der Energieverbrauch sehr stark erhöht, so dass der Ausbau erneuerbarer Energien damit umso dringender wird. Entsprechend schlägt der WBGU die politische Herstellung kommunaler Gegenstrategien vor, die alle Bevölkerungsgruppen mit ihren jeweiligen Lebens- und Interaktionsweisen berücksichtigt. Das heißt nicht nur, dass für die „,wirtschaftliche Entwicklung“ einer Stadt die „Bedeutung der informellen Wirtschaft anerkannt und adäquat berücksichtigt“" werden muss, sondern auch, „dass neben allen anderen Akteuren (z.B. nationale Regierungen, private Investoren, internationale Durchführungsorganisationen) auch städtische Armutsgruppen eine Stimme erhalten und die Verbesserung ihrer Lebensbedingungen mitgestalten können" (ebd.). Etwa dadurch, dass eine „urbane Wirtschaftspolitik“ den Kommunen ermöglichen muss, „Armut, Arbeitslosigkeit, soziale Deprivation und Vulnerabilität durch Förderprogramme zur Beschäftigung Jugendlicher, zur Stärkung der Handlungskapazitäten marginalisierter Gruppen und zur Förderung von Geschlechtergerechtigkeit [...] bekämpfen“" zu können (ebd.).

Eine solche vergleichsweise umfangeiche Form der Armutsbekämpfung setzt allerdings die volle Handhabe der StadtbewohnerInnen über die Flächennutzung und bauliche Gestaltung der Städte voraus. Wie aber in Kap. 3 bereits herausgestellt wurde, ist die baulich-räumliche Gestalt der Städte maßgeblich vorgeprägt durch die Vernetzung der Städte durch Wasserleitungen, Kanalisationen, Stromtrassen, Straßen und Gleisbettanlagen und den daraus entstandenen Sachzwängen des weiteren Städtebaus, die die transformative Umgestaltung der Städte „erheblich[]“ vorprägen und „die auf lange Sicht schwierig zu ändern sind“ (ebd.: 167), weil diese ,raumstrukturelle[n] Weichenstellungen“ auch „das kommunale und planerische Handeln“ vorprägen (Schott 2014: 303). Hinzu kommt ein mit der kapitalogenen Industrialisierung der Städte einhergehendes urbanes Machtverhältnis, das Benevolo (Benevolo 2007: 813) als ,postliberale Stadt" auf den Begriff bringt und das die Rechtslage der Stadtverwaltungen, auf die Nutzung der Flächen Einfluss zu nehmen, bis heute stark begrenzt, während ,,[g]leichzeitig [...] die Eigentümerin die Möglichkeit [hat], andere von der Nutzung der Fläche auszuschließen“ (WBGU 2016b: 173). Zwar kann die „Verfügungsgewalt der Grundeigentümer [...] durch hoheitliche Regelungen gestaltet und begrenzt werden, zum Beispiel zum Wohle der Allgemeinheit“, allerdings sind „solche Instrumente [...] eher schwach ausgestaltet und haben in der Praxis kaum Auswirkungen“, was „dazu [führt], dass die Steuerbarkeit der städtischen Entwicklungen durch staatliche Akteure begrenzt ist" (ebd.: 186). Erschwerend kommt zudem noch die ,weltweite[e] Zunahme an nationalen und inter- 
nationalen spekulativen Boden- und Immobiliengeschäften“ (ebd.: 174) hinzu. Aus der Annahme, ,dass 60-70 \% der Bankgeschäfte in Industrieländern im Zusammenhang mit Boden- und Immobilienspekulation stehen“ (ebd.), leitet der WBGU die Prognose ab, dass

„der Einfluss von großen Immobilieninvestoren in den Metropolen vieler Industrie- und Schwellenländer so prägend [ist], dass Stadtverwaltungen und andere Verantwortliche eine am Menschen orientierte, nachhaltige Stadtentwicklung und gute Lebensqualität nicht mehr hinreichend beachten werden“ und „Anlass zur Sorge“ gibt (ebd.: 8).

Zwar mangelt es weder an boden- und baupolitischen Reformvorschlägen (etwa DIfU 2017; Deutscher Städtetag 2017), aber sie mildern das Problem bloß auf der Oberfläche ab. Stadtentwicklung bleibt dadurch weiterhin ein postliberal strukturiertes und repräsentatives Projekt, das zwar die Einflussnahme der Stadtverwaltungen zu stärken beansprucht, letztlich aber auf der Ebene deliberativer Partizipation verbleibt und die Belange sowie emanzipatorischen Bedürfnisse der StadtbewohnerInnen dennoch bloß indirekt in den Entwicklungsprozess der Städte einfließen lässt. Mit anderen Worten: Die Bildungs- und Politisierungsfrage der Subjekte bleibt ungestellt, weil Stadtentwicklung weiterhin auf einer repräsentativen Ebene verbleibt.

Dagegen macht der WBGU in seinem Gutachten mehrere Transformationsvorschläge und knüpft sie an die Forderung einer ,polyzentrische[n] Organisation des Urbanen“ (WBGU 2016b: 41), die eine gesellschaftliche Reichweite beansprucht und auch globalpolitisch ausgreift, womit einem planetaren Problem wie dem Klimawandel ja erst gerecht werden kann.

\subsection{Kritische Betrachtung der Transformationsvorschläge des WBGU}

Als "Gegenmodell zum privaten Eigentum an Flächen“ sieht der WBGU „öffentliches Grundeigentum“ an (ebd.: 173). Für das Generieren öffentlichen Grundeigentums mit oder gar trotz der für transformative Zwecke hinderlichen Privateigentumsstrukturen an städtischen Flächen, schlägt der WBGU mehrere Prinzipien transformativer Flächennutzung vor:

- „Flächenverbrauch durch dezentrale Konzentration und Revitalisierung minimieren“, mit dem Ziel ,einseitige Konzentrationen zu vermeiden und eine ausgeglichene, polyzentrische Raum- und Siedlungsstruktur zu entwickeln“ (ebd.: 180).

- „Gemeinwohlorientierung urbaner Flächen“, bei der zur „Wiedererlangung öffentlicher Gestaltungsmacht in von privaten Investitionsinteressen geprägten Stadträumen“ „Interessenskonflikte zwischen Politik, 
Verwaltung, Bürgern und Privatwirtschaft bei der Flächennutzung [...] berücksichtigt werden [müssen]“ (ebd.: 181).

- „Flexibilisierung der Flächennutzung: urbane Frei- und Begegnungsräume schaffen“, um so die „Gefahr“ zu reduzieren, dass mit der „Privatisierung öffentlicher Räume“ der „Ausschluss bestimmter Bevölkerungsgruppen" verbunden sind (ebd.).

- „Urbane Eigentumsmodelle diversifizieren“, indem „,der - auch private Erwerb von Eigentum an städtischem Grund und Boden durch nachhaltige Kriterien und unter vielfältigen Bedingungen erfolgt", etwa durch „eine Sozialverträglichkeitsprüfung bei Grundstücksverkäufen“, ,[u]m Stadtflächen der einseitigen Gewinnlogik privater Eigentümer zu entziehen und sie wieder stärker dem Gemeinwohl zuführen zu können“" (ebd.: 182).

- „Nutzungsregulierungen“ unter der „Beteiligung aller relevanten Akteure, unabhängig von wirtschaftlicher oder politischer Macht, bei der Erarbeitung von Plänen sowie verbindliche Einbeziehung der Dialogergebnisse“ (ebd.). Das verlangt die „Einbeziehung informeller Praktiken“ (ebd.: 183) in die Nutzungsregulierungen, so dass sich die entsprechenden politischen Erarbeitungsprozesse der Regulierungen durch die Anerkennung soziokultureller Interaktionsformen und eine Milieusensibilität auszeichnen müssen.

- „Zwischennutzung“ „von Gebäuden oder Flächen, deren ursprüngliche Nutzung aufgegeben wurde, und deren anderweitige Nutzung temporär gestattet wird, bis die Nachnutzung realisierbar ist (ebd.). Etwa durch „Shared Space“-Projekte „als Planungsansatz, der die Zwischen- und Mehrfachnutzung öffentlicher Räume“, durch eine gemeinsame Raumnutzung ,ermöglichen soll“ (ebd.: 184).

- Ermöglichung von „Urban Commons“, wobei es dem WBGU „weniger um die Stadt als Ressource [geht], sondern vielmehr um die Prozesse (urban commoning), in denen sich Gruppen von Stadtbewohnern die Verantwortlichkeit über urbane Projekte teilen“ und die sich auf „z.B. Gemeinschaftsgärten, Car-Sharing-Konzepte, Food-Kooperativen, oder darüber hinaus auf gemeinschaftlich geregelte Nachbarschaften beziehen“( (ebd.).

Da es hierbei seitens des WBGU bewusst nicht um die Stadt als Gesamtressource geht, bleibt das vielfach kritisierte Hindernis des Privateigentums städtischen Grund und Bodens im transformativen Praxiskonzept gänzlich unverständlich. Das bleibt gerade auch im Zusammenhang mit der Forderung des WBGU unverständlich, dass ,,[i]Im Rahmen einer transformativen Flächennutzungsgestaltung [...] von Seiten der Stadtverwaltungen aktiv Steuerungsmechanismen geschaffen werden [sollten], die eine Ausweisung und Sicherung von öffentlichen Räumen sowie von urbanen Gemeinschaftsflä- 
chen ermöglichen, die sich einer marktwirtschaftlichen Verwertungslogik entziehen" (ebd.).

Der Staat wird bei all diesen vorgeschlagenen Transformationsprojekten „als Garant eines Möglichkeitsraumes zur Entwicklung von Gemeinschaftsgütern“ und der „Schaffung urbaner Laboratorien zu bestimmten urbanen Themen" beansprucht, in denen die „Regelungen zur nachhaltigen Bewirtschaftung [...] primär durch die Gruppen selbst bestimmt werden [sollten], damit Freiräume für eine transformative Entwicklung erhalten bleiben“" (ebd.). Allerdings werden die historischen Verflechtungen privatwirtschaftlicher Interessen mit den staatlichen Institutionen kaum thematisiert. Aber auch wenn die nationalstaatliche Einbettung des städtischen Gesamtkontextes vom WBGU kaum in den Blick genommen wird, so sind doch die von ihm vorgeschlagenen ,gemeinschaftsbasierte Wohnformen“ (ebd.: 185) die notwendige Voraussetzung, um mit dem Zusammenschluss der Wohnprojekte und der sie bedingenden subsistenten Infrastrukturen und Flächen die Stadt als Ganzes sukzessive zu commonisieren. Nur so ließe sich die kollaborative Regulierung der urbanen Flächennutzung tatsächlich allen - oder wenigstens möglichst vielen - StadtbewohnerInnen an die Hand geben. Doch damit wäre das Ansinnen des WBGU bereits überstiegen. An dem Fokus auf ,[g]emeinschaftsbasierte Wohnformen" lässt sich aber dennoch festhalten, weil sie den „private[n] Wohnbereich zugunsten der gemeinschaftlichen Bereiche für die soziale Interaktion reduzier[en]", was zum einen den Verbrauch städtischer Wohnflächen reduziert und zum anderen ,der wachsenden sozialen Isolation entgegen“ tritt und darüber hinaus die „Möglichkeit“ bietet, „finanzielle, soziale (z. B. gemeinsame Kinderbetreuung, Unterstützung älterer Menschen) und ökologische (z. B. geringerer Ressourcenverbrauch durch gemeinsam genutzte Küchengeräte, geringerer Flächenverbrauch) Vorteile miteinander zu kombinieren" (ebd.).

Als Organisationsformen plädiert der WBGU neben den Baugemeinschaften und Beteiligungsgesellschaften (etwa dem Mietshäuser Syndikat), vor allem für die Genossenschaft, da sie durch ,,ihre demokratischen Strukturen [...] sicher[stellen], dass die Bewohner die Entwicklung und Gestaltung ihres Zuhauses mitbestimmen können“ (ebd.: 394). Schließlich fordert der WBGU sogar, ,[n]eue oder wiederentdeckte Formen alternativer Ökonomie (genossenschaftliche Strukturen, Regionalgeld, Selbstversorgungsdynamiken) $[\ldots]$ zu erforschen“ (ebd.: 455).

Damit sind die Forderungen des WBGU nahtlos anschlussfähig an das ökosoziale Nachhaltigkeitsparadigma Sozialer Arbeit (Elsen 2018), das sich zugleich die „Notwendigkeit der Rückgewinnung des Territorialen in Form der Kommune“ (Richter 2001: 144), d.h. in Form demokratischer Mittel der politischen Partizipation im Hinblick auf eine kommunale Subjektbildung aller StadtbewohnerInnen durch die kollaborative Bewirtschaftung der städtischen Commons, in den Begriff der Professionalität Sozialer Arbeit einge- 
schrieben hat. Zudem ist der WBGU damit ebenso nahtlos anschlussfähig an Konzepte Sozialer Arbeit, die das Genossenschaftsmodell nicht nur ins Zentrum sozialarbeiterischer Organisationsformen, sondern auch ins Zentrum städtischer Organisationsformen stellen und in deren Hervorbringung sie einen Hauptaspekt sozialarbeiterischer Professionalität zur politischen Hervorbringung eines menschlichen Gemeinwesens erblicken (May 2017b; Kunstreich 2005; Kunstreich 2006a; Kunstreich 2015; Kunstreich 2018; Elsen 2018; Schmidt 2019).

Wenn der WBGU im Anschluss an seine Vorschläge zur baulichen und Flächennutzungsgestaltung fordert, dass ,politische Teilhabe ermöglicht, Innovationen stimuliert und Prozesse gefunden werden“ sollen, die „den Menschen bei der Stadtentwicklung nicht nur rhetorisch in den Mittelpunkt [...] stellen“ und das ,jede Stadt die für sie geeignete Konkretisierung finden muss", indem sie „spezifische Transformationsstrategien erarbeiten, auf die sich die städtischen Akteure verständigen können“ und dabei „,einen langfristigen Horizont (bis 2050 und darüber hinaus) enthalten“ (WBGU 2016b: 216) sollen, dann lässt sich darin zumindest ein Umriss transformativer Stadtentwicklung erblicken, den es für die weitere Untersuchung lohnt weiter zu verfolgen.

Kritisch im Blick behalten werden muss dabei aber, dass der transformative Prozess nicht nur aus den gebauten, administrativen und finanziellen Pfadabhängigkeiten (Schott 2014: 303ff.), sondern auch aus der Subjektivität der ,,imperialen Lebensweise“ (Brand/Wissen 2017) (Kap. 3.2) der StadtbewohnerInnen, aber auch der AkteurInnen der Stadtverwaltungen, der Politik und der Unternehmen herausgebildet werden muss. Denn gerade von ihnen wurde das postliberale urbane Machtverhältnis entlang von aktuellen Stadtkonzepten - etwa im Konzepten der neoliberalen (Schipper 2018), der postpolitischen (Michel/Roskamm 2013a; Swyngedouw 2013; Koch/Beveridge 2018), der austeritären (Eckard 2018) oder der globalen Stadt (Krätke 2018) - verinnerlicht. Bei allen unterschiedlichen konzeptionellen Nuancierungen ist den gegenwärtig vorherrschenden Stadtkonzepten dennoch gemeinsam, dass sie die postliberalen Kräfteverhältnisse der Herrschaft des Kapitals und die Macht der Kapitaleigner gegenüber den Stadtverwaltungen sowie der StadtbewohnerInnen nicht aufgeben, sondern bloß modernisieren und damit weiterhin nicht in Frage stellen. Wenn Wulf (2020) Mimesis als elementaren Aspekt lebendiger Bildungsprozesse herausstellt (Schmidt 2021a [i.E.]), dann muss davon ausgegangen werden, dass sich die Menschen im Rahmen gouvernementaler Regierungs- und Subjektivierungsstrategien (nicht erst) des Neuen Steuerungsmodells an die unternehmerischen Strukturen des Städtischen als ihre äußeren Naturverhältnisse (Stichwort Stadt als zweite Natur des Menschen) subjektiv angeschmiegt und daran entlang ihre innere Natur als unternehmerisches Selbst herausgebildet haben. Entlang der mimetischen Anähnlichung der Wahrnehmung von inneren und äußeren Verhältnissen im 
urbanen Alltag (urbane Praxis) gerät nun auch die Wahrnehmung der unternehmerischen und imperialen Strukturen der Produktionsweisen des Städtischen (Praxis der Urbanisierung) aus dem Blick (zum Überblick von Foucaults Gouvernementalitätsbegriff: Foucault 2006a; Foucault 2006b; Bröckling/Krasmann/Lemke 2000; Ruoff 2009: 45ff., 130ff.), was in Kap. 4.2 mit Lefebvre bereits als „Entfremdungen zweiten Grades“ (Lefebvre 1975c: 68) begrifflich gefasst wurde. Eben deswegen lassen sich die urbanisierten Subjekte, das hatte schon Marx in seiner sechsten Feuerbachthese herausgestellt, als „das Ensemble der gesellschaftlichen Verhältnisse“ (Marx 1978b: 6) verstehen, an die eine grundlegende transformative Bildung nur dann Anschluss finden kann, wenn sie an die darin verschütteten, blockierten bzw. zum Schweigen gebrachten Bedürfnisse und Wünsche, d.h. an ihre Residuen Anschluss findet. Erst dadurch ließe sich verhindern, dass jegliche Transformationsbegehren zur Überwindung der ,imperialen Lebensweise“ (Brand/Wissen 2017), die ihnen von Experten aus den Sachzwängen des Klimawandels deduktiv bloß hergeleitet und abverlangt werden, als neuerliche herrschaftliche Bevormundung und Entfremdung erlebt werden (vgl. Kap. 5).

Sollen die klimabedingten Transformationsnotwendigkeiten (mit Bloch 2013a: 235ff.: „Kältestrom“ der Transformation) also nachhaltig getragen werden, müssen sie als sozial nachhaltige Subjektbildungsprozesse hervorgebracht werden, was letztlich heißt, dass sie an die residualisierten Emanzipationsbegehren der Menschen anschließen müssen (mit ebd.: „Wärmestrom“ der Transformation), die subjektiv mit den städtischen Lebensweisen verbunden werden und ja überhaupt erst den „Umzug der Menschheit in die Städte“ (WBGU 2016b: 2) plausibel machen. Daraus ergibt sich das Dilemma, dass durch gouvernementale Subjektivierungsstrategien entlang der „Urbanisierung des Kapitals“ (Harvey 2014: 126) die ersehnte Emanzipation gerade in den städtischen Lebensweisen erblickt werden, die als ,imperiale Lebensweise" (Brand/Wissen 2017) überwunden werden sollen und vor dem Hintergrund der Klimaproblematik überwunden werden müssen. Das Dilemma zeigt sich also darin, den Menschen gerade das streitig machen zu müssen, das ihnen urbane Freiheit verheißt. Wird dieser Anschluss an die subjektiven Emanzipationsbegehren aber verpasst oder gar nicht erst gesucht, greifen Transformationsprojekte ins Leere bzw. können nur von kurzer Dauer und mit wenig revolutionärer Kraft sein. D.h. ohne gesellschaftliche Reichweite und Belang. Als Alternative bleibt dann vor dem Hintergrund der klimabedingten Transformationsnotwendigkeiten nur die marktwirtschaftliche Herstellung transformativer Prozesse, die zwar den vorherrschenden unternehmerischen Subjekten entspricht, allen anderen allerdings nur zum Zwang gereicht, womit die ganze Klimathematik als weitere Entfremdung erlebt und eher abgelehnt wird. Folglich ist abzusehen, dass im Alltag nach Strategien und Nischen gesucht wird, sich den Klimadiskursen zu entziehen bzw. von 
Grund auf zu negieren. Von sozialer Nachhaltigkeit, die die westliche „'organisierte Friedlosigkeit" (Senghaas) und ,strukturelle Gewalt" (Galtung)“ (Wulf 2020: 210f.) zugunsten einer „Kultur des Friedens“ und der „Kultur der kulturellen Vielfalt" (ebd.: Kap. 12) zu überwinden sucht, kann hierbei allerdings keine Rede mehr sein. Eine Marktgesellschaft, die ihre nicht willfährigen AkteurInnen durch ökonomistische Rahmensetzungen dazu bringen will, dass sie tun, was sie sollen, organisiert mit struktureller Gewalt eine Angleichung der kulturellen Vielfalt an eine marktförmige Lebensweise. Damit organisiert sie letztlich die Unterdrückung individueller menschlicher Vermögen und Interaktionsweisen und damit die reichhaltigen Entwicklungsmöglichkeiten des subjektiven Gemeinwesens sowie die Reproduktion bestehender, gar die Produktion neuer sozioökonomischer Ungleichheiten. Sie produziert also Residuen, schürt Unbehagen und produziert Entfremdungen, die sich zwischen resignativer Anpassung und aggressiver Revolte (Lefebvre 1987: 313ff.) offenbaren. Kurz: sie organisiert Friedlosigkeit.

Zugleich öffnet sich in diesem Dilemma ein weiteres: nämlich möglichst rasch handeln zu müssen, um den Klimawandel und dessen Folgen möglichst gering zu halten, dabei zugleich aber besonnen vorzugehen (WBGU 2016b: 142). Die größte Herausforderung der klimabedingten Transformationsnotwendigkeiten besteht also darin, trotz Zeitdruck (Stichwort Kippelemente, vgl. Kap. 1) die Transformationen in emanzipatorischer Hinsicht demokratisch und partizipatorisch $\mathrm{zu}$ Wege zu bringen, was per se langwierig und langsam ist und nur allzu schnell die Notwendigkeit nahe legt, die Klimafrage von der sozialen Frage abzukoppeln bzw. gesellschaftliche Transformationen ökonomistisch herzustellen, um Zeit zu gewinnen. Doch gerade diese ökonomistische Chronopolitik erzeugt resignative und/oder aggressive Gegenbewegungen, die entweder den Prozess abermals verlangsamen oder aber weitere drastische Marktlösungen erfordern, was auf ein Wettrüsten hinausläuft und die Spannungen zwischen obrigkeitsstaatlichem Zwang und den individuellen Fluchtversuchen, sich ihm im Alltag zu entziehen, weiter verschärfen.

Gerade dieses zeitliche Dilemma kann also marktwirtschaftliche Strategien legitimieren, die im Vergleich zu demokratischen Aushandlungsprozessen durchaus schneller Lösungen generieren können (Nassehi 2008: 13ff.). Zugleich aber müssen, soll nicht der demokratische Anspruch transformatorischer Prozesse entlang der Despotie des Zeitdrucks aufgegeben werden, die marktwirtschaftlichen Strategien auch politisch resp. demokratisch regulierbar sein, so dass sie mit der sukzessiven Überwindung ,imperialer Lebensweisen“ (Brand/Wissen 2017) bei gleichzeitigem Aufbau subjekt- und residuenorientierter, kollaborativer Stadtentwicklungsstrukturen politisiert und demokratisch reguliert und dadurch sukzessive wieder zurückgenommen werden können. Damit ist die Notwendigkeit offenbar, urban Commons nicht nur in einzelnen zu vernetzenden Wohnformen zu erblicken, sondern in der 
gesamten Stadt, samt ihrer Produktions- und Reproduktionsbedürfnisse, der objektiven ihrer baulichen Infrastrukturen und der subjektiven ihrer BewohnerInnen. Erst durch die Commonisierung bzw. Kommunalisierung der Städte würde es möglich, die zur Transformation subjektiv benötigten städtischen Infrastrukturen und damit die städtischen Produktionsweisen selbst zu regulieren und $\mathrm{zu}$ bewirtschaften. Und erst durch einen solchen kollaborativen Kommunalismus würde Stadtentwicklung eine echte Alternative zu den vorherrschenden deliberativen und an die vorherrschenden plutokratischen Verhältnisse angepassten Stadtentwicklungskonzepte und -strategien darstellen. Der in Kap. 4.2 erarbeitete Begriff revolutionäre-transformativer Bildung kann nun also aufgehoben werden zu einem Begriff revolutionär-transformativer bzw. kommunalisierender Stadtentwicklung. Ihre globalgesellschaftliche Reichweite im Kontext der Klimafrage erhält die Kommunalisierung der Städte allerdings nur, wenn urban Commons im Zusammenhang mit global Commons verstanden werden (Meere und Gewässer, Landschaften, Wälder und Atmosphäre - kurz: alle erdökologischen Aktanten zwischen Muttergestein und Stratosphäre), die aber erst durch die Politisierung der Städte als Ganzes, d.h. der Lebensweise in, mit und durch den Städten, als global Commons politisiert und ihre Nutzung demokratisch reguliert werden können.

Diese Handlungsautonomie bildet zum einen den transformativen Zielhorizont emanzipatorisch politischer Subjektbildung in der Frage transformativer Stadtentwicklung vor dem Hintergrund der Klimafrage, und zum anderen auch den Verantwortungshorizont der Frage nach einem möglichen Anthropozän durch eine sozial-ökologische Stadtentwicklung. Ob und wie sich das Konzept hierfür eignet, soll folgend näher untersucht werden.

\section{Der „normative Kompass“ des WBGU zum Ersten: Partizipation und Eigenart}

Für die Verwirklichung seiner urbanen Transformationsvorschläge schlägt der WBGU einen „,normativen Kompass“ (WBGU 2016b: Kap. 3) vor. Dieser geht von den Prämissen der ,Städte als Treiber und Betroffene des globalen Wandels“ aus, die, um zu einer „Pluralität der Transformationspfade“ zu gelangen, auf die Handlungsfähigkeit der in den Städten lebenden Menschen angewiesen ist (ebd.: 140f.). In einer Zusammenschau beinhaltet der „,normative Kompass“" des WBGU drei miteinander verschränkte Problemkomplexe: Im Vordergrund steht dabei die Erhaltung der natürlichen Lebensgrundlagen entlang von städtischen Lebensweisen. Hierfür erachtet es der WBGU für notwendig, dass ,universelle Mindeststandards für substanzielle, politische 
und ökonomische Teilhabe eingehalten werden“, so dass eine „Pluralität der Transformationspfade“ (ebd.) zur langfristigen Erhaltung der natürlichen Lebensgrundlagen ermöglicht werden kann. Dafür kommt es dem WBGU darauf an, dass sich die Transformationspfade nicht nur an den StadtbewohnerInnen orientieren, sondern dass sie vor dem Hintergrund kollaborativer Partizipationsprozesse an der Erarbeitung von transformativen Stadtentwicklungspfaden maßgeblich von ihnen selbst, d.h. von ihren lebensweltlichen Handlungssubjekten ausgehen sollen, so dass sich dadurch je städtische Eigenarten der Transformationspfade herausbilden können, die entlang einer weltweit vernetzten ,polyzentrischen Verantwortungsarchitektur“ der Städte eine veränderte Urbanisierung der Erde zu Wege bringen können (ebd.: Kap. 8). Nur so, so ließe sich die Grundannahme WBGU-Konzepts zusammenfassen, könnte politisch ermöglicht werden, dass die Erhaltung der natürlichen Lebensgrundlagen, die er in einem Leitplankenkonzept zusammenfasst (WBGU 2014b, 2016b: 145ff.), weltweit nicht nur eingehalten, sondern auch sozial nachhaltig verwirklicht werden und sich zum alternativen Lebensstil gerade westlicher Gesellschaften verselbstständigen können.

Im Folgenden wird der normative Kompass näher beleuchtet und vor dem Hintergrund kommunalisierender Stadtentwicklung diskutiert.

\subsection{Partizipation als kollaborative Stadtentwicklung? Zur Kritik des WBGU aus sozialarbeiterischer Perspektive}

Unter Partizipation versteht der WBGU „substanzielle, politische und ökonomische Teilhabe“, durch die alle Menschen die Möglichkeiten haben sollen, ,ihre individuellen gemeinschaftlichen Lebensentwürfe zu entfalten und umzusetzen“ (WBGU 2016a: 15) und „basiert [...] auf der Überlegung, dass Menschen entsprechende Verwirklichungschancen benötigen“" (WBGU 2016b: 9). Unter substanzieller Teilhabe wird der gleiche Zugang „der gesamten Stadtbevölkerung“ zu Nahrung, sauberem Trinkwasser, sanitären Anlagen, Gesundheitsversorgung, (adäquaten) Wohnraum, Bildung, modernen Energie- und Telekommunikationsdienstleistungen, Mobilität, elementarer Abfallentsorgung (zur Gewährleistung hygienischer Mindeststandards) sowie persönlicher Sicherheit in privaten und öffentlichen Räumen zusammengefasst (ebd.: 9, 148ff.). Unter ökonomischer Teilhabe wird entlang substanzieller Teilhabe der gleiche Zugang ,der gesamten Stadtbevölkerung“ zu „formalen und informellen Märkten, insbesondere zum Arbeits- und Immobilienmarkt" sowie „die Möglichkeit[,] diese Mitzugestalten“ (ebd.: 9, 148, 150), zusammengefasst. Um substanzielle und ökonomische Teilhabe verwirklichen zu können, brauchen die StadtbewohnerInnen politische Teilhabemöglichkeiten, um ihre substanzielle und ökonomische Teilhabe nicht nur 
einzufordern, sondern auch rechtsverbindlich durchsetzen zu können. Unter politischer Teilhabe fasst der WBGU daher im Anschluss an die internationalen Diskurse um ein Recht auf Stadt das „Recht auf Bestimmung der Stadtregierung und Mitwirkung der Stadtbevölkerung an lokalen Entscheidungsprozessen“ zusammen, das von der Anhörung, über Mitsprache, Mitentscheidung, Mitverantwortung bis hin zur kommunalen Selbstorganisation der Stadtentwicklung reicht (ebd.: 9, 148, 152f.).

Mit der Betonung der kommunalen Selbstorganisation der Stadtentwicklung geht der WBGU, wie bereits in den vorangegangenen Kapiteln herausgestellt, konzeptionell weit über die deliberativen Partizipationspraktiken im Stadtentwicklungsdiskurs hinaus und spricht mit White (1996), Cornwall (2008) und Herrle (2015) auch von ,transformative[r] Partizipation“ und „Kollaboration“ (im Sinne von kollaborativer Partizipation) (ebd.: 115). Um zu verhindern, dass - wie es die Überforderungserfahrungen der Gemeinwesenarbeit in den 1970er Jahren berechtigterweise nahe legen (Drilling/Oehler 2016: 20ff.) - die Ermöglichung kollaborativer Partizipation ,,aller Akteursund Einkommensgruppen" am transformativen Stadtentwicklungsprozess weder die Bevölkerung noch die öffentliche Verwaltung überfordern, gar in „Abstumpfung und Desinteresse“ münden (WBGU 2016b: 152), sind dem WBGU „die zivilgesellschaftlichen Akteure zu befähigen“ und „die strukturellen Voraussetzungen und Freiheitsgrade für die Beteiligung zu schaffen“ (ebd.: 115). Mit anderen Worten: Kollaborative Partizipation bedarf zum Gelingen der Subjektbildung ein fachlich begleitetes sozial- und kommunalpädagogisches Ortshandeln (Kap. 4.2), um so allen bzw. möglichst vielen AkteurInnen ihre subjektiven Möglichkeiten zu eröffnen, die transformativen Prozesse sozial-ökologischer Stadtentwicklung tatsächlich kollaborativ vollziehen zu können. Dass und wie dies im Stadtentwicklungsprozess erfolgen soll, bleibt allerdings vom WBGU konzeptionell unerwähnt, wird allerdings zwischen den Zeilen unausgesprochen vorausgesetzt.

Als Schwierigkeit bleibt vom WBGU entsprechend unausgesprochen, dass strukturell marginalisierte und subaltern(iert) $\mathrm{e}^{37}$ Bevölkerungsgruppen

37 Der Begriff der Subalternen, mit dem Gramsci (Gramsci 1994b: 1325) „,der Legende nach in seinen Gefängnistagebüchern (1934-35) den Begriff des Proletariats durch den der Subalternen ersetzt haben“ soll, bezieht sich bei ihm ,auf jene Gruppen der Gesellschaft, die der Hegemonie der herrschenden Klassen ausgesetzt" und auf Grund sprachlicher Verständigungsschwierigkeiten ,,von gesellschaftlicher Repräsentation ausgeschlossen waren“ (vgl. Steyerl 2008: 8f.). Im hier verwendeten Kontext bezieht sich der Begriff der Subalternen an der von Spivak (Spivak 2008a, 2008b) vorgenommenen Kritik an Gramscis Begriff und fokussiert das „Bemühen sich selbst in die Repräsentation einzubringen“ (vgl. Spivak 2008b: 145), was ihnen aber zumeist dadurch nicht gelingt bzw. gelingen kann, weil die „Ordnung der Diskurse“, wie Steyerl Spivaks Argumentation zusammenfasst, ,die Artikulation bestimmter Sachverhalte nicht [erlaubt]“ (vgl. Steyerl 2008: 10ff.), da sie nicht in die hegemonial vorherrschenden Diskurse passen. Subalterne sind also nicht von sich aus subaltern, sondern werden entlang der Ordnung der Diskurse, subalterniert resp. sprachlos gemacht. „Das ist das Moment, das ich nicht sprechen nenne.“ (vgl. Spivak 2008b: 145) Das Nicht- 
überhaupt erstmal (wieder) erreicht werden müssen (Winkler 2006), um mit ihnen nicht nur wieder (oder überhaupt) ein Interesse am politischen Prozess, sondern mitunter auch eine diesbezügliche Sprache zu entwickeln, in der sie ihre Anliegen und Bedürfnisse artikulieren und die zugleich auch von gesellschaftlich anerkannten Statusgruppen, die die Bürgerbeteiligungsprozesse bislang dominieren - den „,neuen A-Gruppen, Anwält innen, Architekt_innen, Akademiker_innen“(Holm 2013: 9) - gehört werden. Darin wird erst die Voraussetzung substanzieller, ökonomischer und politischer Teilhabe geschaffen, die die ,gesamte[] Stadtbevölkerung“ (WBGU 2016b: 148) kollaborativ in den transformativen Stadtentwicklungsprozess zu involvieren vermag. Dass insgesamt das Problem besteht, eine transformative Stadtentwicklung auf den Weg zu bringen, die es tatsächlich vermag, die ,imperiale Lebensweise" (Brand/Wissen 2017) der alltäglichen diskursiven urbanen Praktiken der gesamten gesellschaftlichen Alltagspraxis zu revolutionieren, also die auch der juristisch-administrativen Praktiken der Verwaltungen und Regierungsbehörden, kann an dieser Stelle nur wiederholt werden. Zusammengefasst: Kommunalpädagogische Subjektbildung müsste allen städtischen AkteurInnen in allen sozialen Statusgruppen ermöglicht werden.

Mit dem Begriff der kollaborativen kommunalen Selbstorganisation, mit dem der WBGU hinsichtlich der Partizipation aus dem Vollen des objektiv Möglichen des Politischen zu schöpfen scheint, geht zugleich aber - in Bezug auf die gattungsgeschichtliche Reichweite des Marxschen Emanzipationsbegriffs (Marx 1981c: 370) - nur ein halbierter Emanzipationsbegriff einher, was das objektiv Mögliche des Politischen zugleich wieder zu Schanden macht. Nur bedingt ist dem WBGU zuzustimmen, dass ,[n]icht kollaborative Partizipationsinstrumente [...] nicht ignoriert oder als unzureichend abgetan werden [sollten]“, weil ,[d]irekte Demokratieelemente [...] auf Quartiersebene [...] leichter als auf Metropolebene anzuwenden [sind]“ (WBGU 2016b: 116). Denn dieses Problem kann ja durchaus mit einer Verkleinerung der (sich) verwaltenden Gruppen und ihrer urbanen Räume angegangen werden (Bookchin 1996: 325f.). Nicht zuzustimmen ist der Konsequenz, die er daraus zieht, wonach eine transformative Partizipation bzw. kollaborative Selbstorganisation ,nicht bei allen Themen oder auf allen Ebenen“ eingesetzt werden könne (WBGU 2016b: 116). Denn eine Begründung, welche Themen auf welchen Ebenen nicht selbstorganisatorisch angegangen werden könnten, bleibt der WBGU schuldig.

Die bereits genannten plutokratischen Hemmnisse radikaler bzw. revolutionär-reformerischer sozial-ökologischer Transformationen überwunden

Sprechenkönnen der Subalternen meint damit, dass bestimmten Gruppen politische Handlungsmöglichkeiten vorenthalten und damit subalterniert werden (vgl. Schmalstieg 2010: 175ff.), so dass ihnen eine Sprache zu erlernen heißen muss, ihnen strukturelle Partizipationsmöglichkeiten zu eröffnen, durch sie ihre Sprache erlernen können, wozu ihnen aber mitunter überhaupt erst einmal wieder ein Wille geweckt werden muss (Winkler 2006). 
werden sollen, wäre es allerdings dringend notwendig, bei den zu demokratisierenden Gesellschaftsbereichen keine Tabus mehr zu dulden und als vermeintlich nomistisch-naturwüchsigen Konsens von der kollaborativen kommunalen Selbstorganisation auszuschließen. Mehr noch: Sollen sich entlang der tatsächlichen Vielfalt urbaner Lebens- und soziökonomischer Produktionsweisen, die entlang der ,imperialen Lebensweise“ (Brand/Wissen 2017) aber marginalisiert und als subjektive Residuen zum Schweigen gebracht werden, je städtische Eigenarten substanzieller, ökonomischer und politischer Teilhabepraktiken herausbilden können, so dass sich darin ein gemeinsamer (konfliktorientierter) und demokratisch regulierter kollaborativer Stadtentwicklungsprozess entwickeln und Antworten auf die ökosoziale und sozial-ökologische Stadtentwicklungsfragen hervorbringen kann, müssen alle bislang nicht demokratisch legitimierten Macht- und Herrschaftsverhältnisse auf die Agenda gesetzt werden. Mit nichts weniger kann sich der emanzipatorische Anspruch praxisphilosophischer Professionalität subjekt- und gemeinwesenorientierter Sozialer Arbeit im Kontext der Klimafrage zufrieden geben.

\subsection{Kollaborative Stadtentwicklung als (eigensinnige) Produktion transformativer Eigenarten der Städte - und die Ergänzung des emanzipatorischen Eigensinns}

Mit dem Begriff der Eigenart bezeichnet der WBGU „ein neues Konzept, um die gängige Diskussionen über Wohlstand und die globale wie urbane Transformation zur Nachhaltigkeit um eine wesentliche Perspektive zu erweitern“ (WBGU 2016b: 153). Bilden der Erhalt der natürlichen Lebensgrundlagen und die Sicherung bzw. (Wieder)Herstellung von Teilhabe den normativen Rahmen des Kompasses, so geht es in der Kategorie Eigenart um die Ermöglichung der eigenartigen resp. eigensinnigen Gestaltung urbaner Räume mit den individuellen subjektiven Vermögen und Fähigkeiten der BewohnerInnen entlang des aufgestellten normativen Rahmens:

„Mit der Dimension der Eigenart erkennt der WBGU zum einen die soziokulturelle wie räumliche Diversität der Städte und Stadtgesellschaften an (deskriptive Eigenart). Zum anderen betont Eigenart als Ziel- oder Orientierungsdimension urbaner Transformationen (normative Eigenart), dass in urbanen Lebensräumen Voraussetzungen dafür geschaffen werden sollten, dass (a) Menschen in den räumlichen Strukturen Selbstwirksamkeit entfalten und urbane Lebensqualität für sich empfinden und herstellen können, dass sich (b) Ortsidentität und soziale Kohäsion entwickeln können und dass (c) soziale sowie ökonomische Kreativitäts- und Innovationspotenziale gestärkt werden, die durch ortsgebundene Interaktionen (Konnektivität) zwischen Akteuren aus verschiedenen gesellschaftlichen Sphären entstehen.“(ebd.: 11, 143) 
Im „Begriff ,Eigen-art““ soll „,durch die Dialektik des ,Eigen“, d.h. des Individuellen, Neuen, Andersartigen, der Differenz und der ,Art', als Ausdruck von Klasse, Gemeinschaft, Gruppe, Verallgemeinerbarkeit“, die Verschränkung des „kollektiven Moments des ,Teilens' und [...] des individuellen „Habens““ zum Ausdruck kommen (WBGU 2016a: 16). Diese Verschränkung ist deswegen wichtig begrifflich und konzeptionell einzuführen, als dass in ,radikalkapitalistische[n] Konzepte[n] der "shareholder society“" beide Sphären unter dem Primat des Individuums getrennt voneinander existieren (ebd.: 16f.). Dadurch wird nun aber geradezu verhindert - so ließe sich der WBGU vor dem Hintergrund des Subjektbildungsanspruchs Sozialer Arbeit ergänzen -, dass Menschen als politisches Gemeinwesen im Hinblick auf ein menschliches Gemeinwesen zusammenkommen können. Aber auch ohne diese Subjektorientierung weiter zu explizieren, zeigt sie sich dennoch aber implizit an der Stelle, wo der WBGU eine „erweiterte Definition von Lebensqualität und Wohlstand" postuliert,

„die über materiell-ökonomische ,objektive“ Faktoren hinaus auch ,subjektive' Faktoren wie z. B. Selbstwirksamkeit, Identität, Solidarität, Zugehörigkeitsgefühle, Vertrauen und soziale Netzwerke einbezieht und die zugleich das soziale Kapital einer Gesellschaft ausmachen: den Kitt, der Gesellschaften zusammenhält“ (ebd.: 17).

Es sind genau diese ,subjektive[n] Faktoren“, d.h. diese gesellschaftlich residualisierten subjektiven Vermögen und Fähigkeiten, die den Ausgangspunkt der Analysekategorie der Eigenart städtischer Transformationsprozesse bilden. Um aber tatsächlich zu städtischen Eigenarten urbaner Transformationspfade zu gelangen, muss der Begriff allerdings weiter gefasst werden und mit dem subjektorientierten Begriff des Eigensinns gekoppelt und verdeutlicht werden.

Der subjektorientierte Begriff des Eigensinns geht mit Marx davon aus, dass die Menschen als historische Subjekte ,ihre eigene Geschichte [machen], aber sie machen sie nicht aus freien Stücken, nicht unter selbstgewählten, sondern unter unmittelbar vorgefundenen, gegebenen und überlieferten Umständen“ (Marx 1960a: 115). Hieran anschließend heben Negt/Kluge hervor, dass Eigensinn als „Protest gegen Enteignung [...] der eigenen Sinne, die zur Außenwelt führen“ und damit aus ,bitterer Not“ entsteht (Negt/Kluge 1981: 767). Daran anschließend lässt sich mit May (May 2013a) Eigensinn verstehen als praktische Manifestation der Reflexion der eigenen situativen Existenz und den tatsächlichen lebensweltlichen Möglichkeiten ihrer interaktiven Bearbeitung. In diesem Sinne schließt auch Lüdke an und betont Eigensinn als ,eigenständige“, ,widerborstige“ und „,querliegende“ bzw. transversale Praxis einzelner AkteurInnen und Gruppen, mit der sie sich ihre jeweiligen existenziellen Situationen „zu eigen“ machen (Lüdtke 2015: 12). Der Begriff des Eigensinns verweist damit auf eine subjektive Aneignungspraxis gesellschaftlicher (Re-)Produktionsverhältnisse durch die eigenen Sinne mit „vorgegebene[n] oder mehrheitlich aktzeptierte[n] Ziele[n]“ (ebd.: 
13), womit sich die AkteurInnen zugleich ihre eigenen Sinne, d.h. ihre innere, sensualistische Leibnatur aneignen und herausbilden.

Damit ermöglicht der Begriff des Eigensinns eine gesellschaftstheoretische Kritik, die es zu beurteilen ermöglicht, ob und wie die subjektive Aneignungspraxis der eigenen Sinne sowie der gesellschaftlichen (Re-)Produktionsverhältnisse „,von den gesellschaftlich-politischen Kommandohöhen formuliert oder signalisiert worden sind" (ebd.) und von den Menschen bis hin zu dessen „Übererfüllen“ in Einklang zu bringen versucht werden. In den Fokus der Kritik muss dabei das Gelingen der lebendigen Arbeit des naturhaften Leibes rücken, der inmitten dieses Verhältnisses nach Erweiterungen subjektiver Entwicklungsmöglichkeiten sucht und sie nur im Zusammenschluss mit anderen AkteurInnen und Gruppen erarbeiten resp. hervorbringen kann. Letztlich muss also kritisch in den Blick genommen werden, ob und wie - genauer: wie gebrochen oder ob überhaupt - diese lebendige Arbeit leiblich interagierender Subjekte gelingt und schlummernde Potenziale, verdeckte Wünsche und Bedürfnisse im Miteinander verwirklicht werden können. Das heißt, wie sie sich $i h r$ historisch gemeinsames Subjekt konstituieren können und was ihnen dabei als Residuum zurück bleibt. Mit anderen Worten: Der subjektorientierte Begriff des Eigensinns erweist sich als emanzipatorischer Begriff, weil er die Beurteilung ermöglicht, ob sich die Subjekte in ihrem gesellschaftlichen Miteinander und entlang von gesellschaftlichen (Re)Produktionsbedingungen als freie Individuen herausbilden können oder ob und wie sie darin gegängelt und blockiert werden und einander fremd $\mathrm{zu}$ werden drohen. Das emanzipatorische Moment des subjektiven Eigensinns lässt sich als „Moment im Kräftefeld von Herrschaft und Freiheit“ (ebd.: 17) erblicken, das aber nur dann die Freiheit der eigenen Sinne ermöglicht, wenn die AkteurInnen und Gruppen auf gesellschaftliche Verhältnisse treffen, die es ihnen ermöglichen, die eigenen Sinne zu entwickeln: Nämlich dadurch, dass sie in diesen Verhältnissen nicht bloß repräsentiert werden - was immer $\mathrm{zu}$ Verzerrungen und Übersetzungsfehlern führt, selbst wenn die Übersetzung nicht herrschaftlich durch einen ,juristisch-administrativen-therapeutischen Staatsapparat" (Fraser 1994: 237ff.) vollzogen wird -, sondern sich selbst darin repräsentieren können, indem sie die Verhältnisse maßgeblich kollaborativ mitgestalten. Mit Winkler gesprochen: sie sich selbst die Gleise legen, auf denen sie sich bewegen (Winkler 1988: 278).

Die aber auch in kollaborativen Stadtentwicklungsprozessen zurückgelassenen bzw. blockierten Bedürfnisse und Wünsche nach bestimmten Interaktionsformen zur Ausbildung und Verwirklichung der eigenen Sinne an und mit Anderen sind als elementare Ausgangspunkte transformativer Potenziale städtischer Eigenart immer wieder und iterativ kritisch in den Blick zu nehmen, wodurch sich an lebensweltlicher Eigenart orientierte Stadtentwicklungsprozesse als historisch unabgeschlossene Prozesse erweisen. Diese Residuen zu entdecken, zur öffentlichen Sprache und damit zu gesellschaftli- 
chen Wirklichkeit zu verhelfen - darin besteht die einzigartige Handwerkskunst Sozialer Arbeit im städtischen resp. kommunalisierenden Transformationsprozess, die keine andere Disziplin und Profession anbieten kann (Bartosch 2020: 20).

Ein sich jeweils an die konkreten, d.h. subjektiven Begebenheiten und Bedürfnisse der StadtbewohnerInnen angepasster Transformationsprozess der Städte, so der WBGU weiter, macht daher „Aushandlungsprozesse notwendig“, die die vielen Lebensweisen und „die vielfältigen Interessen innerhalb der Städte mit den Transformationserfordernissen in Einklang [...] bringen“, „so dass Stadtregierungen nicht nur die Stadtbevölkerung beteiligen müssen, sondern auch auf eine enge Vernetzung mit anderen Akteuren angewiesen sind" (WBGU 2016b: 216), etwa Unternehmen, staatliche Behörden und Institutionen. Diesem Anspruch versucht der WBGU unter Berufung auf Lefebvres „Recht auf Stadt“ (Lefebvre 2016) gerecht zu werden, das sie als „als kollektive Forderung, bisweilen auch als gesellschaftliche Utopie“ vor allem in „zwei zentrale[n] Rechte[n] für die Stadtbevölkerung“ (WBGU 2016b: 154) erblicken:

„Das Recht auf Partizipation: also die Einbindung der Stadtbevölkerung in Entscheidungen, die Auswirkungen auf den städtischen Raum haben - und das Recht auf Aneignung: also die Möglichkeit der Stadtbevölkerung, nicht nur urbane Räume, sondern auch die Vorteile und Errungenschaften von Stadt in gleichem Maße nutzen zu können (Purcell, 2002: 102 f.; Holm und Gebhardt, 2011).“ (ebd.)

Mit dem Bezug auf Lefebvres „Recht auf Stadt“ (Lefebvre 2016) fokussiert der WBGU ein Konzept „polyzentrische[r] Organisation des Urbanen“ (WBGU 2016b: 41) bzw. einer urban governance (ebd.: 101ff.), das ,staatliche[] Akteure und nicht staatliche[] und Institutionen" $\mathrm{zu}$ gemeinsamen Handlungen zusammen bringen soll, ,mit dem Ziel, die gemeinsamen Angelegenheiten einer Stadt zu organisieren (ebd.: 544). Urban Governance wird dabei als ,ein andauernder Prozess“ verstanden, „durch den widersprüchliche Interessen in Einklang gebracht und kooperatives Handeln befördert werden können [...], gleichgültig ob sie das Resultat eines parlamentarischen Gesetzgebungsprozesses oder das Ergebnis zivilgesellschaftlicher Selbstorganisation sind“ (ebd.). Indes ist Lefebvres „Recht auf Stadt“ (Lefebvre 2016) im Kontext seines weiteren Werkes allerdings sehr viel weitreichender, als es vom WBGU herausgestellt wird, weshalb sich mit dem „Recht auf Stadt“ hinsichtlich seines Potenzials für ökosoziale und sozial-ökologische Gesellschaftstransformationen im Folgenden näher beschäftigt werden soll. 


\section{2 „Recht auf Stadt“ im Werk Lefebvres ${ }^{38}$}

\subsection{Von der „Kritik des Alltagslebens“ zum „Recht auf Stadt" - Lefebvres praxisphilosophische Soziologie als „strategische Hypothese“}

Lefebvres „Recht auf Stadt“ erscheint zwar erst 1968, bahnt sich allerdings bereits in seinen 1939 erschienen Werken zu Nietzsche (Lefebvre 1939) und Marx (Lefebvre 1971a) an, in denen er jeweils die leibliche Bedürftigkeit und Bildbarkeit des menschlichen Subjekts als Zentrum seiner anthropologischen Praxisphilosophie ${ }^{39}$ herausstellt. Entsprechend ist ihm die philosophische Figur des „Übermenschen“ Nietzsches ein zentraler Bezugspunkt seiner anthropologischen Praxisphilosophie. In der philosophischen Figur des „Übermenschen“ entwirft Nietzsche das Bild eines zukünftigen Menschen, der sich mit den konkreten leiblichen Bedürfnissen, Wünschen und Begehren immer wieder neu erfindet und entwirft und damit immer wieder nur vorübergehender Mensch ist, ohne einem bestimmten So-sein verhaftet sein zu müssen. Der künftige Mensch ist „Brücke und kein Zweck“, ist Tänzer auf einem „Seil, geknüpft zwischen Tier und Übermensch“ (Nietzsche 1954a: 281). Er wird Übermensch, indem er sich durch Fühlen, Erleben und Wollen als leiblich werden-wollender Mensch zu begreifen beginnt, der sich jedem So-sein entzieht. Markiert wird damit eine radikale Diesseitsphilosophie, die die lebensphilosophische Priorisierung des Erlebens und Fühlens mit der existenzphilosophischen Aufgabe zur individuellen Ausgestaltung des Menschseins und die Ausgestaltung bzw. die Verwirklichung dabei als Selbstverwirklichung des physisch erlebten Leibes auf und mit der Erde sieht. So ist für Nietzsche der „Übermensch“ der „Sinn der Erde“ (ebd.: 280), indem er sich der Erde zuwendet und sie sich für sein Werden sinnhaft ausgestaltet (Joisten 1994: 215f.; vgl. auch Kap. 4.3 und Kap. 12.2.1 in der vorliegenden Arbeit). Für Lefebvre ist daher „,[d]as Übermenschliche [...] das Menschliche“ (Lefebvre 1939: 164). Nietzsche begleitet ihn sein Werkleben hindurch.

38 In dem folgenden Kapitel handelt es sich um eine gekürzte, aber zugleich stark überarbeitete Version meines bei sozialraum.de erschienenen Artikels (Schmidt 2020). Verändert wurde vor allem hinsichtlich der Ausformulierung des dialektischen Verhältnisses von ökosozialer und sozial-ökologischer Transformation, wodurch es möglich wurde, Lefebvres Werk für das Ansinnen der vorliegenden Arbeit kritisch(er) zu Lesen.

39 Mit der Formulierung einer anthropologischen Praxisphilosophie soll zum einen zum Ausdruck kommen, dass Lefebvre durchaus an die anthropologischen Überlegungen von Marx und Nietzsche der Menschwerdung anschließt, zugleich aber die Disziplin der (philosophischen) Anthropologie ablehnt (Lefebvre 1975c: 324). 
Bei genauerem Besehen findet sich Nietzsches lebens- und existenzphilosophische Argumentation bereits bei Marx“ Figur des „totalen Menschen“, der sich „sein allseitiges Wesen [gemeint ist sein Wesen des Menschwerdens, MS] auf allseitige Art aneignet" (Marx 1968b: 539) und hierfür mit der Erde resp. der Natur als seinem ,unorganische[m] Leib [...] in beständigem Prozeß bleiben muß, um nicht zu sterben“ (Marx 1968b: 516, 1983: 396). Wie später Nietzsche sieht bereits Marx in diesem anthropologischen Grundverhältnis bzw. dieser „negativ zu fassenden Ontologie“ (Schmidt 2016: 103) einen Gestaltungsauftrag zur Menschwerdung angelegt, bloß dass Marx noch deutlich stärker auf die Notwendigkeit der Gegenseitigkeit und Gesellschaftlichkeit zur Menschwerdung insistiert und den Gestaltungsauftrag zur Menschwerdung damit politisiert. Lefebvre betont den Marxschen „totalen Menschen" daher als „das freie Individuum in der freien Gesellschaft", „die vollentfaltete Individualität in der unbegrenzten Mannigfaltigkeit möglicher Individualitäten“(Lefebvre 1971a: 134).

Nietzsches anthropologische Philosophie und Marx" anthropologische Praxisphilosophie bilden ein maßgebliches Fundament Lefebvres weiteren Schaffens (zum Überblick weitere wichtiger Bezugspunkte, etwa auch in der Kunst: Meyer 1973). 1946 kündigt Lefebvre im ersten Band seiner „Kritik des Alltagslebens" schon unter Bezug auf den industrialisierten Städtebau (Lefebvre 1987: 234f.) zwar eine daraus hergeleitete bedürfnis- bzw. subjektorientierte Praxisphilosophie an, bleibt darin aber letztlich noch ziemlich blass. Der im Deutschen als zwei Bände herausgegebene zweite Band der „Kritik des Alltagslebens“ (1961) beginnt daher mit einer umfangreichen Klarstellung des Verhältnisses von Bedürfnis und Wunsch: Während das Bedürfnis ,"gattungsbedingt““ ist und physiologisch zur „Spezies Mensch [gehört]“, ist der Wunsch ,individuell und gesellschaftlich zugleich, d.h. anerkannt (oder tabuisiert) von einer Gesellschaft" (ebd.: 261), vermittelt durch gesellschaftliche „Produktionstätigkeiten und Konsumtionsweisen [.], die Kultur, Vergangenheit, und Geschichte, die Sprache, die Normen, die Befehle und Verbote, die Hierarchie der Werte und Neigungen" (ebd.: 262). Das Bedürfnis wird zum Wunsch, wenn es unbefriedigt brach liegt und das Individuum dadurch antreibt, Konfrontationen und Konflikte für die Bedürfnisbefriedigung in Kauf zu nehmen. Erst wenn der Wunsch ,,vitale und geistige Gewalt wird, angenommen und ausgeübt vom Individuum, Leben, das in kreatives, schaffendes und geschaffenes Bewusstsein umgewandelt worden ist - kurzum, wenn er wieder Bedürfnis wird“, lässt sich für Lefebvre von einem wirklichen Wunsch sprechen (ebd.: 262f.). „Am Anfang ist das Bedürfnis Natur; es wird Werk und vollendet sich in Werken.“ (ebd.: 263) Erst durch den Drang, entlang des Bedürfnisses Werke zu schaffen, um sich darin zu verwirklichen, und erst, wenn die bedürftigen Menschen auf gesellschaftliche Möglichkeiten treffen, ihre Bedürfnisse mit den Mitteln des gesellschaftlichen resp. urbanen Zusammenlebens eigensinnig zur Entfaltung zu 
bringen, können sie sich allseitig entwickeln und sich über ihre Werke im vollen Umfange ihrer Subjektivität bewusst werden. D.h. nicht nur ihres je individuellen Menschseins, sondern auch der Abhängigkeit der eigenen Individualität von Anderen und dem gemeinsamen resp. sozialen Miteinander. Aber nur, wenn das gesellschaftliche Alltagsleben in und mit der Stadt dies zulässt und hierfür frei gestaltet werden kann. Daran entzündet sich der ganze spätere Gedanke eines Rechts auf Stadt. Doch gerade diese Voraussetzung schrumpft mit dem Funktionalismus der neuen (Nachkriegs-)Städte. „Die Häuser sind ,Wohnmaschinen' [...] und die Stadt ist eine Maschine zur Versorgung des Arbeiters außerhalb der Arbeit. Jedes Objekt, determiniert durch seine Funktion, reduziert sich auf ein Signal: [...] es stiftet Verhaltensweisen, es konditioniert“ (ebd.: 333). Das Alltagsleben ,schrumpft [...] zum Privatleben“ (ebd.: 332) - im wortwörtlichen Sinn als „Privation, Entzug, EntblöBung von allem“ (ebd.: 345).

Le Corbusier, der philosophische Ahnherr dieses Städtebaus, beschrieb bereits 1925 Städte als „biologische Phänomene“, die „Herz und bestimmte Organe [haben], die für ihr Leben unerlässlich sind“ (Pehnt 2015). Die Organe des städtischen Lebens - Wohnen, Büros, Industrie, Freizeit - sind durch Infrastrukturen wie Straßen und Straßenbahnlinien räumlich sauber voneinander getrennt angeordnet und müssen funktional erst wieder zusammengebracht werden (Russo 2016: 300). „Diese Aufgliederung“, so Pehnt weiter, „bestimmte jahrzehntelag das Denken modernistischer Planer“ und zeitigte „,verhängnisvolle Folgen“: ,Sie isolierte menschliche Tätigkeiten, verhinderte Kontakte und nachbarschaftliches Miteinander, erschwerte Mischung und soziale Kommunikation [...]. Straße und Plätze verloren ihre Bedeutung als soziale Räume“ (Pehnt 2015). Entsprechend entwickelte sich der öffentliche Raum vom Aufenthaltsraum und Wohnraum zum Raum, den es bloß zu durchqueren galt. Folglich kam dem Transportsystem enorme Bedeutung zu, da dies „für das Leben in der Stadt [sorgt]“ (Russo 2016: 300). Menschen haben in diesem funktionalistischen Stadtorganismus, für den Le Corbusier das Wort „Wohnmaschine“ prägt, lediglich die Funktion, die ihnen zur Verfügung gestellten Infrastrukturen zu nutzen und den Raum zu durchqueren, um in der geometrischen Totenstarre der Stadt geordnete funktionale Bewegungsabläufe als Lebendigkeit zu simulieren. Entsprechend stehen im Zentrum seiner Stadtplanung die Autobahnkreuzung und der Hauptbahnhof als „Symbol[e] des Austausches, des Austausches von Informationen, Talenten, Freuden“" (vgl. ebd.). Damit prägte Le Corbusier die Auffassung von Stadt noch bis in die 1980er Jahre hinein. Das bis heute die Städte dominierende Städtebaukonzept der ,autogerechten Stadt“ konnte baulich wie konzeptionell hier nahtlos anknüpfen und es fortsetzen, indem es lediglich das öffentliche Transportsystem durch ein privates, nämlich das Auto, ersetzte (Bernhardt 2017). 
Vor dem Hintergrund dieser Stadtentwicklungen begann Lefebvre sich seit den 1960er Jahren an der Human- oder Sozialökologie der Chicagoer Stadtforschung (Park et al. 1967 [1925]) abzuarbeiten und kritisiert an ihr, dass sie - erstens - übersieht, dass der städtische Raum kein natürliches Habitat ist, sondern das Ergebnis einer hoheitlichen Fachplanung. Ersonnen von einer sozialen Statusgruppe für andere soziale Statusgruppen, die dadurch ihre Repräsentation des Raums auch für andere geltend macht. Und dass sie - zweitens - übersieht, dass die von der Chicago-Schule konstatierte Angleichung der BewohnerInnen keine natürliche, sondern eine erzwungene ist, weil die Leute eines „Habitats“/Wohngebiets den gleichen städtebaulichen Infrastrukturen ausgesetzt sind und auch nur ähnlich begrenzte Möglichkeiten haben, sie sich individuell anzueignen. Lefebvre macht darauf aufmerksam, dass menschliche Tätigkeiten und Zusammenhänge durch die Industriearbeit ohnehin zeitlich fragmentiert und als Arbeitszeit, Freizeit und Privatzeit einander entfremdet sind, da sie außer den jeweiligen Menschen, die sie wieder zusammenführen müssen, kaum noch inhaltliche Berührungen haben. Aber durch den modernen Städtebau entfremden sich die zeitlich fragmentierten Lebenszusammenhänge nun auch räumlich.

Zeitgleich zum zweiten Band der „Kritik des Alltagslebens“ schreibt Lefebvre von 1959-1961 seine „Zwölf Präludien“ zur „Einführung in die Modernität" (veröffentlicht 1962), wo er im siebenten Präludium schreibt:

„Man stellt uns vor eine ,Welt‘ aus Fragmenten, zerstückelt in tausend kleine ,Welten“. Zur gleichen Zeit ist diese Dislokation - die bis an die Grundlagen der Praxis, bis an die Fundamente des Bewusstseins, bis an die Wurzeln des Handelns reicht - von einer immer bündigeren Integration begleitet. Auf diesem weiträumigen Feld der Bruchstücke erhebt sich der Staat als Wächter. [...] Die Tendenz zur Totalisierung und zur ,Integration“ (in das gesellschaftliche Ensemble, d.h. den Staat) kaschiert die Separationen. Die Zersplitterung der Alltäglichkeit, umfassender noch als die der Arbeit, verschleiert die Unifizierung von oben und die Unterdrückung der ursprünglichen Differenzen.“(Lefebvre 1978: 146)

In diesem Funktionalismus der Wohnmaschinen sieht Lefebvre die Menschen sich einander ähnlich werden. Sie haben die gleichen Wege, gehen in den gleichen Einkaufzentren einkaufen, suchen im selben Sozialzentrum denselben Rat und vergnügen sich in denselben Freizeitzentren (ebd.: 143). Und er sieht, dass die Leute alles daran setzen werden, sich in dieser Gleichheit zu unterscheiden (ebd.: 149). Um gemäß ihrer ,höchste[n] Objektivität: die der lebendigen Tätigkeit des Menschen, der bewusst das Menschliche hervorbringt“" (Lefebvre 1971a: 76f.), d.h. um gemäß ihrer inneren Leibnatur sich dennoch individualisieren und als menschliche Subjekte herausbilden zu können, werden die im Städtebau funktional eingepferchten Menschen jede Nische nutzen (Lefebvre 1978: 150) oder aber entgegen ihrer vorgesehenen Nutzung jeden Raum für sich und ihre subjektiven Repräsentationen umfunktionieren, was sie zugleich als Abweichende hervorbringt und den Staat als Wächter und Organisator der Integration notwendig werden lässt. Aber er sieht vor allem, dass dieser Städtebau nicht zufällig vom Himmel fällt, son- 
dern das Resultat einer bereits etablierten gesellschaftlichen Alltagspraxis ist. Die Leute lebten bereits so selbstverständlich industriell durchfunktionalisiert und in die Bereiche Arbeit, Freizeit und Privatleben fragmentiert, dass der funktionale Städtebau der Nachkriegszeit als notwendige Entsprechung folgen musste.

Geht es Lefebvre schon im ersten Band seiner „Kritik des Alltagslebens“ um die Frage, wie die Leute diese Zusammenhänge wieder herstellen, um ihre Fragmentierungen bewusst oder unbewusst wieder zusammenzuführen, d.h. welche Solidarisierungen sie eingehen, um ihren (bewussten oder unbewussten) Entfremdungen auszuweichen (Lefebvre 1987: 234f.). ${ }^{40}$ So geht es ihm im zweiten Band ,darum, auf den Erfordernissen einer radikalen Umwandlung des Alltagslebens eine langfristige Politik zu errichten“ (ebd.: 295), um so den politischen Konsequenzen aus den wissenschaftlichen Erkenntnissen durch die Ermöglichung einer - wie es mit der WidersprücheRedaktion genannt werden kann - Politik des Sozialen (Kap. 6.1) bei ihrer Verwirklichung zu helfen. ${ }^{41}$ Im ersten Präludium seiner „Einführung in die Modernität" spricht er diesbezüglich von einer „mondiale[n] Mäeutik“, der Geburtshilfe einer „Zukunft, die die Gesellschaft in sich trägt“ (Lefebvre 1978: 23). „2 „Die Mäeutik der Modernität“, so schreibt er weiter, „geht nicht ohne einen gewissen Utopismus“" (ebd.: 57). Utopismus meint dabei aber nicht das Erträumen von Luftschlössern und bis ins Detail ausgemalte $\mathrm{Zu}$ kunftsszenarien. Lefebvre meint damit stattdessen ganz im Sinne Blochs

40 Lefebvre schreibt: „Das menschliche Wesen - das aufhört, menschlich zu sein - wird ein Instrument im Dienst von Instrumenten (den Produktionsmitteln), einer Sache im Dienst einer Sache (des Geldes) und Objekt einer Klasse, Gebrauchsgegenstand für Individuen, die selbst ihrer Wirklichkeit und Wahrheit ,beraubt" sind (die Kapitalisten). Und seine Arbeit, die ihn zum Menschen machen sollte, wird, statt ein grundlegendes und menschliches Bedürfnis zu sein, nur unter Zwang verrichtet, weil sie selbst nur ein Mittel ist (, seinen Lebensunterhalt zu verdienen'), statt einen Teil des sich frei betätigenden menschlichen Wesens zu bilden. [...] die eigene Tat des Menschen wird ,ihm zu einer fremden gegenüberstehenden Macht, die ihn unterjocht, statt dass er sie beherrscht '." (Lefebvre 1987: 170) Zugleich geht es Lefebvre aber darum, in dieser kapitalistischen und städtebaulichen Entfremdung ,die Wiederherstellung der Gemeinschaft in den Fabriken und Arbeiterquartieren“ ausfindig zu machen: „Hier herrscht ein anderer Stil des täglichen Lebens, andere Bedürfnisse; neue Sorgen treten in Konflikt mit den Bedingungen des täglichen Lebens, die durch die kapitalistische Struktur der Gesellschaft und des Lebens aufgezwungen werden; sie haben die Tendenz, eine Solidarität, eine wirksame Verbindung zwischen den Individuen und den Gruppen, zu bewirken. Wie manifestiert sich dieser Konflikt? Wie drückt sich diese immer zerschlagene, immer wieder auflebende Solidarität aus? Wie setzt sie sich konkret um? Genau das muss die Kritik des Alltagslebens in ihren positiven Aspekten herausfinden und beschreiben?“ (ebd.: 234f.)

41 In „Der Marxismus“ von 1948 stellt Lefebvre den dialektischen Materialismus als das methodologische Instrumentarium des Marxismus als „eine wissenschaftliche Soziologie mit politischen Konsequenzen“ (Lefebvre 1975a: 17) heraus.

42 Dass Sünker hieran seine „Theorie der Sozialpädagogik“ (Sünker 1989) entfaltet, die auf die kulturrevolutionäre Transformation der Gesellschaft insistiert, um darin die Herausbildung des emanzipatorischen Subjekts zu ermöglichen, wurde in Kap. 4 bereits dargelegt. 
Begriff der „Tendenz-Latenz-Utopie“ (Bloch 1978), unabgegoltene Tendenzen der Praxis, Residuen des funktionalistischen Alltags, die sich empirisch ermitteln lassen und denen beim Verwirklichen geholfen werden muss. Für die Ermittlung des Unabegoltenen plädiert Lefebvre für die Analyse der von AkteurInnen artikulierten Ironie, die einen gewissen „Abstand gegenüber der Gegenwart, dem Aktuellen, das viele Menschen überwältigt, überrollt“, schafft und worin er überhaupt erst die „Chance“ sieht, das Unabgegoltene bildhaft überspitzt und nur andeutend zum Ausdruck bringen zu können (Lefebvre 1978: 58). Im zweiten Band seiner „Kritik des Alltagslebens“ wird zur Ermittlung des Unabgegoltenen der Praxis ein wissenschaftlicher Ansatz formuliert:

„Wir operieren an einem Objekt [...], das erst noch verwirklicht werden muss. Wie anders als durch Bilder könnte man es in den Griff bekommen? Um von gesicherten Erfahrungen zur Konstruktion virtueller Objekte zu gelangen, kommt man um gewisse Schritte nicht herum: Formulieren einer Problematik, Ausarbeiten von Hypothesen, Vorschläge über das, was möglich ist, Erfindung von Bildern usw.“(Lefebvre 1987: 370f.)

Das impliziert die transdisziplinäre „Teilnahme der Betroffenen“ am Forschungsprozess, die „Vorschläge über das, was möglich ist", machen, die dann anschließend „geprüft, einander konfrontiert und diskutiert [werden]“ (ebd.). Durch die kollaborativ-partizipatorische Mitgestaltung aller Beteiligtengruppen an der Herausarbeitung dessen, was als Residuum - oder um noch einmal mit Bloch zu sprechen, da sich beide sehr nah sind, ohne sich zu rezipieren -, als unabgegoltenes Noch-Nicht des Wirklichen, als „Möglichkeit im passiven Sinne, als Potentialität" (Bloch 2013a: 267f.) bezeichnet werden kann, können über die Analyse der Bilder latente, aber subalternierte Tendenzen der Praxis diskursiv herausgebildet und sichtbar gemacht werden, an denen ein sozial- und kommunalpädagogisches Ortshandeln ansetzen kann, durch das die zu Residuen subalternierten Tendenzen der Subjektbildung befreit und weiter ausgebildet werden können. ${ }^{43}$

Zugleich erhält die wissenschaftliche Forschung dadurch den „demokratischen Charakter des gesellschaftlichen Lebens“" (Lefebvre 1987: 372). Die „Kritik des Alltagslebens“ ist damit nicht nur ein Instrument der Erkenntnis, sondern auch einer poietischen Praxis. Wissenschaft ist für Lefebvre nicht nur das Ermitteln dessen was ist, sondern Ermitteln dessen was möglich ist und - darin entfaltet sich Lefebvres Anspruch an den Marxismus als Wissenschaft mit politischen Konsequenzen (Lefebvre 1975a: 17) - wie, mit Bloch (2013a: 267f.) gesprochen, die passive Potenzialität der Praxis in aktive Potenzialität umschlagen und verwirklicht werden kann. Es ist genau dieser

43 Vor dem Hintergrund der Sichtbarmachung schlägt May eine ikonografische Ergänzung von Winklers Konzept „,sozialpädagogische[s] Ortshandeln[s]“ (Winkler 1988: 278ff.) vor, indem er es mit Freires (Freire 1975) Prinzip Kodierung/Dekodierung kombiniert (May 2017b: 162ff.; May/Herzog 2017; May 2018a, 2019; Kunstreich/May 2020). In Kap. 19 der vorliegenden Arbeit wird hieran Anschluss gesucht. 
Doppelaspekt der „Kritik des Alltagslebens“, der sie als transdisziplinäres und subjektorientiertes transformatives Forschungs- und Bildungsprogramm ökosozialer und sozial-ökologischer Transformationen auszeichnet. Die „Kritik des Alltagslebens" ist dabei nicht nur ein Instrument partizipatorischemanzipatorischer Praxis zur qualitativen Verbesserung alltäglicher urbaner Interaktionen, sondern vielmehr ein empirisch-utopierendes, sprich praxisphilosophisches Instrument der Arbeit am Sozialen entlang der tatsächlichen Arbeit des Sozialen. Der emanzipatorische Anspruch zeigt sich im Anspruch der Verwirklichung eines objektiv möglichen, d.h. angefangenen aber im funktionalistischen Alltag allenfalls nur begrenzt verwirklichbaren menschlichen Gemeinwesen, durch das allseitig sich entwickelnde Individuen resp. „totale Menschen“ erst ermöglicht werden können, weil gemeinsam mit den AkteurInnen und Gruppen nach Wegen gesucht wird, das Noch-Nicht gesellschaftlicher Praxis durch politische Aushandlungsprozesse zu verwirklichen. Die „Kritik des Alltagslebens“ zielt damit auf ein politisches Gemeinwesen zur Verwirklichung eines menschlichen Gemeinwesens. D.h. zur Verwirklichung des Reichtums dessen, zudem Menschen miteinander fähig sind, wenn sie nicht von einer, wie er es in „Der dialektische Materialismus“ nannte, „,brutalen Objektivität“ historisch-städtebaulicher und ökonomischer Determinierungen (Lefebvre 1971a: 76f.) in ihren Interaktionen begrenzt werden.

Hatte Lefebvre schon 1939 in „Der Dialektische Materialismus“ die „Aufhebung“ der gesellschaftlichen Praxis in der Theorie ,ihren Ort in der Bewegung des Handelns“ und ,nicht in der reinen Zeit des philosophischen Geistes"44 (ebd.: 84), so arbeitet er diesen Anspruch im zweiten Band der „Kritik des Alltagslebens“ als „strategische Hypothese“ (Lefebvre 1987: 372) politischer Konsequenzen weiter aus: ,Sie beginnt beim entferntesten Möglichen“, d.h. vom bildhaft gemachten unabgegoltenen Möglichen der Praxis, „kehrt vom fernen Möglichen zurück zum nahen Wirklichen und versucht, die Kraftlinien und Tendenzen des Wirklichen bis zu jenem äußersten Möglichen zu verlängern" (ebd.), um das bildhaft zum Ausdruck gebrachte Unabgegoltene mit den vorhandenen und, wo diese fehlen, noch zu erarbeitenden Mitteln der jeweiligen Gegenwart zu verwirklichen. Die strategische Hypothese „hält den Kontakt mit den Tatsachen, sie entdeckt neue Tatsachen, sie ordnet sie ohne zwanghafte Systematisierung, sie ist verifizierbar. Ihre Verifizierung geschieht in der Praxis. “" ${ }^{45}$ (ebd.) Nämlich in der veränderten Praxis, die nun politisch eingefordert werden kann. Den Weg vom Hier zum Dort entlang der „strategischen Hypothese“ nennt er Transduktion (vgl. Kap. 6.2),

44 Darin findet sich bereits Lefebvres Lesart des praxisphilosophischen Theorems Feuerbachs, wonach die „Philosophie [...] nicht mit sich, sondern mit ihrer Antithese, mit der Nichtphilosophie zu beginnen“ (Feuerbach 1969: 181) hat, die er in „Metaphilosophie“ noch einmal verdichtet vorlegt.

45 In Kap. 6.2 wurde der inhärente Wahrheitsbegriff des Ansatzes strategischer Hypothesen als apothekarische Wahrheit herausgestellt, die subjektiv zu heilen und objektiv zu helfen vermag (Hörisch 2010: 27). 
die „vom Wirklichen (Gegebenen) zum Möglichen voran[schreitet]“; d.h. sie „schreite[t] vom Gegenwärtigen zum Virtuellen, vom gegebenen zum Möglichen voran, in einer unaufhörlichen Erkundungstätigkeit.“(ebd.: 373f.).

Mit anderen Worten: man beginnt mit der „Formulierung einer Problematik“, geht über zur empirisch gestützten „Ausarbeitung von Hypothesen“ und „Vorschläge[n] über das, was “ - mit Bloch gesprochen - „objektiv-real möglich“ (Bloch 2013a: 271ff.) ist und stellt es als Bilder, Utopien, Begriffe (das geht bei Lefebvre alles fließend ineinander über) heraus, an denen sich die Praxis zur Lösung eines Problems strategisch orientieren kann (Lefebvre 1987: 370). Lefebvre geht es also nicht darum, Probleme für Menschen oder Gruppen zu lösen, sondern mit ihnen (Stichwort Arbeitsprinzip Partizipation, Kap. 9). Also darum, ihnen das benötigte Bewusstsein alltäglicher Begrenzungen zu ermöglichen, damit sie sich die zur Überwindung ihrer Begrenzungen benötigten politischen Mittel einfordern bzw. selbst erarbeiten können, um sich in Auseinandersetzung mit den sie begrenzenden Lebensweisen anderer Status- und Interessensgruppen emanzipieren zu können.

Mit dem Ansatz der „strategischen Hypothese“ kündigt sich bereits an, was er später als „Recht auf Stadt“ (1968) ausformulieren wird: eine partizipatorische Wissenschaft emanzipatorischer Stadtentwicklung. In dieser kollaborativen Zusammenarbeit von Forschenden und zu Beforschenden erweist sich der Ansatz Lefebvres als transdisziplinäre Wissenschaft in transformatorisch-partizipatorischer Hinsicht, die den beteiligten Gruppen eine kommunale Selbstorganisation als Politik ihres Sozialen eröffnen soll (Kap. 6.1). Eine dergestalt subjektorientierte Transformationsstrategie ermöglicht es den AkteurInnen bzw. Transformationssubjekten, sich „,ie Gleise [zu] legen, auf welchen sie sich bewegen wollen“" (Winkler 1988: 279). Zuvor aber folgt 1965 noch eine kritische Auseinandersetzung mit der Philosophie, aus der die Grundsteinlegung einer „Metaphilosophie“ hervorgeht, ohne die das „Recht auf Stadt" in seiner Reichweite unverstanden bleibt.

\subsubsection{Lefebvres „Metaphilosophie“ als praxisphilosophischer Begründungsrahmen ökosozialer Transformation}

In „Metaphilosophie“ macht Lefebvre eine Inventur der Philosophie und rettet wichtige Begriffe wie Totalität, Entfremdung, Subjekt, Mimesis und Poiesis, indem er sie praxisphilosophisch wendet und mit dem Themenfeld Stadt aus seiner „Kritik des Alltagslebens“ zusammenbringt. Dabei legt er eine Entscheidungskaskade frei, durch die erst Feuerbachs Diktum - „Philosophie hat $[\ldots]$ nicht mit sich, sondern mit ihrer Antithese, mit der Nichtphilosophie zu beginnen“ (Feuerbach 1969: 181) - verwirklicht, d.h. entlang der erst die Wendung der Philosophie zur Praxisphilosophie vollzogen werden 
kann (diese Entscheidungskaskade ist Marx' Praxisphilosophie zwar implizit, bleibt aber unausgesprochen):

„Entweder der Philosoph gibt zu, daß es keine spezifisch philosophischen Probleme gibt, son-
dern nur menschliche, kulturelle oder gesellschaftliche Probleme. In diesem Falle kann er weder
bevorzugte Aufmerksamkeit noch besonderes Rederecht in Anspruch nehmen. Jeder kann mitre-
den, seine Meinung und seine Einschätzung formulieren, seine Lösung dieser Probleme vortra-
gen. Die Meinung des Philosophen ist nur eine unter anderen, besser dargelegt, vielleicht mit
besseren Argumenten untermauert, aber keineswegs von den Meinungen der anderen so klar
unterschieden wie die Wahrheit vom Irrtum oder von der bloßen Annäherung. Oder der Philo-
soph behauptet, er sei ein Mensch mit Problemen oder gar der Mann der Probleme, und er habe
sehr wohl eigene Probleme: eine Problematik. Dann wird er eine Liste dieser Probleme aufstel-
len [....." (Lefebvre 1975c: 55)

Und weiter:

„Entweder erklärt die Philosophie, sie habe die nichtphilosophische Welt, die ganze Welt bereits in sich aufgesogen und das System sei vollendet. [...] Oder die nichtphilosophische Welt bleibt gegenüber der Philosophie und der philosophischen Welt bestehen, sei‘s als erbitterter Widersacher und hartnäckige Realität [...].“ (ebd.: 57)

Aber vor dem Hintergrund, dass die „Erfahrung des Philosophen oder die philosophische Erfahrung [...] niemals imstande [ist], die gesamte menschliche Erfahrung zu umfassen“" (ebd.: 59), schlussfolgert Lefebvre weiter:

„Um aus diesem Konflikt herauszukommen und ihn zu lösen, bleibt nur ein Weg: Die Philosophie muß weltlich werden, aber nicht als Philosophie, sondern als Projekt, das sich in der Welt verwirklicht und durch eben diese Verwirklichung selbst im Prozeß der Aufhebung ${ }^{46}$ negiert. Dann erst verlieren sowohl die philosophische als auch die nichtphilosophische Welt ihre Einseitigkeit und werden beide überwunden. Die Verwirklichung der Philosophie wird zugleich ihre Größe und ihren Verlust herbeiführen.“(ebd.: 57)

Praxisphilosophie, so lässt sich resümieren, heißt also nicht Philosophieren um des Philosophierens Willen, sondern Philosophieren um der grundlegenden Transformation bzw. Revolutionierung der gesellschaftlichen Praxis Willen. Doch sowohl der Begriff der Welt, auf den sich das PhilosophischWerden der Welt und das Weltlich-werden der Philosophie bezieht, als auch der Begriff der gesellschaftlichen Praxis bleiben blass, wenn sie nicht aus ihren begrifflichen Wolken auf die Erde geholt werden. So schreibt Lefebvre: „Unsere Welt ist die Erde, und was sich über die ganze Erde ausbreitet, das verweltlicht, mondialisiert sich." (ebd.: 61) Und wenn es unsere kapitalogene urbane Praxis ist, so lässt sich fortführen, die sich über die ganze Erde ausbreitet und ihre Bewohnbarkeit zerstört (Stichwort Kapitalozän), dann muss diese Praxis (Stichwort ,imperiale Lebensweise“, Brand/Wissen 2017) von Grund auf erneuert werden, damit zu einer poietisch veränderten (ökosozia-

46 Aufheben meint bei Lefebvre im Sinne Hegels (Hegel 1970b: 94f.) einmal das Beenden des bisherigen theoretischen, praxisabstinenten Philosophierens und durch das Aufheben der Philosophie auf eine andere Ebene, die der Praxis, um das Philosophieren dort praktischtätig, d.h. weltlich fortzuführen bzw. fortzuentwickeln (vgl. Kap. 6.2). 
len und sozial-ökologischen) Praxis der Urbanisierung der Erde gelangt werden kann. Dafür allerdings muss die Praxisphilosophie auch die Schwierigkeiten angehen,

„die sich aus dem Verhältnis zwischen Philosophie und Politik ergeben. Entweder läßt der Philosoph das politische Handeln, den Staat und die Politik außerhalb seines Denkens: Doch sobald er es ablehnt, sich mit den politischen Fragen zu belasten, erfaßt sein Denken nicht mehr die Totalität. Es läßt sie sich entgleiten, wendet sich von der Praxis ab [...]. [...] Oder der Philosoph tritt mitten ins politische Leben ein, d. h. er läßt die Politik und den Staat in seine Philosophie eintreten: Dann muß er sofort die peinliche Wahl zwischen verschiedenen Wegen treffen, von denen keiner als philosophisch befriedigend angesehen werden kann.“ (Lefebvre 1975c: 71)

Das Verhältnis von Mensch-Stadt-Erde ist der Praxisphilosophie also genuin. So wie die Menschen leben, so denken sie. Und so wie die Menschen denken, so planen und realisieren sie ihre Städte und urbanisieren damit ihre menschlichen und nicht-menschlichen Sozial- und Naturverhältnisse der Erde. Dadurch wird die Stadt den Menschen entlang ihrer Techniken der Urbanisierung zur zweiten (künstlichen) Natur (ebd.: 268), zu ihrem (Kunst-) Werk - das entlang grenzenlosen Wirtschaftswachstums die terrestrischen Lebensbedingungen zu zerstören droht: Der einstige städtische Zusammenhang von Gesellschaft und Staat, durch den die Städte als politische Städte zur freien Gesellschaft für freie Individuen hätten entwickelt werden können, wurde und wird mit der kapitalistischen „Industrialisierung unter der Ägide des Staats [...] an sein Ende“ geführt (ebd.: 124). „Das Ende der Stadt, der Zerfall dessen, was einst schönstes Werk und die prächtigste Wohnstatt des Menschen war“, so Lefebvre weiter, „mahnt uns gebieterisch, neue Werke zu schaffen." (ebd.: 125). Auf die historische räumliche Parzellierung der Erde in Grundstücke folgte mit der Industrialisierung die zeitliche und zementierte über den Städtebau die räumliche. Aus der physischen Grundbestimmung des Menschen, dass er ,gehalten [ist], sich seine Wohnstätte [in der Praxis und auf der Erde] selbst zu schaffen" (ebd.: 351), erwachsen dieser doppelten Manifestation der Welt der Bruchstücke allenthalben Versuche, die die räumlichen und zeitlichen Fragmentierungen des menschlichen Daseins wieder zu einem zusammenhängenden System zusammenzuführen.

Die Religion und der quasi-religiöse Philosophismus der abendländischen Metaphysik in all ihren Spielarten von Platon bis Hegel und nicht minder der dogmatische Marxismus sowie der dogmatische urbane Funktionalismus entlang des kapitalistischen Industrialismus - all diese und generell alle Systeme, so Lefebvre, ,sind gefährlich, weil sie dem ,Wirklichen“ eine neue, fast vollendete, nahezu endgültige Form aufzwingen und es in dieser Form zum ,Wirklichen“ konstituieren" (ebd.: 352). Damit setzen sie die gesellschaftlichen Produktionsverhältnisse, die ein bestimmtes System der Kompensierung der herrschaftlich eingeführten räumlichen und zeitlichen Fragmentierungen ja erst haben notwendig werden und hervorgehen lassen, fest und reproduzieren dadurch ebendiese Produktionsverhältnisse. Doch der 
„gesellschaftliche Determinismus“ (Lefebvre 1971a: 120) der Systeme, d.h. der auf ein bestimmtes So-sein, nämlich dem des Systems, aus ist, widerspricht dem ,physischen Determinismus“" (ebd.: 118) des lebendigen Werdenmüssens ${ }^{47}$, das sich jeder Systematisierung und Funktionalisierung entzieht. Die „,brutale Objektivität“ der Teleologie eines jeden - ob nun gesellschaftlichen, ökonomischen, technischen und/oder wissenschaftlichen Systems widerspricht der „höchsten Objektivität“", dem nach vorne offenen Telos lebendigen Werdenmüssen (ebd.: 76f.). Keine systemische Wirklichkeit kann daher jemals deckungsgleich sein mit der wirklichen Wirklichkeit. Sie hinterlässt einen nicht ins System einpflegbaren Rest, ein Residuum, eine Nicht-Identität, das/die sich die Subjekte inmitten eines wie offen und kollaborativ auch immer gestalteten Gesellschaftssystems miteinander selbst aneignen müssen, um daran ihren Subjektbildungsprozess selbst zu bestimmen und selbst zu vollziehen (Stichwort Politik des Sozialen, Kap. 6.1). In „Die Zukunft des Kapitalismus“ (1973) fasst Lefebvre dieses nicht-inkludierbare Residuum des Menschen als emanzipatorische Sinnlichkeit seines Leibes zusammen, die sich ,nicht widerspruchslos verstümmeln, in Fragmente zerlegen, des Rhythmus berauben und auf katalogisierte Bedürfnisse, auf Bilder und Spezialisierungen reduzieren lässt. Ein unbeugsames Element der Subversion inmitten des Raumes [...]“" (Lefebvre 1974: 107).

Daraus folgt nun zwingend, dass gesellschaftliche Transformationsprojekte nicht und nie nach Plan verlaufen können, auch wenn diese mit noch so ausgeklügelten Modellen und Bilanzierungen eine noch so bestechende Realität simulieren. Aus dem (simulierten) Sein folgt kein Sollen (Hume 1978: 211f.), auch kein Können und kein Wollen. Die Lebendigkeit des Leibes macht jede Planung zu Schanden, und dort, wo Systeme bzw. Systemrealitäten entlang einer verordneten Subjektbildung verwirklicht werden sollen, dort tun sie den leiblichen Menschen Gewalt an, indem sie sie als Simulacren des Systems herzustellen versuchen und damit unweigerlich Residuen produzieren. Wenn den Menschen durch sanktionierende und aktivierende Inklusionsmaßnahmen zugleich das Opponieren gegen und/oder das Resignieren vor ihrer Systematisierung verunmöglicht wird, dann wird diese organisiere Friedlosigkeit zur alltäglichen Zerreißprobe für Mensch und System, was, wie bereits erwähnt, den Staat und seine Apparaturen (wie bspw. Soziale Arbeit) als Wächter über die permanent brodelnde Gewalt und als Wächter

47 Allein die Tatsache, dass wir Altern, der Alterungsprozess selbst aber nicht mit inhärenten Zielen - vom Tod einmal abgesehen - ausgestattet ist, sondern erst durch die soziale Praxis der Menschen mit dem Alterungsprozess verwoben werden, belegt dieses telische, aber nicht teleologische Werdenmüssen der Physis, die Lefebvre recht irreführend als physischen Determinismus bezeichnet. Käme darin ein harter Determinismus zum Ausdruck, würde Lefebvres Bemühen, den Poiesisbegriff praxisphilosophisch aufzubereiten, ad absurdum geführt. Für diesen telischen, aber nicht teleologischen Determinismus der Physis als Werdenmüssen ließe sich daher wohl besser der Begriff des Indeterminismus aufbringen. 
der gewalttägigen Inklusion ins System notwendig werden lässt (Lefebvre 1978: 146).

Die einem System zwingend inhärente Logik ist das kybernetische Denken, d.h. das Denken von einer angenommenen Zukunft her, die zugleich alle anderen möglichen Zukünfte suspendiert und stattdessen das jeweilige System als die künftige Wirklichkeit projiziert und die Gegenwart für die hierfür die notwendigen Schritte systematisiert (zum Überblick: Wiener 1977; Weizsäcker 1989; Vester 1986). ${ }^{48}$ Der Unterschied zwischen dem kybernetischen Denken und der „strategischen Hypothese“ (Lefebvre 1987: 372) ist, dass die strategische Hypothese beansprucht, die je projizierte Zukunft nicht aus einem wie auch immer begründeten festgesetzten objektiven SollensZustand, sondern aus den Residuen und einem nur bildhaft umrissenen subjektiven Wollens-Zustand heraus zu entwickeln und zu politisieren. Politisieren heißt, dass die je individuellen Zukunftsvorstellungen unverwirklichter Subjektresiduen miteinander in Diskussion zu bringen sind und sich entlang ihres jeweiligen politischen Dissenses poietisch entwickeln zu lassen, so dass sich - etwa hinsichtlich der Klimafrage - die selbstverständlich auch objektiven Transformationsnotwendigkeiten zum Erhalt des eigenen terrestrischen Wohnraums zur eigenen Subjektentwicklung öffentlich und subjektiv angeeignet sowie ausgestaltet werden können. Öffentlich heißt dabei, dass der Transformationsprozess nicht ins Privatleben abgeschoben, d.h. zum Privatproblem gemacht wird, von wo aus es den Menschen in ihren eigenen Verantwortungsbereich verlegt wird, ob und wie (ökosoziale und sozial-ökologische) Transformationen gelingen. Entlang solcher Privatisierungsdiskurse gesellschaftlicher Probleme - wie etwa das des Klimawandels - wird es geradezu überflüssig, noch genauer hinschauen zu müssen, ob die Menschen nicht nur tun können, was sie sollen, sondern auch es so tun zu können, wie sie es wollen. Die Zerstörung der Grundlage des menschlichen wie terrestrischen Gemeinwesens, in und mit dem sich die Menschen entwickeln können ist der existenzielle Sachzwang, aus dem die objektiven Transformationsnotwendigkeiten des Klimawandels resultieren, die den Menschen aber nur dann auch die Möglichkeit zur emanzipatorischen Bildung eröffnen, wenn sie sich die Klimaproblematik subjektiv aneignen können und zugleich über die Mittel verfügen, nicht nur ihre Probleme mit der Klimaproblematik zu politisieren, sondern auch Stadt und Erde als Gemeingüter hervorzubringen und de-

48 Wiener weist noch kurz vor seinem Tod auf die „Gefahr“ hin, „dass wir uns von dem dringenden Bedürfnis nach mathematischen Methoden zur Anwendung ausgeklügelter Feinheiten verleiten lassen, denen in der beobachtbaren Wirklichkeit nichts entsprechend eindeutig Messbares oder gar Bestimmbares gegenübersteht. Mit Sicherheit kann man wohl sagen, dass kybernetische Überlegungen sehr anregend für die Sozialforschung wirken können und wirken, dass uns aber die Entwicklung strenger Techniken im einzelnen vor manche Schwierigkeiten stellen wird.“ (Wiener 1977: 492) Das ist gerade angesichts der gegenwärtigen Inflation technischer Überlegungen zur gesellschaftlichen Bearbeitung der Klimafrage von höchst aktueller Brisanz. 
mokratisch $\mathrm{zu}$ bewirtschaften, um sie so vor weiteren finanzialisierenden Zugriffen und ihrer weiteren Vernutzung zu bewahren.

Damit werden zwingend Konflikte und Widersprüche zwischen den verschiedenen Gruppen und den Repräsentationen ihrer Lebensweisen und Lebenswerte sichtbar und dadurch überhaupt erst gemeinsam bearbeitbar gemacht, was die Reproduktion plutokratischer Herrschaftsverhältnisse überhaupt erst durchbrechen könnte. In Fortführung seines Ansatzes einer „mondiale[n] Mäeutik“, der Geburtshilfe einer „Zukunft, die die Gesellschaft in sich trägt“" (Lefebvre 1978: 23), schreibt Lefebvre:

„Im Lauf dieser theoretischen und praktischen Versammlung müssen die residualen Elemente einander begegnen und anerkennen. Sie müssen sich verändern: durch Konvergenz und Kampf gegen die Systeme, von denen sie ausgestoßen und durch den Ausstoß bestimmt werden [...]: auf daß jedes einzelne wieder die Würde und Kraft einer Essenz erlange, jener Essenz, die von derselben Macht, die sie zerstören wollte, überhaupt erst hervorgetrieben wird [...]. Auf die Residuen setzen in einem initiierenden poietischen Akt, sodann die Residuen in der Praxis bündeln und den wohlgefügten Systemen und Formen entgegenstellen, um neue Formen aus ihnen zu ziehen - das ist die große Herausforderung" (Lefebvre 1975c: 336)

Sich dieser Herausforderung zu stellen, Wege und Mittel zu suchen und zu finden, die es vermögen auch ,die Verweigerung in Kreativität um[zu]wandeln“ (ebd.: 125), indem entlang von „strategischen Hypothesen“ (Lefebvre 1987: 372) die reichhaltigen Möglichkeiten menschlicher Interaktionen für die Gestaltung des Werdens hervorgebracht werden können - darin erblickt Lefebvre die Aufgabe und das Potenzial seiner „Metaphilosophie“ als Ausformulierung des praxisphilosophischen Begründungsrahmen seiner „Kritik des Alltagslebens“, die den Leuten ihre subalternierten Bedürfnisse zugänglich zu machen beansprucht, um sie als politisiertes Verlangen hervorzubringen. Damit ist „Metaphilosophie“ nicht nur ein praxisphilosophischer Begründungsrahmen einer emanzipatorischen Kritik des imperialen Alltagslebens, sondern auch eines emanzipatorischen ökosozialen Transformationsbegriffs, der es vermag die Klimafrage über einen kollaborativen Stadtentwicklungsprozess mit der Frage der Verwirklichung menschlicher Subjektivität $\mathrm{zu}$ verbinden. Zur Frage steht nun, ob und wie es Lefebvres „Metaphilosophie“ gelingen kann, die Frage ökosozialer Transformation zur Frage sozial-ökologischer Transformation zu übersteigen, worin sich ja die Frage künftiger, d.h. einer ein Anthropozän bildenden Stadtentwicklung erst vervollständigt.

\subsubsection{Lefebvres „Metaphilosophie“ als praxisphilosophischer Begründungsrahmen sozial-ökologischer Transformation?}

Lefebvres „Metaphilosophie“ ist nicht ohne Grund mit „Prolegomena“ untertitelt. Sie stellt die Basis dar, auf der die weiteren Überlegungen zur Stadt und zum Wohnen weiter aufbauen. Wohnen, das heißt metaphilosophisch 
verstanden, als Sterblicher auf der Erde sein, wie Heidegger in seinem berühmten Vortrag „Bauen, Wohnen, Denken“ von 1951, d.h. mitten in der Wiederaufbauphase der kriegszerstörten Städte, etymologisch rekonstruiert (Heidegger 2000b). Während Heidegger aber die Wohnung des Seins bereits in seinem „Humanismusbrief“ (Heidegger 2000c) in der Sprache ausfindig zu machen versucht, erblickt Lefebvre sie ,in der Praxis und auf der Erde“ (Lefebvre 1975c: 351).

Den Zusammenhang von Praxis und Sein stellt Lefebvre als Verhältnis von Praxis, Mimesis und Poiesis dar. Praxis arbeitet er dabei als ,das Wirkliche der Menschen“ heraus, die durch ihre „Beziehungen zur Natur und zur Materie“, d.h. durch gesellschaftliche Verstoffwechselung der Materialität der Erde (ebd.: 61) ihre (Menschheits-)Geschichte hervorbringen, mit der sie sich ihres Seins bewusst werden (ebd.: 12f.). Praxis ist damit nicht nur „Schöpferin von Geschichte“ und des begriffenen Seins, sondern ist zugleich auch „Ort und Ursprung der Begriffe“ (ebd.: 13), womit Lefebvre an Marx/ Engels' Diktum anschließt, dass das gesellschaftliche Sein das Bewusstsein prägt (Marx/Engels 1978: 26ff.).

Mit der Betonung der Praxis als „Schöpferin von Geschichte“ (Lefebvre 1975c: 13) wird zugleich ihr poietisches Moment betont. Als Poiesis bezeichnet er ,menschliche Aktivität, soweit sie auf Aneignung der ,Natur' (physis) abzielt, [...] sowohl der Natur im Umkreis des menschlichen Wesen als auch der Natur in ihm (seiner inneren Natur: Sinne, Empfindungsvermögen, Sinnlichkeit, Bedürfnisse und Wünsche etc.)" (ebd.: 14), und dabei Kreationen bzw. Werke hervorbringt. Die Stadt ist für Lefebvre nur ein Beispiel, zugleich aber auch das für die Entwicklung der Menschheitsgeschichte - und angesichts der erdgestalterischen Effekte der Stadt: auch für die Entwicklung der Erdgeschichte (Stichwort Kapitalozän) - historisch umfassendste menschliche Werk (Lefebvre 1975c: 157f., 2014: 158). Diese Verbindung von Praxis und Poiesis, wird damit als mimetisches Verhältnis herausgestellt, sich durch die Praxis die eigene innere Natur der äußeren ähnlich zu machen. Mimesis wird dabei von Lefebvre weniger als anthropologisches Vermögen ins Auge gefasst, wie etwa bei Wulf (Wulf 1989, 1994, 1997, 2014, 2020), sondern eher als „,soziologische Angelegenheit“, da sie sich zwar in der Erziehbarkeit der Menschen zeigt, diese zugleich aber immer durch einen gesellschaftlichen Alltag vermittelt ist, d.h. „logisch, juristisch, zeremoniell, gestisch, rituell sein [kann]" (Lefebvre 1975c: 17) und dadurch ihre jeweilige historische und gesellschaftliche Form erhält, wie und womit sich im Inneren den äußeren Verhältnissen ähnlich gemacht werden muss. Entsprechend begreift Lefebvre den Menschen aus einer anthropologisch-(praxis)philosophischen Perspektive

a) als ,,alltäglich“, da er sich im urbanen Alltagsleben und mit den Bordmitteln der Erde ,vollenden“ muss, 
b) als „mimetisch“, da er sich entlang des gesellschaftlichen Alltagslebens, d.h. durch die alltägliche Verstoffwechslung von gesellschaftlichen Naturverhältnissen hervorbringt und dadurch sich und seine gesellschaftliche Verstoffwechselung der Erde reproduzierend produziert, er dadurch aber auch beides allmählich transformiert, was ihn

c) als ,poietisch“ ausweist (ebd.: 269) und physiologisch überhaupt dazu befähigt, (bewusst oder unbewusst, absichtlich oder unabsichtlich) die Erd- und Menschheitsgeschichte mitzugestalten.

Um sich in und mit der Geschichte als totaler Mensch (Marx) bzw. Übermensch (Nietzsche) bewusst verwirklichen zu können - und auf diese Poiesis kommt es Lefebvre unentwegt an - bedarf es einerseits eine soziologische „Kritik des Alltagslebens“, aber andererseits zugleich einen festen Entschluss der PraxisakteurInnen. Deshalb sieht Lefebvre die Mimesis in der modernen funktionalistischen Alltagspraxis nur dann als Poiesis vollendet, wenn sich den ökonomischen Zwängen der industriellen Produktionsweise zur alltäglichen Wiederholung und Reproduktion derselben durch eine persönliche „Entscheidung, das Alltagsleben zu verändern“ (ebd.: 16), zu entsagen begonnen wird. Mimesis „war fruchtbar, solange große symbolische Bilder sich ihr zur ,Nachahmung' anboten. Erst in der modernen Alltäglichkeit wird Mimesis zur platten Imitation von ,Modellen', die ihr als abstrakte Objekte gesetzt sind" (ebd.: 268):

„Zwischen den Menschen und die Natur, zwischen den Menschen und seine eigene Natur hat die Technik eine zweite Natur geschaltet. Doch heute ist diese zweite Natürlichkeit nicht mehr die Stadt oder die Kunst oder die Sprache, nicht einmal mehr die gegenständliche Welt allgemein, sondern eben jene Technik, die zugleich Instrument, Mittel, Vermittlung, Mitte [...] ist. Diese Technik imitiert den Menschen imitiert die Natur und den Menschen, die sich ihrerseits gegenseitig imitieren“. (ebd.)

In dieser alltäglichen Nachahmung der Moderne ,wird Mimesis zum lächerlichen Füllsel der Alltäglichkeit und Modernität" und

„stellt die Menschen vor die Grundfrage: [...] Entweder rückt nun die Poiesie wieder an die höchste Stelle in einem neuen Verhältnis zwischen Mensch und ,Natur' oder ,Sein', oder der Mensch wird von seinem Werk gepackt und nicht mehr losgelassen." (ebd.)

- und, so ließe sich ergänzen, verfängt sich im Pleonasmus bis hin zur Selbstzerstörung durch die Zerstörung der Existenzbedingungen auf und mit der Erde. Gegenwärtig zeigt sich der selbstzerstörerische Pleonasmus des ökonomistischen Funktionalismus in der kapitalistischen Wachstumsideologie, von der aufgrund gesellschaftlicher Sachzwänge der ,imperialen Lebensweise" (Brand/Wissen 2017) solange nicht abgelassen und nur zu Modifikationen, d.h. zum grünen Kapitalismus führen kann, solange sich nicht im persönlichen Umfeld dafür entschieden wird, der alltäglichen ,,imperialen Lebensweise" (ebd.) radikal entsagen zu wollen. Auch wenn sich dabei zugleich bewusst gemacht werden muss, ihr nur gemeinsam mit Anderen und 
vor allem nur langfristig und strategisch, also nur durch ein theoriegeleitetes kommunalpädagogisches Ortshandeln (Winkler 1988, 2006; Richter 2001, 2019b) bzw. Sozialraumentwicklung-/Organisation (Alisch/May 2013, 2015; May 2017b), radikal entsagt werden kann. Das wiederum bedeutet aber gerade dort, wo dieses gemeinsame Handeln im funktionalen Alltag zerbrochen bzw. entfremdet ist, muss dieses gemeinsame Handeln durch kommunalpädagogische Sozialraumentwicklung erst wieder ermöglicht werden, um zu einer solchen apodiktischen Entscheidung zu gelangen. An diesem fehlenden Gemeinsamen und dem dadurch fehlenden gemeinsamen Handlungssubjekt entzündet sich die ganze Schwierigkeit gesellschaftlicher Transformationsprozesse.

Der von Lefebvre herausgestellte Zusammenhang des Menschen als alltägliches, mimetisches und poietisches Wesen deklassiert nicht nur kybernetische Plan-Transformationsphantasien als naiv, sondern auch radikale Bruchtheorien, auch wenn diese verführerisch nahe liegen. ${ }^{49}$ Stattdessen müssen Transformationsprozesse mit Lefebvre immer als mimetische Prozesse verstanden und ermöglicht werden, die an die vorherrschende Alltagspraxis Anschluss suchen müssen, um sie kreativ bzw. poietisch weiterentwickeln zu können - immer vor dem Hintergrund des festen Entschlusses, sie perspektivisch an der Wurzel zu verändern und letztlich eine gänzlich andere Lebensweise zu Wege zu bringen. Dieser Prozess bedarf der gegenseitigen Reflexion, um sich der eigenen „imperialen Lebensweise“ (Brand/Wissen 2017) auch in den kleinsten Winkeln der eigenen Existenzbearbeitung, aber auch um sich der darin unterdrückten (residualisierten) Wünsche, Vermögen und Utopien nicht nur bewusst werden zu können, sondern diese auch politisieren und demokratisch regulieren zu können. Eben darin besteht die von Lefebvre verfolgte Argumentationslinie: die „Kritik des Alltagslebens“ als „strategische Hypothese“ und „Methode der Residuen“ in einem „Recht auf Stadt" aufgehen zu lassen, durch das in einer „Revolution der Städte“ eingemündet werden kann, in der - und hier schließt die vorliegende Studie an sich ökosoziale und sozial-ökologische Transformationen ausdrücken und verselbstständigen können. Darin wäre der mimetische Transformationsprozess in einer Poiesis der Praxis aufgegangen, die die Aneignung der Natur,

49 Wright schreibt, dass Bruchtheorien gerade für diejenigen attraktiv sein können, denen die „,bestehenden Macht-, Privilegien- und Ungleichheitsstrukturen [...] dem Streben nach menschlicher Entfaltung dermaßen abträglich [scheinen], dass die Vorstellung, sie einfach zu zerschlagen, um etwas Neues und Besseres zu schaffen, ansprechend sein kann" (Wright 2017: 419). Zudem ,kann ein deutliches Verständnis der Logik der Grenzen einer auf Bruch beruhenden Strategie gesellschaftlicher Transformation zu einem klaren Verständnis der Alternativen beitragen“ (ebd.: 149). Und ebenso „,können beschränktere Formen des Bruchs in bestimmten institutionellen Kontexten möglich sein, und es gibt Aspekte dieser Strategie - etwa die Betonung harscher Konfrontationen mit den herrschenden Klassen und dem Staat -, die unter bestimmten Bedingungen wichtig sein können“ (ebd.: 419). 
„sowohl der Natur im Umkreis des menschlichen Wesen als auch der Natur in ihm" (Lefebvre 1975c: 14) revolutioniert hat.

Im praxisphilosophisch gewendeten Begriff der Poiesis erweitert sich der Begriff des totalen Menschen, „das freie Individuum in der freien Gesellschaft“ (Lefebvre 1971a: 134), aus „Der Dialektische Materialismus“ (1939), um die „Kritik des Alltagslebens“ zu einer „strategischen Hypothese“ (Lefebvre 1987: 372f.) des Möglichen und noch Unverwirklichten der Praxis, dessen latente Tendenzen ausfindig gemacht werden können und an die entschlossen Anschluss zu suchen ist, um sie zu verwirklichen (Stichwort „Methode der Residuen“, Lefebvre 1975c: 332ff.). Die Entschlossenheit muss sich dabei aus dem transduktiven Wissen eines anderen Wirklichen als „InMöglichkeit-Seiendes“ (Bloch 2013a: 238ff.) speisen können, das ein politisches Gemeinwesen bedarf, um vom Modus des Möglich-Seins zum Modus des Wirklich-Seins überführt werden zu können. Das bedeutet letztlich, dass entsprechende politische Strukturen erarbeitet werden müssen, um verbindlich vom Hier zum Dort zu gelangen. Poiesis erweist sich damit auch als Begriff politischer Transformation und ist in seiner meta- bzw. praxisphilosophischen Wendung der Schlüsselbegriff für Lefebvres „Recht auf Stadt“.

Dass Lefebvres „Metaphilosophie“ als praxisphilosophischer Begründungsrahmen ökosozialer Transformationen verstanden werden kann, wurde bereits herausgestellt. Die Frage, ob sie auch als praxisphilosophischer Rahmen sozial-ökologischer Transformationen erachtet werden kann, für die eine multi- und transdisziplinäre Wissenschaft mit nicht-wissenschaftlichen städtischen PraxisakteurInnen als Bedingung herausgestellt wurde (Kap. 6.2), ist damit aber noch nicht beantwortet. Hierfür müssen auch seine weiteren Werke weiter in Betracht gezogen werden, in denen Lefebvre seine Metaphilosophie weiterentwickelt, zu der das Buch „Metaphilosophie“ bloß das Vorwort war.

\subsubsection{Recht auf Stadt als kollaboratives Transformationskonzept}

Neben seinem 1968 erschienenen Werk „Das Alltagslebens in der modernen Welt“, in dem Lefebvre bereits ein „Recht auf Urbanität“ (Lefebvre 1972: 208) erwähnt, erscheint im selben Jahr auch „Das Recht auf Stadt“ (1968), das er dort als ein „Recht auf das städtische Leben“ (Lefebvre 2016: 166) beschreibt, das

„sich als höhere Rechtsform [offenbart]: das Recht auf Freiheit, auf Individualisierung in der Vergesellschaftung, auf das Wohngebiet und das Wohnen. Das Recht auf das Werk (auf mitwirkende Tätigkeit) und das Recht auf Aneignung (klar zu unterscheiden vom Recht auf Eigentum) bringen sich in dieses Recht auf Stadt ein.“"(ebd.: 189)

Das Recht auf Stadt ist für Lefebvre die Forderung nach der Wiedererlangung lebendiger Poiesis mit den Mitteln des Urbanen und damit eine 
Kampfansage an die „brutale Objektivität“ des „ökonomische[n] und historische[n] Determinismus“ (Lefebvre 1971a: 76) des industriellen Städtebaus, der die „höchste Objektivität“ (ebd.: 77) des Menschen, seine lebendige Menschwerdung entlang des Kapitalkreislaufs funktionalisiert, und zum Simulacrum der bestehenden Verhältnisse reduziert. Soweit fügt Lefebvre in „Recht auf Stadt“ seinem Werk nichts Neues hinzu. Auch bleibt er weitgehend im Ungefähren, welchen Rechtsstatus das „Recht auf Stadt“, das er weder als juristisches Recht noch als Naturrecht herausstellt, beanspruchen kann. Stattdessen ,legitimiert [es] die Weigerung, sich durch eine diskriminierende, segregierende Organisation aus der städtischen Wirklichkeit verdrängen zu lassen“" (Lefebvre 2016: 216). Es bedeutet, wie Lefebvre in einem späteren Aufsatz zu „Raum und Politik“ von 1972 weiter schreibt, „die Herstellung oder Wiederherstellung einer räumlich-zeitlichen Einheit, einer Sammlung statt Fragmentierung“, das die „Kenntnis einer Produktion, jener des Raums" voraussetzt und anwendet (ebd.: 216f.).

Das eigentliche Novum besteht vor allem in Vorschlägen, wie eine Wissenschaft der Stadt aussehen kann, um den StadtbewohnerInnen zu einem Recht auf Stadt zu verhelfen. Hier greift er die strategische Hypothese bzw. die Transduktion, die er 1961 im zweiten Band der „Kritik des Alltagslebens“ entwickelt hat, erneut auf:

„Die Transduktion erarbeitet und konstruiert einen theoretischen Gegenstand, einen möglichen Gegenstand, und zwar ausgehend von Informationen über die Wirklichkeit sowie eine Problematik, die durch diese Wirklichkeit aufgeworfen ist. Die Transduktion setzt ein unaufhörliches Feedback zwischen dem verwendeten begrifflichen Rahmen und den empirischen Beobachtungen voraus. Ihre Theorie (Methodologie) bringt einige spontane gedankliche Arbeitsgänge des Urbanisten, des Architekten, des Soziologen, des Politikers, des Philosophen in Form. Sie bringt Strenge in den Einfall und Erkenntnis in die Utopie.“(ebd.: 154f.)

Eine Wissenschaft der Stadt soll also in Erfahrung bringen, was den BewohnerInnen durch die urbane Praxis an Residuen entsteht und zugleich transduktiv ermitteln, wie es ihnen durch eine veränderte urbane Praxis ermöglicht werden könnte, sie zu verwirklichen, um sich als allseitige (totale) Menschen entwickeln zu können. Es handelt sich um eine „experimentelle Utopie“, „indem ihre Auswirkungen und Folgen vor Ort untersucht werden“ (ebd.: 155). Sie liefert den vorherrschenden politischen Programmen ,eine theoretische und kritische Grundlage zur Stadtreform“ (ebd.: 163). Die transduktiven „urbanistische[n] Projekte“ sollen eine empirisch gestützte „Phantasiewelt“ eröffnen, ,die sich für Aneignung (von Zeit, von Raum, von physiologischem Leben, von Begehren)“ (ebd.: 161) einsetzt. Bei dieser „Phantasiewelt" handelt es sich um „Vorschläge“, die ,den Lebensstil, die Lebensweise in der Stadt, die Entwicklung des Urbanen [...] betreffen“" (ebd.) und die zur Sache der städtischen Politik werden müssen.

In einem rückblickenden Vorwort zu „Die Revolution der Städte“ fasst Klaus Ronneberger das „Recht auf Stadt“ zusammen als - erstens - das 
„Recht auf die Differenz“ bzw. auf „Differenz in Gleichheit“ (Ronneberger 2014: XIII). D.h. das Recht auf Anerkennung dessen, zu dem sich ein Mensch noch entlang seiner residualisierten subjektiven Vermögen und Fähigkeiten individuell entwickeln kann. Dieses Recht auf Differenz setzt ein politisches Gemeinwesen voraus, das dieses Recht als Recht auf „allgemeine Selbstbestimmung" (Lefebvre 2014: 159f.) ins Zentrum des Politischen setzt, was - zweitens - als „Recht auf Zentralität“ bezeichnet wird (Ronneberger 2014: XIII). Diese politische Zentralität muss auch in der physischen Stadt verwirklicht werden können, was - drittens - als „Recht auf Straße“ bezeichnet wird (Lefebvre 2014: 160; Ronneberger 2014: XIII). D.h. als Recht auf Öffentlichkeit und öffentliche Erfahrungsräume des politischen Dialogs. Mit dem „Recht auf Stadt“, d.h. auf ein städtisches Leben, fordert Lefebvre letztlich eine Wissenschaft zur Unterstützung und Verwirklichung des Rechts, Lebensentwürfe frei zu wählen und mit den sozialen wie politischen Produktionsmitteln der Stadt ausgestalten und verwirklichen zu können. Es steht damit ganz im Dienste der anthropologischen Philosophie des ,freie[n] Individuum[s] in der freien Gesellschaft“, der ,,vollentfaltete[n] Individualität in der unbegrenzten Mannigfaltigkeit möglicher Individualitäten“ (Lefebvre 1971a: 134) - wie er sie schon 1939 in „Nietzsche“ und „Der Dialektische Materialismus“" zu erarbeiten beginnt und die beide - Nietzsche und Marx nicht ohne ihr poietisches Verständnis des Verhältnisses von Erde und Menschwerdung verstanden werden können, was Lefebvre über das Themenfeld Stadt zu verdeutlichen und methodologisch zu verarbeiten sucht. Das „Recht auf Stadt" ist damit mit seinem metaphilosophischen Hintergrund ein wissenschaftlicher Orientierungsrahmen gesellschaftlicher Transformationen mit kollaborativem Partizipations- und Emanzipationsanspruch. Die eigentliche Tragweite seines meta- bzw. praxisphilosophischen Rechts auf Stadt offenbart sich allerdings erst in seinen folgenden Werken.

\subsection{Vom „Recht auf Stadt“" zur „Revolution des Urbanen“ - Lefebvres soziologische Praxisphilosophie}

In „Revolution der Städte“ (1970) - im Original: „Revolution des Urbanen“ setzt Lefebvre dem alltäglichen Begriff des Wohnens einen von Nietzsche und Heidegger inspirierten metaphilosophischen Begriff des Wohnens habiter $^{50}$ - entgegen. In dieser Bedeutung verwendet er ihn ganz im An-

50 „Habiter"e vom lat.: habitare, so Guelf, ,deutet in seiner ursprünglichen Bedeutung auf das wiederholte Tun hin - (davon abgeleitet ,habitude" (lat.: habitudo) für Gewohnheit)" - und „,bedeutet darüber hinaus auch wohnen. Mitte des elften Jahrhunderts beschreibt das Verb die Gewohnheit irgendwo zu sein, eine Wohnung zu haben“ (Guelf 2010: 81, FN 256). 
schluss an den in „Metaphilosophie“ zentralen Begriff Poiesis als „schöpferisches Sprechen" durch die Praxis (Lefebvre 1975c: 73), d.h. die dichte Zusammenführung von Poesie und Wahrheit im alltäglichen Hervorbringen von Kreationen und Werken (ebd.: 338), was Lefebvre in der vorsophistischen Bedeutung des Wortes Logos bei Heraklit (zum Überblick: Bremer/Dilcher 2013) und dann erst wieder bei Nietzsche ausfindig macht, der den lange unter der Last der europäischen Metaphysik des Begriffsrealismus begrabenen „Bund[] zwischen Poesie und Philosophie“ wiederbelebt hat (Lefebvre 1975c: 138f.), und den er bei Heidegger fortgesetzt sieht. Um die Weite des Begriffs des Wohnens in „Revolution der Städte“ zu erblicken, bedarf es folgend einer kurzen näheren Betrachtung dieser beiden ,heikle[n] Fälle“ (ebd.: 139).

\subsubsection{Nietzsche und Heidegger als Protagonisten des metaphilosophischen Begriffs des Wohnens}

Das Wohnen wird von Lefebvre bei Nietzsche hervorgehoben als mimetische Beziehung der Menschen zur Welt. Das findet sich nicht nur im „Zarathustra“ (1883), sondern auch kurz zuvor in „Die fröhliche Wissenschaft“ (1882), etwa am Beispiel der Stadt Genua:

„Ich habe mir diese Stadt, ihre Landhäuser und Lustgärten und den weiten Umkreis ihrer bewohnten Höhen und Hänge eine gute Weile angesehen; endlich muß ich sagen: ich sehe Gesichter aus vergangenen Geschlechtern - diese Gegend ist mit den Abbildern kühner und selbstherrlicher Menschen übersäet. [...] Ich sehe immer den Bauenden, wie er mit seinen Blicken auf allem fern und nah um ihn her Gebauten ruht, und ebenso auf Stadt, Meer und Gebirgslinien, wie er mit diesem Blick Gewalt und Eroberung ausübt: alles dies will er seinem Plane einfügen und zuletzt zu seinem Eigentume machen, dadurch, daß es ein Stück desselben wird.“ (Nietzsche 1954b: 170)

Schaut man aber den Gedankengang Lefebvres Begriff des Wohnens in „Revolution der Städte“" weiter an, kommt darin vor allem eine subjektive Beziehung der Menschen zur Erde zum Vorschein - mit deren Vergesellschaftung und der daran sich entwickelnden Menschen, ihren Produktions- und Erkenntnisweisen erst ihre Welt(en) entstehen -, die bei Nietzsche ebenfalls einen zentralen Stellenwert einnimmt. So ist Nietzsches Figur des Übermenschen der „Sinn der Erde“:

„Bereits in der ersten, schnell scheiternden Ansprache, erklärt Zarathustra den Übermenschen zum ,Sinn der Erde', nimmt diese Seinsbestimmung aber sogleich auf eine Willensbestimmung des versammelten Volkes zurück: ,Seht, ich lehre euch den Übermenschen! Der Übermensch ist der Sinn der Erde. Euer Wille sage: der Übermensch sei der Sinn der Erde! Ich beschwöre euch,

Lefebvre führt dieses Wort „als erster“ als soziologischen Begriff ein und beschreibt seit 1967 damit das Wohnen als einen ,soziale[n] und doch poetische[n] Akt, ein Generator von Poesie und Werken“, wie Lefebvre es 1981 im dritten Band seiner „Kritik des Alltagslebens“" zusammenfasst (Lefebvre 1981, 94 zit. in ebd.: 81, FN 256, eigene Übersetzung). 
meine Brüder, bleibt der Erde treu und glaubt Denen nicht, welche euch von überirdischen Hoffnungen reden!‘ (Za I, Vorrede 3, KSA 4, 14 f.). [...] Die Verbindung zur Erde im Sinn einer Einrichtung des Lebens ohne gleichzeitige Ausrichtung auf externe bzw. transzendente Referenzen muss im Zeitalter nach dem Tod Gottes ihrerseits erst einmal herbeigeführt und lernend erworben werden. Der Übermensch kann also erst dann zum ,Sinn der Erde' werden, wenn die Menschen denkend, fühlend und wertend in neuer Verbundenheit zur Erde leben. [...] Erst durch die Überwindung feststehender Bilder und Begriffe vom Menschen kann demnach die Sicht auf den Übermenschen geöffnet werden [...].“(Müller 2019a: 236f.)

War die Erde für Marx ein Arbeitsmittel zur Menschwerdung ist sie für Nietzsche „,vielmehr ein globales Prinzip mit immanentem Charakter einerseits, andererseits Indikation des Metaphernbereichs, dessen er sich bedient, um Begriffe mit philosophischem Gehalt zu schaffen bzw. traditionelle kritisch anzugehen“" (Günzel 2011: 219). Gleichwohl ist sie für beide ein „Kampfplatz der Wertsetzungen“ (ebd.) und eine Kampfansage an die metaphysisch abgeschaffte physische Welt des Leibes und der Erde, sowie ihres (physiologischen bzw. ökologischen) Verhältnisses zueinander, worin sie die von Kant eingeleitete Kopernikanische Wende der Philosophie (Kant 1977: 25f.) erst vollenden: Nicht nur ist die Erde nicht der Mittelpunkt der Universums, um die sich die Sterne drehen (Kopernikus), und nicht nur ist der Mensch nicht der Mittelpunkt der Erkenntnis, um den sich die Objekte der Erkenntnis drehen (Kant), wohl aber werden die Dinge von der Erde aus, d.h. aus der Perspektive von Erdbewohnern erkannt. Damit wurde zwar das Mensch-Erde-Verhältnis stärker betont, um aber die Erde praxisphilosophisch in den Mittelpunkt der Menschwerdung setzen zu können, muss sie für Marx erst wieder aus der kapitalistischen Vernutzung befreit und für Nietzsche an die vakant gewordene Stelle des gestorbenen Gottes gerückt werden. Erst dann kann die Erde für den Menschen eine poietische Bedeutung haben, an der und mit der er sich selbst als poietisches Wesen begreifen kann.

Schon in seinen „Nachgelassenen Fragmenten“ aus den Jahren 18751879 lässt sich dieser Bezug bei Nietzsche ausmachen. Mit dem Tod Gottes entfällt auch die Erziehung des Menschen nach seinem Bilde, die ,vielfältig geeignet [ist], ihn recht unglücklich zu entwickeln. [...] Von nun an hat die Erziehung sich ökumenische Ziele zu stecken [...]: - die Aufgabe ist so groß, daß eine ganz neue Gattung von Erziehern, ein neues Gebilde aus Ärzten Lehrern Priestern Naturforschern Künstlern der alten Kultur" (Nietzsche 1988: 436) die Bühne der Erde betreten muss. In „Metaphilosophie“ hat Lefebvre in Anlehnung an den Science-Fiction-Roman von Alfred Elton van Vogt „Die Welt der Null-A“ (van Vogt 1982) diese „ganz neue Gattung“ (Nietzsche 1988: 436) von WissenschaftlerInnen als „Nexialisten“ (Lefebvre 1975c: 342) bezeichnet, denen die Aufgabe zukommt, „die Begegnung von Ideen und Techniken, die anscheinend nichts miteinander gemeinsam haben, vorauszuplanen und zu organisieren" und 
„sich nicht mit der Zusammenführung verschiedener Leute [befassen], sondern verschiedener Parzellen der Realität, der Erkenntnis und des Handelns. Dazu braucht er keine philosophische Theorie [...], sondern er muss sich im Gegenteil befreien von den fiktiven Begegnungen, die Philosophen erdacht und in die Philosophie gelegt haben“" (ebd.: 368).

Gleichwohl muss sich die neue Gattung nexialistischer WissenschaftlerInnen, zumindest wenn sie nicht abermals die konkreten leiblich-subjektiv bedürftigen Menschen übergehen und sie stattdessen strukturalistisch oder systemtheoretisch auf bloße Zeichengeber und Informationsquellen reduzieren wollen - und darin geht Lefebvre im entscheidenden Maße über van Vogt hinaus -, aber dennoch mit „,der Zusammenführung verschiedener Leute [befassen]“ (ebd.). Allerdings nicht entlang der „fiktiven Begegnungen, die Philosophen erdacht und in die Philosophie gelegt haben" (ebd.), sondern entlang ihrer Residuen (ebd.: 334ff.). Erst darin wird der praxisphilosophische Schritt von der metaphysischen Philosophie in die Physis der Praxis vollzogen und eben dadurch, wie Lefebvre es nennt, „Metaphilosophie“ betrieben, wodurch die Praxis erst philosophisch und die Philosophie erst praktisch werden kann (ebd.: 25). Und zwar nicht nur ,in der Praxis und auf der Erde“ (ebd.: 351), sondern, und darin muss Lefebvre präzisiert werden, auch in der Praxis mit der Erde.

Eine solche umfassende Wissenschaft, wie sie in der vorliegenden Untersuchung als terrestrische Nachhaltigkeitswissenschaft sozial-ökologischer Transformation zu fassen gesucht wird, muss bzw. setzt sich qua Hervorbringung ökumenische Ziele. Diese ökumenischen Ziele stehen im Gegensatz zur „kleinbürgerliche[n] Privat-Achtbarkeit der Sitte“ der Morallehre Kants (Nietzsche 1988: 460) und werden dann von Nietzsches „Zarathustra“ ausgeführt. Im Anschluss an die Feststellung von Gottes Tod sind nicht mehr nur „die Umstände, Gesellen, Eltern, Geschwister, Ereignisse der Zeit, des Ortes“ (ebd.: 436) die Erzieher der Menschen, sondern vor allem die Erde als werdende Physis, die Natur in werdender Entwicklung. Nämlich als Erziehung durch die Physis der Erde und auf diese Physis der Erde hin, kurz: Erziehung zum „Sinn der Erde“ (Nietzsche 1954a: 280). Die Erde ist für Nietzsche die Antwort auf den Tod Gottes, weil dadurch erst der freie Mensch, der sich endlich jenseits allen metaphysischen So-seins entwickeln kann, geboren wird (Lefebvre 1975c: 101). Die entlang eines Gottes basierende Lebensweise und Alltagspraxis basiert auf einer Idee, die zugleich eingebettet ist in ein teleologisches Wofür und Wohin, womit der irdischen Physis im gleichen Atemzug eine Entwicklungstendenz untergeschoben wird. Und genau diese So-Seins-Teleologie, sich einem fixen Bild ähnlich machen zu müssen, ist für Nietzsche mit Gott gestorben und hat das offene Werden (wieder) gebären lassen.

Da es für Nietzsche nun keinen meta-physischen Urheber der physischen Intentionalität mehr gibt, schlussfolgert er daraus, dass auch jedes philosophische »Du sollst! « hinfällig wird und daher letztlich nur das »Ich will« als 
Drang leiblicher Lebendigkeit übrigbleibt. So lässt er seinen Zarathustra sagen: „Leib bin ich ganz und gar und nichts außerdem“ (Nietzsche 1954a: 300). Allein dem leiblichen Wollen (Bedürfen, Wünschen, Begehren) im alltäglichen Leben nachgehen zu können, ermöglicht es, sich als gesunden Menschen dieser Erde hervorzubringen. Für Nietzsche gibt es daher nicht die Gesundheit, sondern ,[t]ausend Pfade gibt es, die noch nie gegangen sind, tausend Gesundheiten und verborgene Eilande des Lebens. Unerschöpft und unentdeckt ist immer noch Mensch und Menschen-Erde.“ (ebd.: 339). So lässt sich für Nietzsche zusammenfassen: Was die Erde ist und wird, ist und wird sie mit den Menschen. Und diesen Zusammenhang - und an dieser Stelle bleibt Nietzsche blass, weswegen hier mit Marx und Lefebvre weitergedacht werden muss - müssen sie im gesellschaftlichen Alltag erst politisch und subjektiv (wieder)herzustellen lernen. Herzustellen ist ein Bild der Erde, das - so Nietzsche in seiner „Genealogie der Moral“ (1887) - „den Willen wieder frei macht, der der Erde ihr Ziel und dem Menschen seine Hoffnung zurückgibt“ (Nietzsche 1954e: 837). Doch auch schon in seinem „Menschliches, Allzumenschliches“"von 1878 schreibt Nietzsche:

„Seitdem der Glaube aufgehört hat, daß ein Gott die Schicksale der Welt im großen leite und trotz aller anscheinenden Krümmungen im Pfade der Menschheit sie doch herrlich hinausführe, müssen die Menschen selber sich ökumenische, die ganze Erde umspannende Ziele stellen. Die ältere Moral, namentlich die Kants, verlangt vom einzelnen Handlungen, welche man von allen Menschen wünscht: das war eine schöne naive Sache; als ob ein jeder ohne weiteres wüßte, bei welcher Handlungsweise das Ganze der Menschheit wohlfahre, also welche Handlungen überhaupt wünschenswert seien; es ist eine Theorie wie die vom Freihandel, voraussetzend, daß die allgemeine Harmonie sich nach eingebornen Gesetzen des Besserwerdens von selbst ergeben müsse. Vielleicht läßt es ein zukünftiger Überblick über die Bedürfnisse der Menschheit durchaus nicht wünschenwert erscheinen, daß alle Menschen gleich handeln, vielmehr dürften im Interesse ökumenischer Ziele für ganze Strecken der Menschheit spezielle, vielleicht unter Umständen sogar böse Aufgaben zu stellen sein. - Jedenfalls muß, wenn die Menschheit sich nicht durch eine solche bewußte Gesamtregierung zugrunde richten soll, vorher eine alle bisherigen Grade übersteigende Kenntnis der Bedingungen der Kultur, als wissenschaftlicher Maßstab für ökumenische Ziele, gefunden sein. Hierin liegt die ungeheure Aufgabe der großen Geister des nächsten Jahrhunderts.“ (Nietzsche 1954d: 465f.)

Geradezu hieran anschließend fragt sich Heidegger mit Hölderlin, ob es ,auf Erden" ein solches Maß gibt und antwortet mit ihm sogleich, dass sich dieses $\mathrm{Maß}$ nicht wissenschaftlich, sondern nur im Denken begründen lässt, ,weil das, was wir nennen, wenn wir sagen, auf der Erde', nur besteht, insofern der Mensch die Erde bewohnt und im Wohnen die Erde als Erde sein lässt" (Heidegger 2000a: 205). Die Erde erhält ihren Wert für den Menschen erst dadurch, dass sie von ihm bewohnt wird und ihre BewohnerInnen sie zu ihrer Herausbildung unhintergehbar brauchen. Entsprechend schließt Heidegger an Nietzsches Figur des Menschseins als Möglichsein ${ }^{51}$ an und betrachtet die

51 Dass Heidegger, was das Möglichsein des Menschsein angeht, durchaus inkonsequent ist und es einerseits als durch die Alltäglichkeit verstellt kritisiert, andererseits aber über seinen zentralen Begriff der Sorge nicht an den Punkt kommt, Menschsein als Möglichsein je 
Menschen als vom Sein $A n$-Gefangene, die sich ihr (Mensch-)Sein als hinausragend/herausstehend ins Möglichsein ${ }^{52}$, auf und mit der Erde - im ursprünglichen Wortsinn - bauend ${ }^{33}$ ausgestalten müssen, ohne ihrer Erdverbundenheit als unhintergehbares Wohnen auf und mit der Erde je enthoben zu sein. Und um dieser unhintergehbaren Bedingung allen Daseins auf Erden gerecht werden zu können, bedarf es ,eines Maßes, das in einem zumal die ganze Dimension betrifft" (ebd.: 202), das sich für Heidegger nur über die Sprache im Denken erschließen lässt (Heidegger 2000c: 54ff.). Dass Lefebvre hieran kritisiert, dass Heidegger „die Wohnung des Seins in der Sprache“ erbaut sieht, Lefebvre hingegen ,in der Praxis und auf der Erde“ (Lefebvre 1975c: 351), wurde in Kap. 12.1 .1 bereits herausgestellt.

Dennoch wird hierin ersichtlich, worin Heidegger Nietzsche folgt, dass nämlich die Erde nur das ist und wird, was sie mit den Menschen ist und wird. Dieses Ist der Erde ist der (wieder) geschlossene „Bund[] zwischen Poesie und Philosophie" (ebd.: 138), den Lefebvre bei Nietzsche und Heidegger ausfindig macht und durch den die Erde überhaupt erst in einem metaphilosophischen Sinne, d.h. als nach-metaphysisch philosophierte Wohnung des Menschen herausgestellt werden kann, was Lefebvre dann mit Marx wieder praxisphilosophisch wendet und über den habiter-Begriff in die Soziologie einführt als regulative Idee und Analysekategorie künftiger urbaner Praxen und Praxen der Urbanisierung.

zu verwirklichen, da das menschliche Existenzial der Sorge bloß die Gegenwart in die $\mathrm{Zu}-$ kunft verlängert (Weber 2018b: 89f.), soll an dieser Stelle nur erwähnt, nicht weiter untersucht werden, da es für die weitere Argumentation nicht von Belang ist.

52 Heidegger entwickelt hierfür den Begriff der Ek-sistenz, der ,sich weder inhaltlich noch der Form nach mit der existentia [deckt]. Ek-sistenz bedeutet inhaltlich Hinausstehen in die Wahrheit des Seins. Existentia (existence) meint dagegen actualitas, Wirklichkeit im Unterschied zur bloßen Möglichkeit als Idee. Ek-sistenz nennt die Bestimmung dessen, was der Mensch im Geschick der Wahrheit ist. Existentia bleibt der Name für die Verwirklichung dessen, was etwas, in seiner Idee erscheinend, ist. Der Satz: ,Der Mensch ek-sistiert ${ }^{`}$ antwortet nicht auf die Frage, ob der Mensch wirklich sei oder nicht, sondern antwortet auf die Frage nach dem ,Wesen' des Menschen." (Heidegger 2000c: 18f.) Das Wesen des Menschen ist für Heidegger ,weder die Verwirklichung einer Essenz, noch bewirkt und setzt die Ek-sistenz gar selbst das Essentielle“, sondern ist das, was die Sprache denkend vermag hervorzubringen (ebd.: 54ff.).

53 In seinem Darmstädter Vortrag „Bauen, Wohnen, Denken“ von 1951 stellt Heidegger heraus: „Das alte Wort bauen, das sagt, der Mensch sei, insofern er wohne, dieses Wort bauen bedeutet nun aber zugleich: hegen und pflegen, nämlich den Acker bauen, Reben bauen. Solches Bauen hütet nur, nämlich das Wachstum, das von sich aus seine Früchte zeitigt. Bauen im Sinne von hegen und pflegen ist kein Herstellen. [...] Beide Weisen des Bauens - bauen als pflegen, lateinisch colere, cultura, und bauen als errichten von Bauten, aedificare - sind in das eigentliche Bauen, das Wohnen, einbehalten." (Heidegger 2000b: 149f.) 


\subsubsection{Habiter als zentraler Begriff ökosozialer Transformationen}

Mit dem Begriff habiter kommt es Lefebvre also darauf an, die Weisen der Vergesellschaftung der Naturverhältnisse, oder wie er es nennt, der Produktion des Raums und mit ihr die Verstädterung der Erde begrifflich zu fassen und die mit der Raumproduktion verbundenen Blockierungen leiblicher Menschschwerdung analytisch in den Blick nehmen zu können, um daran entlang Möglichkeiten gesellschaftlicher Transformationen zu erforschen, die die bislang verhinderten subjektiven Möglichkeiten als Möglichkeiten des urbanen Bewohnens der Erde zu verwirklichen. „Recht auf Stadt“ liefert hierbei als „,experimentelle Utopie“, die „Auswirkungen und Folgen vor Ort untersucht" (Lefebvre 2016: 155), ,eine theoretische und kritische Grundlage zur Stadtreform“ (ebd.: 163), die eine empirisch gestützte „Phantasiewelt“ eröffnen, „die sich für Aneignung (von Zeit, von Raum, von physiologischem Leben, von Begehren) einsetzt" (ebd.: 161). Soweit eine kurze Widerholung.

Wohnen heißt in diesem metaphilosophischen Sinne Lefebvres - ganz im Anschluss an seine frühen Überlegungen von 1939 und 1946 - sein eigenes Leben mit dem gesellschaftlichen Alltag als Werk hervorbringen zu können. Werk und Wirken hängen hierbei aufs Engste zusammen: Sich als Werk hervorzubringen heißt, sich als wirkender, als etwas bewirken-könnender, als wirklicher Mensch bewusst werden zu können. Es geht darum, dass das Wohnen den Menschen ermöglicht, individuelle Lebensstile frei entwickeln (oder verwerfen) zu können. Mit der funktionalistischen Alltäglichkeit entlang der politischen Ökonomie des städtischen Raums (Stichwort ,imperiale Lebensweise“, Brand/Wissen 2017), die den Wohnraum Erde als geplantes Funktionshabitat hervorbringen, wird aber nicht nur das Bewirken-können des Menschen auf (s)ein Funktionieren-sollen reduziert, sondern es reguliert und begrenzt auch die Möglichkeiten, sich die Mitwelt mit allen Sinnen anzueignen und sich dadurch als Individuum resp. als totalen Menschen zu hervorzubringen.

An den subjektiven Vermögen und Fähigkeiten menschlichen Miteinanders, die durch die abverlangte Funktionalität im alltäglichen Leben in ihrer Entwicklung gegängelt, gar unterdrückt werden, entzündet sich das „Recht auf Stadt“. Mit „Die Revolution der Städte“ verschiebt sich aber zugleich Lefebvres Fokus von der urbanen Praxis zur Praxis der Urbanisierung, d.h. der dialektischen Verschränkung beider und ihrer gegenseitigen Hervorbringung. Und hier wird dann auch der ökologische Aspekt explizit gemacht, der sich in „Metaphilosophie“ bereits implizit ankündigt. Urbanisierung wird von Lefebvre dabei in seiner weitestmöglichen Fassung begriffen als Prozess „,von der ,reinen Natur', der den ,Elementen“ ausgelieferten Erde [.] bis zur gänzlichen Vollendung“" (Lefebvre 2014: 13) der ,verstädterten Gesellschaft, die aus der Industrialisierung entsteht“ (ebd.: 7), und „die ganze Erde erfasst“" (ebd.: 158). Entlang dieses dialektischen Prozesses der Erdgeschichte, der 
sich vom Geologischen zum Sozialen vollzogen hat und als solcher noch immer fort geführt wird (vgl. Exkurs in Kap. 6.2), transformiert sich das Ökologische, der Haushalt des Wohnraums Erde in ein „Produkt der sozialen Arbeit" (ebd.: 164), d.h. in einen sozialen Raum. Mit dem frühen Aufkommen der industriellen Produktionsweise, die sich eine ihr entsprechende urbane Praxis einforderte, kam damit zugleich eine Urbanisierungspraxis auf, die sich die benötigten Rohstoffe, sowie den Rohstoff- und Warentransport als auch ihre ArbeiterInnen und KonsumentInnen herstellt und sicherstellt und dadurch den Funktionalismus der modernen Lebensweise notwendig macht und so entlang der urbanen Praxis die moderne (Industrie-)Stadt hervorbringt, womit die industrialisierten Lebensweisen in Zement gegossen wurden (vgl. Kap. 3).

Somit ist die „Produktion des Raums [...] an sich nichts Neues“ gewesen (ebd.: 165). „Neu ist die globale und totale Produktion des sozialen Raums“, wobei die ,gewaltige Ausweitung der Produktionstätigkeit [...] im Interesse derer vollbracht [wird], die sie erfinden, sie leiten und (im großen Umfang) von ihr profitieren“ (ebd.). „Der Raum“, so Lefebvre weiter, „wird dabei nicht nur in die Produktion des Mehrwertes hineingezogen“, sondern auch durch die Zuhilfenahmen staatlicher Institutionen fortwährend und global immer weiter unter die Herrschaft der Kapital(re)produktion gestellt, die dadurch ebenfalls mehr und mehr in die Produktion des Mehrwertes hineingezogen werden. In den Städten wurde und wird dadurch ,eine vollständige Neuorganisation der von den Entscheidungs- und Informationszentren aus geleiteten Produktion" hervorgebracht (ebd.), die auf Regierungsebene die entscheidenden Weichen dafür stellen, den Raum als Kapital, als kapitalistischen Raum zu produzieren, der alles, das er umfasst und konstituiert, in Wert setzt. Die Erde wird dadurch über die politökonomisch-etatistische Organisierung der Urbanisierung vom Wohnraum zur privatwirtschaftlichen Handelsware transformiert und kapitalgenerierende Wohngebiete - was Lefebvres vor dem Hintergrund der Begriffsverwendung der Chicagoschule als habitat bezeichnet - hervorgebracht, was dann begrifflich als Gentrifizierung gefasst werden kann. ${ }^{54}$

54 Vor dem Hintergrund Lefebvres meta- bzw. praxisphilosophischen Begriff des Wohnens (habiter) darf der Begriff Gentrifizierung nicht nur auf die aufwertende Inwertsetzung (bereits bestehender) städtischer Flächen und Räume in Anschlag gebracht werden (zum Überblick der gegenwärtigen Gentrifizierungsforschung: Eckardt 2018), sondern muss auf alles Terrestrische ausgeweitet werden, das durch die kapitalistische Urbanisierung resp. Raumproduktion hervorgebrachte ,imperiale Lebensweise“ (Brand/Wissen 2017) an menschlichen und nicht-menschlichen Naturverhältnissen (inkl. Aktanten) in-Wert-gesetzt (finanzialisiert) und einem objektiven Tauschwert zugeführt bzw. verwertet wird, während dessen subjektiver Gebrauchswert zugleich vernutzt wird. Hier wie da findet eine profitorientierte Aufwertung statt und verursacht die herrschaftliche Überformung und Verdrängung autochthoner Akteure samt der Nutzung und Produktion ihrer Räume und Ökotope, wobei der Akteursbegriff der Gentrifizierung hier sowohl menschliche als auch nicht-menschliche Akteure umfasst. 
Wenn Raum von Lefebvre analog zu Marx beschrieben wird als Produkt eines sozialen ,Stoffwechsels zwischen Mensch und Natur, ewige Naturbedingung des menschlichen Lebens und daher unabhängig von jeder Form dieses Lebens" (Marx 1962a: 198), dann erweist sich Raumproduktion darin als ökologischer Prozess, der sozial bzw. kollektiv vollzogen wird. Als sozial-ökologischer Prozess. Lefebvres habiter-Begriff öffnet damit eine Untersuchungsperspektive gesellschaftstheoretischer Kritik, auf welche Weise der sozial-ökologische Prozess der Erdentwicklung in den Prozess der Kapital(re)produktion aufgesogen wurde und wird. Er umfasst damit einerseits die „Historiografie des Kapitalismus“ (Moore 2016: 602) als Geschichte der Urbanisierung der Erde entlang des Kapitalkreislaufs und öffnet über das „Recht auf Stadt" andererseits zugleich auch die kollaborativen Möglichkeiten ökosozialer Transformationen. Und umfasst zudem die strategische Erforschung objektiver wie subjektiver Möglichkeiten der Transformationsentwicklung. In diesem transduktiven Anspruch des „Rechts auf Stadt" entlang einer „Kritik des Alltagslebens“ als strategische Hypothese ermöglicht der habiter-Zugang zur Erforschung der Verschränkung von urbaner Praxis und der Praxis der Urbanisierung den forscherisch begleiteten Menschen zumindest perspektivisch auch eine sozial-ökologische Subjektbildung. Etwa durch die Forschungsprojekte selbst, indem sie Räume zur Subjektbildung herstellen und begleiten. Für Lefebvre müssten solche Forschungsprojekte allerdings von dem emanzipatorischen Leitgedanken getragen sein, den er als „Recht auf Stadt" formuliert und das darauf insistiert, dass sie den Menschen entlang von Forschungsprojekten die Verfügungsgewalt über die Nutzung und Bewirtschaftung ökosphärischer resp. globaler Gemeingüter, wie Boden, Gewässer, Landschaften, Atmosphäre, aber auch urbaner Gemeingüter wie städtische Flächen und Räume ${ }^{55}$ samt ihrer baulichen und ökosozialen und klimaneutralen Ausgestaltung verschaffen und sich dadurch wieder als erdbewusste Menschen hervorbringen können, sich also durch eine ökosoziale urbane Alltagspraxis ein sozial-ökologisches Erdbewusstsein erarbeiten können. Entsprechend lässt sich Lefebvres „Recht auf Stadt“ im Zusammenhang mit der „Revolution des Urbanen“ als Recht auf die ökosoziale und sozial-

55 Städtische Flächen und Räume sind zwar rein juristisch privates Eigentums, aber vor dem Hintergrund, dass die Urbanisierung dieser einst unbebauten Flächen und Räume des Gemeinguts Erde nur durch kollektive Arbeit hervorgebracht und bewirtschaftet wurde/wird, woraus die Werte entstehen, die entlang des Eigentumsrechts beschützt und entlang der Immobilienmarktwirtschaft an Wert steigt, welcher ebenfalls entlang des Eigentumsrecht beschützt wird, können urbane Flächen und Räume jenseits des positiven Rechts wohl kaum als Privateigentum erachtet werden. So schreibt Harvey im Anschluss an Lefebvres „Recht auf Stadt“ und „Die Revolution der Städte“ in „Rebellische Städte“: „Gemeingüter sind also nichts, das es früher einmal gegeben hat und nun verschwunden ist, sondern etwas, das fortlaufend produziert wird, wie etwa die urbanen Gemeingüter. Das Problem ist, dass sie beständig eingehegt und in ihrer kommodifizierten und monetisierten Form vom Kapital beschlagnahmt werden, während die kollektive Arbeitskraft sie kontinuierlich weiterproduziert.“ (Harvey 2014: 144f.) 
ökologische Revolutionierung bzw. Transformation des urbanen Lebens begreifen. Ein solches Forschungsprogramm will die Wirklichkeit nicht bloß beschreiben, sondern Veränderungen ermöglichen, d.h. objektiven Möglichkeiten beim Verwirklichen helfen. „Geburtshilfe einer „Zukunft, die die Gesellschaft in sich trägt“, „,mondiale Mäeutik“ (Lefebvre 1978: 23).

Wenn der WBGU in seinem Gutachten auf Reallabor-Forschung setzt, um inter- und transdisziplinär städtisch-eigenartige, d.h. lebensweltlich und sozialräumlich nachhaltige Transformationsstrategien zu erarbeiten (WBGU 2016b: Kap. 10), dann benennt er zwar zu Recht Lefebvres „Recht auf Stadt“ als Kronzeugen dieses Ansinnens (ebd.: Kap. 3). Zugleich bleibt er aber was den emanzipatorischen Anspruch angeht weit hinter Lefebvre zurück. Nicht nur weil der Kollaborationsansatz des WBGU letztlich inkonsequent bleibt (Kap. 11.1), sondern auch hinsichtlich der gesamten Forschungsarchitektur (zur ausführlichen Kritik der inter- und transdisziplinären Forschungsarchitektur des WBGU siehe Teil D). Denn mit Lefebvre ist für einen solchen Transformationsprozess also gerade nicht bei den Forderungen nach planetarischen Leitplanken (WBGU 2014b, 2016b) anzufangen, sondern bei der Befreiung der in der ,imperialen Lebensweise“ (Brand/Wissen 2017) zu Residuen verkümmerten sozialen Produktionsweisen des städtischen Raums.

Eben diese Residuen der sozialen Produktionsweise des städtischen Raums integriert Richter in den Begriff der Kommune und lässt daran sein Konzept kommunaler Pädagogik des Sozialen ansetzen, das die Ökonomie des ganzen Hauses im Blick hat, welche heute als Gemeinwesenökonomie (zum Überblick: Lindenberg 2004; Kunstreich 2006b; Kunstreich 2018; Elsen 2018) bzw. als Postwachstumsökonomie (zum Überblick: Brand 2014; D'Alisa et al. 2016; Eversberg/Muraca 2019; Schmelzer/Vetter 2019; Brand/Krams 2018; Paech 2014, 2017, 2018) den Klimadiskurs zu gestalten sucht. Richter:

„Die Wirtschaft des , ganzen Hauses“ war dadurch gekennzeichnet, dass man den Markt grundsätzlich nicht brauchte, weil man seinen Abnehmer kannte. Vom Produkt, das man herstellte, wusste man, es wird für eine bestimmte Person angefertigt. Man kannte die Bedürfnisse des anderen und konnte sie befriedigen, ohne ihn noch in irgendeiner Weise von irgendetwas überzeugen zu müssen. Vergesellschaftung fand nicht eigentlich durch den Warentausch statt, sondern unabhängig davon." (Richter 2019b: 104)

Als Wirtschaft des ganzen Hauses bezeichnet Richter also eine gemeinwesen- und subsistenzorientierte Wirtschaftsform, die sich, wie Richter an anderer Stelle expliziert (ebd.: Kap. 10.2), ihrer kommunalen Einbettung in erdökologische Naturverhältnisse bewusst ist. Gemeint ist die Einbettung des Kommunalen in globale Gemeingüter resp. erdökologische Aktanten, die die Menschen für die kommunale Hervorbringung ihrer lokalen urbanen Lebensbedingungen benötigen und bewirtschaften: Wälder, Gewässer, Landschaften, Ressourcen und Atmosphäre. Doch genau dieser Akteurs-AktantenZusammenhang wird in der unter marktwirtschaftlichen Lebensverhältnissen 
als aus ihrem Zusammenhang gerissene Fragmente bewirtschaftet. So als wären Ökonomie, Ökologie und Soziales letztlich drei getrennte Bereiche des Lebens statt der ontische Lebenszusammenhang schlechthin. Richters Begriff der Kommune und das daran anschließende Plädoyer für eine gemeinwesenund subsistenzorientierte Wirtschaft des ganzen Hauses zielt also darauf ab, den marktgesellschafts-ideologisch fragmentierten erdökologischen AkteursAktanten-Zusammenhang subjektiv und politisch-ökonomisch wieder herzustellen, indem es die sozialen und ökologischen Voraussetzungen und Effekte des Wirtschaftens nicht nur im Blick hat, sondern auch politisch zu regulieren sucht. Statt von einer Wirtschaft des ganzen Hauses ließe sich also auch von einer kommunalen resp. sozial-ökologisch orientierten Gemeinwesenökonomie sprechen.

Mit anderen Worten: Durch die gemeinsame Urbanisierung und Kultivierung des Zusammenhangs von lokaler Erde und Arbeit, mit der sich die AkteurInnen ihre äußeren und inneren Naturverhältnisse aneignen und dadurch ihre Sozialität erarbeiten, bringen sich die AkteurInnen ihr (Handlungs)Subjekt hervor, das zu regulieren sich in ihrer subjektiven Sozio- und Wirtschaftskultur einer Produzierendensozialpolitik ausdrückt und das sich mit Richter als Kommune bezeichnen lässt. Eine Stadt lässt sich entsprechend als Raum der Vielheit subjektiver Sozio- und Wirtschaftskulturen bzw. Produzierendensozialpolitiken betrachten, der je nach den Logiken in Administration und Politik eine verobjektivierte Kommune von subjektiven Kommunen darstellt, der die kulturelle Vielfalt der kommunalen resp. subjektiven Produzierendensozialpolitiken repräsentiert oder aber repräsentativ überformt, weil bestimmte Sozio- und Wirtschaftskulturen dominieren und andere marginalisieren. Wo nun aber bestimmte kommunal bzw. subjektiv eigensinnige Produzierendensozialpolitiken durch die Sozio- und Wirtschaftskultur der „Urbanisierung des Kapitals“ (Harvey 2014: 126), also durch die Produktionsweisen solcher gesellschaftlicher Statusgruppen, die - etwa über private Eigentumsverhältnisse an Grund und Boden - die Macht dazu haben, ihre Produktionsweisen des Sozialen gegen andere herrschaftlich durchzusetzen, gegängelt und blockiert werden, bleiben die subjektiven Interaktionsformen und Produktionsweisen des Sozialen (des städtischen Raums) der marginalisierten AkteurInnen als unabgegoltene bzw. unverwirklichte Residuen zurück. Diese Residuen lassen sich also als verkümmerte Bedürfnisse menschlich-kommunaler Interaktionen erblicken, die unter der marktwirtschaftlichen Herrschaft verschüttet wurden/werden und erst durch ein subjektorientiertes kommunalpädagogisches Ortshandeln (wieder) ausfindig gemacht und politisch organisiert werden müssten, um den marginalisierten AkteurInnen ihre Emanzipation, d.h. das Recht auf die Repräsentation auch ihrer Produzierendensozialpolitik(en) im städtischen Raum zu verwirklichen.

Sollen gesellschaftliche Transformationen im Kontext von Lefebvres „Recht auf Stadt“ eine „Wirtschaft des ,ganzen Hauses““ (Richter 2019b: 
104), d.h. eine kommunale resp. sozial-ökologisch eingebettete Wirtschaft (wieder) ermöglichen, dürfen sie also nicht nur pauschal auf kurze resp. regionale Wertschöpfungs- und Lieferketten sowie auf eine pauschale Produktions- und Konsumbedarfsreduktion (Suffizienz) insistieren (Paech 2014, 2017, 2018). Sondern müssen an die kommunal-subjektiven Residuen der Menschen Anschluss suchen und sie dergestalt emanzipatorisch politisieren, dass sie es letztlich sind, die die Gestaltung der Sozio- und Wirtschaftskultur einer Stadt prägen. Angesichts der Klimafrage stellt sich nun aber die zusätzliche Herausforderung, die verschiedenen Sozio- und Wirtschaftskulturen einer Stadt mit den kommunalen geo-ökologischen Bedingungen der biophysischen Reproduktion in Einklang zu bringen und zur umfassenden Kommunalpolitik zu erheben, so dass auch die lokalen Unternehmen, ihre Produktionsweisen und Lieferketten, der kommunalpolitischen Kontrolle unterliegen, um dadurch eine Wirtschaftsweise urbaner Suffizienz zu Wege zu bringen, die entlang der kommunalen Sozialitäten auf den tatsächlichen resp. subjektiven Bedürfnissen nach Mitteln für das kommunale und urbane Leben menschlicher Verwirklichung aufbaut. Nur so ließe sich der urbane Ressourcenverbrauch (wieder) gebrauchswertorientiert und nicht nur tauschwert- und wachstumsorientiert regulieren, womit über die Politisierung der urbanen und regionalen Wirtschaftspraxis zugleich eine Politisierung der Urbanisierung innerer und äußerer Naturverhältnisse einhergeht. Es findet sich hierin die Ausformulierung einer die verschiedenen Produzierendensozialpolitiken einer Stadt übergreifenden und an einer kommunalen Wirtschaft des ganzen Hauses bzw. am sozial-ökologischen Gemeinwohl orientierten Politik des Sozialen, was hinsichtlich Lefebvres „Recht auf Stadt“ oben als Recht auf die ökosoziale und sozial-ökologische Revolutionierung bzw. Transformation des urbanen Lebens bezeichnet wurde. Bislang ist aber eine nur menschzentrierte Transformation des gesellschaftlichen Lebens noch nicht überstiegen, so dass der hier angestrebte sozial-ökologische Anspruch in Lefebvres „Recht auf Stadt“ und Richters „Kommunalpädagogik“ sich letztlich noch immer auf der Ebene ökosozialer Transformationen bewegt. Zur Frage steht aber weiterhin, wie sich der Anspruch sozial-ökologischer Transformation realisieren ließe.

Ein hierfür vielversprechender Ansatz ist Alisch ‘s/May's Sozialraumentwicklung/-organisation (Alisch/May 2013, 2015; May 2017b), die an Lefebvres „Methode der Residuen“ (Lefebvre 1975c: 334), die ja nun präzisiert werden kann als Methode der kommunalen Residuen, Anschluss sucht und über das Arbeitsprinzip Partizipation (Kunstreich 2014: 272f.; vgl. auch Kunstreich/May 2020) zu einer die verschiedenen Sozio- und Wirtschaftskulturen der Produzierendensozialpolitiken übergreifenden und an einer kommunalen Wirtschaft des ganzen Hauses bzw. am sozial-ökologischen Gemeinwohl orientierten Politik des Sozialen vorzudringen in Aussicht stellt. Mit Lefebvre und auch Richter sind die subjektiven Residuen aber ,nicht als 
Überrest [...], überlegener Ebenen““ zu untersuchen, sondern müssen als „,das dauernde Primat des Wohnraums" Erde (Lefebvre 2014: 92) begriffen werden. Mit Richters und Elsens Forderung, neben Boden, Wasser, Wälder, Luft etc. auch ,soziale Organisationsformen wie öffentliche Räume, Daseinsvorsorge" (Elsen 2018: 1061) - die an dieser Stelle als kommunaler (subjektive) Interaktionsformen von Produzierendensozialpolitiken (Widersprüche Redaktion 2012: 6f.) konkretisiert werden können - zu den zur Erde gehörenden Gemeingütern anzuerkennen, kann in dieser Hinsicht sogar über Lefebvre hinausgegangen werden. Aus einer dialektischen Perspektive Sozialer Ökologie (vgl. Exkurs in Kap. 6.2) müssen die Residuen als ,untilgbare[r] Erdenrest" (Schmidt 1988a: 85) des menschlichen Leibes bzw. der innermenschlichen Natur begriffen werden, den Schmidt bereits in Feuerachs Leibphilosophie ausfindig macht (siehe Kap. 2) und an der, wenn auch in kritischer Auseinandersetzung mit ihr, sich die Marx'sche Praxisphilosophie entwickelt. Allerdings, und in dieser Hinsicht mehr an Hegel als an Feuerbach orientiert, wenden Marx/Engels - und in deren Fortentwicklung ist Lefebvres „Metaphilosophie“ letztlich nur zu begreifen - Feuerbachs ,,untilgbaren Erdenrest" (Schmidt 1988: S. 85) sozial, d.h. interaktiv und dialektisch, wonach sich nur in interaktionalen Sozialitäten der gemeinsamen Lebensmittelproduktion zur Bedürfnisbefriedung die erdangefangenen Naturwesen vom Tier zum Menschen herausbilden können (Marx/Engels 1978: 28ff.).

Um also die Residuen als „das dauernde Primat des Wohnraums“ Erde (Lefebvre 2014: 92) und „untilgbare[n] Erdenrest“ (Schmidt 1988a: 85) in den Produktionsweisen imperialer Alltagspraxen städtischer Wirklichkeiten aufzuspüren und emanzipatorisch zu politisieren, „sind Begriffe und Kategorien erforderlich, die ins Diesseits des Erlebten des Bewohners hinabsteigen, ins Unbekannte und Verkannte der Alltäglichkeit, und die darüber hinausreichen, zur allgemeinen Theorie, der Philosophie und Metaphilosophie" (Lefebvre 2014: 90). Habiter kann als Versuch eines solchen Begriffs angesehen werden, der es vermag, die Residuen der ,imperialen Lebensweise“ - der ja bereits selbst ein Begriff kritischer Gesellschaftstheorie ist (Brand/Wissen 2017; vgl. Kap. 23) - strategisch mit einer Subjektbildung entlang ökosozialer Transformationsprozesse ins Verhältnis zu setzen, welche durch eine politische Bildung des Ökosozialen eine Subjektbildung am Ökosozialen zu ermöglichen verspricht, die wiederum ein emanzipatorisches sozial-ökologisches Subjekt, d.h. ein sich der Erde als „Produkt sozialer Arbeit“ (Lefebvre 2014: 165) bewusstes Gemeinwesen politisch verwirklichen könnte. Aber nur, wenn die Menschen die Erde nicht mehr nur als Arbeitsmittel für ihre eigene Gattung, sondern auch für nicht-menschliche Lebensformen anerkennen. Erst damit wäre entlang der Klimafrage die Bildungs- und Politisierungsfrage der Menschen zu einer Frage der Verwirklichung menschlicher 
Subjektivität verbunden, die über eine sozial-ökologische Stadtentwicklungsfrage die Frage nach einem möglichen Anthropozän umfasst.

Im hier favorisierten praxisphilosophischen Begriff sozial-ökologischer Stadtentwicklung lässt sich die von Hegel eingeführte Dialektik des ,,allgemeine[n] Begriffs" (Hegel 1970c: 273; vgl. Exkurs in Kap. 6.2) in einer materialistisch gewendeten Variante wiederfinden. Übertragen auf die gegenwärtigen Sozialen Bewegungen wie Fridays For Future, Students For Future, Scientists For Future etc. lässt sie sich formulieren: Erst wenn von den (zumeist bürgerlichen) Protagonisten klimawandelbedingter Transformationen (etwa AkteurInnen von Fridays For Future und sie unterstützende Gruppen wie Scientists For Future) entlang des dialektischen Begriffsverhältnisses von Allgemeinheit (als übergreifende Politik Sozialer Ökologie der allen gemeinsamen Erde), Besonderheit (die verschiedenen kommunalen Subjekte und Produzierendensozialpolitiken) und Einzelheit (die konkreten AkteurInnen) begonnen wird, sich so zu organisieren, dass ein politisches Gemeinwesen in der Klimafrage nicht über die Ausklammerung, sondern über die Einbeziehung von anderen, gar gegensätzlichen Positionen (etwa Klimawandelskeptizisten und -negationisten) herauszubilden versucht wird, ließe sich konfliktorientiert und diskursiv ein allen AkteurInnen gemeinsamer subjektiver Bezugspunkt, nämlich das gemeinsame Verständnis einer gemeinsamen Erde bzw. der Erde als allen gemeinsames subjektives Wesen erarbeiten, hinter den historisch nicht mehr zurück gegangen werden kann (Bewusstsein kann nicht rückgängig gemacht werden). Denn erst dann könnten sich alle AkteurInnen eines Gemeinwesens gewiss sein, aus dem die AkteurInnen auch dann nicht mehr ausgeschlossen werden können, wenn sie eine klimawandelskeptizistische/-negationistische Perspektive vertreten. Erst durch die gemeinsame Auseinandersetzung um die adäquate Beschreibung und Erklärung der gegenwärtigen Klimaphänomene, die alle Perspektiven mit einbezieht, ließe sich eine gemeinsame Aufgabenbewältigung der Klimafrage erblicken, die die verschiedenen und konfligierenden AkteurInnen (Einzelheit) und ihre jeweiligen kommunalen Produzierendensozialpolitiken (Besonderheit) zu einer übergreifenden Politik Sozialer Erdökologie (Allgemeinheit) zusammenzubringen vermag, die sowohl die Politikform als auch ihre Inhalte kollaborativ erarbeiten und nicht von vornherein herrschaftlich vorgegeben würde.

Sozial-ökologische Stadtentwicklung hieße damit also, in der Stadt und mit der Stadt ein subjektives Gemeinwesen als Stadt politisch zu verwirklichen, die es ihren AkteurInnen im politischen Diskurs ermöglichen könnte, den eigenen Alltag auf und mit der Erde als jeweils individuelles und zugleich die Erde als ihr gemeinsames und allgemeines (Kunst-)Werk (Gaia) hervorzubringen, das nicht mehr nur die menschliche Gattung ins Zentrum des Politischen der Stadt stellt, sondern neben Menschenrechten auch bspw. Tier- und Pflanzen- und Aktantenrechte, kurz: ein Recht für das Leben und 
seine erdökologischen Bedingungen anzustreben sucht. Nämlich dadurch, dass der urbane Alltag so organisiert werden kann, dass er den Menschen bewusst machen könnte, dass sie Teil des Gemeinwesens Erde sind und die Erdökologie durch ihr alltägliches und politisches Handeln - auf welche Weise auch immer, ob als WindkraftgegnerIn oder ÖkosozialistIn - mitgestalten und dass diese Mitgestaltung den Kern der Stadtentwicklung ausmacht. Darin wäre die politische Bildung des Sozialen verschränkt mit einer sozial-ökologischen (Subjekt-)Bildung am Sozialen, womit ein Anthropozän angestoßen würde, dessen Begriff sich erst und nur über die urbanen politischen Diskurse - etwa dem Recht für das Leben und seine erdökologischen Bedingungen im Kontext der menschlichen städtischen Lebensweisen - mit Inhalten füllen würde. Solange aber die Verhältnisse der urbanen Praxen und der Praxen der Urbanisierung innerer wie äußerer Naturverhältnisse nicht politisiert werden, solange bleiben gesellschaftliche Transformationsansprüche auf technologische Lösungsansätze (ökologische Modernisierung) beschränkt und lassen das historisch mögliche Projekt eines Anthropozäns als unabgegoltene Möglichkeit der Erdgeschichte zurück.

Wie also ließe sich über ökosoziale Transformationen des Städtischen zur sozial-ökologischen Transformation des Gesellschaftlichen mit globalgesellschaftlich-planetarischer Reichweite gelangen?

\subsubsection{Politische Konsequenzen Lefebvres und nochmal zur Frage von Lefebvres „Metaphilosophie “ als praxisphilosophischer Begründungsrahmen sozial-ökologischer Transformation}

1973 spitzt Lefebvre seine bisherigen Überlegungen zur sozialen Raumproduktion in „Die Zukunft des Kapitalismus“ (orig. „Das Überleben des Kapitalismus") noch einmal ökologisch zu:

„Es ist nicht nur die gesamte Gesellschaft, die zum Ort der Reproduktion (der Produktionsverhältnisse und nicht mehr nur der Produktionsmittel) wird, sondern auch der gesamte Raum. Vereinnahmt vom Neokapitalismus, sektorisiert, zu einem homogenen und dennoch fragmentierten und zerstückelten Milieu reduziert (nur in winzigen Stückchen wird der Raum an die ,Kundschaft' verkauft), wird der Raum zum Sitz der Macht. Die Produktivkräfte erlauben denen, die über sie verfügen, die Herrschaft über den Raum und sogar die Produktion des Raums. Diese Macht zur Produktion des Raumes erfasst die ganze Erde und reicht sogar darüber hinaus. [...] Während einerseits das Wachstum der Produktivkräfte die Natur zerstört und den materiellen Raum umformt, führt andererseits das Privateigentum (am Boden, also am natürlichen Raum) die Produktivkräfte zurück in den Rahmen früherer, überholter Epochen der landwirtschaftlichen Produktion und der ländlichen Natur.“" (Lefebvre 1974: 100)

Und weiter:

„Was man als Umwelt und Umweltverschmutzung nennt, ist nur ideologische Verschleierung; vor allem der Begriff ,Umwelt‘ hat keinerlei präzise Bedeutung; er meint alles und nichts, die ganze Natur ebenso wie die städtischen Randgebiete. Die Vergiftung, die Umweltkrise ist nur ein 
Symptom viel tiefreichender Probleme, zu denen die Entfesselung einer unkontrollierten Technologie gehört [...].“( (ebd.: 125f.)

Was sich als damals schon - in der Zeit der Erstveröffentlichung des Berichts des Club of Rome „Die Grenzen des Wachstums“ von 1972 (Meadows 1987) - als unsere heutige Öko- und Klimakrise ankündigt - und damit ist die ganze Aktualität Lefebvres für unsere heutigen Öko- und Klimaprobleme auf den Punkt gebracht -, , ist eine Krise der Reproduktion der Produktionsverhältnisse“, bei der „,das Versagen der Zentren und der Zentralität“ der Städte „im Vordergrund steht" (Lefebvre 1974: 140). Gerade dieses epochale Versagen macht ein „Recht auf Stadt“ zur revolutionär-transformativen bzw. kommunalisierenden Wiederherstellung der politischen Handlungsfähigkeit durch eine „Umorientierung des Wachstums von den individuellen Bedürfnissen auf die spezifisch gesellschaftlichen Bedürfnissen“ notwendig, die „eine allmählich fortschreitende Begrenzung des Wachstums einschlie $\beta[t]$ und so wohl [sic!] die brutale Unterbrechung des Wachstums als auch seine grenzenlose Fortsetzung vermeide[t]" (ebd.: 143f.). Vor dem Hintergrund, dass diese „spezifisch gesellschaftliche[n] Bedürfnisse“ „,in zunehmenden Maße spezifisch städtische Bedürfnisse sind und mit der Produktion des Raumes wie mit der Verwaltung des Raumes zusammenhängen“, muss ein „vollständiges und detailliertes Projekt für eine Organisation des Lebens und des Raumes [...] der Selbstverwaltung den größtmöglichen Raum geben" (ebd.: 144; Hervorh. MS). Zugleich ist mit einer kommunalen Selbstverwaltung nicht das Ende des Umwelt-, besser: Klimaproblems erreicht, sondern erst der Anfang von dessen politischer Bearbeitung. Denn es darf nicht unbesehen bleiben, dass zum einen die durch die Klimaerwärmung bereits angestoßenen Veränderungsprozesse klimatologischer Kippelemente (Kap. 1) sich kaum noch umkehren lassen und dass zum anderen auch ,die Selbstverwaltung ebenso viele Probleme aufwirft wie sie löst" (ebd.: 144).

Kommunale Selbstverwaltung ,zielt auf das kollektive Leben und kann nicht anders als kollektiv ins Werk gesetzt werden““56, ,getragen [...] von einem vielfältigen, qualitativen Spektrum von Bewegungen, Forderungen und Aktionen“, „und zwar zugleich in der Praxis und der Theorie“ (ebd.:

56 Obschon es zwar deutlich geworden sein sollte, soll an dieser Stelle dennoch betont werden, dass Selbstverwaltung nicht zu verwechseln ist mit den von Foucault als „Gouvernementalität“ (Foucault 2006b, 2006a; Bröckling/Krasmann/Lemke 2000) kritisierten Selbstregierungstechniken. Der wohl entscheidende Unterschied zu Lefebvres Begriff der Selbstverwaltung ist, dass es Lefebvre darauf ankommt, die individualistische Ebene der neoliberalen Selbstverantwortungsethik auf der kommunalen Ebene des Politischen zu überwinden. Foucaults „Ästhetik der Existenz“ (Foucault 2007; Trebbin 2007) hingegen, d.h. der „Kunst der freiwilligen Unknechtschaft, der reflektierten Unfügsamkeit" (Foucault 1992: 15), um ,nicht dermaßen regiert zu werden" (ebd.: 12), verbleibt auf der Ebene des neoliberal individualistischen Management der Selbstverantwortung, wenn auch in befreiungsethischer Hinsicht und nicht mehr als „Arbeitskraft-Unternehmer“ (Pongratz/Voß 1998; Resch/Steinert 2011: 288). 
144f.), um sie in die Theoriebildung aufzunehmen und ihnen entlang ihrer tatsächlichen Bewegungen und blockierten bzw. residualisierten objektiven Möglichkeiten mögliche Wege (Stichwort strategische Hypothese) und Fallstricke vorherrschender Reproduktionsstrategien aufzuzeigen - etwa wenn sich gesellschaftliche Problemlagen auf subjektiver Ebene wieder als private Probleme angeeignet zu werden drohen (,Reprivatisierungsdiskuse“, Fraser 1994: 241f.). Selbstverwaltung bedeutet für Lefebvre daher die „Vergesellschaftlichung der Produktionsmittel“ (Lefebvre 1974: 163) und ist ,auf alle die aus[zu]dehnen, die die Einrichtungen der städtischen Wirklichkeit , benutzen', und auf diese ganze Wirklichkeit, gesehen in ihrem Doppelaspekt der Produktion und des Konsums, des Tauschs und Gebrauchs" (ebd.: 177). Wenn in deliberativer Hinsicht von politischer Mitbestimmung die Rede ist, dann hat Mitbestimmung, wenn sie nicht zugleich auch konsequent kollaborativ verstanden wird, ,keinen Sinn“, sondern ist bloß „Mitverwaltung“ (ebd.: 163), die ,nur die Verwaltung im Auge behält und Kritik und Opposition von vornherein auf den gewohnten Rahmen beschränkt, statt diesen Rahmen selber zu bekämpfen“" (ebd.: 164).

Das nun ist der entscheidende Unterschied zum Kollaborationskonzept des WBGU, das im Namen Lefebvres „Recht auf Stadt“ zwar eine kollaborative Selbstverwaltung der Städte auf kommunaler Ebene anvisiert, sie zugleich aber darin beschränkt, dass sie „nicht bei allen Themen oder auf allen Ebenen“ zum Tragen kommen kann (WBGU 2016b: 116), sondern nur ,[s]ofern es sich sinnvoll realisieren lässt“, dass die „Mitwirkungsrechte [...] nicht zu Überforderung der öffentlichen Verwaltung führen [dürfen]“" und/oder die Bevölkerung durch Überforderung abzustumpfen droht (ebd.: 152f.). Dieser substanzielle Widerspruch zu Lefebvres „Recht auf Stadt“ wird vor dem Hintergrund der konzeptionellen Blindstelle revolutionärtransformativer Subjektbildung des WBGU zwar erklärbar, verhindert aber nicht, dass der Kollaborationsansatz des WBGU damit ad absurdum geführt wird, weil er damit letztlich für die Beibehaltung kollaborativ-demokratisch nicht legitimierter Strukturen argumentiert, die diese Einschränkungen legitimieren und durchsetzen und die StadtbewohnerInnen dadurch statt zur Selbstverwaltung letztlich doch wieder nur zur Mitverwaltung deklassiert werden.

Für Lefebvre hingegen muss der kommunale Selbstverwaltungsprozess und darin besteht der permanente kulturrevolutionäre Aspekt Lefebvres (Lefebvre 1972: 263ff.), den Sünker (Sünker 1989) in den Professionalitätsbegriff Sozialer Arbeit einschreibt - „einen gesellschaftlichen Erziehungsprozess [implizieren]" (Lefebvre 1974: 163f.), der nicht nur der berechtigten Sorge vor der Überforderung aller AkteurInnen und politischen Verwaltungsstrukturen Rechnung zu tragen sucht, sondern darin überhaupt erst eine revolutionär-transformative bzw. kommunalisierende Subjektbildung ermöglicht. Nämlich dadurch, dass die AkteurInnen selbst darüber in Aushandlung kom- 
men - um an dieser Stelle noch einmal Winklers (Winkler 1988: 279) Metapher zu bemühen -, welche transformativen Gleise wie verlegt werden müssen, um sich selbst darauf bewegen und so ihre Residuen emanzipatorisch verwirklichen zu können.

Um zu wissen, welche Strukturen ihnen hierfür hinderlich sind, müssen sie die bestehenden nicht nur bereits durchschaut und auf ihre Möglichkeiten und Grenzen hin analysiert haben, sondern auch das eigene Selbst als darin blockiertes Möglichsein erkannt haben, was voraussetzt, dass sie sich selbst als - im nietzscheanischen Sinne - über-menschliches, d.h. zukunftsoffenes Möglichsein antizipiert und anerkannt haben. Mit anderen Worten: Die AkteurInnen müssen die gesellschaftlichen Strukturen, in die ihre bisherige Subjektbildung eingebettet ist, als Begrenzung erleben können und sich zugleich darüber bewusst werden können, dass jenseits der strukturellen Grenzen ein objektives Mehr an subjektivem Möglichsein lauert, das ausgestaltet und verwirklicht werden könnte, wenn die Strukturen andere wären. Eben darin bestünde die Professionalität Sozialer Arbeit in diesem Prozess: Durch kommunalpädagogisches Ortshandeln den AkteurInnen solche Erfahrungen von - wie Freire (Freire 1975: 84f.) ${ }^{57}$ sie nennt - „Grenzsituationen“ und „Grenzakten“ zu ermöglichen, worin sie ihr Menschsein auf und mit der Erde herrschaftlich, weil noch nicht vollumfänglich, d.h. kollaborativ demokratisch legitimiert, begrenzt erfahren und sich Situationen erarbeiten können, diese Herrschaft über sich selbst, selbst zu übernehmen, d.h. kollaborativ auszugestalten, und sich selbst die politischen und administrativen Strukturen zu schaffen, die sie brauchen, um ihre individuellen Möglichkeiten zu verwirklichen und dabei an einem gemeinsamen Projekt, der gemeinsamen Aufgabe des Klimaproblems zu arbeiten.

Deliberative Stadtentwicklungsprozesse, bei denen die Transformationsgewalt der StadtbewohnerInnen bloß repräsentativ übersetzt wird in verwaltbare und strukturell legitime Bedürfnisse - mit Fraser lässt sich von einem ,juristische[n], administrative[n] und therapeutische[n] Management der Bedürfnisbefriedigung“ (Fraser 1994: 240) sprechen -, bei denen also das letzte Wort von den AkteurInnen der Stadtverwaltungen und anderer nationalstaatlicher Behörden gesprochen wird und alle anderen am Transformationsprozess Beteiligten zur Mitverwaltung deklassiert werden, stehen solch

57 Freire in seiner „Pädagogik der Unterdrückten“: ,Zusammengefasst: In Grenzsituationen ist die Existenz von Menschen mitgesetzt, denen diese Situation direkt oder indirekt dient, und von solchen, deren Existenzrecht durch sie bestritten wird und die man an die Leine gelegt hat. Begreifen letztere eines Tages diese Situation als Grenze zwischen Sein und Menschlicher-Sein und nicht mehr als Grenze zwischen Sein und Nichts, dann beginnen sie ihre zunehmend kritischen Aktionen darauf abzustellen, die unerprobte Möglichkeit, die mit diesem Begreifen verbunden ist, in die Tat umzusetzen." (Freire 1975: 85) Die in die Tat umgesetzten kritischen Aktionen zur Erprobung bislang unerprobter Möglichkeiten des Menschlicher-Seins nennt Freie Grenzakte (ebd.). (zum Überblick der aktuellen Diskussion um Freire in der Sozialen Arbeit: Widersprüche 2020) 
kommunal-kollaborativen Selbstverwaltungsnotwendigkeiten der Subjektbildung diametral entgegen.

In seinem zwischen 1976 und 1978 erschienenen und bislang weder ins Englische noch ins Deutsche übersetzte - und daher bislang kaum erschlossene $^{58}$ - vierbändige Hauptwerk „De L'État“ führt Lefebvre den Grund hierfür näher aus. Hier beschreibt er den Staat ,als besondere Form der Machtpraxis“, die als Prozess aus dem Tauschakt der Geldwirtschaft hervorgeht (Wex 2001: 186f.). Dem Tauschakt, dem immer schon ein Gewaltakt zu eigen ist, „weil hier ungleiche Dinge als Gleiche getauscht werden“, wohnen für Lefebvre, so Wex, „,drei abstrakte[] Formen“ inne - „Logik (Austausch von Gleichem)“", „Jurisprudenz (zur Regelung von Streitigkeiten)“, „Ethik (Loyalität der Verkäufer)“ -, die im historischen Prozess der Geldwirtschaft den Staat hervorgebracht haben, der sie zusammenfasst und ,sich zusätzlich durch eine Art Heiligsprechung als oberster Schiedsrichter installiert" (ebd.: 187).

Dieser Prozess des Hervorbingens des Staates ist als sozialräumlicher Prozess zu verstehen: „'Es wird eine moralische, soziale und politische Kontrolle der Orte der Zusammenkunft ausgeübt, des Marktes (im räumlichen Sinn der Marktplatz)“, wodurch ,"[s]ehr schnell [...] das Bedürfnis nach der Präsenz einer Polizei, eines Gerichts, einer religiösen und/oder politischen Autorität [entsteht], die die unvermeidlichen Diskussionen vermeidet. “" (Lefebvre De l'État, 1976, Bd. III, S. 15 zit. in. ebd.). Der Staat als ebendiese Polizei des Marktplatzes, der bereits in dieser Funktion bei den Griechen im Entstehen begriffen ist (Stein-Hölkeskamp 2015; Sommer 2012, 2013; Reden 2015), ist also von Anfang an ein apolitischer Marktwächter, der den Konsens darüber voraussetzt, dass der Staat zur Gewährleistung der Reproduktion der Produktionsverhältnisse des Marktes dessen Organisation und Wächterschaft übernimmt. Er entsteht für Lefebvre dort, wo das Politische, die unvermeidlichen Diskussionen und wirtschaftlichen Aushandlungsprozesse auf logischer (Diskussion um Preisbildung), juristischer (Diskussion um Qualität und Gewährleistung der Ware) und ethischer (Diskussion um Moralität des Handels) Ebene vermieden werden und stattdessen ersetzt werden durch ein logisch-juristisch-ethisches Regulativ - mit Fraser: durch einen ,juristischadministrativ-therapeutischen Staatsapparat" (Fraser 1994: 237ff.) -, das bzw. den Wex im Anschluss an Lefebvre als „Logistik der Macht“ (Wex 2001: 187) bezeichnet.

Dieser seit mittlerweile Jahrtausenden bestehende Prozess verstärkt sich im Mittelalter mit der „Urbanisierung des Kapitals“ (Harvey 2014: 126) (Kap. 3), indem er sich unentbehrlich macht für den auf Geld und kapitaler Inwertsetzung menschlicher wie nichtmenschlicher Naturverhältnisse beruhenden Tauschakt und ,als geschlossener Dritter in die gesellschaftlichen

58 Lefebvre Staatstheorie wird daher hier nur sekundär wiedergegeben. 
Beziehungen ein[tritt]“ (Wex 2001: 188). Die Macht des Staates ist somit in den „Netzwerken, Kreisläufen, Begegnungsorten [...] also in der Logistik der Gesellschaft“" (ebd.) zugleich überall und allgegenwärtig präsent. Dieser von Anfang an Staatsgrenzen vorausgehende und damit immer schon übersteigende Markt fordert sich entlang der geografisch-territorialen Grund- und Bodenbesitzverhältnisse ebenso von Anfang an einen staatlichen Wächter ein, der die der Marktwirtschaft zugrunde liegenden geografisch-territorialen Grund- und Bodenbesitzverhältnisse zur Reproduktion des Marktes reproduziert. Ein solch nationaler Marktwächterstaat drängt schon seit der Antike nach Verwirklichung (Stichwort Hellenismus), kommt aber erst mit der „Urbanisierung des Kapitals“ (Harvey 2014: 126) seit dem 12. Jahrhundert allmählich und mit der Industrialisierung dann völlig zum Durchbruch (Blickle 2000b, 2000a; Bookchin 1996).

Durch nationalstaatliche Regulierungen ist die Transnationalität des Marktes zwar fragmentiert, aber nur oberflächlich zerbrochen. Die von Anfang an eingewurzelte grundlegende Strukturtendenz des Marktes, sich entlang des grenzüberschreitenden Gebrauchs des Marktes (etwa um sich mit Rohstoffen zu versorgen, die es vor Ort nicht gibt, aber für das urbane Leben benötigt werden) grenzüberschreitend zu entwickeln, wirkt der nationalstaatlichen Zersplitterung permanent entgegen und drängt die Nationalstaaten gewissermaßen als Polizei des globalen Marktes - auf gemeinsame Strategien, Instrumente und Institutionen und organisiert damit ihre globale $\mathrm{Zu}$ sammenführung zu einem globalen Marktstaat. Damit tragen die Nationalstaaten zum Funktionieren und zum Erhalt des globalen Marktes bei, während sie sich dadurch selbst global transnationalisieren (Stichwort Globalisierung). „Der Staat mondialisiert sich, wird also weltweit und gleichzeitig Welt“ (Wex 2001: 189). Seine Reichweite wächst mit der Reichweite der Märkte rund um den Globus und zugleich wächst seine Reichweite über die mit der Urbanisierung entstehenden Lebensverhältnisse der StadtbewohnerInnen bis in die kleinräumigen lokalen Verhältnisse der Menschen hinein und dehnt die Tauschakt-Ökonomie bis in die intimsten Lebensbereiche hinein aus. Erst dadurch, dass die marktwirtschaftliche Organisation des alltäglichen urbanen Lebens der StadtbewohnerInnen zur lebensweltlich-globalen resp. totalen Stadtkultur und damit zu ihrer äußeren Natur geworden ist, mussten und müssen sie sich, d.h. ihre innere Natur bis zur Ununterscheidbarkeit mimetisch an diese äußere anschmiegen. ${ }^{59}$ Dadurch werden ihnen

59 Mit Horkheimer/Adorno und Lefebvre ließe sich das hier beschriebene mimetische Weltverhältnis als „organisierte Handhabung der Mimesis“ (Horkheimer/Adorno 2006: 189) konkretisieren, nämlich organisiert durch die „bürokratische Gesellschaft des gelenkten Konsums“ (Lefebvre 1972: 99ff., 210ff.), durch die „die menschlichen Äußerungen sowohl beherrschbar als zwangsmäßig [werden]“ (Horkheimer/Adorno 2006: 190) und den Menschen als „Kybernanthropen, die Parodie des totalen Menschen“ (Lefebvre 1975c: 16; Lefebvre 1972: 217) hervorbringen: „Die Gesellschaft setzt die drohende Natur fort als den dauernden, organisierten Zwang, der, in den Individuen als konsequente Selbsterhaltung 
nicht nur die marktwirtschaftlichen Alltagsverhältnisse global, d.h. lebensweltlich umfassend, sondern auch ihre subjektive Individualität (hierin kommt nochmals Lefebvres Kritik an der Chicagoschule zum Vorschein, die diesen mimetischen Angleichungsprozess von BewohnerInnen eines Stadtteils noch als natürlichen Prozess weis machen wollte). Der sich dergestalt total mondialisierende Markt produziert auf nationalstaatlicher Ebene damit unweigerlich die transnationale Notwendigkeit der Wächterfunktion des globalen Wirtschaftsraums, die die Reproduktion der Produktions- und Gesellschaftsverhältnisse auf globaler Ebene sicherstellt: „Der gesamte Raum wird nun mittels Raumplanung für Herrschaftszwecke mobilisiert; er soll homogen hergestellt werden und zerfällt doch nur in Einzelteile.“ (ebd.: 191). Zusammengehalten werden die Fragmente des Raums durch die weltweite Angleichung lebensweltlicher Zusammenhänge entlang derselben technischen und ökonomischen Rationalisierungen zur globalisiert-urbanen Alltagspraxis der Leute rund um den Globus, womit die ,imperiale Lebensweise“ (Brand/Wissen 2017) erst global und total wird und sich dadurch unentrinnbar mehr Erden zu verbrauchen einfordert, als vorhanden sind. Und dadurch die Bewohnbarkeit des Planeten nicht nur für Menschen ruiniert (Stichwort Kapitalozän, Kap. 3).

Damit gereicht die ,imperiale Lebensweise“ (ebd.) der Marktgesellschaft eigentlich zum Kulturpessismus. Dass Lefebvres Argumentation aber gerade nicht im Kulturpessismus mündet, begründet sich in seinem Naturbegriff und dessen „höchste[r] Objektivität“ des physiologisch unbedingten Werdenmüssens (Lefebvre 1971a: 77), durch die der menschliche Leib sich nicht restlos und vollständig vergesellschaften lässt (Lefebvre 1974: 107), sondern immer ein Residuum des Nicht-Identischen zurücklassen muss (Lefebvre 1975c: 332ff.). Mit anderen Worten: die Totalisierung der ,imperialen Lebensweise“ (Brand/Wissen 2017) produziert pausenlos Residuen, an denen sich überhaupt erst die Hoffnung entzündet, in der Klimaproblematik durch radikalreformerische Transformationen, zumindest wenn sie tatsächlich von den Residuen ihren Ausgang nehmen, noch etwas bewegen und noch utopische, weil noch nicht verwirklichte, aber objektiv mögliche Alternativen des gesellschaftlich-urbanen Zusammenlebens zu Wege bringen zu können. Die Residuen sind der Hoffnungsschimmer gegen den sich aufdrängenden Kulturpessimismus, der statt in politischer Produktivität letztlich doch bloß im Rückzug ins Private mündet - wie sich im Kontext der Mondialisierung des Staates in der griechischen Antike bei Epikur ${ }^{60}$ zeigt. Auch wenn dieses, wie etwa bei Epikur (Hossenfelder 2006) oder gegenwärtig bei Marianne Gronemeyer (Gronemeyer 2012), konvivial organisiert ist.

sich reproduzierend, auf die Natur zurückschlägt als gesellschaftliche Herrschaft über die Natur.“ (Horkheimer/Adorno 2006: 190)

60 Ein solcher Rückzug ins Private zeigt sich bei Epikur etwa in Weisungen wie: „Befreien muss man sich aus dem Gefängnis der Alltagsgeschäfte und der Politik.“(Epikur 2007: 93) 
Soweit Lefebvre schon in seinen bisherigen Werken. In „De L'État“ wird er konkreter: Zusammengehalten werden die Fragmente des Raums durch die Netzwerke der Zivilgesellschaft (società civile), in die der Staat hineinregiert und seine Machtreproduktion nach dort delegiert. Als Zivilgesellschaft wird „'eine Gesellschaft, die weder von der Religion, noch von der Kirche ... noch von einer Militärmacht, noch von einer politischen Instanz oder einem Ensemble kodifizierter, fixierter und konstituierter Institutionen rund um einen Staat abhängt" (Lefebvre: De L'État [ohne weitere Angabe] zit. in MüllerSchöll 2001: 209), bezeichnet. Lefebvre bestimmt Zivilgesellschaft damit als „Gesellschaft frei von staatlicher Reglementierung“ (ebd.) und verortet sie auf einer „Ebene oberhalb der Familie und unterhalb des Staates“, wo sie ihre „sie allgemein betreffende Angelegenheiten kommunikativ oder in Selbstverpflichtung lösen“, etwa durch „Vereine und Verbände, Räte wie der Presserat, die Gewerkschaften usw.“ (ebd.: 212). Diese Machtdelegation des Staates in die Zivilgesellschaft wurde zuvor bereits von Gramsci als Hegemonie gefasst (zum Überblick: Langemeyer 2009; Haug 2004) und wird Jahre später unter dem Begriff Postpolitik (zum Überblick: Michel/Roskamm 2013b, 2013a; Swyngedouw 2013) näher analysiert und kritisiert.

Schon Hegels Herr-Knecht-Parabel (Hegel 1970b: 145ff.) stellt heraus, dass Herrschende den Konsens der Unterdrückten brauchen, um Herrschende sein zu können. Ebenso verhält es sich mit der Herrschaft des Staates, dessen Regierungsherrschaft den Konsens der Regierten bedarf. Vor dem Hintergrund, dass der Staat aus der Herrschaft des Marktes hervorgegangen ist, braucht die Herrschaft des Marktes den Konsens des Staates, den er sich über die Zivilgesellschaft einholt und sicherstellt. Entsprechend hatte Gramsci den Staat beschrieben als ,politische Gesellschaft + Zivilgesellschaft, das heißt Hegemonie, gepanzert mit Zwang“ (Gramsci 1994a: 783). Gramscis Hegemoniebegriff versucht das Verhältnis zu fassen zwischen juristischen und administrativen Institutionen des Staates sowie - um es mit Lefebvre (Lefebvre 1972: 219ff., 2006, 2002) zu sagen - die damit bürokratisch-herrschaftlich angeordnete gesellschaftliche Raumrepräsentation, die als vermeintlicher Konsens gesetzt wird und nicht zur politischen Debatte steht, als auch der Zivilgesellschaft, die sich diesen Konsens entlang der gesetzten bürokratischen Lenkung anzueignen hat, ihn dadurch verteidigt und erst sozial legitimiert. Gramscis Hegemoniebegriff betont damit die Bedeutung der politischen Kultur zum Erhalt von Macht und Herrschaft, aber auch zur machtvollen Veränderung gesellschaftlicher Herrschaftsverhältnisse (Langemeyer 2009: 74ff.). Dass der Herrschaftskonsens bzw. der Konsens zu bestimmten herrschaftlichen Gesellschaftsverhältnissen nicht zur politischen Debatte steht, kennzeichnet ihn als apolitischen Konsens, der unter dem irreführenden Forschungsbegriff Postpolitik (als hätte es je eine Zeit gegeben, in der dieser Konsens politisiert war und er es jetzt nicht mehr ist) näher untersucht wird. 
Unter Postpolitik wird in der kritischen Stadtforschung ein diskursiver Regierungsstil bezeichnet, bei dem gesellschaftliche Macht- und Herrschaftsverhältnisse nicht öffentlich ausgetragen werden, sondern durch Konsenstechnologien, die sich in den letzten Jahrzehnten durch Programme, wie etwa Soziale Stadt (Walther/Günther 2007) und der damit verbundenen kommunikativen Wende in der Stadtplanung, vermehrt und verfeinert haben, verhindert werden. Kern postpolitischer Regierungsstile ist zwar die „Direktheit der Kommunikation (Austausch von Argumenten und Diskussion in direkter face to face-Kommunikation)“, die „Freiwilligkeit und die Gleichheit der Teilnahme, Offenheit des Teilnehmerkreises“, eine „explizite oder implizite Entscheidungsorientierung (Ermöglichung legitimerer oder rationalerer Entscheidungen aufgrund der Einbeziehung diverser kognitiver, interessen- und wertbezogener Perspektiven)“ (Hebenstreit 2013: 87f.). Aber eben jeweils auf Grundlage einer „Konsensorientierung (möglichst konsensuales Votum aller Verfahrensbeteiligten)“ bei gleichzeitig ,fehlende[r] formale[r] Bindungskraft ihrer Ergebnisse“ (ebd., vgl. auch Schubert 2017). Mit Selle ließe sich daher von einem „Particitainment“ sprechen:

„Statt substanzieller Diskurse im Kontext einer lebendigen lokalen Demokratie wird eine Bürgerbeteiligung inszeniert, die Teilhabe an Meinungsbildung und Entscheidungen suggeriert, ohne dies einlösen zu können. De facto bleiben viele Ergebnisse dieser Prozesse ohne wesentlichen Einfluss auf die Stadtentwicklung und verändern auch die eingespielten Mechanismen der lokalen Politik und Verwaltung nicht. Mehr noch: Die Inflationierung nachhaltig wirkungsloser Teilhabe-Verfahren könnte womöglich Politik- und Planungsverdrossenheit befördern." (Selle 2013: 276f.)

Das Postpolitische zeigt sich hierbei etwa in der herrschaftlichen Interpretation von Bedürfnissen vor dem Hintergrund einer vermeintlich prinzipiellen Konsensfähigkeit (etwa durch die von den einladenden Organisatoren der Stadtverwaltung einberufenen ModeratorInnen: vgl. Schubert 2017). Konsensfähig heißt dabei, dass auf individuelle Bedürfnisse nur dann Rücksicht genommen werden kann, wenn sie sich die gewaltenteiligen juristischadministrativen Rahmenbedingungen der bestehenden Staatsapparatur sowie den Status Quo der herrschenden gesellschaftlichen Verhältnisse - etwa den privatwirtschaftlich organisierten städtischen Grund- und Bodenverhältnissen - einpflegen lassen. Trotz dem Anspruch der Einbindung möglichst vieler verschiedener lebensweltlicher Zugänge und Perspektiven in den Stadtentwicklungsprozess, wird der nicht konsensfähige Teil marginalisiert oder durch geschickte Moderationstechniken zum Schweigen gebracht. „Das Postpolitische lebt also davon", so Swyngedouw an Zižek und Ranciére anschließend,

,alle in eine konsensuelle pluralistische Ordnung einzubeziehen und/oder diejenigen, die sich außerhalb des Konsenses stellen, radikal auszuschließen. [...] Die Produktion neuer kreativer und unternehmerischer Eliten stellt in Wirklichkeit einen der Schlüsselbereiche zur Konstruktion dieses postpolitischen Konsenses dar. Hier nämlich wird 'Politik im eigentlichen Sinne nach und nach durch eine Sozialadministration der Experten ersetzt ${ }^{`}$ (Zizek 2005: 117) Der postpolitische 
Konsens ist daher radikal reaktionär. Er verhindert es, für künftige städtische Möglichkeiten und Assemblagen abweichende, konfliktträchtig und alternative Entwicklungslinien zu artikulieren.“ (Swyngedouw 2013: 148)

\section{Und weiter:}

„Die Postpolitik zielt somit auf die Verwaltung (polizeiliche Kontrolle) sozialer, ökonomischer und anderer Angelegenheiten, die natürlich voll und ganz im Bereich des Möglichen, der bestehenden sozialen Verhältnisse bleiben. [...] Die Postpolitik verweigert eine Politisierung im klassischen griechischen Sinne der Verallgemeinerung partikularer Forderungen, die ,mehr anvisiert als einen bloßen Interessensausgleich.“ (ebd.: 147)

Damit ,[bewahren] demokratische Institutionen und Verfahrensweisen [...] eine eigentümliche Präsenz“, befördern aber zugleich den „Einfluss von wirtschaftlichen bzw. sozioökonomisch privilegierten Eliten“, wodurch „die Demokratie refeudalisiert werde und in vordemokratische Muster zurückfalle (Crouch 2008: 13)“ (Mullis/Schipper 2013: 81f.). Entsprechend folgt auf eine Politisierung emanzipatorischer sozialer Bewegungen erst durch den vermeintlich politischen Verhandlungsprozess nicht selten ihre Depolitisierung, weil grundlegende Konflikte und Widersprüche unter einem Konsensanspruch hegemonial zum Schweigen gebracht werden, statt sie politisch zu bearbeiten. Für Lefebvre - und darin übersteigt er sowohl Gramscis Hegemonie-Ansatz als auch das Forschungskonzept der Postpolitik - müssen gerade diese zum Schweigen gebrachten Residuen zum Ausgangspunkt gesellschaftlicher Transformationen, d.h. zum Ausgangspunkt weiterer transduktiv-praxisforscherischer Untersuchungen emanzipatorischer Stadtentwicklung (Stichwort strategische Hypothese) gemacht werden und nicht die am apolitischen Konsens orientierten Ergebnisse der deliberativen Partizipationsworkshops (insofern sie überhaupt eine Relevanz haben und nicht bloß der bürgerlichen Unterhaltung dienen).

Es ist hierin der Grund zu erblicken, warum Lefebvre deliberative bzw. alle nicht bis zur konsequenten kollaborativen Demokratie vordringenden Partizipationsprozesse zum Scheitern verurteilt sieht, weil sie es strukturell nicht vermögen, den Konsens der grundlegenden Produktionsverhältnisse des Gesellschaftlichen zu durchbrechen. Hinsichtlich der Klimafrage heißt das, dass alle nicht bis zur konsequenten kollaborativen Demokratie vordringenden Partizipationsprozesse zu Scheitern drohen, weil sie es strukturell nicht vermögen, den vorherrschenden Konsens der grundlegenden Produktionsverhältnisse der Vergesellschaftung von Naturverhältnissen durch die kapitalistische Inwertsetzung von menschlicher wie nichtmenschlicher Natur politisierend in Frage zu stellen. Entsprechend drohen sie daher die Bildung eines emanzipatorischen Transformationssubjekts zu verpassen, durch das es aber erst möglich würde, in der Klimafrage eine umfassende Selbstverantwortung zu übernehmen, weil sich die dafür benötigen Mittel, etwa Strukturen zur urbanen Subsistenz und Suffizienz, kommunal, d.h. entlang der Bedürfnisse der kommunalen Subjekte und Residuen erarbeitet werden könnten. Stattdes- 
sen sprechen deliberative Partizipationsprozesse nachweisbar und auch künftig absehbar nur solche Handlungssubjekte an, die bereits bis zur zweitgradigen Entfremdung (Lefebvre 1975c: 68) marktwirtschaftlich einsozialisiert sind. Damit tendiert der Klimadiskurs weiterhin dazu, alle nicht konsensfähigen AkteurInnen und ihre Handlungssubjekte vom Stadtentwicklungsprozess auszuschließen und sie durch obrigkeitsstaatlichen Zwang, d.h. mit den fiskalpolitischen Mitteln des Marktstaates zu zwingen, sich marktwirtschaftlich am Transformationsprozess zu beteiligen (etwa in Form von Emissionssteuern und -zertifikaten). Die entfremdenden Strukturen der staatlich organisierten Residuenproduktion bleiben dadurch nicht nur unangetastet, sondern die bisherigen marktwirtschaftlich induzierten Spaltungen der Gesellschaft drohen vertieft zu werden, während zugleich absehbar neue hinzukommen werden, was beides die soziale Kohäsion der Gesellschaft weiter untergraben würde (falls sie es nicht gegenwärtig schon tun). Vor dem Hintergrund dieser Vorhersehbarkeiten zeigt sich die dringende Notwendigkeit, die vorherrschenden - und bestenfalls deliberativ organisierten - Transformationsprozesse ideologiekritisch-forscherisch $\mathrm{zu}$ begleiten und den subalternierten AkteurInnen und Residuen zur emanzipatorischen Sprache zu verhelfen sowie nach Wegen zu suchen, die exkludierenden Mechanismen des „Particitainments“ (Selle 2013: 276f.) des ,juristisch-administrativ-therapeutischen Staatsapparats“ (Fraser 1994: 237ff.) zu überwinden. Lefebvres „Recht auf Stadt" hat sich bei genauerem Besehen als eine solche Forschungsstrategie emanzipatorischer Subjekt- und Stadtentwicklung herausgestellt, die es verheißt, deliberative Postpolitikdiskurse kollaborativ zu überwinden, oder wenigstens punktuell hartnäckig zu durchbohren und löchrig zu machen. Oder noch weiter abgemildert: ...die es wenigstens vermag, die Kritik an den permanenten systematischen Schließungsversuchen marktwirtschaftlicher Herrschaftsverhältnisse empirisch basiert am Leben zu erhalten.

Zur emanzipatorischen Subjektbildung kann entsprechend nur vorgedrungen werden, wenn - so die hier sich ergebene docta spes (Bloch 2013a: 8) - obrigkeitsstaatlich-institutionalisierte Organisationsstrukturen städtischer Transformationsprozesse von Grund auf in Frage gestellt und durch konsequent kollaborative Partizipationsprozesse zu einer Politik des Sozialen vorzudringen versucht wird. Denn dadurch könnten nicht nur auch denjenigen die gleichberechtigte Mitgestaltung des Politischen auf und mit der Erde eingeräumt werden, die diesen Konsens in Frage stellen und ihn damit überhaupt erst zum Politikum machen. Sondern auch all jenen subjektiven Interaktionsformen bzw. Produzierendensozialpolitiken, die bislang nicht demokratisch in Erscheinung treten (konnten) und erst im kollaborativ organisierten kommunalen Bildungsprozess die Möglichkeiten eingeräumt bekommen würden, artikuliert werden zu können. Dass im Ansatz kollaborativ kommunalisierender Selbstverwaltung notwendigerweise eine Abwendung vom „klassische[n] Modell der Repräsentation und des Repräsentativen, 
[dem] Modell der formalen Demokratie“, impliziert ist, damit die ,vielfältigen Interessen der Basis [...] präsent“ sein können und „nicht bloß ,repräsentiert', also delegiert an Mandatsträger" (Lefebvre 1974: 165), liegt auf der Hand. Auch, dass „an der Basis ein kompliziertes Netz von Organisationen geschaffen“ werden muss, das sich „unaufhörlich[], unablässig“ erneuert „und ihre Organisationskraft aus sich selber" schöpft (ebd.). Keinesfalls liegt es aber, wie Lefebvre es vorschlägt, auf der Hand, dass sich dieses komplizierte Netz von Organisationen von vornherein als „direkte[] Demokratie“ (ebd.) organisiert, gar dass es als ein solches eingefordert werden könne. Vielmehr können auch andere, a priori nicht bestimmbare politische (Zwischen-)Formen notwendig sein, um wirklich allen AkteurInnen und ihren kommunalen Interaktionsformen (Produzierendensozialpolitiken) die kollaborierende Teilnahme an der politisch selbstverwalteten Organisation des Städtischen zu ermöglichen. Eine solche kollaborativ erarbeitete Politik des Sozialen muss notwendigerweise Sache der Aushandlungsprozesse aller AkteurInnen sein und kann nicht vorher festgelegt sein. Darin versteht sich der demokratische Charakter kollaborativer Demokratie (Rohr 2012, 2013), worin er sich als Politikbegriff erweist, der alle beteiligten kommunalsubjektiven Produzierendensozialpolitiken zu umfassen und zu übergreifen vermag. Nämlich als „Polyphonie von Sozialpolitiken der Produzierenden“ (Widersprüche Redaktion 2012: 6f.).

Diesen Prozess herzustellen verlangt nun aber letztlich auch einen mehrheitsfähigen Konsens, das bislang noch nicht Politisierte durch eine intraund interkommunale Selbstverwaltung zu politisieren. Hierin lässt sich nun auch der Grund erblicken, warum kommunale Selbstverwaltung einen gesellschaftlichen Erziehungsprozess implizieren muss (Lefebvre 1974: 164), der von einer kommunale Pädagogik des Sozialen (Sozialraumentwicklung, Alisch/May 2013: 19f.) zu einer integrativen Politik der Produzierendensozialpolitiken vorzudringen sucht, die auch kommunale Behörden staatlicher Institutionen umfasst (Sozialraumorganisation, Alisch/May 2015: 20) - kurz: die entlang der Arbeit des Sozialen zur Arbeit am Sozialen vordringt: Einerseits, um für einen umwälzenden Transformationsprozess notwendige Mehrheiten demokratisch und politisch bilden zu können, was - erstens - voraussetzt, dass es Leute gibt, die die Notwendigkeit der Umwälzung der Transformation der Vergesellschaftung von Naturverhältnisse (an)erkennen. Und was - zweitens - eine gewisse politische Bildung und Urteilsfähigkeit voraussetzt, die mitunter erst milieu-übergreifend (wieder) gebildet werden muss (Winkler 2006). Beides sind notwendige Voraussetzungen, damit das dem Staat und seinen RepräsentantInnen und AkteurInnen apolitisch überlassene Monopol der Wächterfunktion der Märkte - und damit der Vergesellschaftung der Naturverhältnisse resp. der gesellschaftlichen Produktion des Raums, die den ganzen Erdhaushalt erfasst hat - durch den Transformationsprozess kommunal- und residuenbezogen politisiert werden kann. Solange 
die Regulierung der Raumproduktion bzw. der Vergesellschaftung von (Erd)Naturverhältnissen dem Markt überlassen bleibt, solange sich also nichts an den Produktionsverhältnissen ändert, die durch die AkteurInnen nationaler Regierungen reproduzierend reguliert werden, solange sind die Gegenbewegungen wie Fridays For Future und ihre sie unterstützenden Gruppen wie etwa Scientists For Future etc. nicht nur gegenüber der Produktionsweise der Naturvergesellschaftung machtlos, sondern auch gegenüber der Reproduktion dieser Produktionsweise. Das zeigt sich ja allein darin, dass sie politisch bloß als Fordernde in Erscheinung treten (können), die bestenfalls hier und da beratend tätig sein können, während sie von den tatsächlichen Entscheidungsprozessen ausgeschlossen bleiben. Mehr noch: Mit der Beibehaltung ebendieser Produktionsverhältnisse des Gesellschaftlichen wird auch die staatliche „Logistik der Macht“ (Wex 2001) beibehalten und damit die postpolitischen Diskurse und diskursiven Praktiken des Netzwerk-Regierens, wodurch dann letztlich auch Forderungen der For-Future-Bewegungen aufgeweicht und vom postpolitischen Konsens absorbiert zu werden drohen.

Dem ließe sich letztlich nur durch eine konsequente kollaborative Selbstverwaltung der öffentlichen Angelegenheiten entziehen, mit der sich durch die radikale Politisierung bislang apolitischer bzw. de-politisierter Produktionsverhältnisse des Sozialen - wie etwa die politische Entscheidungsfrage oder die Eigentumsfrage an Grund und Boden des Gemeingutes Erde, die durch postpolitische Diskurse erst depolitisiert wurden/werden - gegen ihre ökonomistische Vereinnahmung zur Wehr gesetzt werden kann, indem sie durch die demokratische Kontrolle über die kommunalen Produktionsweisen auch die Produktionsverhältnisse der Vergesellschaftung der Naturverhältnisse verändern. Erst wenn sich die ,städtische Praxis [...] durch kohärente Totalisierung partieller Praktiken“ der Selbstverwaltung zu „konstituieren“ begönne (Lefebvre 1974: 228), könne sich für Lefebvre das „Recht auf Stadt“ herausbilden, mit dem auch nicht-konsensfähige AkteurInnen und Positionen politische Machtmittel an die Hand bekämen, um durch die „Umgestaltung der bestehenden Welt in Übereinstimmung mit den grundlegendsten Tendenzen und die Überwindung der Widersprüche dieser Welt" (ebd.), das objektiv Mögliche zum subjektiv Wirklichen zu transduzieren. Und damit das Klimaproblem als kommunalpädagogisches Projekt zur subjektiven Emanzipation bearbeiten.

\subsection{4 (Zwischen-)Fazit}

Lefebvres Argumentationslinie eines „Rechts auf Stadt“ ist im Kontext seiner dialektisch-materialistischen „Kritik des Alltagslebens“ und im Hinblick auf eine kommunal-selbstverwaltete revolutionäre Transformation des Urbanen mit dem Anspruch emanzipatorischer Subjektbildung - kurz: im Kontext 
seiner „Metaphilosophie“ zu verorten. Es lässt sich zusammenfassen als „strategische Hypothese“ (Lefebvre 1987: 372), genauer: als strategisches Programm einer Wissenschaft urbaner Raumproduktion mit politischen resp. kommunalistischen Konsequenzen, die das bislang privat- und gewinnwirtschaftlich organisierte Verhältnis von „Erde-Arbeit-Kapital“ (Lefebvre 1975b: 115; Lefebvre 1974: 7ff.) grundlegend in ein gesellschaftlich organisiertes zu überführen suchen, um es kollaborativ-demokratisch gestalten zu können. Das „Recht auf Stadt“ lässt sich dabei nicht nur als Kritik der politischen Ökonomie verstehen, sondern eröffnet zugleich die Möglichkeit einer politischen Ökologie, die den ,[gefährlich gestörten] organische[n] Stoffwechsel zwischen der Gesellschaft und der Erde“ und dessen „katastrophale Auswirkungen“" (Lefebvre 1975b: 115), wie sie schon von Marx hervorgehoben wurden und aktuell als Öko- oder Klimakrise diskutiert werden, in den Griff zu bekommen. Erst wenn die Erde als bewohnbarer Wohnraum erhalten bleibt, kann im ganzheitlichen Sinne von einem ganzheitlichen, totalen Menschen gesprochen werden, der sich allseitig und frei entwickeln können soll.

Lefebvres Kritik umfasst dabei nicht nur die Kritik des „Urbanismus der Wohlmeinenden“, „der Verwalter im öffentlichen (staatlichen) Sektor“ und „der Bauträger" (Lefebvre 2016: 56ff.), sondern auch die Kritik an den Wissenschaften, die sich um den „Pseudo-Begriff der Umwelt" (Lefebvre 2014: 196; Lefebvre 1974: 125f.) drehen: jede Wissenschaft erzeugt ihren Umweltbegriff, nämlich als etwas, das ihren Untersuchungsgegenstand als jeweiliges Außen umgibt (Lefebvre 2014: 196). Der „Begriff ,Umwelt' hat", wie Lefebvre in „Die Zukunft des Kapitalismus“ zuspitzt, „keinerlei präzise Bedeutung, er meint alles und nichts, die ganze Natur ebenso wie die städtischen Randgebiete“ (Lefebvre 1974: 125). Durch diese Unschärfe und die inflationäre Beliebigkeit der Anwendung des Umweltbegriffs gerät er ins Fahrwasser der vorherrschenden Organisierung der Reproduktion der Produktionsverhältnisse und dient letztlich bloß der Fortsetzung der Zerstückelung des Raums auf theoretischer Ebene. Das „Recht auf Stadt“ als transdisziplinärstrategische Analyse der Produktion des Raums (Lefebvre 2016: 217), mit dem die kommunalen Subjekte ihre Residuen verwirklichen und ein subjektives Gemeinwesen auf und mit der Erde politisch verwirklichen können, muss daher als Wissenschaft verstanden werden, die es ermöglichen soll, den parzellierten Einzelwissenschaften einen die Disziplinen übergreifenden Arbeitsrahmen zu erarbeiten, der ihn zugleich insofern übersteigt, als dass Forschende und $\mathrm{zu}$ Beforschende in einem kollaborativen Forschungsprozess zusammengebracht werden, mit dem sie sich gemeinsam ihrer gemeinsamen Erde bewusst werden können. Auch wenn Lefebvre letztlich blass bleibt, wie diese Zusammenarbeit konkret aussehen soll und die verschiedenen, teils sich widersprechenden Erkenntnisparadigmen, zu einer fruchtbaren Syntheseproduktion zusammengebracht werden können, ist sein Ansatz der strategischen Hypothese ein wegweisender Ansatz - um an dieser Stelle an Mittelstraß 
(Mittelstraß 2005) Unterscheidung anzuschließen - nicht nur praktischer, sondern auch theoretischer Transdisziplinarität, der im Folgenden weiter verfolgt werden soll.

Aber was ist nun mit der Frage, ob seine „Metaphilosophie“ nicht nur für ökosoziale, sondern auch für sozial-ökologische Transformationen einen praxisphilosophischen Begründungsrahmen bietet? Eine terrestrische Nachhaltigkeitswissenschaft sozial-ökologischer Transformation, so wurde in Kap. 6.2 zusammengeführt, muss, wenn sie integrativ und partizipativ angelegt ist und diesen Anspruch ernst nimmt, neben verschiedenen disziplinären und methodologischen Zugänge wissenschaftlicher AkteurInnen auch die verschiedenen lebensweltlichen Zugänge nicht-wissenschaftlicher Akteure in den wissenschaftspraktischen Theoriebildungsprozess transformativer Praxis einbeziehen, um im gemeinsamen Forschungsprozess die Probleme des Klimawandels dergestalt bearbeiten zu können, dass sich darin ein gemeinsames Handlungssubjekt zu entwickeln beginnt, mit der nicht nur Theorie und Praxisstruktur gesellschaftlicher Transformationen ihre Bildung erfahren, sondern auch die agierenden AkteurInnen. Soweit ja auch Lefebvres Argumentation. Aber: Zugleich wurde auch gesagt, dass sich der Begriff sozial-ökologischer Transformation erst darin vollumfänglich erschöpft, wenn er die ganze Erde, also auch nicht-menschliche Akteure und Aktanten dieser Erde im politischen und subjektiven Bildungsprozess nicht nur berücksichtigt, sondern als ebenso an der sozialen Arbeit der Ökologie der Erde beteiligte Akteure anerkannt werden, so dass eine Politik Sozialer Ökologie nicht nur für die Gattung Mensch Politik betreibt, sondern für die menschliche Gattung als Gattung unter Gattungen auf und mit dieser Erde. So erst, so wurde dargelegt, böte sich die historische Möglichkeit einen strategisch-hypothetischen gemeinwesenorientierten Anthropozänbegriff auf den Weg zu bringen, der die Gesamtökologie Erde als sympoietischen Komplex (Haraway 2018) zu politisieren vermag und sich zugleich mit menschlichen und nichtmenschlichen Akteuren mit Inhalten füllt. Und erst dadurch ließe sich die Erde nicht nur als menschliches, sondern als terrestrisches resp. sozialökologisches Gemeinwesen politisch verwirklichen, das keine menschliche Lebensweise mehr ausschließt und möglichst viele nicht-menschliche Lebensformen und globale Aktanten als nicht-menschliche Mitwelt in die menschliche Politik einbezieht. Darin erst können die anthropozentrischen Engführungen der Marxschen Gemeinwesen- bzw. Naturphilosophie überstiegen werden, die auch Lefebvres metaphilosophischen Poiesisbegriff innewohnen und von dort aus auch sein, wie sich ebenso zusammenfassen ließe, Recht auf die praxisphilosophische Revolutionierung des Urbanen durchziehen. Erst dann würde nicht mehr über die Natur der nichtmenschlichen Mitwelt nur philosophisch argumentiert, sondern praxisphilo- 
sophisch mit ihr alliiert und Blochs Vorschlag einer Naturallianz ${ }^{61}$ (Bloch 1975: 251) verwirklicht. Mit der homo-mensura-Prämisse verpasst aber nicht nur schon die Marxsche, sondern auch die Lefebvresche Naturphilosophie den letzten notwendigen Schritt von der ökosozialen zur sozial-ökologischen Transformation.

So lässt sich abschließen resümieren: Lefebvres „Metaphilosophie“ eignet sich zwar vollumfänglich als praxisphilosophischer Begründungsrahmen ökosozialer Transformationen, aber nur bedingt auch für sozial-ökologische Transformationen. So lassen sich mit ihr zwar die notwendigen politischen Strukturen sozial-ökologischer Transformationen rechtfertigen. Aber bezüglich der konkreten Subjektbildung, mit der nicht nur die Stadt, sondern auch die Erde als gemeinsames Alltags- und Kunstwerk hervorbringen ließe, an der auch nicht-menschliche Akteure und Aktanten mitproduzieren, bleibt sie letztlich blass. Zur Frage steht also weiterhin, wie es den menschlichen Subjekten ermöglicht werden könnte, die Erde als Gaia-Gemeinwesen hervorzubringen, in dem sie sich der Erde als nicht nur ihr sozial hervorgebrachtes ökologisches Werk und Gemeinwesen bewusst werden können. Und zwar dergestalt, dass sie sich dabei zwar als zentrale politische AkteurInnen, zugleich aber nur als exzentrisch positionierte Wesen bewusst werden können.

Ein methodischer Vorschlag zur theoretisch und praktisch transdisziplinären sozial-ökologischen Subjektbildung, die den Schritt zur sozialökologischen Transformation subjektiv zu inspirieren vermag, wird in Teil D näher beleuchtet. Zuvor sollen allerdings weitere politische Konsequenzen gezogen werden, mit denen sich Lefebvres politische Konsequenzen im Hinblick auf die Klimafrage und der Möglichkeit sozial-ökologischer Transformationen weiterdenken lassen.

61 Mit Blochs an Marx angelehnten Diktum der „Naturalisierung des Menschen, Humanisierung der Natur“ (Bloch 1975: 264) steht auch Blochs Vorschlag letztlich noch im Marxschen Anthropozentrismus. 


\section{Teil C \\ Von der „Revolution des Urbanen“ zum \\ Transformationsprojekt Soziale Ökologie? \\ Ein kommunalistisches Gedankenexperiment im Anschluss an Lefebvres ,Recht auf Stadt“"}





\section{Weiterführende Zusammenfassung von Teil A und $\mathrm{B}$}

Wurde in Teil A die Bildbarkeit des Subjekts als ursächliche Notwendigkeit herausgestellt, die Klimafrage als politische Frage zur Verwirklichung menschlicher Subjektivität zu einer Frage ökosozialer und sozial-ökologischer Stadtentwicklung zu verdichten, so wurde in Teil B die Notwendigkeit herausgestellt, sie kollaborativ zu beantworten. Im Anschluss an das „Arbeitsprinzip Partizipation“ Sozialer Arbeit (Kunstreich 2014: 272f.; Kunstreich/May 2020: 49f.) und den „,normativen Kompass“" des WBGU (WBGU 2016b: Kap. 3) wurde das „Recht auf Stadt“ Lefebvres (Lefebvre 2016) im Kontext seines weiteren Werks hinsichtlich des darin enthaltenen Kollaborationsbegriffs näher untersucht. Dabei zeigte sich,

a) dass der WBGU Lefebvres „Recht auf Stadt“ sowohl um den gesellschaftlichen Subjektbildungs- als auch den gesellschaftlichen Staatserziehungsaspekt verkürzt. Denn das Kollaborationskonzept des WBGU bricht den Stadtentwicklungsprozess konzeptionell an der Stelle ab, an der sich die StadtbewohnerInnen die kommunalen Verwaltungs- und Regierungsstrukturen erarbeiten müssten, die sie für ihre subjektiv eigensinnigen Transformationspfade ökosozialer und sozial-ökologischer Stadtentwicklung tatsächlich benötigten.

b) dass dieses „Recht auf Stadt“-light, womit der WBGU seinen eigenen konzeptionellen Anspruch der Kategorie „Eigenart“ (WBGU 2016b: $153 \mathrm{ff}$.) verpasst, auf theoretischer Ebene eine notwendige Konsequenz ist, weil er den Menschen konzeptionell nicht als Subjekten, d.h. nicht als Ensemble sozialer Interaktionen gerecht wird und entsprechend Subjektbildung ausgehend von den Residuen nicht zum Dreh- und Angelpunkt seines Kollaborationsansatzes erhebt, sondern das „Recht auf Stadt“" stattdessen anstrebt, um die „Akzeptanz forschungsgeleiteter Problemlösung und deren langfristiger Implementierung [zu erhöhen“ (ebd.: 466).

Gleichwohl zeigte sich aber auch hinsichtlich Lefebvres „Recht auf Stadt“ als Wissenschaftsprogramm kollaborativer Stadtentwicklung mit emanzipatorischem Subjektbildungsanspruch,

c) dass sich dessen metaphilosophischer Begründungsrahmen zwar als praxisphilosophischer Begründungsrahmen ökosozialer Transformationen des Gesellschaftlichen eignet, ihm aber die notwendigen Ansätze 
fehlen, eine sozial-ökologische Subjektbildung zu ermöglichen, die auch nicht-menschliche Akteure und Aktanten einbezieht.

d) Denn das „Recht auf Stadt“ vermag zwar urban Commons herzustellen und als kommunalisierte Gemeingüter kommunalistisch zu verwalten sowie deren Nutzung zu regulieren, lässt hierfür aber offen, wie daraus eine subjektive Beziehung mit der gesamten Erde entstehen soll, die das Bild der Erde als fremdgewordenes Gegenüberobjekt überwindet und sie stattdessen in wissenschaftlicher Theorie- und gesellschaftlicher Praxisbildung als sympoietisches Gaia-(Kunst-)Werk begreiflich werden lässt, wonach der Mensch zwar zentraler Akteur einer Politischen Ökologie ist, im ökologischen Gesamtkomplex Erde er aber nur Gattung unter Gattungen ist.

Gegenüber dem WBGU fällt zudem ins Auge - und darum soll es in diesem Teil gehen -,

e) dass Lefebvres „Recht auf Stadt“ ein städteübergreifender Vernetzungscharakter fehlt, womit es auf der Ebene einzelner Städte und der Verwaltung sowie Nutzungsregulierung ihrer urban commons verbleibt, eine die selbstverwalteten Städten zu überlokalen Regionen, gar zur globalen Regionen vernetzende Ebene zur Verwaltung und Nutzungsregulierung auch von global commons (erdökologische Aktanten wie Meere, Gebirge, Landschaften, Atmosphäre) aber missen lässt.

Mit dem WBGU lässt sich hierfür der konzeptionelle Ansatz einer polyzentrischen Verantwortungsarchitektur fruchtbar machen.

\section{Der ,normative Kompass“ des WBGU zum Zweiten: polyzentrische Verantwortungsarchitektur}

Unter einer polyzentrischen Verantwortungsarchitektur versteht der WBGU, dass Städte nicht nur auf der lokalen Ebene die Verantwortung „für ihre Transformationspfade [...] anerkennen“ und die BewohnerInnen ,auch zur Verantwortungswahrnehmung befähigen“" (ebd.: 410) sollen. Dass der WBGU hierbei nur die Ermöglichung durch politische Strukturveränderungen konzipiert, die zugleich nicht weit genug gehen, um auch den Menschen tatsächlich zu ermöglichen, die Verantwortung entlang ihrer biografischen Subjektivität zu übernehmen (Stichwort soziale Nachhaltigkeit), wurde be- 
reits an anderer Stelle kritisiert. Hier soll es darum gehen, „,dass Städte nicht nur auf lokaler, sondern auch auf nationaler und globaler Ebene tätig werden“ sollen (ebd.). In vertikaler wie horizontaler Weise. Hierfür „,[sollten] [v]ertikale, top-down-Governance-Strukturen [...] durch Bottom-up-Ansätze ergänzt werden“, so dass die „Planungs- und Gestaltungsmacht von Städten für die Organisation ihrer Angelegenheiten gestärkt werden“"(ebd.: 410f.). Etwa dadurch, dass ,innerhalb nationalstaatlicher Verfassungen die Existenz der Städte" konstitutiv ,über ein kommunales Selbstverwaltungsrecht" anerkannt werden sollen (ebd.: 384). Zudem sollen die vertikalen Strukturen der Städte, die eine „Einbeziehung der Städte in alle Belange mit Stadtbezug“ gewährleisten sollen (ebd.), horizontal erweitert werden und zivilgesellschaftliches Networking ermöglichen, da die „Transformation[] einer Stadt [...] nur dann dauerhaft Erfolg haben [wird], wenn sie von der gesamten Stadtgesellschaft getragen wird und diese Verantwortung übernimmt" (ebd.: 411). Städte bedürfen daher ,einer funktionierenden Öffentlichkeit [...] mit offenen Diskursräumen, in die alle Akteure eingebunden werden. Sie bilden den Rahmen für einen gemeinsamen Suchprozess [...]“ (ebd.). Außerdem, so der WBGU weiter, müssen wie auf lokaler, so auch auf nationaler Ebene öffentliche und offene Diskursräume ermöglicht werden (ebd.), die letztlich eine ,neue Staatlichkeit" (WBGU 2011c: 215) und eine ,neue Kultur der Teilhabe“ (ebd.: 218) erfordern (Kap. 11). Die neue Staatlichkeit bezeichnet der WBGU als „gestaltenden Staat [...], der selbst eine proaktive Transformationspolitik betreibt" (ebd.: 216) und den Städten ihre Transformationseigenarten ermöglicht - etwa indem er die zeitlich dringenden Klimafragen (etwa $\mathrm{CO}_{2-}$ Reduktion) zwar marktwirtschaftlich und fiskalpolitisch organisiert (etwa $\mathrm{CO}_{2}$-Steuer, Emissionshandel), perspektivisch aber auf kommunaler Ebene kollaborativ erarbeitete und politisch regulierte Antworten ermöglicht: „Um dies zu fördern und zu stärken, muss es insbesondere ein Anliegen der Nationalstaaten sein, Städte bzw. ihre Stadtregierungen zu befähigen, den Transformationsprozess gestalten zu können“" (WBGU 2016b: 411). Das Konzept des gestaltenden Staates, vermittelt damit also

„zwei Aspekte, die häufig getrennt oder konträr gedacht werden: die Stärkung des Staates, der aktiv Prioritäten setzt und diese (etwa mit Bonus-Malus-Lösungen) deutlich macht, und andererseits die Stärkung der Städte durch verbesserte Mitsprache-, Mitbestimmungs- und Mitwirkungsmöglichkeiten der Bürgerinnen und Bürger“"(WBGU 2011c: 219),

sowie ihrer horizontalen Vernetzung auf globaler Ebene. Als Beispiele solcher transnationalen Städtenetzwerke auf horizontaler globaler Ebene nennt der WBGU die United Cities and Local Governments (UCLG), Local Governments für Substainability (ICLEI), C40 sowie die aus den drei globalen Städtenetzwerken hervorgegangenen Klimaschutzinitiative Compact of Mayors (WBGU 2016b: 118).

Daraus ergeben sich nun aber verfassungsrechtlich schwierige Verhältnisse „bezüglich des , außenpolitischen“ Handelns von Städten im Innenver- 
hältnis zum Nationalstaat", die zwar gegenwärtig rechtswissenschaftlich bearbeitet, aber ,noch ungeklärt sind und intensivere (wissenschaftliche) Auseinandersetzung“ bedürfen (ebd.: 119). Dazu gehört einerseits die Frage, was das Recht auf kommunale Selbstverwaltung (Art. 28 II 1 GG) konkret bedeutet und wie weit es gehen kann, ob es also beinhaltet, „dass das Handeln der Städte auf internationalen Parkett gerechtfertigt wäre" und „,mit einer weiten Auslegung des Art. 28 II GG begründet werden [könnte], die der ,zunehmenden Ausdifferenzierung der auf internationaler Ebene handelnden Akteure' Rechnung trägt (Aust, 2014: Rn. 5)“ (ebd.). Dazu gehört aber andererseits auch die „Frage, ob nicht Städte oder Städtebündnisse als Völkerrechtssubjekte anerkannt werden sollten oder beispielsweise eine gänzlich neue Rechtsform des ,transnationalen öffentlichen Rechts' geschaffen werden müsste (Aust, 2013: 675)“ (ebd.). Zum einen sprechen Argumente dafür, weil ,in manchen Megastädten mehr Menschen [leben] als in vielen Staaten“; zum anderen wäre diese Zuerkennung des rechtlichen Status der Städte als Völkerrechtssubjekte nicht notwendig, wenn ihnen im national-verfassungsrechtlichen Rahmen diese rechtliche Möglichkeit eröffnet würden (ebd.).

Perspektivisch sind solche weltweit horizontal vernetzten Städtenetzwerke zwar unverzichtbar ,für eine ausgewogene, gerechte Raumordnungspolitik $^{62 ،}$ (ebd.: 61). Aber solange die Städte keinen national-verfassungsrechtlich verbindlichen Rahmen für ihr autonomes Agieren zugestanden bekommen und dadurch kein eigenständiges politisches Mandat eingeräumt bekommen, stehen die Nationalstaaten und die internationale Staatengemeinschaft an der Scharnierstelle zwischen den Städten, wo der WBGU (ebd.: 410ff.) sie in ihr Konzept einer ,polyzentrischen Verantwortungsarchitektur“ im Rahmen der gegebenen juristisch Möglichen ja auch folgerichtig setzt. Daraus ergeben sich nun weitere strukturell bedingte Folgeprobleme. Statt eine weltweit horizontale Städte-Konföderation kann so nur ein zentrifugaler Föderalismus verwirklicht werden, der die bestehenden Pfadabhängigkeiten der historisch gewachsenen polit-ökonomischen Verflechtungen von Staat und privatwirtschaftlich organisierter (Wachstums-)Ökonomie tendenziell eher bloß reproduziert als auf radikal-reformerischen Wege tatsächlich eine echte Alternative hervorzubringen (Kap. 12.2.3). Die zentrale Erkenntnis des WBGU, ,dass es für die Transformation eher mehr als weniger Demokratie bedarf" (WBGU 2011a: 252), kann so kaum zur neuen vorherrschenden Praxis werden, da ein stetes und konsequentes Mehr an Demokratie letztlich auf eine vollständig horizontale Demokratisierung des Politischen vom Kommunalen bis zum Globalen hinausläuft. Entlang der ungeklärten Rechtslage setzt der WBGU die global urban governance daher eher reaktionär als

62 Der WBGU lässt bewusst offen, was darunter zu verstehen ist und strebt an, es sich in politischen Aushandlungsprozessen inhaltlich füllen zu lassen, wobei sich der Diskurs allerdings an kategorischen Richtlinien globaler und intergenerationaler Gerechtigkeit orientieren soll (WBGU 2016b: 11, 145). 
zentrifugalen Föderalismus, der die Städte in den nationalstaatlichen Hierarchieebenen konzeptioniert:

„Diese [global urban governance] wird definiert als die Handlungen staatlicher und nicht staatlicher Akteure mit dem Ziel, für und durch eine Stadt nationale und globale Governance-Prozesse und Strukturen zu gestalten. Neben zentralen multilateralen Institutionen und Verhandlungsstrukturen, die sich mit Blick auf die Themen Urbanisierung und Stadtentwicklung identifizieren lassen (z. B. UN-Habitat [...]) lässt sich Global Urban Governance in eine vertikale [...] und eine horizontale Dimension unterteilen [...]: die Einbindung von Städten im hierarchischen Mehrebenensystem und grenzüberschreitende Städtebündnisse.“ (WBGU 2016b: 117)

Damit folgt der WBGU letztlich der „Rio-Erklärung über Umwelt und Entwicklung" der UN von 1992, die ganz auf die Zentralität der Nationalstaaten hin ausgerichtet ist (Vereinte Nationen 1992). In fast allen der dort formulierten 27 Artikel werden die Staatsregierungen als zentrale Akteure gesetzt. Auffällig ist der dadurch entstehende Widerspruch, dass der WBGU einerseits die Kommunen und Städte bis hin zur Selbstverwaltung ihrer Angelegenheiten stärken will (WBGU 2016b: 384), und zugleich aber die Nationalstaaten als Scharniere zwischen dem lokalen und globalen urbanen Handeln setzt. Offen bleibt dabei aber die Frage, „ob die heutigen Regierungen die politischen Mittel zum drastischen Umsteuern besäßen, selbst wenn sie einen solchen Kurswechsel tatsächlich wollten“, oder ob es sich bei der „Imagination des mächtigen Nationalstaats“ der UN und des WBGU, die „die Klimadebatte bis in die Gegenwart [prägt]“, um eine „Illusion der nationalstaatlichen Verfügungsmacht“ handelt, die „tief in die globale Klimapolitik eingeschrieben [ist]" (Uekötter 2019: 13).

Vor diesem Hintergrund lässt sich die gegenwärtig zu etablieren versuchte global organisierte nationalstaatliche Klimapolitik auch als Konsolidierungs- und Legitimierungsversuch begreifen, ebenjene Macht der Staaten wieder oder überhaupt erst herzustellen. So konstatiert Walkenhorst, dass „[i]m Ringen um globale Hegemonie [...] die Klimafrage seit Beginn des 21. Jh. eine zunehmend wichtige Rolle [spielt]" und in dessen Zusammenhang auch die seit den 1990er Jahren zu verzeichnende „Metaphernverschiebung vom kritisierten >Krieg gegen das Klima (oder allgemeiner: ,Krieg gegen die Umwelt", metaphorisch negiert im Namen ,Greenpeace") hin zum ,Krieg um/für das Klima' [...] (vgl. Weingart u.a. 2002, 113ff.)" (Walkenhorst 2008: 1053) einzuordnen ist. „Klimaschutz könnte somit zum Legitimationsangelpunkt eines neu zu etablierenden Hegemonieblocks werden.“ (ebd.) Mit Haug lässt sich Walkenhorsts Kritik dahingehend präzisieren, dass Gramscis Hegemonie-Begriff seit dem zweiten internationalen Gramsci-Kongress 1967 auch zum Ausgangspukt genommen wird für die Untersuchung der „Krise des Nationalstaats und die Suche nach einem internationalen Subjekt", genauer: dem „Übergang von der Struktur zur Sphäre der komplexen Superstruktur, von den spezifischen Interessen einer Gruppe oder Klasse zur Ausbildung von anscheinend universellen Institutionen und Ideologien" (Haug 
2004), was sich mit Walkenhorst (2008) in der internationalen Klimapolitik erblicken lässt. Aus einer Hegemonie-Perspektive nützt die internationale Klimapolitik vor allem jenen gesellschaftlichen AkteurInnen und Gruppen, die ihm Rahmen kostspieliger Investitionen in den ökologisch-transformativen Stadtumbau als Privatinvestoren angefragt werden (WBGU 2016b: 390). In der internationalen Klimapolitik zeigt sich damit letztlich auch der mit Lefebvre in Kap. 12.2.3 herausgestellte Drang des transnationalen Marktes zur Transnationalisierung der Nationalstaaten hin zu einem globalen Marktstaat als „Voranschreiten einer ,Ökonomie auf weltweiter Stufenleiter““ (Haug 2004) unter der Hegemonie staatlich verwalteter plutokratischer Macht- und Herrschaftsverhältnisse, die entlang der Klimapolitik - nicht zuletzt auch durch Konzepte wie dem des WBGU - nun global als Konsens gesetzt werden und dessen Zustimmung - etwa über ein national (WBGU 2016b) bzw. international (UN-Habitat 2010; UN-Habitat III 2017) konzeptionell instrumentalisiertes Recht auf Stadt-light - lokal in den Städten eingeholt und auf Dauer gestellt zu werden versucht wird. ${ }^{63}$

Vor dem Hintergrund der postpolitischen Implikationen und Blindstellen für die vorherrschenden hegemonialen Nationalstaatsdiskurse gerät also auch das Konzept der polyzentrischen Verantwortungsarchitektur des WBGU in ein gefährlich-reaktionäres Fahrwasser. Diese grundsätzliche Kritik am WBGU-Konzept gilt umso mehr, als dass einerseits durch die weitere Reproduktion bestehender staatlich organisierter privatwirtschaftlicher Eigentumsverhältnisse an Grund- und Boden notwendigerweise auch die Lebensweisen mit reproduziert werden, die als Ursachen der ,imperialen Lebensweise“ (Brand/Wissen 2017) herausgestellt werden können: Reproduktion von Lohn- und Wohnabhängigkeiten und Produktion von Suburbanisierung durch Gentrifizierungseffekte, Reproduktion des individualen Autoverkehrs durch Suburbanisierung bei gleichzeitigem Abbau des ÖPNV, Reproduktion des Konsumismus durch marktwirtschaftliche Durchregelung urbaner Flächengestaltung und Raumproduktion und dadurch verhinderte urbane Subsistenz. Zum anderen aber auch aufgrund der vom WBGU nicht weiter begründeten Annahme, das zur Transformation der Städte benötigte Kapital zur Finanzierung könne nur durch ,eine zunehmende Koordinierung und Zusammenarbeit von öffentlichen Sektor und der Finanzwirtschaft" (WBGU 2016b: 390) akquiriert werden und nicht etwa durch andere Formen staatlicher Einnah-

63 Diese Kritik wird aber weder dem WBGU-Konzept noch dem UN-HABITAT-Konzept auf ganzer Linie gerecht und will keinesfalls das zugrunde liegende Klimaproblem in Abrede stellen oder schmälern (vgl. Kap. 1 und 2). Aber Gramscis Hegemonie-Begriff, Lefebvres Staatsanalysen und der Postpolitik-Begriff der kritischen Stadtforschung verweisen auf die Dringlichkeit einer kritisch-theoretischen Begleitung dieser postpolitisch-hegemonialen Entwicklungen der der „imperialen Lebensweise“ (Brand/Wissen 2017) zugrundliegenden und sie ja erst bedingenden Gesellschaftsverhältnisse, die sie nicht nur kritisch untersucht, sondern zugleich auch strategische Transformationsmöglichkeiten der Gesellschaftsverhältnisse aufzeigt, die gegenhegemoniale Bewegungen des Sozialen hervorzubringen hilft. 
men. Dabei weist der WBGU schon selbst darauf hin, dass diese Kapitalakquise ,insbesondere in Sektoren möglich ist, in denen langfristig positive Renditeerwartungen bestehen“ (ebd.: 391), was aber letztlich nichts anderes heißt, als dass weniger Rendite versprechende Sektoren weiterhin unterfinanziert bleiben werden.

Vom WBGU nicht beachtet, aber anschlussfähig an die Forderung des WBGU nach „,mehr Offenheit für Umverteilungsmaßnahmen“, um so der „bestehenden Vermögensungleichheit entgegen[zu]wirk[en] und für gleichere Ausgangsbedingungen [zu] sorg[en]“ und wonach es daher ,ethisch geboten [ist], Vermögen nicht allein an die eigenen Nachkommen zu transferieren, sondern sie zur Gestaltung einer gemeinsamen Zukunft zu nutzen“ (WBGU 2016c: 26f.), ist etwa die Wiedereinführung einer Bodenwertzuwachssteuer (Löhr 2015), wie es selbst das DIfU (2017) fordert. Ebenso kommen die Finanztransaktionssteuer, die Erhöhung des Spitzensteuersatzes (sog. Reichensteuer) oder die Besteuerung maschineller Arbeit in Frage. $\mathrm{Zu}$ untersuchen wäre auch, wie sich Geldgenerierungsmöglichkeiten fruchtbar machen lassen, die mit Digitalwährungen einhergehen. Aber auch die im Grundgesetz (Art. 14 Abs. 3 GG) verbriefte Möglichkeit der Enteignung ,zum Wohle der Allgemeinheit" - vorausgesetzt, ,dass die Eigentumsposition zur Erfüllung öffentlicher Aufgaben benötigt wird oder als Abwehrrecht der Erfüllung dieser Aufgaben entgegensteht" und insofern ein Gesetz die Entschädigung ,unter gerechter Abwägung der Interessen der Allgemeinheit und der Beteiligten“" regelt (Wissenschaftliche Dienste des Deutschen Bundestags 2019) wäre im Rahmen der vom WBGU angeregten Debatte um soziale Gerechtigkeit noch deutlich stärker in Betracht zu ziehen. Nicht zu vergessen ist die ebendort verbriefte Möglichkeit der Vergesellschaftung (Art. 15 GG) von „Grund und Boden, Naturschätze[n] und Produktionsmittel[n]“, die „zum Zwecke der Vergesellschaftung durch ein Gesetz, das Art und Ausmaß der Entschädigung regelt, in Gemeineigentum oder in andere Formen der Gemeinwirtschaft überführt werden [können]" (ebd.).

Aber nicht nur durch das im Grunde reaktionäre Plädoyer für eine ,zunehmende Koordinierung und Zusammenarbeit von öffentlichen Sektor und der Finanzwirtschaft" (WBGU 2016b: 390), das die Kluft zwischen von öffentlichen Sektor und Finanzwirtschaft als bestehendes Produktionsverhältnis des Gesellschaftlichen bestehen lässt, statt es als herrschaftliches Machtverhältnis benannt und unter die demokratische Kontrolle des öffentlichen Sektors gebracht würde, sondern auch der vom WBGU (2016c, 2018) zur Kompensation der absehbaren Unterfinanzierung bestimmter Bereiche vorgeschlagene Transformationsfond bleibt auf einer reaktionären Ebene. Ein solcher Transformationsfond soll „die Möglichkeit“ öffnen, „,dort tätig zu werden, wo sich private Investoren aufgrund der kurzfristigeren Gewinnerwartungshorizonte und Anreizstrukturen des Finanzsystem bislang zurückhalten“"(WBGU 2016c: 24). Oder aber zur Finanzierung von Klagen genutzt 
werden, die als „Anstoß und Treiber für die langfristige Etablierung von Mechanismen für einen gerechten Schadensausgleich für vom Klimawandel Betroffene" (WBGU 2018: 22f.) notwendig werden. Zugleich liegt der Zugang zu den Fondgeldern aber ganz im Rahmen des Konservativen, da die Transformationsfonds als „eigenständige Institution“ vorgeschlagen werden, „die einem parlamentarischen Aufsichtsgremium zwar periodisch rechenschaftspflichtig ist, geeignete Investitionsobjekte national wie auch international grundsätzlich jedoch in Eigenregie identifizieren“"(ebd.: 32f.). Das so für allgemeine Zwecke verfügbare Geld des Fonds obliegt somit nicht der allgemeinen Verfügbarkeit, sondern einem Antragstellungsverfahren und Beschlussgremium, das stark an das von Fraser als herrschaftlich kritisierte Wohlfahrtsstaatsmodell westlicher Gesellschaften, das den Staat als ,juristisch-administrativ-therapeutischen Staatsapparat" (Fraser 1994: 237ff.) in Erscheinung treten lässt, erinnert. Ergänzt um eine wissenschaftliche Relevanzprüfung der Berechtigung der Anliegen und Bedürfnisse. Der Staat tritt dadurch in Erscheinung als juristisch-administrativ-szientistisch-therapeutischer Staatsapparat. Die potenziellen KlägerInnen treten abermals als Antrags- und Bittstellende in Erscheinung, die ihre Anliegen und Bedürfnisse sowohl in eine staatliche Verwaltungslogik (das ist der juristisch-administrative Aspekt) als auch in messbare Klimawandelbedürfnisse (das ist der Aspekt der szientistischen Relevanzprüfung) einpflegen lassen müssen. Dabei wird es in ihren sie zugleich erziehenden Verantwortungsbereich gelegt, sie eigenständig als juristisch-administrativ einpflegbare und klimatologisch relevante Bedürfnisse und Anliegen darzulegen (das ist der therapeutische Aspekt), da ihnen der Einfluss auf die Definition, was als unterstützungswürdig gilt und was nicht, systematisch entzogen ist und abermals in einem Kompetenzbereich liegt, der sie nicht als ExpertInnen ihrer selbst, sondern als Laien etikettiert und subalterniert. Auch wenn diese Subalternierung diesmal durch wissenschaftliche Methodologien und Parameter erfolgt, so erfolgt sie dennoch abermals unter expertokratischer Berufung auf objektive Standards, die mitzugestalten ihnen vorenthalten bleibt. Den zivilgesellschaftlichen Laien bleibt dadurch nur die Funktion ,wach“ zu sein und „sich nicht als passiver Zuschauer staatlicher Handlungen und gesellschaftlicher Entwicklung“ zu erachten, sondern ,als ,Citizens', als mündige, aktiv mitgestaltende Bürgerinnen in Netzwerkgesellschaften“ (WBGU 2016c: 30) ohne allerdings wirklich mitgestaltende Einflussmöglichkeiten auf die Verwendung der ihnen durch Steuern erhobenen Gelder des Transformationsfonds zu haben. Hierin erweist sich das Repräsentationsmodell der Demokratie als zynisch, weil das aktive Mitgestalten auf einer bloß repräsentativen Ebene verbleibt und dort abermals nur die gut gebildeten, rhetorisch gut geschulten und gut vernetzten AkteurInnen bevorteilt, während es offenen Auges alle bis dato ohnehin subalternierten Bevölkerungsgruppen weiterhin subalterniert und ihnen das Auffangen der Effekte des Klimawandels in ihren 
Verantwortungsbereich legt, wobei ihnen zugleich die urbanen bzw. staatlichen Mittel, sich adäquat helfen zu können, mit für sie kaum erreichbaren Hürden belegt. Das unterstreicht noch einmal, dass das Repräsentationsmodell der Demokratie durch ein kommunalistisch-kollaboratives ersetzt werden muss, wenn mit den Transformationsnotwendigkeiten in der Klimafrage auch ein emanzipatorisches Moment verknüpft werden soll.

Mit anderen Worten: Vor dem Hintergrund der Staatsanalysen Lefebvres (Kap. 12.2.3), wonach den Nationalstaaten von Anfang an das apolitische Moment der (Re-)Produktion marktwirtschaftlicher Gesellschaftsverhältnisse (Stichwort postpolitisches Netzwerkregieren) inne wohnt, und vor dem Hintergrund der Analysen zur ,imperialen Lebensweise“ (Brand/Wissen 2017) (Kap. 3), deren Reproduktionszwänge solange das gesellschaftliche Alltagsleben dominieren, solange Urbanisierung als notwendiger Bestandteil des alltäglichen Kapital(re)produktionsprozesses nicht politisiert und demokratisch reguliert ist, ist die zentrale Positionierung der Nationalstaaten im (inter)nationalen Transformationsprozess und seiner Finanzierung eher hinderlich für sozial nachhaltige Stadtentwicklungsprozesse. Selbst wenn die Nationalstaaten die strukturellen Mittel dazu hätten, marktwirtschaftliche Lösungen in politische Lösungen auf kommunal-kollaborativer Ebene überführen zu können, müssten sie auch dem gestaltenden Staatsmodell, wie es der WBGU vorschlägt, durch gesellschaftliche Erziehung entlang kollaborativer Stadtpolitiken und ihrer - und dies ist die Blindstelle Lefebvres - konföderativen Vernetzung mit staatspolitischer Kompetenzerweiterung abgerungen werden, weil nicht absehbar ist, dass mit allmählicher Herausbildung dieses weltweiten Netzwerkes die Nationalstaaten darin aufgehoben und die Regulierung staatlicher Aufgaben sukzessive auf die global vernetzten und kollaborativ arbeitenden Städte und Regionen rund um den Globus übertragen würde. Darin lässt sich also der transformative Zielhorizont emanzipatorisch politischer Subjektbildung im Kontext der Klimafrage und auch der Verantwortungshorizont eines möglichen Anthropozäns durch sozialökologische Stadtentwicklungen erblicken.

Wie durch die vom WBGU konzeptionierte polyzentrische Verantwortungsarchitektur ein neuer Gesellschaftsvertrag zustande kommen soll, ,der das gesellschaftliche Verständnis der Notwendigkeit einer Transformation beinhaltet und somit Legitimation und Akzeptanz für die Große Transformation schafft (WBGU 2011)“ (WBGU 2016b: 383), bleibt der WBGU schuldig zu beantworten. Vor allem vor dem Hintergrund, dass er weder den AkteurInnen eine konsequent kollaborative Mitgestaltung und Selbstverwaltung des Gesellschaftsvertrages ermöglicht, selbst wenn sie als StadtbewohnerInnen global vernetzt wären, noch dass er auf eine Subjektbildung insistiert, die alle Beteiligten unterstützt, die an sie gestellte Verantwortung strukturell und subjektiv realisieren und sich daran als Menschen, gar als Menschheit entwickeln zu können. Vor dem Hintergrund also, dass sich der WBGU zuvörderst 
auf die ohnehin gut vernetzten und politisch sich einbringenden „Pioniere des Wandels"664 (WBGU 2011c: 7, 2016b: 13) bezieht, insistiert er folgerichtig auch nur auf eine „Weltbürgerbewegung“, die „die vertikale Delegation von Verantwortung an die Klimadiplomatie [horizontal] ergänzt" (WBGU 2014a: 2), statt auf die politische und subjektive Hervorbringung von ErdbewohnerInnen. Etwa durch sozial-ökologische Subjektbildung entlang von ökosozialen Transformationsprozessen des Städtischen.

Entsprechend soll es im Folgenden darum gehen, Lefebvres „Recht auf Stadt" mit den Überlegungen des WBGU hinsichtlich einer transnationalen Vernetzung von städtischen AkteurInnen und Städten zusammenzubringen und mit Murray Bookchins Überlegungen zum libertär-kommunalistischen Städtekonföderalismus unter dem von Lefebvre betonten Aspekt der emanzipatorischen Subjektbildung weiterzudenken. Im Fokus steht dabei weiterhin die noch offene Frage nach dem konkreten Wie der Hervorbringung sozialökologischer Handlungs- und Transformationssubjekte in, an und mit den ökosozialen Transformationsprozessen des Städtischen.

\section{Kommunalismus - von der sozial-ökologischen Revolutionierung des Urbanen zum Anthropozän?}

Dass Lefebvres Begriff der städtischen bzw. kommunalen Selbstverwaltung der Begriff Kommune bzw. des Kommunalen Subjekts inne wohnt, der mit Richter (Richter 2019b: 154) als ,unaufhebbare Einheit von Boden und Arbeit sowie Kultur und Sprache bzw. Interaktion“ zusammengefasst werden kann, wurde bereits in Kap. 12.2.2 herausgestellt. An dieser Stelle kann er im Anschluss an die Rekonstruktion der meta- bzw. praxisphilosophischen Argumentation Lefebvres in Kap. 12 (samt Unterkapitel) präzisiert werden als anthropologischer Zusammenhang von Arbeit und Interaktion zur sozialen und transgenerativen Herausbildung gelingender Raumproduktion subjektiver Repräsentation in Form der Kommune ${ }^{65}$ durch die soziale Bearbeitung resp. Urbanisierung von Erdboden und der politischen Bewirtschaftung des

64 Als solche „Pioniere des Wandels“ fasst der WBGU die zahlreichen lokalen „Ansätze transformativer Strategien“ zusammen, ,die auf den jeweiligen Gegebenheiten aufsetzen“ und ,[d]eren Protagonisten [...] Bausteine und Optionen aus[probieren] und [...] so neue Leitbilder bzw. Visionen zu entwickeln [helfen], an denen sich der gesellschaftliche Wandel orientieren kann" (WBGU 2016b: 13).

65 Diese an May (May 2004, 2005) und Lefebvre (Lefebvre 2002, 2006, 1977, 2014) orientierte Formulierung scheint mir geeigneter zu sein als die von Richter durchaus problematische Formulierung der Identität, sei es nun als kommunale oder interkulturelle Identität (Richter 2001, 2019b, 2019a). 
dadurch erschaffenen Urbanen. Im Folgenden geht es daher darum, den darin zum Ausdruck kommenden Begriff des Kommunalismus näher zu beleuchten.

Mit dem Begriff Kommunalismus wird in der Geschichtswissenschaft ein Forschungskonzept bezeichnet, das den „Drang zur freien Assoziation“" auf den Begriff bringt, der ,,in die Geschichte Europas tief eingelagert[]“ ist und sich seit der Antike, bis auf eine ,vierhundertjährige[] Phase der 'patriachalen' Herrschaft" zwischen dem 9. und 13. Jahrhundert (Blickle 2000b: VIII) und einer über den Städtebau seitherigen systematischen Abschwächung der kommunalistischen zugunsten der nationalstaatlichen Organisation des Alltagslebens, strukturell und soziokulturell bis heute nachweisen lässt. ${ }^{66}$ Auf Grund dieser historischen Konstanz spricht Blickle auch von ,einer universalhistorischen Kategorie" (ebd.: IX), mit der zugleich auch immer eine herrschaftskritische Befreiungspraxis zum Ausdruck kommt. Walther resümiert:

„Der Kommunalismus ist diejenige Form politischer Organisation zusammenlebender Menschen, in der die Regeln des Zusammenlebens und die alle betreffenden Entscheidungen unter aktiver Mitwirkung aller (communis) Zustandekommen, die also Selbstorganisation der Betroffenen ist. Der Kommunalismus gründet in der Erfahrung, dass die gemeinsame, einvernehmliche Ausübung der dem einzelnen eigenen Handlungsmacht die Chance eröffnet, als niederdrückend empfundenen Formen personaler Herrschaft widerstehen und sich diesen gegenüber behaupten zu können. Es ist also die Erfahrung der Möglichkeit erfolgreichen gemeinsamen (communis) Betreibens der Angelegenheiten des eigenen Lebensbereiches auch gegen vorhandene personale Herrschaft, welche dem Kommunalismus als einer der Formen der Emanzipation aus dem ,Feudalismus' zugrunde liegt.“(Walther 2009: 127)

Dass sich der Kommunalismus weder als Vergesellschaftungsform noch als Forschungsperspektive in der Geschichtswissenschaft durchsetzen konnte, liegt für Blickle an der schleichenden und durch die „Affinität“ insbesondere der mittelalterlichen kommunalen Selbstverwaltungen „zum Republikanismus als Staatsform“ (Blickle 2000a: 2) begünstigenden In-Beschlagnahme der Kommunen durch die europäische Nationalstaatenbildung, die auch die Geschichtswissenschaft dominiert. Die vorherrschende Geschichtsperspektive ist nach Blickle die „Geschichte der Auflösung des Kommunalismus“, die

66 Strukturell lassen sich Spuren des historischen Kommunalismus heute noch in dem oppositionellen Verhältnis zwischen demokratisierenden Kommunalisierungsstreben und bürgerlich-familistisch herrschaftlichen Nationalstaatsbestrebungen als auch in der Architektur des deutschen Rechts ausfindig machen. Das im Grundgesetz (Art. 28, Abs. 2 GG) verbriefte „Satzungsrecht einer Gemeinde [...] ist ein Produkt“ dieser historisch ,wilde[n] Assoziation“, wobei Landesrecht und Satzungsrecht der Gemeinden ,in einem wissenschaftlich nicht befriedigend gelösten Verhältnis zueinander [stehen]“ (Blickle 2000b: 175f.). „Das moderne Recht als gesatztes Recht“, so Blickle weiter, speist sich daher aus dem Widerspruch der „kommunalen und der herrschaftlichen“ Gesetzgebung (ebd.: 176), der sich durch die Geschichte Europas zieht. Soziokulturell findet sich der Drang zu Kommunalisierungen heute weiterhin vor allem dort, wo sich gegen herrschaftliches Regiertwerden gewehrt wird: in Bürgerinitiativen, Foren sowie autonomen Haus- und Hofprojekten. 
durch den ,sich formierende[n] frühmoderne[n] Staat mit Ordonannces, Polizeien und Landesordnungen“ (ebd.: 146) letztlich eine ,zunehmende[] Verstaatlichung und Individualisierung Europas“ (ebd.: 360) bedeutet(e). Die „enormen und ständig steigenden Staatssteuern“, für deren Eingang „die Kommunen $[\ldots]$ hafteten“, ruinier(t)en die „Gemeinden nicht nur wirtschaftlich [...], sondern auch politisch" (ebd.: 361) und bringt sie seither als staatlich organisierte und hierarchisch eingepflegte Obrigkeiten, als „Repräsentativkörperschaften“" und „Hüter[] der [nationalen, MS] Verfassung“ hervor (Blickle 2000b: 158f.). Gegenüber der kommunalistischen Perspektive haben sich in der Geschichtswissenschaft entsprechend die „Geschichten der Staufer, Wittelsbacher, Württemberger und Habsburger, auch solche über das Reich und jedes Territorium“ durchgesetzt, die eine „Geschichte der Freiheit indessen fehl[en]" lassen (ebd.: 122).

An dieser Stelle setzt der libertäre Kommunalismus an und wendet die Perspektive von der Frage nach der Vergangenheit des Kommunalismus zur Frage nach einer möglichen und den Kommunalismus wiederbelebenden Zukunft, d.h. wie unter den heutigen gesellschaftlichen Bedingungen eine befreiungsethische und zugleich ökosoziale Kommunalisierung des Alltagslebens wieder aufgenommen werden kann, die zugleich ein sozial-ökologisch transformiertes Verhältnis zur Erde verwirklicht. Mit anderen Worten: Es geht im Folgenden um die kritische Nachfrage, ob und wie Lefebvres metaphilosophisches Recht auf Stadt als Transformationsstrategie ökosozialer und teils sozial-ökologischer Praxisphilosophie libertär-kommunalistisch verwirklicht werden könnte, um so zu einer sozial-ökologischen Subjekt- und Politikbildung vordringen zu können, deren Politik auch nicht-menschliche Akteure und Aktanten umfasst; ob also letztlich Menschen als zentrale politische AkteurInnen hervorgebracht werden könnten, die sich zugleich als exzentrisch positionierte ErdbewohnerInnen bewusst wären.

\subsection{Libertärer Kommunalismus}

Libertarismus wird gemeinhin mit Anarchismus gleichgesetzt und als die Überwindung einer hierarchischen Gesellschaftsordnung verstanden. Aber die Überwindung einer vertikalen Ordnung liegt nicht in keiner Ordnung, sondern in einer horizontalen. Entsprechend liegt die Überwindung von gesellschaftlichen Hierarchien nicht in einer Anarchie, sondern in einer Heterarchie. Libertär bedeutet im kommunalistischen Zusammenhang daher eine kollaborative Demokratie (Kap. 9, 10) und unterscheidet sich gerade darin vom historischen Kommunalismus und dessen „Affinität zum Republikanismus als Staatsform“ (Blickle 2000a: 2). Zudem nimmt der libertäre Kommunalismus einen kritischen Bezug zum Anarchismus und zum Marxismus. So 
setzt er sich einerseits „vom Individualismus des Anarchismus und seinem oft energischen Antirationalismus“" sowie dessen „Tyrannei des Konsens[es]“ ab und plädiert demgegenüber für eine kollaborative Mehrheitsdemokratie (Bookchin 1992a: 172, 175), die die Überstimmten aber nicht zum Schweigen bringt, sondern als zentrales konstruktives Moment weiterer politischer Diskurse und Prozesse erachtet (Biehl 1998: 62). Darin unterscheidet er sich andererseits auch von „den autoritären Teilen des Marxismus“, ,wie sie der Bolschewismus verkörpert" (hat) (Bookchin 2015a: 36). Zugleich übernimmt er vom Anarchismus „die Ablehnung“ eines postpolitisch-herrschaftlichen Staates sowie die „Befürwortung des Konföderalismus“ (ebd.: 35), und vom Marxismus ,das grundlegende Ziel, eine rational-systematische und schlüssige Theorie des Sozialismus aufzustellen, die Philosophie, Geschichte, Ökonomie und Politik mit einschließt“ (ebd.). Als „Philosophie des sozialen Wandels“ (Bookchin/Taylor 2015: 13) möchte der libertäre Kommunalismus $^{67}$

„die Regierungsinstitutionen einer Stadt von Grund auf zu demokratischen Volksversammlungen umgestalten, die von Nachbarschaften, Dörfern und Städten ausgehen. In diesen Volksversammlungen regeln Bürger_innen - einschließlich der Mittelschicht und Arbeiterklasse - die Angelegenheiten des Gemeinwesens von Angesicht zu Angesicht, treffen politische Entscheidungen in einem direkten demokratischen Verfahren und verleihen dem Ideal einer humanistischen und rationalen Gesellschaft praktische Realität.“ (Bookchin 2015a: 38)

Vor dem Hintergrund des Anspruchs einer kollaborativen Demokratie (Rohr 2012, 2013) sowie einer die verschiedenen kommunal-subjektiven Produzierendensozialpolitiken übergreifenden Politik des Sozialen (Kap. 6.1, 12.2.2) muss, wie Lefebvres (Lefebvre 1974: 165) Vorschlag (Kap. 12.2.3), auch Bookchins Vorschlag einer direkten Demokratie für die kommunale Selbstverwaltung abgelehnt werden. Denn um den Anspruch verwirklichen zu können, bestimmte Milieus und Interaktionsformen sowie darin sozialisierte AkteurInnen nicht von vornherein auszuschließen, muss selbst die Politikform als Aushandlungssache der beteiligten AkteurInnen erachtet werden und kann daher nicht von vornherein festgelegt werden (vgl. Kap. 6.1, 9, 10). Gleichwohl muss an der kommunalistischen Grundidee beider Autoren festgehalten werden, nicht nur ,das politische Gesellschaftsleben, sondern auch das wirtschaftliche [zu] verändern“, indem ,die Produktionsmittel in das eigentliche Gemeindeleben so eingeglieder[t]“" werden, „dass bei jedem produktiven Unternehmen die örtliche Gemeindeversammlung entscheidet, wie es geführt werden soll, damit die Interessen der ganzen Gemeinschaft erfüllt werden“" (Bookchin 2015a: 39; vgl. auch Lefebvre 1974: 163, 177). Nur über eine solche Gemeinwohlökonomie bekommen die StadtbewohnerInnen bzw. kommunalen AkteurInnen politischen Einfluss auf die Produktionsweise, die Produktpalette, die verarbeiteten Rohstoffe und Halbzeuge sowie die Logistik

67 Bookchin spricht statt von einem libertären Kommunalismus auch von einem libertären Munizipalismus. 
und den Schadstoffausstoß der ortsansässigen Unternehmen, denen gegenüber sie ansonsten weiterhin bloß als Bittstellende mit moralischen Forderungskatalogen in Erscheinung treten und denen die diesbezügliche Mitsprache letztlich nur über ihr Konsumverhalten möglich ist (mit allen transformativen Unzulänglichkeiten, die in Kap.1 herausgestellt wurden). Dass genau dieses Verhältnis durchbrochen werden muss, zeigt sich nicht nur darin, dass der apolitische Gegensatz von Produktivkräften und Produktionsverhältnissen kapitalistischer Verhältnisse, sondern auch der in den Produktionsverhältnissen eingeschriebene Imperativ imperialer Ausweitung wachstumsökonomischer Gesellschaftsprozesse ansonsten weiterhin unangetastet blieben, während sämtliche ökologische Folgeprobleme in den Verantwortungsbereich der Subjekte verlegt werden. Mehr noch: Mit der „Urbanisierung des Kapitals“ (Harvey 2014: 126) als zentraler Motor kapitalbildender Produktionsverhältnisse (Kap. 3) werden urbane Subsistenz verhindernde privatwirtschaftliche Eigentumsverhältnisse städtischer Flächen und Räume produziert, die im Zusammenhang mit der anhaltenden weltweiten Zunahme der Stadtbevölkerungen immer mehr Lohn- und Wohnabhängigkeitsverhältnisse hervorbringen, die durch den steigenden Konsumismus von industriellen Produktionsgütern kompensiert werden muss, so dass ökobewusstes Einkaufsverhalten das Ökoproblem nicht nur nicht lösen kann, sondern auch das Grundproblem des weltweit stetigen Ressourcenverbrauchs systematisch weiter depolitisiert und das wachstumsgenerierende Wertgesetz zugleich weiterhin als Quasi-Ontologie im Raum des Apolitischen belässt.

Es geht Bookchin wie Lefebvre mit der ökosozialen Revolutionierung des Politökonomischen daher darum, dass die politische Möglichkeiten der Städte dem emanzipatorischen Anspruch einer ,ethischen Gemeinschaft mit menschlichem Maß, die in eine schöpferische Interaktion mit ihrer natürlichen Umgebung tritt" (Bookchin 1994: 31), gerecht werden können, wobei als ethische Gemeinschaft eine ,an menschlichen Maßstäben ausgerichtete und demokratisch organisierte Bürgerschaft (civitas)“ und als ,ein mögliches Zuhause für eine allgemeine Menschheit (humanitas)“" (Bookchin 2015e: 128 ) begriffen wird. Diese transformative Revolutionierung des Politökonomischen nennt er Soziale Ökologie (auch Sozialökologie):

„Soziale Ökologie muss diejenigen Weichenstellungen innerhalb der sozialen Evolution untersuchen, wo die Brüche entstanden, die die Gesellschaft mehr und mehr in einen Gegensatz zur Natur brachten, und muss eine Antwort darauf finden, wie sich dieser Gegensatz bis zu unserer modernen Zeit herausbildete.“ Dabei „muss Soziale Ökologie vor allem diejenigen Faktoren benennen, die so viele Menschen zu Parasiten statt zu aktiven Partnern an der Seite der organischen Evolution werden lassen.“ (Bookchin 1992a: 21)

Soziale Ökologie versteht sich bei Bookchin als „Ethik eines radikalen Naturverständnisses“ (Bookchin 1985b), bei dem Natur, analog zum poietischen Naturbegriff bei Lefebvre (Lefebvre 1975c), als sich selbst organisierendes und kreierendes Subjekt begriffen wird (Bookchin 1985a: 262), in dessen 
Entwicklung sich die ,Arten [...] nur gemeinsam und symbiotisch [entwickeln]“ (Bookchin 1985b: 24). Bookchins Begriff der Natur kann mit Kropotkin (Kropotkin 2018; vgl. auch Kunstreich 2006b: 11ff.) als mutualistisch bezeichnet werden, der sich letztlich auch in Haraways Begriff der Sympoiesis (Haraway 2018: 86) und Lovelocks Gaia-Begriff (Lovelock 1992) wiederfindet (Kap. 6.2). Natur entwickelt sich aus diesem Verständnis heraus mit einer eigenen sich regulierenden und organisierenden Logik resp. Eigensinnigkeit, aus der heraus sie eine „eigene Botschaft“ (Bookchin 1985a: 270) impliziert - die der ,ökologische[n] Komplementarität und [des] symbiotische[n] ,Mutualismus“" (ebd.: 13) von Natur und Gesellschaft - und eine „konkrete Utopie“ (Bookchin 1992b) solidarischer Ökonomie eröffnet. Mit Bookchin lässt sich die in Kap. 3 mit Brand/Wissen vorgeschlagene ,solidarische Lebensweise" (Brand/Wissen 2017: Kap. 8), die sie als Alternative zur „imperialen Lebensweise“ (ebd.) letztlich nur grob skizzieren, konkretisiert werden. Nämlich als eine ,ökologische Gesellschaft, die sich um das konföderale System einer Kommune von Kommunen strukturiert, von denen jede an das Ökosystem und die Bioregion angepasst ist, in der sie gelegen ist" (Bookchin 1992a: 193). Hierin erweist sich Bookchins Soziale Ökologie als philosophische Begründung der solidarischen Lebensweise des libertären Kommunalismus. Im Folgenden soll nun der Frage nachgegangen werden, ob und wie Bookchins Ansatz Sozialer Ökologie zur sozial-ökologischen Transformation gereicht, wie sie in Kap. 6.2 begrifflich umrissen wurde und wodurch sich ja erst eine Politik Sozialer Ökologie als ,politische Revolution mit einer sozialen Seele" (Marx 1981b: 409) auf der Ebene der kulturellen Revolutionierung der Urbanisierung der Erde verwirklichen ließe.

Die kommunalistische Organisierung der Vergesellschaftung bzw. Urbanisierung erdökologischer Naturverhältnissen leitet Bookchin aus der ,eigene[n] Botschaft" (Bookchin 1985a: 270) eines sympoietischen, mutualistischen Naturverständnisses ab, ohne sie auf dieses zurückzuführen (Bookchin 1985b: 26) ${ }^{68}$, sondern es als ,gute[n] Boden für die Pflege menschlicher Ethik" zu handhaben, ,ohne ethisch im gewöhnlichen anthropomorphen Sinn des Wortes zu sein“ (ebd.). Das Leben und „letztendlich[] Überleben auf diesem Planeten diktiert uns, dass wir unser Verständnis der städtischen Lebensweise und die Beziehungen der Städte zu ihrem ökologischen Nährboden neu bestimmen“ müssen und legt ,ein Überdenken unserer Technologien und der mit ihnen hergestellten Waren, ja unserer ganzen Einstellung zur Natur“ nahe (Bookchin 1992a: 186). Damit legen die unhintergehbaren metaboli-

68 Bookchin: „Tatsächlich ist die Gesellschaft genaugenommen ein menschliches Phänomen und nicht eines der Natur." Es gibt „keine Parallelen in der Natur [...] - Monarchien, Republiken, Demokratien, gesetzgebende Körperschaften, Gerichte, Polizei- und Militäreinrichtungen und ähnliches, unterscheiden sich von Naturgemeinschaften nicht nur durch ihre scheinbare Kompliziertheit, sondern durch ihre auffällige Absichtlichkeit." (Bookchin 1985b: 25) 
schen Existenzverhältnisse, die entlang der planetaren Herausbildung des Lebens zum Leben auf und vor allem mit der Erde zwingen, für Bookchin ein sympoietisch-mutualistisches und den Anthropozentrismus übersteigendes Verständnis der (Erd-)Natur nahe, das auf die Vergesellschaftungs- resp. Urbanisierungspraxen dieser Erdnaturverhältnisse ausgreifen muss, um die bürgerlich-instrumentelle Konkurrenz- und Beherrschungspraxis von menschlichen wie nicht-menschlichen Naturverhältnissen, die letztlich geradewegs in die gegenwärtige Öko- und Klimakrise geführt hat, zu überwinden. Das führt Bookchin zum Überdenken der Eigentumsfrage am Gemeingut Erde, womit er das im Kommunalismus historisch eingewurzelte Eigentumsverständnis fortführt.

Das kommunalistische Verhältnis von Eigentum und Kommune verdeutlicht Blickle mit der Esel-Schatten-Metapher in Wielands „Geschichte der Abderiten“ (Blickle 2000b: 167ff.), die sich mit der Frage $»$ Wem gehört der Schatten des Esels? « zusammenfassen lässt. Kurzer Umriss des Romans: Jemand mietet einen Esel bei einem Eseltreiber. Bei einem langen Ritt durch die Hitze kommt dem Mieter der Einfall, sich in den Schatten des Esels zu setzen, worauf hin der Vermieter eine extra Miete verlangt, da der Schatten des Esels nicht mitgemietet worden sei. Der Mieter bestreitet das, der Schatten gehöre zum Esel. Es geht vor Gericht. Dort findet sich für jede Streitpartei jeweils ein Anwalt. Dem Gericht wird klar, dass die Gesetzgebung in dieser Eigentumsfrage nicht klar geregelt ist und regelt entlang der jeweiligen Argumentationen im Prozess detaillierter und minuziöser nach. Die Antwort aus kommunalistischer Perspektive auf die Frage, wem der Schatten des Esels gehört, ob demjenigen, der den Esel mietet, oder demjenigen, dem der Esel gehört, liegt aber jenseits von diesem Entweder-Oder. Der Schatten gehört demjenigen, der ihn produziert bzw. hervorbringt oder erzeugt - dem Esel. Aber: Ein Esel produziert zwar seinen Schatten, der anderen einen Nutzen und Profit einbringen kann. Aber damit ein Esel existiert, brauchte es andere Esel, die ihn gezeugt, gefüttert und aufgezogen haben. Zudem: Kein Esel, auch keine noch so große Esel-Kommune kann einen Schatten aus sich selbst hervorrufen. Für einen Schatten braucht es zugleich die Sonne, als elementare Ermöglicherin irdischen Lebens (auch das des Esels und der EselKommune), und es braucht einen Erdboden, auf den der Schatten geworfen werden kann und von wo aus er überhaupt erst anderen nützlich sein kann. Der Schatten des Esels ist also ein Resultat des Verhältnisses von außererdigen Aktanten, dem Esel und seiner topografischen Umgebung, in die er eingebettet ist. Kommunalistisch betrachtet kann nur das Sonne-Esel-BodenVerhältnis den Schatten als Eigentum beanspruchen. Vertragspartner sein bzw. politisch agieren kann aber nur die Esel-Kommune, nicht die Sonne und nicht der Erdboden, welche aber beide einbezogen werden müssen, um den Esel in seiner ökologischen resp. terrestrischen Ganzheit (inkl. dem Schatten, den er wirft) betrachten zu können. 
Um das Bild wieder zu verlassen: Aus kommunalistischer Perspektive kann Eigentum nicht losgelöst betrachtet werden von den Produzierenden, die es herstellen, und der Erde, auf und mit der sie es herstellen. ${ }^{69}$ Grundeigentum kann daher nur kommunales Gut sein und ist in seinem Grundbesitz unveräußerlich. Eigentümer sind die Kommunen, die den Boden urbar und urban machen, nicht diejenigen, die ihn kaufen (können). Es ist an die Produzierenden und an die terrestrische Mitwelt gebunden, in der deren sozialökologischer Verschränkung es produziert wird, und kann lediglich in Nutzbesitz übergehen. Nutzbesitzer können variieren, nicht aber - zumindest aus kommunalistischer Perspektive - die Eigentümer als Grundbesitzer. Von daher kann es aus dieser Warte keinen Verkauf von kommunalem Eigentum geben, das den Grundbesitz überträgt, sondern nur Pacht oder Miete, die den Nutzbesitz überträgt. Zu welchem Zweck, darüber kann im Grunde nur der Eigentümer verfügen, nämlich die Kommune, die kommunalistisch gemeinsam rechtlich regeln müssen. Rousseau, den Blickle als „de[n] Theoretiker des Kommunalismus“ (Blickle 2000a: 349) herausstellt, schreibt in seiner „Abhandlung über den Ursprung und die Grundlagen der Ungleichheit unter den Menschen“"von 1755:

„Der Erste, welcher ein Stück Landes einzäunte, sich in den Sinn kommen ließ zu sagen: dieses ist mein, und einfältige Leute antraf, die es ihm glaubten, der war der wahre Stifter der bürgerlichen Gesellschaft. Wieviel Laster, wieviel Krieg, wieviel Mord, Elend und Gräuel hätte einer nicht verhüten können, der die Pfähle ausgerissen, den Graben verschüttet und seinen Mitmenschen zugerufen hätte: ,Glaubt diesem Betrüger nicht: ihr seid verloren, wenn ihr vergesst, dass die Früchte euch allen, der Boden aber niemandem gehört. “" (Rousseau 1978: 230)

\section{Entsprechend konstatiert auch Bookchin:}

„Niemand hat das Recht, etwas zum Eigentum zu haben, von dem das Leben anderer - sei es moralisch, gesellschaftlich oder ökologisch - abhängig ist. Ebensowenig hat irgend jemand das Recht, privat betriebene technische Anlagen, die sowohl die menschliche Gesundheit als auch die des Planeten gefährden, zu entwickeln, anzuwenden oder der Gesellschaft aufzuzwingen.“ (Bookchin 1992a: 187)

\section{Daraus folgt:}

„Die Erde kann nicht länger besessen werden; sie muss geteilt werden. Ihre Früchte, einschließlich der durch Technik und Arbeit produzierten, können nicht länger von einigen wenigen angeeignet werden; sie müssen allen zugänglich gemacht werden, je nach den Bedürfnissen. Wie die materiellen Güter, so muss auch die Macht der Kontrolle durch die Eliten entrissen und so umverteilt werden, dass alle daran teilhaben können.“(ebd.: 171)

\section{Daher}

,[ertönt] [i]n der Botschaft der Sozialen Ökologie [...] nicht nur der Ruf nach einer Gesellschaft frei von Hierarchie und von hierarchischen Reflexen, sondern ebenso nach einer Ethik, die der

69 Außererdige Aktanten werden hier nicht weiter berücksichtigt, da sie erst dann relevant würden, wenn bspw. die Urbanisierung des Mondes oder des Mars an Bedeutung für das Leben auf und mit der Erde gewännen. 
Menschheit in der Natur die Aufgabe zuweist, der Evolution - in der Natur wie in der Gesellschaft - das volle Bewusstsein ihrer selbst und eine möglichst uneingeschränkte Fähigkeit zu vermitteln, in äußerster Rationalität die Bedürfnisse aller Lebewesen, auch des Menschen zu erfüllen.“(ebd.: 204)

Der im libertär-kommunalistischen Transformationsprojekt Soziale Ökologie durchaus zum Ausdruck kommende Begriff eines Anthropozäns im Sinne einer Politischen Ökologie des politisch zu verwirklichenden subjektiven Gemeinwesens Erde (Kap. 5,6) führt Bookchin zu einer existenzphilosophischen Entscheidungsfrage, die praxisphilosophische Konsequenzen verlangt:

„entweder wir akzeptieren scheinbar ,utopische‘ Lösungen auf der Basis der Dezentralisierung, eines neuen Ausgleichs[.] mit der Natur und der Harmonisierung sozialer Beziehungen, oder wir stehen vor der realen Vernichtung der materiellen und natürlichen Grundlagen auf diesem Planeten." (ebd.: 185)

Diese utopische Lösung erblickt Bookchin in der libertär-kommunalistischen Verwirklichung Sozialer Ökologie als einem historischen Transformationsprojekt, das zum einen dem Marxschen Emanzipationsbegriff des menschlichen Gemeinwesens (Marx 1981b: 408, 1981c: 370), das sich ihres gemeinsamen Wesens erst im „Verein freier Menschen [...], die mit gemeinschaftlichen Produktionsmitteln arbeiten und ihre vielen individuellen Arbeitskräfte selbstbewußt als eine gesellschaftliche Arbeitskraft verausgaben“" (Marx 1962a: 92f.), subjektiv bewusst werden und es als Kommune verwirklichen kann, gerecht zu werden sucht. Zum anderen wird mit dem Transformationsprojekt Soziale Ökologie der im Marxschen Gemeinwesenbegriff enthaltene nicht instrumentelle Anthropozentrismus (Kirchhoff 2020: 39) - der, wie in Kap. 12.4 herausgestellt, auch in Lefebvres „Metaphilosophie“ nicht überwunden wird - versucht terrestrisch zu öffnen, um so das allen gemeinsame Wesen Erde allen Menschen subjektiv bewusst werden zu lassen und politisch $\mathrm{zu}$ verwirklichen. $\mathrm{Ob}$ und wie es ihm gelingt, muss allerdings kurz näher untersucht werden.

Anders als syndikalistisch-libertäre Ansätze betonen Bookchin und Biehl die Notwendigkeit der partizipativen Mitgestaltung staatlicher Institutionen und der staatlich eingehegten (Kommunal-)Politik (Biehl 1998: 76ff.). Allerdings allein mit dem Ziel, ,aus dem Stadtparlament ein Föderationsrat zu machen, in dem die Bürgerversammlungen der Stadtbezirke ihre Delegierten entsenden können“" (ebd.: 119). Und gerade in dieser Hinsicht ist der libertäre Kommunalismus bzw. Munizipalismus global gesehen gegenwärtig recht aktuell (Vollmer 2017), auch wenn in Deutschland davon „wenig zu spüren und zu hören [ist]“ (ebd.: 154) - weder in der Öffentlichkeit des alltäglichen Lebens noch in der fachlichen Öffentlichkeit der Sozialen Arbeit. Das verwundert allerdings auch nicht allzu sehr, bleibt Bookchin letztlich doch auf einer eher idealistischen Ebene der Argumentation stehen, während hingegen gerade fachliche Diskurse Sozialer Arbeit sich materialistischen Fragen stellen müssen. Dass diese Fragen bei Bookchin/Biehl ausbleiben, zeigt sich 
nicht zuletzt daran, dass sie das Einbeziehen realer Erfahrungen und Schwierigkeiten munizipaler Bewegungen, die sich auf staatspolitisch eingehegte (Kommunal-)Politik einlassen, weitgehend außen vorlassen. Diese nämlich zeigen, wie wenig Möglichkeiten auch trotz einer Regierungsmehrheit in den Stadtparlamenten bleiben, dort auch tatsächlich etwas zu bewirken. Der salopp formulierte Anspruch, ,aus dem Stadtparlament ein Föderationsrat zu machen, in dem die Bürgerversammlungen der Stadtbezirke ihre Delegierten entsenden können“ (Biehl 1998: 119), muss daher als von Bookchin/Biehl zu oberflächlich zurückgewiesen werden, da letztlich immer auch die Verwaltungstätigkeit geändert werden muss, was sich trotz politischer Beschlusslage als äußerst zäh erweist: Eine „Regierung zu stellen, heißt [...] noch lange nicht, dass sie damit auch die Verwaltung übernehmen kann“" (Vollmer 2017: 153). So ist das Ver- und Behindern von Politik durch die Verwaltungsapparate nicht zu unterschätzen, so dass ,auch die besten neuen Gesetze oder Instrumente nicht helfen, wenn ihre Implementierung auf administrativer Ebene scheitere" (ebd.) und sich dadurch letztlich auch libertär-munizipale Bürgerversammlungen als „Particitainment“ (Selle 2013: 276f.) erweisen können. Wie Mullis/Schipper mit Crouch (2013) aufzeigen, nimmt ,der Einfluss von wirtschaftlichen bzw. ökonomisch privilegierten Eliten [...] zu“" (Mullis/Schipper 2013: 81f.), sodass eine munizipale (Re-)Organisierung des Kommunalen vor dem Problem steht, zunächst die mit „Lobbygruppen“ verfilzten Verwaltungsstrukturen von eingeschliffenen Handlungsroutinen befreien zu müssen (Vollmer 2017: 153), wenn sich ökosoziale und sozialökologische Stadtentwicklungen mit administrativer Verbindlichkeit und dadurch ermöglichter gesellschaftstransformativer Reichweite durchsetzen sollen.

Wenn Bookchin und Biehl in Bürgerversammlungen - durch die sich kommunale Nachbarschaften ${ }^{70}$ von kleinräumigen Interessensgruppen bis hin zur ganzen Stadt und ihrer staatlichen RepräsentantInnen (kon)föderal nach Interessen und nicht (nur) nach Adressenorganisieren können - als dialogische Räume zu begreifen suchen, die das Repräsentationsmodell der Demokratie perspektivisch durch ein kommunalistisches Kollaborationsmodell

70 Als Nachbarschaft wird dabei nicht nur ein Ort verstanden, ,wo die Menschen sich häuslich einrichten, ihre Kinder aufziehen und viele der Waren erwerben, die sie konsumieren“, sondern auch als politischer Ort, ,wo die Leute sich versammeln, um Fragen der Politik und Gesellschaft zu besprechen“" (Bookchin 2015d: 67). Aus kommunalistischer Perspektive können Nachbarschaften als territoriale sowie als relationale Räume des Politischen verstanden werden, an und mit denen die Diskurse und Beschlüsse der Bürgerversammlungen praktisch werden, bzw. als Räume, aus deren Praxis heraus Belange der Bürger in die Bürgerversammlungen eingehen. Nachbarschaften lassen sich daher in Anlehnung an Negts Diktum, sich „Nicht nach Köpfen, sondern nach Interessen [zu] organisieren“ (Negt 1977), auch als Organisierung nach Interessen, nicht nach Adressen fassen. Denn die räumliche Organisation von Interessen kann gänzlich anders umrissen sein, als sie in einem rein containerisierenden Nachbarschaftsbegriff territorial gesetzt würde. 
ersetzen könnten. Dann erweist sich diese Überlegung - zudem ohne jeden Ansatz emanzipatorisch-strategischer Praxisforschung - vor dem Hintergrund der hegemonialen Staatspraxis postpolitischer Stadtentwicklung als geradezu hilflos naiv. Zwar betonen sie die Notwendigkeit „duale[r] Macht“" (Bookchin 1996: 323), womit sie darauf verweisen, dass Bürgerversammlungen keine Orte bzw. Räume postpolitischer Konsensbildung, sondern konfliktorientierter Partizipation und kollaborativer Demokratie seien (Biehl 1998: 113). Aber gegenüber Lefebvre, der ebenfalls den notwendigen „Dualismus der Macht“ (Lefebvre 1974: 159) betont, bleiben sie ungleich zurück. Es fehlt ihnen ein konkreter Vorschlag, wie der Macht-Dualismus in ein dialektisches Verhältnis gesetzt werden kann, aus dem durch eine kommunal(istisch)e Selbstverwaltung eine kollaborative „öffentliche Erziehung des Staates“ (Marx 1981a: 95) hervorgehen kann. Etwa indem durch den Gebrauch gemeinsamer Produktionsmittel auch ein gemeinsamer Bildungsprozess auf subjektiver wie kommunaler Ebene in Gang gesetzt wird, der in Lefebvres Begriff der ,strategischen Hypothese“ (Lefebvre 1987: 372ff.) und in der „Methode der Residuen“ (Lefebvre 1975c: 334ff.) stark gemacht wird. Erst in diesem Sinne ließe sich in kollaborativ-transformativer Hinsicht von der Herstellung von urban und global commons als politische Bildung des Ökosozialen zur sozialökologischen (Subjekt-)Bildung am Ökosozialen sprechen. Aber von einer solchen an den Residuen orientierten Subjektbildung fehlt in Bookchins libertär-kommunalistischen Politikkonzept jede Spur.

Was bleibt also von der libertär-kommunalistischen Transformationsstrategie? Vor dem Hintergrund der in Kap. 6.2 eingeführten Unterscheidung in ökosoziale und sozial-ökologische Transformationen verbleibt Boockchins Anspruch, trotz des Anspruchs der Überwindung anthropozentrischer Gesellschaftsverhältnisse, auf der Ebene ökosozialer Transformation, weil ihm letztlich ein Ansatz der Subjektbildung fehlt. Während Lefebvre die Überwindung anthropozentrischer Gesellschaftsverhältnisse missen lässt und dafür die emanzipatorische Subjektbildung stark macht, lässt Bookchin die emanzipatorische Subjektbildung missen und macht dafür die Überwindung anthropozentrischer Gesellschaftsverhältnisse stark - allerdings ohne zu konkretisieren, wie dies gelingen soll. Von sozial-ökologischer Transformation kann in der vorliegenden Untersuchung aber nur gesprochen werden, wenn all dies in einem Stadtentwicklungsprozess zusammenkommt. Aber auch als Begründungsrahmen ökosozialer Transformationen kann Bookchins libertär-kommunalistischer Ansatz Sozialer Ökologie gegenüber Lefebvres umfangreichen praxisphilosophischen Ansatz eines „Rechts auf Stadt“ (Kap. 12) nur bedingt in Anspruch genommen werden, weil dem Politikkonzept des libertären Kommunalismus ein Ansatz der gesellschaftlichen Erziehung des Staates fehlt und stattdessen geradezu naiv auf eine demokratisch legitimierte Übernahme staatlicher Institutionen insistiert. 
Warum dann überhaupt die Einführung des Kommunalismuskonzepts in die Argumentation der Untersuchung? Weil darin die Möglichkeit sozialökologischer Transformation angelegt ist. Zum einen in der terrestrischen Öffnung des Anthropozentrismus. Und zum anderen in der globalen StädteKonföderation (Bookchin 1996: 313ff., 2015b), die, insofern der Kommunalismusansatz nicht libertär, sondern - wie in Kap. 15.2 und 15.4 zu zeigen sein wird - radikal-reformerisch (Hirsch 2007) und genossenschaftlich (Kunstreich 2018) gefasst würde, auch einen emanzipatorischen Subjektbildungsprozess zu ermöglichen verheißt, der zugleich einen gesellschaftlichen Erziehungsprozess staatlicher Institutionen bedeuten könnte, durch den es zu ermöglichen in Aussicht steht, den vom WBGU favorisierten proaktiv Transformationen initiierenden gestaltenden Staat (Kap. 14) konföderal selbst zu gestalten und einen neuen Gesellschaftsvertrag hervorzubringen.

\subsection{Kommunalistische Infrastrukturpolitik}

Vor dem bereits herausgestellten Hintergrund, dass eine Politik des Sozialen nicht nur integraler Bestandteil subjekt- und gemeinwesenorientierter Sozialer Arbeit ist, sondern auch für eine ökosoziale Transformationsstrategie Sozialer Arbeit, die auf die Herstellung und kollaborative Bewirtschaftung von urban und global Commons insistiert (Kap. 6.1), soll es im Folgenden darum gehen, dessen Ermöglichung und Verwirklichung näher zu untersuchen, und dabei zugleich den kritischen Blick beizubehalten, ob und wie sie auch den Schritt von ökosozialen zu sozial-ökologischen Transformationen zu vollziehen vermögen. Kurz: ob und wie mit einer die kommunal-subjektiven Produzierendensozialpolitiken übergreifenden Politik des Sozialen das Transformationsprojekt Soziale Ökologie, wie ein mögliches Anthropozän mit Bookchin auch genannt werden kann, nicht nur ermöglicht, sondern auch verwirklicht werden könnte.

May (May 2013b: 188) stellt - ganz analog zu Marx und Lefebvre - heraus, dass es nur „zur Herausbildung von Sozialpolitiken der Produzierenden“ kommen könne, wenn ihnen - etwa durch kommunalpädagogisches Ortshandeln bzw. Sozialraumentwicklung/-organisation - Infrastrukturen zur Verfügung gestellt würden, über die sie selbst verfügen könnten, um mit ihnen jene ausgelassenen Realitäten subjektiver Vermögen und Eigenschaften der Kooperationsfähigkeit zu entfesseln, die gegen das Verwertungsinteresse stehen und entlang kommodifizierter und funktionalisierter Zugänge und Nutzungen von Infrastrukturen zu Residuen blockiert wurden bzw. unterdrückt werden mussten (Widersprüche Redaktion 2012).

Statt Infrastrukturen im üblichen Sinn als Voraussetzung der gesellschaftlichen Kapital(re)produktion durch rechtliche Regelungen, Handels- 
und Verkehrswege, Wasser-, Strom- und Kommunaktionsnetze, und aufs Mindestmaß reduzierte Gesundheits-, Bildungs- und Wohnversorgung zu begreifen, wodurch eine gelingende Raumproduktion subjektiver Repräsentation zur Privatangelegenheit (v)erklärt wird, dreht der Begriff der sozialen Infrastruktur, wie er von der AG Links-Netz ausformuliert wird, den Fokus von der gesellschaftlichen Kapital(re)produktion auf die gesellschaftliche (materielle, soziale und kulturelle) (Re-)Produktion menschlicher Verwirklichung bzw. auf das „Betreiben des eigenen Lebens“ (AG Links-Netz 2013a: 58). Nämlich indem eine soziale Infrastrukturpolitik „,die Grundlagen dafür zur Verfügung [stellt], dass alle die Arbeiten getan werden können, die zur gesellschaftlichen Reproduktion und also zum (nach den herrschenden Standards) guten Leben aller und das heißt: zur gesellschaftlichen und politischen Teilhabe aller notwendig sind“ (ebd.: 62). Mit Bloch ließe sich hierbei von einer „konkreten Utopie“ (Bloch 2013a: 180), mit Wright von einer ,realen Utopie“ (Wright 2017) sprechen, da soziale Infrastrukturen „im Prinzip durchaus im Rahmen der bestehenden kapitalistischen Verhältnisse realisierbar wären“ (AG Links-Netz 2013a: 51):

„Wir verstehen unter sozialer Infrastruktur die in der Regel kostenlose oder gegen geringes Entgelt dargebotene Bereitstellung öffentlicher, für alle gleichermaßen zugänglicher Güter und Dienstleistungen, die die Grundvoraussetzung dafür sind. Dies betrifft vor allem die Bereiche der Gesundheitsvorsorge, des Verkehrs, des Wohnens, der Bildung und der Kultur [sowie Ernährung, ebd. S. 58].“ (ebd.: 57)

Wie diese ,über Steuern von allen finanziert[en]“ (ebd.: 62) Infrastrukturen kommunal auszugestalten sind, ,ist eine Frage der politischen Aushandlung“ (ebd.: 58) auf der Ebene kommunal organisierter Regionalpolitiken und Öffentlichkeiten. Das heißt, die konkrete Ausgestaltung der Infrastrukturen ist eine Angelegenheit der beteiligten AkteurInnen und ihrer subjektiven Interaktionsformen (Produzierendensozialpolitiken) und ihren draus resultierenden Bedürfnissen. Dass das Vermögen, sich dergestalt seiner (residualisierten) Bedürfnisse bewusst zu sein und artikulieren zu können mitunter erst erarbeitet werden muss, sollte bereits deutlich geworden sein, weshalb eine soziale Infrastrukturpolitik als die verschiedenen Produzierendensozialpolitiken übergreifende Politik des Sozialen nicht ohne kommunalpädagogische Subjektbildung in die transformatorische Reichweite kollaborativer Demokratie vordringen kann. Denn erst das macht sie, neben ihrem Anspruch der sozialen Ermöglichung der subjektiven (Re-)Produktion des eigenen Menschseins, tatsächlich zu sozialen Infrastrukturen, was bei der AG Links-Netz erstaunlich blass bleibt und dadurch die Formulierung des „Betreiben[s] des eigenen Lebens" (ebd.) recht sachlich an einen Betriebsablauf denn an eine lebendige Selbstregulierung (May 2004, 2005) durch die Politisierung der sozialen Praxis des Urbanen erinnern lässt. Das wiederum ändert aber nichts an dem darin zum Ausdruck kommenden gesellschaftlich-revolutionären Transformationsvorhaben, um das es hier gehen soll. 
Von der herkömmlichen Weise ihrer Bereitstellung unterscheiden sich soziale Infrastrukturen neben ihrer kommunalen Politisierung vor allem in der beanspruchten Reichweite der kommunalen Politisierung. So müssen auch die die Infrastrukturen bereitstellenden Betriebe und Unternehmen kommunalisiert und kollaborativ demokratisiert werden, so dass es möglich würde, Begriffe wie Arbeit und Haushalt aus ihrem kapitalgenerierenden Begriffskorsett zu befreien, um sie so überhaupt erst als Angelegenheiten der Kommune, und nicht mehr nur als Angelegenheiten in einer obrigkeitsstaatlich als territoriale Verwaltungseinheit gesetzten Kommune zu bearbeiten. Denn auch das Verständnis von Arbeit muss kommunalisiert werden, da das kommunale Herstellen und Bewirtschaften sozialer Infrastrukturen die Lebenszeit der AkteurInnen beansprucht, die ihnen aber nicht gleichermaßen zur Verfügung steht, wenn sie entlang sozioökonomischer Ungleichheitsverhältnisse bzw. ungleicher Lohn- und Wohnabhängigkeitsverhältnisse unterschiedlich an Lohnarbeitsverhältnisse gebunden sind. Entsprechend reicht es nicht, im Kontext der Klimafrage in postwachstumsökonomischer Hinsicht bloß die Arbeitszeitreduktion zu fordern, so dass daraus eine industrielle Produktionsreduktion einhergeht (Paech 2014, 2017, 2018), ohne zugleich auch die Unternehmen mit zu kommunalisieren, so dass Lohnarbeit und gesellschaftliche bzw. kommunale Sorgearbeit ineinander aufgehen können.

Das Verständnis von Arbeit muss in diesem kommunalistischen Sinne gesellschaftliche und subjektive (Re-)Produktion umfassen und in einem kommunalistischen Sorgebegriff aufgehen, mit dem die alltägliche Sorge für sich selbst über die alltägliche Sorge um das Gesellschaftliche zum Ausdruck kommt. D.h. „das ,Politische“ am ,Privaten“ zu seinem Gegenstand macht“ (Hirsch 2007: 183). Gemeint ist die poietisch-kreative Tätigkeit, die dem Kapitalismus ohnehin zu Grunde liegt und ihn durch vermeintlich private Sorgetätigkeiten für sich und andere entlang subjektiver Vermögen und Fähigkeiten überhaupt erst ermöglicht. Allerdings mit dem Unterschied, dass diese poietische „Fundamentalökonomie“ (Foundational Economy Collective 2019) bzw. dieser ,alltägliche[] Kommunismus“ (Streeck im Vorwort zu ebd.: 7) zum Kernbestand des Arbeitsbegriffs werden muss. Wie die kapitalistische Vergesellschaftung, so sind auch über soziale Infrastrukturen vergesellschaftete Sozialitäten bzw. Kommunen auf diese lebendige Arbeit menschlicher Poiesis angewiesen, nur dass das kommunalistische Herstellen und Bewirtschaften sozialer Infrastrukturen zugleich auch die Möglichkeit eröffnet, auch informelle Wirtschaftsweisen anzuerkennen (WBGU 2016b: 170). Und zudem den kommunal produzierten urbanen Mehrwert nicht länger privatwirtschaftlich, sondern kommunal abschöpfen zu können, so dass er nicht nur einigen Wenigen zu Gute kommt (in der Hoffnung, er würde von ihnen an die Allgemeinheit weitergeleitet), sondern allen AkteurInnen der Kommune, und zwar verbindlich. Dadurch erst würden soziale Infrastrukturen sukzessive kommunale Handlungsspielräume nicht nur subjektbildender 
Art, sondern auch finanzieller Art öffnen, die klimabedingte ökosoziale Stadtentwicklungsprojekte urbaner Flächennutzung, Raumgestaltung und Raumproduktion (Kap. 10) mit Armutsbekämpfung verbinden und jenseits gesellschaftlicher plutokratischer Herrschafts- und Machtverhältnisse gegenhegemoniale Stadtentwicklungsprozesse anstoßen könnten, die ihnen sukzessive die Stirn zu bieten vermögen. Und erst dadurch könnten urbane Eigenarten in städtischen Transformationsprozessen ermöglicht werden, die tatsächlich an den subjektiven Eigensinn der AkteurInnen anschließen und ihn emanzipatorisch bilden (Kap. 11.2).

Letztlich machen soziale Infrastrukturen mit ihrer implizierten Revolutionierung des Arbeitsbegriffs zugleich aber auch noch andere gesellschaftliche Finanzierungen des individuellen Alltagslebens notwendig, die über ein kommunen-übergreifendes garantiertes, bedingungsloses Grundeinkommen, das jede/r unabhängig vom Einkommen als Ergänzung zu ,(prinzipiell) kostenlosen und für alle zugänglichen öffentlichen Gütern“ in ,ausreichend[er]“ Höhe bekommen kann (AG Links-Netz 2013a: 61), bewerkstelligt werden könnten. Damit würde nicht nur der ,Zwang, Lohnarbeit unter allen Bedingungen annehmen zu müssen“, beendet und „damit einiges zur ,Humanisierung' der Arbeitsverhältnisse“" (ebd.) beigetragen, sondern auch zur Reduktion der Verwaltungstätigkeit, indem es die bisherigen Transferleistungen zur sozialen Sicherung zu einer zusammenführt (ebd.: 64; zur kritischen Bestandsaufnahme der Diskussion um ein BGE siehe auch Völker 2013). Auf die Diskussion der vielen Varianten des bedingungslosen Grundeinkommens kann an dieser Stelle nicht eingegangen werden (zum Überblick der Bandbreite des Begriffs: Blaschke/Otto/Schepers 2012; Blaschke 2012, 2017). Wichtiger ist es an dieser Stelle, den damit von der AG Links-Netz symbolisierten grundsätzlichen Paradigmenwechsel zu betonen, der von der nach dem Versicherungsprinzip geregelten Auszahlung, wonach sich die Höhe der Auszahlung nach den zuvor eingezahlten Leistungen bemisst, hin zu einer steuerfinanzierten Auszahlung in gleicher Höhe für alle ${ }^{71}$ vollzogen werden soll, da den auf dem Versicherungsprinzip basierten sozialen Sicherungssystemen wegen grundlegend veränderter Arbeitsmarktbedingungen, Arbeitsverhältnissen und demografischen Veränderungen die reale Grundlage entzogen ist (AG Links-Netz 2013a: 54).

Nicht nur, aber vor allem in der Finanzierungsfrage sozialer Infrastrukturpolitiken kommt der für Bookchins (Bookchin 1996: 313ff., 2015b) libertären Kommunalismus so zentrale Gedanke der konföderativen Kommunali-

71 Zwar soll der AG Links-Netz nach jede/r ein bedingungsloses Grundeinkommen erhalten, jedoch bemisst sich die Besteuerung nach dem Gesamteinkommen, womit bei höherem Gesamteinkommen eine höhere Steuer gezahlt werden muss (AG Links-Netz 2013a: 61f.). Ob es angesichts des enorm ungleich verteilten Besitz- und Eigentumsvermögen tatsächlich sinnvoll, gar gerecht ist, die Besteuerung lediglich nach dem Einkommen zu bemessen und nicht auch nach dem Besitz- und Eigentumsvermögen, kann an dieser Stelle nur angefragt und angeregt werden, näher zu untersuchen. 
sierung, d.h. der regionalen und überregionalen politischen Vernetzung selbstverwalteter Kommunen zur selbstverwalteten Kommune selbstverwalteter Kommunen mit staatsersetzendem Charakter allerdings an seine begrifflichen Grenzen. Denn es kommt letztlich nicht nur darauf an, eine Gegenmacht zur staatlichen Macht zu sein, sondern auch eine staatliche Reichweite und Verbindlichkeit zu entfalten: a) um die Steuern für die Herstellung und Pflege der Infrastrukturen einnehmen zu können; b) um die Ausgaben in Form von überregionalen Transferleistungen und Investitionen in die klimabedingte Stadtentwicklung kollaborativ selbst regulieren zu können. Damit kommt nun ein entscheidender Unterschied zum libertär-kommunalistischen Ansatz Bookchins zum Vorschein, der entlang der Notwendigkeit der ,dualen Macht" (Bookchin 1996: 323) zwischen Staatsapparat und kommunalen AkteurInnen betont, den Staatsapparat nur zu nutzen, um ihn konföderativ zu überwinden. Demgegenüber ,spielt der Staat“ im Ansatz sozialer Infrastrukturen hingegen ,eine wichtige Rolle“, da „eine Gesellschaft, die auf Freiheit und Gleichheit beruht, zumindest angesichts ihres gegenwärtigen historischen Entwicklungsstandes eine zentrale Instanz [benötigt], um das eine zu garantieren und das andere durchzusetzen" (AG Links-Netz 2013b: 14). Vor dem Hintergrund der in Kap. 12.2.3 vorgenommenen Untersuchung der postpolitisch-hegemonialen „Logistik der Macht“ (Wex 2001) muss der Staat, d.h. müssen die AkteurInnen staatlicher Institutionen aber selbst erst einmal insofern gestärkt werden, dass sie einen ,gestaltenden Staat" hervorbringen können, „der selbst eine proaktive Transformationspolitik betreibt“" (WBGU 2011c: 216). Die Herausforderung besteht nun darin, dass sie sich dabei ihrer bisherigen Funktion als Organisationsbüro der Reproduktion marktgesellschaftlicher Produktionsverhältnisse entkleiden und sich stattdessen gewissermaßen über den Markt und dessen Hegemonialmacht stellen müssten, wobei sie von Anfang an im Blick haben müssten, die ihnen zugestandene Macht mit der Herausbildung einer selbstverwalteten Kommunal- und Städtekonföderation sukzessive an diese $\mathrm{zu}$ übergeben. Andernfalls muss die Städtekonföderation dem gestaltenden Staat seine gestärkte Gestaltungsmacht ebenfalls erst wieder abringen. Beides verweist auf die Notwendigkeit strategischer Transformationsprozesse, die Marx ' und Lefebvres kommunalistischtransformativen Ansätze hinsichtlich einer gesellschaftlichen Erziehung des Staates von Bookchins libertären Ansatz demokratischer Übernahme und Ersetzung staatlicher Institutionen unterscheiden.

Mit anderen Worten: Der Staat als Ensemble staatlicher Institutionen kann nicht einfach konföderativ überwunden oder übernommen werden, sondern muss über die Subjektbildung seiner AkteurInnen konföderativ erzogen werden. Dahinter steckt die Einsicht, dass ,[w]enn nicht Steuern erhoben werden, was unter den bestehenden und nicht utopischen Bedingungen nur durch Zwang möglich ist, [...] eine ausreichend gleiche materielle Ausstattung der Gesellschaftsmitglieder - soziale Sicherung - nicht möglich [ist]", 
sondern stattdessen nur durch ,,private Mildtätigkeit mit den damit verbundenen Abhängigkeiten“ (AG Links-Netz 2013b: 14), d.h. der Reproduktion plutokratischer Verhältnisse ermöglicht werden kann. Bookchin müsste also entweder auf die (wenig aussichtsreiche) Hoffnung einer strengen Rationalität und Selbstverpflichtung der AkteurInnen setzten, oder aber er muss hinter den libertären Anspruch jeglicher Zwangsfreiheit zurücktreten und die freiwillig nicht Zahlenden per staatlichen Zwang letztlich doch zu verpflichten.

Zudem kann ein konföderatives Netzwerk, auf das Bookchin setzt, aus der historisch gewachsenen Rechtsarchitektur Deutschlands nicht „die Durchsetzung von allgemein verbindlichen Rechtsansprüchen" (AG LinksNetz 2013b: 15) beanspruchen, weil es hierfür in Deutschland (noch) „keine Grundlage in der Bundesverfassung“ gibt und etwaige Versuche „keinen verfassungsrechtlichen Bestandsschutz" haben (Krumm 2015: 303) - was einmal mehr für die konföderative Erziehung des Staates spricht. Doch nicht nur die Gewährleistung der Finanzierung der sozialen Infrastrukturpolitik, sondern auch die Zugänge zu den Infrastrukturen müssten staatlich, d.h. zentral garantiert werden. Zudem müssten auch ihre kommunal-dezentrale, basisdemokratische Organisierung staatlich legitimiert sein; „,keine Dezentralisierung, ohne zentrale Ermöglichung“ (Streeck im Vorwort zu Foundational Economy Collective 2019: 28). Darin kommt nun die Notwendigkeit zum Vorschein, den Begriff der Transformation näher zu bestimmen.

\subsection{Zum Begriff der Transformation: symbiotische Freiraumstrategien statt libertärer Bruch}

In Kap. 12.1.2 kam vor dem Hintergrund Lefebvres Analysen bereits mit Wright zum Ausdruck, dass radikale Bruchtheorien, trotz ihrer Attraktivität zurückzuweisen sind. Stattdessen, so wurde betont, müssen sie aus den bestehenden gesellschaftlichen Alltagsverhältnissen herausgearbeitet werden, immer entlang des festen Entschlusses, sie allmählich zu überwinden (poietische Mimesis). Entsprechend schreibt Wright:

„Um demokratische, egalitäre Ideale voranzubringen, muss das Ausmaß gesellschaftlicher Ermächtigung innerhalb der wirtschaftlichen Strukturen kapitalistischer Gesellschaften radikal erweitert werden. Eine nennenswerte Entwicklung hin zu realer gesellschaftlicher Ermächtigung bedroht aber die Interessen mächtiger Akteure, die am stärksten von kapitalistischen Strukturen profitieren und ihre Macht einsetzen können, um solche Entwicklungen zu bekämpfen. Wie lassen sich also nennenswerte Entwicklungen in Richtung gesellschaftlicher Ermächtigung erreichen?" (Wright 2017: 375)

Wright stellt anschließend drei miteinander verschränkte ,grundlegende Logiken der Transformation“ heraus: „die Logiken des Bruchs, des Freiraums und der Symbiose“, die ,im Großen und Ganzen der revolutionär sozi- 
alistischen, der anarchistischen und den sozialdemokratischen Tradition des Antikapitalismus [entsprechen]“ (ebd.: 414f.). Die Strategie des Bruchs „[gipfelt] in einem Frontalangriff auf den Staat" und arbeitet mit den Mitteln der ,harrsche[n] Konfrontation“, bei der die „Kapitalisten“ durch Gewaltandrohungen „,zu Zugeständnissen gezwungen werden“ (ebd.: 417). Damit wird aber jegliche Möglichkeit der Bildung eines menschlichen Gemeinwesens verfehlt, die auch die „Kapitalisten“ vom Joch der Kapital(re)produktion befreien. Nichts desto Trotz wird der „Bruch mit dem Kapitalismus [...] als notwendig begriffen“ (ebd.: 445). Aber es kommt darauf an, ihn nicht als Hau-Ruck-Ereignis, sondern als (trans-)generativen Revolutionierungsprozess zu verstehen, so wie der Revolutionsbegriff ja auch im Kontext der neolithischen, industriellen oder digitalen Revolution begriffen wird: als einen langesamen Umbruch entlang einer, ,revolutionären Realpolitik“ (Luxemburg) bzw. einem „radikalen Reformismus“72, der ,durch den allmählichen Wandel gesellschaftlicher Werte und Verhaltensweisen“ „auf die Veränderung grundlegender gesellschaftlicher Strukturen“ (AG Links-Netz 2013b: 15) insistiert. Nämlich dadurch, dass Freiräume gesucht, genutzt und strategisch ausgeweitet werden, um so „allmählich Umfang und Tiefgang“ von Handlungen und „Aktivitäten [zu] erweitern, so dass kapitalistische Zwänge aufhören, ihnen verbindliche Grenzen aufzuerlegen" (Wright 2017: 443f.). Solche „Freiraumstrategien“ (ebd.: 436) eröffnen gesellschaftlichen Transformationen neue Möglichkeiten, indem durch kommunale soziale Infrastrukturpolitiken die Bedingungen solcher Räume verbindlich umgestaltet werden können, „unter denen schließlich ein Bruch vollzogen werden könnte“ (ebd.: 443f.).

Das wird aber letztlich nur durch die Hinzuziehung und durch die öffentliche Erziehung staatlicher Institutionen möglich, die damit also nicht nur zur Finanzierung und Legitimierung sozialer Infrastrukturen von zentraler Bedeutung sind, sondern vor allem auch als Zöglinge einer ,wahre[n], öffentliche[n] Erziehung des Staates“" (Marx 1981a: 95). Libertäre Ansätze greifen durch ihre radikale Ablehnung staatlicher Institutionen für den Transformationsprozess entsprechend zu kurz und verpassen ebenjene kommunalpädagogisch-emanzipatorischen Möglichkeiten sozialer Infrastrukturpolitiken, die „sich auf die eine oder andere Weise mit dem Staat auseinandersetzen und ihn einsetzen, um den Prozess emanzipatorischer gesellschaftlicher Ermächtigung voranzutreiben“ (Wright 2017: 452). Dem entspricht die Forderung der AG links-netz, durch den „Ausbau der Sozialen Infrastruktur [...] das gesellschaftliche Bewusstsein und damit die sozialen Kräfteverhältnisse so zu verändern, dass sich der Charakter der staatlichen Apparatur verändert und

72 „'[R]adikal' deshalb, weil auf die Veränderung grundlegender gesellschaftlicher Strukturen gezielt wird, ,Reformismus', weil dies nicht durch Macht und Gewalt, sondern nur durch den allmählichen Wandel gesellschaftlicher Werte und Verhaltensweisen erreichbar ist.“ (AG Links-Netz 2013b: 15) 
damit zugleich die Bedingungen für soziale Kämpfe verbessert werden“ (AG Links-Netz 2013b: 15).

Solche Verbesserungen der Bedingungen für soziale Kämpfe sind aber nur zu erreichen, wenn ,sich die Akteure aufrichtig auf experimentelle, kooperative Interaktionen einlassen“ (Wright 2017: 482), was am ehesten dadurch ermöglicht wird, wenn ,die wechselseitig vorteilhafte Kooperation gegensätzlicher gesellschaftlicher Kräfte“ auf Kompromisse und „Win-WinLösung[en]" gemeinsam bearbeiteter Probleme aus ist, statt auf radikale Konfrontation (ebd.: 481f.). Solche mit Wright als „symbiotisch[]“ bezeichnete Transformationsstrategien haben das „Potenzial [...], den Raum für gesellschaftliche Ermächtigung auszuweiten und relativ stabile Formen positiver Kollaboration zu schaffen" (ebd.: 484) - die der WBGU zwar auch anstrebt, aber letztlich den notwendigen Bruch zur tatsächlichen Transformation des Staatsapparates unterbindet (WBGU 2016b: 151f.). Dadurch erst würde der Staat aus seiner inhärenten Funktion der infrastrukturellen Organisation der Reproduktion der kapitalbildenden Produktionsbedingungen entlang global bestehender Eigentums- und Besitzverhältnisse entlassen und in die kommunal kontrollierte Produktion sozialer Infrastrukturen überführt werden können. Dies aber auch nur, wenn Staat, Wirtschaft und Zivilgesellschaft radikal zusammengedacht ${ }^{73}$, zusammengebracht und ihr Verhältnis „radikal demokratisiert“ (Wright 2017: 492) wird, wodurch

„die wirtschaftliche Macht der gesellschaftlichen Macht untergeordnet wird. Das bedeutet im Grunde, dass das Privateigentum an Produktionsmitteln aufhört, Allokation und Einsatz produktiver Ressourcen zu bestimmen. Schließlich, und das ist vielleicht am schwierigsten, bedeutet gesellschaftliche Ermächtigung auch, dass die Zivilgesellschaft selbst demokratisiert wird: dass also eine assoziativ dichte Zivilgesellschaft geschaffen wird, bestehend aus sowohl begrenzten als auch umfassenden Vereinigungen, die in Einklang mit demokratisch-egalitären Prinzipien organisiert sind.“ (ebd.: 488)

Darin kommt nun auch bei Wright eine zentrale kommunalistische Komponente zum Vorschein, die sich auch bei der AG links-Netz findet, wonach „eine freie und humane Gesellschaft nur durch politisch-soziale Selbstorganisation, eine unabhängige Öffentlichkeit, soziale Bewegungen und praktische

73 Dieses Zusammendenken arbeitet Wright zuvor schon als „[p]artizipative[n] Sozialismus“ bzw. „,[e]tatistische[n] Sozialismus mit ermächtigter Partizipation“ heraus: „Staat und Zivilgesellschaft organisieren gemeinsam verschiedene Arten der Güter und Dienstleitungsproduktion. Im partizipativen Sozialismus ist die Rolle des Staates ausgeprägter und unmittelbarer als in der reinen Sozialwirtschaft. Der Staat beschränkt sich nicht auf die Bereitstellung finanzieller Mittel und die Festlegung der Rahmenbedingungen, sondern er beteiligt sich auf verschiedene Weisen unmittelbar an der Organisierung und Produktion wirtschaftlicher Tätigkeit" (Wright 2017: 212), was ihn als gestaltenden Staat im Sinne des WBGU (WBGU 2011c: 216) auszeichnet. Dahinter steht die Skepsis Wrights, dass ,Transformationen den Staat einfach zerschlagen könnten“ (Wright 2017: 452), wohl aber, dass er durch eine radikale Demokratisierung kollaborativ erzogen werden kann (ebd.: 452ff, 492), womit Wright an Marx Anspruch der ,wahre[n] ,öffentliche[n] Erziehung des Staates“ (Marx 1981a: 95) erinnert. 
Initiativen erreichbar ist" (AG Links-Netz 2013b: 15). Lefebvre, Bookchin, Wright und AG links-netz teilen damit die grundsätzliche Einsicht, dass gesellschaftliche Veränderungen nicht vom Staat aus gedacht werden können. Mit Wrights dreifach gefächerten Begriff revolutionär-reformerischer (Transformations-)Praxis und dem Transformationsprogramm sozialer Infrastrukturpolitiken der AG links-netz wird die begrenzte transformative Reichweite des libertären Kommunalismus sichtbar, indem sie mit Bookchins (offensichtlich naiver) Hoffnung brechen, mit dem Staat je radikal brechen zu können, statt ihn bloß revolutionär zu reformieren resp. zu transformieren. Damit bleibt nun aber als schaler Beigeschmack das Dilemma zurück, immer auch die von Lefebvre herausgestellte marktwirtschaftliche Organisationskraft des Staates zu reproduzieren, was zugleich bedeutet, sie stets kritisch, d.h. gesellschaftstheoretisch im Blick zu behalten und jede Nische und Freiraum strategisch zu nutzen, sie symbiotisch revolutionär zu reformieren resp. gesellschaftlich zu erziehen.

Gleichwohl ist Bookchins kommunalistisches Transformationsprojekt Soziale Ökologie und die darin enthaltene radikale Politisierung des sozialökologischen Gesamtkomplex“ Erde als öffentliches Gemeingut bei weitem nicht obsolet. Der Anspruch auf die Emanzipation menschlicher Subjekte und vor allem auch der auch auf nicht-menschliche Lebensformen und Aktanten ausgreifende Anspruch der Kommunalisierung des Gemeinguts Erde ist ja gerade der elementare Aspekt, mit dem Bookchin über Marx und Lefebvres anthropozentrisches „Recht auf Stadt“ weit hinaus geht. Dennoch bedarf die hierfür benötigte Kommunalisierungsstrategie eine radikal-reformerische, statt libertäre Vorgehensweise. Statt von einem libertären Kommunalismus soll an dieser Stelle daher von einem radikal-reformerischen Kommunalismus gesprochen werden. Dass Bookchins Transformationsprojekt Soziale Ökologie zu seiner Verwirklichung zudem auch um Möglichkeiten sozialökologischer Subjektbildung ergänzt werden muss und damit ebenso - trotz des verheißungsvollen Begriffs - auf der Ebene ökosozialer Transformationen verbleibt, muss an dieser Stelle nicht mehr vertieft werden (Kap. 15.1).

Wichtiger ist es an dieser Stelle noch einen genaueren Blick auf das zu einer Gemeinwesenökonomie zu kommunalisierende Verhältnis von Zivilgesellschaft, Staat und Ökonomie als Kernelement ökosozialer Transformation (Elsen 2018: 1063) zu werfen. Denn zur Frage steht auch in einem radikalreformerischen Kommunalismusansatz, ,wer nach welchen Kriterien über deren Verteilung [die der Ressourcen sozialer Infrastrukturen, MS] zu entscheiden hat" (May 2013b: 190)? Und zudem, wie der Übergang von der zunächst zentralen sozialstaatlichen Bereitstellung von Infrastrukturen zu ihrer dezentralen (kommunalen) sozialen Selbstorganisierung und Selbstverwaltung gelingen soll, ohne dass diese den Rahmen privater Organisationsstrukturen reproduzieren, mit denen sie ja entlang des neoliberalen Erbringungskontextes sozialstaatlicher Leistungen über outgesourcte Privat- 
unternehmen (Stichwort New Public Management durch PPP) zunächst zur Verfügung gestellt werden?

\subsection{Genossenschaftliche Organisierung sozialer Infrastrukturpolitiken als Bedingung der Herausbildung einer übergreifenden Politik des Sozialen}

Wenn Elsens Beitrag im „Handbuch Soziale Arbeit“ „Genossenschaften [...] als Organisationsform der ökosozialen Transformation“ und darin „Schulen der Demokratie“ erblickt (Elsen 2018: 1063f.), dann soll hier nun näher untersucht werden, wie sie für das zu kommunalisierende Verhältnis von Zivilgesellschaft, Staat und Ökonomie als Kernelement ökosozialer Transformation furchtbar gemacht werden könnten.

Wie Kunstreich betont, lässt sich die Notwendigkeit von (Sozial-)Genossenschaften ,nicht aus historischer Reminiszenz [...] begründen, sondern aus den aktuellen gesellschaftlichen Konflikten“ (Kunstreich 2018: 272). Gesellschaftliche Konflikte kommen ,,[ü]berall dort“ zum Ausdruck und machen Sozialgenossenschaften notwendig, ,wo durch Ausschluss von sozialen Teilhaberechten die praktische Wahrnehmung politischer Rechte eingeschränkt und zivile Schutz- bzw. Freiheitsrechte ausgehebelt werden" (Kunstreich 2005: 113). Entlang der Tendenzen nationalstaatlicher Politiken zur marktwirtschaftlichen Reproduktion der marktwirtschaftlichen Produktionsverhältnisse des Gesellschaftlichen (Kap. 12.2.3), tendieren nationalstaatlich organisierte Bearbeitungen des Klimaproblems dazu, das gesellschaftliche Leben durch marktwirtschaftlich-technologische Instrumentarien an das Klimaproblem bloß anzupassen, statt die gesellschaftlichen Ursachen der kapitalozänen „,imperialen Lebensweise“ (Brand/Wissen 2017) anzugehen. Aber durch solcherlei Klimawandeladaptionen bleiben die gesellschaftlichen Ursachen des Klimawandels nicht nur unangetastet, sondern verschärfen auch die bestehenden globalen und lokalen sozialen Ungleichheiten des Kapitalozäns. Etwa die ungleiche Verursachung des Klimawandels und die ungleiche Betroffenheit von den Folgen des Klimawandels infolge „ungleiche[r] Klassen-, Körper-, Natur- oder Geschlechterverhältnisse[]" sowie der damit verbundene ungleiche „Zugang zu Arbeit, Einkommen, Landeigentum, Technologien, Krediten und politischen Entscheidungsprozessen, als notwendige Voraussetzung für den Umgang mit Klimawandelfolgen“" (Bauriedl/Hackfort 2016: 99f.; zum Überblick siehe auch Liedholz 2021: Kap. 4).

Zugleich erschwert das dem Klimaproblem inhärente Zeitproblem die emanzipatorische Bearbeitung von dessen Ursachen und Folgen. Stattdessen 
bahnt es einem logozentrischen Utilitarismus den Weg, der zwischen Partikular- und Gesamtinteressen abwägt und vor dem Hintergrund der möglichst raschen und ökonomisch effizienten (adaptiven) Bearbeitung des Klimaproblems dazu tendiert, die politische Bearbeitung von gesellschaftlichen und sozialen Ungleichheiten abermals hintanzustellen und dessen geologische Auswirkungen (Stichwort Kapitalozän) unsichtbar zu machen. Biologistischen Marginalisierungen und Subalternierungen drohen geologistische zu folgen, die die Reproduktion von gesellschaftlichen Verhältnissen auf eine neue Ebene von hegemonialen Begründungs- und Legitimationsmustern heben. Nicht mehr kann die politisch-emanzipatorische Bearbeitung global(isiert)er sozialer und gesellschaftlicher Ungleichheiten nur auf Grund rassisierender Gründe hintangestellt werden, sondern nun auch auf Grund der Dringlichkeit des Klimaproblems und der sog. Rettung der Erde. Die Aushebelung der praktischen Wahrnehmung von politischen Rechten und die damit einhergehende Einschränkung von zivilen Schutz- bzw. Freiheitsrechten (Kunstreich 2005: 113) droht dadurch in geologischen Zeitmaßstäben auf Dauer gestellt zu werden.

Um dieser Entwicklung eine gegenhegemoniale Entwicklung entgegensetzen zu können, sind Genossenschaften ein wertvoller Organisationsrahmen sozialer Infrastrukturpolitik (May 2017b; Kunstreich 2018), da es Genossenschaften inhärent ist, sich kollaborativ und gut vernetzt die sozialen Infrastrukturen zu be-/erarbeiten und als Commons resp. Gemeingüter zu bewirtschaften, die die Emanzipation ihrer Mitglieder und - im Falle von Gemeinwohl- bzw. Sozialgenossenschaften - auch die ihrer NutzerInnen in Aussicht stellen (zum Überblick Schröder/Walk 2014b).

Kunstreich unterscheidet mit Flieger (2003), ,[v]ier genossenschaftliche Prinzipien“" (Kunstreich 2005: 107; analog dazu Kunstreich 2006a), die sich zugleich als kommunalpädagogische Prinzipien der Hervorbringung von Commons lesen lassen: Das „Förderprinzip““ von Genossenschaften, das „eng an den Gebrauchswert von Aktivitäten gebunden“" ist (Kunstreich 2005: 107). Das Förderprinzip stellt zugleich den Zweck von Genossenschaften dar. Nämlich den GenossInnen/Mitgliedern die heterarchisch solidarische Selbstverwaltung ihrer genossenschaftlich zu regelnden Belange zu sichern, was zugleich das Moment des „Identitätsprinzip[s]“ bzw. des Prinzips der gelingenden Raumproduktion subjektiver Repräsentation darstellt, das ,weit über Mitbestimmung im Sinne des Betriebsverfassungsrechts hinaus[geht]“ (ebd.). Mit diesem ,"Demokratieprinzip“" erblickt Kunstreich in der Genossenschaft mit Arendt (1990, 45) die Möglichkeit gegenhegemoniale Macht zu entwickeln, indem sich Menschen „'mit anderen zusammen[]schließen und im Einvernehmen mit ihnen [...] handeln““ (ebd.). Dieses „Solidaritätsprinzip“, das machtvoll zu tun ermöglicht, „was keine Person für sich leisten könnte“ (ebd.), ermöglicht aber nicht nur gegenhegemoniale Macht zu organisieren, sondern auch Erfahrungen und Interessen (May 1997a). Diese vier Prinzipien 
kennzeichnen das „Genossenschaftskonzept als Ganzes“ (Kunstreich 2005: 108). Ergänzend lässt sich von Gemeinwohl- oder Sozialgenossenschaften sprechen, wenn sie „das Ökonomische vom Sozialen her“ (ebd.: 114) denken und durch eine genossenschaftlich gerahmte dialogische „Politik der Bedürfnisinterpretation" (Fraser 1994: 237ff.) eine mutualistische Gemeinwesenökonomie (Kunstreich 2006b: 12f.) anstreben. Den Gemeinwohl- oder Sozialgenossenschaften käme zudem dann ein emanzipatorisches Moment zu, wenn sie den beteiligten GenossenschaftsakteurInnen (GenossInnen) ermöglichen, ihre schlummernden, aber residualisierten Potenziale gegenseitig zu entdecken und im Rahmen der genossenschaftlichen Selbstverwaltung der hierfür benötigten (ggf. hierfür erst genossenschaftlich herzustellenden) sozialen Infrastrukturen zu verwirklichen, ohne dabei der Sorge anheimfallen zu müssen, durch allzu große Individualität aus dem politischen Gemeinwesen zu fallen. Kommunen bzw., wie Kunstreich sie auch nennt, Sozialitäten (als die sich Genossenschaften ja begreifen lassen), zeichnen sich für ihn gerade dadurch aus, dass sich ,handelnde Personen [...] ihrer Einmaligkeit dadurch versichern, dass sie Mitglied in Sozialitäten sind“, in denen ,man ,seine Neigungen einigermaßen ungezwungen sprechen lassen [... $]^{`}$ ([Aries] 1978: 4)“ kann (ebd.: 13).

In Genossenschaften lässt sich damit die politische Organisationsform der in Kap. 6.2 (Exkurs) und Kap. 12.2.2 ausgeführten Dialektik von Allgemeinen, Besonderen und Einzelnen erblicken. Mit anderen Worten: (Sozial-) Genossenschaften ermöglichen und fördern das Verwirklichen subjektiver Produzierendensozialpolitiken und bieten zugleich den organisatorischen Rahmen, sich - nach Interessen und nicht nach Köpfen (Negt 1977) - zu einer die verschiedenen subjektiven Produzierendensozialpolitiken übergreifenden Politik des Sozialen zu organisieren, mit der sich die AkteurInnen aneinander zu Individuen entwickeln können. Erst in diesem emanzipatorischen Sinne kommt der Grundgedanke des Wortes Genossenschaft zum Ausdruck, nämlich als Praxis einer einander möglich werdenden Genese sowie des Genießens eines gemeinsamen Gutes (Grimm/Grimm 1971: Spalte 3483 bis 3485). Vor diesem Hintergrund zeigt sich, dass Sozial-/Gemeinwohlgenossenschaften nicht zu verwechseln sind mit unternehmerischer Sozialbzw. Gesellschaftsverantwortung, da es ihnen nicht um die Stärkung des Charitygedankens oder um eine „Rückkehr der Almosenkultur“ (Elsen 2013: 55) geht, sondern - zumindest vom Selbstanspruch her, den Elsen in ihren Studien abbildet - um eine Gemeinwohlökonomie. D.h. um eine solidarische und - da es, wie Elsen weiter herausstellt, Gemeinwohl-/Sozialgenossenschaften häufig nicht nur um soziale Nachhaltigkeit, sondern häufig vor allem auch um ökologische Nachhaltigkeit geht - ökologisch bewusst(er)e Kultur der politischen Ökonomie.

Neben dieser aus gesellschaftlichen Konflikten hergeleiteten Notwendigkeit von Gemeinwohl-/Sozialgenossenschaften lassen sich seit den zahlrei- 
chen paradigmenhaften (neoliberalen) wohlfahrtsstaatlichen Reformen der Sozialgesetzgebungen hin zu einem neuen Steuerungsmodell durch öffentlich-private Partnerschaften (Schmale/Ravensburg 2017: 440; SchulzNieswandt 2017: 349) auch jenseits der Klimafrage und auch jenseits radikalreformerischer Kontexte vor allem im Dritten Sektor zunehmend Genossenschaftsgründungen konstatieren (Blome-Drees et al. 2017: 421f.; Schmale/Ravensburg 2017: 443; Thürling 2017: 464). Da es mit den Reformen auch „keinen Vorrang der freien Wohlfahrtsträger vor privaten Trägern [mehr] gibt" (Schulz-Nieswandt 2017: 346) und Genossenschaften seit 2006 neben wirtschaftlichen auch die sozialen und kulturellen Belange der Mitglieder fördern dürfen (Blome-Drees et al. 2017: 424), übernehmen sie - ob gewollt oder nicht - die von der Sozialstaatspolitik outgesourcten sozialen Dienste. Damit nehmen sie gesellschaftlich „eine Art Lückenbüßer-Funktion“ ein, indem sie „für Regionen ganz wichtige Aufgaben der Daseinsvorsorge [übernehmen]" (Schulz-Nieswandt 2017: 346f.).

Vor dem Hintergrund, dass im Kontext neoliberaler Steuerungs- und Austeritätspolitiken und der dadurch erzeugten Ökonomisierung der Infrastrukturen zahlreiche Infrastrukturen der urbanen Daseinsvorsorge wegbrechen oder wegzubrechen drohen, gründen sich in den letzten Jahren zahlreiche Multi-Stakeholder-Genossenschaften (Thürling 2018). Sie setzen sich aus verschiedenen Interessengruppen zusammen, um urbane Infrastrukturen am Leben zu erhalten und als urban commons sozial und ökologisch bewusster $\mathrm{zu}$ bewirtschaften. Im Kontext dieser Entwicklungen interessieren sich, so zeigen die Forschungen von Thürling (ebd.), seit wenigen Jahren auch AkteurInnen aus dem Sektor der offiziellen Politik, den kommunalen Verwaltungen oder den Wohlfahrtsverbänden für genossenschaftliche Kooperationsmodelle. Im Folgenden soll daher ausgelotet werden, welches Potenzial darin steckt, wenn es den GenossInnen gelänge, solche genossenschaftlichen MultiStakeholder-Kooperationen zu einer genossenschaftlich organisierten MultiStakeholder-Governance des Städtischen zu entwickeln, die soziale Einrichtungen, Unternehmen, InvestorInnen und Verbände einer Stadt, ebenso AkteurInnen aus Politik und Verwaltung einbeziehen würde, so dass Stadtentwicklung, d.h. die Entwicklung der sozialen, ökonomischen, ökologischen, politischen, administrativen und kulturellen Belange eines Quartiers, eines Stadtteils oder der ganzen Stadt letztlich als stadt- oder kommunalgenossenschaftlich organisiertes Projekt betrieben werden könnte. In dieser Hinsicht lässt sich auch Kunstreichs später modifiziertes Genossenschaftsplädoyer lesen: „Überall dort, wo durch Ausschluss von sozialen Teilhaberechten die praktische Wahrnehmung politischer Rechte eingeschränkt und zivile Schutzbzw. Freiheitsrechte ausgehebelt werden, sind Commons in Form von Sozialgenossenschaften notwendig." (Kunstreich 2018: 274)

Damit ist nicht gesagt, dass der heutige Rechtsrahmen des Genossenschaftsgesetzes ein geeigneter Rahmen ist für eine solch umfassende Kom- 
munalisierung oder Commonisierung des Städtischen. Aber damit ist gesagt, dass eine genossenschaftlich verfasste Stadt einen demokratischen Organisationsrahmen für die kollaborative Bearbeitung von städtischen Angelegenheiten eröffnet, der zugleich allen Stadtbewohnenerinnen das Recht und die Möglichkeit einräumt, sich gegen strukturelle und konkrete Ausschließungspraktiken zu wehren, weil jede/r StadtbewohnerIn das Recht auf die fachliche, (infra)strukturelle und solidarische Förderung der eigenen sozialen und kulturellen Belange und damit der eigenen individuellen Entwicklung hätte. Damit erst wäre dem „Recht auf Stadt“ (Kap. 12ff.) und einer ,solidarischen Lebensweise“ (Brand/Wissen 2017: Kap. 8) sowie einer „Care-Gesellschaft“ (Winker 2015) ein weiteres Stückchen näher gekommen. Das Potenzial von Stadt- bzw. Kommunalgenossenschaften liegt also vor allem darin, dass eine städtische Sozialraumentwicklung und Sozialraumorganisation (Alisch/May 2013, 2015; May 2017b) ermöglicht würde, die durch genossenschaftlich verfasste soziale Infrastrukturpolitiken (Kap. 15.2) ökosoziale Transformationen des Städtischen (Kap. 6.1) auf den Weg bringen könnten, die an den Subjekten und ihren Residuen ihren Ausgang zu nehmen. Zugleich würden sich mit solchen Kommunal- bzw. Stadtgenossenschaften auch objektive Möglichkeiten öffnen, an den Ansatz einer weltweit zu organisierenden und $\mathrm{zu}$ vernetzenden polyzentrischen Verantwortungsarchitektur zur politischen Herstellung und kollaborativen Bewirtschaftung von urban und global Commons Anschluss zu suchen. Allerdings, so wurde in Kap. 14 herausgestellt, konzeptioniert der WBGU seinen Ansatz der polyzentrischen Verantwortungsarchitektur nationalstaatszentriert, statt konsequent transnationalkonföderativ und droht dadurch der oben skizzierten nationalstaatspolitischen Tendenz zur Reproduktion der gesellschaftlichen Produktionsverhältnisse zu verfallen (Kap. 12.2.3), statt eine echte, d.h. radikal-reformerische Alternative hervorzubringen.

Stadtgenossenschaften könnten dabei auch ein Lösungslicht auf das Verteilungsproblem der vom WBGU vorgeschlagenen Transformationsfonds werfen. Zumindest wenn es einen staatspolitischen Beschluss gäbe, die eingenommenen Gelder nicht länger über die Staatsapparatur und dessen Rechtsarchitektur, sondern durch jene - etwa genossenschaftlich verfassten Organisationen, die sich um solche Mittel bewerben, zu verwalten. Denn dadurch müssten die ,unterschiedliche[n] sozialpolitische[n] Initiativen der Produzierenden selbst einen Modus der Verteilung finden“", bei der sie nicht nur „borniert ihr spezifisches Eigeninteresse“ fokussieren können, sondern „sich [...] auf ein ,Gemeinwohl' beziehen [müssen], das durch diesen - einer übergreifenden Politik des Sozialen zuzurechnenden - Prozess politisch an Konturen gewinnt“ (May 2013b: 190). Darin ist nicht nur ,die Frage, wer nach welchen Kriterien über deren Verteilung zu entscheiden hat" (ebd.), beantwortet. Darin kommt zudem auch eine Weiterentwicklung der schon in 
den 1980er Jahren von der Widersprüche-Redaktion vorgeschlagenen gesellschaftlichen Fonds zum Ausdruck:

„Diese Forderung nach Verfügung über kommunale oder regionale z.T. auch bundesweite Fonds
haben nichts von der Naivität der Forderung nach Umverteilung über das Finanzamt sondern
stellen einen direkten Angriff auf das Herz des Sozialstaates dar: auf die diskriminierende und
kontrollierende Vergabe von Geldern für gesellschaftlich notwendige Zwecke. [...] Grundsätz-
lich müßte es möglich sein, alle gesellschaftlich sinnvollen Projekte damit zu finanzieren. Was
dabei jeweils gesellschaftlich sinnvoll heißt, ist Gegenstand eines kollektiven Auseinanderset-
zungs- und Politikprozesses und nicht mehr individuelle Entscheidung.“ (Widersprüche Redakti-
on 1985)

Zugleich würde mit einer Erweiterung der Idee der Fonds zu transnationalen Transformationsfonds auf globaler Ebene einmal mehr der überregionale und globale Gehalt des Begriffs sozialer Infrastrukturen deutlich, die zwar entlang kommunaler Bedürfnisse ausgestaltet und verwaltet werden müssen, aber die immer auch die überregionale und globale Zusammenarbeit erfordern.

Eine solche globale Zusammenarbeit wird allein schon vor dem Hintergrund notwendig, dass selbst wenn sich eine ganze Stadt genossenschaftlich organisieren würde, sie sich dennoch in einer global organisierten und wachstumsorientierten Marktwirtschaft verorten müsste, wodurch, ,jedes noch so gut gemeinte kooperative Experiment“ zu scheitern droht, weil es ,unter dem Druck der Konkurrenz Schritt für Schritt in ein kapitalistisches Unternehmen [verwandelt], obgleich [es] immer noch kollektiv besessen und geführt werden mag" (Biehl 1998: 107). Eine autarke Stadt, die die benötigten Mittel und Ressourcen zur Produktion und Instandhaltung ihrer urbanen Infrastrukturen aus sich selbst schöpfen kann, ist vermutlich eher Fiktion. Entsprechend ließe sich das Problem des stadtgenossenschaftlichen Herstellens von sozialen Infrastrukturen jenseits der wachstumsorientierten Marktlogik auch nur durch einen regionalen, gar globalen kollaborativen Zusammenschluss von Städten bearbeiten. Dadurch könnten die lokalen mutualistischen Gemeindeökonomien fraktal fortgesetzt und im global-konföderativen Verbund eine commonsbasierte Postwachstumsökonomie zu Wege gebracht werden, in der sie sich gegenseitig mit Ressourcen unterstützen und deren alltägliche politische (Re-)Produktion der Unterstützung zugleich in den kommunalen Produzierendensozialpolitiken und ihren kollaborativen städtischen Aushandlungen untereinander verbleibt. Jedoch nicht länger ohne Rücksicht auf die Produzierendensozialpolitiken und dessen kollaborative Aushandlungen in anderen Städten und Kommunen. Damit wäre Bookchins libertärer Kommunalismus, wonach die Macht ,nicht von oben nach unten“, sondern „von der Basis ausgehend nach oben hin ausgeübt [wird]“ und ,immer mehr ab[nimmt], je höher die Räte angesiedelt sind und je weiter ihre Zuständigkeitsbereiche geographisch ausgreifen“ (Bookchin 1996: 320), nicht nur radikal-reformerisch eingeholt, sondern auch genossenschaftlich aufgehoben.

In der Verlängerung des Ansatzes genossenschaftlich organisierter städtischer Multi-Stakeholder-Governance ins Globale liegt damit auch das Poten- 
zial für eine langfristige und weltweite konsequente Politisierung von jedweden gesellschaftlichen Grundlagen der ,imperialen Lebensweise“ (Brand/ Wissen 2017). Bestenfalls, um sie ganz zu überwinden, wenigstens aber, um sie so zu regulieren, dass ihre weltweiten sozialen und ökologischen Voraussetzungen und Folgen sichtbar und weltweit politisch verhandelbar würden. Und zudem böten global vernetzte Stadt- und Kommunalgenossenschaften die Möglichkeit zur gemeinsamen, aber je lokalen Bewirtschaftung von global commons (erdökologischen Aktanten), wodurch erst die Erde weltweit als gemeinsames terrestrisches Subjekt des politischen Gemeinwesens erfahren werden kann, das nicht mehr nur die Gedeihlichkeit menschlicher Entwicklung fokussiert (sozial-ökologische Transformation, Kap. 6.2).

Gegenwärtig aber stehen solche kommunalstischen Stadtentwicklungsprojekte selbst auf der lokalen urbanen Ebene noch vor gewaltigen Hürden. Zum einen bräuchte es zu dieser Entwicklung einen verwaltungsinternen Beschluss, dass ,,bei der Vergabe Organisationen demokratischer Selbstverwaltung gegenüber erwerbswirtschaftliche[n] Organisationsformen de[r] Vorzug gegeben“ wird, was sich ,europarechtlich sogar gut fundieren“ ließe (Schulz-Nieswandt 2017: 352), aber offensichtlich noch nicht großflächig zur Anwendung kommt. Zum anderen bräuchte es aber auch einen politischen Beschluss, dass sich Bereiche der Verwaltungen genossenschaftlichen Organisationen verbindlich anschließen dürfen, was offensichtlich ebenfalls noch nicht großflächig zum Durchbruch gekommen ist.

Aber auch wenn sich auf internationaler Ebene munizipalistische Bewegungen zusammenzuschließen suchen (Vollmer 2017), so tun sie es aber kaum auf genossenschaftliche Weise. Auch die gegenwärtig zu beobachteten Genossenschaftsgründungen suchen bislang nur selten die Kooperation mit städtischen Unternehmen und Verwaltungen (Schröder/Walk 2014a: 304), so dass sie ihre „Lückenbüßer-Funktion“ (Schulz-Nieswandt 2017: 346f.) offenbar noch eher reaktionär entgegennehmen, als dass sie tatsächlich proaktiv nach revolutionär-transformativen Gestaltungsmöglichkeiten des Städtischen Ausschau halten. Entsprechend gilt weiterhin Harveys durch Bookchins inspirierte Forderung:

„Die Rückkehr der Gemeingüter als politisches Thema muss vollständig und auf bestimmte [resp. entschlossene, MS] Weise in den antikapitalistischen Kampf integriert werden. [...] Dafür ist ein zweigleisiger politischer Angriff erforderlich: Der Staat muss gezwungen werden, mehr und mehr öffentliche Güter für öffentliche Zwecke zur Verfügung zu stellen, und Bevölkerungsgruppen müssen sich selbst organisieren, um diese Güter auf eine Art und Weise in Besitz zu nehmen, zu nutzen, zu ergänzen, die die Qualität der nichtkommodifizierten und ökologischen Gemeingüter sowie die Gemeingüter der sozialen Reproduktion erweitert und verbessert.“ (Harvey 2014: 160f.)

Was der Verwirklichung dieses Schrittes letztlich konkret im Wege steht und wie es aus dem Weg geschafft werden könnte, das muss letztlich die konkrete Praxisforschung erweisen und Lefebvres „Recht auf Stadt“ hat sich als ein solches Forschungsprogramm herausgestellt. 
Soziale Arbeit kann diesen Prozess als nicht-moderates moderatives Moment unermüdlich kommunalpädagogisch und praxisforscherisch begleiten und entlang ihres Nachhaltigkeitsbegriffs (Elsen 2018) bzw. einem Nachhaltigkeitsmandat (Bartosch 2020: 30) ihre Professionalität weiter entwickeln. Nicht nur in Form von Gemeinwesenarbeit, Stadtteil- oder Quartiersmanagement, sondern auch allgemein. Etwa indem sie ihre Einrichtungen genossenschaftlich organisiert, um die NutzerInnen und AkteurInnen ihrer Arbeitsfelder als GenossInnen zu gewinnen und sie von Anfang an heterarchisch einbeziehen zu können. Dadurch könnten sie selbst bestimmen, was ihr Problem ist, was es bedingt und wie es im urbanen Zusammenleben infrastrukturell und politisch gelöst werden könnte (Kap. 6.1). Gleichwohl könnten die Stunden- oder Tagessätze seitens des Kostenträgers als Genossenschaftsanteile gelten, über deren Verwendung die Genossenschaft, also die Fachkräfte, die NutzerInnen und die Kostenträger bestimmen und dabei stets versuchen, alle am Arbeitsfeld beteiligen Arbeitsfelder und Einrichtungen Sozialer Arbeit genossenschaftlich einzubeziehen (Schmidt 2019). Kurzum: erst durch eine genossenschaftliche Organisation Sozialer Arbeit können die Nutzenden selbst zum Auftraggeber werden, sich für ihre Angelegenheiten professionell und mit allen städtischen Infrastrukturen unterstützen zu lassen, statt sich, wie sonst üblich, postpolitisch bloß bemanagen und in den hegemonialen Konsens einlullen, d.h. sich zu stets einsatzbereiten und hochmotivierten MarktbürgerInnen aktivieren zu lassen, oder aber bloß verwaltet $\mathrm{zu}$ werden (Gronemeyer 2012: 143ff.; Lutz 2012).

Zusammenfassend: Das Verführerische am Gedanken von Kommunal- bzw. Stadtgenossenschaften und ihres (bestenfalls weltweiten) regionalen Zusammenschlusses ist das Potenzial zur Verwirklichung einer die verschiedenen subjektiven Produzierendensozialpolitiken übergreifenden Politik des Sozialen, die durch die Einbeziehung auch staatlicher AkteurInnen staatliche Institutionen zu erziehen verheißen und damit nicht bloß eine alternative nationalstaatliche Sozialpolitik bedeuten, sondern eine Alternative zur nationalstaatlichen Sozialpolitik. Damit wäre nicht nur einem gestaltenden Staat ein Stückchen näher gekommen, ,der selbst eine proaktive Transformationspolitik betreibt" (WBGU 2011c: 216) und bei dem Produzierende, AdressatInnen und NutzerInnen des Staates weitestgehend zusammenfallen. Und der sich zudem den marktwirtschaftlichen Reproduktionszwängen sukzessive zu entziehen sucht, statt sie durch postpolitisch-hegemoniale Konsensdiskurse zu kaschieren. Damit wäre vor allem auch einem Gesellschaftsvertrag ein Stückchen näher gekommen, der im Gegensatz zum Konzept des WBGU (WBGU 2011c, 2016b) auch über die Mittel verfügt, dass ihn auch wirklich alle Gesellschaftsmitglieder kollaborativ erarbeiten. Mit Bookchin gesprochen: 
„Entscheidend für eine Realisierungschance des Föderalismus ist die Interdependenz der Gemeinschaften - das bedeutet ein gegenseitiges Geben und Nehmen bei der Verwendung der Ressourcen und der Produkte und überhaupt bei der Entscheidung über einzuschlagende Wege. Alle Gemeinschaften müssen in irgendeiner Weise genötigt sein, zur Deckung eigener Bedürfnisse oder zur Realisierung gemeinsamer Ziele auf andere zu zählen und somit Teil eines vernetzten größeren Ganzen zu sein; falls nicht, droht sofort die Gefahr eines kurzsichtigen Einzelgängertums. Nur wenn wir uns klarmachen, dass der Föderalismus als eine Weiterentwicklung partizipatorischer Verwaltung - in der Form föderaler Netze - verstanden werden muss, lässt sich verhindern, dass die zu großen Ensembles zusammengeschlossenen Gemeinschaften sich im Zeichen von Dezentralismus und ,Lokalismus' borniert auf sich selbst zurück ziehen und das Zusammenleben der Menschen Schaden leidet.“(Bookchin 1996: 320)

Ein genossenschaftlich-kollaborativ organisierter Konföderalismus beherbergt also das Potenzial für alle beteiligten und betroffenen AkteurInnen, die Spielregeln dieses größeren Ganzen nicht nur herrschaftlich vorgesetzt zu bekommen, sondern politisch mitzugestalten. Und zwar entlang der konkreten Bedürfnisse konkreter Subjekte in konkreten Städten und Regionen dieser Erde, statt diese Spielregeln als mathematisches resp. nicht politisierbares Abstraktum ontologisiert zu bekommen, wodurch die Spielregeln nicht nur naturalisiert, sondern zugleich vor jeglicher Kritik immunisiert werden. Denn das ist ja letztlich gerade das Imperiale der „imperialen Lebensweise“ (Brand/Wissen 2017): dass der ontologisierte ihr inhärente Wachstumsimperativ sich solange auf alles und jeden ausdehnt, bis alles nicht marktlogisch und logozentrisch Einpflegbare zum marginalen Rest (Residuum) reduziert und zum Schweigen gebracht wurde und sich dadurch herrschaftlich mondialisiert und quasi als Kollateraleffekt, die gedeihliche Bewohnbarkeit der Erde ruiniert.

Im Folgenden soll daher ein möglicher Umriss einer postwachstumsorientierten Städte-Konföderation skizziert werden, der an Bookchins Anspruch räumlicher Gerechtigkeit Anschluss sucht und zugleich über ihn hinausgeht, weil der Begriff der räumlichen Gerechtigkeit zugleich als strategische, d.h. auf Emanzipation zielende Forschungskategorie umrissen werde soll.

\section{5 (Sozial-)Räumliche (Klima-)Gerechtigkeit - Versuch des Umrisses eines strategisch-hypothetischen Begriffs}

Der gegenwärtige Postwachstums- oder Degrowth-Diskurs ist eine Gemengelage verschiedener ökologischer, gesellschaftskritischer und polit-ökologischer Ansätze, der Aspekte der Klimagerechtigkeit bzw. -ethik umfasst (Eversberg/Muraca 2019: 487ff.). Er entfaltet dabei eine Bandbreite, die „,von sozialreformerischen Agenden, über traditionell linke Theorieperspektiven, bis hin $\mathrm{zu}$ sogenannten voluntaristischen, zivilisationskritisch-suffizienzorientierten sowie alternativ-praxislinken Ansätzen [reichen]“ (Schoppek 
2018: 45; Schoppek 2019). In dieser Breite positionieren sich die verschiedenen Ansätze unterschiedlich konsequent in der perspektivischen Lossagung vom Inwertsetzungsimperativ kapitalistischer Wirtschaftslogik (zum Überblick auch: Schmelzer/Vetter 2019; D’Alisa et al. 2016).

Bei all diesen unterschiedlichen Herangehensweisen und strukturellen Reichweiten steht die Postwachstumsperspektive aber ,generell weniger für einen vollständigen Gesellschaftsentwurf als für eine Veränderungsrichtung“ (Eversberg/Muraca 2019: 489) des Ökonomischen, die sich in ihrer wohl strukturell weitreichendsten Variante in „drei Kernanliegen“ zusammenfassen lässt:

„Zuallererst gilt es, die extraktivistische Übernutzung von Ressourcen und die Überbelastung von Senken mit ihren verheerenden Folgen für die Selbstgestaltung der Lebensgrundlagen insbesondere indigener und lokaler Gemeinschaften im Globalen Süden soweit wie möglich zu beenden, vor allem also: auf die Förderung und Verbrennung der noch vorhandenen fossilen Ressourcen bewusst zu verzichten (Temper et al. 2013). Diese Forderung läuft zwangsläufig auf einen sehr grundsätzlichen Konflikt mit der kapitalistischen Eigentumsordnung und den Akteuren, die von ihr profitieren, hinaus. Ferner setzen die angestrebten alternativen Lebensweisen voraus, dass das Notwendige und Wünschenswerte nicht von einer zentralen Autorität dekretiert, sondern unter Berücksichtigung der Grenzen des in einem global verallgemeinerbaren Rahmen Möglichen unter Beteiligung aller politisch ausgehandelt wird. Das wiederum verlangt die umfassende Demokratisierung aller Bereiche wirtschaftlicher Tätigkeit, die ihrerseits nicht nur weitreichende Machtfragen aufwirft, sondern aus Degrowth-Sicht auch mit einer möglichst weitreichenden Regionalisierung, Entflechtung großräumiger Wertschöpfungsnetzwerke und Zerschlagung von Konzernstrukturen einhergehen muss (Muraca 2014).“(ebd.: 490)

Damit ist die Postwachstumsperspektive prinzipiell anschlussfähig an die bisherigen Überlegungen zur radikal-reformerischen Kommunalisierung städtischer Infrastrukturen. Hier wie da geht es um die Ermöglichung einer konsequenten Demokratisierung gesellschaftlicher Naturverhältnisse und der damit verknüpften „(Rück-)Gewinnung [...] kollektiver, demokratischer Gestaltungsmacht über die gemeinsamen Lebensbedingungen, und damit auch die Stärkung sozialer Bindungen“ durch den Abbau der „Dominanz der formalen Erwerbsarbeit über andere Formen gesellschaftlicher Tätigkeit" und deren Verwirklichung durch solidarische Zusammenschlüsse im globalen Rahmen zur politischen Aushandlung der sozialen, ökonomischen und ökologischen Belange der Städte ,unter Beteiligung aller“ kommunalen AkteurInnen (ebd.). In dieser Hinsicht hebt auch Brand hervor, dass es

,,in Zukunft darauf ankommen [wird], eine bestimmte Deutung des Degrowth-Begriffs zu stärken - nämlich jene, die unauflöslich mit Fragen der Gerechtigkeit und mit zu verändernden Herrschaftsverhältnissen verbunden ist. Andernfalls wird der Begriff [...] zur radikalen, aber politisch folgenlosen Geste einer jüngeren und nicht mehr so jungen ökolibertären Mittelschicht mit geringer Sensibilität für sozialstrukturelle Ungleichheit und Machtfragen, bei der manchmal sogar eine Portion elitäres Unverständnis für die immer noch an der ,Konsum- und Wachstumsnadel hängenden Massen“ mitschwingt.“ (Brand 2014: 32)

Um von der normativen Forderung nach einem Gerechtigkeitsbegriff zu einem empirisch anzureichernden und inhaltlich konkret auszugestaltenden 
strategisch-hypothetischen Gerechtigkeitsbegriff zu gelangen, braucht es ein entsprechendes begriffliches Analyseinstrument, das die Frage sozialer Gerechtigkeit räumlich stellt. Denn erst dadurch wäre es gewährleistet, dass die Normativität der Postwachstumsperspektive mit den tatsächlichen Bedürfnissen der kommunalen AkteurInnen angereichert und konkret ausformuliert werden kann. Mit dem Ziel - das ist der strategische Aspekt des räumlichen Gerechtigkeitsbegriffs -, dass durch soziale Infrastrukturpolitiken eine regional übergreifende interkommunale Zusammenarbeit verwirklicht werden kann, die nicht nur den eigenen kommunalen Bedürfnissen, sondern auch denen in anderen Städten und Kommunen gerecht zu werden versucht und resilient ist gegenüber den hegemonialen Strategien der neoliberalen Aushöhlung jedweder emanzipatorischen Transformation des Nationalstaatsmodells. Dass eine solche gerechtigkeitsorientierte kommunalisierende Regionalisierung städtischer sozialer Infrastrukturpolitiken zumindest objektiv möglich ist, wurde bereits herausgestellt und ist der hypothetische Aspekt des räumlichen Gerechtigkeitsbegriffs. Was noch fehlt ist der transduktive Aspekt des räumlichen Gerechtigkeitsbegriffs.

\subsection{1 (Sozial-)Räumliche Gerechtigkeit-zur Reichweite eines ungewöhnlichen Begriffs}

Zwar ,[kann] Gerechtigkeit selbst [...] nicht räumlich sein. Wohl aber können die Konsequenzen von Handlungen und Entscheidungen, die zu bestimmten Verteilungen von Menschen und Objekten geführt haben, als räumlich bezeichnet werden." (Redepenning 2013: 5). Entsprechend befasst sich räumliche Gerechtigkeit mit „Fragen sozialer Ungleichheit und ihres Ausgleichs durch Verteilungsgerechtigkeit [...] der räumlich-materiellen Grundlagen der Gesellschaft“" wie „Ressourcen sowie technische und soziale Einrichtungen (wie etwa Essen, Sicherheit, Wohnen, Einkommen, Gesundheit und Bildung), die für die alltägliche Reproduktion des Sozialen notwendig sind" (ebd.: 4). Damit unterstützt der Begriff der räumlichen Gerechtigkeit als „Ergänzung der vorherrschenden sozialwissenschaftlichen Perspektive auf Verteilung“ (ebd.) - die „Rückgewinnung des Territorialen in Form der Kommune" (Richter 2001: 144), die Richter als notwendige Voraussetzung jeder kommunal- resp. subjektorientierten Sozialen Arbeit herausstellt.

Der Begriff der räumlichen Gerechtigkeit kann daher nur negativ aus sozial ungerecht erlebten (An-)Ordnungen des Raums, d.h. entlang von blockierten und residualisierten Entwicklungsmöglichkeiten eines (Handlungs)Subjekts ausformuliert werden. Dass die Frage nach der räumlichen Verteilungsgerechtigkeit an diese Residuen anschließen muss, sollte vor dem Hintergrund der bisherigen Ausführungen deutlich geworden sein. Ebenso, dass die Frage nach den AkteurInnenen der Verteilung kaum mit einem repräsen- 
tativen StellvertreterInnenmodell beantwortet werden kann, da subjektive Residuen nur dadurch erfahrbar und artikulierbar werden, wenn die gesellschaftliche Wirklichkeit den Subjekten nicht bloß als zugeteilte und gegebene in Erscheinung tritt, sondern als selbst gestaltete erlebt wird. Nämlich vor allem dadurch, dass sie - um abermals mit Winkler (Winkler 1988: 278f.) zu sprechen - selbst die Gleise legen können, auf denen sie sich bewegen wollen und ihnen erst dadurch erfahrbar werden kann, was sie für die Verwirklichung ihrer kommunalen Produzierendensozialpolitiken brauchen und was nicht. Entsprechend muss räumliche Gerechtigkeit immer als sozialräumliche Gerechtigkeit und zudem immer auch als ,strategischen Hypothese“ (Lefebvre 1987: 372f.) begriffen werden, die entlang von kollaborativ-demokratischen Prozessen auf die emanzipatorische Entwicklung des Subjekts, d.h. auf die Befreiung der in der alltäglichen Raum(re)produktion und -aneignung der vorherrschenden ,imperialen Lebensweise“ (Brand/Wissen 2017) systematisch erzeugten Residuen zielt. Der Begriff (sozial-)räumlicher Gerechtigkeit steht damit im engen Kontext mit Lefebvres strategischem Praxisforschungsprogramm „Recht auf Stadt“ (Kap. 12) sowie dem von der Widersprüche-Redaktion (Kap. 6.1) entwickelten strategischen Begriff der übergreifenden Politik des Sozialen.

Dabei kann es aber nicht nur um räumliche Zugänge zu Ressourcen und Infrastrukturen und die kollaborative Einbindung der StadtbewohnerInnen in die Prozesse der Entwicklung einer Stadt oder einer Region gehen. Ein Begriff (sozial)räumlicher Gerechtigkeit muss - gerade wenn er sich als strategischer Begriff im Kontext von Lefebvres Werk bewegt - vor allem auch die Analyse global organisierter nationalstaatlicher Zusammenhänge urbaner Subjektbeziehungen umfassen und dabei berücksichtigen, dass sich, wie mit Lefebvre bereits herausgestellt, das Machtzentrum nationalstaatlicher Gewalt marktwirtschaftlich transnationalisiert (hat) und sich daher nicht mehr genau geografisch lokalisieren lässt (vgl. Lefebvres Staatsanalysen in Kap. 12.2.3). Zudem wird mit der globalistischen Universalisierung subjektiv-kommunaler und kommunal sowie regional kultureller Unterschiede durch logozentrische und ökonomistische Isotopisierungen des Raums nicht nur die subjektivkommunalen und kommunal sowie regional kulturellen Unterschiede zum Schweigen gebracht (Lefebvre 2014: 85ff.), sondern auch die geografischökologischen, d.h. die topografischen und klimatologischen Unterschiede. Doch nur aus denen heraus werden kommunal ähnliche und regional unterschiedliche soziale Bedürfnisse verstehbar, die im Hinblick auf die Überwindung marktwirtschaftlicher Universalisierungen der weltweiten kulturellen Vielfalt von Produzierendensozialpolitiken Berücksichtigung finden müssen, wenn eine „Kultur des Friedens“ (Wulf 2020: 210f.) entstehen soll (vgl. Kap. 5). So sind etwa küstennahe Regionen des globalen Südens vom Klimawandel deutlich anders betroffen als etwa Festlandregionen des globalen Nordens, oder aber werden ressourcenhaltige Landschaften des globalen Südens 
deutlich anders extraktivistisch ausgebeutet, als weniger ressourcenhaltige Landschaften im globalen Norden, woraus sich regional je andere Problemlagen und Bedürfnisse ergeben. Dies systematisch analytisch zu ignorieren, bedeutet letztlich Unfrieden zu reproduzieren.

Der Begriff (sozial)räumlicher Gerechtigkeit stellt damit eine „Absage an ein raumbezogenes Gleichheitsideal" (Redepenning 2013: 10) dar und betont stattdessen die Frage nach dem je regionalen Beitrag zum global-kollektiven Wohlergehen. Entsprechend konkretisiert Redepenning die zentrale Frage des Begriffs „Was soll wo sein?“ zu der „Frage, wie die räumliche Lokalisierung von Ressourcen in einer Region die Entwicklung und die Chancen anderer Regionen beeinflusst (spread effects)“ (ebd.: 11). Daraus „ergibt sich bspw. ein enormer, dabei sozial gerechtfertigter Bedarf an Investitionen in benachteiligte urbane Randgebiete“ und ,jene[] Regionen“, „die die Ursprungsorte für Wanderungsbewegungen in die Megastädte sind", so dass es letztlich um die „Stärkung von Annehmlichkeiten in den Push-Regionen“, aus denen es die Menschen wegzieht, ,und gleichzeitiger Minderung der Lasten in den Pull-Regionen" (ebd.: 12), in die es die Menschen hinzieht, gehen muss.

Der hierin zum Ausdruck kommende Prioritarismus, wonach „die Schlechterstellung der von vornherein relativ schlechter gestellten Betroffenen als gravierender beurteilt wird als die Schlechterstellung relativ gut gestellter Betroffener"“ (Birnbacher 2017: 57; zum Überblick auch: Lumer 2011; Gesang 2011: Kap. $3^{74}$ ), umfasst „zwei Forderungen“, „um zu einer gerech-

74 Gesang unterscheidet in seiner „Klimaethik“ zwischen einem absoluten und einem gewichteten Prioritarismus. Der absolute Prioritarismus findet sich bereits in Rawls „Theorie der Gerechtigkeit“, wonach ,[s]oziale und wirtschaftliche Ungleichheiten [...] den am wenigsten Begünstigten den größtmöglichen Vorteil bringen [müssen]“ (Rawls 2012: 336). Dieser wird aber mit Gesangs Analysen als „unmoralisch und irrational“ (Gesang 2011: 122) herausgestellt, da sich in dieser absoluten Formulierung nicht vermeiden lässt, dass die ,ehemals schlechter gestellten Personen [...] in der neuen Verteilung besser da[stehen] “ (ebd.: 102), als die ehemals besser gestellten Personen. Demgegenüber plädiert Gesang für einen „gewichtete[n] oder moderate[n] Prioritarismus“ (ebd.: 122), der , auch die alltagsmoralischen Maßstäbe für Gerechtigkeit und Mitleid beachtet“ (ebd.: 124). Etwa die alltäglichen Interaktionsweisen verschiedener Produzierendensozialpolitiken. Dieser „Prioritarismus zweiter Ebene" (ebd.: 129) ist insbesondere in der Klimafrage relevant, zumindest wenn ihre gesellschaftlichen Beantwortungsversuche weltweit (sub)kulturelle Unterschiede beachten und ihre Vielfalt erweitern, oder wenigstens beibehalten möchten und nicht mit isotopisierenden logozentrischen Lösungsansätzen „"strukturelle Gewalt" (Galtung)“ mehren und in einer ,"organisierten Friedlosigkeit" (Senghaas)“ münden wollen, womit sie die gesellschaftliche Ermöglichung einer Friedenskultur der kulturellen Vielfalt verpassen und damit die Kernelemente eines möglichen Anthropozäns (Wulf 2020: Kap. 12; vgl. Kap. 5). Gesang schlägt daher vor, „Menschen aus Schwellen- und Entwicklungsländern bei Auszahlungen aus dem Emissionshandel doppelt zu zählen“ (Gesang 2011: 132). Ob mit dieser rein marktwirtschaftlichen Lösung aber tatsächlich verhindert werden kann, dass die ,ehemals schlechter gestellten Personen [...] in der neuen Verteilung besser da[stehen]“ (ebd.: 102), womit auch der gewichtete Prioritarismus nicht nur als ,unplausibel“ und „kontraintuitiv“, weil er die „soziale Stellung sehr viel höher als Nutzen gewichtet“ (ebd.: 133), kritisiert werden muss, sondern, gleich dem absoluten Prioritarismus, auch als ,unmoralisch 
ten Bestimmung der gerechten räumlichen Verteilung staatlicher Güter in den betreffenden Regionen zu gelangen“":

„1. Die Verteilung von knappen Ressourcen (incl. ihrer Verfügungsgewalt) sollte zunächst die Bedürfnisse der Bevölkerung in jeder (Teil)Region erfüllen; darüber hinaus sollte die Ressourcenverteilung interregionale Multiplikationseffekte (spread effects) hervorbringen und schließlich sind weitere Ressourcen so einzusetzen, dass Erschwernisse, die aus der physischen und sozialen Umwelt stammen, direkt kompensiert werden.

2. Die politischen, ökonomischen, institutionellen und organisatorischen Mechanismen, die raumbezogene soziale Gerechtigkeit herstellen sollen, müssen daher sicherstellen, dass die Chancen der am stärksten benachteiligten Gebiete größtmöglich sind.“ (Redepenning 2013: 12f.)

Im Begriff (sozial)räumlicher Gerechtigkeit finden sich analog zur Raumdiskussion seit dem spatial turn entsprechend „Zwei Formen des Raumes [...], die mit sozialer Gerechtigkeit in Zusammenhang gebracht werden können“ (ebd.: 14): Einmal ein relationaler Raumbegriff, der in der Frage nach der

und irrational“ (ebd.: 122) zurückgewiesen werden muss, muss an dieser Stelle offen bleiben. Wichtiger ist an dieser Stelle die Kritik am ganzen logozentrischen Vorhaben, soziale Ungleichheiten wirtschaftlich rationalisierend und mathematisierend bzw. geometrisierend statt politisch angehen zu wollen. Denn während der Versuch die Frage, wer schlechter gestellt ist, zu rationalisieren, das Problem offenbart, dass sie sich nicht adäquat rationalisierend beantworten lässt, ohne nicht-quantifizierbare, d.h. bislang nur angelegte und noch nicht ausgebildete subjektive Vermögens- und Fähigkeitspotenziale der AkteurInnen zu residualisieren, lässt sich dieses Problem nur durch die konsequente kollaborative Einbeziehung der Subjekte und ihrer subjektiven noch in Bildung befindlichen Fähigkeiten und Vermögen umgehen. Eingelöst werden könnte dies aber allenfalls in einer konsequenten konföderal-kollaborativen Demokratie, die aufgrund der planetaren Reichweite der Klimafrage im globalgesellschaftlichen Maßstab realisiert werden müsste (etwa entlang des just city-Ansatzes von Davoudi/Bell 2016, vgl. Kap. 15.5.2), um die Klimafrage weltweit (sozial)räumlich gerecht anzugehen. Auf eine solche Kollaboration als „Kooperation zwischen vernünftigen und rationalen Bürgern“ (Rawls 1998: 185), die in einem „übergreifenden Konsens [...] über die politische Konzeption“ (ebd.: 219) münden soll und die ,politische Macht als kollektive Macht der Bürger versteh[t]" (ebd.: 223), setzt letztlich auch Rawls selbst, der die „Ausübung politischer Macht nur dann völlig angemessen“ ansieht, „wenn sie sich in Übereinstimmung mit einer Verfassung vollzieht, deren wesentliche Inhalte vernünftigerweise erwarten lassen, dass alle Bürger ihnen als freie und gleiche im Lichte von Grundsätzen und Idealen zustimmen, die von ihrer gemeinsamen menschlichen Vernunft anerkannt werden“ (ebd.). Und weiter: „Ein grundlegendes Merkmal einer wohlgeordneten Gesellschaft besteht darin, dass nicht nur ein öffentliches Einverständnis darüber besteht, welche Arten von Ansprüchen Bürger angemessenerweise geltend machen können, wenn Fragen der politischen Gerechtigkeit aufkommen, sondern auch darüber, wie solche Ansprüche zu begründen sind." (ebd.: 272) Ob diese aber mit der von Rawls in Anlehnung an die „Pareto-Optimalität“ (Rawls 2012: 100) präferierten quantifizierenden und geometrisierenden - kurz: logozentrischen - Methodologie subjektorientiert begründet werden können, ohne in den von Gesang (Gesang 2011: Kap. 3) herausgestellten Schwachstellen des Prioritarismus zu münden, muss allerdings bezweifelt werden. Stattdessen spricht nun letztlich alles dafür, (sozial)räumliche Gerechtigkeitsfragen nicht ohne eine kommunalpädagogischemanzipatorische Subjektbildung beantworten zu können, die zur vollumfänglichen Wahrnehmung politischer Verantwortung für die politische Bildung des Ökosozialen zur subjektiven Bildung am Ökosozialen, die im Rahmen einer kollaborativen Demokratie an die Subjekte gestellt werden, befähigt. 
„räumliche[n] Verteilung von Annehmlichkeiten und Lasten“ kumuliert, die „dann die politisch brisante und nach wie vor aktuelle Frage“" aufwirft, „ob nicht die Konzentration von räumlich gebundenen und flächenintensiven Lasten in einer Region, genau durch die damit einhergehende gleichzeitige Abwesenheit eben dieser Einrichtungen in anderen Regionen, auch einen Beitrag zum kollektiven Wohlergehen darstellt" (ebd.: 15). Zur analytischen Kernfrage (sozial-)räumlicher Gerechtigkeit steht also: Was kann wem, wo und vor dem Hintergrund welcher regional-geografisch induzierten kommunalen Bedürfnisse zugemutet werden?

Darin kommt zugleich auch die zweite im Begriff (sozial)räumlicher Gerechtigkeit enthaltene Raumbedeutung, nämlich die des Container-Raums, zum Ausdruck. Gemeint ist damit nicht ein Newtonisch absoluter Raum, sondern ein physischer Raum mit klaren Grenzen, wie er in der Klimafrage in Form der physischen Grenzen der Erde eine zentrale Rolle spielt. Die Erde als Containerraum mit regionalen Unterschieden an Geodeterminierungen kann bei aller notwendigen Betonung sozialer Relationalitäten nicht geleugnet werden. Eben dies kennzeichnet ja die Erdvergessenheit der Moderne, die sich zwar als Leben auf der Erde, kaum noch aber als Leben mit der Erde bewusst ist und eine entsprechende sozial-ökologische resp. terrestrische Subjektbildung ja erst über die politische Bildung des globalen Ökosozialen (wieder) verwirklicht werden müsste. Die Erde als Containerraum bzw. als „wohl verproviantiertes Schiff, auf [und vor allem mit, MS] dem wir durch den Raum dahin segeln“"75 (George 2017: 199) zu verstehen, heißt im Begriff (sozial)räumlicher Gerechtigkeit also ausdrücklich nicht politische und kulturelle Aspekte naturalistisch herzuleiten, sondern geografische und klimatische, kurz: ökologische Aspekte anzuerkennen, die nicht länger ignoriert und aus dem Politischen suspendiert werden können (Stichwort „Klimaregime“, Latour 2017, 2018). Das regionale Leben und Wirtschaften kann durch diese ökologischen Bedingungen deswegen aber - um es noch einmal zu betonen ausdrücklich nicht als deterministisch durchdekliniert verstanden werden, sind also nicht von ihnen gefangen, sondern bloß an-gefangen. Wenn hier noch von einem Geodeterminismus gesprochen werden möchte, dann allenfalls von einem Geodeterminismus-light, da es, um diese ökologischen $\mathrm{An}$ fangsbedingungen für das politische Handeln verbindlich anzuerkennen, der politischen Entscheidung bedarf, die entlang der alltäglichen Reproduktionszwänge der die planetaren Grenzen des unbegrenzten Wirtschaftswachstums suspendierenden ,imperialen Lebensweise“ (Brand/Wissen 2017) aber erst kommunal erarbeitet werden muss. Darin besteht ja gerade die gemeinsame

75 An dieses von George bereits 1880 entworfene Bild vom „Raumschiff Erde“ schließt dann zum Ende der 1960er Jahre auch Buckminster Fuller (Buckminster Fuller 2013) an, durch den das Bild erst populär geworden ist und an das Crutzen et. al im Kontext der Klimafrage noch hinzufügt, dass das „Raumschiff Erde [...] keinen Notausgang [hat]“ (Crutzen et al. 2011). 
Aufgabenbewältigung der ganzen Klimafrage. Kurz: Die ökologischen Anfangsbedingungen kommunaler und regionaler Existenz zu erkennen, ist das eine. Sie aber als verbindlich zu anzuerkennen und das eigene Handeln daran entscheidend auszurichten, ist etwas anderes und folgt daraus nicht zwingend. Um sie anzuerkennen, darf der Containerraumbegriff nicht voreilig verworfen werden, sondern muss als kritischer Begriff in den Begriff (sozia)räumlicher Gerechtigkeit aufgenommen werden. So schreibt Redepenning:

„Diese Raumform in der wissenschaftlichen Diskussion wegen einer formalen Nähe zum absoluten Raum zu vernachlässigen, hieße auf die konstruktive Funktionalität der durch strikte Grenzen markierten raumbezogenen Unterscheidung innen/außen zu verzichten, aus der der Containerraum hervorgeht. [...] Anstatt das Containerraumkonzept voreilig abzulehnen, wäre ein nüchterner Blick auf die Leistungsfähigkeit und Funktionalität von Containern [...] zu bevorzugen“ (Redepenning 2013: 17).

- und, so ließe sich ergänzen, sozial-ökologisch auf die Erde resp. das Terrestrische auszudehnen, womit sich die ganze planetare Reichweite des relationalen Raumbegriffs im Begriff (sozial)räumlicher Gerechtigkeit offenbart. Zur Frage steht nun, entlang welcher Fragen dieser Begriff empirisch gefüllt werden könnte, um ihn als praxisphilosophisch-strategischen Begriff gesellschaftlicher Transformation fruchtbar zu machen. D.h. um die Frage der sozialräumlichen Verteilung von gesellschaftlichen/urbanen und terrestrischen Ressourcen nicht nur an den Residuen der Subjekte zu entzünden, sondern auch in die kollaborativen Hände der städtischen AkteurInnen zu legen.

\subsection{2 „Just City“ - ein räumlicher Ansatz sozialer Klimagerechtigkeit mit globaler Reichweite und kulturrevolutionärem Anspruch}

Simin Davoudi“s und Derek Bell's „Just city“-Konzept ist der Versuch einer räumlichen, genauer: ,pluralistischen, relationalen und multiskalaren Theorie der Gerechtigkeit"“ (Davoudi/Bell 2016: 273f., eigene Übersetzung). Sie entwickeln sie in kritischer Auseinandersetzung mit dem von Harvey schon zu Beginn der 1970er Jahre in die Urbanisierungsdiskurse eingebrachten Zusammenhang von „Social Justice and the City“ (Harvey 1973) sowie in Erweiterung von Rawls in etwa zeitgleich vorgeschlagener ,Theorie der Gerechtigkeit" (Rawls 2012) (zum Überblick: Großmann 2018). Zum einen geht es ihnen darum, die innerstädtischen Entwicklungen in den Blick zu nehmen, d.h. ob und wie es gelingt, die Stadt als ,physisch-räumlich-sozial-politischwirtschaftlich-kulturelle Infrastruktur" (Davoudi/Bell 2016: 271, eigene Übersetzung) zu kommunalisieren, um so die intrakommunalen sozialräumlichen Gerechtigkeitsaspekte in der Klimafrage zu politisieren. Und zum anderen geht es ihnen darum, in den Blick zu nehmen, ob und wie es gelingt, die 
sozialräumlichen Gerechtigkeitsaspekte in der Klimafrage auch zwischen den Städten zu politisieren. Den Zusammenhang von ,Social justice and the city“ (Harvey 1973) konkretisieren sie dafür als ,justice in, of, for and by the city“ (ebd.: 270), wobei sich auf jeder Ebene eigene und im Rahmen von Sozialraumentwicklung und Sozialraumorganisation zu erörternde und strukturell zu beantwortende Fragen stellen. Damit konkretisieren sie zugleich auch Lefebvres Begriffe der urbanen Raumproduktion sowie des „Rechts auf Stadt" (Kap. 12ff.), womit nun auch greifbarer gemacht werden kann, auf welche Fragen eine ökosoziale Revolutionierung der Praxis der Urbanisierung entlang der verschiedenen urbanen Praxen rund um den Globus insistieren müsste, um eine transformative Subjektbildung in und mit den urbanen Infrastrukturen zu ermöglichen.

Auf der intrakommunalen Analyseebene einer Gerechtigkeit in den Städten stellen sich vor allem Fragen, wie sich kollaborative Politikstrukturen ermöglichen lassen, um subjektorientierte Zugänglichkeiten zu urbanen Produktionsmitteln bzw. Infrastrukturen zu suchen und zu finden, um die Stadt als gemeinsame ,physisch-räumlich-sozial-politisch-wirtschaftlich-kulturelle Infrastruktur" (ebd.: 271, eigene Übersetzung) gemeinsam, aber je subjektiv unterschiedlich zu nutzen. Entsprechend geht es vor allem auch um die kollaborative Erarbeitung von gemeinsamen Regeln und Prinzipien ihrer Nutzung sowie um die kollaborative Erarbeitung von Strategien der Verteidigung von dessen Ergebnissen. Die genossenschaftliche Verfassung des urbanen Infrastrukturkomplex ‘ ,Stadt' könnte dafür einerseits den verbindlichen Rahmen für eine kollaborative Gerechtigkeitsfindung darstellen, während die mit Kunstreich dargelegten mutualistischen Genossenschaftsprinzipien - Förder-, Identitäts-, Demokratie-, Solidaritätsprinzip (Kunstreich 2005: 107f.; Kap. 15.4) - andererseits auch die diskursive Struktur eines sozialräumlichen (Klima)Gerechtigkeitsbegriffs anfangen können. Zugleich würde das Genossenschaftsmodell auch ein verbindliches Vertragsinstrument darstellen, das trotz aller Dissensorientierung und Interessenskonflikte nicht in seine Einzelteile zerfällt, sondern gerade darin seine grundsätzliche Verteidigung eröffnet, weil - wie in Kap. 15.4. herausgestellt - Genossenschaften als ,Schulen der Demokratie“ (Elsen 2018: 1064) ja gerade subjekt- und residuenorientierte Räume dissensorientierter Politik- und Gesellschaftsentwicklung ermöglichen.

Auf der intrakommunalen Analyseebene einer Gerechtigkeit, die von der Stadt als ,physisch-räumlich-sozial-politisch-wirtschaftlich-kulturelle Infrastruktur" (Davoudi/Bell 2016: 271, eigene Übersetzung) ausgeht, ist es notwendig den Fragen nachzugehen, wie die Stadt als Infrastrukturkomplex zur $(\mathrm{Re})$ produktion sozialer Ungleichheit und Ungerechtigkeit zwischen den in der Stadt lebenden Menschen und Gruppen beiträgt. Und wie sie sich im Rahmen einer gemeinsamen Infrastrukturpolitik politisch bearbeiten lassen, um so zu einer übergreifenden Politik des Sozialen vorzudringen. Allerdings 
muss hierfür zunächst eine „übergreifende ,proletarische Öffentlichkeit““ (May 2017b: 170) hergestellt werden, wofür Ansätze kommunalpädagogischer Sozialraumentwicklung und -organisation unterstützend tätig sein können.

Auf der interkommunalen Analyseebene einer Gerechtigkeit für die Stadt muss ebenfalls zwei Fragen nachgegangen werden. Zum einen wie sich regional, national oder global ausgerichtete Politiken anderer Städte auf die Lebensweisen in der eigenen Stadt auswirken und die Möglichkeiten einer eigenen sozialen resp. kollaborativen Infrastrukturpolitik begünstigen oder beschränken. Zugleich haben aber die Gerechtigkeitsansprüche für die eigene Stadt auch Effekte auf andere Städte und damit eine Bedeutung für andere Städte. Entsprechend muss also in der eigenen Stadt immer auch den Fragen nachgegangen werden, was die eigenen Gerechtigkeitsansprüche für andere Städte, d.h. für das urbane Leben und ihrer Herausbildung sozialer Infrastrukturpolitiken in anderen Städte bedeuten bzw. wie sich die eigenen Gerechtigkeitsansprüche für die BewohnerInnen anderer Städte hinsichtlich der Herausbildung von Gerechtigkeit in anderen Städten begünstigend oder beschränkend auswirken (Davoudi/Bell 2016: 272). Dabei dürfen allerdings nicht die eigenen Bedürfnisse und Interessen als Maßstäbe gelten, sondern die jeweiligen in den anderen Städten. Die Frage, die sich hier also stellen muss, ist, wie auch andernorts eine subjektorientierte Stadtentwicklung und städtische Eigenart ${ }^{76}$ ökosozialer sowie sozial-ökologischer Transformation ermöglicht werden kann und wodurch die eigene Stadt hierfür förderlich sein kann oder gar hinderlich ist. Zudem muss nach politischen Wegen und Strategien gesucht werden, wie sich dagegen gewehrt bzw. wie es verändert werden kann, wenn in der eigenen oder in irgendeiner Stadt die Herausbildung transformativer Eigenarten durch andere Städte verhindert wird. Mit anderen Worten: es geht auf der Analyseebene einer Gerechtigkeit für die Städte um die gemeinsame Herausbildung einer interkommunalen kollaborativen $\mathrm{Zu}$ sammenarbeit zur Erarbeitung gemeinsamer Gerechtigkeitsmaßstäbe, wofür auch hier das Modell der intrakommunalen Stadtgenossenschaft zu einem Modell einer interkommunalen Regionalgenossenschaft von intrakommunalen Stadtgenossenschaften weiterentwickelt werden kann. Allerdings müsste auch hierfür zunächst eine „übergreifende ,proletarische Öffentlichkeit““ (May 2017b: 170) hergestellt werden, wofür auch hier Ansätze kommunalpädagogischer Sozialraumentwicklung und -organisation unterstützend tätig sein können.

Diese strukturellen Fragen und politischen Erörterungen kumulieren auf der interkommunalen Analyseebene einer Gerechtigkeit durch die Städte, welche Gerechtigkeit durch die Städte/Städtenetzwerke für die Städte und in den Städten möglich ist, bzw. wie und wodurch sie sich gegenseitig daran

76 Dass dem Begriff Eigenart auch der Begriff des subjektiven Eigensinns innewohnt, wurde in Kap. 11.2 herausgestellt. 
hindern bzw. wie und womit sich daran etwas ändern ließe. Relevant werden diese Fragen vor allem hinsichtlich der Herausbildung gemeinsamer Richtlinien zur Nutzung und Bewirtschaftung von gemeinsamen Aktanten (global commons) unter Berücksichtigung der städtischen Infrastrukturpolitiken und der damit einhergehenden intra- und interkommunalen Probleme. Damit ist nun auch das Desiderat der vorherrschenden Diskussion um Klimagerechtigkeit (zum Überblick der gegenwärtigen Diskussion: Ekardt 2012; Gesang 2011; Laurent 2012) sozialräumlich eingeholt und in den Zusammenhang des Fragenkomplexes von ,justice in, of, for and by the city" (Davoudi/Bell 2016: 270) gerückt. $^{77}$

Die Notwendigkeit der Kommunalisierung städtischer Infrastrukturen und ihre regional, gar global ausgreifende konföderale Vernetzung mit gegebenenfalls genossenschaftlicher Rahmung zeigt sich hierbei nicht nur hinsichtlich der politischen Herstellung je kommunal bestimmter Gerechtigkeit, sondern auch hinsichtlich der politischen Herstellung regional bzw. global bestimmer Gerechtigkeit, bei der die je kommunalen Gerechtigkeitsdiskurse und ihre Auswirkungen auf andere Städte und Regionen den Ausgangspunkt von Klimagerechtigkeit bilden. Wird Klimagerechtigkeit also sozialräumlich verstanden, birgt sie das Potenzial, das sich mit ihrer Hervorbringung ein transnationales Städtenetzwerk entwickelt, das lokale Angelegenheiten gesellschaftlicher Transformationen auf alltagsrevolutionärer Ebene und im global-regionalen Maßstab erörtert. Dadurch, dass die jeweils städtische Bewohnerschaft mit AkteurInnen der kommunalen Politik, Verwaltung, ortansässigen Verbänden und Unternehmen, bereits bestehenden Städtenetzwerken sowie der national- und supernationalstaatlicher Institutionen (etwa EU und UNO) interagieren können, öffnet sich mit der politischen Entwicklung von sozialräumlicher Klimagerechtigkeit die Möglichkeit, das Verhältnis von Zivilgesellschaft, Ökonomie und Staat zu einer ,polyzentrischen Verantwortungsarchitektur" (WBGU 2016b , Kap. 8) zu organisieren, bei der nicht länger die nationalstaatlichen Institutionen die Scharnierstelle zwischen den Städten bilden, sondern das urbane Alltagsleben der AkteurInnen des/der Städtenetzwerk/e selbst. D.h. die fraktale Solidarisierung der Städte und Regionen müsste darauf abzielen - und hierin nimmt Fraser im Grunde die

77 Mit Großmann lässt sich Davoudi‘s/Bell’s Bezug zur Klimagerechtigkeit weiter aufspalten in Umweltgerechtigkeit, die ,den ungleichen Zugang zu Umweltgütern und eine unfaire Verteilung von Umweltlasten [thematisiert]“; in Energiegerechtigkeit, die danach fragt, „wie der Zugang zu Energiedienstleistungen wie Heizenergie oder Strom fair geregelt werden kann, welche sozialen Gruppen besonders benachteiligt sind, wann, wo und wie innerhalb des Energiesystems Ungerechtigkeiten entstehen und wie diese beseitigt werden können (Simcock 2016; Jenkins et al. 2016; Sovacool und Dworkin 2015)“; und in Mobilitätsgerechtigkeit, die danach fragt, ,wie Mobilitätschancen ausgeprägt sind und für welche sozialen Gruppen Benachteiligungen im Zugang zu Transport und Nahverkehr bestehen“, und ,bezieht sich nicht nur auf die Mobilität von Menschen, sondern auch auf die von Informationen und Ressourcen" (Großmann 2018: 183f.). 
vorangestellten Überlegungen in weiten Teilen bereits vorweg -, dass „bei sonst gleichen Umständen, die besten Bedürfnisinterpretationen jene sind, die mittels kommunikativer Prozesse erreicht werden, welche den Idealen von Demokratie, Gleichheit und Fairness möglichst nahe kommen“ (Fraser 1994: 281). Die hier zum Ausdruck kommende radikal-reformerisch-kommunalistische Weiterentwicklung der vom WBGU (WBGU 2016b: Kap. 8) vorgeschlagenen polyzentrischen Verantwortungsarchitektur findet auch Anschluss an den Begriff des Konföderalismus bei Bookchin. Nämlich

,als bewusst gestaltete Einrichtung gegenseitiger Abhängigkeiten, die eine partizipatorische Demokratie in den Gemeinden mit einem strikt überwachten System zur Koordinierung verknüpft. Dazu zählt die dialektische Entwicklung von Unabhängigkeit und Abhängigkeit in vielfältigere Formen der gegenseitigen Abhängigkeiten, genau so wie ein Mensch in einer freien Gesellschaft von seiner kindlichen Abhängigkeit zur jugendlichen Unabhängigkeit heranwächst, so dass beide aufgehoben werden und in eine gegenseitige Abhängigkeit zwischen den Menschen und zwischen Mensch und Gesellschaft übergehen. Der Konföderalismus ist folglich ein wandelbarer, sich stets weiterentwickelnder sozialer Metabolismus, in dem das Wesen einer ökologischen Gesellschaft durch seine Unterschiedlichkeiten und durch sein Potenzial zu einer immer feineren Differenzierung bewahrt bleibt. Der Konföderalismus markiert gewiss nicht das Ende der sozialen Geschichte [...], sondern vielmehr den Ausgangspunkt für eine neue ökologisch-soziale Geschichte, die von einer partizipatorischen Entwicklung innerhalb der Geschichte wie auch zwischen Gesellschaft und Natur geprägt ist.“ (Bookchin 2015b: 99f.)

Damit wird nun auch das Konzept der die Produzierendensozialpolitiken übergreifenden Politik des Sozialen auf die Ebene global-konföderaler Politik gehoben. Aber damit mit den dadurch entstehenden neuen alltäglichen Organisation-, Arbeits- und Sinnzusammenhänge zwischen Zivilgesellschaft, Ökonomie und Staat tatsächlich auch eine „wahre ,öffentliche“ Erziehung des Staates" (Marx 1981a: 95) auf der Ebene der politischen Kultur einhergeht, die die postpolitisch organisierten Reproduktionsdiskurse der wachstumsorientierten marktwirtschaftlichen Produktion gesellschaftlicher Naturverhältnisse samt der darin eingelassenen ,imperialen Lebensweise“ (Brand/Wissen 2017) überwindet und den Staat als ,der Gesellschaft [...] durchaus untergeordnetes Organ“ (Marx 1987: 27) hervorbringt, braucht es dringend praxisforscherisch-emanzipatorische Ansätze von Sozialraumentwicklung und organisation, die ihre kommunalisierenden Methoden auf regionaler und globalregionaler Ebene strategisch weiterentwickeln. Mit dem Ziel hegemoniale Blockierungszusammenhänge der subjektiven Mikroebenen und der städtischen Mesoebenen auch auf globalregionaler Makroebene zu erforschen und mit den jeweiligen kommunal-subjektiven AkteurInnen in den verschiedenen Städten postwachstumsorientierte Strategien ihrer gemeinsamen Überwindung , in, of, for and by the city“ (Davoudi/Bell 2016: 270) zu entwickeln. Ob Postwachstum dabei Nullwachstum heißen muss, muss angesichts der ja durchaus auch produktiven Wirkungen wirtschaftlichen Wachstums für die Entwicklung von urbanen und globalregionalen Infrastrukturen durchaus mit Skepsis betrachtet werden. Stattdessen müsste es zuvörderst darum gehen, die sozialen und ökologischen Voraussetzungen und Folgen 
des Wirtschaftswachstums zu politisieren. Mit Fraser gesprochen: „Viel wäre schon gewonnen, wenn es uns gelänge, die Frage nach dem Wachstum (wenn Wachstum, dann wie viel Wachstum, welche Art von Wachstum, in welchen Bereichen und wofür?) zu einer politischen Frage zu machen" (Fraser 2020: 124f.) und in eine ,pluralistische, relationale und multiskalare Gerechtigkeitstheorie“ (Davoudi/Bell 2016: 273f.) einzubetten, d.h. „in, of, for and by the city“ (ebd.: 270) zu beantworten zu versuchen.

Erst in einem solchen freiwilligen Zusammenschluss lässt sich überhaupt über einen Gesellschaftsvertrag nachdenken, den der WBGU zwar vorschlägt (WBGU 2011c), aber völlig unterbestimmt lässt, wer ihn mit wem und womit beschließt. Die in den vorangehenden Kapiteln untersuchte praxisphilosophische Gedankenexperiment des kommunalen Zusammenschlusses von Sozialgenossenschaften zu Stadtgenossenschaften und dessen Zusammenschluss zu Regional- bzw. Globalgenossenschaften kann an dieser Stelle weitergedacht werden. Es öffnet die Aussicht auf einen genossenschaftlichen (Welt)Gesellschaftsvertrag, ohne dafür auf das philosophische Nirgendwo, d.h die Metaphysik eines konkurrierenden (Hobbes 2005) oder kooperierenden (Rousseau 2006) Naturzustandes oder einen amnestischen „Schleier des Nichtwissens“ (Rawls 2012) rekurrieren zu müssen, sondern einzig auf die axiomatisch zwingende Tatsache des physiologischen Metabolismus der Erdnatur, weshalb

„[d]ie Natur [...] der unorganische Leib des Menschen [ist] [...]: Die Natur ist sein Leib, mit dem er in beständigem Prozeß bleiben muß, um nicht zu sterben. Daß das physische und geistige Leben des Menschen mit der Natur zusammenhängt, hat keinen andren Sinn, als daß die Natur mit sich selbst zusammenhängt, denn der Mensch ist ein Teil der Natur. (Marx 1968b: 516)

Dass daraus folgt, sein natürliches Leben auf und mit der Erde als seinem wie Marx den Begriff der Natur als Erde konkretisiert - unorganischen Leib (Marx 1983: 396) praktisch zu vollziehen und politisch gestalten zu müssen, sollte in den Untersuchungen der vorliegenden Arbeit deutlich geworden sein. Durch die politische Erarbeitung und gesellschaftsvertragliche Fixierung gemeinsamer Regeln zur gerechten Benutzung und Bewirtschaftung von gemeinsamen Aktanten (global commons) wäre der Möglichkeit ein Stückchen näher gekommen, die Erde als gemeinsamer unorganischer Leib und gemeinsames Handlungssubjekt von Menschen erfahren zu können. Allerdings bewegt sich die gesamte Argumentation an dieser Stelle noch immer nur auf der Ebene ökosozialer Transformation. Dadurch ist die Frage sozialökologischer Transformation, d.h. die Frage nach der Herausbildung eines Handlungssubjekts für das Transformationsprojekt Soziale Ökologie bzw. einem Anthropozän, das die Bewohnbarkeit der Erde nicht nur für menschliche Interessen und Bedürfnisse politisiert, weiterhin nicht berührt. Im Folgenden Teil D soll daher dem in Kap. 6.2 angerissenen Umriss einer möglichen terrestrischen Nachhaltigkeitswissenschaft sozial-ökologischer Transformation weiter nachgegangen werden. 


\section{Teil D}

Umriss einer möglichen terrestrischen Nachhaltigkeitswissenschaft sozial-ökologischer Transformation - zum Verhältnis ökosozialer Transformationen und sozial-ökologischer Subjektbildung 



\section{Weiterführende Zusammenfassung von Teil A, B und $\mathrm{C}$}

Wurden in Kap. 6.2 die Fragen aufgeworfen, wie 1) zu ökosozialen und 2) zu sozial-ökologischen Transformationen des Gesellschaftlichen gelangt werden könnte, so wurde bislang in Teil B und C nur Frage 1) beantwortet. Zusammenfassend lässt sich sagen: Ökosoziale Transformationen könnten gelingen,

a) wenn es durch eine kommunalpädagogische Subjektbildung gelänge, den gesamten Stadtentwicklungsprozess im Kontext der Klimafrage, d.h. des „neuen Klimaregimes“ (Latour 2017) zur genossenschaftlich verfassten kommunalistischen Angelegenheit aller StadtbewohnerInnen zu machen, so dass die Stadt als gemeinsamer Raum der politischen Bildung ihres Sozialen für ihre je eigensinnige Subjektbildung an ihrem Sozialen hervorgebracht werden könnte. Kurz: wenn es gelänge, die Stadt als genossenschaftlich verfasstes Commons hervorzubringen und es gemeinsam zu bewirtschaften und zu verwalten (Teil B).

Und wenn zugleich

b) die als Commons hervorgebrachten Stadtkommunen sich weltweit transnational konföderativ vernetzen würden und dadurch eine gegenhegemoniale Macht entwickeln könnten, mit der sie den global organisierten plutokratischen Gesellschaftsverhältnissen der Städte eine alternative urbane Praxis der Urbanisierung abzuringen vermögen, um so entlang einer öffentlichen Umgestaltung nationalstaatlicher Infrastrukturpolitiken eine gemeinsame transnationale soziale Infrastrukturpolitik hervorbringen zu können. Eine solche - wie es mit dem WBGU (WBGU 2016b: Kap. 8) genannt werden könnte - polyzentrische Verantwortungsarchitektur der politischen Bearbeitung des Klimawandels behielte die kommunalen und regionalen kulturellen Unterschiede der Produzierendensozialpolitiken bei, würde sie aber zugleich insofern übergreifen, als dass sie die gemeinsamen global Commons demokratisch zu verwalten ermöglicht, dabei aber die kommunalen Autonomien der Regulierungen ihrer urban Commons unangetastet ließe, sie aber gleichwohl miteinander in ein (sozial)räumlich-diskursives Gerechtigkeitsverhältnis setzen würde (Teil C). Dadurch würden sowohl die Städte als auch die Erde als kommunal regulierte und zugleich weltweit öffentliche Gemeingüter hervorgebracht, deren jeweilige Nutzungsrechte durch einen genossenschaftlichen Gesellschaftsvertrag reguliert werden könnten. 
Aber dieser kommunalistisch-genossenschaftlichen Kernsanierung der urbanen Organisierung des Politischen muss - wie in a) betont - von Anfang an eine kommunalpädagogisch angelegte transdisziplinäre Subjektbildung eingenäht werden, die die Erde nicht mehr nur für den Menschen politisiert. Erst dann ließe sich von einer sozial-ökologischen Transformation sprechen, die es über ökosoziale Transformationen des Städtischen vermag, eine Politik Sozialer Ökologie resp. ein Anthropozän hervorzubringen (Kap. 5, 6ff.). Bereits herausgestellt wurde, dass sich Aussagen darüber, welche politischen Strukturen und welche Produktionsmittel in welcher Stadt konkret benötigt würden, erst entlang der Subjektbildung kommunalpädagogisch angelegter transdisziplinärer Stadtentwicklungsprozesse konkretisieren ließen. Nämlich wenn die städtischen AkteurInnen sie für ihre Emanzipation subjektiv als jeweils fehlend, als noch ausstehend, aber in Möglichkeit-seiend (Bloch 2013a: 238ff.) erfahren. Dass setzt voraus, dass die AkteurInnen diskursiv in Situationen gebracht würden, in denen sie die vorgefundenen politischen Strukturen subjektiv als begrenzend erleben können und sie dadurch zu Akten inspiriert würden, diese Strukturgrenzen diskursiv neu abzustecken und in Auseinandersetzung mit anderen Akteur(sgruppen) politisch für sich einzufordern und zu verwirklichen. Im Hinblick auf eine Politik Sozialer Ökologie könnte dies aber nur durch die praxisforscherische Erweiterung ihrer Kenntnisse der Welt und ihrer Zusammenhänge mit dieser Erde gelingen, die ihnen ihre bisherige subjektive Weltkenntnis als fruchtbar, aber dennoch als begrenzend aufzeigt. Nämlich in einer Weise, die sie zu einer Weitung ihrer Weltsicht inspiriert und sie dadurch nicht nur nach objektiv Möglichen sozial-ökologischen Seinsmodi des subjektiven Wohnens auf und mit der Erde Ausschau zu halten beginnen, sondern auch nach politischen Wegen und Strategien, sie zu verwirklichen.

Die zu Grunde liegende strategische Hypothese formal formuliert: Erst wenn ein objektiv mögliches $Z$ (sozial-ökologische Seinsmodi des subjektiven Wohnens auf und mit der Erde) subjektiv in Aussicht steht, tritt für Subjekt $A$ aus seiner gesellschaftlichen Praxis $X$ (residualisierende imperiale Lebensweise) heraus $Y$ (ökosoziale Transformationsstrategien) als erstrebenswert in Erscheinung, mit dem sich $A$ von $X$ zu $Z$ hin entwickeln kann (emanzipatorische Bildung eines sozial-ökologischen Subjekts, Anthropozän). Darin besteht die strategische Hypothese sozial-ökologischer Transformation, die zugleich insofern zukunftsoffen und nur richtungsweisend ist, als dass vorher weder gesagt werden kann, worin $Z$ konkret besteht, noch wie sich $A$ in Situation $X$ sein/ihr subjektiv in Aussicht stehendes $Z$ subjektiv aneignet und mit $Y$ zu verwirklichen sucht, da sich die subjektive Aneignung von $Z$ an den Residuen von $A$ orientieren muss, die sich wiederum nur im Zusammenhang mit Subjekt $B$ und $C$ konkretisieren lassen und sich erst von dort aus entscheidet, was $Y$ konkret sein muss, so dass sich auch das subjektive $Z$ von $B$ und $C$ von ihren Residuen aus mit $Y$ verwirklichen lässt. Damit ist also nicht nur $Z$, son- 
dern auch $Y$ nur als gemeinsames $Y Z$-Subjekt von $A, B$ und $C$ im Zusammenhang von ihrem jeweiligen $X$ zu begreifen, das ihre Residuen zu verwirklichen in Aussicht stellt. Dass durch das $X Y Z$-Subjekt als $A B C$-Kompromiss unweigerlich jeweils neue Residuen entstehen, weil sich ,[j]ede Repräsentation schaffende Tätigkeit“ zugleich ,als produktiv und als entfremdend [erweist]: produktiv zuerst, entfremdend danach“, so dass ,[j]eder Versuch“, mit $Y$ der Entfremdung durch $X$ zu entkommen, ,schließlich in einer neuen Entfremdung [landet][,] bis das Alltagsleben zum wichtigsten Werk der endlich bewussten Praxis wird“ (Lefebvre 1987: 438ff.), verweist darauf, dass $Z$, die emanzipatorische Herausbildung eines sozial-ökologischen Transformationssubjekts (Anthropozän) als nach vorne offenes resp. dialektisches Projekt begriffen werden muss, das in der urbanen resp. gesellschaftlichen Alltagspraxis der AkteurInnen seinen Ausgangs- und Zielort erblicken muss.

Für die kommunalpädagogische Bildung eines sozial-ökologischen Transformationssubjekts, das bereits als terrestrisches Gemeinwesen, Gaia, Naturallianz, Soziale Ökologie bzw. Anthropozän auf einen offenen Strategiebegriff gebracht wurde, muss mit Marx und Schmidt daran erinnert werden, dass sich Aussagen über die Natur bzw. die Erde ,überhaupt nur mit Hilfe gesellschaftlicher Kategorien formulieren und anwenden" lassen (Schmidt 2016: 84). Dass Natur bzw. Erde immer nur gesellschaftlichsymbolisch vermittelt ist (etwa als inwertzusetzende Ressource, als machina mundi, die nach Naturgesetzen funktioniert, oder als Wohnraum), verbietet zwar einerseits einen Natur-Gesellschaft-Dualismus, der Natur als jenseits gesellschaftlicher Symbolisierungen darzustellen versucht. Darf aber andererseits ebenso wenig zu einer Identität von Erde/Natur und Gesellschaft führen, die den je eigentätigen Materialismus der Relata Erde und Gesellschaftspraxis in ihrer Relationalität auflöst und ineins setzt. Insbesondere letzteres führt unweigerlich in die philosophische und wissenschaftliche Theoriebildung, die den Bezug zur Erde verloren hat:

„Tatsächlich gehört es zu den Sonderbarkeiten der Moderne, dass die Definition der Materie so wenig materiell, so wenig erdbezogen war. Sie rühmt sich eines Realismus, den umzusetzen sie nie in der Lage war. Wie kann man ernsthaft Menschen als Materialisten bezeichnen, die imstande sind, aus Fahrlässigkeit in einen Planeten zu schlittern, der sich um 3,5 $\mathrm{Grad}^{78}$ erwärmt, oder die ihre Mitmenschen bezichtigen, Agenten des sechsten Massenaussterbens der Arten zu sein, und ohne dass dies bemerkt wird?" (Latour 2018: 76)

Auch mit Altvater ist zu konstatieren, dass sozialwissenschaftliche Ansätze und Untersuchungen bislang ,im besten Falle ,soziale Auswirkungen' von Naturkatastrophen zum Gegenstand ihrer Analysen machen“ (Altvater 2015: 145), während hingegen ihre gesellschaftlichen Ursachen weitgehend aus

78 Eine Begründung seiner konkreten Angabe bleibt Latour schuldig. Vermutlich bezieht er sich auf das wahrscheinlichste Szenario künftiger Erderwärmung (Aisch 2019; Blaha 2019). Wichtiger ist an dieser Stelle jedoch der Kern der Aussage Latours, der auch nachdenklich stimmt, wenn der Bezugspunkt der Grad-Angabe unklar bleibt. 
dem Blick geraten sind. Das wird vor allem dadurch bezeugt, dass es in den letzten Jahren vor allem geologische Wissenschaften waren, die auf die gesellschaftlichen Ursachen der gegenwärtigen Naturkatastrophen und den Klimawandel hingewiesen haben. Erst über den Umweg der „Überlegungen seriöser Geologen“, den „Historiker[n] der Natur“, hat „dieses Oxymoron aus Geologie und Menschheit" den Weg in die Sozialwissenschaften gefunden, die diesen „bis vor kurzem nicht das geringste Interesse entgegenbrachten“, sondern stattdessen ,wie besessen waren von der Verteidigung der ,menschlichen Dimension“ gegen die ,Übergriffe' der Naturwissenschaft und die Risiken einer exzessiven ,Natur“" (Latour 2017: 202f.).

Nun sollen die Aporien und Gefahren naturwissenschaftlicher Gesellschaftsbeschreibungen und Gesellschaftserklärungen gerade auch im Kontext Sozialer Arbeit (zum Überblick: Dungs 2009; Behnisch/Winkler 2009) keinesfalls klein geredet und vom Tisch gewischt werden. Gleichwohl kann dies aber nicht länger dazu führen, die Diskurse um den gesellschaftlich bedingten Klimawandel sozialwissenschaftlich und gerade auch seitens Sozialer Arbeit zu ignorieren und/oder in ihnen bloß eine weitere Aufblähung des Anthropozentrismus oder eine weitere Naturalisierung zu erblicken. Stattdessen müssen sie ,diese von den Naturwissenschaftlern ausgehende Innovation auf[]nehmen, als sie sofort wieder durch die x-te Kritik an der Naturalisierung zu begraben und damit sich um die Chance zu bringen, das neue Klimaregime zu verstehen" (Latour 2017: 205). Als neues Klimaregime bezeichnet Latour die schlichte Tatsache, dass die Erde als unerbittliche politische Akteurin das Leben auf und mit der Erde dominiert und dass sich dies endlich in der Politik gesellschaftlicher Naturverhältnisse, bzw. wie es in der vorliegenden Untersuchung begrifflich konkretisiert wurde, in einer Politik Sozialer Ökologie widerspiegeln muss. Denn während „das alte Klimaregime lediglich einen Waffenstillstand darstellte“, tritt das „neue Klimaregime“ „als Bedrohung in Erscheinung“ und sensibilisiert „für die schlichte Schwierigkeit, von dieser Erde zu sein. [...] Wenn wir davonkommen wollen, dürfen wir nicht länger an die einstige Zukunft glauben (ebd.: 413), sondern müssen endlich nicht nur die „Zugehörigkeit zu einem Boden“ (Latour 2018: 66), sondern auch ,unsere Auffassung von Ökologie [...] repolitisieren “ (Latour 2017: 377).

Statt also im wissenschaftlichen Alltag weiterhin die bisherige Trennung von Natur- und Sozialwissenschaften zu reproduzieren, muss der dem ,neuen Klimaregime“" inhärente politische Imperativ dazu zwingen, das Verhältnis von Sozialwissenschaften und Naturwissenschaften neu $\mathrm{zu}$ bestimmen, so dass daraus ein neues, ein soziales Verständnis von Ökologie erwachsen kann. Latour: „Ökologie ist nicht der Name einer Partei, nicht einmal der bestimmten Art von Anliegen, sondern der eines Appells, die Richtung zu ändern: ,Hin zum Terrestrischen'.“ (Latour 2018: 71) Für diese Neuausrichtung wurde bereits in Kap. 6.2 vorgeschlagen, das Verhältnis von Sozialwis- 
senschaft und Naturwissenschaft neu zu fassen: Unter Sozialwissenschaften ließen sich alle methodologischen Zugänge zusammenfassen, die die Erde von innen heraus, d.h. entlang der menschlichen wie nicht-menschlichen Akteure und Aktanten der Erde und ihren jeweiligen verflochtenen Entwicklungen auf und mit ihr als sympoietisch sich entwickelnde Prozessnatur zu beschreiben versuchen. Demgegenüber ließen sich unter Naturwissenschaften alle methodologischen Zugänge zusammenfassen, die die Erde von außen her betrachten und ihre Entwicklung entlang mechanistisch ablaufender Naturprozesse zu beschreiben versuchen. Gleichwohl wurde als Notwendigkeit herausgestellt, transversal zu diesem Entweder-Oder einen dritten, einen den Widerspruch aufhebenden Zugang zu benötigen, der die forschenden und beforschten menschlichen AkteurInnen mit ihren gesellschaftlich erzeugten subjektiven Residuen einbezieht und mit ihnen und ihren jeweiligen wissenschaftlichen und nicht-wissenschaftlichen Expertisen nach unabgegoltenen (blockierten bzw. residualisierten) objektiven Möglichkeiten sozialer und gesellschaftlicher Alternativen des Wohnens in den Städten und mit der Erde Ausschau hält. Eine solch dritter Zugang wurde in Lefebvres transduktiven Ansatz strategischer Hypothesen (Lefebvre 1987: 372ff.) erblickt, der mit den AkteurInnen theoretisch wie praktisch transdisziplinär (Mittelstraß 2005) vom Hier und Jetzt zum objektiv Möglichen vorzudringen vermag und von dorther nach Möglichkeiten und Strategien für das Hier und Jetzt sucht, das bislang noch residualisierte und unabgegoltene objektiv Mögliche zu verwirklichen.

Vor diesem Hintergrund wurde bereits in Kap. 6.2 der praxisforscherische Vorschlag einer terrestrischen Nachhaltigkeitswissenschaft sozialökologischer Transformation eingebracht, die ausgehend von Lovelocks Gaia-Hypothese (Lovelock 1992) nicht nur das Gesellschaftliche bzw. Soziale ökologisch, sondern auch das Ökologische sozial zu begreifen versucht. Nämlich - wie es hier nun weiter präzisiert werden kann - als dialektisch sich entwickelndes Raumproduktionsverhältnis, das die Relata Erde und Gesellschaftspraxis nicht in ihrer Relationalität auflöst, sondern als zwar miteinander verschränkte, aber je eigentätige Sphären der Raumproduktion zu vermitteln sucht. Genauer: Sie muss der Frage nachgehen, wie diese Vermittlung wissenschaftlich adäquat dargestellt werden kann und wie sich daran eine sozial-ökologische Subjektbildung entzünden kann, die ein Anthropozän bzw. eine Politik Sozialer Ökologie ermöglicht, das/die das Kapitalozän und den historisch gewachsenen und gesellschaftlich verwachsenen Anthropozentrismus hinter sich zu lassen vermag. Das Ökologische sozial zu begreifen heißt in dieser Hinsicht also nicht nur, es gesellschaftlich zu begreifen, sondern die menschliche Vergesellschaftung der Erde nicht als einzigen Beitrag zur Ökologie der Erde zu begreifen. Aus diesem Anspruch heraus wird ein Nachhaltigkeitsbegriff notwendig, der nicht nur im reaktionären Sinne auf eine regenerationsorientierte Verlangsamung des Verbrauchs der Erde, son- 
dern über die politisch-konföderative Herstellung von urban und global Commons auf einen alternativen Gebrauch der Erde insistiert. Das Gebrauchen der Erde darf sich hierbei aber nicht nur auf die gedeihliche Entwicklung und politische Gemeinwesensbildung menschlicher Subjektivität beschränken, sondern muss auch die gedeihliche Entwicklung nicht-menschlicher Lebensformen umfassen, was sich sowohl in der menschlichen Subjektbildung als auch in einer Politik Sozialer Ökologie wiederfinden muss. Nur darin ließe sich in einem das Kapitalozän zu überwinden suchenden möglichen Anthropozän die weitere Aufblähung des Anthropozentrismus verhindern.

Die Überwindung des historisch gewachsenen und gesellschaftlich verwachsenen homo-mensura-Paradigma, wonach der Mensch das Maß aller Dinge ist (Grawe 1974; Meister 2010: 143), muss zumindest dann politisch ernsthaft anvisiert werden, wenn „die höchste Objektivität“ der Natur, „die der lebendigen Tätigkeit" (Lefebvre 1971a: 76) und der schöpferischen Kreativität (Poiesis) (Lefebvre 1975c) nicht nur den Menschen und der menschlichen Natur zuerkannt werden soll, sondern auch nicht-menschlichen Lebensformen und ihren spezifischen Naturen. D.h. ihren Naturaneignungs- und Raum(re)produktionspraktiken, die ansonsten außerhalb der lebendigen Tätigkeit der Natur angesiedelt würden - was aber weder für Tiere noch für Pflanzen oder Pilze, Viren und Bakterien gelten kann, da auch sie ihren lebendigen, wenn auch graduell abgestuften schöpferischen Beitrag zum Gesamt der Erdökologie leisten und die Erde ebenfalls zu der machen, die sie zu jedem Zeitpunkt $x$ ist. Wenn nun aber Menschen und nicht-menschlichen Lebensformen lebendige, d.h. weltschaffende bzw. raumproduzierende (poietische) Naturtätigkeiten und damit ein elementarer Beitrag zur Ökologie der Erde zuerkannt werden, dann folgt daraus, dass das Ökologische sozial zu verstehen heißen muss, dieses Soziale des Ökologischen der Erde nicht bloß in der menschlichen Gesellschaft, sondern in der menschlichen Gesellschaft inmitten einer nicht-menschlichen Mitwelt zu begreifen und dass dieses Miteinander politisch so zu gestalten ist, dass es eine gedeihliche Entwicklung für möglichst viele an der sozialen Produktion der Erde beteiligten Akteure ermöglicht. Eine Politik, die undifferenziert alle Akteure und Aktanten der Erdökologie die gedeihliche Entwicklung ermöglichen würde, führt sich selbst ad absurdum, da sie auch Coronaviren, Hurricane, Hochwasserereignisse, gar den Klimawandel selbst die gedeihliche Entwicklung ermöglichen müsste. Demgegenüber wird hier dafür plädiert, dass sich eine Politik Sozialer Ökologie an der iterativen Diskussion und der naturethischen Abwägung entzünden muss, welche nicht-menschlichen Akteure und Aktanten den politischen Schutz ihrer gedeihlichen Entwicklung erhalten sollen und welche nicht. Es geht also darum, dass zwar einerseits die gesamte Erdökologie politisch als (terrestrische) Gesellschaft hervorgebracht wird, wobei aber andererseits zugleich politisch diskutiert und reguliert werden muss, was schützens- 
wert ist und was nicht, da nicht davon ausgegangen werden kann, das alles natürlich Existierende einen schützenswerten Eigenwert in sich trägt (siehe folgender Exkurs). Die einer terrestrischen Nachhaltigkeitswissenschaft sozial-ökologischer Transformation inhärente Gaia-Hypothese Lovelocks (Lovelock 1992) verpflichtet damit zu einer diskursiven Politischen Ökologie der Verwirklichung terrestrischer Sympoiesis, d.h. zur emanzipatorischhistorischen Hervorbringung eines terrestrischen Gemeinwesens (Gaia), und entfaltet darin zugleich auch die Notwendigkeit, das menschliche Bewohnen der Erde neu, nämlich konsequent politisch, d.h. als naturethisch-diskursiven Aushandlungsprozess zu begreifen. Und das beginnt in den Städten bzw. muss dort am dringendsten neu erlernt werden, wo es entlang der knapp 1000jährigen „Urbanisierung des Kapitals“ (Harvey 2014: 126) systematisch verlernt wurde (Kap. 3). Damit stellt sich zugleich auch die Frage, wie der historisch gewachsene und gesellschaftlich verwachsene Anthropozentrismus überwunden werden könnte, um das Wohnen auf und mit der Erde, ausgehend von den subjektiven Residuen der ,imperialen Lebensweise“ (Brand/Wissen 2017), sozial-ökologisch zu politisieren und demokratisch sowie naturethisch zu regulieren, um wiederum dadurch erst das allen gemeinsame Wesenssubjekt Erde als Gaia politisch zu verwirklichen.

\section{Exkurs zu der im Begriff der Politik Sozialer Ökologie zugrundeliegenden Naturethik}

Dem hier erarbeiteten Begriff der Politik Sozialer Ökologie liegt eine mit Lefebvres habiter-Begriff (Kap. 12.2.2) modifizierte Variante der holistischen Ethik (Ökozentrik) zu Grunde (zum Überblick der aktuellen Naturethikdiskussion etwa: Krebs 2016a; Ott/Dierks/Voget-Kleschin 2016; zu den naturethischen Implikationen des habiter-Begriffs bei Lefebvre: Schmidt $2021 b$ [i.E.]). Am Grundgedanken der holistischen Ethik entzündet sich auch der Grundgedanke des Natur-, Umwelt oder Klimaschutzes, da den Naturverhältnissen im Ganzen ein schützenswerter Eigenwert zugesprochen wird. Sie geht von der Erde als im Gesamt schützenswerten Gut aus. Unter diesem Hauptgedanken differenziert sich die holistische Ethik weiter aus in einen individualistischen Holismus, wonach allen einzelnen menschlichen und nicht-menschlichen Akteuren und Aktanten des ökologischen Gesamtkomplex Erde ein je individueller schützenswerter Eigenwert zukommt (zum Überblick: Dierks 2016b). Da es in der vorliegenden Untersuchung aber weder um Natur-, Umwelt- oder Klimaschutz geht, sondern einzig darum das urbane Wohnen auf und mit der Erde zu verändern, so dass die gedeihliche Bewohnbarkeit der Erde nicht nur für Menschen erhalten bleibt bzw. wieder hergestellt wird, geht auch die ethische Fragestellung in eine andere Richtung. Entsprechend ist hier nicht die Perspektive des individualistischen Holismus von Belang, sondern die des pluralistischen Holismus. 
Der pluralistische Holismus spricht zwar auch allen einzelnen menschlichen und nicht-menschlichen Akteuren und Aktanten der Erde einen Eigenwert zu. Aber er spricht ihn ihnen nicht als Wert an sich zu. „Die egalitaristische Sichtweise verschließt [...] nicht die Augen davor, dass unser eigenes Leben ohne Schädigung oder Beeinträchtigung von anderen Wesen und ohne deren partielle Instrumentalisierung unmöglich ist" (Dierks 2016a: 180). Zugleich aber hebt der pluralistische Holismus zum obersten Gebot, ,dass andere Wesen und Gesamtsysteme so wenig und schonend wie möglich instrumentalisiert werden sollten (Gorke 2010, 113)“ (ebd.). Damit wird die Schutzwürdigkeit nicht-menschlicher Akteure und Aktanten relativiert und ins Verhältnis des Füreinander gesetzt, bei dem nicht nur die gedeihliche Entwicklung von Menschen ihre Berücksichtigung findet. Damit verweist der pluralistische Holismus wieder zurück auf eine biozentrische Ethik, aber erweitert um die unbelebte Natur und der Annahme, die Erde würde sich als holistischer „Superorganismus“, der mit Lovelock (1992) etwa „Gaia“ genannt werden kann (Kap. 6.2), selbst organisieren wollen - wenn auch nur telisch und nicht teleologisch. D.h. die Selbstregulierung des Erdhaushalts wird als Dialektik von Allgemeinheit-Besonderheit-Einzelheit angenommen (vgl. Exkurs in Kap. 6.2) angenommen, nicht als eine von vornherein bestimmte Selbstregulierung (Dierks 2016b: 174).

Hieran lassen sich nun zwei Kritiken anknüpfen. Zum einen, dass es „,der Mensch ist, der die Natur in seinen Begriffen beschreibt und ihr moralische Werte beimisst" und daher ,ohnehin alle ökologische Ethik anthropozentrisch [sei]“" (Krebs 2016b: 342). Aber diese Kritik reduziert den Anthropozentrismus auf den Begriff einer naiven Epistemologie, was den verschiedenen Spielarten des Anthropozentrismus sicher nicht gerecht wird (ebd.: 343). Daher eine gehaltvollere zweite Kritik, die an der Annahme des Wollens, dass sich also die sich Erde im Ganzen oder ihre einzelnen menschlichen und nicht-menschlichen Akteure und Aktanten organisieren wollen, ansetzt. Die Annahme eines Wollens impliziert immer auch eine bewusste Absicht, die letztlich nicht in dem vollen Umfang begründet werden kann, wie es holistische Ansätze beanspruchen. Die Wollens-Argumentation bleibt auch dann schwierig, wenn sie auf naturgesetzliche Determinanten insistiert und als Alsob-Wollen bzw. Quasi-Wollen darzustellen gesucht wird. Etwa in Latours Präzisierung von Lovelocks Gaia-Hypothese, wonach nicht gesagt wird, „dass sie [die Erde, MS] lebendig ist, sondern bloß, dass sie nicht tot ist“" (Latour 2017: 126f.).

Der Diskussion um einen pluralistischen Holismus wäre Abhilfe getan, wenn das (Quasi-)Wollen durch ein Brauchen ersetzt würde: für ihre gedeihliche Entwicklung brauchen und nutzen menschliche und nicht-menschliche Akteuren nicht nur geosphärische Aktanten der Erde, sondern auch biosphärisch interne, aber gattungsübergreifende Kooperationen (Haraway 2018). Und im Gesamt dieser Interaktionen bilden und entwickeln sie den „Superor- 
ganismus" Erde. Gleichwohl muss auch der pluralistische Holismus anerkennen, dass es allein der menschlichen Politik obliegt, den einzelnen menschlichen und nicht-menschlichen Akteuren und ihren Aktanten einen gewollten Schutz zukommen zu lassen oder es zu unterlassen.

Was heißt das? Zum einen ist nicht von der Hand zu weisen, dass die Politisierung des Bewohnens der Erde eine menschliche Angelegenheit ist, die sich aus menschlichen Expertisen und Begriffen speist. Zugleich ist das aber keine hinreichende Rechtfertigung, die Politisierung des Bewohnens der Erde nur auf Belange der menschlichen Gattung und die für ihre gedeihliche Entwicklung relevanten nicht-menschlichen Akteure und Aktanten einzuengen. Nur weil nicht behauptet werden kann, dass die Erde nicht im Ganzen als (quasi)lebendiger Organismus mit Eigenwert bzw. eigenwertigen Akteuren und Aktanten erfasst werden kann, kann daraus nicht der Schluss gezogen werden, sie sei nur für den Menschen von Wert. Die Schwierigkeit besteht also darin politische Strategien zu entwickeln, die menschliche Verantwortung ihres urbanen Bewohnens der Erde sozial-ökologisch auszuweiten und sie dabei politisch so zu gestalten, dass eine Abstufung im Bereich des Schützenswerten, d.h. der Wertig- und Würdigkeit von nicht-menschlichen Akteuren und Aktanten multi- und transdisziplinär erforscht werden kann. Denn nur so ließe sich verhindern, dass auch Corona-Viren dieselbe Unantastbarkeit der Würde zugesprochen werden muss wie Menschen, was die menschliche Verantwortung offenbar ad absurdum führen würde. Die Herausforderung besteht also darin, die menschliche Verantwortung sozialökologisch auszuweiten, ,ohne dass eine unangemessene Benachteiligung für Mensch oder Natur eintritt" (Altner 1991: 33). Entsprechend lässt sich eine naturethisch informierte und inspirierte politische Regulierung der sozialen und ökologischen Bedingungen menschlichen Bewohnens und Bewirtschaftens der Erde unter Berücksichtigung auch nicht-menschlicher Akteure und der für ihre gedeihliche Entwicklung relevanten Aktanten zwar nur allzu leicht einfordern. Aber diese Forderung greift noch weitgehend ins Leere. Sie trifft noch auf kein historisches Subjekt, das ihr entsprechen und eine gesellschafts-transformative Kraft und Reichweite entfalten könnte. An diesem gesellschaftshistorischen Desiderat setzt nun die Bildung eines sozialökologischen Transformationssubjekts an, aus der heraus sich erst eine Politik Sozialer Ökologie entwickeln kann.

Eine Ethik, die ihren Ausgangspunkt in der gedeihlichen Sozialität von menschlichen und nicht-menschlichen Akteuren nimmt und dabei das gemeinsame Brauchen von Aktanten stärker betont und zudem nach einer terrestrischen Nachhaltigkeitswissenschaft sozial-ökologischer Transformation Ausschau hält, ohne dabei in einen naiven individualistischen Holismus zu verfallen und den pluralistischen Holismus als Resultat menschlicher Urbanisierungs- und Erkenntnisleistungen formuliert und politisiert, ließe sich als sozial-ökologische Ethik bezeichnen, die Lefebvres habiter-Begriff (Kap. 
12.2.2) $\mathrm{zu}$ integrieren sucht (zur weiteren Ausführung der Diskussion: Schmidt 2021b [i.E.]). Der in der vorliegenden Arbeit erarbeitete Begriff des Anthropozäns bzw. Politik Sozialer Ökologie impliziert eine solche sozialökologische Ethik. - Exkurs Ende

Ging es in der vorliegenden Studie bislang nur um die strukturellen Voraussetzungen einer solchen umwälzenden Revolutionierung der gesellschaftlichen Alltagspraxis, so soll es im Folgenden um eine holzschnittartige Ausformulierung des methodischen Aspekts der transdisziplinären sozialökologischen Subjektbildung einer strategischen Wissenschaft sozialökologischer Transformation gehen. Sie muss nicht nur eine an den Residuen orientierte theoriebildende Zusammenarbeit zwischen wissenschaftlichen und nicht-wissenschaftlichen AkteurInnen ermöglichen, sondern auch zwischen wissenschaftlichen AkteurInnen verschiedener Disziplinen, die hier vorgeschlagen wurden, sie typologisch in (Sozial- und Natur-)Wissenschaften der Prozessnatur und (Sozial- und Natur-)Wissenschaften der Naturprozesse neu ins Verhältnis zu setzen. Ziel einer solchen Zusammenarbeit muss, wie bereits herausgestellt, die gemeinsame Erarbeitung eines alle Beteiligten repräsentierenden Problemgegenstandes sowie dessen gemeinsame subjektive Bearbeitung sein, bei der die unterschiedlichen disziplinären wie lebensweltlichen Zugänge anerkannt und kollaborativ einbezogen werden. Eine solche subjektbildende Zusammenarbeit soll hier, wie bereits in Kap. 6.2 angerissen, als transdisziplinär-transduktive terrestrische Nachhaltigkeitswissenschaft sozial-ökologischer Transformation bezeichnet werden.

Damit diese Zusammenarbeit gelingt, so wird gemeinhin - mehr oder weniger ausdrücklich auch vom WBGU (WBGU 2011c, 2016b) - behauptet, bedürfe es ein gemeinsames Systemverständnis der Problemlage. Damit aber wird, wie gleich zu zeigen sein wird, der anerkennende Anschluss an die lebensweltlichen und (sub)kulturellen Unterschiede der Bildungspraxen der verschiedenen Produzierendensozialpolitiken der wissenschaftlichen wie nicht-wissenschaftlichen AkteurInnen verpasst, durch die aber Bildung erst von ihrem instrumentellen Charakter befreit würde und zu einer gemeinsamen subjektiven Bildung vorgedrungen werden könnte. Den methodologischen Ausgangspunkt bei einem (vermeintlich) gemeinsamen Systembegriff zu nehmen, bedeutet außerdem auch methodologische Unterschiede zwischen den (Sozial- und Natur-)Wissenschaften der Prozessnatur und den (Sozialund Natur-)Wissenschaften der Naturprozesse zu verwischen. Im Folgenden wird daher im Anschluss an eine kritische Untersuchung des populär gewordenen Systemdenkens in wissenschaftlicher und alltäglicher Praxis (Kap. 17) eine mögliche Alternative (Kap. 18) aufgezeigt und als ikonografische Methode sozial-ökologischer Subjektbildung (Kap. 19) konkretisiert. Im Anschluss wird die Bedeutung Sozialer Arbeit im sozial-ökologischen Transformationsprozess knapp umrissen (Kap. 20). 


\section{Zur Kritik der emergenzmaterialistischen Verkürzung dialektisch-materialistischer Kritik und die Notwendigkeit komplementärer Transdiszplinarität für eine sozial-ökologische Subjektbildung}

Der Systembegriff des „Emergenzmaterialismus“ (Lindner 2008: 38), wie er insbesondere im critical realism zum Ausdruck kommt, geht davon aus, dass „chemische Mechanismen auf physikalischen, biologische auf chemischen, mentale auf biologischen und soziale auf mentalen [beruhen]" (Lindner 2021: 44). Dabei werden die „spezifischen sozialen und mentalen Mechanismen, die Menschen auszeichnen, [...] an biologische, chemische und physikalische Voraussetzungen gebunden, ohne die sie nicht existieren könnten - was umgekehrt jedoch nicht gilt" (ebd.). Nur aus der Betrachtung eines solchen autopoietischen Gesamtzusammenhanges lässt sich, so das emergenzmaterialistische Postulat, erklären, ,warum Menschen bestimmte Grundbedürfnisse haben, warum sie Krankheiten bekommen und irgendwann sterben müssen oder warum der Klimawandel überhaupt ein Problem darstellt" (Lindner 2008: 37). Über den Emergenzbegriff wird dadurch versucht, den „metaphysischen Bruch zwischen Natur und Gesellschaft, der einen Methodendualismus zwischen Natur- und Sozialwissenschaften rechtfertigen würde“ (ebd.), $\mathrm{zu}$ überwinden, weil „Erklärungen in den Sozial- und Naturwissenschaften trotz wichtiger Unterschiede eine strukturähnliche Logik besitzen: In beiden Bereichen geht es um die theoretische Rekonstruktion der Strukturen, Mechanismen und Entwicklungsverläufe, die den zu untersuchenden Phänomenen zugrunde liegen bzw. diese hervorbringen“" (Mader et al. 2017: 42). Und diese sind letztlich sowohl in den Natur- als auch den Sozialwissenschaften, als „Kausalität“ zu beschreiben, womit von Mader et al. zugleich gesagt wird, ,[w]issenschaftliches Erklären bedeutet, einen Kausalzusammenhang bzw. die Funktionsweise einzelner seiner Elemente zu erhellen“, weshalb „sich auch keine klare Grenze zwischen Warum- und Wiefragen, zwischen Erklärung und Beschreibung ziehen [lässt]"“ (ebd.; vgl. Lindner 2021: 51).

Damit lässt sich der emergenzmaterialistische Ansatz als systemtheoretisches Erkenntnisparadigma für (Sozial- und Natur-)Wissenschaften von Naturprozessen ausfindig machen, das vom Vorhandensein von Kausalzusammenhängen und quasi-automatischen, nämlich autopoietischen Mechanismen in Strukturprozessen ausgeht und die Frage nach der gesellschaftlichen Praxis der Strukturierung und des Herstellens dieser Zusammenhänge außen vor lässt. Demgegenüber lässt sich aus dialektischer Perspektive zwar zustimmen, dass sich Natur resp. Erde keinesfalls nur als gesellschaftliche Kategorie begreifen lässt, die sich ,ohne verbleibenden Rest in die historischen 
Prozesse ihrer Aneignung auflös[t]" (Schmidt 2016: 84). Dadurch ist es auch aus der Perspektive des Dialektischen Materialismus gerechtfertigt von ontologisch vorausliegenden Zusammenhängen auszugehen. Während die dialektische Perspektive aber diese Ontologie als ,negativ zu fassende Ontologie“ (ebd.: 103) zu begreifen sucht, wodurch die Erkenntnis von Natur bzw. Erde nur aus einem gesellschaftlichen Entwicklungs- und Erkenntnisprozess heraus zu begreifen ist, wird sie aus der emergenzmaterialistischen Perspektive allerdings als positive Ontologie zu fassen gesucht, die „ontologischen Realismus, epistemologischen Konstruktivismus und Begründungsrationalität“" $\mathrm{zu}$ vereinen beansprucht, wodurch zugleich einem Letztbegründungsanspruch zu entgehen versucht wird (Lindner 2021: 50).

Mit anderen Worten: Der Emergenzmaterialismus geht davon aus, dass Phänomene historisch hervorgebracht werden und dass sich die Hervorbringung rational und emergentistisch rekonstruieren lässt, weil „,chemische Mechanismen auf physikalischen, biologische auf chemischen, mentale auf biologischen und soziale auf mentalen [beruhen]" (ebd.: 44). Ob aber die innere Emergenz beobachtbarer Phänomene in genau dieser Hierarchisierung existiert, steht dabei aber nicht zur Diskussion. Hingegen bestreitet die dialektisch-materialistische Perspektive zwar ebenfalls nicht, dass der Erkenntnis etwas Ontisches zugrunde liegt und ihr voraus geht. Aber sie lässt offen, wie das Apriori-Ontische beschaffen ist, d.h. ob es genau so beschaffen ist, wie es zu erkennen gemeint und für wahr gehalten wird, oder aber - je nach gesellschaftlicher und kultureller Praxis, aus denen heraus menschliche Erkenntnisleistungen von statten gehen - ob es auch anders sein kann. Während der dialektisch-materialistischen Perspektive also ein gewisser Skeptizismus innewohnt, wohnt dem Emergenzmaterialismus also ein gewisser Dogmatismus inne, der die Phänomene in eine als fix angenommene Hierarchiestruktur bringt und damit das gesellschaftlich konstruierte Für-wahr-halten der Erkenntnis und die innere Struktur der Phänomene in-eins setzt und behauptet, erst auf dieser ontologisch gesetzten Grundlage rational über die Welt diskutieren zu können. Damit wird zum einen der selbst beanspruchte Verzicht auf Letztbegründungen durch die Hintertür wieder aufgegeben. Und damit wird zum anderen der Welt und damit auch der gesellschaftlichen Praxis und er menschlichen Lebensweisen in naturalisierender Weise eine Struktur unterstellt, was dann letztlich auch Auswirkungen auf den Begriff gesellschaftlicher Transformation hat. Denn aus der emergenzmaterialistischen Perspektive stecken letztlich die physikalische Naturerkenntnis und die ingenieurswissenschaftliche Könnerschaft den Möglichkeitsrahmen sozialer und gesellschaftlicher Veränderungen ab, so dass gesellschaftlich nur veränderbar wäre, was natur- und ingenieurswissenschaftlich für möglich gehalten wird. Entsprechend folgerichtig lässt der WBGU (WBGU 2016b) seinen ,normativen Kompass" auch mit seinem Konzept planetarischer Leitplanken (WBGU 2014b) beginnen, das weltweit gleichermaßen einzuhalten dann mittels parti- 
zipatorischer und transdisziplinärer Methoden ermöglicht werden soll (WBGU 2016b: 466). Statt dass mit der politischen Auseinandersetzung um die weltweit regional unterschiedlich ausgeprägten kapitalogenen Urbanisierungs- und Vergesellschaftungsweisen innerer wie äußerer Naturverhältnisse und den daraus resultierenden subjektiven Residuen begonnen würde, um daraus regionale Leitplankenkonzepte zu erstellen (vgl. Kap. 12.2.2), die sich zu einer planetaren Landkarte zusammensetzen ließen.

Demgegenüber lässt sich mit Bloch in Anlehnung an den aristotelischmarxschen Naturbegriff neben jenem emergenzmaterialistischen Transformationsbegriff des nur ,sachhaft-objektgemäß Mögliche[n]“ (Bloch 2013a: 264ff.) allerdings noch ein dialektisch-materialistischer Transformationsbegriff des „objektiv-real Mögliche[n]“ (ebd.: 271ff.) in Aussicht stellen. Danach lässt sich das Mögliche nicht nur darin erblicken, was sich als menschliche Subjektivität und gesellschaftliche Praxis samt der darin sich entwickelten menschlichen Könnerschaft bislang verwirklicht hat bzw. verwirklicht werden konnte, um daraus seine weitere Entwicklung in der Zukunft zu induzieren bzw. kausal zu linearisieren. Sondern was sich als menschliche Subjektivität und gesellschaftliche Praxis samt der darin sich entwickelten menschlichen Könnerschaft noch entwickeln und verwirklichen kann. Bloch: „Das wirklich Mögliche beginnt mit dem Keim, worin das Kommende angelegt ist. [...] die Anlage [des Werdens, MS] entfaltet sich in der Entfaltung“ des Prozesses der Natur und ist nicht schon von Anbeginn in ihm enthalten (ebd.: 274), so dass es gerechtfertigt wäre anzunehmen, das wirklich Mögliche des Künftigen allein im bereits Gewordenen zu erblicken. Eben darin begründet sich der Begriff der Prozessnatur resp. „Prozessmaterie“ (ebd.: 273), der zwar das wirklich gewordene Mögliche umfasst und die darin sich herausgebildeten latenten Entwicklungstendenzen für das Künftige fokussiert. Aber er lässt sich nicht auf sie reduzieren, weil er nicht nur die bereits beobachtbaren bzw. messbaren, weil verwirklichten Entwicklungstendenzen fokussiert, sondern vor allem die noch nicht messbaren, noch unverwirklichten, aber in-Möglichkeit-seienden Tendenzen, die in der Gegenwart oft nur ironisch andeutend vorscheinen (vgl. Kap. 12.1), statt schon voll verständlicher Bedeutung zu sein (ebd.: 274ff.). Beobachten heißt hier nicht messen, sondern ermessen - nämlich ermessen, was wirklich werden will, aber blockiert wird.

Aus dialektischer Perspektive ist die Wirklichkeit der Erdnatur also nicht bloß als ahistorisches Ablaufen mechanistisch-autopoietisch-emergenter Natur(system)prozesse zu begreifen, sondern als historischer Raum sympoietischer Produktion, d.h. als Raum verwirklichter und noch unverwirklichter Möglichkeiten sympoietischer Sozialität der Naturakteure und -aktanten. „Sympoiesis umfasst Autopoiesis, erlaubt ihre Entfaltung und erweitert sie.“ (Haraway 2018: 86) Eine solche Darstellung der Wechselwirkung der materiellen Entwicklung der Wirklichkeit der (Erd-)Natur und dem Benutzen dieser 
entwickelten Wirklichkeit zur Herausbildung sich (weiter) entwickelnder Materialität seitens der lebendigen Akteure der (Erd-)Natur - womit nicht nur die menschlich-gesellschaftliche Wirklichkeit als Möglichkeitsraum (weiter) entwickelt wird, sondern die Natur als Möglichkeitsganzes, deren Teil die Menschen und ihre gesellschaftliche Praxis ja sind - vermag nur eine Darstellungsweise, die Natur als komplexen sozial-ökologischen Dialektikprozess abzubilden sucht, wie es etwa für (Sozial- und Natur-)Wissenschaften der Prozessnatur charakteristisch ist (vgl. Kap. 6.2). Was wirklich möglich ist, ist erst am Ende der Naturgeschichte wissbar, nicht bereits zu jedem Zeitpunkt des naturwissenschaftlichen Hinsehens im Prozess des geschichtlichen Werdens. Revolutionäre Entwicklungen zeichnen sich ja gerade dadurch aus, dass nicht vorher gewusst werden kann, was als ihre Entwicklung möglich ist, weil sie sich zunächst sukzessiv, dann explosiv, d.h. paradigmen- bzw. sprunghafthaft zu etwas Neuem entwickeln. So etwa die kambrische, neolithische, urbane, industrielle oder digitale Revolution. So also auch eine objektiv mögliche sozial-ökologische Revolution, die zur paradigmen- bzw. sprunghafthaften Entwicklung zu etwas Neuem offensichtlich der mäeutischen Unterstützung einer terrestrischen Nachhaltigkeitswissenschaft sozialökologischer Transformation bedarf, um die hegemonialen Verharrungskräfte plutokratischer Gesellschaftsverhältnisse zu überwinden.

Eine solche Darstellung der Wirklichkeit beansprucht zwar auch der Emergenzmaterialismus, da sein Realismusbegriff nicht zuletzt auch aus Marx ${ }^{6}$ Materialismus herausgearbeitet wird. Aber ein an Marx ${ }^{6}$ kritischer Gesellschaftstheorie orientierter Begriff materialistischer Dialektik - und damit auch das an der Marxschen Dialektik orientierte „Recht auf Stadt“ Lefebvres (Lefebvre 2016) - würde mit der Reduzierung der Wirklichkeit auf emergenzmaterialistische Natur- und Gesellschaftsprozesse unzulässig verkürzt, weil ,'dialektisch““ nur noch bedeutet, dass ,soziale Strukturen immer schon da [sind], wenn gehandelt wird; sie werden durch Handlungen nicht jeweils neu geschaffen, sondern reproduziert oder transformiert" (Mader et al. 2017: 17). Entsprechend ist aus dieser Perspektive "'Gesellschaft"“ die „Voraussetzung als auch Ergebnis menschlicher Praxis“ und Praxis das „,intentionale[] Handeln sowie nicht-intendierte Strukturreproduktion“, die ,als Relationengefüge zwischen Menschen untereinander und bezogen auf Ressourcen bzw. Artefakte gefasst [werden]“ (ebd.). „Um es ,dialektisch“ zu formulieren: Der Critical Realism favorisiert keinen Mittelweg, der die Vermittlung hypostasiert, sondern er versucht, beidem gerecht zu werden, der Vermittlung (Praxis) wie auch dem Vermittelten (Akteuren, Artefakten und sozialen Strukturen).“(ebd.: 26).

Dass „soziale Strukturen immer schon da [sind], wenn gehandelt wird“ und dass ,sie [...] durch Handlungen nicht jeweils neu geschaffen, sondern reproduziert oder transformiert [werden]" (ebd.: 17), ist sicher keine problematische Aussage. Aber anstatt bestehende Strukturen bzw. hegemonial er- 
zeugte Strukturierungen des gesellschaftlichen Alltags entlang von sozialen Macht- und Herrschaftsverhältnissen kritisch zu untersuchen und nach Wegen ihrer Politisierung zu suchen, um sie sich im Fluss der tatsächlichen Bewegungen des gesellschaftlichen Sozialen (wie sie etwa in sozialen Bewegungen wie „Recht auf Stadt“ oder „Fridays For Future“ zum Ausdruck kommen) demokratisch (weiter-)entwickeln $\mathrm{zu}$ lassen, verkürzt der Emergenzmaterialismus die Gesellschaftskritik des Marxschen Materialismus um die Untersuchung der postpolitisch organisierten konservativen Verharrungskräfte des Bestehenden. Vor dem Hintergrund der im Anschluss an Lefebvre (Lefebvre 1971b: 55f.) erblickten Intention des dialektischen Materialismus, „die durch ideologische Legitimation entwicklungshemmender Herrschaftsverhältnisse verzerrten Bilder von Möglichkeiten der Selbstaneignung des Menschen in Produktion und Reflexion wiederherzustellen (kritische Rekonstruktion) und auszumalen (utopische Projektion)“ (Frese 1972: 202), vernachlässigt der Emergenzmaterialismus sowohl die kritische Rekonstruktion der gesellschaftlichen Produktion von subjektiven Residuen, die sich nicht in den hegemonialen Konsens einpflegen lassen, als auch die utopische Projektion der Möglichkeiten ihrer Befreiung bzw. Verwirklichung.

Sicher sind nicht nur ein beidseitiges Gerechtwerden, sondern auch der ganze Emergenzbegriff notwendige Implikationen eines dialektisch-materialistischen Ansatzes gesellschaftskritischer Sozialwissenschaften. So sieht Fuchs Emergenz als ,die Grundform vieler, wenn nicht sogar aller Dialektik“ (Fuchs 2008: 114), weil das „Prinzip der Emergenz [...] den Hegelschen Kategorien der Aufhebung und der Negation der Negation [entspricht]" und auch „die Kategorien der Kontrollparameter, des Bifurkationspunktes, des Phasenübergangs, der Nichtlinearität, der Selektion, der Fluktuation und der Intensifikation können als Neuformulierung des dialektischen Prinzips des Übergangs von Quantität in Qualität erachtet werden“ (ebd.). Aber zugleich ist es falsch, das Prinzip des „Umschlags von Quantität in Qualität“" (Engels 1975: 349), in dem sich der Emergenzbegriff erschöpft, als ,zentrale[n] Aspekt der Dialektik der Natur“ zu betrachten (Fuchs 2008: 115). So tritt Emergenz zwar ,in kritischen Phasen auf und ist ein Aufhebungsprozess“, aber ,[o]ffen ist jedoch, zu welchem Grad das Neue Bewahrung und Eliminierung ist und ob es überhaupt zur Emergenz des Neuen kommt oder die Transformation stillgehalten wird" (ebd.). Mit dieser eklatanten Verkürzung dialektisch-materialistischer Kritik ist es letztlich auch unzulässig, den Emergenzmaterialismus als interdisziplinäres Paradigma für alle Disziplinen zu beanspruchen, wodurch (ideologie-)kritische Sozialwissenschaften um ihre Kritik gebracht werden. Denn dadurch wird die Untersuchung, was als Neues entsteht und was zwar entstehen will, aber nicht entstehen kann bzw. soll nicht nur vernachlässigt, sondern von Grund auf suspendiert. Suspendiert wird also die kritische Untersuchung und Bewertung, ob durch Transformati- 
onen der gesellschaftlichen Alltagspraxis die gesellschaftliche Wirklichkeit bloß reaktionär oder wirklich revolutionär reformiert wird.

Diese Verkürzung und Suspendierung lässt sich auch im Konzept des WBGU ausfindig machen. Nämlich darin, dass er hinsichtlich der transformativen Eigenart der Städte versucht, sowohl den lebensweltlichen Eigenarten der Praxis der StadtbewohnerInnen als auch den Verwaltungsstrukturen gerecht zu werden, indem einerseits zwar ein Kollaborationsansatz verfolgt wird, diesen aber andererseits nur insofern verfolgt, als dass weder Bürger noch Verwaltungsstrukturen durch das kollaborative Miteinander im Transformationsprozess überfordert werden (WBGU 2016b: 152f.). Darin kommt zum Ausdruck, dass es dem WBGU offensichtlich nur insofern auf die Verschränkung zweier Eigenarten bzw. Eigenlogiken ankommt, als dass er beiden gerecht werden will, dabei aber nur bis zu dem Punkt geht, an dem ein Transformationsprozess beginnt substanziell, d.h. revolutionär zu werden, wodurch historisch geronnene Gesellschaftsstrukturierungen und sich transformativ bildende Subjektivität ja aber erst beginnen würden, sich aneinander umzubilden. Erst dadurch würde zu einer gesellschaftlichen Erziehung des Staates vorgedrungen, wie es im „Recht auf Stadt“ angelegt ist (Kap. 12ff.).

Durch diese verpasste transformative Subjektbildung verpasst der WBGU letztlich auch seinen eigenen Anspruch transformativer Bildung. Mehr noch: er verhindert sie gar in letzter Konsequenz, da sie sich doch bloß an der Reproduktion bestehender Strukturen auszurichten hat - seien es nun bestehende Verwaltungsstrukturen oder bestehende lebensweltliche Strukturierungen der Subjekte. Statt - etwa praxisforscherisch-kommunalpädagogisch begleitet durch Soziale Arbeit - unterstützend behilflich zu sein, dass sich sowohl Verwaltungsstrukturen als auch lebensweltliche Strukturierungen der subjektiven Wahrnehmungen an den tatsächlichen Erfordernissen des Transformationsprozesses transformativ bilden resp. entwickeln und aufkommende Konflikte durch die Problembetroffenen selbst politisch reguliert werden können, wird der Bildungsprozess vom WBGU entlang eines kritisch-realistischen Emergenzbegriffs konzeptionell begrenzt, um allen Beteiligten gerecht zu werden. Mit anderen Worten: Statt entstehende Konflikte zu politisieren zu ermöglichen, an denen sich ein revolutionärer Transformationsprozess entzünden könnte, werden sie im bestehenden hegemonialen Konsens postpolitisch erstickt. Damit wird nun aber ebenfalls verpasst, plutokratische Herrschaftsverhältnisse und daran sich entzündende Hemmnisse eigensinniger Eigenartproduktion revolutionär-transformativer Stadtentwicklungsprozesse öffentlich zu politisieren und zu demokratisieren. Allen beteiligten AkteurInnen gleichermaßen gerecht zu werden, wäre also nur dann sozial gerecht, wenn bei allen Beteiligten gleiche soziale Voraussetzungen gegeben wären. Ist dies aber, wie alltäglich zu beobachten, nicht der Fall, kann ein soziales Gerechtwerden aller AkteurInnen nur prioritaristisch gewährleistet werden. Lediglich hinsichtlich der subjektiven Residuen bzw. der 
subjektiven Vermögen und Fähigkeiten, die im Transformationsprozess zum Residualen zu werden drohen, lässt sich eine allen Beteiligen gleichermaßen zukommende Interessensberücksichtigung im Transformationsprozess rechtfertigen (Kap. 15ff.).

Mit diesem Nachweis der elementaren Blindstelle des Emergenzbegriffs wird offensichtlich, dass sich die Erkenntnisperspektive des critical realism und damit auch die konzeptionellen Ansätze des WBGU sämtlicher Analysen sozialer Herrschaft und diesen inhärenten Residuen produzierenden Reproduktionsstrategien entledigt und damit auch der eigentlichen Kritik der politischen Ökonomie in Marx“ „Kapital“, aus der Lindner (Lindner 2008) den Emergenzmaterialismus des critical realism herzuleiten versucht. Die Tendenz des wissenschaftlichen Realismus, ,die Realität der alltäglichen Welt [zu] leugne[n]" (Caro 2015: 32), nämlich vor allem die der politökonomisch herrschaftlich durchdrungenen postpolitischen Alltagspraxis, bleibt damit auch bei Lindners (Lindner 2008) bzw. Mader/Lindner/Pühretmayers (Mader et al. 2017) critical realism und damit auch dem Konzept des WBGU zentral.

Mehr noch: Entgegen des eigenen Anspruchs, sich mit einem critical realism einer Einheitswissenschaft entgegen $\mathrm{zu}$ stellen (Lindner 2008: 37; WBGU 2016b: 466), wird ihr mit der emergenzmaterialistischen Gleichsetzung von Kausalität und Dialektik stattdessen die Tür geöffnet. Denn mit der ausgesprochenen (Lindner 2008; Mader et.al 2017) oder unausgesprochen gesetzten (WBGU) Behauptung eines gemeinsamen erkenntnistheoretischen Emergenzparadigmas von Natur- und Sozialwissenschaften wird die disziplinäre wissenschaftliche Praxis nicht etwa von einer multidisziplinären Praxis der Zusammenarbeit in eine interdisziplinäre überführt, sondern in eine unidisziplinäre. Das ist dann zwar keine Einheitswissenschaft im positivistischen Sinne, so doch insofern eine, als dass ein - nämlich das emergentistische Erkenntnisparadigma für allgemein gesetzt wird, das die unterschiedlichen erkenntnistheoretisch fundierten Methodologien der Disziplinen auf eine emergenzmaterialistische und das jeweils Disziplinäre auf die bloße Methodenwahl zur Erkenntnis der jeweiligen Emergenzen in den jeweiligen Disziplinen reduziert. Dadurch aber würden die systematischen Blindstellen des Emergenzbegriffs systematisch auf alle Disziplinen übertragen und Phänomene wie soziale bzw. gesellschaftliche Herrschaft blieben systematisch unbeforscht und unerkannt. Damit wiederum blieben sie dem gesellschaftlichen Geschichtsverlauf des ökonomischen Determinismus überlassen und würden über das Transformationskonzept des WBGU entlang des nur halbherzigen Kollaborationsansatzes in die Zukunft verlängert.

Unbeforscht bleibt damit auch - wie alltäglich zu beobachten -, warum sich manche Leute und Gruppen klimaneutrale und $\mathrm{CO}_{2}$-reduktive Lebensweisen subjektiv aneignen und in ihrer Praxis aufgehen lassen können, während andere dies hingegen nicht tun (können) und - mehr oder weniger subtil - zur Zielscheibe öffentlich diskreditierender Etikettierungen aller Art erklärt 
werden. Dass dadurch aber letztlich bloß neue Demarkationslinien durch die Gesellschaft gezogen werden und notwendige Transformationen mit revolutionärer gesellschaftlicher Reichweite eher erschweren als ermöglichen, liegt auf der Hand und wurde schon vor mehr als 30 Jahren von Egon Becker mit Henri Lefebvre (Lefebvre/Régulier 1979: 187f.) kritisiert:

„Wenn die wissenschaftliche Ökologie sich zu einer ,Allgemeinen Systemökologie“ verallgemeinert, entwirft sie zugleich ein menschliches Entwicklungskonzept der Natur: Ein gestörter Naturzusammenhang soll planvoll entstört werden. Greift die politische Ökologiebewegung zu den systemökologischen Allgemeinbegriffen [etwa Emergenz, MS], dann übernimmt sie zugleich deren technisches Apriori und muss auf etablierte Politik, planende Bürokratien und ein Inventar technischer Lösungen setzen. Die Reparatur der bio-kybernetischen Weltmaschine ist zum wissenschaftlich-technischen Problem geworden. So transformiert sich denn auch das Krisenbewusstsein der Ökologiebewegung in dem Maße in ein systemisches Problembewusstsein, wie diese Bewegung versucht, ihre Vorstellungen mit den Mitteln der vorhandenen Institutionen, politischen Apparate und mit den in der Gesellschaft vorhandenen rechtlichen und technischen Möglichkeiten durchzusetzen. [...] Ökologische Politik wird in diesem Prozess sukzessive technisiert und verrechtlicht. Für Gefühle, Ängste und Hoffnungen der protestierenden Menschen bleibt dabei wenig Platz. Die im politisch-ökologischen Krisendiskurs vorhandenen subjektiven Momente lassen sich nur unvollständig mittransformieren. Selbstverständlich erzeugt auch eine solche Politik subjektive Anteile oder verstärkt vorhandene: Lust am Spiel der Macht, Freude über gelungene Lösung von Teilproblemen, Machbarkeitsphantasien etc. Sie lässt aber viele Menschen mit ihrer Wut und ihren Ängsten allein und das Abgespaltene entwickelt sein Eigenleben. Es ist daher nicht verwunderlich, dass sich der ökologische Krisendiskurs spaltet: Auf der einen Seite eine pragmatische Öko-Politik und eine system-ökologische Denkweise; auf der anderen Seite ein ökologischer Irrationalismus, kybernetischer Spiritualismus à la Carpa oder Rückzug ins Private. Und der Diskurs pragmatischer Öko-Politik spaltet sich weiter in einen zweckrationalen und in einen moralischen Anteil, zweckrationale Öko-Politik und moralisierende Rhetorik.“ (Becker 2016f.: 308ff.)

Dass sich die heutigen gesellschaftlichen Spaltungsverläufe weniger zwischen system-ökologischer Denkweise und kybernetischen Spiritualisten verläuft, sondern zwischen „Klimawandel-Negationis[ten]“ (Latour 2018: 44) und „Erdverbundenen“ (ebd.: 110) - oder wie hier nun auch gesagt werden kann: Sozial-Ökologen -, ist nur ein Nebenschauplatz. Viel bedeutsamer ist $\mathrm{zu}$ erkennen, dass eine auf ein gemeinsames Systemverständnis setzende Interdisziplinarität eine konsensuale Herrschaftslogik impliziert, wie sie im gesellschaftlichen Kontext diskursiver Herrschaft als Postpolitik bezeichnet wird und hier als Postwissenschaft bezeichnet werden kann. Das hegemonialdiskursive Herstellen eines Konsenses wird erreicht durch Suspendierung und Marginalisierung nicht systemtheoretisch einpflegbarer Erklärungen zu einem bloßen Hintergrundrauschen (May 2010: 111f.).

Statt den ,einzelnen Disziplinen [...] eine systemtheoretische Reorientierung" (Becker 2016f: 300) zu empfehlen, wird im Folgenden mit der Kritik Beckers Anschluss gesucht an Mittelstraß‘ Begriff der Transdisziplinarität, wonach „Kooperation zu einer andauernden, die fachlichen und disziplinären Orientierungen selbst verändernden wissenschaftssystematischen Ordnung 
führt“ und Interdisziplinarität damit ,in Wahrheit“ immer schon Transdisziplinarität ist (Mittelstraß 2005: 19):

„Unser Wissenschaftssystem ist auf eine beunruhigende Weise unübersichtlich geworden. Das gilt nicht nur hinsichtlich eines sich immer stärker beschleunigenden Wachstums des Wissens, sondern auch in organisatorischer und institutioneller Hinsicht. Eine fachliche und disziplinäre Partikularisierung nimmt zu; die Fähigkeit, noch in Disziplinaritäten, d. h. in größeren wissenschaftlichen Einheiten, zu denken, nimmt ab. Grenzen der Fächer und Grenzen der Disziplinen, wenn man sie so überhaupt noch wahrnimmt, drohen dabei mehr und mehr nicht nur zu institutionellen Grenzen, sondern auch zu Erkenntnisgrenzen zu werden. Entsprechend verbindet sich mit dem Begriff der Interdisziplinarität, der dieser Entwicklung seit langem entgegengesetzt wird, aber auch eine Reparaturvorstellung, die auf Umwegen und auf Zeit zu einer neuen wissenschaftlichen Ordnung führen soll. [...] Aus Partikularitäten soll wieder ein Ganzes entstehen, im systematischen wie im institutionellen Sinne. [...] Das aber bedeutet, dass es unter der in dieser Situation beschworenen Interdisziplinarität auch nicht um ein modisches Ritual geht, sondern um Zwänge, die sich durch die Problementwicklung selbst stellen. [...] Mit anderen Worten, ganz gleich, in welchem Sinne hier Interdisziplinarität verstanden wird, als Interdisziplinarität, die größere disziplinäre Orientierungen wiederherstellt, oder als tatsächliche Erweiterung des Erkenntnisinteresses innerhalb von Fächern und Disziplinen und über Fächer und Disziplinen hinweg, eines dürfte klar sein: Interdisziplinarität im recht verstandenen Sinne geht nicht zwischen den Fächern oder den Disziplinen hin und her oder schwebt, dem absoluten Geist nahe, über den Fächern und den Disziplinen. Sie hebt vielmehr fachliche und disziplinäre Engführungen, wo diese der Problementwicklung und einem entsprechenden Forschungshandeln im Wege stehen, wieder auf; sie ist in Wahrheit Transdisziplinarität.“ (ebd.: 18f.)

Diese Transdisziplinarität wird allerdings insofern verhindert, als dass bei der Zusammenarbeit der Disziplinen mit - wie auch immer offen ausgetragener Herrschaftsgewalt - auf ein bereits feststehendes Erkenntnisparadigma, etwa das systemtheoretische bzw. emergenzmaterialistische, gedrängt wird. Etwa wenn zur Bearbeitung eines Problems, etwa dem Klimaproblem, ,an den Schnittstellen zwischen Ingenieurs-, Erdsystem- und Sozialwissenschaften“ (WBGU 2011c: 24, 2016b: 453) die gemeinsame „Betrachtung des systemischen Problemkontextes“ (WBGU 2016b: 465f.) zur Voraussetzung gemacht wird, statt sie erst gemeinsam zu erarbeiten. Statt mit einer methodologischen Logik die Sache des Klimaproblems zu überformen und darin einzuhegen, muss es also stattdessen möglich werden, der einer Sache inhärenten Logik in der ganzen Bandbreite seiner Darstellbarkeit auf die Spur zu kommen. D.h., dass die multidisziplinäre Zusammenarbeit der Disziplinen von Anfang an anerkennend angelegt sein muss, um Transdisziplinarität zu ermöglichen:

„Dabei stellt sich Transdisziplinarität zum einen als eine Forschungs- und Arbeitsform der Wissenschaft dar, wo es darum geht, außerwissenschaftliche Probleme, z. B. die schon genannten Umwelt-, Energie- und Gesundheitsprobleme, zu lösen. Zum anderen ist Transdisziplinarität auch ein innerwissenschaftliches, die Ordnung des wissenschaftlichen Wissens und der wissenschaftlichen Forschung selbst betreffendes Prinzip [...].“ (Mittelstraß 2005: 19)

Die von Mittelstraß getroffene Unterscheidung zwischen ,theoretische[r] Transdisziplinarität", „die aus der Lösung innerwissenschaftlicher Problemstellungen entsteht", und ,praktische[r] Transdisziplinarität", „die sich auf außerwissenschaftliche Problemstellungen bezieht" (ebd.: 21), hebt die Un- 
terscheidung in Interdisziplinarität und Transdisziplinarität auf. Wenn Mittelstraß aber betont, dass ,uns die Probleme, wissenschaftliche wie außerwissenschaftliche, nicht den Gefallen tun, sich selbst disziplinär oder gar fachlich zu definieren“, sondern es stattdessen „eben besonderer Anstrengungen [bedarf], die in der Regel aus den Fächern oder Disziplinen herausführen“" (ebd.: 19), dann kann die "systemtheoretische Reorientierung“ der Disziplinen (Becker 2016f: 300) zwar durchaus als eine solche besondere Anstrengung verstanden werden. Da diese aber letztlich in die oben genannten erkenntnistheoretischen Anpassungen und Forschungsdefizite führen, bedarf es offensichtlich anderer besonderer transdisziplinärer Anstrengungen. Für eine solche transdisziplinär anzustrengende Zusammenarbeit der Disziplinen kann es daher nur um eine dialektische Vermittlung beider Zugänge - des Verständnisses der Erde als Prozessnatur und des Verständnisses der darin sich vollziehenden Naturprozesse (Kap. 6.2) - gehen, bei der ihre methodologischen Eigenständigkeiten nicht beendet, sondern so ergänzend zueinander ins Verhältnis gesetzt werden, dass sie sich gegenseitig helfen, ihre je theoretischen und methodologischen Blindstellen zu erkennen und zu beleuchten. ${ }^{79}$ Vorschläge für eine solche die Relata beibehaltende Relationalität, die dennoch in einer gemeinsamen Theorie- und Subjektbildung zu münden ermöglicht, lässt sich auf der Seite der (Sozial- und Natur-)Wissenschaften der Prozessnatur bei Marx/Engels' dialektischen Materialismus und auf der Seite der (Sozial- und Natur-)Wissenschaften der Naturprozesse bei Niels Bohr ausfindig machen.

Becker/Jahn plädieren hinsichtlich einer transdisziplinären Wissenschaft Sozialer Ökologie daher für die Bohrsche „Denkfigur der Komplementarität“ der frühen Quantenphysik, wonach „für mikrophysikalische Objekte je nach den Versuchsbedingungen zwei Beschreibungsformen möglich sind, die sich scheinbar logisch ausschließen und doch im empirischen Sinne beide als wahr gelten müssen“ (Becker/Jahn 2016: 437). So lassen sich Klimaphänomene jeweils als Naturprozesse und jeweils als Phänomene einer Prozessnatur beschreiben. Statt also beide Erkenntnisperspektiven und Erklärungen in eine gemeinsame Systemsprache und -logik zu einzupflegen, kommt es in einer komplementären bzw. transdisziplinären Zusammenarbeit darauf an, dass beide in ihren auch fundamentalen Unterschieden und Widersprüchen nicht ineinander aufgelöst werden, sondern dass sich durch solidarische Kritik des je anderen Standpunktes eine gemeinsame (Weiter)Bildung der eigenen Perspektive entzünden kann. Wie im gesellschaftlichen, so im wissenschaftlichen Alltag entsteht ein gemeinsames Neues nur im dialogischen

79 Entsprechend ist auch vom Begriff des Ökosystems abzuraten, da der Begriff, wenn er eine Transdisziplinarität umfassen soll, verwischt, dass das Verständnis der Ökologie der Erde kein bruchlos und glattes, sondern ein mit unglättbaren Kanten zusammengesetztes Verständnis ist, so dass stattdessen der Begriff des Ökogefüges (Altner 1987: 170) bzw. des Ökokomplexes zu bevorzugen ist. 
Konflikt und es kommt hier wie da darauf an, die Konflikte produktiv und integrativ, d.h. die Konfliktparteien in ihrer jeweiligen Andersheit komplementär und gegenseitig anerkennend auszutragen.

Da alle Erkenntnisse der jeweiligen Erkenntnisbereiche der Disziplinen nur über Erhebungsinstrumente und Apparaturen generiert sind, verbindet sie nur der wissenschaftlich-kritische Realismus, den sie sich gemeinsam dialogisch herstellen. Nicht einer, der schon irgendwie seiend vorhanden ist und nur abgelesen zu werden braucht, wobei es nur auf die richtige Lesart ankäme. Im Anschluss an Bohrs Komplementaritäts- und Korrespondenzprinzip lässt sich mit Karen Barad diesbezüglich von einem ,agentiellen Realismus“ sprechen:

„Die Behauptung, daß Apparate Phänomene hervorbringen, mag die Quelle eines gewissen Unbehagens seitens derjenigen sein, die an humanistische und antihumanistische Sichtweisen gewöhnt sind. Humanistische Sichtweisen fassen dieses Hervorbringen als eine direkte Folge menschlicher Handlungen, Entscheidungen, Absichten, Verpflichtungen, Ideen, Werte, Begriffe, Überzeugungen, Vorannahmen, Ziele und dergleichen auf. Im Gegensatz zu dieser Ansicht würde ich geltend machen, daß menschliche Subjekte mit bestimmten Grenzen und Eigenschaften nicht schon vor ihrem ,Einbezogensein“ in natürlich-kulturelle Praktiken existieren. [...] Dem agentiell-realistischen Ansatz zufolge sind menschliche Subjekte weder äußere Beobachter von Apparaten noch unabhängige Subjekte, die in die Funktionsweise eines Apparats eingreifen, noch die Produkte gesellschaftlicher Techniken, die sie hervorbringen.“(Barad 2012: 74f.)

Mit anderen Worten: Über die Realität jenseits apparate- und methodengestützter Wirklichkeitserkenntnis lässt sich keine verbindliche Aussage treffen. Alles was wir sagen können, sagen wir theoretisch vermittelt und methodisch dargestellt und ist damit immer schon involviert in eine Natur- und Gesellschaftsgeschichte. Dieses „Einbezogensein“ durchwest das erkennende Subjekt und damit alle je hervorgebrachten Erkenntnisapparaturen. Und weiter:

„Der agentiell-realistischen Sichtweise zufolge sind Diskurspraktiken keine von Menschen gestützten Aktivitäten, sondern spezifische materielle (Re-)Konfigurationen der Welt, durch die Grenzen, Eigenschaften und Bedeutungen je auf verschiedene Weise in Kraft gesetzt werden. [...] Auf diesen Punkt versuchte Niels Bohr durch sein Insistieren darauf zuzusteuern, daß unsere Erkenntnistheorie die Tatsache berücksichtigen muß, daß wir ein Teil jener Natur sind, die wir zu verstehen versuchen.“(ebd.: 98f.)

Dieser an die Wissenschaftstheorie des dialektischen Materialismus (zum Überblick: Zelený 1972; Schmidt 2018a) erinnernde „,agentielle Realismus“ (Barad 2012) samt dem darin eingelassenen „Korrespondenzprinzip“ der Quantenphysik wird von Becker/Jahn als „methodologisches Prinzip“ vorgeschlagen (Becker/Jahn 2016: 438), weil sich dadurch ,komplementäre[] Beschreibungen sozialökologischer Phänomene [...] aufeinander beziehen, in ein Verhältnis setzen und das jeweils für wahr gehaltene vom jeweils für falsch gehaltene unterscheiden [lassen]" (ebd.). Somit wird es möglich eine kritische Theorie der Vergesellschaftung menschlicher wie nichtmenschlicher Naturverhältnisse sowohl in einer sozialwissenschaftlichen als auch in einer naturwissenschaftlichen Begriffswelt zu erarbeiten, die beide Perspektiven in 
sich aufhebt, ohne ihre Unterschiede und Widersprüche zu erwischen. Dafür reicht es aber nicht, bloß die ,pauschale Zurechnung der gesamten Naturwissenschaften zum Positivismus und zur instrumentellen Vernunft [...], die von der kritischen Theorie aufgebaut worden war", aufzugeben, da sich daraus „keine kritische Theorie gesellschaftlicher Naturverhältnisse entwickeln [lässt]" (ebd.: 427). $\mathrm{Zu}$ einer Kritischen Theorie der Vergesellschaftung menschlicher wie nichtmenschlicher Naturverhältnisse, die beansprucht objektive Möglichkeiten sozial-ökologischer Transformationsprozesse sowie Strategien ihrer Realisierungen zu ergründen, lässt sich nur vordringen, wenn sich die jeweiligen Disziplinen der Prozessnatur sowie der Naturprozesse durch gegenseitige solidarische Kritik dabei unterstützen, sich ihrer durch Begriffe und Kategorien verschleierten „Verflechtung von gesellschaftlichen mit sprachlichen Bornierungen“ zu durchschauen und aufzulösen, „mit dem Ziel [...] alle [...] ideologischen Grenzen der Vergegenständlichung immer wieder theoretisch zu überschreiten" (Frese 1972: 202). Nur dadurch ließe sich verhindern, dass die gemeinsame theoretische Erörterung und praktische Erforschung objektiver Möglichkeiten sozial-ökologischer Transformationsprozesse sowie der Strategien ihrer Realisierungen die „Reflexion des sozialen Ganzen und seiner geschichtlichen Möglichkeiten“ ausklammert und stattdessen „,im Bann des Bestehenden [verharrt]“" (Schmidt 2018a: 69f.).

Sowohl aus dem „heuristische[n] Prinzip“ (Becker et al. 2006: 190f.) der Komplementarität, als auch aus dem der materialistischen Dialektik ergeben sich nun zwei Anschlussprobleme. Erstens bleibt eine Multidisziplinarität bestehen, weil die methodologische Eigenständigkeit der Disziplinen weder beendet noch durch ein gemeinsames Erkenntnisparadigma einander bündig gemacht werden, sondern stattdessen nur über den Dialog in ein dialektisches Bildungsverhältnis gesetzt werden, in dem sie sich einander kritisch zu ergänzen und dabei in eine gemeinsame Theoriebildung einzumünden suchen müssen. Zwischen den Disziplinen bleibt damit eine Lücke, ein im wörtlichen Sinne Inter-Disziplinäres, ein Zwischen den Disziplinen bzw. ein ZwischenRaum bestehen, der nur dialogisch gefüllt werden kann und eine Transdisziplinarität ,als eine Forschungs- und Arbeitsform der Wissenschaft“ (Mittelstraß 2005: 19) notwendig macht. Damit bleibt aber - zweitens - das Problem akut, ein Wissenschaftsethos seitens der wissenschaftlichen PraktikerInnen $\mathrm{zu}$ entwickeln, sich auf theoretischer wie praktischer Ebene zusammenfinden und verstehen $\mathrm{zu}$ wollen und sich das auch gegenseitig sprachlich zu ermöglichen - was bislang nicht wirklich zufriedenstellend gelöst werden konnte. ${ }^{80}$ Offen bleibt daher auch bei Becker/Jahn, wie dieser

80 Die Konsequenz daraus war und ist ja die seit den 1980er Jahren zu beobachtende ,systemtheoretische Reformulierung“ (Becker 2016f: 300) der Disziplinen, um über ein gemeinsam geteiltes systemtheoretisches Weltverständnis einander anzunähern und Transformationsmöglichkeiten zu erforschen - wodurch die bereits beschriebenen erkenntnistheoretischen 
Bildungsprozess theoretischer wie praktischer Transdisziplinarität entlang einer solidarischen Kritik ermöglicht, gar verwirklicht werden könnte, von wo aus erst residuen- und gemeinwesenorientierte, sprich emanzipatorische ökosoziale Transformationen angeschoben werden könnten, die letztlich in einer sozial-ökologischen Transformation resp. in einem emanzipatorischen Transformationsprojekt Sozialer Ökologie, im Anthropozän münden. Damit stellt sich die Frage nach der Möglichkeit sozial-ökologischer Subjektbildung.

\section{Mimetische Subjektbildung Sozialer Ökologie durch solidarische Kritik}

Ein Prozess theoretisch- wie praktisch-transdisziplinärer Theoriebildung und gesellschaftlicher Praxisentwicklung sozial-ökologischer Transformation kann nicht, zumindest wenn er zugleich eine emanzipatorische Subjektbildung ermöglichen soll, ohne eine anerkennend vollzogene solidarische (Ideologie-)Kritik je anderer lebensweltlicher und/oder disziplinärer Weltzugänge gedacht werden. Eine solche solidarische Kritik muss dabei dem mimetischen Weltverhältnis der Subjekte gerecht werden (Kap. 4.2, 5, 6.2). Mit Lefebvre lässt sich als Ort der subjektiven Mimesis die gesellschaftliche Alltagspraxis ausfindig machen, die entlang der „Urbanisierung des Kapitals“ (Harvey 2014: 126) eine „imperiale Lebensweise“ (Brand/Wissen 2017) hervorbringt (Kap. 3) und auf zerstörerische Weise die ganze Ökologie menschlicher wie nicht-menschlicher Erdnaturverhältnisse erfasst (Kap. 1). Die „,imperiale Lebensweise“ (ebd.), die bereits zuvor als von Lefebvre als staatlich organisierte „bürokratische Gesellschaft des gelenkten Konsums“ (Lefebvre 1972: 99ff.) herausgestellt wurde, reguliert sich postpolitisch (Kap. 12.2.3). Das heißt, dass staatlicherseits nur die Organisation des bürokratischen Sanktionsapparats für Abweichungen der "imperialen Lebensweise“ (Brand/Wissen 2017), die die Reproduktion der ihr zugrundeliegenden gesellschaftlichen Produktionsverhältnisse der „Urbanisierung des Kapitals“ (Harvey 2014: 126) gefährden, übernommen wird und die konkrete subjektive Ausgestaltung bzw. die „beherrschte“ (Horkheimer/Adorno 2006: 190) mimetische Anschmiegung an die Erfordernisse der ,imperialen Lebensweise" (Brand/Wissen 2017) offen gelassen und den zivilgesellschaftlichen Netzwerken anheimgestellt wird. Dadurch erst wird den Subjekten das Gefühl ermöglicht, ungezwungen vom Staat die eigenen Sinne frei entwickeln

Blindstellen der Systemtheorie systematisch auch auf andere Disziplinen und Forschungsprogramme übertragen wurde. 
zu können, während sie zugleich hegemonial zugerichtet werden, ohne in dieser Welt der vermeintlich freien Entscheidung für eine bestimmte Lebensweise ein subjektives Emanzipationsempfinden missen zu müssen. Dadurch erst kann in der in der ,imperialen Lebensweise“ (ebd.) inhärenten ausbeuterisch inwertsetzenden Beherrschung menschlicher wie nichtmenschlicher Naturverhältnisse eine freiheitlich-demokratische Lebensweise erblickt werden, die in weiten Teilen der Gesellschaft nicht weiter in Frage gestellt wird.

Soll also durch gesellschaftliche Transformationen die ,imperiale Lebensweise“ (ebd.) überwunden werden, muss sie die Residuen dieser hegemonialen Subjektbildung ausfindig machen und an sie anschließen. Mit Adorno gesprochen: Soll durch gesellschaftliche Transformationen die staatlich „organisierte Handhabung der Mimesis“ (Horkheimer/Adorno 2006: 189) überwunden werden, muss stattdessen eine „reflektorische Mimesis“ ermöglicht werden, die es vermag, den bürgerlich-historischen „Übergang“ in der gesellschaftlichen Arbeit des Sozialen ,von reflektorischer Mimesis zu beherrschter Reflexion“ (ebd.: 190) auf historischem Niveau zu beenden. Nämlich dadurch, dass die kontrollierte und verwaltbare Mimesis der technischinstrumentellen Beherrschung der eigenen inneren sowie der äußeren Natur, d.h. das technisch kontrollierte Anschmiegen ans Außen durch eine lebendige Gestaltung der Beziehung zwischen innerer und äußerer Natur, dass also die instrumentelle Naturbeherrschungsvernunft der Technik und der Maschinen durch eine reflexive Vernunft des reziproken Dialogs und der mutualistischen Sozialität ersetzt wird. Dadurch erst dominiert im alltäglichen Leben nicht länger die tote Arbeit technischer und quasi-maschinistischer Abläufe, orientiert an objektiv gesetzten Modellen, sondern die lebendige Arbeit dialogischer und sozialer Vollzüge, orientiert an subjektiv symbolisierten Residuen, bei der die Produktion als auch die Befreiung der Residuen zum Politikum, d.h. zum Gegenstand politischer Aushandlungen wird, durch die sich die Zukunft der Gesellschaft entlang dieser politischen Arbeit des Sozialen ausgestaltet. Ermöglicht und verwirklicht könnte diese an den Residuen orientierte Politik des Sozialen allerdings nur in und mit den reflexiven Institutionen der kommunalen Selbstverwaltung, die, wie hier nun vervollständigt werden kann, eine theoretisch- wie praktisch-transdisziplinäre transduktive Wissenschaft sozial-ökologischer Subjektbildung umfasst, wie sie in Lefebvres „Recht auf Stadt“" angelegt, aber nicht ausformuliert ist.

Wenn das mimetische Weltverhältnis der Subjekte für eine sozialökologische Transformation nicht länger szientistisch und (nur) instrumentell organisiert werden soll, müssen die subjektiven wie gesellschaftlichen Effekte der auch weiterhin notwendigen Naturbeherrschung zugunsten einer reflektierten Naturallianz im Sinne einer Politik Sozialer Ökologie politisiert und kollaborativ demokratisch reguliert werden. Um es an dieser Stelle einmal deutlich auszusprechen: Eine sozial-ökologische Naturallianz bedeutet 
zwar eine konsequent demokratisch regulierte und in ihren zerstörerischen Auswirkungen deutlich gezähmte Naturbeherrschung, ist aber dennoch nur als Naturbeherrschung denkbar, die weiterhin auch invasive Erdgestaltungsprozesse umfassen muss, wenn Urbanisierung auch weiterhin der Befreiung vom Naturzwang dienen soll. Der wohl fundamentale Unterschied zur kapitalogenen, wenn man so will, reinen instrumentellen Naturbeherrschung ist die Achtung der sympoietischen Gedeihlichkeit menschlicher und nichtmenschlicher Akteure sowie Aktanten des erdökologischen Gesamtkomplexes, die in einer sozial-ökologischen Naturbeherrschung im Sinne einer Naturallianz ins Zentrum der politischen Regulierung rückt.

Um im klimawandelbedingten gesellschaftlichen Transformationsprozess zu einer solchen (Naturallianz-)Politik Sozialer Ökologie vordringen zu können, müssen die jeweiligen subjektiven Residuen der AkteurInnen, die ihnen durch die „imperiale Lebensweise“ (Brand/Wissen 2017) entstehen, durch gegenseitige, solidarische, aber durchaus schonungslose Kritik zur Sprache gebracht werden. Nicht zuletzt durch pädagogische und praxisforscherische Unterstützung, um überhaupt erst subjektiv zur Sprache bringen zu können, was aus subjektiver Sicht wie und womit zu kritisieren wäre, um sich an diesem voraussetzungsvollen Prozess beteiligen zu können (Winkler 2006; Spivak 2008a; May 2017a; zum Überblick der Diskussion, wie und womit „Marginalisierte (wieder)sprechen [können]“: Dege et al. 2010)

May, der mit Wulf an Horkheimer/Adorno anzuschließen sucht, sieht darin die „Basis jeglicher professioneller [und disziplinärer, MS] Arbeitsbündnisse (Vgl. May 2015/2016; 2016a), denen es um die Verwirklichung menschlicher Subjektivität geht (Vgl. May 2014a, 2016)“ (May 2018b: 202), da dadurch erst disziplinäres wie alltägliches Wissen als im Kontext alltäglicher imperialer und logozentrischer Systemlogiken stehend erkennbar und kritisierbar wird und zugleich für AkteurInnen der jeweils anderen Disziplinen, aber auch für nicht-wissenschaftliche PraxisakteurInnen (Laien) veränderbar wird. Damit erst wird für die wissenschaftlichen wie nicht-wissenschaftlichen AkteurInnen im gesellschaftlichen Transformationsprozess ein Subjektbildungsprozess möglich, der mit Mührel (Mührel 2020) im Anschluss an den WBGU (WBGU 2016b) als "transformative Bildung“ bezeichnet werden kann und durch die hier anvisierte methodologische Konkretisierung zugleich über die dortige begriffliche Fassung weit hinausgeht: Sieht der WBGU (ebd.: 451ff.) transformative Bildung nur als letzten Teilaspekt eines Forschungsprogramms an - angefangen von einer grundlagenforscherischen Transformationsforschung (was ist überhaupt theoretisch möglich?), die übergeht in eine transformative Forschung (was ist lokal vor Ort theoretisch möglich?), an die eine Transformationsbildung anschließt (wie lässt es vor Ort sich vermitteln?) und in eine transformative Bildung übergeht (wie lassen sich lokale Praxisakteur-Innen in den Vermittlungsprozess einbeziehen?) -, dreht der hier verwendete Begriff transformativer Bildung diese 
szientistische Methodologie vom idealistischen Kopf auf die materialistischen Füße (angelehnt an Engels 1989: 48). D.h., er hebt - erstens - den Begriff ökosozialer Transformation zu einem Begriff sozial-ökologischer Transformation auf, lässt ihn - zweitens - mit der Einbeziehung der Residuen der PraxisakteurInnen beginnen, schreitet - drittens - mit ihnen gemeinsam zu den Fragen fort, was objektiv möglich ist und wie es strukturell realisiert werden kann und orientiert sich dabei - viertens - an Mührel, der eine solch aufgehobene transformative Bildung mit „Natorps Vision einer Sozialpädagogik" in Verbindung bringt:

„Dort skizzierte er die Vorarbeit zu einer Konzeption eines politischen Programms einer Demokratie als Lebensform mit den Paradigmen Soziale Erziehung, Soziale Wirtschaft und Soziale Politik, die er dann in seiner Schrift Sozialidealismus von 1920 umfassender ausarbeitete. Im Kern geht es dabei um eine genossenschaftlich organisierte Gemeinschaft, die eine gleichberechtigte und solidarische Mitbestimmung der jeweiligen Akteure in den Bereichen der Erziehung und Bildung, der Wirtschaft und der politischen Willensbildung vorsieht. Eine aktualisierte Sozialpädagogik vor dem Hintergrund der Konzeption Natorps könnte als eine pädagogische Handlungswissenschaft verstanden werden, die grundlegend in einer Korrespondenz mit handlungswissenschaftlichen Theorien anderer wissenschaftlicher Disziplinen das Handeln von Menschen samt Handlungsbefähigungen und Handlungskrisen in den jeweiligen Lebenszusammenhängen und deren Umsetzungschancen erörtert und erforscht.“ (Mührel 2020: 171f.)

Entsprechend fasst Mührel transformative Bildung auch deutlich weiter als der WBGU und sieht darin

„eine Theorie der Willenserziehung auf der Grundlage einer kommenden Weltgemeinschaft. Diese Theorie fragt nach dem Weg (der Willenserziehung), wie Menschen sich zu bilden vermögen, damit sie in die Lage einer reflexiven Haltung und einer kreativen Mitgestaltung der Transformationsprozesse gelangen können." (ebd.: 171)

Wie ein solche transformative Bildung im Sinne einer sozial-ökologischen Subjektbildung, zu einer ,reflexiven Haltung und einer kreativen Mitgestaltung der Transformationsprozesse gelangen“" (ebd.) kann, lässt Mührel hingegen offen. Im Folgenden soll daher abschließend eine mögliche Methode umrissen werden.

Zuvor soll aber noch einmal zusammenfassend konkretisiert werden, was „reflektorische Mimesis“ (Horkheimer/Adorno 2006: 189f.) im Kontext sozial-ökologischer Transformation heißt. Sie heißt, dass in der politischkollaborativen Organisation aller gesellschaftlichen AkteurInnen durch mimetische Anschlusssuche an ihre subjektiven Residuen, die ihnen in, mit und durch die ,imperiale Lebensweise“" (Brand/Wissen 2017) gebildet werden, die Erde als gemeinsamer Wohn- und Entwicklungsraum der Subjekte, als gemeinsames Wesenssubjekt symbolisch erfahrbar gemacht wird. Dadurch erst würde von den AkteurInnen in ihrer jeweiligen alltäglichen Praxis erfahren werden können, dass die Erde nicht nur ,auf das reagiert, was wir ihr antun" (Latour 2017: 126, Hervorherbung MS), sondern dass sie als sympoietischer Gesamtkomplex auf das reagiert, was wir Menschen uns antun. Und erst daraus könnte die Konsequenz geschlussfolgert werden, dass sie als 
unser menschliches politisches Gaia-(Kunst)Werk politisch erst erstritten werden muss, so dass wir Menschen uns an diesem Gaia-(Kunst)Werk subjektiv so bilden können, dass wir uns zwar als zentrale politische AkteurInnen, zugleich aber nur als menschliche Gattung von Erdbewohnern unter nicht-menschlichen Gattungen von Erdbewohnern erfahren. Darüber - so das Plädoyer der vorliegenden Arbeit - müssen wir Menschen in der Klimafrage ins Gespräch kommen!

Wie aber könnte dieser „Streit zwischen Erde und Welt" (Heidegger 2003: 72$)^{81}$ - und das ist ja das zentrale transformative Moment sozialökologischer Subjektbildung - im konkreten Alltag (städtischer) AkteurInnen subjektiv erfahrbar, politisch kritisierbar und ökosozial bearbeitbar gemacht werden? Deutlich werden müsste, wie die alltägliche Welt gesellschaftlich eingebetteter lebensweltlicher Praxen die Erde formt und ebenso die Widerständigkeit der Eigentätigkeit der Erde gegen ihre Verweltlichung resp. Vergesellschaftung bzw. Urbanisierung, so dass ich hieran eine sozial-ökologische Subjektbildung entwickeln kann, durch die in der urbanen Alltagspraxis der Eigentätigkeit nicht-menschlicher Akteure und Aktanten der Erde erfahren werden kann.

Wer bzw. was diesen Streit entfacht hat, ist mit Teil A beantwortbar geworden: die „Urbanisierung des Kapitals“ (Harvey 2014: 126) und die daraus resultierenden Sachzwänge der ,imperialen Lebensweise“ (Brand/Wissen 2017). Wie sich die Erde als Werk jenseits ihres zerstörerischen Reagierens auf das, was wir uns und ihr mit der westlichen Welt antun (Latour 2017: 126), hervorbringen ließe, ist mit Teil $\mathrm{B}$ und $\mathrm{C}$ beantwortbar geworden: nämlich dadurch, dass das allägliche urbane Leben zum subjektiven wie politischen (Kunst-)Werk der städtischen AkteurInnen gemacht wird bzw. (wieder) gemacht werden müste, um den Streit zwischen Welt und Erde, der sich im Klimawandel als des kapitalogen-instrumentalisierten Menschen Werk offenbart, austragen zu können. Im letzten Kapitel dieses Teil D wurde herausgestellt, dass dieser Prozess als mimetischer verstanden werden muss. Multiund transdisziplinäre transformative Subjektbildung muss daher einen Raum poietisch-reflektorischer Mimesis schaffen, mit dem sich die Subjekte nicht mehr nur als Stadt- oder WeltbürgerInnen, sondern auch als ErdbewohnerInnen erfahren können, und sie dieses Verhältnis von Weltbürgertum und Erdbewohnerschaft zugleich als einen Konflikt erfahren, der nur im kollaborativen Zusammenwirken von wissenschaftlichen, polit-ökonomischen und administrativen Aspekten in den Transformationen des Gesellschaftlichen, kurz: ökosozial(istisch) angegangen werden kann, wobei der Anspruch beste-

81 Die Formulierung „des Streites von Erde und Welt“ (Heidegger 2003: 72) ist zwar von Heidegger (zum Überblick Heideggers philosophischen Bezugs zur Erde: Kern 2013; Polt 2013; Harries 2013) entnommen, wird hier aber nicht weiter verfolgt, sondern dient nur als Steigbügelhalter eigener weiterer Theoretisierungen. 
hen muss, mit der bestehenden gesellschaftlichen Alltagspraxis strategisch über sie hinauszugehen und sie dadurch sukzessive hinter sich zu lassen.

Für eine solche poietisch-mimetische Gesellschaftstransformation mit reflektorisch-emanzipatorischem Anspruch schlägt der WBGU lediglich eine „[e]manzipatorische Kartografie“ vor, durch die auch marginalisierten und/oder „lokale[n] Graswurzelgruppen“ möglich werden soll, ,ihre Positionen in öffentlichen Diskussionen besser zu vertreten“ und ,politische Prozesse anzustoßen oder ihre Positionen mit anderen Akteursgruppen zu stärken“ (WBGU 2016b: 348f.). Über den WBGU hinausgehend schlagen Becker/Jahn bzw. das Institut für sozial-ökologische Forschung (ISOE) im Sinne von Horkheimers/Adornos „Dialektik der Aufklärung“ die „Kritik der Naturbeherrschung“ (Becker/Jahn 2016: 429) vor. Allerdings bleiben sie weitgehend unkonkret hinsichtlich der Frage, worin die Emanzipation konkret $\mathrm{zu}$ fassen wäre und wie sie methodisch ermöglicht werden könnte. Sie bleiben dabei an vier entscheidenden Punkten unscharf: Erstens wird die „Politisierung von Verteilungsfragen“ nur an ein „Mindestmaß an Demokratie und Governance“ geknüpft, ,um zu friedlichen Verhandlungsprozessen zu kommen“ (Lux et al. 2006: 432), weil der - zweitens - transdisziplinär angelegte Partizipationsbegriff zwar auf „Einbeziehung von Stakeholdern“ (Kluge et al. 2006: 355), aber letztlich nur auf deren Einbeziehung „durch qualitative Interviews" (ebd.: 358) aus ist und damit selbst gegenüber des inkonsequenten Kollaborationsansatzes des WBGU weit zurückfällt. Dadurch bleibt drittens - der mit dem Begriff der nachhaltigen Entwicklung verbundene Gerechtigkeitsbegriff als „Leitbild für alle Gesellschaften (internationale Gerechtigkeit), für heutige ebenso wie für zukünftige (inter- und intragenerationelle Gerechtigkeit) sowie für alle Menschen in Beziehung zu ihrer natürlichen Umwelt (ökologische Gerechtigkeit)“ (Keil/Hummel 2006: 241) eine bloß normative Papier-Forderung (,Gerechtigkeitspostulat“, Kluge/Hummel 2006: 260), die es durch einen fehlenden Ansatz der Förderung von Subjektbildung verpasst, in der Praxis verwirklicht werden zu können. Damit wiederum bleibt - viertens - auch der Emanzipationsbegriff selbst ein bloß indirekt erwähnter, der bis auf den Hinweis, Ökonomie von den konkreten Bedürfnissen der Subjekte ausgehend begreifen zu müssen und einen veränderten Arbeitsbegriff (Care) zu benötigen (Schultz et al. 2006), inhaltlich recht mager ist.

Entsprechend bleiben auch die vom WBGU und dem ISOE abgesteckten Transformationsfelder - Wasser (Kluge et al. 2006), Konsum (Schultz/Götz 2006), Ernährung (Hayn/Stieß 2006), Mobilität (Götz et al. 2006), Bauen und Wohnen (Stieß et al. 2006), Bevölkerungsentwicklung (Hummel/Lux 2006), Versorgungssysteme (Lux et al. 2006), Gender und Environment (Schultz et

82 In Teil B war diesbezüglich mit Lefebvre (Lefebvre 1987: 372f.) von strategischer Hypothese, in Teil C mit Wright (Wright 2017: Kap. 10 und 11) von symbiotischen Freiraumstrategien die Rede. 
al. 2006), sowie urbane Flächennutzung und Raumgestaltung (WBGU 2016b: 170ff.), Materialien und Stoffströme (ebd.: 186) sowie Urbane Gesundheit (ebd.: 199ff.) - wenig revolutionär und bleiben letztlich hinter den Ansätzen ökosozialer Transformationen, wie sie etwa von Elsen (Elsen 2018) im „Handbuch Sozialer Arbeit“ zusammengetragen werden und in der vorliegenden Studie weiter entwickelt werden, weit zurück. Statt auch ins Fördern und des Bildens alternativer gesellschaftlicher und politischer Strukturen und damit verbundener subjektiver wie kommunaler Bildungsprozesse vorzudringen, bleiben sie politisch auf der Ebene des Forderns stehen. Aber erst durch das Fördern subjektiver wie kommunaler Bildungsprozesse würde nicht nur Nachhaltigkeit von der Leitbildfloskel auf dem Papier in die urbane Praxis geholt und dort als soziale Nachhaltigkeit verwirklicht, sondern auch eine sozial-ökologische Subjektbildung angeregt. Worauf also stattdessen insistiert werden muss, ist ein methodisch gerahmter mimetischer Subjektbildungsprozess, der das konflikthafte Verhältnis von Gesellschaft und Natur bzw. Erde und Welt in den genannten Transformationsfeldern eher künstlerisch subjektiv denn technologisch objektiv zum Ausdruck bringen kann, sie aber zugleich wissenschaftlich erarbeitend und fundierend zu transformieren sucht.

Die Hürde und damit zugleich Aufgabenfeld transdisziplinärer sozialökologischer Subjektbildung ist, dass möglichst viele nicht-wissenschaftlichen AkteurInnen - im Folgenden sind damit alle Status- und Interessengruppen einer Stadtbewohnerschaft angesprochen, also auch AkteurInnen der offiziellen Politik, der Verwaltung und der Ökonomie - kollaborativ einbezogen werden und dadurch die notwendigen Kenntnisse erwerben können, die sie brauchen, um sich zu (transformations-)mündigen AkteurInnen entwickeln zu können, die ein gemeinsames Transformationssubjekt politisch erarbeiten und bearbeiten.

Wissenschaften, die dergestalt ,nicht vom Prozess des Lernens und der Praxis, der sie angehören" (Feyerabend 1984: 8) unterschieden werden können, weil sie durch die AkteurInnen, die sie beanspruchen, mitbestimmt werden und sich dadurch in der Praxis, der sie angehören, bilden können, lassen sich mit Feyerabend als Kunst bezeichnen. Er verweist damit zugleich darauf, dass ,[a]lle Fächer zuerst Künste waren (technai bei den Griechen)“ (ebd.). In dieser Hinsicht plädiert auch schon zuvor Lefebvre im Sinne der Ermöglichung und Verwirklichung poietisch-mimetischer Entwicklung emanzipatorisch-gesellschaftlicher Naturverhältnisse für das mimetische Wiederzusammenführen von „,poiesis, physis und techné“ (Lefebvre 1975c: 149). Wie könnte es nun aber gelingen, Wissenschaft als partizipatorische Kunst der Subjektbildung und die partizipatorische Kunst zugleich als subjektbildende Wissenschaft zu gestalten, so dass dadurch das konflikthafte Verhältnis von (kapitalogener) Welt und Erde als konflikthaftes gesellschaftliches Naturverhältnis intersubjektiv erfahrbar, politisch kritisierbar und im Hinblick (sozial- 
)räumlicher Gerechtigkeit ökosozial bearbeitbar werden kann? Kurz: Wie könnte eine sozial-ökologische Transformation gelingen?

\section{Fotografie als künstlerisch-wissenschaftliche Ermöglichung mimetischer sozial-ökologischer Subjekt- und Theoriebildung zur Erfahrbarmachung, Kritik und Bearbeitung des „Streites zwischen Erde und Welt"}

Dass bildgebende Wissenschaften - wie sie sich bis in die altertümlichen Anfänge der Geometrie zurückverfolgen lassen und sich bis hin zu aufwendigen Computersimulationen in die Gegenwart fortgesetzt haben - gesellschaftliche Verhältnisse aufgreifen, auf sie zurückwirken und dadurch die subjektive Praxis insbesondere der westlichen Gesellschaftsverhältnisse objekthaftrationalisierend (Stichwort Logozentrismus) fortentwickeln (Sohn-Rethel 1989, 1990; May/Schmidt 2021), ist sicher nicht unumstritten (zur Kritik der Darlegung Sohn-Rethels: Reichardt 2008), gleichwohl jedoch nicht von der Hand zu weisen. Doch nicht nur in quantifizierenden (Sozial- und Natur)Wissenschaften der Naturprozesse kommt dieses Potenzial zur Anwendung, sondern lässt sich auch in qualitativen (Sozial- und Natur-)Wissenschaften der Prozessnatur zur Anwendung bringen. Nämlich in Form der Fotografie, mit der ,die Soziologie als Wissenschaft ganz in die Nähe der künstlerischen Tätigkeit [gelangt]“" (Harper 2013: 402).

Die Fotografie offenbart zum einen immer gesellschaftliche bzw. urbanisierte innere wie äußere Naturverhältnisse, die in Mimik, Gestik und räumlichen Konstellationen der fotografierten Objekte und der zum Objekt gemachten Subjekte ${ }^{83}$ inmitten von urban(isiert)en räumlichen Verhältnissen sichtbar gemacht werden. Damit ,akkumuliert“ die Fotografie „eine schier unglaubliche Menge von Informationen", was sich allein darin zeigt, dass die Beschreibung eines „Foto[s] eines komplexen gesellschaftlichen Ereignisses oder einer vielschichtigen materiellen Gegebenheit [...] zu seiner Beschrei-

83 Magg betont, dass die Fotografie das Subjekt zwangsläufig zum Objekt machen muss, weil die „FotografInnen besehen, begrenzen und [...] ihre Objekte ins Bild [bringen]. Diesen Objekten wird von den Fotografierenden nur eine vorübergehende ,metaphorische“ Existenz verliehen. Die fotografierten Objekte sind dazu verurteilt, für immer einen Ausdruck zur Schau zu stellen. Nicht umsonst heißt die Linse der Kamera ,Objektiv ‘ - als Gegenteil zu ,subjektiv' suggeriert der Begriff eine sachliche, unvoreingenommene Sicht auf die Welt. Mit dem Objektiv werden jedoch rein subjektive, d.h. von persönlichen Gefühlen, Interessen und Vorurteilen bestimmte Bilder aufgenommen.“ (Magg 2006: 442) 
bung mehrere Textseiten [erfordert]“ (ebd.: 403). Die Fotografie „als visuelle Ausdrucksform für subjektive Gedanken und Gefühle“, d.h. der eigenen Lebenswelt (Schmolling 2006: 59), offenbart aber vor allem auch die „Laientheorie“ der/s jeweils fotografierenden Akteurs/in, das mit der Fotografie „die wahrgenommene, jedoch noch nicht analysierte Welt abzubilden" sucht (Harper 2013: 413). „Denn die Fotografie ist subjektiv und selektiv, sie steht weit mehr für menschliche Hoffnungen, Ängste, Erinnerungen, Träume, Vorlieben und Aktivitäten als für die Wirklichkeit" (Magg 2006: 436) und „dienen somit zur Konkretisierung von Erfahrungen“ (Harper 2013: 414). Mit Freires Prinzip Kodierung/Dekodierung ${ }^{84}$ (Freire 1975: 87f.) lässt sich diesbezüglich von einer Kodierung sprechen (siehe hierzu auch: May/Herzog 2017; May 2018a).

Damit Fotografien aber auch zur transdisziplinären Subjektbildung beitragen, müssen die fotografierenden AkteurInnen in den Forschungsprozess insofern eingebunden werden, als dass sie bestimmen zu welchem Sachverhalt gesellschaftlicher Naturverhältnisse bzw. der Urbanisierung der Erde sie welche Fotos machen ${ }^{85}$ - Kodierung - und dass sie anschließend auch in

84 In seiner „Pädagogik der Unterdrückten“ schreibt Freire: „Wo jedoch Menschen die Wirklichkeit als festgefügt, undurchdringlich und abgeschlossen begreifen, ist es unerlässlich, die Untersuchung auf dem Weg der Abstraktion voranzutreiben. Diese Methode bedeutet nicht, dass das Konkrete auf das Abstrakte reduziert wird (denn damit würde ja seine dialektische Natur geleugnet), sondern vielmehr, dass beide Elemente als Gegensätze aufrechterhalten werden und sie sich im Akt der Reflexion dialektisch aufeinander beziehen. Diese dialektische Denkbewegung lässt sich an der Analyse einer konkreten, existenziellen, ,kodierten' Situation vorzüglich zeigen. Ihre ,Dekodierung' verlangt, dass man sich vom Abstrakten auf das Konkrete zu bewegt. Man muss also vom Teil zum Ganzen kommen und dann zu den Teilen zurückkehren. Dies wiederum verlangt, dass das Subjekt sich im Objekt wiedererkennt (die kodierte, konkrete, existenzielle Situation) und das Objekt als die Situation erkennt, in der es sich selbst mit anderen Subjekten zusammenfindet. Wenn die Kodierung gelungen ist, dann führt diese Bewegung von Fluss und Rückfluss, vom Abstrakten zum Konkreten, die in der Analyse einer kodierten Situation entsteht, zur Überwindung der Abstrakten durch die kritische Auffassung des Konkreten, das damit bereits aufgehört hat, eine festgefügte, undurchdringliche Wirklichkeit zu sein.“ Und weiter: „Wo das Individuum mit einer existenziellen Situation in verschlüsselter Form konfrontiert wird (einer Skizze, einer Fotografie, die durch Abstraktion zur Konkretion der existenziellen Realität führt), tendiert es dazu, diese kodierte Situation ,aufzuspalten'. Diese Trennung entspricht im Prozess der Dekodierung jener Stufe, die wir ,die Beschreibung der Situation “ nennen, und erleichtert die Entdeckung der Interaktion unter den Teilen des aufgelösten Ganzen. Dieses Ganze (die kodierte Situation), ursprünglich nur diffus begriffen, beginnt Sinn anzunehmen, wo das Denken aus den verschiedenen Dimensionen zu ihm zurückfließt.“ (beide Zitate: Freire 1975: 87f.)

85 May weist darauf hin, dass aufgrund der ,soziokulturell höchst unterschiedlich verteilte[n] Kompetenz, fotografische Techniken als persönliches Ausdruckmittel zu nutzen [...] eine gewöhnliche Autofotografie nicht unbedingt Hinweise auf die ,personale Eigenart" [liefert]" (May 2018a). Zwar geht es in der hier favorisierten Foto-Methode weniger um Selbstfotografien (obschon sie eine Rolle spielen können), dennoch sind technische Fragen der Belichtung, der Perspektive, des Objektivs keine unwesentlichen Fragen und auch für die hier favorisierte Methode zur Darstellung gesellschaftlicher Naturverhältnisse wichtig, 
einen intersubjektiven (dialogischen) Auswertungsprozess - Dekodierung einbezogen werden. „Bei geschicktem Einsatz dieser Methode werden die Rollen im Forschungsprozess vertauscht. Die untersuchte Person wird zum Lehrer, die forschende Person lernt.“ (Harper 2013: 415). Etwa in dem versucht wird über die auf den Fotos dargestellten Zusammenhänge von Orten und ihren räumlichen (An)Ordnungen von Dingen und Personen bzw. AkteurInnen und Aktanten auf Befindlichkeiten, Gefühle und Assoziationen eigener alltäglicher Erfahrungen unverwirklichter subjektiver Möglichkeiten sowie ihren möglichen gesellschaftlichen Hintergründen und Ursachen zu sprechen zu kommen, gar erst zur Sprache bringen zu können. ${ }^{86}$ Daran entzündet sich die Frage, wie und womit Wissenschaften ihren Beitrag leisten könnten, an den jeweiligen gesellschaftlichen Begrenzungen gleichermaßen politisch, ökonomisch und administrativ etwas zu ändern. Denn an diesen Residuen müssen Transformationstheorien und -praktiken, wie nun schon mehrfach herausgestellt, anknüpfen können, um sozial nachhaltig, weil emanzipatorisch zu sein.

Um den Gesamtkomplex der sozial-ökologischen Dialektik der Erde (Exkurs in Kap. 6.2) fotografisch einzufangen und hinsichtlich notwendiger gesellschaftlicher Transformationen analysieren zu können, muss die fotografische Datenerhebung neben dem Beziehungsverhältnis zwischen menschlichen und nicht-menschlichen Akteuren sowie Aktanten auch dem Beziehungsverhältnis zwischen nicht-menschlichen Akteuren und Aktanten (bspw. Verhältnis von Tieren und Pflanzen im Kontext der Klimafrage) sowie zwischen Aktanten (bspw. Verhältnis von Gebirgen und Meeren im Kontext der Klimafrage bzw. klimatologischer Kippelemente untereinander) Rechnung tragen, um es seitens der forschenden AkteurInnen überhaupt erforschen und politisieren zu können. Damit kommt den Forschenden - wie Laux im Anschluss an Latour hervorhebt - die Rolle von „Diplomaten“ zu, die zwischen den bislang noch getrennten Bereichen menschlicher und nicht-menschlicher Akteure sowie Aktanten vermitteln und den politischen „Friedensschluss“ resp. eine Naturallianz zwischen ihnen suchen, um „mit Hilfe globaler Diplomatie und kollektiver Aktivitäten das Schlimmste abzuwenden" (Laux 2014: 276). „Anders formuliert: Die Diplomatie [resp. Naturallianz, MS] gilt als letzte Hoffnung im Kampf gegen die ökologische Gefährdung der Menschheit.“ (ebd.) Damit ist noch einmal die Relevanz von Fotografien bzw. Bildern, die die Urbanisierung nicht-menschlicher Akteure und Aktan-

so dass eine Unterstützung durch kompetente Fachkräfte hilfreich, gar notwendig werden kann. Ohne dass diese allerdings letztlich die Fotografie dominieren.

86 Insbesondere an dieser Stelle können durchaus weitere Kodierungen (Fotos, Skizzen, Theaterinszenierungen, etc.) notwendig werden, mit denen die Subjekte, gerade wenn sie mit ihren Erfahrungen bislang nicht in Austausch gekommen sind und entsprechend noch keine Sprache hierfür haben entwickeln können, ihr Gemeintes auszudrücken, um es dann anschließend in der Gruppe dialogisch zu dekodieren und allmählich eine Sprache zu entwickeln (May 2017b: 166). 
ten thematisieren, betont, um an dem damit zum Ausdruck gebrachten „Streit zwischen Erde und Welt" (Heidegger) eine transformative Subjektbildung entzünden zu können. Solche Fotos/Bilder reichen

„von Detailaufnahmen, die zumeist Einzelphänomene auf der Mikroebene visualisieren (z.B. Personen, Alltagssituationen, Bodenprofile uvm.), über mesoskalige Abbildungen von Stadtstrukturen oder Geländeausschnitten bis hin zu großmaßstäbigen Darstellungen ganzer Erdteile, wie sie moderne Luft- und Satellitenbilder liefern“ (Falk 2006: 215).

Auch Fotoserien im Zeitraffermodus über größere Zeiträume hinweg sind denkbar, um Folgen und Effekte der Urbanisierung der Erde zu thematisieren. Es ist klar, dass insbesondere meso- und makroskalige Abbildungen nicht von Laien gemacht werden können, sondern sich anderweitig besorgt werden müssen, wobei aber auch die Recherche als Kodierung zu betrachten ist. Solche meso- und makroskaligen Bilder sind keine zu unterschätzenden Instrumente zur Verdeutlichung der großflächigen Schäden, die durch Waldrodungen, Kohleabbau und vor allem auch den Metallabbau (seltene Erden) entstehen und für die Digitalisierung und Elektromobilität westlicher Gesellschaften in Kauf genommen werden. Hinsichtlich einer zu erstrebenden globalen (sozial-)räumlichen Gerechtigkeit (Kap. 15.5) müssten diese Bilder durch makro-, meso- und mikroskalige Aufnahmen der betroffenen Bevölkerungsgruppen, sowohl die der Abbaugebiete als auch die NutzerInnen der im Namen ihres Wohlstandes digitalisierten und elektrifizierten Gesellschaften, etwa in Kontexten ihrer Nutzungen und/oder unreflektierten Vernutzungen, ergänzt werden. (Es handelt sich hierbei aber nur um Vorschläge und eigene Überlegungen, die die Eigenaktivität der fotografierenden Subjekte keinesfalls ersetzen möchte.)

Mit Betz/Kirchner (2016) lassen sich hinsichtlich der Dekodierung der Bilder drei Schritte einer möglichen ,sequenzanalytischen Bildhermeneutik“ vorschlagen, die im Weiteren kommentiert und weiterentwickelt werden:

1. Irritation des alltäglichen Blicks auf das Bild durch Segmentierung des Bildes und nur schrittweises Aufdecken der Bildsegmente ,in nichtalltäglicher Reihenfolge“ (ebd.: 266f.). Die Segmentierung des Bildes sollte vom „symbolisch unspezifischen zum immer Konkreteren“, also „nicht schlichtweg anhand der Wahrnehmbarkeit" vorgenommen werden, „sondern anhand von (vermuteten) symbolischen Verdichtungen“ (ebd.: 267f.), so dass das, was die Interpretation entlang der (vermuteten) Subjektivität des/der Interpretierenden dominieren würde, zunächst verdeckt wird.

2. Entwickeln möglichst vieler Interpretationen der Bildsegmente und des gesamten Bildes sowie die Suche nach Bestätigungen und Widerlegungen der Interpretationen. Zum einen durch das Abgleichen der jeweiligen Interpretationen der Bilder und Bildsegmente im Kontext von anderen Bildsegmenten des Bildes, oder auch Bildsegmenten anderer Bilder, ins- 
besondere bei „symbolisch verdichteten Bildelementen“ (ebd.: 269). Etwa durch mimetisches Nachahmen dargestellter Bildinhalte (,Mimik, Positionen und Szenerien"), einerseits zum Nachvollziehen der dargestellten Bildinhalte, andererseits zum erarbeiten eigener Perspektiven bzw. Interpretationen der Bildsegmente bzw. des Bildes (ebd.: 270).

3. Verdichten zu „(vorläufigen) Seharten des Gesamtbildes“ im Kontext des Bildes: einmal hinsichtlich des ,konkrete[n] Verwendungskontext[es], das heißt, wo im Feld das Bild vorgefunden [insbesondere bei meso- und makroskaligen Bildern, MS]“" bzw. gemacht wurde (ebd.), und einmal hinsichtlich des ,jeweilige[n] produktions- und Gebrauchskontext[es] [...], wie die Bildproduzenten ihre Handlungssituation gedeutet haben (,Weil-Motive', Soeffner 2004) und was sie mit ihrem Handeln - also der Gestaltung und Auswahl von Bildern - bezwecken wollten (,Um-zu-Motive“, Soeffner 2004)““(ebd.: 271).

Ob und wie diese Schritte tatsächlich zu realisieren sind, muss allerdings mit den AkteurInnen vor Ort immer wieder neu entschieden werden. An dieser Stelle soll auch ganz entschieden dem Selbstanspruch der der Sequenzanalyse zugrundeliegenden objektiven Hermeneutik widersprochen werden, wonach sich die „Gültigkeit der Analyse [...] vor allem aus der richtigen Anwendung der hermeneutischen Kunstlehre ab[leitet]“, weil nur das „'richtige[] Entdeckungsverfahren [...] die Sache selbst zum Sprechen' (Oevermann 1984, S. 11)“ zu bringen und „'Wahrheit““ verheißt (Reichertz 2013: 517f.). Statt objektive Wahrheit zu entdecken bzw. rekonstruieren, geht es im vorliegenden Kontext um die Rekonstruktion gesellschaftlicher Konstruktion subjektiver Wirklichkeit imperialer Lebensweisen durch gesellschaftliche Urbanisierungsverhältnisse innerer und äußerer Natur und der darin enthaltenen herrschaftlichen Konstruktion von Residuen. Die Rekonstruktion gesellschaftlicher Konstruktion subjektiver Wirklichkeit lässt sich bereits damit initiieren, dass die Irritierung der alltäglichen Bildsegmentierung (Nr. 1) nicht von externen ModeratorInnen übernommen wird, sondern von den GruppenakteurInnen selbst. Da sie bereits hierfür Wege finden müssen, sich gegenseitig kennen und einschätzen zu lernen, um miteinander herauszufinden, welche Bildinterpretation bei wem und warum dominieren würde. Interessant ist dabei vor allem die Einschätzung von Person A über Person B, weil sich gerade darin von A subjektiv verinnerte Wirklichkeitskonstruktionen offenbaren. Aber gerade für diesen gegenseitigen Kennenlernprozess kann eine (externe) pädagogisch-fachliche Moderation durchaus hilfreich sein.

Insbesondere kann eine fachliche Moderation sich die in Kap. 12.2.2 herausgestellte habiter-Perspektive Lefebvres zu nütze machen, da die habiterPerspektive die Residuenproduktion der vorherrschenden kapitalogenen Urbanisierung innerer und äußerer Naturverhältnisse in den Blick nimmt und 
mit der Suche nach subjektiv-emanzipatorischen Strategien politischer Transformationen der urbanen Praxis sowie der Praxis der Urbanisierung verknüpft. Mit May lässt sich hierfür das in Nr. 2 vorgeschlagene mimetische Nachahmen dargestellter Bildinhalte um Boals „Theater der Unterdrückten“ ergänzen. Etwa indem Szenen nachgestellt bzw. nachgespielt werden, die entlang der kapitalogenen Urbanisierung als misslungenes gesellschaftliches Naturverhältnis interpretiert werden (Kodierung) und dann mit der Gruppe sequenziell und iterativ zu erschließen versucht werden (Dekodierung), um so zu ,impliziten Themen und Dimensionen“ vorzudringen, die neue Handlungsmöglichkeiten, aber auch gesellschaftliche Begrenzungen ihrer Realisierung erfahrbar werden lassen (May 2017b: 166). „Hier öffnet sich dann auch der Raum für Fragen von Sein und Schein bzw. wie ausgehend von solchen gesellschaftlichen Repräsentationen sich die Dekodierenden eine Öffentlichkeit für ihre Repräsentation in der Gesellschaft (Lefebvre 1977 Bd. II, S. 69) erschließen können." (May 2018a) Erst mit der Frage nach einer solchen die Subjekte repräsentierenden Öffentlichkeit öffnet sich die Möglichkeit einer öffentlichen subjektorientierten Diskussion gesellschaftlicher Transformationsprozesse.

Entsprechend muss auch die an Alfred Schütz orientierte Unterscheidung von „Weil-Motiven“ und „Um-zu-Motiven“ in Nr. 3 weiter gefasst werden, als die sequenzanalytische Bildhermeneutik dies vorsieht. Mit May lassen sie sich weiter ausführen als einerseits das Verfolgen von Ziel-Mittel-Relationen (,um-zu-Motive“) und andererseits als Gründe für das Scheitern bzw. Verfehlen der angestrebten Ziele mit den verwendeten Mitteln (May 2005: 121f.), mithin als Gründe der gesellschaftlichen Residualisierung subjektiver Möglichkeiten (,weil-Motive“). Sozial-ökologische Subjekltbildung in der Bildhermeneutik hat entsprechend darauf hinzuarbeiten ,,zur Erkenntnis der grundlegenden Wechselwirkung zwischen Zielen und Mitteln" (ebd.: 122) sowie zur Veränderung der Strategie der Verwirklichung der subjektiven Möglichkeiten $\mathrm{zu}$ verhelfen, wofür eine Bildsequenzanalyse durchaus hilfreich zu sein verspricht. Dies gelingt aber nur, so mit May weiter, wenn sie sichtbar machen kann, wie ,aktuelle Konstellationen sozialer Handlungen durch einen in der Vergangenheit liegenden eigentlich problemgenerierenden Kontext überlagert werden" (ebd.: 158) und sich als hinderlich erweisen, sich politisch produktiv mit der Klimathematik bzw. der imperialen Vergesellschaftung innerer wie äußerer Naturverhältnisse auseinanderzusetzen. Gerade deswegen ist es ja umso wichtiger, in diese transdisziplinären Settings subjektiver Bildungsprozesse auch reaktionäre $\mathrm{NIMBY}^{87}$-Initiativen (bspw. Windkraftgegner) einzubeziehen, um gemeinsam die Frage zu erörtern, worüber miteinander ins Gespräch zu kommen ist, statt sie von vornherein als vermeintliche KlimawandelskeptikerInnen bzw. KlimawandelnegationistIn-

87 NIMBY steht für Not In My Backyard. 
nen oder bloß rechte Spinner zu diffamieren und auszuschließen. An dieser Stelle sei ein kurzer Exkurs gestattet.

\section{Exkurs zur Einbeziehung von KlimawandelskeptikerInnen und - negationistInnen}

Soweit die Belange, Welterklärungen und Argumentationen von KlimaskeptikerInnen und -negationistInnen auf der Ausdrucksebene auch hergeholt erscheinen mögen, so müssen sie doch als Ausdruck einer gesellschaftlichen Entfremdung verstanden werden, die sie entlang der gesellschaftlichen (Re)Produktionsverhältnisse für das gelingende Entwickeln und die Sicherung ihres gesellschaftlich induzierten Lebensentwurfs auf sich allein stellt. Der hierfür notwendige Kampf um knappe bzw. herrschaftlich verknappte gesellschaftliche Güter und Ressourcen, der nur durch unerbittliche Leistungsmaximierung und Selbstoptimierung $\mathrm{zu}$ gewinnen ist, lässt die Menschen als KonkurrentInnen in Erscheinung treten, die sich entsolidarisieren und einander gegenüber fremd werden (Gronemeyer 1988: 40ff.). Vor allem unter kapitalistischen Effizienzkriterien brauchen sie in ihrer alltäglichen Wahrnehmung zur gelingenden Reproduktion eben gerade keine Diskussion um urbane Subsistenz, Entschleunigung und radikale gesellschaftliche Transformation, sondern das Weiter-so der Produktion einer ,verbrauchsfertigen Welt", in der jede „materielle und immaterielle Ausstattung des Lebens“ fertig parat liegen muss und reibungslos funktionieren muss (Gronemeyer 2014: 127). Das dergestalt durch gesellschaftliche Produktionsverhältnisse hervorgebrachte und seinen inneren wie äußeren Naturverhältnissen fremd gewordene Subjekt, das sich selbst und seine äußeren Naturverhältnisse konsumfertig produzieren und konsumieren muss, wird so zum „Doppelagent[en] der Beschleunigung: Optimierungsaktivist und konsumistischer Nutznießer in Personalunion" (ebd.). D.h. zum vermeintlichen Blödian einer selbstsüchtig-imperialen Plastikwelt, der eine zerstörerische Lebensweise verteidigen muss, die ihm letztlich die eigene Lebensgrundlage auf und mit dieser Erde entzieht. Um den eigenen verinnerten Lebensentwurf zu verteidigen, muss der Klimawandel also geradezu verharmlost und, etwa in Form von NIMBY-Initiativen, zur organisierten Reaktion auf die erstarkenden Proteste gegen das Weiter-so der ,imperialen Lebensweise“ (Brand/Wissen 2017), etwa in Form von Fridays For Future, ausgeholt werden. Statt solcherlei Initiativen zu belächeln, muss darin, wie bei Fridays For Future auch, „eine Form von Beteiligung“ erblickt werden, „die aus dem gemeinsamen Verfolgen eines Zieles (bei durchaus divergierenden Interessen) entsteht" und „voller Energie ist, die jedoch vielfach intensiv dazu herausgefordert werden muss, auch innovativ zu werden und so etwas wie ein emanzipatorisches Potenzial zu entwickeln, das über reine Besitzstandswahrung hinausreicht" (Menzl 2014: 79). Und dies gelingt nicht durch diffamierende Protestaktio- 
nen und naive Abwertungstechniken - da sie die Produktionsverhältnisse der „imperialen Lebensweise“ (Brand/Wissen 2017) unangetastet lassen ${ }^{88}$-, sondern einzig durch eine Subjektbildung, die die in diesen Produktionsverhältnissen zurückgelassenen Vermögen und Fähigkeiten subjektiver Interaktionsformen (Residuen) bewusst werden lässt. Und genau darin ist der Grund zu erblicken, warum auch reaktionäre NIMBY-Initiativen in die transdisziplinären Settings subjektiver Bildungsprozesse einzubeziehen sind. Einerseits um erfahren zu können, dass der »Gegner « der dringend notwendigen sozialökologischen Transformationen nicht in irgendwelchen Anderen zu erblicken ist, sondern in den kapitalogenen Produktionsverhältnissen der ,imperialen Lebensweise" (ebd.), die statusgruppen- und milieuabhängig, d.h. lebensweltabhängig bloß unterschiedlich zum Ausdruck kommt und entsprechend je unterschiedliche Residuen sowie je unterschiedlichen Umgang mit ihnen erzeugt, letztlich aber die gesellschaftliche Residuenproduktion auf der selben gesellschaftlichen Alltäglichkeit plutokratischer Verhältnisse beruht. Anderseits um milieuspezifisch differenziert, aber gemeinsam nach objektiv möglichen Wegen zu suchen, die jeweiligen Residuen über eine dissensorientierte, aber gemeinsam ausgehandelte Stadtentwicklung politisch zu verwirklichen.

- Exkurs Ende

Mit anderen Worten: Erst wenn im Rahmen der o.g. Fotoanalyse die Residuen aller gesellschaftlichen Statusgruppen zur Sprache gebracht werden, lässt sich von dort aus eine subjektorientierte öffentliche Diskussion über die Zirkelzwänge der „imperialen Lebensweise“ (ebd.) führen, um sie gemeinsam durch gesellschaftliche Transformationen des Städtischen resp. Sozialraumentwicklung/-organisation zu überwinden. Die Bedeutung der hierfür benötigten politischen Mittel kann nicht deutlich genug herausgestellt werden. Welche es genau bedarf, kann nicht vorab verordnet werden, sondern muss in einem solchen transdisziplinären Setting subjektorientiert und kollaborativ erarbeitet werden. Gerade darin müssen sich künftige Prozesse gesellschaftlicher Transformationen als partizipatorisch, demokratisch und zugleich emanzipatorisch auszeichnen, indem sie es vermögen, im Rahmen kollaborativer Stadtentwicklung die gesellschaftlichen Gruppen und AkteurInnen nicht noch weiter zu spalten, sondern zu einem politischen Gemeinwesen zusammenzu-

88 Auch wenn die Sorgen von bspw. Windkraftgegnern um qualitative wie finanzielle Einbußen ihrer Grundstückswerte den Bestrebungen einer notwendigen flächendeckende Energiewende von fossilen auf erneuerbaren Brennstoffen entgegenstehen, so sind doch zumindest die Sorgen um finanzielle Einbußen der Grundstückswerte entlang der neoliberal depolitisierten Immobilienmarktlogik nicht aus der Luft gegriffen. Ebenso sind die Sorgen um ihre qualitativen (Lebens-)Werte, die sie mit ihren Immobilien verbinden, nicht losgelöst von gesellschaftlichen Strukturen zu betrachten, die diese Werte entlang einer gesellschaftlich abgenötigten ,imperialen Lebensweise“ (Brand/Wissen 2017) ja erst hervorbringen. 
bringen und ihnen ein gemeinsames Transformationssubjekt zu erarbeiten zu ermöglichen, an dem sich ein subjektives Gemeinwesen herausbilden kann. Und in dieser Hinsicht lässt sich mit Latour (Latour 2018: 67) dafür plädieren, die vorherrschenden Rechts-Links-Spaltungen der Gesellschaft zu überwinden und gegenseitig ideologisierende Berührungsängste zu durchbrechen. Die Frage ist dabei nicht, ob und wie mit KlimawandelskeptikerInnen und negationistInnen zu sprechen ist, sondern worüber - und das ist eine explizite Praxisforschungsfrage.

Die Kernfrage der hier entwickelten Forschungsstrategie sozial-ökologischer Subjektbildung lautet zusammengefasst: Vor dem Hintergrund welcher subjektiven Residuen der „imperialen Lebensweise“ (Brand/Wissen 2017) lässt sich die Klimafrage vom wem wie diskutieren und transformativ angehen, so dass in ihrer Beantwortung zugleich eine subjektive Emanzipation verwirklicht werden kann? Kurz: Worüber muss in der Klimafrage ins Gespräch gekommen werden? Mit May ist entsprechend darauf hinzuweisen,

„dass Menschen der Existenz einer Problemsituation [etwa den Zirkelzwängen der imperialen Lebensweise, MS] zwar gewahr werden können, wenn einzelne problemkonstituierende Faktoren im Verfolgen von 'um-zu-' oder 'weil-Motiven' für sie bedeutsam werden. Eine praktische Relevanz als Problem wird diese Situation für sie jedoch erst dann gewinnen können, wenn sie eine Veränderbarkeit des Stoffes der Problemsituation als ,sachhaft-objektgemäß möglich (vgl. Bloch 1979: 264ff.) erkennen und damit auch eine prinzipielle Veränderbarkeit zumindest einzelner Problemfaktoren antizipieren.“ (May 2005: 160)

Subjektive Emanzipation wird also am ehesten dadurch verwirklicht, wenn die kodierend/dekodierende Bildhermeneutik in einen Kontext kommunalpädagogischen Ortshandelns eingebettet ist, das den Subjekten gemeinsame urbane Erfahrungsräume öffnet, die je eigene Entwicklung gesellschaftlich durch das „sachhaft-objektgemäß“ (Bloch 2013a: 264ff.) nur Mögliche der „,imperialen Lebensweise“ (Brand/Wissen 2017) als begrenzt zu erleben „Grenzsituationen“ (Freire 1975: 85) - und den Subjekten aneinander und miteinander zugleich dialogisch ermöglicht, jenseits ihrer „Reallage“ ihre je subjektive „Ideallage“ (Winkler 1988: 274f.) zu entdecken und sie dabei unterstützt, politische Strategien zu erarbeiten, das als Ideallage entdeckte „objektiv-real Mögliche“ (Bloch 2013a: 271ff.) des Subjekts durch „symbolvermitteltes Handeln“ (May 2005: 163) - „Grenzakte“" (Freire 1975: 85) gemeinsam zu verwirklichen. Kurz: wenn ihnen geholfen wird, die Klimafrage als gemeinsames Problem bearbeiten zu können - und zwar jede/r vor dem Hintergrund seiner/ihrer subjektiven Residuen und den Versuchen, sie mit ihren individuellen Bearbeitungen der Klimafrage zu befreien.

„Diese lebendige Arbeit erlaubt nun nicht nur das Verhältnis zwischen den vielfältigen Selbstregulierungen im Binnenverhältnis der Person so zu organisieren, dass die einzelnen im Menschen praktisch arbeitenden Eigenschaften ein inneres Gemeinwesen bilden. Indem damit zugleich auch eine selbstregulierende Vermittlung zur Gesellschaft außerhalb der Person angeregt wird, verwirklicht sie dergestalt das in der Situation 'objektiv real Mögliche“." (May 2005: 162) 
Vor diesem Hintergrund ist es wichtig, mit einer ,sequenzanalytischen Bildhermeneutik" über diese hinaus zu gehen und nicht nur, wie es der Sequenzanalyse zu eigen ist, der „Rekonstruktion der latenten Sinnstrukturen“ (Oevermann 1996, S. 4 zit. in Reichertz 2013: 514) nachzuhängen, sondern vor allem die Residuen der Subjekte aufzuspüren, sie nach und nach versuchen zur Sprache zu bringen und ihre subjektive wie politische „Revolte“ zu organisieren $^{89}$ (Lefebvre 1975c: 334) - was eine fachliche Moderation der gemeinsamen Auswertungsrunden und Gruppendiskussionen notwendig werden lassen kann (May 2018a). Dieser Moderation sollte nun aber gerade nicht die wichtige Funktion überlassen werden, a priori festzulegen, mit welchen Bildsequentierungen sich welche Subjektivität irritieren lässt (Nr. 1). Stattdessen ist dies in den sozial-ökologischen Subjektbildungsprozess einzubeziehen und die Subjekte untereinander selbst aushandeln zu lassen. Nur so lässt sich auch die Gefahr der Verkennung und der Instrumentalisierung der emanzipatorischen ,um-zu-Motive“ der Subjekte minimieren (May 2005: 181), die aber nicht nur durch die Moderation bzw. Fachkräfte Sozialer Arbeit entstehen können. Sondern insbesondere auch dadurch, wenn die kommunalpädadogisch und bildhermeneutisch erarbeiteten Strategien emanzipatorischer Sozialraumentwicklung-/organisation sozial-ökologischer Subjektbildung nicht kollaborativ, sondern die AkteurInnen und ihre Strategien nur auf der Ebene der offiziellen Politik repräsentierend realisiert werden können. Das verweist nun einmal mehr auf die Notwendigkeit kollaborativer Stadtentwicklung (Teil B und C).

Damit foto-/bild-inspirierte transdisziplinäre Subjektbildungsprozesse aber auch zur transdisziplinären Theoriebildung führen, müssen auch wissenschaftliche AkteurInnen verschiedener Disziplinen nicht nur in den intersubjektiven Auswertungsprozess der Fotos einbezogen werden, sondern auch in den Prozess des Fotografierens. Etwa, dass ihnen zur Aufgabe gestellt wird, ihre jeweils disziplinären Beschreibungen gesellschaftlicher Naturverhältnisse im gesellschaftlichen Alltag auf Fotos darzustellen, die dann nach obigem Methodenvorschlag mit anderen wissenschaftlichen und nicht-wissenschaftlichen AkteurInnen gemeinsam intersubjektiv ausgewertet werden. Einerseits um an den Fotos ihre verschiedenen disziplinären Expertisen zu entfalten, andererseits aber auch um durch ihre „Laientheorien“ (Harper 2013: 413) und „möglicherweise ,bornierten“ Deutungen“ (Maiwald 2006: 117) zu einer gemeinsamen, theoretisch gehaltvolleren Interpretation zu gelangen, die dann für die je disziplinären Theoriebildungen, aber auch der daraus sich entwickelnden gemeinsamen Theoriebildung sozial-ökologischer Transformationen, versucht werden kann fruchtbar zu machen.

89 Lefebvre formuliert als „Methode der Residuen“, geradezu nahtlos an Freires (Freire 1975: 87f.) Ansatz von Kodierung/Dekodierung anschließend: „Man spürt die Residuen auf, man setzt auf sie, man enthüllt ihre kostbare Essenz, man faßt sie zusammen, man organisiert ihre Revolte und totalisiert sie.“(Lefebvre 1975c: 334; vgl. Kap. 12ff.) 
Sozial-ökologische Subjektbildung ist allerdings keine einmalige Angelegenheit, sondern ein iterativer und lebenslanger Prozess. Entsprechend muss darunter das Verwirklichen einer solidarisch-experimentierenden Lebensweise verstanden werden, durch die nach und nach und immer wieder subjektive Erfahrungen gemacht werden können bzw. für die immer wieder neue urbane Erfahrungsräume eröffnet werden müssen, sich in den Städten als totale Menschen (Marx 1968b: 539f.) und dabei als menschliche Erdbewohner unter nicht-menschlichen Erdbewohnern begreifen zu können - und zwar immer wieder neu, immer wieder anders, immer wieder nur vorübergehend. Hierin findet sich die von Lefebvre (Lefebvre 1939, 1971a, 1975c; Kap. 12.1) marxistisch aufgehobene nietzscheanische Figur des „Übermenschen" (Nietzsche 1954a), des immer wieder vorübergehenden und sich stets neu erfinden und ausgestalten könnenden totalen Menschen wieder, dem notwendigerweise immer auch ein „Sein zum Tode“ (Heidegger 1967) zu eigen ist, weil das Zukunftsverhältnis eines immer nur vorrübergehenden Menschseins ein stetes und immer wieder neues „Endlichkeitsverhältnis“ (Marquard 2013: 225ff.) ist, dem ein unendliches Reich endlichen Möglichseins offen steht (Lefebvre 1975c: 358). Zumindest, wenn die Menschen ihr Menschsein auf und mit dieser Erde nicht durch ihre gesellschaftlichen Lebensweisen und den darin enthaltenden Reproduktionszwängen auf sich selbst und ihre eigene Lebensspanne zurückgeworfen sehen, sondern stattdessen sich selbst und ihre terrestrische Mitwelt als transgenerative Sympoiesis erfahren können, die zu ihrer Verwirklichung ökosoziale Transformationen des Gesellschaftlichen verlangt.

Zusammengefasst: Der Zugewinn durch die Fotografie in der sozial-ökologischen Subjektbildung sowohl wissenschaftlicher als auch nicht-wissenschaftlicher AkteurInnen besteht zum einen darin, dass alltägliche imperiale Vergesellschaftungen von inneren und äußeren Naturverhältnissen bzw. der „Streit zwischen Welt und Erde“ (Heidegger) - sei er innerhalb der Städte im eigenen Wohnumfeld oder außerhalb der Städte in den Landschaften vollzogen -, die der alltäglichen Wahrnehmung sonst entgehen, sichtbar gemacht und diskutiert werden können oder gar in der Diskussion überhaupt erst sichtbar werden. Zum anderen vor allem aber auch darin, dass die fotografierenden Subjekte zum Ausdruck bringen können, was ihnen sprachlich noch nicht zugänglich ist, sie diese Sprache aber in der gemeinsamen Auswertung mit und an anderen erlernen können. Aus diesen Interpretationen erst lassen sich subjektorientierte „Handlungstheorien, -konzepte und -methoden für die unterschiedlichen pädagogischen Handlungsfelder“ ableiten, „beispielsweise von der Frühpädagogik über die Schulpädagogik wie auch den Bereichen außerschulischer Bildung bis hin zur Hochschulbildung, Berufspädagogik und Erwachsenenpädagogik“" (Mührel 2020: 172). Dadurch erst können sozial-ökologische Transformationstheorien und -strategien erarbeitet werden, die 
die tatsächliche gesellschaftliche Arbeit der je residualisierten Produzierendensozialpolitiken in sich aufnehmen und zugleich beanspruchen, mit der gesellschaftlichen Arbeit des Sozialen entlang der Verwirklichung der subjektiven Residuen zu einer solchen gesellschaftlichen Arbeit am Sozialen zu gelangen, die eine sozial-ökologische Vergesellschaftung von Naturverhältnissen in Form einer übergreifenden Politik Sozialer Ökologie zu Wege zu bringen vermag, weil ökosoziale Transformationen für die eigene Emanzipation subjektiv als zwingende Voraussetzung erkannt werden. Damit lässt sich nun resümieren, dass der "Streit zwischen Welt und Erde“ (Heidegger), der sich im Klimawandel als Werk kapitalogen-instrumentalisierter Menschen offenbart, durch eine (auto)fotografische Methode im Sinne emanzipatorischer Bildhermeneutik nach dem Prinzip Kodierung/Dekodierung (Freire 1975: 87f.) im konkreten lebensweltlichen Alltag (städtischer) AkteurInnen subjektiv erfahrbar und politisch kritisierbar gemacht werden kann, um daran eine sozial-ökologische Subjektbildung zu entzünden. Von sozial-ökologischer Subjektbildung lässt sich also erst dann sprechen, wenn den Subjekten ein terrestrisches Gemeinwesen zum Bedürfnis der eigenen gedeihlichen Entwicklung wird; wenn Gaia also als Werk und Bedürfnis des ,untilgbare[n] Erdenrest[s]" (Schmidt 1988a: 85) sich als Menschen bewusst werdender ErdnaturakteurInnen gewollt und erlebt wird. Mit Lefebvre gesprochen:

„Der Wunsch entsteht erst, wenn das Individuum ihn durch seine Konflikte hindurch auf sich nimmt, wenn es ihn will oder akzeptiert und ihn bewusst mit dem ,Gut (Objekt) und dem dadurch verschafften Genuß konfrontiert. Wirklicher Wunsch wird er erst, wenn er vitale und geistige Gewalt wird, angenommen und ausgeübt vom Individuum, Leben, das in kreatives, schaffendes und geschaffenes Bewusstsein umgewandelt worden ist - kurzum, wenn er wieder Bedürfnis wird. Am Anfang ist das Bedürfnis Natur; es wird Werk und vollendet sich in Werken." (Lefebvre 1987: 263)

Zur abschließenden Frage steht nun, welchen professionellen Beitrag Soziale Arbeit zur transdisziplinären Subjektbildung sozial nachhaltiger sozialökologischer Transformation leisten könnte bzw. leisten müsste? Darin eingebunden ist die „Frage, wie in ihrem Schicksal isolierte Menschen über professionelles Handeln eingebunden werden können“ (May 2017b: 166) und daraus eine gemeinsame Aufgabenbewältigung der politischen Verwirklichung eines terrestrischen und nicht nur menschlichen Gemeinwesens erwachsen kann? 


\section{Professionalität Sozialer Arbeit - kommunalisierende Praxisphilosophie zwischen Reallaboren und transformativer Hochschule}

Der Beitrag Sozialer Arbeit als kommunalpädagogisches Ortshandeln in Form von Sozialraumentwicklung und -organisation wurde die Untersuchung hindurch bereits zur Genüge ausgearbeitet und muss an dieser Stelle nicht abermals zusammengefasst werden. An dieser Stelle ist es interessanter nicht länger nur dem historischen Ort sozial-ökologischer Subjektbildung im alltäglichen kulturellen Bewusstsein der Gesellschaft nachzugehen, sondern der Frage nach dem konkreten Ort eines solchen transdisziplinären Settings in den jeweils konkreten Städten. Als einen solchen konkreten Ort nennt der WBGU (WBGU 2016b) Reallabore, bei denen die Stadt selbst zum Labor wird, in denen wissenschaftliche und nicht-wissenschaftliche AkteurInnen „durch Ausprobieren und Experimentieren gemeinsam Wissen und Problemlösungen für die urbane Transformation erarbeiten" (ebd.: 21) und sich dabei weltweit mit anderen Reallaboren austauschen. Entsprechend schlägt er vor „global verteilt 50 urbane Reallabore entstehen zu lassen, die Wissen über Transformationsprozesse im urbanen Kontext aufbauen, untereinander austauschen und international verfügbar machen" (ebd.: 484).

Der im deutschsprachigen Raum vergleichsweise junge Begriff der Reallabore (Wagner 2017: 81) ist bislang nur vage umrissen. Einigkeit besteht vor allem darin, dass er auf die transdisziplinäre Schließung der „Lücke zwischen Forschung und Praxis“" und damit auch der Lücke zwischen den Disziplinen (Kap. 17) zielt und ,wissenschaftliche Forschung mit Beiträgen zu einem gesellschaftlichen Wandel kombinieren“ (Beecroft et al. 2018: 75) soll. Reallabore umreißen damit einen „Rahmen für transdisziplinäre Projekte“ in der Form von „Realexperimente[n], bei denen in einem kooperativen Prozess zwischen AkteurInnen aus der Wissenschaft und aus der Praxis Experimente geplant, durchgeführt und ausgewertet werden (Co-Design und Co-Produktion)“ (ebd.: 76). Damit lässt sich das Konzept der Reallabore als transdisziplinärer Rahmen transformativer Projekte zusammenfassen, die ,gesellschaftlich legitimierte, ethisch gut begründete und gemeinwohlorientierte Ziele [verfolgen]“ (ebd.: 78). Damit bieten sie gerade im Kontext ökosozialer und sozial-ökologischer Transformationsdiskurse ein nicht zu unterschätzendes Potenzial, weil sie die dringend benötigte Schnittstelle zwischen Stadtbevölkerung, Verwaltung, Politik, Ökonomie und Wissenschaften bilden ${ }^{90}$ und

90 Exemplarisch zu nennen wären etwa die Reallabore „Asylsuchende in der Rhein-NeckarRegion (Reallabor Asyl)“ (https://www.reallabor-asyl.de/reallabor-asyl/reallabor-asyl.html) und "'Urban Office': Nachhaltige Stadtentwicklung in der Wissensgesellschaft" (https:// www.ifeu.de/projekt/reallabor-urban-office-nachhaltige-stadtentwicklung-in-der-wissens 
damit das urbane Experimentier- und Handlungsfeld kommunalpädagogischer Sozialraumentwicklung und -organisation darstellen, das es vermag, das Verhältnis von Zivilgesellschaft, OOkonomie und Staat radikal zu demokratisieren (Kap. 15.3).

Zugleich finden sie entlang ihrer staatspolitischen Anbindung aber auch ihre thematische wie strukturelle Zurichtung (zum Einblick: BMWi 2019), wodurch ihr innovativer transdisziplinärer Charakter zugleich wieder ad absurdum geführt wird. Dennoch bieten Reallabore trotz ihrer staatspolitischen Einhegungsversuche nicht zu verkennende Möglichkeiten transversaler Freiraumstrategien symbiotischer Transformationsbegehren, wonach „Kämpfe um emanzipatorische Transformationen den Staat nicht einfach ignorieren sollten“, sondern ,ihn einsetzen, um den Prozess emanzipatorischer gesellschaftlicher Ermächtigung voranzutreiben“" (Wright 2017: 452). Reallabore bieten damit eine weitere Möglichkeit, die Belange der BürgerInnen zu Belangen der Staatspolitik zu machen, indem gegebene bzw. zugestandene Reallabor-Freiräume sich angeeignet und strategisch ausgeweitet werden können. Mit anderen Worten: als Reallabore werden wissenschaftlich unterstützte und begleitete Projekte bezeichnet, die den gesellschaftlichen PraxisakteurInnen einerseits ermöglichen, dass sie entlang ihres lebensweltlichen und biografischen Erfahrungswissens eigene Transformationsprojekte anstoßen und verwirklichen können. Und dass sie andererseits ihre subjektiven mit den in den wissenschaftlichen und staatspolitischen Diskursen bereits diskutierten und angegangenen Transformationsprojekte entlang ihrer lebensweltlichen und biografischen Erfahrungen in Diskussion bringen können und diese subjektiv weiterentwickeln können - und zwar im globalen konföderativen Austausch zur Gewährleistung (sozial-)räumlicher (Klima-)Gerechtigkeit (Kap. 15.5).

Soziale Arbeit bietet sich hierfür „wie keine andere“ (Bartosch 2020: 20) Disziplin und Profession an, solche Reallabore entlang gemeinwesenorientierter und Kommunen bildender Subjektansätze zu moderieren und praxisforscherisch (bspw. ikonografisch, Kap. 19) zu begleiten. Erst entlang solcher auf ein politisches wie gleichermaßen subjektives Gemeinwesen zielenden kommunalpädagogischen Transformationsstrategien transversaler Bildung von (Handlungs-)Subjekten sowie politischen resp. gesellschaftlichen Strukturen, in, an und mit denen sich transformative (Handlungs-)Subjekte (heraus)bilden können, ließen sich gegenhegemoniale Öffentlichkeiten bilden, durch die sozial-ökologische Transformationen als sozial nachhaltige, weil emanzipatorische Prozesse hervorgebracht werden können, bei denen die ökologischen Effekte wirtschaftlichen Wachstums durch gesellschaftliche Entwicklung politisiert und (sozial)raumgerecht reguliert werden können.

gesellschaft/); zum Überblick gegenwärtiger Reallabore zur Energiewende: https:// www.bmwi-energiewende.de/EWD/Redaktion/Newsletter/2019/07/Meldung/topthema.html (alle online Abrufe zuletzt geprüft am 21.03.2020). 
Was in den Reallaboren also entstehen müsste, kann ganz analog zu der „Entstehung des Politischen bei den Griechen“ (Meier 1983) in der Antike erblickt werden: Nämlich die Entstehung eines transgenerativen politischen Projekts, das durch die Antizipation eines objektiv-realen Gemeinwesens allmählich mimetisch zu realisieren gesucht wird und dabei nach und nach seinen Projektbereich ausweitet. Dehnten die Griechen den Projektbereich des Politischen zunächst noch zwischen den Menschen klassenspezifisch aus, so entwickelten sie dabei aber dennoch allmählich eine Vorstellung einer menschlichen Ökumene, d.h. einer gemeinsam bewohnten Erde (Kaerst 1903). Analog dazu käme es heute darauf an, nicht nur die nach wie vor bestehenden klassenspezifische Unterschiede zwischen den Menschen aufzuheben, sondern dabei auch den politischen Projektbereich von einer menschlichen Ökumene zu einer Gaia-Ökumene von menschlichen und nichtmenschlichen Akteuren und Aktanten auszuweiten. So wie die alten Griechen „keine Griechen vor sich [hatten]“ und sie ,also nichts von der Möglichkeit einer Demokratie [wussten], bevor sie sie selbst verwirklichten, indem sie sich politische Institutionen erfunden und geschaffen hatten, ,durch die eine regelmäßige Mitwirkung in politics möglich, ja denkbar" wurde (Meier 1983: 51), so haben wir heute ebenso keine konkreten historischen Vor-Bilder vor uns, die uns eine Soziale Ökologie resp. ein terrestrisches Gemeinwesen zeigen können und an denen wir uns orientieren können. Wir müssen sie uns mimetisch selber schaffen, um uns »am eigenen Schopf aus dem Sumpf« ziehen zu können.

Gleichwohl müssen wir eine Soziale Ökologie aber auch nicht aus dem Nichts völlig neu erfinden. Die Wissenspraxis und das Praxiswissen indigener Völker - wie sie in jüngster Zeit auch für Theorie und Wissenschaft Sozialer Arbeit furchtbar zu machen versucht werden $^{91}-$, ihre unterschiedlichen Vorstellungen der ganzheitlichen Einbindung des Menschen in einen holistisch-ökologischen Kontext, ihre physiozentrisch-relationalen und zirkulären Kosmovisionen (Weber 2018a; Müller 1991), die zwar keinen Gegensatz, wohl aber einen Unterschied zwischen menschlichen und nicht-menschlichen Ak-teuren und Aktanten kennen, können und sollten unsere gegenwärtigen Diskussionen inspirieren. Es müsste darum gehen, ein Gespür für $i h r$ terrestrisches Gemeinwesen, ihre Soziale Ökologie und ihre diesbezüglichen gesellschaftlichen Produktionsweisen zu bekommen und sich dadurch für sozial-ökologische Transformationen westlicher Gesellschaften inspirieren zu lassen. Zugleich müsste es auch darum gehen, ein Gespür für konkrete Unterschiede, Möglichkeiten, Grenzen und Inkommensurabilitäten der jeweiligen gesellschaftlichen Naturverhältnisse zu bekommen. Aber auch und vor allem ein Gespür für den westlichen Imperialismus kapitalogener Lebensweisen

91 Am 19.06.2020 fand unter dem Titel „Perspektiven auf indigenes Wissen in der Sozialen Arbeit" ein gemeinsames Treffen der DGSA-Sektion Theorie und Wissenschaft mit der Fachgruppe Internationale Soziale Arbeit statt. 
und dessen Begrenzungen von Lebensweisen an anderen Orten zu bekommen. Genauer: ein Wissen um die weltweite Ausgrenzungen und Verunmöglichung anderer Lebensweisen durch die eigene „imperiale Lebensweise“ (Brand/Wissen 2017), ihre kapitalogenen Ursachen und ihre kapitalozänen Zerstörungen.

Methodisch gewendet: Denkbar ist im Kontext einer Bildhermeneutik vor dem Hintergrund des Prinzips Kodierung/Dekodierung entlang von eigens gemachten oder eigens recherchierten Bildern sich gegenseitig das jeweilige Verständnis gesellschaftlicher Naturverhältnisse zu verdeutlichen. Es könnten gemeinsam, oder auch jede Akteurs-Gruppe für sich in ihren alltäglichen Lebenswelten, Fotos gemacht und gemeinsam (dialogisch) - gegebenenfalls auch online - ausgewertet werden. Es könnten - gegebenenfalls auch online - Exkursionen gemacht werden in die Gebiete, in denen für die westliche Digitalisierung und Elektromobilisierung ganze Landstriche, d.h. Wirkräume klimatologischer Aktanten und Lebensräume menschlicher und nichtmenschlicher Akteure extraktivierend langfristig zerstört werden (bspw. in Lateinamerika), um dort Fotos zu machen bzw. von den Betroffenen vor Ort machen zu lassen, um sie anschließend gemeinsam mit den Betroffenengruppen - den dort vor Ort Betroffenen, denen der Lebensraum streitig gemacht wird, als auch den hier vor Ort Betroffenen, die diese Technologien nutzen bzw. zu nutzen haben - dialogisch (gegebenenfalls auch online) auszuwerten. Dies alles scheint umso notwendiger vor dem Hintergrund mimetischen Lernens, wonach Transformationsstrategien beginnen sich im Kreis zu drehen, wenn sie die gesellschaftliche Alltäglichkeit des Logozentrismus nicht verlassen können.

Hierin ausgedrückt ist ein Plädoyer für eine Art weltweiter sozio-ökologischer Berichterstattung gesellschaftlicher Naturverhältnisse in, of, for and by the city (in Anlehnung an Davoudi/Bell 2016; vgl. Kap. 15.5). Eine im wahrsten Sinne des Wortes „Geo-Grafie der Beschwerden“" menschlicher und nicht-menschlicher Akteure und Aktanten (Latour 2018: 112), an der entlang sich ein Leitplankenkonzept der Urbanisierung entwickeln und den weltweiten Unterschieden der kulturellen Lebensweisen gerecht werden kann. Statt also ,planetarische Leitplanken“ logozentrisch-deduktiv zu setzen als ,objektive[] Grenzen, die physikalisch bestimmt werden können“ (WBGU 2014b, 2016b), müssen sie ,dahingehend betrachtet werden, dass ab einem bestimmten Moment die lokale, regionale oder gar globale biophysische Reproduktion nicht mehr funktioniert" (Acosta/Brand 2018: 96). Genauer: dass „die lokale, regionale oder gar globale biophysische Reproduktion“ (ebd.) gelingender Raumproduktion subjektiver Repräsentation in Form der Kommune nicht mehr gewährleistet ist. Statt biophysische bzw. ökologische Grenzen der Urbanisierung als planetarisch gleichermaßen gesetzt anzunehmen, könnten die vernetzten urbanen Reallabore dafür genutzt werden, regionale Leitplankenkonzepte transdisziplinär politisch $\mathrm{zu}$ erarbeiten und überregional 
zusammenzuführen zu einer sozial-ökologischen Landkarte. „[N]icht als zweidimensionalen Landkartenausschnitt, sondern als etwas, wovon die Subsistenz abhängt, was expliziert und visualisiert werden kann, was verteidigt werden muss" (Latour 2017: 443). Hierfür müssen geeignete Mittel und Wege gefunden werden. Dieser Prozess ist der Praxisvollzug sozial-ökologischer Subjektbildung hin zu einer Politik Sozialer Ökologie, diesen Konflikt zu führen der notwendige Praxisvollzug für die Verwirklichung von Gaia als politisches Gemeinwesen; kurz: für die Hervorbringung eines Anthropozäns.

Als methodologische Schwierigkeit bleibt aber dennoch bislang völlig unberührt, wie sich im Transformationssubjekt nicht nur die Vielfalt menschlicher Lebensweisen, sondern auch die Vielfalt nicht-menschlicher Lebensformen und die je spezifischen (gattungsbedingten) Interaktionsformen mit ihren Aktanten abbilden lassen? Und gerade diese offene Frage macht multiund transdisziplinäre Settings von Reallaboren zur sozial-ökologischen Handlungssubjektbildung so fundamental wichtig, um mit BotanikerInnen, ZoologInnen, IngenieurInnen, SozialwissenschaftlerInnen usw. sowie mit konkreten PraxisakteurInnen aus Politik, Verwaltung, Wirtschaft und der Bewohnerschaft konkreter Stadtteile und Quartiere gemeinsam - etwa anhand der in Kap. 19 vorgeschlagenen Methode, die in konkreten Forschungsprojekten weiter konkretisiert werden müsste - nach transformativen Mitteln und Wegen zu suchen, eine Stadtentwicklung hervorzubringen, die nicht nur der Vielfalt menschlicher Lebensweisen, sondern auch der Vielfalt nichtmenschlicher Lebensformen und ihren je spezifischen (gattungsbedingten) Interaktionsformen mit ihren Aktanten gerecht werden kann.

Damit stellt sich die Frage nach dem konkreten Ort solcher multi- und transdisziplinären Reallabor-Settings. Und im Zusammenhang mit der Frage nach dem konkreten urbanen Ort solch transformativer Reallabore stellt sich auch die Frage und Notwendigkeit ,transformativer Hochschulen“, die ihre Perspektiven vom „'Inside-Out“ zum ,Outside-In““, d.h. von ,einer industriezur gesellschaftsgetriebenen Wissenschaftspolitik" wechseln, und ihre inhaltliche wie strukturelle Organisierung ,auf die gesamte Bandbreite gesellschaftlicher Herausforderungen im Kontext einer nachhaltigen Entwicklung [erweitern]" (Schneidewind 2014: 221). Eine solche in begrifflicher Anlehnung an Dyllick/Muff (2014) „True University Sustainability“

„[...] geht nicht vom bestehenden Betrieb und den bestehenden Forschungs- und Lehrfeldern aus und versucht diese aus einer Nachhaltigkeitssicht zu betrachten, sondern nimmt die gesellschaftlichen Herausforderungen und die Perspektiven der betroffenen Akteure als Ausgangspunkt, um nach ihren strategischen Beiträgen zu diesen Herausforderungen zu fragen." (ebd.: 223)

Gekennzeichnet ist eine „transformative Hochschule“ dadurch, dass sie einerseits ,[i]n der Lehre [...] Forschungsfragen auf[greift], die gesellschaftlich bewegen“, und „Studierende entlang dieser Fragestellungen [motiviert], disziplinäre Methoden und die Verknüpfung mit anderen Disziplinen zu verstehen" (ebd.). Zugleich ist sie auch dadurch gekennzeichnet, dass sie anderer- 
seits ,auch betroffene Akteure und deren Wissen in den Wissenschaftsprozess mit ein[bezieht]" und zur "öffentlichen Wissensplattform [wird] und [...] in die Mitte der Gesellschaft [rückt]" und dadurch forschendes Lernen nicht nur für Studierende und Professionelle der verschiedenen Disziplinen, sondern auch für nicht-wissenschaftliche PraxisakteurInnen ermöglicht (ebd.).

Damit die Hochschulen als theoretisch wie praktisch transdisziplinäre Orte sozial-ökologischer Subjektbildung in Erscheinung treten können, verlangt das aber nicht nur seitens der Forschenden und Lehrenden ,sich auf von außen gestellte Forschungsfragen einzulassen und die Mühen der Verständigung und Kooperation mit z.T. weit entfernten Disziplinen und PraktikerInnen in Kauf zu nehmen“ (ebd.), sondern verlangt im Ganzen eine Bildungseinrichtung, die neben der transdisziplinären Erarbeitung und Vermittlung von Wissen die Betonung auf die kommunale Bildung von Subjekten sowie die revolutionäre Transformation gesellschaftlicher Strukturen legt. Eine „transformative Hochschule“ als kommunalpädagogischer Ort müsste zudem konsequent darauf hinarbeiten, nicht nur in die "Mitte der Gesellschaft" (ebd.: 222) zu rücken, sondern vor allem auch an die marginalisierten Ränder der sogenannten bildungsfernen Milieus und sich auch dort als Raum offenbaren, der sich subjektiv angeeignet und ausgestaltet werden kann. Zudem bedarf es eine strukturell verbindliche Organisierung der Hochschulen, die die AkteurInnen als heterarchisch gleichgestellte in Erscheinung treten lässt, um so das scholastische Lehrer-Schüler-Verhältnis aufzubrechen und die verschiedenen AkteurInnen als Lernende und Lehrende unter Lernenden und Lehrenden ins dialogische Verhältnis zu setzen. Vor allem braucht eine solchermaßen praktizierte Praxisphilosophie neben einem entsprechenden $\mathrm{Zu}-$ fluss frei verfügbarer, d.h. kollaborativ selbstverwalteter finanzieller Mittel vor allem eine qualitative und bauliche Stadtentwicklung, die es den StadtbewohnerInnen ermöglicht, die Hochschule von klein auf als zentralen Ort, wenn man so will als moderne Agorá des urbanen Lebens zu erleben. All das sind Fragen sozialer Infrastrukturpolitik, die nur im Kontext kollaborativer Stadtentwicklung in kommunalistischer Hinsicht angegangen werden können. Hierfür kann und muss Sozialer Arbeit einen einzigartigen professionellen und disziplinären Beitrag leisten.

Diese Überlegung ist nicht neu. Sie feiert in diesen Jahren ihren sogar 100. Geburtstag: Schon Paul Natorps Vision einer - im wörtlichen Sinne universitären Bildungseinrichtung spricht sie aus und geht damit schon über die von Schneidewind geforderte transformative Hochschule im Sinne einer „True University Sustainability“ hinaus. Natorp fordert eine

,[...] Hochschule für alle, als Volkshochschule, die das ganze soziale Leben auch des schon im Beruf stehenden Erwachsenen begleitet. [...] So und nur so stände die Schule, in voller Autonomie, nicht neben dem Leben, sondern mitten in ihm. Ihren Grund böte allgemein die Genossenschaft; nicht bloß so, dass sie auf dieser sich aufbaute, sondern ganz in sie eingebaut wäre; und zwar durch alle Stufen hindurch, von der Gilde zur Gemeinde zum Staat, als dem Gesamtsystem 
der Genossenschaften, Genossenschaften von Genossenschaften und so fort. Alles zugleich: Leibespflege und Heilkunst, Landbau, Handwerk, Fabrik, Handel, Verkehr, und in Beziehung auf all dieses die rechtliche Regelung jeder Stufe, Gesetzgebung, Verwaltung, Gerichtsbarkeit, auf diesem festen Erdgrund dann der ganze herrliche Überbau des ,Geistes“: Wissenschaft, Kunst, Religion - alles das müsste in einheitlichem Wirken dahin zusammenstreben, den Menschen, und zwar jeden, zu der Stufe seines Menschtums zu bringen, die nach dem Maße und der Sonderart seiner Befähigung ihm erreichbar ist. Diese Einheitsrichtung der Menschenbildung aber hätte die recht verstandene Universität zu vertreten; das ist eigentlich ihr Begriff, den sie daran kann [auch heute noch, MS] leider kein Zweifel sein - gegenwärtig nicht erfüllt, der aber doch keineswegs in Vergessenheit geraten ist." (Natorp 1922: 131f.)

In der Verschränkung von urbanen Reallaboren und „transformativer Hochschule“ zu einer Stadt, die sich als Universität im Natorpschen Sinne versteht, liegt nun auch das Potenzial einer theoretisch wie praktisch transdisziplinären terrestrischen Nachhaltigkeitswissenschaft sozial-ökologischer Transformation, die sich ökosozialer Strategien bedient.

Soziale Arbeit kann dabei aber nicht nur in der Rolle der Moderation in Erscheinung treten. Stattdessen kommt sie als subjekt- und gemeinwesenorientierte Profession gar nicht umhin zugleich auch als eigenständige und gerade nicht-moderate, prioritaristische und zugleich für die subjektiven Residuen allparteiliche Disziplin und Profession der praxisphilosophischen Umwälzung kultureller Subjektbildung in Erscheinung zu treten. Soziale Arbeit in Zeiten des Klimawandels, so lässt sich abschließend zusammenfassen, das ist der Versuch einer subjektorientierten Verwirklichung der Städte als universitäre Kommunalgenossenschaften zur subjektiven wie politischen Bildung eines nicht nur menschlichen, sondern terrestrischen Gemeinwesen. Unermüdliche Arbeit an Gaia auf und mit der Erde, dem ,Laboratorium “ (Marx 1983: 400) des Lebens, nicht nur von Menschen. Auf die Frage, worüber wir in der Klimafrage ins Gespräch kommen müssen, lässt sich also antworten: über die Residuen der imperialen Vergesellschaftung innerer wie äußerer (Erd-)Naturverhältnisse und dem konkreten Ort der gemeinsamen politischen Arbeit an Strategien, sie zu verwirklichen - ohne abermals nur die menschliche Entwicklung zum Maß aller Dinge zu machen. Anders: über das Recht emanzipatorischer Stadtentwicklung und der hierfür notwendigen „Rückgewinnung des Territorialen in Form der Kommune" (Richter 2001: 144) sowie ihrer kollaborativen Verfasstheit. Nochmal anders: über eine terrestrische Nachhaltigkeitswissenschaft sozial-ökologischer Transformation, d.h. über eine transdisziplinär erarbeitete, sozial nachhaltige und anti-speziezistische Politik gesellschaftlicher Naturverhältnisse. Kurz: über eine global organisierte urbane Politik Sozialer Ökologie. Hierfür hat die vorliegende Untersuchung einen Beitrag zu leisten gesucht.

Im Folgenden wird die in den Kapiteln der Teile A-D entwickelte Argumentation in die gegenwärtige Diskussion einer Kritischen Theorie gesellschaftlicher Naturverhältnisse eingeordnet. 
Teil E

Zusammenfassende Einordnung des Entwurfs einer terrestrischen Nachhaltigkeitswissenschaft sozial-ökologischer Transformation in die Diskussionen um eine Kritische Theorie gesellschaftlicher Naturverhältnisse 



\section{Einordnung der vorliegenden Argumentation in Marx“ „Kritik der Erde“}

Marx“ „Kritik der Erde“ (Marx 1981d: 379), wie er sein Lebenswerk bereits in der Einleitung der „Kritik der hegelschen Rechtsphilosophie“ von 1843/44 programmatisch wohl eher nebenbei auf den Begriff gebracht hat, hat ihn bis zu seinem postum erschienenen dritten Band des „Kapital“ zu dem Aufweis eines „unheilbaren Riß [...] in dem Zusammenhang des gesellschaftlichen und durch die Naturgesetze des Lebens vorgeschriebenen Stoffwechsels“" (Marx 1964: 821) geführt, der für Marx nur in einer kommunistischen Gesellschaftsformation wieder überwunden werden kann, in der die Erde wieder aufhört „Gegenstand des Schachers“ zu sein (Marx 1968b: 508). ${ }^{92}$ Für Marx/Engels ist eine Gesellschaft dann kommunistisch, wenn sie sich in ihrer Alltagspraxis der „Erde [...] als unorganischen Leib“ (Marx 1983: 400, 1968b: 516) und existenzielles „Arbeitsmittel“ (Marx 1962a: 194) ${ }^{93}$, genauer: als das Subjekt des Menschen (Marx 1983: 396) bewusst ist und sie den unhintergehbaren Naturstoffwechsel von Erde und Gesellschaft, d.h. ihre gesellschaftlichen Naturverhältnisse zur vollen (totalen) Entwicklung der Menschen dergestalt vollumfänglich politisiert hat, dass die menschlichen Bedürfnisse in dieser Politik nicht über eigenmächtige Mandatsträger repräsentiert werden, sondern sich selbst darin repräsentieren können (Marx/ Engels 1977). Von daher ist Kommunismus für Marx/Engels nichts anderes als „die wirkliche Bewegung, welchen den jetzigen Zustand aufhebt“" (Marx/ Engels 1978: 35), nämlich „,dadurch, dass er die Grundlage aller bisherigen Produktions- und Verkehrsverhältnisse umwälzt und alle naturwüchsigen

92 Marx schreibt schon in seinen „Ökonomisch-philosophischen Manuskripten von 1844“: „Die Assoziation, auf Grund und Boden angewandt, teilt den Vorteil des großen Grundbesitzes in nationalökonomischer Hinsicht und realisiert erst die ursprüngliche Tendenz der Teilung, nämlich die Gleichheit, wie sie denn auch auf eine vernünftige und nicht mehr durch Leibeigenschaft, Herrschaft und eine alberne Eigentumsmystik vermittelte Weise die gemütliche Beziehung des Menschen zur Erde herstellt, indem die Erde aufhört, ein Gegenstand des Schachers zu sein, und durch die freie Arbeit und den freien Genuß wieder ein wahres, persönliches Eigentum des Menschen wird.“ (Marx 1968b: 508)

93 Marx im ersten Band des „Kapital“: „,Der Gegenstand, dessen sich der Arbeiter unmittelbar bemächtigt - abgesehn von der Ergreifung fertiger Lebensmittel, der Früchte z.B., wobei seine eignen Leibesorgane allein als Arbeitsmittel dienen - ist nicht der Arbeitsgegenstand, sondern das Arbeitsmittel. So wird das Natürliche selbst zum Organ seiner Tätigkeit, ein Organ, das er seinen eignen Leibesorganen hinzufügt, seine natürliche Gestalt verlängernd, trotz der Bibel. Wie die Erde seine ursprüngliche Proviantkammer, ist sie sein ursprüngliches Arsenal von Arbeitsmitteln. Sie liefert ihm z.B. den Stein, womit er wirft, reibt, drückt, schneidet usw. Die Erde selbst ist ein Arbeitsmittel, setzt jedoch zu ihrem Dienst als Arbeitsmittel in der Agrikultur wieder eine ganze Reihe andrer Arbeitsmittel und eine schon relativ hohe Entwicklung der Arbeitskraft voraus.“ (Marx 1962a: 194) 
Voraussetzungen zum ersten Mal mit Bewusstsein als Geschöpfe der bisherigen Menschen behandelt", sie also ,ihrer Naturwüchsigkeit entkleidet und der Macht der vereinigten Individuen unterwirft" (ebd.: 70). Eine solche umwälzende, revolutionär-transformative Praxis sieht Marx in kommunalen Assoziationen ermöglicht, d.h. in einem „Verein freier Menschen“, die sich nicht nur „wechselseitig erziehen“ (Marx 1981a: 95), sondern, wie er später im „Kapital“ präzisiert, auch „mit gemeinschaftlichen Produktionsmitteln arbeiten und ihre vielen individuellen Arbeitskräfte selbstbewußt als eine gesellschaftliche Arbeitskraft verausgaben“, so dass das „Gesamtprodukt des Vereins [...] ein gesellschaftliches Produkt [ist]“ (Marx 1962a: 92f.).

Diesen Kommunismus sah Marx später in der Pariser Kommune versucht zu verwirklichen (Marx 1962b: 340). In ihr sieht er die „Wiederbelebung der mittelalterlichen Kommunen, welcher jener Staatsmacht [die für Marx „,doch nur ein Schmarotzerauswuchs war", ebd.] erst vorausgingen und dann ihre Grundlagen bildeten" (ebd.). Statt von Kommunismus ließe sich daher durchaus auch von Kommunalismus sprechen, wobei sich allerdings der Pariser Kommunalismus in seiner basisdemokratisch-heterarchischen Organisationsstruktur, die Marx lobend betont (ebd.), von der „Affinität zum Republikanismus als Staatsform“ (Blickle 2000b: 178, 2000a: 2) des historischen Kommunalismus unterscheidet (Kap. 15f.).

Auch wenn der Begriff des Kommunalismus erst weit nach Marx von Blickle (Blickle 2000b, 2000a) aufgebracht wurde, so bezieht er sich hier wie da auf die historischen Kommunenbildungen und deren Versuche, sich der übergreifend herausbildenden Nationalstaatsmacht zu erwehren und als autarke, emanzipatorische Assoziationen zu behaupten, was letztlich auch im Zentrum des Kommunalismusbegriffs bei Bookchin steht (Bookchin 1992a, 1996) und in der vorliegenden Studie eine zentrale Rolle spielt. Zugleich aber wird Bookchins Kommunalismusbegriff in der Untersuchung von seinen anarchistischen Idealismen befreit, wonach der Staat bloß übernommen und abgeschafft werden soll, und in einem radikal-reformerischen (Hirsch 2007) Transformationsbegriff, d.h. in einer ,wahre[n] ,öffentliche[n] ' Erziehung des Staates“ (Marx 1981a: 95), einer kommunalpädagogischen Politik des Sozialen aufgehoben. Am Kommunalismusbegriff ist aber, trotz aller vorgenommenen ökosozial(istisch)en Renovierungen, allein deswegen festzuhalten, weil dessen sozial-ökologischer Kern auf dieselbe gattungsgeschichtliche Emanzipation der Menschen insistiert (Bookchin 1992a: 198ff.), auf die auch Marx insistiert, allerdings im Weg dorthin irrt. Zudem fordert der Kommunalismusbegriff zugleich eine Öffnung des Marxschen Anthropozentrismus ein, der den Menschen nur noch als politischen Akteur zentral, ihn in der Erdökologie aber nur exzentrisch positioniert. Nicht mehr kann es gesellschaftspolitisch nur darum gehen, die Erde als ,persönliches Eigentum des Menschen“ (Marx 1968b: 508) hervorzubringen, sondern als Eigentum und Gemeingut aller auf und mit der Erde lebenden Akteure. Darin geht der hier favorisierte 
Begriff des Kommunalismus über den Begriff des Kommunismus hinaus (abgesehen davon ist er auch nicht so historisch vernutzt, wie der Begriff des Kommunismus).

Doch trotz dieses Unterschieds kommt sowohl im Begriff des Kommunismus als auch im Begriff des Kommunalismus die Notwendigkeit der strategischen Bildung kommunaler Selbstverwaltungen zum Ausdruck (bei Marx: politische Revolution), mit denen die BürgerInnen ihre alltäglichen Angelegenheiten selbst bearbeiten und sich die dazu benötigten Mittel und Infrastrukturen und politischen Vernetzungen mit anderen selbstverwalteten Kommunen selbst hervorbringen, um so - entlang der strategischen Hypothese der langfristigen Überwindung des bürgerlichen Staatsapparates - nicht nur auf die Befreiung von kapitalogenen Herrschaftsverhältnissen von Menschen über Menschen abzuzielen (bei Marx: soziale Revolution), sondern auch auf die Befreiung von kapitalogenen Herrschaftsverhältnissen von Menschen über ihre gesamte nicht-menschliche Mitwelt (sozial-ökologische Transformation). In diesem Kontext wird in der vorliegenden Untersuchung Lefebvres „Recht auf Stadt“" positioniert, mit dem er ein transdisziplinär ausgerichtetes strategisches Wissenschaftsparadigma zur Ermöglichung subjektiver Emanzipation auf kulturrevolutionärer Ebene umreißt und das hier ausformuliert wird zu einem Recht auf die sozial-ökologische Revolutionierung des Urbanen, da die alltägliche Raumproduktion des Städtischen als der (Re)Produktionsort der kapitalogenen Herrschaftsverhältnisse von Menschen über Menschen sowie über ihre gesamte nicht-menschliche Mitwelt herausgestellt werden konnte. $\mathrm{Zu}$ politisieren sind, so lässt sich zusammenfassen, die ökonomische Wachstumsproduktion und ihre Inwertsetzungen menschlicher und nicht-menschlicher Erdnaturverhältnisse, wobei die Notwendigkeit der ökonomischen Wachstumsproduktion für die sozialstaatliche Wohlfahrtsproduktion nicht in Abrede gestellt werden soll, wohl aber der demokratischen Regulierung untergestellt werden muss.

Marx“ kommunalistische „Kritik der Erde“ (Marx 1981d: 379) war und ist nicht nur eine ökologische Kampfansage an die zerstörerische kapitalistische Urbanisierung der Erde, sondern auch gegenüber dem neuzeitlich mechanistischen Natur- und Gesellschaftsverständnis ein philosophisch unzeitgemäßer Paukenschlag, die bis heute noch kaum Eingang in die Soziologie gefunden hat, obschon sie ihr weitest mögliches Theorie- und Forschungsfeld eröffnet (hat). 


\section{Das Verlieren des Marxschen Erdbezugs in der Soziologie}

Gerade das zur Zeit Marx aufgekommene und nach Marx Tod zum Durchbruch kommende biologistisch-naturalistische Gesellschaftsverständnis, das von geodeterministischen und sozialdarwinistischen Erklärungen gesellschaftlicher Phänomene bis hin zu biorassistischen Ressentiments reichte (und letztlich im Gesetz zur Verhütung erbkranken Nachwuchses mündete) zwang geradenach dazu, Soziologie - allen voran durch Durkheim, Simmel und Weber - als eigenständige Disziplin herauszustellen, die soziale Phänomene ausschließlich sozial zu erklären sucht(e) und damit jeglichen Naturbezug suspendiert(e) (zum Überblick: Grundmann 1997; Lemke 2007). Damit wurde auch der Marxsche Erdbezug samt der damit verbundenen notwendigen kommun(al)istischen Konsequenzen aus der Soziologie verbannt. $\mathrm{Ob}$ vorrangig wegen den politischen Konsequenzen oder dem Naturbezug, muss an dieser Stelle offen bleiben.

Dieser Soziozentrismus führte aber nicht nur zu einem Verständnis von Natur als zu vernachlässigende Umwelt der Gesellschaft, sondern implizierte auch eine wissenschaftstheoretische dualistische Trennung von Gesellschaft und Natur in der Theoriebilddung (Soziologismus), den Horkheimer und Adorno über den Rückbezug auf den Marxschen Stoffwechselbegriff vorsichtig wieder rückgängig zu machen suchen. So konstatiert Adorno 1959 „Zum gegenwärtigen Stand der deutschen Soziologie“:

„Die Ausscheidung der eigentlich ökonomischen Fragen, der nach dem tragenden Produktionsund Reproduktionsprozeß der Gesellschaft, der den sogenannten Formen der Vergesellschaftung ihr Leben einbläst, führte zur Verdünnung der soziologischen Thematik. Wissenschaft, die durch Abstraktion von der Beziehung sozialer Momente auf die Selbsterhaltung der Gesellschaft und deren Problematik das Gesellschaftliche auszukristallisieren hofft, ist dazu gedrängt, einen Rest, die ,zwischenmenschlichen Beziehungen', zu fetischisieren; es entfällt deren Funktion im Stoffwechsel mit der Natur wie mit der sozialen Totalität samt allen essentiellen Widersprüchen. So wird Soziologie zu dem, was ihr nach dem Maß der szientifischen Flurbereinigung nicht weniger peinlich ist, zu Sozialpsychologie. [...] Dem entspricht im übrigen auf der anderen Seite, daß die auf der Landkarte der Wissenschaften von der Soziologie getrennte Ökonomie auch ihrerseits auf den Anspruch, die tragenden Lebensprozesse der Gesellschaft zu begreifen, verzichtet, wohl gar ihn der Soziologie überläßt, die ihm selber sich entzieht; die gegenwärtige Ökonomie entwirft mit höchstentwickeltem mathematischen Apparat Schemata für mögliche Relationen innerhalb bereits entwickelter Tauschgesellschaften, ohne die Analyse des Tauschverhältnisses selbst, seines gesellschaftlichen Wesens und seiner Dynamik in ihrem Themenkreis zu dulden. In dem Graben zwischen Soziologie und Ökonomie verschwindet das Interesse, das beiden Disziplinen ihre eigentliche raison d'être verleiht; die eine erwartet von der anderen, was diese nicht leistet und worum nicht sich zu kümmern ihren szientifischen Stolz ausmacht.“ (Adorno 1972: 504f.)

Doch schon zuvor stellt Horkheimer in seinem Aufsatz zur „traditionellen und kritischen Theorie“ von 1937 heraus, dass das „Verhältnis der ersten 
begrifflichen Zusammenhänge zur Faktenwelt [...] nicht wesentlich das von Gattungen und Exemplaren ist", sondern geprägt ist durch „den Prozess zwischen Gesellschaft und Natur" (Horkheimer 1988: 199). In der daraus sich entwickelnden gesellschaftlichen Wirklichkeit ist für ihn auch das ökonomische Tauschverhältnis zu verorten, in das der Aspekt des Stoffwechsels wieder ,eingefügt" werden muss, ,um von dieser grundlegenden Struktur zur differenzierten Realität zu gelangen“ (ebd.). Diese ist „nicht durch einfache Deduktion wie in der fachlich abgekapselten Theorie" zu erlangen, sondern nur durch die „Kenntnis über Mensch und Natur“ (ebd.). Darin kommt eine aus dem Durkheimschen Diktum, soziale Phänomene als objektive Tatbestände zu betrachten (Durkheim 1980: 114f.), herrührende Kritik am soziozentrischen Soziologismus der Soziologie zum Vorschein, die dann vor allem 1944 in Horkheimer/Adorno“s „Dialektik der Aufklärung“ fortgeführt wird. Hier kritisieren sie sowohl die Verdinglichung von Gesellschaftsverhältnissen durch die deduktivistische Herangehensweise an soziologische Erklärungen gesellschaftlicher Phänomene als auch die Verdinglichung innermenschlicher Naturverhältnisse durch ihre kapitalistisch-funktionalistische Vereinnahmung und insistieren in ihrer Kritik an der techn(izist)ischen Naturbeherrschung dabei auch auf den Marxschen Ansatz des Naturstoffwechsels. Görg fasst zusammen:

„Mit der Dialektik der Aufklärung wird die Kritik der Naturbeherrschung zu einem der zentralen Motive kritischer Theorie, die den Fortschrittsutopien der Moderne eine deutliche Absage erteilt und die Kritik an den herrschaftsförmigen Implikationen des Naturbegriffs mit der Erfahrung der >Nichtidentität der Natur verbindet.“ (Görg 2003: 43)

Und weiter:

„Naturbeherrschung meint jedoch in der Dialektik der Aufklärung etwas anderes als die Aneignung oder Transformation von Natur zu menschlichen Zwecken, die in der Tat unverzichtbar ist (und auf die verzichten zu wollen die Ausblendung des gesellschaftlich organisierten Stoffwechselprozesses implizieren würde). Die Thematisierung von Naturbeherrschung in diesem Werk zielt dagegen primär auf die symbolische Konstruktion der Natur, auf einen Naturbegriff, der durch eine bestimmte Klassifizierung, eine projizierte Ordnung der Natur gebildet wird und der dem wissenschaftlichen Denken wie der technisch-praktischen Aneignung der Natur zugrunde liegt." (ebd.: 45f.)

\section{Und noch weiter:}

„Der Grund dafür liegt aber nicht darin, dass Adorno und Horkheimer den Zwang zur Aneignung, zum Stoffwechsel mit der Natur nicht als eine Tatsache ansehen würden. Sie wenden sich jedoch dagegen, diesen Zwang als unveränderliche Notwendigkeit zu einem Quasi-Naturgesetz zu erhöhen, weil dies eine dualistische und hierarchische Verfestigung des Verhältnisses von Notwendigkeit und Freiheit implizieren würde. Das Reich der Freiheit würde den Naturverhältnissen abstrakt entgegen gestellt und damit Natur ,als ganz fremd gesetzt“ (ebd.).“(ebd.: 48f.)

Mit anderen Worten: Mit ihrer konsequenten Kritik an der Verdinglichung der Natur schrecken Horkheimer und Adorno davor zurück, die Erde und den dialektischen Stoffwechsel zwischen Entwicklung auf der Erde und Entwick- 
lung mit der Erde zu einer „negativ zu fassenden Ontologie“ (Schmidt 2016: 103) zu konkretisieren, weil damit notwendigerweise eine Verdinglichung der Prozessnatur einhergehen würde. Mit dieser Vorsicht gerät ihnen aber auch die Marx'sche Synonymität von Erde und Natur als Erdnatur aus den Händen, womit es Marx aber noch gelungen war, den dialektischen Stoffwechsel zwischen Entwicklung auf der Erde und Entwicklung mit der Erde im Entwicklungsfluss der Prozessnatur zu halten.

Es ist genau diese Sorge, weswegen es Horkheimer und Adorno vermeiden, das Reich der Freiheit nur mit dem erdökologischen Naturstoffwechsel in den Blick zu bekommen, weswegen die (ältere) Kritische Theorie zu den Öko- und Klimafragen letztlich nicht viel beitragen konnte. Verstärkt wurde dieses Schweigenmüssen durch die ,fehlende Beschäftigung mit den Naturwissenschaften“ (Görg 2003: 50), die sie zwar in ihrer „Dialektik der Aufklärung" zunächst noch in Francis Bacons induktiv-empirisch konzipierter Naturwissenschaft wertschätzen (Horkheimer/Adorno 2006: 9f.), letztlich aber „,in Gänze dem instrumentellen Handeln und der Naturbeherrschung zurechnen“ (Görg 2003: 51).

Eine sozial-ökologische Naturallianz, wie sie in der vorliegenden Studie für erstrebenswert gehalten wird, ist zwar eine konsequent demokratisch regulierte und in ihren zerstörerischen Auswirkungen deutlich gezähmte, aber dennoch nur als Naturbeherrschung denkbar, die weiterhin auch invasive Erdgestaltungsprozesse umfassen muss, wenn Urbanisierung auch weiterhin der Befreiung vom Naturzwang dienen soll. Über den Begriff der Naturallianz wird in der vorliegenden Studie aber dennoch weniger an Bloch Anschluss gesucht, der die Resurrektion der gesamten Natur aus den Marx'schen Frühschriften entgegen Marx' eigener Denkentwicklung konsequent weiterverfolgt (zum Überblick: Schmidt 2016: 177ff.), als vielmehr an die späteren Schriften von Marx und Engels, in denen von der ,wahre[n] Resurrektion der Natur, de[m] durchgeführte[n] Naturalismus des Menschen und de[m] durchgeführte[n] Humanismus der Natur“" (Marx 1968b: 538) nicht mehr viel die Rede ist und stattdessen darauf insistieren, dass

,[i]n Zukunft [...] nicht die Ausbeutung der Natur aufhören [soll], sondern die menschlichen Eingriffe in sie sollen so rationalisiert werden, daß auch ihre entfernteren Auswirkungen kontrollierbar bleiben. Damit soll die Natur Schritt für Schritt um die Möglichkeit gebracht werden, sich an den Menschen doch noch für deren Siege über sie zu rächen." (Schmidt 2016: 177f.).

Aber genau deswegen und dafür wird eine umfassendere Kritische Theorie gesellschaftlicher (Erd-)Naturverhältnisse benötigt, da eine in ihren zerstörerischen Ausmaßen gezähmte Naturbeherrschung ein Wissen um Lebensräume und Eigentätigkeiten nicht-menschlicher Akteure sowie die Eigentätigkeit erdökologischer Aktanten und den zu erwartenden Reaktionen auf das, was wir ihnen antun (Latour 2017: 126), verlangt, welches mit nur gesellschaftstheoretisch fundierten Methodologien offensichtlich nicht erarbeitet werden kann. Eine Kritische Theorie sozial-ökologischer Naturallianz muss also 
immer auch als transdisziplinäre Wissenschaftsallianz aller die Erde betreffenden Disziplinen begriffen werden. Sowohl der Disziplinen, die die Erde als dialektisch entwickelnde Prozessnatur darzustellen suchen, als auch der Disziplinen, die die Erde als mechanistisch ablaufende Naturprozesse darzustellen suchen. Beide Disziplinentypen, und darauf kommt es hier an, müssen zu einer auch mit nicht-wissenschaftlichen AkteurInnen gemeinsamen Theoriebildung resp. zu einer terrestrischen Nachhaltigkeitswissenschaft sozialökologischer Transformation zusammenfinden, bei der ihre je disziplinären Zugänge nicht aufgegeben, sondern komplementär aufgehoben werden. Aber gerade diese theoretische wie praktische Transdisziplinarität (Mittelstraß 2005) vermeidet die Kritische Theorie bei Horkheimer und Adorno, weil sie keinen Unterschied mehr machen zwischen der kapitalistischen Naturbeherrschung und der Naturbeherrschung einer sozial-ökologischen Naturallianz, wie sie bereits Engels zu formulieren suchte. In seiner „Dialektik der Natur“ schreibt er,

„daß wir keineswegs die Natur beherrschen, wie ein Eroberer ein fremdes Volk beherrscht, wie jemand, der außer der Natur steht - sondern daß wir mit Fleisch und Blut und Hirn ihr angehören und mitten in ihr stehn, und daß unsre ganze Herrschaft über sie darin besteht, im Vorzug vor allen andern Geschöpfen ihre Gesetze erkennen und richtig anwenden zu können“ (Engels 1975: 453).

Ob wir Menschen die Gesetze der Natur erkennen können oder sie nur adäquat darzustellen vermögen und die wahren Gesetze der Produktionsweise der (Erd-)Natur unerkannt bleiben müssen, ob also Engels das menschliche Erkenntnisvermögen überschätzt, ist eine andere, hier nicht zu entscheidende Frage. Sie schmälert aber keineswegs die von ihm getroffene Unterscheidung der Formen der Naturbeherrschung auf die es hier ankommt.

Gegenüber Adorno/Horkheimer lassen sich bei Herbert Marcuse aber durchaus Spuren der Beschäftigung mit auch ökologischen Fragestellungen im Kontext der Kritischen Theorie finden (Marcuse 2009), mit denen „lange vor dem Auftauchen der ökologischen Problematik ihr Erscheinen" hätte vorausgesagt werden können (Brieler 2019: 364). Zugleich muss aber auch hier einschränkend konstatiert werden, dass der „Topos der Zerstörung der Natur [...] zwar hier und da [erscheint]“, aber ein „Schwerpunkt [...] Ökologie [...] auch mit viel gutem Willen nicht zu erkennen [ist]", sondern lediglich eine Problematisierung ,negativer Folgen von Herrschaft" und die auch nicht gerade bahnbrechende Erkenntnis, dass eine Ökologiebewegung zur „radikale[n] Veränderung gesellschaftlicher Verhältnisse auch die Trieb- und Bedürfnisstruktur der Individuen einbegreifen muss“" (Kaven 2016). Und wenn zudem Marcuses Feststellung aus „Der eindimensionale Mensch“, dass „[d]ie späte Industriegesellschaft“" mit ihrer ,unaufhörliche[n] Rationalisierung“ und „rücksichtslose[n] Anwendung fortgeschrittener Technik und der Wissenschaft“ „das Bedürfnis nach parasitären und entfremdeten Funktionen (für die Gesamtgesellschaft, wenn auch nicht für das Individuum) eher erhöht als verringert [hat]“ (Marcuse 1970: 69), bei Brieler zum Beleg genommen 
wird, mit Marcuse ,lange vor dem Auftauchen der ökologischen Problematik ihr Erscheinen voraussagen“ (Brieler 2019: 364) zu können, dann zeigt das, mit wieviel wohlwollender Lesart eine erdökologische Bezugnahme der Kritischen Theorie ex post herzustellen versucht wird.

Aber auch diese zarten Pflänzchen der ,tastenden Denkversuche“ Marcuses ökologischer Kapitalismuskritik entlang einer ,,alternativen Rationalität in Technik und Wissenschaft“ wurden spätestens mit „Habermas“ Dichotomie von Arbeit und Interaktion“ nicht nur ,abgewürgt“ (Rehmann 2019: 665). Sondern wurden durch die innere Theoriestruktur der habermasianischen Kommunikationstheorie systematisch aus der Kritischen Theorie ausgeschlossen, womit die „Abkehr der Frankfurter Schule von den Grundlagen der Marx'schen Kritik der politischen Ökonomie“ besiegelt wurde (Dörre 2019a: 957). Diese wegweisende Blindstelle der kritischen Gesellschaftstheorie erweist sich nun ,angesichts überlebensgefährdender ökologischer Zerstörungen" (Rehmann 2019: 695) als höchst problematisch, weil sie dazu geführt hat, dass die Kritische Theorie hinsichtlich der großen Sozialen Frage der Gegenwart und der kommenden Jahrhunderte - der Klimafrage - ihre Sprache der Kritik verloren hat und gegenwärtig erst mühsam wieder erlernt werden muss.

Zwar haben sich seit den 1980er Jahren durchaus nicht wenige WissenschaftlerInnen mit ökologischen Krisenphänomenen beschäftigt und denen auch daran gelegen war, ,die Tradition der kritischen Theorie in diese Diskussionen einzubringen“, allerdings wurden diese Bemühungen ,nicht von denen unternommen, die in der Öffentlichkeit als >Erben der Frankfurter Schule gehandelt wurden“, sondern „,kam[en] [...] eher von den >Rändern der Tradition“ und es wurde dabei ,auf ganz andere theoretische Traditionen zurückgegriffen (vgl. Böhme/Manzei 2003)““ (Görg 2003: 41). Vor allem auf systemtheoretische, wie die theoretischen Auseinandersetzungen aus den 1980er Jahren zeigen und die gegenwärtigen Diskurse bis heute dominieren (zur Kritik: Becker 2016f, 2016b, 2016e) und sich auch in der Kritischen Theorie positionieren (etwa Scherr 2019). Vor diesem Hintergrund wundert es nicht, dass sich die aktuellen Öko- und Klimadebatten insofern durch eine „sozialwissenschaftliche Unterbestimmtheit“ (Leggewie 2015: 67) auszeichnen und dass sie trotz zunehmender Aufmerksamkeit in den Sozialwissenschaften (MCC 2020) eine Kritik der politischen Ökonomie, mehr noch: eine „Kritik der Erde“ (Marx 1981d: 379) missen lassen und damit an der gegenwärtigen systemtheoretisch-technischen Depolitisierung der Problemursachen mitwirken (Becker 2016f). Gleichwohl haben sich in den letzten Jahrzehnten mehrere Ansätze einer Kritischen Theorie gesellschaftlicher Naturverhältnisse herausgebildet, die zur Klimafrage eine Sprache der Kritik zu entwickeln suchen. Aber eine gemeinsame Kritische Theorie gesellschaftlicher Naturverhältnisse ist ,gegenwärtig allenfalls in Umrissen entwickelt" (Dörre 2019a: 958). 


\section{Zwischen Beschreiben und Fordern: Zur aktuellen Diskussion um eine Kritische Theorie gesellschaftlicher Naturverhältnisse in vier Varianten}

Trotz des konsequenten Bezugs auf Brand/Wissens Begriff der „,imperialen Lebensweise" (Brand/Wissen 2017) in der vorliegenden Studie wird in Bezug auf dessen theoretische Einbettung in eine Kritische Theorie gesellschaftlicher Verhältnisse, die Brand zusammen mit Wissen (Brand/Wissen 2011) und Görg (Görg 1999, 2003; Brand/Görg 2003) entwickelt, aber dennoch Abstand genommen. Es müssen an dieser Stelle nicht alle 33(!) Kritikpunkte, die Stache (Stache 2017: 276ff.) an der Wiener Variante einer Kritischen Theorie gesellschaftlicher Naturverhältnisse um Brand/Görg detailliert herausstellt, wiedergegeben werden, sondern nur dessen „Hauptproblem [...], dass die vermittelnde Instanz zwischen Natur und Gesellschaft nicht deutlich herausgearbeitet wird“ (ebd.: 537). Offen bleibt dadurch, ,woher die kritisierten Diskurse, Vorstellungen und Begriffe [etwa der imperialen Lebensweise, MS] kommen, welchen Charakter sozialökologische Kämpfe haben, wer ihre Träger sind und in welchem Verhältnis sie zur politischen Ökonomie kapitalistischer Klassengesellschaften stehen" (ebd.: 538). Ebenso bleibt unklar, ,auf welcher ökonomischen Basis die sozialen Beziehungen und politischen Kämpfe um das gesellschaftliche Naturverhältnis sich entfalten“ (ebd.).

Dadurch, dass die „ökonomisch-gesellschaftliche Praxis“ in der Kritischen Theorie gesellschaftlicher Naturverhältnisse bei Brand und Görg unterbeleuchtet bleibt, verbleibt sie auf einer kulturalistisch-diskursiven Ebene der Kritik ${ }^{94}$, die die „Dialektik zwischen Natur und Gesellschaft [...] einseitig um die Seite der Natur verkürzt" (ebd.: 276), wodurch Natur vollständig in der gesellschaftlichen Vermittlungspraxis aufgelöst wird und damit verunmöglicht wird zu untersuchen, wie die Natur der Erde ,auf das reagiert, was wir ihr antun" (Latour 2017: 126). Wenn die Relata Gesellschaft und Natur, zwischen denen sich ein Handeln abspielt, aber einseitig in den Relationen der gesellschaftlichen Vermittlung aufgelöst werden, dann werden die widersprüchlichen Realitäten von Gesellschaft und Erdnatur durch die Überbewertung der ,individuelle[n] Handlungsebene, sowohl bei der Verursachung von Naturzerstörung [...] als auch bei der Neugestaltung des gesellschaftlichen Naturverhältnisses“" (Stache 2017: 538), aber bloß wegargumentiert bzw. theoretisch zum Verschwinden gebracht. Damit lassen sich dann aber Transformationsstrategien letztlich nur noch gesellschaftstheoretisch entwickeln.

94 Aus diesem Grunde musste ja der Begriff der imperialen Lebensweise in Teil A der vorliegenden Studie aus einer „Historiografie des Kapitalismus“ (Moore 2016: 602) im Sinne einer kapitalismuskritischen Urbanisierungskritik abgeleitet werden (Kap. 3). 
Disziplinen, die die Eigentätigkeit der Erdökologie in den Blick nehmen, etwa die Weiterentwicklung des Kippens der klimatologischen Kippelemente auch nach der Reduktion der Erderwärmung (Kap. 1), werden hingegen aus dem Transformationsdiskurs suspendiert. Obschon Görg selbst die einseitige Kritik der älteren Kritischen Theorie bei Horkheimer/Adorno kritisiert (Görg 2003: 50f.), bleibt aber auch die Wiener Variante eine Alternative schuldig, die den verschiedenen Disziplinen eine transdisziplinäre Zusammenarbeit ermöglicht, durch die die Konflikte in den „Konstellationen im Verhältnis von Gesellschaft, Individuum und Natur" (ebd.: 59) untersucht werden könnten, ohne den herrschaftlichen Anspruch zu vertreten, die Untersuchungen der Erdnatur hätten sich wie selbstverständlich in den „Referenzrahmen einer Kritischen Theorie“ (ebd.) einzupflegen.

Einen solchen Vorschlag einer multidisziplinären und auch in die Praxis nicht-wissenschaftlicher gesellschaftlicher AkteuInnen übergreifenden Transdisziplinarität unterbreitet hingegen die Frankfurter Variante einer Kritischen Theorie gesellschaftlicher Naturverhältnisse des ISOE um Becker und Jahn (Becker/Jahn 2006; Becker 2016d). Statt Natur einseitig in die sie gesellschaftlich vermittelnden Relationen aufzulösen (wie die Wiener Variante), plädieren sie dafür, sowohl die theoretischen und methodologischen Eigenständigkeiten der Disziplinen als auch die Eigentätigkeiten ihrer je untersuchten epistemologischen Objekte, d.h. die Relata in ihrer Relationalität anzuerkennen und entlang eines Komplementaritätsprinzips transdisziplinär zu ergründen (Kap. 17). Dabei verpassen sie aber, wie in Kap. 18 herausgestellt, in ihre Variante einer Kritischen Theorie gesellschaftlicher Naturverhältnisse einen gehaltvollen Emanzipationsbegriff einzuarbeiten, was ihnen aber methodologisch auch nur gelänge, wenn das Komplementärprinzip dialektisch mit einer kritischen Gesellschaftstheorie verschränkt würde. Eine solche kritische Gesellschaftstheorie macht zwar die Wiener Variante stark, sie unterlässt aber bei ihrer Darstellung exktraktivistisch ausgebeuteter Naturverhältnisse entlang der Logik der Kapital(re)produktion (Acosta/Brand 2018), die „Urbanisierung des Kapitals“ (Harvey 2014: 126) als konkrete Stadtentwicklung nachzuzeichnen, worin sich ja erst strategische Freiräume gegenhegemonialer Bewegungen in Form der von Brand/Wissen vorgeschlagenen „solidarischen Lebensweise“ (Brand/Wissen 2017: Kap. 8) konkretisieren lassen - worauf die Frankfurter Variante gleich auf ganzer Länge verzichtet. Da dies ausbleibt, verbleiben die „Konturen einer solidarischen Lebensweise" (ebd.) der Wiener Variante lediglich auf der Ebene eines hypothetischen Irgendwo und verlegen sie damit zugleich in den kaum zu erfüllenden privaten Verantwortungsbereich der Individuen, die dadurch letztlich selbst dafür verantwortlich gemacht werden, sich die irgendwo im Raum des urbanen Alltags möglichen Nischen für eine solidarische Lebensweise irgendwie anzueignen, um sie zu verwirklichen. 
Daran ändert auch die Jenaer Variante einer Kritischen Theorie gesellschaftlicher Naturverhältnisse um Dörre (Dörre 2018, 2019a, 2019b) nichts, die sich gegenüber der Frankfurter Variante gleichwohl deutlich stärker durch eine Kritik der politischen Ökonomie auszeichnet und entlang ihrer Analysen eine „ökonomisch-ökologische Zangenkrise“ (Dörre 2019a: 974ff.) konstatiert:

„Die historische Einmaligkeit der ökonomisch-ökologischen Zangenkrise ergibt sich daraus, dass das bis dato wichtigste Mittel zur Überwindung ökonomischer Krisen - die Generierung von Wirtschaftswachstum - mehr und mehr sowohl in ökologische Zerstörung als auch in sozial destruktives Wachstum umschlägt. [...] Sollen die ärmeren Länder, die längst nicht mehr mit dem globalen Süden identisch sind, unter den Bedingungen dieser Zangenkrise künftig überhaupt noch eine Entwicklungs- und das heißt immer auch eine Wachstumschance haben, so müssen nicht nur, aber in erster Linie die Ökonomien und Gesellschaften der reichen Staaten mit hohem Ressourcenverbrauch und Schadstoffausstoß eine tiefgreifende Transformation durchlaufen. Im Grunde genommen bleiben diesen Gesellschaften als Ausweg aus ihrem Wachstumsdilemma nur zwei Optionen: 'One is to make growth sustainable; the other is to make degrowth stable.' Deshalb durchlaufen die alten kapitalistischen Zentren gegenwärtig eine tiefgreifende gesellschaftliche Transformation, die zwingend eine Abkehr von jahrzehntelang dominanten Wachstumsmustern beinhalten wird. Diese Transformation ist bereits im Gange. Sie lässt sich nicht aufhalten. Es ist aber möglich, die Weichenstellungen zu beeinflussen, mit denen über die Richtung des Wandels entschieden wird.“ (Dörre 2019b: 22)

Mit Müller lässt sich hingegen hierin die „Problematik eines praktischen ,Experimentalismus', das heißt eines ,social piecemeal engineering' (Popper) von links“ ausfindig machen, die bei Dörre „mit einer grundsätzlichen Verkennung des transformationstheoretischen Status der gesamten Marxschen politischen Ökonomie einhergeht“ und einem ,traditionellen, linearen Modell verhaftet" bleibt (Müller 2019b). Dass es tatsächlich ohne Experimentieren gehen sollte, wie es bei Müller im Umkehrschluss zum Vorschein kommt, muss entlang der Argumentation in der vorliegenden Studie allerdings bestritten werden und soll an dieser Stelle auch nicht weiter diskutiert werden. Entscheidender ist an dieser Stelle die bei Dörre kritisierte Linearität bzw. Induktivität in dessen Argumentation. Statt die Kritische Theorie gesellschaftlicher Naturverhältnisse - um mit Bloch zu sprechen - mit einer „Aussichtserforschung des [objektiv-real, ebd. 271ff.] In-Möglichkeit-Seienden“ (Bloch 2013a: 240) zu verbinden - wie es in der vorliegenden Studie im Anschluss an Lefebvres (Lefebvre 1987: 272ff.) Vorschlag der transdisziplinär-praxisforscherischen Erarbeitung strategischer Hypothesen (Teil B) mit Methoden der kommunalpädagogischen Politik- (Teil C) und Subjektbildung (Teil D) ausformuliert wird -, verbleibt die Jenaer Variante Dörres ganz im Rahmen der Analyse des „sachhaft-objektgemäß Möglichen“ (Bloch 2013a: 264) und damit bloß reaktionär. Dadurch verkennt sie das geschichtsgestaltende Potenzial der Subjekte, die ihre tatsächlichen, objektiv-realen Alternativen möglicher Zukünfte immer schon in ihren gesellschaftlich blockierten/begrenzten Möglichkeiten sozialer Interaktionen, d.h. in den Residuen ihrer imperial vergesellschafteten Subjekte in sich tragen (Lefebvre 1978: 
23). Statt sich also den gesellschaftlichen Subjekten und ihren Residuen zuzuwenden, verbleibt Dörre damit auf der Ebene der gesellschaftlichen Objekte staatspolitischer Ökonomie, d.h. den internationalen Beziehungen und darin sich entwickelnden ,innere[n] und äußere[n] Landnahmen“ (Dörre 2019a: 975f.). Zwar verheißt die Jenaer Variante Dörres mit ihrer Formulierung „,innere[r] und äußere[r] Landnahmen“ (ebd.) die Fokussierung eines dialektischen Subjektverhältnisses von innerer und äußerer Erdnatur der Menschen, bezieht sich damit aber dennoch nur auf die austeritätspolitische Landnahme gesellschaftlicher Sozialverhältnisse, die politikwissenschaftlich unterschieden wird in internationale (äußere) und inner-nationale Landnahmen des Sozialen, d.h. der Wohlfahrtsstaatlichkeit durch die wachstumsgenerierende, neoliberale „Verzahnung von Produktions- und Sorgeregime“ (ebd.: 973).

Nichts destotrotz offenbaren die Untersuchungen der Jenaer Variante Dörres im Zusammenhang mit den Postwachstums-Diskussionen ein handfestes Problem, das trotz aller Kritik an der Linearität in Dörres Argumentation nicht vom Tisch gewischt werden kann: Einerseits ,ist derzeit völlig offen“, „[w]ie sich dauerhaft niedrige Wachstumsraten auf die institutionelle Stabilität von Demokratie und Wohlfahrtsstaat auswirken“ (ebd.: 975), so dass weiterhin ,in der Erzeugung von Wachstum“ das ,wichtigste Mittel zur Überwindung wirtschaftlicher Stagnation“ erblickt werden muss, das zugleich aber andererseits ,unter den gegebenen Bedingungen notwendig zur Verstärkung ökologischer Destruktion führt“ (ebd.: 977). Entsprechend

„muss die Frage, ob der Kapitalismus die ökonomisch-ökologische Zangenkrise überleben kann, mit einem klaren Ja beantworten werden. Die Herrschaft kapitalistischer Eliten ist im Stande auch schwerste Krisen zu überleben. Sie kann zu neuen Landnahmen, sei es der Biosphäre, sei es des Wissens, durchaus in der Lage sein. Die Frage ist nur, zu welchem Preis und ob wir ihn bezahlen wollen (vgl. Harvey 2014, S. 209).“ (ebd.: 978)

Dieses wohl nur innerhalb (s)einer linearen (induktiven) Argumentation Gültigkeit beanspruchen könnende „Ja“ Dörres heißt aber trotz aller Ernüchterung lediglich, dass in den plutokratischen Herrschaftsstrukturen der kapitalistischen Produktionsweise des gesellschaftlichen Alltagslebens das Potenzial steckt, auch die Klimakrise zu überleben. Nicht aber, dass ihnen nichts entgegengesetzt werden kann, um die „ökonomisch-ökologische Zangenkrise“ (ebd.: 974) durch Postwachstumsstrategien zu verlangsamen (Rosa 2019: 1359, vgl. auch Schmidt 2016: 18; Eversberg/Muraca 2019; Schmelzer/Vetter 2019; D'Alisa et al. 2016) und radikal-reformerisch zu politisieren und sie darüber sukzessive zu regulieren - womit das Kennzeichen kapitalistischer Gesellschaftsformationen, nämlich ihre strategische Depolitisierung der ökonomischen Wachstumsproduktion, durchbrochen und entsprechend nicht mehr im bislang gekannten Sinne von Kapitalismus gesprochen werden kann, der die Krise überlebt. Von einer Kritik an der statischen Substanzialisierung hinsichtlich Dörres Auffassung von „der Kapitalismus“ (Dörre 
2019a: 978) wird an dieser Stelle abgesehen. Es sollte in der vorliegenden Studie klar geworden sein, dass es den Kapitalismus nicht geben kann, sondern dass der Kapitalismus stets als Lebensweise, genauer: als ,imperiale Lebensweise" (Brand/Wissen 2017) begriffen werden muss, wie die Wiener Variante ja klar herausstellt.

Aber solcherlei Gegenstrategien bleiben solange bloß fantastische Theoretisierei, die zwar in der Theorie richtig sein mögen, aber nicht für die Praxis taugen, solange eine Kritische Theorie gesellschaftlicher Verhältnisse nur beschreibt und damit das gesellschaftliche Sein, so unterschiedlich es in seinen theoretisierenden Varianten auch ausformuliert sein mag, als bloß beschriebenes Sein so sein lässt, wie es ist. Solange eine Kritische Theorie gesellschaftlicher Naturverhältnisse nicht auch die strategische Erforschung der Förderungsmöglichkeiten transformativer Subjektbildung umfasst, wie dies in der vorliegenden Studie im Anschluss an Lefebvres Konzept der „strategischen Hypothesen“ (Lefebvre 1987: 372ff.) versucht wird, solange

1. linearisiert sie die Klimaproblematik,

2. privatisiert sie dessen Lösungen und

3. legt sie trotz beherzter Kritik und gesellschaftstheoretischer Aufweise dennoch in den Verantwortungsbereich der kapitalistisch individualisierten und einander entfremdeten Subjekte, was ihnen, wie auch ihre Entfremdung von ihrer leiblichen Natur- resp. Erdverbundenheit, mehr und mehr aus den Augen ihrer Subjektivität entschwindet.

4. Dadurch reproduziert sie nolens volens die vorherrschenden elitären Klassenstrukturen, die entlang dieser Entfremdungen immer wieder reproduziert werden.

5. Dadurch wiederum wird nicht nur der Verantwortungsbereich der Subjekte in geradezu naiv unreflektierter Weise und bis zu dessen (nachvollziehbaren) resignierenden Ohnmächtigkeit überfrachtet, sondern

6. drohen in ihren Versuchen, ihrer strukturellen Ohnmacht durch vehemente Forderungen zu entkommen, durch ,"überstürzende[] Geltungsansprüche“ (Negt/Kluge 1993: 32)“ (May 2017b: 167) seitens der verschiedenen Interessensgruppen der verschiedenen transformativen Bewegungen sich selbst und ihrem dringend notwendigen Miteinander im Wege zu stehen.

7. Beides zerstört die dringend notwendige revolutionäre Bewegung des gesellschaftlichen Sozialen, durch die nur gesellschaftliche Transformationen als sozial nachhaltige hervorgebracht werden können.

Entsprechend konstatiert Stache in einer Hamburger Variante einer Kritischen Theorie gesellschaftlicher Naturverhältnisse,

„dass eine versöhnte Relation, also eine Gestaltung der Beziehung der menschlichen Gesellschaft zur äußeren und inneren Natur ohne gesellschaftlich verursachte Zerstörungen und unter 
Berücksichtigung der natürlichen Qualitäten, überhaupt nur dann möglich (sic!) ist, wenn die gesellschaftlichen Verhältnisse revolutioniert werden, die der kapitalistischen Produktionsweise zugrunde liegen. Das bedeutet, es ist erforderlich, dass erstens die gesellschaftliche Arbeit nicht über den Markt beziehungsweise über den Verkauf und Kauf von Waren, sondern von den direkten Produzenten demokratisch organisiert wird. Zweitens ist es unabdingbar, dass das Kapitalverhältnis aufgelöst wird, die Produktionsmittel kollektiv besessen und verwaltet werden, entsprechend die Trennung von Produktionsmitteln und Produzenten sowie die Entfremdung der Lohnarbeiter aufgehoben werden." (Stache 2017: 541)

Diesem Anspruch wurde vor dem Hintergrund der subjektbildenden Prämisse der „Bildung des Sozialen“ zur „Bildung am Sozialen“ (Kunstreich/May 1999) durch ein kommunalistisch ausformuliertes „Recht auf Stadt“ versucht gerecht zu werden (Teil B, C). Dabei wurde zugleich die ,vermittelnde Instanz zwischen Natur und Gesellschaft" (Stache 2017: 537), die Stache in Brands/Görgs Wiener Variante vermisst, die aber zugleich auch in Beckers/Jahns Frankfurter Variante als vermisst gemeldet werden muss, ausfindig gemacht. Gefunden wird sie aber nicht, worin Staches Hamburger Variante und auch Dörres Jenaer Variante sie erblicken, nämlich im Staat sei es in der Fassung Dörres als postpolitische Organisations- und Verwaltungsapparatur kapitalgenerierender Urbanisierung, bestehend in einem $\mathrm{Ne}-$ xus aus „Staat-Finanzwelt-Nexus, Staat-Unternehmens-Nexus und StaatArbeit-Reproduktions-Nexus“ (Dörre 2019a: 965), oder in der demgegenüber recht mager ausfallenden Fassung Staches als „bürgerlicher Staat" (Stache 2017: 543) -, sondern in den Städten, genauer: in der urbanen Alltagspraxis. Mit der Fokussierung des (bürgerlichen) Staates und der „bürgerlichen Denkformen“ (ebd.) als „vermittelnde Instanz zwischen Natur und Gesellschaft“ (ebd.: 537) wird aber letztlich der tatsächliche Praxisherd der (Re)Produktion von staatlich organisierten bürgerlichen Denkformen verkannt und verweist zudem auf eine gewisse Geschichtsblindheit. Nicht der Staat bringt bürgerliche Denkformen hervor, sondern das urbane Leben in den Städten, genauer: die in der städtischen Alltagspraxis (re)produzierten Produktionsverhältnisse des Sozialen entlang der sich seit dem 11./12. Jahrhundert historisch verobjektivierenden Sachzwänge der „Urbanisierung des Kapitals“ (Harvey 2014: 126). Sie haben es notwendig werden lassen, sich zur Bearbeitung des städtischen Alltags global und kolonial mehr und mehr Produktionsmittel beschaffen zu müssen, dessen Bewältigung und übergreifende Organisation wiederum erst Nationalstaaten haben notwendig werden lassen, die wiederum die Städte als kommunalistisch verfasste Entitäten des Politischen abgelöst haben, womit zugleich die nationalstaatliche Organisationsherrschaft der kapitalistischen Eliten legitimierend durchgesetzt wurden und damit die plutokratischen Produktionsverhältnisse des Sozialen stärkten (Blickle 2000a, 2000b; Bookchin 1996; Lefebvre 2016; vgl. Kap. 3). So ist die Fokussierung auf den Staat nicht falsch, wohl aber verkehrt, weil sie - wenn diese Floskel gestattet ist - »das Pferd von hinten aufzäumt«. Mit Harvey lässt sich entsprechend resümieren: 
„Damit ein Kapitalist ein Kapitalist bleibt, muss er einen Teil seines Überschusses reinvestieren, um noch mehr Überschuss zu erwirtschaften. [...] Die Politik des Kapitalismus wird beeinflusst von dem ständigen Bedürfnis, profitable Terrains für die Produktion und Absorbtion von Kapitalüberschüssen zu finden.“ (Harvey 2014: 31)

Und Harvey (vgl. ebd.: 31ff.) stellt zugleich verschiedene Weisen des (Er)Findens finanzialisierender Instrumente heraus, die der Produktion und Absorbtion von Kapitalüberschüssen dienlich sind:

1. die Disziplinierung vorhandener Arbeitskräfte, Lohnsenkungen bereitwillig hinzunehmen (etwa durch Erzeugung von Arbeitslosigkeit oder durch die Erzeugung einer Drohkulisse von Arbeitslosigkeit). Ergänzend: die Erzeugung neuer Arbeitskräfte, etwa durch den politisch gelenkten Zuzug von MigrantInnen oder der Proletarisierung und Prekarisierung von immer weiteren Bevölkerungsteilen.

2. das Finden und Wecken von neuen Bedürfnissen, Lebensstilen und Trends bei gleichzeitiger systematisch medial inszenierten Bedarfsdeckungsangeboten, die lokal und überlokal befriedigt werden können, wodurch neue (inter-)nationale Märkte erzeugt resp. er- und gefunden werden.

3. das (Er)Finden neuer Kreditinstrumente und Derivatmöglichkeiten, damit als notwendig deklarierte Investitionen spätere Kapitalüberschüsse generiert und seitens der Investoren bzw. investierenden Konzerne abgeschöpft werden können. So forciert nicht zuletzt der Kommodifizierungs- und Finanzialisierungsboom nicht erst seit der letzten Finanzkrise 2008/09 die extraktivistische Vernutzung klimatologisch relevanter Aktanten wie Landschaften, Gewässer und (Ur)Wälder, sondern erschwert, gar verhindert auch die Hervorbringung von urban und global Commons (Tricarico/Löschmann 2012). Dadurch wird nicht nur der Klimawandel weiter vorangetrieben, sondern es werden auch die Strategien, ihn zu begrenzen, unterminiert - was ja die ,ökonomischökologische Zangenkrise“" (Dörre 2019a: 274ff.) kennzeichnet.

Das alles wird zwar entlang „bürgerlicher Denkformen“ (Stache 2017: 543) staatlich organisiert, institutionalisiert und legitimiert. Aber gefunden, besser: erfunden wird das alles in den Städten. Nämlich mit den urbanen Lebensweisen der Stadtbevölkerung entlang der dort über die Inwertsetzung des Erdbodens (re)produzierten plutokratischen Gesellschaftsverhältnisse und den daraus resultierenden sowie den dafür notwendigen Ressourcenverbräuchen. Diese erst bringen in anderen Teilen der Erde (neo)extraktivistische Urbanisierungseffekte hervor und erzeugen so erst die staatlich organisierte „ökonomisch-ökologische Zangenkrise" (Dörre 2019a: 274ff.), die die internationalen Beziehungen und Abkommen notwendig werden lassen, an denen sich die verschiedenen Varianten der Kritischen Theorie gesellschaftlicher Natur- 
verhältnisse ja auch zu Recht abarbeiten. Aber mit der Fokussierung des Staates als Ursache der „ökonomisch-ökologische Zangenkrise“ (ebd.) wird der Staat letztlich als irgendwie immer schon seiendes Gebilde untersucht, nicht aber was ihn notwendig macht und dessen alltägliche (Re)Produktion im Alltagsleben der Städte sowie der dort auffindbaren Möglichkeiten revolutionärer Transformationen. Untersucht werden muss daher, wie und wodurch „kapitalistische Klassenmächte in der Lage sind, den urbanen Prozess zu bestimmen“, denn das

,impliziert nicht nur die Herrschaft der kapitalistischen Klasse über den Staatsapparat (insbesondere über die Aspekte staatlicher Macht, die die sozialen Bedingungen und die Infrastruktur innerhalb territorialer Strukturen verwalten und lenken), sondern auch über die gesamte Bevölkerung - über ihren Lebensstil und ihre Arbeitskraft, ihre kulturellen und politischen Werte sowie ihre Vorstellungen von der Welt. Ein solches Ausmaß an Kontrolle ist, wenn überhaupt nicht leicht zu erreichen." (vgl. Harvey 2014: 126f.)

Während die poststrukturalistische (Swyngedouw 2013; Schipper/Latocha 2018; Schipper 2018; Mullis/Schipper 2013; Mössner 2016; Michel/Roskamm 2013b, 2013a; Helbrecht/Weber-Newth 2017) und marxistische Stadtforschung in Anlehnung an Lefebvre (Lefebvre 2016, 2014, 2002, 1987, 2006; Holm 2012, 2013, 2018; Harvey 2014) diese Entwicklungen schon länger und intensiv erforschen, fehlt nicht nur der von Marx abgewandten jüngeren Kritischen Theorie des Frankfurter Instituts für Sozialforschung hierfür das theoretische Fundament (Dörre 2019a: 957), sondern auch den gegenwärtigen Diskussionen um eine Kritische Theorie gesellschaftlicher Naturverhältnisse.

Diese Blindstelle der analytischen Kritik der postpolitischen Staats(re)produktion im urbanen Alltagsleben verhindert nun letztlich auch, mit den aktuellen Varianten einer Kritischen Theorie gesellschaftlicher Naturverhältnisse die vielen, unscheinbaren kleinräumigen gemeinwesenökonomischen Gegenbewegungen und Strategien lebendiger Care-Arbeit (Produzierendensozialpolitiken), die sich in den Nischen des städtischen Alltagslebens gegen die alltägliche Instrumentalisierung ihrer inneren Natur zur Wehr setzen, ausfindig zu machen. Aber nur an diesen subjektiven Residuen der ,imperialen Lebensweise" (Brand/Wissen 2017) lassen sich transformative Hoffnungen empirisch ergründen. Und sie sind es, denen bei der Organisation einer die verschiedenen Produzierendensozialpolitiken übergreifenden Politik des Sozialen in Form einer sozialen Infrastrukturpolitik des Städtischen (May 2013b; AG Links-Netz 2013a; Foundational Economy Collective 2019) geholfen werden muss (Teil B und C).

Wo diese Untersuchung bereits auf theoretischer Ebene ausbleibt, ist es nur folgerichtig zu schlussfolgern, dass ,der Kapitalismus die ökonomischökologische Zangenkrise überleb[t]“" (Dörre 2019a: 978). Aber auch wenn Staches Hamburger Variante demgegenüber zu dem Schluss eines strategischen „Bruch[s] mit der real existierenden kapitalistischen Gesellschaftsfor- 
mation“ durch eine „'revolutionäre Realpolitik' (Luxemburg GW 1.2: 373)“ (Stache 2017: 545) kommt - dem vor dem Hintergrund der in der vorliegenden Studie entfalteten Argumentation in diesem Punkt zugestimmt werden kann und muss(!) -, darf trotzdem nicht übersehen werden, dass auch Stache letztlich auf der Ebene des Forderns bleibt, weil auch hier - wie bei den drei anderen Varianten - die urbane Subjektebene vernachlässigt bleibt.

Zusammenfassend: Alle vier Varianten einer Kritischen Theorie gesellschaftlicher Naturverhältnisse sind sich darin einig, dass der Kritischen Theorie nach Marx der die Erde umspannende ökologische Anspruch verloren gegangen ist. Doch gerade dieser erdökologische Anspruch hatte die Gesellschaftstheorie durch Marx und Engels ja gerade als kritische Gesellschaftstheorie hervorgebracht, weil sie nicht nur die gesellschaftliche Ausbeutung und Unterdrückung menschlicher Erdnaturverhältnisse in den Blick nimmt, sondern auch - wenn auch mit der Einschränkung auf die Bedeutung für den Menschen - die der nicht-menschlichen, erdökologischen Naturverhältnisse. Aber da sie diesen Verlust je unterschiedlich begründen, gelangen sie letztlich auch $\mathrm{zu}$ je unterschiedlichen Konsequenzen, diesen Verlust zu kompensieren, und damit zu je unterschiedlichen transformativen Reichweiten. Bei der Wiener Variante, so konstatiert Stache, die auf die ,[politizistische] Strategie des radikalen Reformismus"“ aufsetzt und damit „Görgs und Brands Teilregression der gesellschaftstheoretischen Zeitdiagnose auf Politikberatung linksreformerischer Politikakteure zum Ausdruck [bringt]“, ,,verbleibt vom radikalen Reformismus maximal die Radikalität in den Forderungen bei gleichzeitigem realpolitisch pragmatistischen zivilgesellschaftlichen Reformismus“ (ebd.: 279). Bei der Frankfurter Variante hingegen „,bleibt offen, wie eine der ökologischen Problematik angemessene Wissenschaftskritik aussehen kann und was die zentralen Gehalte dieser Kritik sein könnte[n]" (Görg 2003: 57). Zwar wird seitens der Frankfurter Variante eine ,systemtheoretische Reorientierung" der Disziplinen und ihrer Theoriebildungen (Becker 2016f: 300) kritisiert und stattdessen ein transdisziplinäres Komplementärprinzip stark gemacht, aber die „ökonomisch-ökologische Zangenkrise“ (Dörre 2019a: 974ff.) lässt sich damit auch nicht in den Blick nehmen. Mit der Kritik, dass dort, ,[w]o allgemeine Kapitalismuskritik mit einer pauschalen Kritik der Naturbeherrschung kurzgeschlossen wird, [...] die empirisch zu beobachtenden Veränderungen gesellschaftlicher Verhältnisse nur noch als illustrierende Beispiele [dienen], und alle Katzen [...] grau [werden]" (Becker 2016c: 463), verzichtet die Frankfurter Variante aber letztlich gleich ganz auf eine Kritik der politischen Ökonomie gesellschaftlicher Naturverhältnisse entlang der „Urbanisierung des Kapitals“ (Harvey 2014: 126) und der kapitalistischen Produktion des urbanen Raums sowie der darin sich entwickelnden Subjektivität der ,imperialen Lebensweise“ (Brand/Wissen 2017). Dieses Urbanisierungsdesiderat füllt zwar die Jenaer Variante, bleibt aber durch ihre lineare 
Lesart des Klimaproblems nur im reaktionären Rahmen des ,sachhaftobjektgemäß Möglichen“ (Bloch 2013a: 264ff.), d.h. auf der Ebene staatspolitischer Realitäten stecken. Zwar übersteigt die Hamburger Variante die Ebene des ,sachhaft-objektgemäß Möglichen“ und insistiert auf ein Darüberhinaus und Jenseits-dessen, lässt aber offen wie sich darin ein „objektiv-real Mögliches““ (ebd.: 271ff.) empirisch begründen lässt.

Allen vier Varianten ist damit gemeinsam, dass sie es allesamt, wenn auch auf ihre je spezifischen Weisen, verpassen, an die unverwirklichten Utopien der gesellschaftlichen Residuen Anschluss zu suchen und die Klimafrage von dort aus neu, nämlich strategisch-utopisch zu beantworten zu versuchen. Darin ließe sich ein Paradigmenwechsel der Klimadebatten vom Fordern zum Fördern markieren, zu dem die vorliegende Studie einen Beitrag zu liefern beansprucht.

\section{Vom Fordern zum Fördern: Zur Positionierung in der Diskussion}

Zwischen diesen beiden Schlussfolgerungen des Überlebens einerseits und des sukzessiven Bruchs mit jedweden kapitalistischen Gesellschaftsformationen andererseits wird hier nun stattdessen Marxens materialistischer Bildungsansatz einer „wahre[n] ,öffentlichen“ Erziehung des Staates“ (Marx 1981a: 95) verortet. Dieser insistiert - als docta spes (Bloch 2013a: 8) - nicht nur auf Transformationen der äußeren gesellschaftlichen Erdnaturverhältnisse der Menschen (ökosoziale Transformationen), sondern auch auf die emanzipatorische Entwicklung ihrer inner-leiblichen Erdnaturverhältnisse (sozialökologische Subjektbildung), durch die den Subjekten für die eigene Entwicklung die Notwendigkeit des bewussten Gestaltens der Erde (als ihr äußerer Leib) mehr und mehr zu Bewusstsein kommen kann und sie daher in ihrem Alltag beginnen, die Erde als sympoietischen Gesamtkomplex, als Gaia ins Werk zu setzen, womit sie zugleich ihren Alltag als ihr Werk hervorzubringen beginnen (sozial-ökologische Transformation). Entsprechend wird nicht nur eine ökosoziale Transformation als ,soziale Revolution mit einer politischen Seele“ (Marx 1981b: 408f.) gefordert, sondern über kommunalpädagogische Ansätze der Subjektbildung eine sozial-ökologische Transformation als „politische Revolution mit einer sozialen Seele“ (ebd.) gefördert, um dadurch noch unabgegoltene sowie noch ungekannte subjektive Möglichkeiten des interaktionalen Seins nicht nur zwischen den Menschen auf und mit der Erde verwirklichen zu können, sondern auch zwischen den Menschen und den nicht-menschlichen Akteuren und Aktanten dieser Erde. Darin lässt sich die in der vorliegenden Studie für erstrebenswert argumen- 
tierte sozial-ökologische Transformation durchaus als ein utopisches und uchronisches Anthropozänprojekt erblicken, das durch eine Politik Sozialer Ökologie räumlich wie zeitlich so weit wie möglich aus dem Rahmen der sachhaft-objektgemäß nur möglichen Wirklichkeit bestehender Kapital(re)produktionssachzwänge herausfallen muss, um die Klimaproblematik so unkonventionell wie möglich bearbeiten zu können.

Zur Frage steht aber: Wo und bei wem anfangen? Wie der WBGU sieht auch Lefebvre die „Pioniere des Wandels“ (WBGU 2011c: 7, 2016b: 13) in (vom Mainstream marginalisierten) AkteurInnen kultureller Nischen:

„In dieser noch immer von der durchgeplanten Organisation der Industrieproduktion beherrschten Gesellschaft verlangt man nach einer ,Kreativität', die nur anomische Gruppen, als außergesellschaftliche gesellschaftliche Gruppen leisten können. [...] Nur Randgruppen erfassen und begreifen die Gesellschaft in ihrer Gesamtheit, indem sie, interessante' Bilder erarbeiten. Diese gleiche Gesellschaft, die von ihnen Werke verlangt, erhebt auch den Anspruch, sie ihren Normen zu unterwerfen und ihre Randständigkeit abzubauen. Sie will sie ,sozialisieren', indem sie ihre Aktivität in die zugleich fiktive und reale Sozialisation der Produktion integriert, also in den derzeitigen Rahmen des herrschenden Neokapitalismus, der über die Produktionsmittel verfügt.“ (Lefebvre 1974: 207f.)

Kreativität entsteht aber ,,nur, wenn innerhalb einer notwendig randständigen und anomischen Gruppe die Normverletzung zur Norm wird“" (ebd.: 208), während sie zugleich - und das ist die Herausforderung in der Klimafrage gesellschaftlich anerkannt werden muss. Ohne dass sie sich dafür letztlich doch in den (vermeintlichen) Konsens der vorherrschenden Alltagspraxis der Gesellschaft einzupassen hat. Eine solche, wenn man so will, multikulturelle Nischengesellschaft lässt sich am ehesten im Rahmen einer kollaborativen Stadtentwicklungspolitik, d.h. in einer kommunalistischen Selbstverwaltung konföderativ vernetzter Städte realisieren (Teil B, C), die die Nutzung und Regulierung der urbanen Raumproduktion - angefangen vom Grund und Boden, den Immobilien, die Anbindung an den ÖPNV, die Strom-, Kommunikations-, Wasser-, Wohnungs-, Bildungs- und Gesundheitsversorgung bis hin zu ihrer ökonomischen und administrativen Selbstorganisation und der Politisierung der ökonomischen Wachstumsrate samt ihrer inwertsetzenden Effekte - in die Hände aller AkteurInnen legt, die diese Infrastrukturen benutzen.

Allerdings bleibt Lefebvre erstaunlich blass, wenn es darum geht, wie die Probleme, die mit der kommunalen Selbstverwaltung entstehen (ebd.: 144), pädagogisch gehandhabt werden können. Es ist dann letztlich genau der Punkt, an dem Soziale Arbeit ,wie keine andere“ (Bartosch 2020: 20) Disziplin und Profession transformativer (Praxis-)Forschung und transformativer Bildung ins Spiel kommt, indem sie den unterschiedlichen und konfligierenden gesellschaftlichen Interessensgruppen nicht nur ein politisches Zusammenkommen, sondern auch ein gedeihliches Auskommen ermöglicht, die ihre jeweilige Gruppenautonomien, d.h. ihre Produzierendensozialpolitiken in einer sie übergreifenden Politik des Sozialen beibehält. Eine solche die 
Produzierendensozialpolitiken übergreifende Politik des Sozialen in Form einer sozialen Infrastrukturpolitik des Städtischen samt dessen ökonomischökologischer Produktionsverhältnisse zielt daher nicht darauf ab, sie einander anzugleichen oder die randständigen Gruppen den hegemonialen sozialverträglich unterzuordnen. Sondern zielt einzig darauf $a b$, dass sie kollaborativ voneinander und miteinander lernen können, für die jeweils eigene Gruppenpolitiken im Hinblick auf die jeweils anderen Gruppenpolitiken nach politischen Wegen und Mitteln zu suchen, die ihre Differenzen anerkennen (Lefebvre 2014: Recht auf Differenz) und so zu regulieren vermögen, dass ihre jeweilige Gruppencharakteristika erhalten bleiben (ebd.: Recht auf Zentralität). Erst so wird es ihnen möglich, dass die Gruppen einander als eigenständige Gruppen in Erscheinung treten und sich gemeinsame öffentliche Räume schaffen können (ebd.: Recht auf Straße), in und mit denen nicht nur ihre Differenzen, sondern auch die dadurch entstehende städtische Eigenart, die der WBGU (2016b) als zentrales Element des gesellschaftlichen Transformationsprozesses herausstellt, mit anderen städtischen Eigenarten politisch regulieren zu können. Erst dadurch ließe sich eine vom Lokalen bis zum Globalen reichende und kommunalistisch-konföderal organisierte sozialraumorientierte Klimagerechtigkeit herstellen, die die Schäden und Lasten, die bei der jeweiligen lokalen Urbanisierung bzw. Vergesellschaftung regionaler Naturverhältnisse der Erde für andere Städte und Regionen der Erde entstehen, ausgleichend regulieren können. Erst dadurch, dass die Leute in den Städten mit ihren unterschiedlichen Lebensweisen die globale Klimafrage als gemeinsame Aufgabe lokal im Hinblick aufs Globale und global im Hinblick aufs Lokale bearbeiten können, können sie sich überhaupt erst als unterschiedlich verschiedene BewohnerInnen nicht nur gemeinsam produzierter Städte, sondern auch einer gemeinsam bewohnten Erde als ihrem gemeinsamen unorganischen Leib (Marx 1983: 396) subjektiv bewusst werden und die politische Macht darüber entwickeln, politische Rechte nicht nur Menschen, sondern auch nicht-menschlichen Akteuren und Aktanten einzuräumen und damit Stück für Stück eine Politik Sozialer Ökologie resp. ein Anthropozän, terrestrisches Gemeinwesen, kurz: Gaia hervorzubringen. Da es einer „Rechtsordnung $[\ldots]$ grundsätzlich frei [steht], wen oder was sie als ein Rechtssubjekt anerkennt", ist die „Anerkennung der Rechtssubjektivität der Natur durch Verfassungsauslegung“ - auch in Deutschland" - ,also durchaus möglich“, so wie sie etwa in der Verfassung Ecuadors ${ }^{96}$ bereits verankert ist (Kersten 2020: 29ff.).

95 Etwa durch Art 19, Abs. 3 GG und Art. 20a GG (zum Überblick der gesetzlichen Ausgestaltungsmöglichkeiten: Kersten 2020)

96 Dort heißt es in Art. 10, Abs. 2: „Die Natur ist Gegenstand der Rechte, die die Verfassung für sie anerkennt". Und in Art. 71: „Die Natur [...] in der das Leben reproduziert wird und stattfindet, hat das Recht auf integralen Respekt für ihre Existenz und für die Aufrechterhaltung und Regeneration ihrer Lebenszyklen, ihrer Struktur, ihrer Funktionen und ihrer Evolutionsprozesse. Alle Personen, Gemeinschaften, Völker und Nationen können sich an die 
Kurzum: Es ist genau dieser Aspekt des strategischen, d.h. transdisziplinär theoriegeleiteten und empirisch fundierten Förderns sozial-ökologischer Subjektbildung, mit dem der in der vorliegenden Studie vorgelegte Entwurf einer terrestrischen Nachhaltigkeitswissenschaft sozial-ökologischer Transformation über die bisherigen Diskussionen um eine Kritische Theorie gesellschaftlicher Naturverhältnisse hinausgeht und sie mit materialistischen Bildungsansätzen und Theorien Sozialer Arbeit verbindet. Sie werden dadurch zugleich in den Kontext der Klimafrage gerückt und damit ein Stückchen näher an die gegenwärtige soziale Frage der anstehenden Großen Transformation und der Frage, wie sie sozial gerecht beantwortet werden kann (Mührel 2020: 167). Genauer: Der vorgelegte Entwurf einer terrestrischen Nachhaltigkeitswissenschaft sozial-ökologischer Transformation geht insofern über die bisherige Diskussion um eine Kritische Theorie gesellschaftlicher Naturverhältnisse hinaus, als dass sie

1. theoretisch wie praktisch transdisziplinär ausgerichtet ist,

2. nicht nur auf die Gestaltung der äußeren Erdnatur der Menschen insistiert, sondern auch auf die emanzipatorische Subjektbildung ihrer inneren Erdnatur resp. ihrer Leiblichkeit,

und

3. weil sie beansprucht, die Kritik am alltäglichen Anthropozentrismus systematisch in die transdisziplinär-transformative Theorie- und Praxisentwicklung einzubeziehen.

„Vom Standpunkt einer höhern ökonomischen Gesellschaftsformation“, so lässt sich mit Marx (Marx 1964: 784) über Marx hinausgehen, muss auch der Anthropozentrismus ebenso „abgeschmackt erscheinen“, wie das „Privateigentum einzelner Individuen am Erdball“ und das „Privateigentum eines Menschen an einem andern Menschen" abgeschmackt erscheinen. Der darin implizierte Materialismusbegriff kehrt nicht nur zur Marxschen Analyse der politischen Ökonomie zurück, sondern auch zu dessen erdökologischen Implikationen und geht dabei mit Engels einen notwendigen Schritt weiter. In seinem „Vorwort zur Neuauflage von 1993“ seiner Dissertation zum „Begriff der Natur in der Lehre von Marx“ plädiert Alfred Schmidt in dieser Hinsicht für einen ökologischen Materialismus:

öffentlichen Behörden wenden, um die Rechte der Natur durchzusetzen. Zur Durchsetzung und Auslegung dieser Rechte sind die in der Verfassung festgelegten Grundsätze zu beachten, soweit dies angemessen ist. Der Staat gibt natürlichen und juristischen Personen und Gemeinschaften Anreize, die Natur zu schützen und die Achtung vor allen Elementen eines Ökosystems zu fördern." (zit. in Kersten 2020: 29; eigene Übersetzung) 
„Heuristisch brauchbar ist auch Engels’ These von der Natur als ,Gesamtzusammenhang ${ }^{\text {‘7 }}$, als in sich reich gegliedertes System universeller Wechselwirkungen. Innerhalb dieses in originärer Selbstgegebenheit sich darbietenden Systems bildet der durch materielle Produktion vermittelte Austausch von Mensch und Natur nur eine von zahllosen Interaktionen. Dadurch wird der bisherige, an menschlicher Praxis und Geschichte orientierte Denkansatz nicht hinfällig, aber relativiert. Der historisch-dialektische erweitert sich zum ,ökologischen Materialismus‘. Dieser begreift, daß die Dialektik von Produktivkräften und Produktionsverhältnissen umschlossen und getragen wird von einer elementarischen Dialektik von Erde und Mensch, den ungeschichtlichen Voraussetzungen aller Geschichte. Hierin bewährt sich der Gedanke, daß die Welt eine materielle Einheit bildet.“ (Schmidt 2016: 18)

Den Begriff des ökologischen Materialismus hat Schmidt bei Carl Amery entnommen, der ihn als „Perspektive des konsequenten Materialismus““”, genauer: als „'Versöhnung mit der Erde“" herausstellt, die nicht zuvörderst darauf insistiert, die Welt zu verändern, sondern sie zu erhalten, wonach „'[n]icht Ende der Entfremdung, nicht Fülle der Güter für den Menschen kann Ziel sein, sondern zunächst und vor allem eine Zukunftsordnung, die sich aus dem Respekt vor jeder Materie, auch nichtmenschlicher ergibt “" (Amery 1976, S. 166, 185 zit. in ebd.: 22). Diese Anfügung ist insofern wichtig, weil an dieser Stelle nochmal die ökumenische Reichweite des ökologischen Materialismusbegriffs herausgestellt wird, der die polit-ökonomischen Analysen des Marxschen Materialismusbegriffs nicht aus den Augen verliert und es zugleich vermag vom Marxschen Anthropozentrismus abzuweichen und die Bedeutung des Menschen im ökologischen Gesamtkomplex Erde zu relativieren, weil er ihn nur als politischen Akteur zentral setzt, nicht aber hinsichtlich des Inhalts seiner Politik. Zugleich macht Schmidt mit Amery aber eine höchst problematische Hierarchisierung der Problembearbeitung auf, die in aller Konsequenz problematisiert werden muss.

Eine zuvörderst erhaltene Erde, auf der weiterhin Ausbeutung und Unterdrückung menschlicher Naturverhältnisse auf der Tagesordnung stehen, tritt dennoch als keine bewohnenswerte in Erscheinung. Denn auch wenn sich die gesellschaftlichen Herrschaftsverhältnisse gegenüber der Erdökologie als äußere Natur des Menschen neu organisieren, dabei aber die bestehenden privatwirtschaftlichen Eigentumsverhältnisse am Erdball und alle damit verbundenen apolitisch belassenen kapitalistischen Knechtungs- und Abhängigkeitsverhältnisse der Menschen unangetastet bleiben und bloß grün angepinselt werden, bleibt die Erde weiterhin ein für das sympoietische Gedeihen unwirtlicher Ort, da sie bloß als langlebiger Ressourcenkomplex für die Kapital(re)produktion hervorgebracht wird, die weiterhin die schonungslose Inwertsetzung (wenigstens) der menschlichen Natur impliziert. So wäre zwar

97 Schmidt bezieht sich hier auf Engels“ „Dialektik der Natur“ „,als Wissenschaft des Gesamtzusammenhangs. Hauptgesetze: Umschlag von Quantität und Qualität - Gegenseitiges Durchdringen der polaren Gegensätze und Ineinander-Umschlagen, wenn auf die Spitze getrieben - Entwicklung durch den Widerspruch oder Negation der Negation - Spirale Form der Entwicklung.“ (Engels 1975: 307) 
„[bereits] [v]iel [...] gewonnen, wenn sich die Menschheit, unter Verzicht auf schrankenloses Wachstum, darauf einrichten könnte, künftig in besserem Einklang mit dem System ${ }^{98}$ der Natur zu leben“" (ebd.: 18). Solange aber die von Marx herausgearbeitete Überwindung der unter dem Wertgesetz stehenden privaten Eigentumsverhältnisse des gesamten Erdkomplexes, also auch der mit ihr lebenden Akteure und sich vollziehenden Aktanten nicht konsequent politisiert und kommunalisiert werden, ist im Grunde, außer dass die Reproduktion der die menschliche Naturverhältnisse ausbeutenden und unterdrückenden Produktionsverhältnisse gesichert und im geologischen (Zeit-)Ausmaß auf Dauer gestellt sind, an der Qualität der Bewohnbarkeit der Erde im emanzipatorischen Sinne rein gar nichts hinzugewonnen. Und genau in diesen Punkten muss ein sozial-ökologischer bzw. terrestrischer Materialismusbegriff über den ökologischen Materialismusbegriffs Amerys und Schmidts hinausgehen, indem er neben den politökonomischen Analysen auch wieder verstärkt an die ethischen Implikationen des Marxschen Materialismusbegriffs ${ }^{99}$ Anschluss sucht, zugleich aber dessen anthropozentrische Implikationen zu überwinden trachtet: Weder kann es also allein ausreichend sein, das ausbeuterische Verhältnis der Menschen untereinander zu beenden und sich der recht naiven Hoffnung hingeben, das Klimaproblem würde sich mit der Überwindung kapitalistisch-entfremdender Verhältnisse zwischen den Menschen von allein erledigen (damit würde die Bedeutung der bereits in klimaerwärmende Bewegung gesetzten klimatologischen Aktanten und Kippelemente völlig verkannt, vgl. Kap. 1). Noch kann es allein ausreichend sein, das ausbeuterische Verhältnis der Menschen zu ihrer äußeren Erdnatur zu beenden, etwa indem die Klimafrage von der sozialen Frage abgekoppelt wird und das Klimaproblem rein systemlogisch und technisch depolitisierend bearbeitet wird.

Wenn die hegelsche Begriffsdialektik vom Allgemeinen, Besonderen und Einzelnen (Hegel 1970c: 273) konsequent materialistisch gewendet und sozial-ökologisch aufgehoben werden soll (vgl. Exkurs in Kap. 6.2), muss ein sozial-ökologischer bzw. terrestrischer Materialismusbegriff beides zusammenbringen. Statt zuerst nur die Bewohnbarkeit der Erde zu erhalten und sie dann von der kapitalistischen Vernutzung der mit ihr lebenden Akteure und sich vollziehenden Aktanten zu befreien, muss beides Hand in Hand gehen und $\mathrm{zu}$ ihrer Realisierung über strategische Transformationsprozesse dialektisch miteinander verschränkt werden: Mit der Befreiung der kapitalistischen

98 Wenn Schmidt in seiner Dissertation zum „Begriff der Natur in der Lehre von Marx“ von 1957 von System spricht, ist damit noch nicht der systemtheoretische Impetus des späteren Systembegriffs zum Ausdruck gebracht, von dem in der vorliegenden Studie Abstand genommen wird (vgl. Kap. 6.2 und Kap. 17).

99 Alfred Schmidt fasst die ethischen Implikationen des Marxschen Materialismusbegriffs darin zusammen, als dass er ,,sich [...] um die Möglichkeit [kümmert], Hunger und Elend auf der Welt abzuschaffen. Mit den ethischen Materialisten der Antike [...] hat Marx ein eudämonistisches Moment gemeinsam." (Schmidt 2016: 51f.; vgl. auch Kap. 2) 
Vernutzung der mit der Erde lebenden Akteure und sich vollziehenden Aktanten muss die Bewohnbarkeit der Erde erhalten werden und umgekehrt muss mit dem Erhalt der Bewohnbarkeit der Erde die Befreiung der kapitalistischen Vernutzung der mit ihr lebenden Akteure und sich vollziehenden Aktanten einhergehen können. Ein sozial-ökologischer bzw. terrestrischer Materialismusbegriff muss also in einem hypothetischen Emanzipationsbegriff aufgehen, der strategisch auf die sympoietische Gedeihlichkeit möglichst vieler Lebewesen aus ist, mithin auf die Hervorbringung möglichst vieler Akteure und Aktanten der Erdatur als Rechtssubjekte und ihrer kommunalistischen Bewirtschaftung und Verwaltung (vgl. Exkurs in Kap. 16).

Ein solch hypothetischer Emanzipationsbegriff könnte dann in einem emanzipatorischen Begriff sozial-ökologischer Transformation bzw. in einem Transformationsprojekt Soziale Ökologie (Anthropozän) in ökosozialistischer Hinsicht aufgehen, wenn er mit einer „Aussichtserforschung des InMöglichkeit-Seienden“ (Bloch 2013a: 240), genauer: mit der Erforschung der tatsächlichen menschlichen Subjektmöglichkeiten und den gesellschaftlichen Möglichkeiten, nicht-menschliche Akteure und Aktanten als politische und juristische Subjekte zu integrieren, verknüpft würde, die strategisch darauf aus wäre, das In-Möglichkeit-Seiende Gaia-Gemeinwesen immer wieder neu empirisch auszuloten, zu konkretisieren und immer wieder neu zu verwirklichen. Dass aufgrund des von Dörre (Dörre 2019a) aufgezeigten ökonomischökologischen Zangen-Dilemma eine erdgeschichtliche Epoche Sozialer Ökologie, ein Anthropozän, entlang einer solchen Aussichtserforschung des objektiv Möglichen erst aus dem tatsächlichen gesellschafts-strukturellen AnGefangensein der historischen Bewegungen der gesellschaftlichen Subjekte und Strukturobjekte (Institutionen etc.) herausgeschält werden muss, wurde bereits ausgiebig ergründet.

Entsprechend unverständlich bleiben ökosozialistische und/oder ökoanarchistische Theorien, die auf einen radikalen Bruch mit den gegenwärtigen gesellschaftlichen Kapitalverhältnissen sowie mit der sie ermöglichenden politischen Ökonomie als auch mit der aus ihnen erwachsenen ,imperialen Lebensweise“ (Brand/Wissen 2017) aus sind und darin das „objektiv-real Mögliche“ (Bloch 2013a: 271ff.) zu verwirklichen können meinen. Etwa in Löwys Verständnis von Ökosozialismus (Löwy 2005, 2016) oder Bookchins ökoanarchistischen libertären Kommunalismus (zum Überblick: Biehl 1998, Bookchin 2015c). Sie ignorieren in geradezu naiver Weise das je strukturelle An-Gefangensein der gesellschaftlichen Praxisverhältnisse im je ,sachhaftobjektgemäß Möglichen“ (Bloch 2013a: 264ff.) und versprechen eine sozialökologische Zukunft, ohne sich die Mittel erarbeiten zu müssen meinen, mit denen eine sozial-ökologische Zukunft erst mimetisch und praxisforscherisch aus der kapitalistisch anti-ökologischen Gegenwart im globalgesellschaftlichen Ausmaß, und nicht nur in kleinen Aussteigerprojekten, überstiegen werden kann. Ihnen droht damit ,eine raffinierte politische Abseitsfalle: 
„Wer jeden New Deal ablehnt, weil er lieber eine Revolution haben möchte, verabschiedet sich zumindest aus der Tagespolitik - ich denke, überhaupt aus den Auseinandersetzungen, in denen sich politische Subjekte und gesellschaftspolitische Bündnisse erst herausbilden können. Wer speziell eine grüne Ausrichtung eines New Deals ablehnt, der wird zum Komplizen derjenigen unter den herrschenden Eliten, die die Ernsthaftigkeit und Dringlichkeit der sich zuspitzenden ökologischen Krise leugnen. [...] Daher gibt es m.E. keine andere Möglichkeit, als sowohl an der Debatte über einen New New Deal, als auch über dessen notwendig grüne Ausrichtung kritisch-konstruktiv teilzunehmen. Nur so kann der Spielverlauf überhaupt noch beeinflusst werden. [...] Eine Politik der radikalen, emanzipatorischen Linken muss sich heute von der falschen Vorstellung befreien, dass sie zwischen der Entfaltung ihrer radikalen Visionen und einem Eingreifen in die Tagespolitik zu wählen hätte. An die Stelle dieses schlechten EntwederOder muss sie ein entschlossenes Sowohl-als-auch setzen - indem sie sowohl ihre radikalen Zukunftsvisionen - klassenlose, herrschaftsfreie Gesellschaft, ökologische Versöhnung der Menschheit mit der Biosphäre, befreite Geschlechterverhältnisse, solidarisches Zusammenleben der Völker in einer friedlichen Menschheit - als solche mutig entfaltet, als auch konkret und genau darüber mitdiskutiert, wie heute sinnvolle erste Schritte zur Überwindung der gegenwärtigen Krisenkonstellation gegangen werden können. Vorschläge für einen Green New Deal sind daher nicht als solche zu verwerfen und zu bekämpfen, sondern konkret im Einzelnen daraufhin zu prüfen, ob die in ihnen vorgeschlagenen Sofortmaßnahmen das leisten können, was sie versprechen (oder vielleicht auch gänzlich ungeeignet sind) - und ob es nicht noch bessere Vorschläge gibt, wie sie sich in anderen Konzeptionen eines Green New Deal finden lassen oder auch aus bereits laufenden Debatten in den wirklichen sozialen Kämpfen entwickeln lassen.“ (Wolf 2009: 155ff.)

Statt einer naiven Bruchtheorie bedarf es also das radikal-reformerisch strategische und entschlossene Handeln ,revolutionärer Realpolitik“ (Luxemburg), das im alltäglichen Handeln und inmitten der alltäglichen Gesellschaftsverhältnisse Hoffnung ermöglicht, indem neue und vor allem gegenhegemoniale, transversale Wege der transgenerativen Transformation der gesellschaftlichen Naturverhältnisse geöffnet bzw. erschlossen werden. Ohne Hoffnung also keine gesellschaftlichen Veränderungen. Aber aus einer praxisphilosophischen Perspektive kann Hoffnung nur als historisch-latente Möglichkeitstendenz eines „gefährliche[n] Vielleicht[s]“ (Nietzsche 1954c: 568) verstanden werden. Wenn schon Marx die „Geschichte des Grundeigentums“ als „Geheimgeschichte" der Reproduktion der Produktionsverhältnisse der römischen Republik ausmacht (Marx 1962a: 96), dann ist es gegenwärtig nötiger denn je, sie auf historischem Niveau endlich zu durchbrechen, um das ,gefährliche Vielleicht" (Nietzsche 1954c: 568) einer politischen Bildung des Ökosozialen zur sozial-ökologischen Subjektbildung am Ökosozialen verwirklichen zu können. Hierin besteht nun letztlich die ganze praktische Notwendigkeit Sozialer Arbeit im sozial-ökologischen Transformationsprozess, da sie sich als Profession und Disziplin gerade dadurch auszeichnet, dass sie sich entlang eines materialistisch-emanzipatorischen (Subjekt-)Bildungsbegriffs (Sünker 1989, 2012) als „sozialpädagogisches Ortshandeln“ (Winkler 1988) und kommunale Pädagogik des Sozialen (Richter 1998, 2001, 2008, 2009, 2016, 2019b) versteht, die auf eine übergreifende Politik des Sozialen insistiert (Alisch/May 2013, 2015; May 2017b, 2013b) und sie genossenschaftlich strukturell zu verankern sucht (Kunstreich 2005, 2006a, 2018), um 
ihr damit einen verbindlichen und zugleich heterarchischen Organisationsrahmen zu geben. Eben deshalb kann und muss Soziale Arbeit in Zeiten des Klimawandels „wie keine andere“ (Bartosch 2020: 20) Profession und Disziplin einen elementaren Beitrag zum sozial-ökologischen Transformationsprozess der Städte leisten. In dieser Hinsicht wird mit Blick auf die Fachkräfte Sozialer Arbeit in all ihren Arbeitsfeldern abschließend noch einmal dafür plädiert,

,alle unsere Ressourcen, Ämter und Mandate gemeinsam dafür [zu] nutzen, aufzuklären und alles dafür zu tun, dass eine mächtige betriebs- und ortsübergreifend und internationale Bewegung entsteht, die die bestehenden Verhältnisse umstößt zugunsten einer globalen ökosozialistischen Demokratie!“ (Ökosozialistisches Netzwerk 2017: 18) 


\section{Literaturverzeichnis}

Acosta, Alberto/Brand, Ulrich (2018): Radikale Alternativen. Warum man den Kapitalismus nur mit vereinten Kräften überwinden kann. München: oekom verlag.

Adorno, Theodor W. (1972): Zum gegenwärtigen Stand der deutschen Soziologie. In: Tiedemann, R. (Hrsg.): Soziologische Schriften I. Gesammelte Schriften. Band 8. Frankfurt am Main: Suhrkamp, S. 500-531.

AG Links-Netz (2013a): Sozialpolitik als Bereitstellung einer Sozialen Infrastruktur. In: Hirsch, J./Brüchert, O./Krampe, E.-M. (Hrsg.): Sozialpolitik anders gedacht. Soziale Infrastruktur. Hamburg: VSA-Verlag, S. 50-74.

AG Links-Netz (2013b): Um was es geht. In: Hirsch, J./Brüchert, O./Krampe, E.-M. (Hrsg.): Sozialpolitik anders gedacht. Soziale Infrastruktur. Hamburg: VSAVerlag, S. 7-19.

Aisch, Gregor (2019): What different degrees of global warming look like. https:// blog.datawrapper.de/climate-crisis-global-warming/ [Zugriff: 21.07.2020].

Albert, Hans (2010a): Brauchen wir Induktion? Antwort auf Norbert Hoersters erneute Kritik. In: Aufklärung und Kritik. Zeitschrift für freies Denken und humanistische Philosphie, Heft 4/2010, S. 22-24.

Albert, Hans (2010b): Der kritische Rationalismus und das Problem der Induktion. Zu Norberts Hoersters Kritik des kritischen Rationalismus. In: Aufklärung und Kritik. Zeitschrift für freies Denken und humanistische Philosphie, Heft 2/2010, S. 144-147.

Albert, Hans (2011): Warum man auf Induktion verzichten kann. Zur Kritik der Hoersterschen Auffassung. In: Aufklärung und Kritik. Zeitschrift für freies Denken und humanistische Philosphie, Heft 2/2011, S. 72-74.

Alisch, Monika/May, Michael (2013): Von der Sozialraumorientierung zu Sozialraumentwicklung / Sozialraumorganisation. In: Alisch, M./May, M. (Hrsg.): Sozialraumentwicklung und Raumaneignung von Kindern und Jugendlichen. Leverkusen-Opladen: Barbara Budrich-Esser, S. 7-28.

Alisch, Monika/May, Michael (2015): Zum Zusammenhang von Normalität, Inklusion, Sozialraumentwicklung und -organisation. In: Alisch, M./May, M. (Hrsg.): „Das Ist Doch Nicht Normal ... !“. Sozialraumentwicklung, Inklusion und Konstruktionen von Normalität. Leverkusen-Opladen: Barbara Budrich-Esser, S. 729.

Ali-Zade, A. A./Aliev, A. (1985): Die Wissenschaft Geologie und ihre Bedeutung für die Umgestaltung der Natur. In: Fabian, E./Guntau, M./Störr, M. (Hrsg.): Philosophie und Geologie. Beiträge zum III. DDR-UdSSR-Symposium zur Geschichte der Geologischen Wissenschaften „Entwicklungsgeschichte von philosophischmethodologischen Ideen in den Geowissenschaften“. 25.-27. Oktober 1983 in Greifswald. Berlin: Akademie-Verlag, S. 69-74.

Altner, Günter (1987): Die Überlebenskrise der Gegenwart. Ansätze zum Dialog mit der Natur in Naturwissenschaft und Theologie. Darmstadt: Wissenschaftliche Buchgesellschaft (WBG).

Altner, Günter (1991): Naturvergessenheit. Grundlagen einer umfassenden Bioethik. Darmstadt: Wissenschaftliche Buchgesellschaft (WBG). 
Altvater, Elmar (2013): Wachstum, Globalisierung, Anthropozän. Steigerungsformen einer zerstörerischen Wirtschaftsweise. In: emanzipation. Zeitschrift für sozialistische theorie und praxis, Heft 1/2013, S. 71-88.

Altvater, Elmar (2014): Dunkle Sonne. Im Erdzeitalter des Kapitals. https://mondediplomatique.de/artikel/!267688 [Zugriff: 05.04.2019].

Altvater, Elmar (2015): Engels neu entdecken. Das hellblaue Bändchen zur Einführung in die „Dialektik der Natur" und die Kritik von Akkumulation und Wachstum. Hamburg: VSA Verlag.

Altvater, Elmar (2017): Kapitalozän. Der Kapitalismus schreibt Erdgeschichte. In: Zeitschrift LuXemburg, Heft 2-3/2017, S. 108-117.

Anhorn, Roland (2012): Wie alles anfing... und kein Ende findet. Traditionelle und kritische Soziale Arbeit im Vergleich von Mary E. Richmond und Jane Addams. In: Anhorn, R./Bettinger, F./Horlacher, C./Rathgeb, K. (Hrsg.): Kritik der Sozialen Arbeit - kritische Soziale Arbeit. Wiesbaden: VS Verlag für Sozialwissenschaften, S. 225-270.

Anhorn, Roland/Balzereit, Marcus (Hrsg.) (2016): Handbuch Therapeutisierung und Soziale Arbeit. Wiesbaden: Springer VS.

Arndt, Andreas (2012): Karl Marx. Versuch über den Zusammenhang seiner Theorie. Berlin: Akademie Verlag.

Bach, Clemens (2016): Robert Owen: Raum und Geschichte als Direktiven einer sozialistischen Pädagogik. In: Paul-Siewert, B./Pfützner, R./Winkler, M. (Hrsg.): Sozialistische Pädagogik. Eine kommentierte Anthologie. Baltmannsweiler: Schneider Verlag Hohengehren GmbH, S. 207-217.

Barad, Karen (2012): Agentieller Realismus. Über die Bedeutung materielldiskursiver Praktiken. Berlin: Suhrkamp.

Bartosch, Ulrich (2020): Nachhaltigkeit ohne Soziale Arbeit? Entdecke die Weltrettung als sozialpädagogisches Projekt! In: Birgmeier, B./Mührel, E./Winkler, M. (Hrsg.): Sozialpädagogische SeitenSprünge. Einsichten von außen, Aussichten von innen: Befunde und Visionen zur Sozialpädagogik. Weinheim: Beltz Juventa, S. 19-32.

Baum, Detlef (Hrsg.) (2007a): Die Stadt in der Sozialen Arbeit. Ein Handbuch für soziale und planende Berufe. Wiesbaden: VS Verlag für Sozialwissenschaften.

Baum, Detlef (2007b): Einleitung. In: Baum, D. (Hrsg.): Die Stadt in der Sozialen Arbeit. Ein Handbuch für soziale und planende Berufe. Wiesbaden: VS Verlag für Sozialwissenschaften, S. 11-14.

Baum, Detlef (2018): Lehrbuch Stadt und Soziale Arbeit. Stadtsoziologische Grundlagen Sozialer Arbeit. Weinheim, Basel: Beltz Juventa.

Baumgartner, Judith (2005): Erbau Dein Haus auf freiem Grund! Bodenreform und Siedlungsidee: Adolf Damaschke und die Siedlungsgenossenschaft EdenOranienburg. In: Hugler, K./Diefenbacher, H./Baumgartner, J./Nothnagle, A. L. (Hrsg.): Adolf Damaschke und Henry George - Ansätze zu einer Theorie und Politik der Bodenreform. Marburg: Metropolis-Verlag, S. 139-154.

Bauriedl, Sybille/Hackfort, Sarah K. (2016): Geschlechtsspezifische Verwundbarkeit. In: Bauriedl, S. (Hrsg.): Wörterbuch Klimadebatte. Bielefeld: transcript-Verlag, S. 95-101.

Becker, Egon (2016a): Bildung und Überlebenskrise. Die Soziale Ökologie im Diskurs über Umwelt und Entwicklung (1990). In: Keine Gesellschaft ohne Natur. 
Beiträge zur Entwicklung einer Sozialen Ökologie. Frankfurt (Main): Campus Verlag, S. 194-216.

Becker, Egon (2016b): Die Ökologie im Banne des Systemdenkens (2011). In: Keine Gesellschaft ohne Natur. Beiträge zur Entwicklung einer Sozialen Ökologie. Frankfurt (Main): Campus Verlag, S. 328-353.

Becker, Egon (2016c): Globalisierte Naturverhältnisse. In: Keine Gesellschaft ohne Natur. Beiträge zur Entwicklung einer Sozialen Ökologie. Frankfurt (Main): Campus Verlag, S. 454-465.

Becker, Egon (2016d): Keine Gesellschaft ohne Natur. Beiträge zur Entwicklung einer Sozialen Ökologie. Frankfurt (Main): Campus Verlag.

Becker, Egon (2016e): Sozial-ökologische Systeme als epistemische Objekte (2012). In: Keine Gesellschaft ohne Natur. Beiträge zur Entwicklung einer Sozialen Ökologie. Frankfurt (Main): Campus Verlag, S. 354-383.

Becker, Egon (2016f): Systemdenken in der wissenschaftlichen Ökologie und in der politischen Ökologiebewegung (1986). In: Keine Gesellschaft ohne Natur. Beiträge zur Entwicklung einer Sozialen Ökologie. Frankfurt (Main): Campus Verlag, S. 293-310.

Becker, Egon/Jahn, Thomas (Hrsg.) (2006): Soziale Ökologie. Grundzüge einer Wissenschaft von den gesellschaftlichen Naturverhältnissen. Frankfurt (Main): Campus Verlag.

Becker, Egon/Jahn, Thomas (2016): Umrisse einer kritischen Theorie gesellschaftlicher Natrurverhältnisse (2003). In: Keine Gesellschaft ohne Natur. Beiträge zur Entwicklung einer Sozialen Ökologie. Frankfurt (Main): Campus Verlag, S. 418442.

Becker, Egon/Jahn, Thomas/Hummel, Diana (2006): Gesellschaftliche Naturverhältnisse. In: Becker, E./Jahn, T. (Hrsg.): Soziale Ökologie. Grundzüge einer Wissenschaft von den gesellschaftlichen Naturverhältnissen. Frankfurt (Main): Campus Verlag, S. 174-197.

Becker-Lindenthal, Hjördis (2017): Sokrates im Anthropozän. Gedanken zum Menschenmöglichen im Ausgang von Blumenberg und Valéry. In: Orozco, P. V./Allerkamp, A. (Hrsg.): Paul Valéry: Für eine Epistemologie der Potentialität. Heidelberg: Universitätsverlag Winter, S. 153-172.

Beecroft, Richard/Trenks, Helena/Rhodius, Regina/Benighaus, Christina/Parodi, Oliver (2018): Reallabore als Rahmen transformativer und transdisziplinärer Forschung. Ziele und Designprinzipien. In: Di Giulio, A./Defila, R. (Hrsg.): Transdisziplinär und transformativ forschen. Wiesbaden: Springer Fachmedien Wiesbaden, S. 75-100.

Behnisch, Michael/Winkler, Michael (Hrsg.) (2009): Soziale Arbeit und Naturwissenschaft. Einflüsse, Diskurse, Perspektiven. München: Reinhardt.

Benevolo, Leonardo (1971): Die sozialen Ursprünge des modernen Städtebaus. Lehren von gestern - Forderungen für morgen. Gütersloh: Bertelsmann.

Benevolo, Leonardo (2007): Die Geschichte der Stadt. Frankfurt am Main: Campus Verlag.

Bernhardt, Christoph (2017): Längst beerdigt und doch quicklebendig. Zur widersprüchlichen Geschichte der »autogerechten Stadt«. In: Zeithistorische Forschungen/Studies in Contemporary History, Heft 3, S. 526-540. 
Betz, Gregor J./Kirchner, Babette (2016): Sequenzanalytische Bildhermeneutik. In: Burzan, N./Hitzler, R./Kirschner, H. (Hrsg.): Materiale Analysen. Methodenfragen in Projekten. Wiesbaden: Springer VS, S. 263-288.

Biehl, Janet (1998): Der libertäre Kommunalismus. Die politische Praxis der Sozialökologie. Grafenau: Trotzdem Verlag.

Birgmeier, Bernd (2012): Soziale Arbeit als Wissenschaft. Wiesbaden: VS Verlag für Sozialwissenschaften.

Birgmeier, Bernd/Mührel, Eric (Hrsg.) (2009): Die Sozialarbeitswissenschaft und ihre Theorie(n). Positionen, Kontroversen, Perspektiven. Wiesbaden: VS Verlag für Sozialwissenschaften.

Birnbacher, Dieter (2017): Utilitarismus und Konsequenzialismus. In: Nida-Rümelin, J./Spiegel, I./Tiedemann, M. (Hrsg.): Handbuch Philosophie und Ethik. Band 2: Disziplinen und Themen. Paderborn: Ferdinand Schöningh, S. 52-59.

Blaha, Barbara (2019): In 5 Grad zur Apokalcpyse. https:/www.moment.at/story/5grad-zur-apokalypse [Zugriff: 21.07.2020].

Blaschke, Ronald (2012): Aktuelle Ansätze und Modelle von Grundsicherungen und Grundeinkommen in Deutschland. In: Blaschke, R./Otto, A./Schepers, N. (Hrsg.): Grundeinkommen. Von der Idee zu einer europäischen politischen Bewegung. Hamburg: VSA Verlag, S. 118-251.

Blaschke, Ronald (2017): Ronald Blaschke: Grundeinkommen und Grundsicherungen - Modelle und Ansätze in Deutschland. Eine Auswahl. Stand Oktober 2017. https:/www.grundeinkommen.de/wp-content/uploads/2017/12/17-10$\%$ C3\%9Cbersicht-Modelle.pdf [Zugriff: 20.07.2019].

Blaschke, Ronald/Otto, Adeline/Schepers, Norbert (Hrsg.) (2012): Grundeinkommen. Von der Idee zu einer europäischen politischen Bewegung. Hamburg: VSA Verlag.

Blickle, Peter (2000a): Kommunalismus. Skizzen einer gesellschaftlichen Organisation. Band 2: Europa. München: de Gruyter Oldenbourg.

Blickle, Peter (2000b): Kommunalismus. Skizzen einer gesellschaftlichen Organisationsform. Band 1: Oberdeutschland. München: de Gruyter Oldenbourg.

Bloch, Ernst (1972): Das Materialismusproblem, seine Geschichte und Substanz. Gesamtausgabe Band 7. Frankfurt (Main): Suhrkamp.

Bloch, Ernst (1975): Experimentum Mundi. Frage, Kategorien des Herausbringens, Praxis. Gesamtausgabe Band 15. Frankfurt (Main): Suhrkamp.

Bloch, Ernst (1978): Tendenz - Latenz - Utopie. Ergänzungsband zur Gesamtausgabe. Frankfurt (Main): Suhrkamp.

Bloch, Ernst (2013a): Das Prinzip Hoffnung. Kapitel 1-32. Band 1. Frankfurt (Main): Suhrkamp.

Bloch, Ernst (2013b): Das Prinzip Hoffnung. Kapitel 33-42. Band 2. Frankfurt (Main): Suhrkamp.

Blöhbaum, Helmut (1992): Zur Dialektik des Ökologiebegriffs. Unter Berücksichtigung des Physisbegriffes bei Aristoteles. Frankfurt (Main): Lang.

Blome-Drees, Johannes/Degens, Philipp/Schimmele, Clemens (2017): Ist die eingetragene Genossenschaft eine geeignete Rechtsform für kleine Initiativen des bürgerschaftlichen Engagements? In: Theuvsen, L./Andeßner, R. C./Gmür, M./Greiling, D. (Hrsg.): Nonprofit-Organisationen und Nachhaltigkeit. Wiesbaden: Springer Gabler, S. 419-427. 
BMWi - Bundesministerium für Wirtschaft und Energie (2019): Freiräume für Innovationen - Das Handbuch für Reallabore. Frankfurt (Main): Druck- und Verlagshaus Zarbock GmbH \& Co. KG.

$\mathrm{BMZ}$ - Bundesministerium für wirtschaftliche Zusammenarbeit und Entwicklung (o. J.): Stadtentwicklung - Hintergrund: Das Zeitalter der Städte. https://www.bmz. $\mathrm{de} / \mathrm{de} /$ themen/stadtentwicklung/hintergrund/index.html [Zugriff: 17.03.2020].

Böhme, Gernot/Schramm, Engelbert (1985): Soziale Naturwissenschaft. Wege zu einer Erweiterung der Ökologie. Frankfurt (Main): Fischer.

Böhnisch, Lothar (2020): Sozialpädagogik der Nachhaltigkeit. Eine Einführung. Weinheim: Beltz Juventa.

Bojanowski, Axel (2019): Journalisten im Klimakrieg. In: APuZ - Aus Politik und Zeitgeschichte, Heft 47/48, S. 35-38.

Bonneuil, Christophe (2015): Die Erde im Kapitalozän. https://monde-diplo matique.de/artikel/!5247299 [Zugriff: 03.04.2019].

Bookchin, Debbie/Taylor, Blair (2015): Einleitung. In: Bookchin, D./Taylor, B. (Hrsg.): Die nächste Revolution. Libertärer Kommunalismus und die Zukunft der Linken. Münster: Unrast, S. 11-20.

Bookchin, Murray (1985a): Die Ökologie der Freiheit. Wir brauchen keine Hierarchien. Weinheim: Beltz.

Bookchin, Murray (1985b): Die Radikalisierung der Natur. Zur Ethik eines radikalen Naturverständnisses. In: Schwarzer Faden, Heft 1/85, S. 22-29.

Bookchin, Murray (1992a): Die Neugestaltung der Gesellschaft. Pfade in eine ökologische Zukunft. Grafenau: Trotzdem-Verlag.

Bookchin, Murray (1992b): Libertärer Kommunalismus - ein Konzept für eine konkrete Utopie. In: Schwarzer Faden, Heft 3/92, S. 20-25.

Bookchin, Murray (1994): Die Frage nach der Zukunft der Städte und ihrer Bürger so deutlich wie möglich aufwerfen. In: Schwarzer Faden, Heft 3/94, S. 28-35.

Bookchin, Murray (1996): Die Agonie der Stadt. Städte ohne Bürger oder Aufstieg und Niedergang des freien Bürgers. Grafenau: Trotzdem Verlag.

Bookchin, Murray (2015a): Das kommunalistische Projekt. (November 2002). In: Bookchin, D./Taylor, B. (Hrsg.): Die nächste Revolution. Libertärer Kommunalismus und die Zukunft der Linken. Münster: Unrast, S. 21-51.

Bookchin, Murray (2015b): Die Bedeutung des Konföderalismus. In: Bookchin, D./Taylor, B. (Hrsg.): Die nächste Revolution. Libertärer Kommunalismus und die Zukunft der Linken. Münster: Unrast, S. 89-103.

Bookchin, Murray (2015c): Die nächste Revolution. Libertärer Kommunalismus und die Zukunft der Linken. Münster: Unrast.

Bookchin, Murray (2015d): Eine Politik des 21. Jahrhunderts. In: Bookchin, D./ Taylor, B. (Hrsg.): Die nächste Revolution. Libertärer Kommunalismus und die Zukunft der Linken. Münster: Unrast, S. 65-88.

Bookchin, Murray (2015e): Städte. Die Entfaltung der Vernunft in der GEschichte. In: Bookchin, D./Taylor, B. (Hrsg.): Die nächste Revolution. Libertärer Kommunalismus und die Zukunft der Linken. Münster: Unrast, S. 119-130.

Boulet, Jean Jaak/Krauss, Ernst Jürgen/Oelschlägel, Dieter (1980): Gemeinwesenarbeit als Arbeitsprinzip. Bielefeld: AJZ-Druck \& Verlag.

Brand, Ulrich (2014): Degrowth: Der Beginn einer Bewegung? In: Blätter für deutsche und internationale Politik, Heft 10, S. 29-32. 
Brand, Ulrich/Görg, Christoph (2003): Postfordistische Naturverhältnisse. Konflikte um genetische Ressourcen und die Internationalisierung des Staates. Münster: Westfälisches Dampfboot.

Brand, Ulrich/Krams, Mathias (2018): Zehn Jahre Degrowth als radikale politische Perspektive: Potenziale und Hürden. Potenziale und Hürden. In: Forschungsjournal Soziale Bewegungen - Analysen zu Demokratie und Zivilgesellschaft, Heft 4/2018, S. 18-26.

Brand, Ulrich/Wissen, Markus (2011): Die Regulation der ökologischen Krise. In: ÖZS - Österreichische Zeitschrift für Soziologie 36, Heft 2/2011, S. 12-34.

Brand, Ulrich/Wissen, Markus (2017): Imperiale Lebensweise. Zur Ausbeutung von Mensch und Natur in Zeiten des globalen Kapitalismus. München: oekom verlag.

Bremer, Dieter/Dilcher, Roman (2013): Heraklit. In: Flashar, H./Ueberweg, F./Holzhey, H. (Hrsg.): Grundriss der Geschichte der Philosophie. Erster und Zweiter Halbband. Basel: Schwabe, S. 602-656.

Brieler, Ulrich (2019): Herbert Marcuses „Der eindimensionale Mensch“: Vorzeitiger Geheimnisverrat. In: Bittlingmayer, U. H./Demirovic, A./Freytag, T. (Hrsg.): Handbuch Kritische Theorie. Wiesbaden: Springer VS, S. 355-380.

Bröckling, Ulrich/Krasmann, Susanne/Lemke, Thomas (Hrsg.) (2000): Gouvernementalität der Gegenwart. Studien zur Ökonomisierung des Sozialen. Frankfurt (Main): Suhrkamp.

Bronfenbrenner, Urie (1981): Die Ökologie der menschlichen Entwicklung. Natürliche und geplante Experimente. Stuttgart: Klett-Cotta.

Brunnengräber, Achim/Dietz, Kristina (2016): Klimagerechtigkeit. In: Bauriedl, S. (Hrsg.): Wörterbuch Klimadebatte. Bielefeld: transcript-Verlag, S. 157-162.

Buckminster Fuller, Richard (2013): Raumschiff Erde (1969). In: Günzel, S. (Hrsg.): Texte zur Theorie des Raums. Stuttgart: Reclam, S. 254-256.

Capelle, Wilhelm (2008): Die Vorsokratiker. Die Fragmente und Quellenberichte. Stuttgart: Alfred Kröner Verlag.

Caro, Mario de (2015): Zwei Spielarten des Realismus. In: Gabriel, M. (Hrsg.): Der neue Realismus. Berlin: Suhrkamp, S. 19-32.

Christ, Tamina/Gellrich, Angelika/Ide, Tobias (2012): Zugänge zur Klimadebatte in Politikwissenschaft, Soziologie und Psychologie. Marburg: Metropolis-Verlag.

Cook, John/van der Linden, Sander/Maibach, Ed/Lewandowsky, Stephan (2019): Handbuch zum Klimakonsens. Warum der wissenschaftliche Konsens zum Klimawandel wichtig ist. Center for Climate Change Communication, George Mason University.

Cremer-Schäfer, Helga (2001): Ein politisches Mandat schreibt man sich zu. Zur Politik (mit) der Sozialen Arbeit. In: Merten, R. (Hrsg.): Hat Soziale Arbeit ein politisches Mandat? Positionen zu einem strittigen Thema. Wiesbaden: VS Verlag für Sozialwissenschaften, S. 55-70.

Cremer-Schäfer, Helga (2008): Individuum und Kritik. Von der Wert-Orientierung zur Gebrauchswertorientierung. In: Widersprüche. Zeitschrift für sozialistische Politik im Bildungs-, Gesundheits- und Sozialbereich, Heft 107, S. 77-91.

Crutzen, Paul/Stoermer, Eugene (2000): The „Anthropocene“. In: IGBP NewsLetter 41, 41, S. 17-18.

Crutzen, Paul J. (2011): Die Geologie der Menschheit. In: Crutzen, P. J./Mastrandrea, M. D./Schneider, S. H./Davis, M./Sloterdijk, P. (Hrsg.): Das Raumschiff Erde hat 
keinen Notausgang. Energie und Politik im Anthropozän. Berlin: Suhrkamp, S. 7-10.

Crutzen, Paul J./Mastrandrea, Michael D./Schneider, Stephen H./Davis, Mike/Sloterdijk, Peter (Hrsg.) (2011): Das Raumschiff Erde hat keinen Notausgang. Energie und Politik im Anthropozän. Berlin: Suhrkamp.

Dabag, Mirhan (1980): Mitwelt. In: Ritter, J./Gründer, K./Gabriel, G. (Hrsg.): Historisches Wörterbuch der Philosophie. Band 5. L-Mn. Basel: Schwabe, S. 14391441.

D‘Alisa, Giacomo/Demaria, Federico/Kallis, Giorgos (Hrsg.) (2016): Degrowth. Handbuch für eine neue Ära. München: oekom verlag.

Davoudi, Simin/Bell, Derek (2016): A fairer city: towards a pluralistic, relational and multiscalar perspektive. In: Davoudi, S./Bell, D. (Hrsg.): Justice and fairness in the city. A multi-disciplinary approach to ,ordinary' cities. Bristol: Policy Press, S. 265-280.

Dege, Martin/Grallert, Till/Dege, Carmen/Chimiri, Niklas (Hrsg.) (2010): Können Marginalisierte (wieder)sprechen? Zum politischen Potenzial der Sozialwissenschaften. Gießen: Psychosozial-Verlag.

Demirović, Alex (2011): Reform, Revolution, Transformation. In: Brie, M./Candeias, M. (Hrsg.): Transformation im Kapitalismus und darüber hinaus. Beiträge zur ersten Transformationskonferenz. 13. und 14. Oktober 2011. Berlin: MediaService GmbH Druck und Kommunikation, S. 33-48.

Descartes, René (1870): Abhandlung über die Methode des richtigen Vernunftgebrauchs (1637). In: Kirchmann, J. H. von (Hrsg.): René Descartes“ philosophische Werke. Erste Abteilung. Berlin: L. Heimann.

Deutscher Städtetag (2017): Neuausrichtug der Wohnungs- und Baulandpolitik. Positionspapier des Deutschen Städtetages. Berlin: o. A.

Diels, Hermann (1906): Die Fragmente der Vorsokratiker. Griechisch und Deutsch. Band 1. Berlin: Weidmannsche Buchhandlung.

Dierks, Jan (2016a): Holismus. In: Ott, K./Dierks, J./Voget-Kleschin, L. (Hrsg.): Handbuch Umweltethik. Stuttgart: J.B. Metzler, S. 177-183.

Dierks, Jan (2016b): Ökozentrik. In: Ott, K./Dierks, J./Voget-Kleschin, L. (Hrsg.): Handbuch Umweltethik. Stuttgart: J.B. Metzler, S. 169-177.

DIfU - Deutsches Institut für Urbanistik und Bundesverband für Wohnen und Stadtentwicklung e.V. (2017): Bodenpolitische Agenda 2020-2030. Warum wir für eine nachhaltige und sozial gerechte Stadtentwicklungs und Wohnungspolitik eine andere Bodenpolitik brauchen.

Dörre, Klaus (2018): Neo-Sozialismus oder: Acht Thesen zu einer überfälligen Diskussion. In: Blätter für deutsche und internationale Politik, Heft 6, S. 105-115.

Dörre, Klaus (2019a): Kritische Theorie und Krise: Landnahme an den Grenzen kapitalistischer Dynamik. In: Bittlingmayer, U. H./Demirovic, A./Freytag, T. (Hrsg.): Handbuch Kritische Theorie. Wiesbaden: Springer VS, S. 953-980.

Dörre, Klaus (2019b): Neosozialismus. Acht Thesen zu einer überfälligen Diskussion. In: Dörre, K./Schickert, C. (Hrsg.): Neosozialismus. Solidarität, Demokratie und Ökologie vs. Kapitalismus. München: oekom verlag, S. 17-32.

Drilling, Matthias/Oehler, Patrick (Hrsg.) (2016): Soziale Arbeit und Stadtentwicklung. Wiesbaden: Springer Fachmedien Wiesbaden.

Dungs, Susanne (2009): Aporien der Theorieentwicklung Sozialer Arbeit angesichts der „Rückkehr der Natur“. In: Birgmeier, B./Mührel, E. (Hrsg.): Die Sozialar- 
beitswissenschaft und ihre Theorie(n). Positionen, Kontroversen, Perspektiven. Wiesbaden: VS Verlag für Sozialwissenschaften, S. 305-317.

Dürbeck, Gabriele (2018a): Das Anthropozän erzählen. Fünf Narrative. In: APuZ Aus Politik und Zeitgeschichte, Heft 21-23/2018, S. 11-17.

Dürbeck, Gabriele (2018b): Narrative des Anthropozän - Systematisierung eines interdisziplinären Diskurses. In: Kulturwissenschaftliche Zeitschrift 3, Heft 1/2018, S. 1-20.

Durkheim, Émile (1980): Die Regeln der soziologischen Methode. Frankfurt (Main): Suhrkamp.

Eckard, Frank (2018): Austerity Urbanism. In: Rink, D./Haase, A. (Hrsg.): Handbuch Stadtkonzepte. Analysen, Diagnosen, Kritiken und Visionen. Wien: UTB GmbH, S. 23-42.

Eckardt, Frank (2018): Gentrifizierung. Forschung und Politik zu städtischen Verdrängungsprozessen. Wiesbaden: Springer VS.

Ekardt, Felix (2012): Klimagerechtigkeit. Ethische, rechtliche, ökonomische und transdisziplinäre Zugänge. Marburg: Metropolis-Verlag.

Elsen, Susanne (2013): Wachstumswende und die Arbeit am Sozialen. In: Elsen, S./Pentini, A. A. (Hrsg.): Gesellschaftlicher Aufbruch, reale Utopien und die Arbeit am Sozialen. Bozen: bu,press, S. 27-60.

Elsen, Susanne (2017): Gemeinwesenökonomie und öko-soziale Entwicklung. In: Hammerschmidt, P./Sagebiel, J. B./Yollu-Tok, A. (Hrsg.): Die Soziale Arbeit im Spannungsfeld der Ökonomie. Neu-Ulm: AG SPAK Bücher, S. 161-176.

Elsen, Susanne (2018): Nachhaltigkeit. In: Otto, H.-U./Thiersch, H./Treptow, R./Ziegler, H. (Hrsg.): Handbuch Soziale Arbeit. München: Ernst Reinhardt Verlag, S. 1055-1066.

Engel, Evamaria (1993): Die deutsche Stadt des Mittelalters. München: Beck.

Engels, Friedrich (1962): Die Lage der arbeitenden Klasse in England. Nach eigner Anschauung und authentischen Quellen. In: Institut für Marxismus-Leninismus beim ZK der SED (Hrsg.): MEW 2. Berlin: Dietz Verlag, S. 225-506.

Engels, Friedrich (1975): Dialektik der Natur. In: Institut für Marxismus-Leninismus beim ZK der SED (Hrsg.): MEW 20. Berlin: Dietz Verlag, S. 307-742.

Engels, Friedrich (1989): Ludwig Feuerbach und der Ausgang der klassischen deutschen Philosophie. Berlin: Dietz Verlag.

Epikur (2007): Briefe, Sprüche, Werkfragmente. Griechisch, deutsch. Reclams Universal-Bibliothek, Band 9984. Stuttgart: Reclam.

Eversberg, Dennis/Muraca, Barbara (2019): Degrowth-Bewegungen. Welche Rolle können sie in einer sozial-ökologischen Transformation spielen? In: Dörre, K./Rosa, H./Becker, K./Bose, S./Seyd, B. (Hrsg.): Große Transformation? Zur Zukunft moderner Gesellschaften. Wiesbaden: VS Verlag für Sozialwissenschaften, S. 487-503.

Falk, Gregor C. (2006): So fern und doch so nah - Fotografische Weltansichten im Geographieunterricht. In: Holzbrecher, A./Oomen-Welke, I./Schmolling, J. (Hrsg.): Foto + Text. Handbuch für die Bildungsarbeit. Wiesbaden: VS Verlag für Sozialwissenschaften, S. 215-230.

Feuerbach, Ludwig (1908): Vorlesungen über das Wesen der Religion. Nebst Zusätzen und Anmerkungen. Stuttgart: Fr. Frommanssa Verlag (E. Hauff.). 
Feuerbach, Ludwig (1969): Vorläufige Thesen zur Reformation der Philosophie (1842). In: Philosophische Kritiken und Grundsätze (1839-1846). Leipzig: Reclam, S. 169-191.

Feyerabend, Paul (1980): Erkenntnis für freie Menschen. Veränderte Ausgabe. Frankfurt (Main): Suhrkamp.

Feyerabend, Paul (1984): Wissenschaft als Kunst. Frankfurt (Main): Suhrkamp.

Feyerabend, Paul (2018): Wider den Methodenzwang. Frankfurt (Main): Suhrkamp.

Fischer, Joachim (2018): Exzentrische Positionalität. Erschließungskategorie einer Lebenssoziologie. In: Laux, H./Henkel, A. (Hrsg.): Die Erde, der Mensch und das Soziale. Zur Transformation gesellschaftlicher Naturverhältnisse im Anthropozän. Bielefeld: Transcript, S. 123-136.

Flashar, Hellmut/Ueberweg, Friedrich/Holzhey, Helmut (Hrsg.) (2013): Grundriss der Geschichte der Philosophie. Erster und Zweiter Halbband. Basel: Schwabe.

Flavell, Alex/Milan, Andrea/Melde, Susanne (2020a): Migration, environment and climate change: Literature review. First report in the "Migration, environment and climate change" series. Texte 42/2020. https://www.umweltbundesamt.de/ sites/default/files/medien/1410/publikationen/2020-03-04_texte_42-2020_ migration-literature-review_1.pdf [Zugriff: 17.03.2020].

Flavell, Alex/Melde, Susanne/Milan, Andrea (2020b): Migration, environment and climate change: Impacts. Second report in the "Migration, environment and climate change" series. Texte 43/2020. https://www.umweltbundesamt.de/sites/ default/files/medien/1410/publikationen/2020-03-04_texte_43-2020_migrationimpacts_2.pdf [Zugriff: 17.03.2020].

Foster, John Bellamy (2017): Interview mit John Bellamy Foster: Eine Widerstandsbewegung für den Planeten (I). https://www.klassegegenklasse.org/interviewmit-john-bellamy-foster-eine-widerstandsbewegung-fuer-den-planeten/ [Zugriff: 20.03.2020].

Foster, John Bellamy/Clark, Brett/York, Richard (2011): Der ökologische Bruch. Der Krieg des Kapitals gegen den Planeten. Hamburg: Laika-Verlag.

Foucault, Michel (1992): Was ist Kritik? Berlin: Merve-Verlag.

Foucault, Michel (2006a): Die Geburt der Biopolitik. Geschichte der Gouvernementalität II. Frankfurt (Main): Suhrkamp.

Foucault, Michel (2006b): Sicherheit, Territorium, Bevölkerung. Geschichte der Gouvernementalität I. Frankfurt (Main): Suhrkamp.

Foucault, Michel (2007): Ästhetik der Existenz. Schriften zur Lebenskunst. Frankfurt (Main): Suhrkamp.

Foundational Economy Collective (Hrsg.) (2019): Die Ökonomie des Alltagslebens. Für eine neue Infrastrukturpolitik. Frankfurt (Main): Suhrkamp.

Fourier, Charles (1988): Die neue industrielle und sozietäre Welt oder Entdeckung des Verfahrens einer anziehenden, natürlichen Industrie, eingeteilt nach Leidenschaftsreihen. In: Opitz, H./Gerlach, H.-M. (Hrsg.): Philosophen-Lesebuch. Band 2. Berlin: Dietz Verlag, S. 658-684.

Fourier, Charles (2016): Die harmonische Erziehung. In: Paul-Siewert, B./Pfützner, R./Winkler, M. (Hrsg.): Sozialistische Pädagogik. Eine kommentierte Anthologie. Baltmannsweiler: Schneider Verlag Hohengehren GmbH, S. 89-100.

Fraser, Nancy (1994): Widerspenstige Praktiken. Macht, Diskurs, Geschlecht. Frankfurt (Main): Suhrkamp. 
Fraser, Nancy (2020): Was heißt Sozialismus im 21. Jahrhundert? In: Zeitschrift LuXemburg, Heft 2/2020, S. 120-127.

Freire, Paulo (1975): Pädagogik der Unterdrückten. Bildung als Praxis der Freiheit. Reinbek bei Hamburg: Rowohlt.

Frese, Jürgen (1972): IV. Die Dialektik von Kant bis zur Gegenwart. Kap. 3.1 Karl Marx. In: Ritter, J./Gründer, K./Gabriel, G. (Hrsg.): Historisches Wörterbuch der Philosophie. Band 2. G-H. Basel: Schwabe, S. 198-205.

Fuchs, Christian (2008): Dialektisches Denken als Grundlage der Kritik des transnationalen informationellen Kapitalismus. In: Zeilinger, D. (Hrsg.): Polyphone Dialektik. VorSchein Nr. 30. Jahrbuch 2008 der Ernst-Bloch-Assoziation. Nürnberg: Antogo Verlag, S. 97-119.

Gadamer, Hans-Georg (2012): Der Anfang des Wissens. Stuttgart: Reclam.

Ganshof, Francois Louis (1963): Das Hochmittelalter. In: Mann, G./Heuss, A. (Hrsg.): Propyläen Weltgeschichte. Islam. Die Entstehung Europas. Band 5. Berlin, Frankfurt (Main): Ullstein, S. 397-488.

George, Henry (2017): Fortschritt und Armut. Eine Untersuchung über die Ursache der industriellen Krisen und der Zunahme der Armut bei zunehmendem Reichtum. Berlin: Elwin Staude Verlag.

Gesang, Bernward (2011): Klimaethik. Berlin: Suhrkamp.

Girardet, Herbert (2007): Die Schaffung lebenswerter und nachhaltiger Städte. In: Girardet, H. (Hrsg.): Zukunft ist möglich. Wege aus dem Klima-Chaos. Hamburg: Europäische Verlags Anstalt, S. 175-214.

Gloy, Karen (1995): Die Geschichte des wissenschaftlichen Denkens. Das Verständnis der Natur. Köln: Komet.

Görg, Christoph (1999): Gesellschaftliche Naturverhältnisse. Münster: Westfälisches Dampfboot.

Görg, Christoph (2003): Dialektische Konstellationen. Zu einer kritischen Theorie gesellschaftlicher Naturverhältnisse. In: Demirović, A. (Hrsg.): Modelle kritischer Gesellschaftstheorie. Traditionen und Perspektiven der Kritischen Theorie. Stuttgart: Metzler, S. 39-62.

Görg, Christoph (2016): Planetarische Grenzen. In: Bauriedl, S. (Hrsg.): Wörterbuch Klimadebatte. Bielefeld: transcript-Verlag, S. 239-243.

Götz, Konrad/Schubert, Steffi/Deffner, Jutta (2006): Mobilität. In: Becker, E./Jahn, T. (Hrsg.): Soziale Ökologie. Grundzüge einer Wissenschaft von den gesellschaftlichen Naturverhältnissen. Frankfurt (Main): Campus Verlag, S. 383-393.

Gramsci, Antonio (1994a): Gefängnishefte. Kritische Gesamtausgabe auf Grundlage der Edition von Valentino Gerratana. Band 3: Heft 4 und 5. Hamburg: ArgumentVerlag.

Gramsci, Antonio (1994b): Gefängnishefte. Kritische Gesamtausgabe auf Grundlage der Edition von Valentino Gerratana. Band 6: Heft 10 und 11. Hamburg: Argument-Verlag.

Grawe, Christian (1974): homo-mensura-Satz. In: Ritter, J./Gründer, K./Gabriel, G. (Hrsg.): Historisches Wörterbuch der Philosophie. Band 3. G-H. Basel: Schwabe, S. 1176.

Grimm, Jacob/Grimm, Wilhelm (1971): Deutsches Wörterbuch. 16 Bände in 32 Teilbänden. Band 5. Leipzig: Hirzel.

Gronemeyer, Marianne (1988): Die Macht der Bedürfnisse. Reflektionen über ein Phantom. Reinbek bei Hamburg: Rowohlt. 
Gronemeyer, Marianne (2012): Wer arbeitet, sündigt. Ein Plädoyer für gute Arbeit. Darmstadt: Primus.

Gronemeyer, Marianne (2014): Das Leben als letzte Gelegenheit. Sicherheitsbedürfnisse und Zeitknappheit. Darmstadt: Wissenschaftliche Buchgesellschaft (WBG).

Großmann, Katrin (2018): Just City. In: Rink, D./Haase, A. (Hrsg.): Handbuch Stadtkonzepte. Analysen, Diagnosen, Kritiken und Visionen. Wien: UTB GmbH, S. 169-191.

Grundmann, Reiner (1997): Die soziologische Tradition und die natürliche Umwelt. In: Hradil, S./Rehberg, K.-S./Pischel, A./Platz, T. (Hrsg.): Differenz und Integration. Die Zukunft moderner Gesellschaften. Verhandlungen des 28. Kongresses der Deutschen Gesellschaft für Soziologie in Dresden 1996. Frankfurt (Main): Campus Verlag, 533-550.

Guelf, Fernand Mathias (2010): La révolution urbaine. Henri Lefebvres Philosophie der globalen Verstädterung. Dissertation. Berlin: TU Berlin/Fakultät I - Geisteswissenschaften.

Günzel, Stephan (2011): Erde: Treue zur Erde. In: Ottmann, H. (Hrsg.): NietzscheHandbuch. Leben - Werk - Wirkung. Stuttgart, Weimar: Verlag J.B. Metzler, S. 219.

Haeckel, Ernst (1866a): Generelle Morphologie der Organismen. Allgemeine Grundzüge der organischen Formen-Wissenschaft. Mechanisch begründet durch die von Charles Darwin reformierte Descendenz-Theorie. Erster Band: Allgemeine Anatomie der Organismen. Berlin: Druck und Verlag von Georg Reimer.

Haeckel, Ernst (1866b): Generelle morphologie der Organismen. Allgemeine Grundzüge der organischen Formen-Wissenschaft. Mechanisch begründet durch die von Charles Darwin reformierte Descendenztheorie. Zweiter Band: Allgemeine Entwicklungsgeschichte der Organismen. Berlin: Druck und Verlag von Georg Reimer.

Haraway, Donna Jeanne (2018): Unruhig bleiben. Die Verwandtschaft der Arten im Chthuluzän. Frankfurt (Main): Campus Verlag.

Harper, Douglas (2013): Fotografien als sozialwissenschaftliche Daten. In: Flick, U./Kardorff, E. v./Steinke, I. (Hrsg.): Qualitative Forschung. Ein Handbuch. Reinbeck: Rowohlt, S. 402-416.

Harries, Karsten (2013): »Das Ding«, »Bauen Wohnen Denken«, »»...dichterisch wohnet der Mensch ... « « und andere Texte aus dem Umfeld. Unterwegs zum Geviert. In: Thomä, D./Grosser, F./Meyer, K./Schmid, H. B. (Hrsg.): HeideggerHandbuch. Leben - Werk - Wirkung. Stuttgart, Weimar: Verlag J.B. Metzler, S. $250-261$.

Harvey, David (1973): Social Justice and the city. Oxford: Basil Blackwell.

Harvey, David (2014): Rebellische Städte. Vom Recht auf Stadt zur urbanen Revolution. Berlin: Suhrkamp.

Haug, Wolfgang Fritz (2004): Hegmonie. Beitrag im Historisch-kritischen Wörterbuch des Marxismus. Band 6, Spalten 1-29. http://www.inkrit.de/e_inkritpedia/e maincode/doku.php?id=h:hegemonie [Zugriff: 15.08.2020].

Hawkins, Ed/Ortega, Pablo/Suckling, Emma/Schurer, Andrew/Hegerl, Gabi/Jones, Phil/Joshi, Manoj/Osborn, Timothy J./Masson-Delmotte, Valérie/Mignot, Juliette/Thorne, Peter/van Oldenborgh, Geert Jan (2017): Estimating Changes in Global Temperature since the Preindustrial Period. In: BAMS - Bulletin of the American Meteorological Society 98, 9, S. 1841-1856. 
Hayn, Doris/Stieß, Immanuel (2006): Ernährung. In: Becker, E./Jahn, T. (Hrsg.): Soziale Ökologie. Grundzüge einer Wissenschaft von den gesellschaftlichen Naturverhältnissen. Frankfurt (Main): Campus Verlag, S. 371-382.

Hebenstreit, Ray (2013): Partizipation in der Wissensgesellschaft. Funktion und Bedeutung diskursiver Beteiligungsverfahren. Wiesbaden: Springer VS.

Hegel, Georg Wilhelm Friedrich (1970a): Grundlinien der Philosophie des Rechts oder Naturrecht und Staatswissenschaft im Grundrisse. Mit Hegels eigenhändigen Notizen und den mündlichen Zusätzen. Hegel Werke Band 7. In: Moldenhauer, E./Michel, K. M. (Hrsg.): Werke in 20 Bänden mit Registerband. Frankfurt (Main): Suhrkamp.

Hegel, Georg Wilhelm Friedrich (1970b): Phänomenologie des Geistes. Hegel Werke Band 3. In: Moldenhauer, E./Michel, K. M. (Hrsg.): Werke in 20 Bänden mit Registerband. Frankfurt (Main): Suhrkamp.

Hegel, Georg Wilhelm Friedrich (1970c): Wissenschaft der Logik II. Erster Teil. Die objektive Logik. Zweites Buch. Zweiter Teil. Die subjektive Logik. Hegel Werke Band 6. In: Moldenhauer, E./Michel, K. M. (Hrsg.): Werke in 20 Bänden mit Registerband. Frankfurt (Main): Suhrkamp.

Heidegger, Martin (1967): Sein und Zeit. Tübingen: Max Niemeyer Verlag.

Heidegger, Martin (2000a): »...dichterisch wohnet der Mensch... «. In: Gesamtausgabe. Band 7. Vorträge und Aufsätze. I. Abteilung: Veröffentlichte Schriften 19101976. Frankfurt (Main): Vittorio Klostermann, S. 189-208.

Heidegger, Martin (2000b): Bauen, Wohnen, Denken. In: Gesamtausgabe. Band 7. Vorträge und Aufsätze. I. Abteilung: Veröffentlichte Schriften 1910-1976. Frankfurt (Main): Vittorio Klostermann, S. 145-164.

Heidegger, Martin (2000c): Über den Humanismus. Frankfurt (Main): Vittorio Klostermann.

Heidegger, Martin (2003): Beiträge zur Philosophie (vom Ereignis) (1936-1938). Gesamtausgabe Band 65. III. Abteilung: Unveröffentlichtes Abhandlungen - Gedachtes. Frankfurt (Main): Vittorio Klostermann.

Heigl, Franz (2008): Geschichte der Stadt. Von der Antike bis ins 20. Jahrhundert. Graz: Akademische Druck- und Verlagsanstalt.

Helbrecht, Ilse/Weber-Newth, Francesca (2017): Die Abschöpfung des Planungsmehrwerts als Repolitisierung der Planung? Eine neue Perspektive auf die aktuelle Wohnungsfrage. In: sub $\backslash \mathrm{u} \mathrm{r} \mathrm{b}$ a $\mathrm{n}$ zeitschrift für kritischen stadtforschung, Heft 1/2, S. 61-86.

Heuss, Alfred (1962): Hellas. In: Mann, G./Heuß, A. (Hrsg.): Propyläen Weltgeschichte. Griechenland. Die hellenistische Welt. Band 3. Berlin, Frankfurt (Main): Ullstein, S. 69-400.

Hillebrandt, Frank (2015): Was ist Gegenstand einer Soziologie der Praxis? In: Schäfer, F./Daniel, A./Hillebrandt, F. (Hrsg.): Methoden einer Soziologie der Praxis. Berlin, Bielefeld: de Gruyter; transcript-Verlag, S. 15-36.

Hirsch, Joachim (2007): Radikaler Reformismus. In: Brand, U./Lösch, B./Thimmel, S. (Hrsg.): ABC der Alternativen. Von ,Ästhetik des Widerstands“ bis „Ziviler Ungehorsam“. Hamburg: VSA-Verlag, S. 182-183.

Hirsch, Joachim/Brüchert, Oliver/Krampe, Eva-Maria (Hrsg.) (2013): Sozialpolitik anders gedacht. Soziale Infrastruktur. Hamburg: VSA-Verlag. 
Hirschmann, Frank G. (2012): Die Anfänge des Städtewesens in Mitteleuropa. Die Bischofssitze des Reiches bis ins 12. Jahrhundert. Dritter Teilband. Stuttgart: Hiersemann.

Hobbes, Thomas (2005): Leviathan, oder Materie, Form und Macht eines kirchlichen und staatlichen Gemeinwesens. Hamburg: Felix Meiner Verlag.

Hoerster, Norbert (2010a): Können wir wirklich auf Induktion verzichten? Eine Antwort auf Hans Albert. In: Aufklärung und Kritik. Zeitschrift für freies Denken und humanistische Philosphie, Heft 2/2010, S. 148-149.

Hoerster, Norbert (2010b): So oder so: Auf Induktion verzichtet niemand. In: Aufklärung und Kritik. Zeitschrift für freies Denken und humanistische Philosphie, Heft $4 / 2010$, S. $25-26$.

Hoerster, Norbert (2011): Ein halbherziger Verzicht auf Induktion. In: Aufklärung und Kritik. Zeitschrift für freies Denken und humanistische Philosphie, Heft 2/2011, S. 75-76.

Holm, Andrej (2012): Gentrification. In: Eckardt, F. (Hrsg.): Handbuch Stadtsoziologie. Wiesbaden: VS Verlag für Sozialwissenschaften, S. 661-687.

Holm, Andrej (2013): Wir bleiben alle! Gentrifizierung - städtische Konflikte um Aufwertung und Verdrängung. Münster: Unrast-Verlag.

Holm, Andrej (2018): Recht auf die Stadt. In: Rink, D./Haase, A. (Hrsg.): Handbuch Stadtkonzepte. Analysen, Diagnosen, Kritiken und Visionen. Wien: UTB GmbH, S. 339-358.

Holz, Hans Heinz (2011): Dialektik. Problemgeschichte von der Antike bis zur Gegenwart. Band I. Sein und Werden. Problemgeschichte der Dialektik in der Antike. Darmstadt: Wissenschaftliche Buchgesellschaft (WBG).

Hörisch, Jochen (2010): Theorie-Apotheke. Eine Handreichung zu den humanwissenschaftlichen Theorien der letzten fünfzig Jahre, einschließlich ihrer Risiken und Nebenwirkungen. Berlin: Suhrkamp.

Horkheimer, Max (1988): Traditionelle und Kritische Theorie (1937). In: Schmidt, A. (Hrsg.): Gesammelte Schriften. Band 4. Schriften 1936-1941. Frankfurt (Main): Fischer, S. 162-216.

Horkheimer, Max/Adorno, Theodor W. (2006): Dialektik der Aufklärung. Philosophische Fragmente. Frankfurt (Main): Fischer Taschenbuch Verlag.

Hossenfelder, Malte (2006): Epikur. München: Beck.

Hume, David (o. A.): Eine Untersuchung über den menschlichen Verstand. Essen: Phaidon.

Hume, David (1978): Ein Traktat über die menschliche Natur. Band II. Hamburg: Meiner.

Hummel, Diana/Lux, Alexandra (2006): Bevölkerungsentwicklung. In: Becker, E./Jahn, T. (Hrsg.): Soziale Ökologie. Grundzüge einer Wissenschaft von den gesellschaftlichen Naturverhältnissen. Frankfurt (Main): Campus Verlag, S. 409422.

IPCC - Intergovernmental Panel on Climate Change (2008): Klimaänderung 2007. Synthesebericht. Ein Bericht des zwischenstaatlichen Ausschusses für Klimaänderungen (IPCC, WMO/UNEP) WMO/UNEP. Deutsche Übersetzung herausgegeben von deutsche IPCC koordinierungsstelle (2008). Geneva: IPCC.

IPCC - Intergovernmental Panel on Climate Change (2019): $1,5^{\circ} \mathrm{C}$ globale Erwärmung. Ein IPCC-Sonderbericht über die Folgen einer globalen Erwärmung um $1,5^{\circ} \mathrm{C}$ gegenüber vorindustriellem Niveau und die damit verbundenen globalen 
Treibhausgasemissionspfade im Zusammenhang mit einer Stärkung der weltweiten Reaktion auf die Bedrohung durch den Klimawandel, nachhaltiger Entwicklung und Anstrengungen zur Beseitigung von Armut. Häufig gestellte Fragen und Antworten. Deutsche Übersetzung herausgegeben von Deutsche IPCCKoordinierungsstelle, ProClim, Akademie der Naturwissenschaften Schweiz, Umweltbundesamt GmbH. Bonn/Bern/Wien: o.A.

Joisten, K. (1994): Die Überwindung der Anthropozentrizität durch Friedrich Nietzsche. Königshausen \& Neumann.

Kaerst, Julius (1903): Die antike Idee der Oekumene in ihrer politischen und kultkurellen Bedeutung. Akademische Antrittsvorlesung an der Universität Leipzig 1903 (Nachdruck). Leipzig: Teubner.

Kaindl, Christina (2011): Subjekte der Transformation. Probleme beim Denken von Übergängen. In: Brie, M./Candeias, M. (Hrsg.): Transformation im Kapitalismus und darüber hinaus. Beiträge zur ersten Transformationskonferenz. 13. und 14. Oktober 2011. Berlin: MediaService GmbH Druck und Kommunikation, S. 7177.

Kant, Immanuel (1977): Kritik der reinen Vernunft. In: Kant, I./Weischedel, W. (Hrsg.): Werkausgabe. In 12 Bänden. Frankfurt (Main): Suhrkamp.

Kappeler, Manfred (2008): Den Menschenrrechtsdiskurs in der Sozialen Arbeit vom Kopf auf die Füße stellen. In: Widersprüche. Zeitschrift für sozialistische Politik im Bildungs-, Gesundheits- und Sozialbereich, Heft 107, S. 33-46.

Kasang, Dieter (o. J.): Das Klima im Phanerozoikum. https://bildungsserver.hamburg. de/klimageschichte/2047210/das-phanerozoikum/ [Zugriff: 04.10.2020].

Kaven, Carsten (2016): Rezension: Marcuse, Herbert: Ökologie und Gesellschaftskritik. Nachgelassene Schriften 6. https://www.ssoar.info/ssoar/handle/document/ 48081 [Zugriff: 20.03.2020].

Keil, Florian/Hummel, Diana (2006): Nachhaltigkeit und kritische Übergänge. In: Becker, E./Jahn, T. (Hrsg.): Soziale Ökologie. Grundzüge einer Wissenschaft von den gesellschaftlichen Naturverhältnissen. Frankfurt (Main): Campus Verlag, S. 240-247.

Kern, Andrea (2013): »Der Ursprung des Kunstwerks«. Kunst und Wahrheit zwischen Stiftung und Streit. In: Thomä, D./Grosser, F./Meyer, K./Schmid, H. B. (Hrsg.): Heidegger-Handbuch. Leben - Werk - Wirkung. Stuttgart, Weimar: Verlag J.B. Metzler, S. 133-144.

Kersten, Jens (2014): Das Anthropozän-Konzept. Kontrakt, Komposition, Konflikt. Heft 3/2014. In: Zeitschrift für rechtswissenschaftliche Forschung, Heft 3, S. $378-416$.

Kersten, Jens (2020): Natur als Rechtssubjekt. Für eine ökologische Revolution des Rechts. In: APuZ - Aus Politik und Zeitgeschichte, Heft 11/2020, S. 27-32.

Kessl, Fabian/Reutlinger, Christian/Maurer, Susanne/Frey, Oliver (Hrsg.) (2005): Handbuch Sozialraum. Wiesbaden: VS Verlag für Sozialwissenschaften.

King, Michalea D./Howat, Ian M./Candela, Salvatore G./Noh, Myoung J./Jeong, Seonsgu/Noël, Brice P. Y./van den Broeke, Michiel R./Wouters, Bert/Negrete, Adelaide (2020): Dynamic ice loss from the Greenland Ice Sheet driven by sustained glacier retreat. In: Communications Earth \& Environment, Heft 1, S. 16.

Kirchhoff, Thomas (2020): Zum Verhältnis von Mensch und Natur. In: APuZ - Aus Politik und Zeitgeschichte, Heft 11/2020, S. 39-44. 
Kluge, Thomas/Hummel, Diana (2006): Transformationen. In: Becker, E./Jahn, T. (Hrsg.): Soziale Ökologie. Grundzüge einer Wissenschaft von den gesellschaftlichen Naturverhältnissen. Frankfurt (Main): Campus Verlag, S. 259-266.

Kluge, Thomas/Liehr, Stefan/Lux, Alexandra (2006): Wasser. In: Becker, E./Jahn, T. (Hrsg.): Soziale Ökologie. Grundzüge einer Wissenschaft von den gesellschaftlichen Naturverhältnissen. Frankfurt (Main): Campus Verlag, S. 344-359.

Koch, Philippe/Beveridge, Ross (2018): Postpolitische Stadt. In: Rink, D./Haase, A. (Hrsg.): Handbuch Stadtkonzepte. Analysen, Diagnosen, Kritiken und Visionen. Wien: UTB GmbH, S. 279-298.

Körner, Stephan (1976): Induktion. Neuzeit. In: Ritter, J./Gründer, K./Gabriel, G. (Hrsg.): Historisches Wörterbuch der Philosophie. Band 4. I-K. Basel: Schwabe, S. 329-332.

Kornhuber, Kai (2019): Wie der Klimawandel unser Wetter der Zukunft beeinflusst. In: APuZ - Aus Politik und Zeitgeschichte, Heft 52/2019.

Krätke, Stefan (2018): Globale Stadt. In: Rink, D./Haase, A. (Hrsg.): Handbuch Stadtkonzepte. Analysen, Diagnosen, Kritiken und Visionen. Wien: UTB GmbH, S. $129-150$.

Krauß, Werner (2016): Klimawissenschaften. In: Bauriedl, S. (Hrsg.): Wörterbuch Klimadebatte. Bielefeld: transcript-Verlag, S. 201-207.

Krebs, Angelika (Hrsg.) (2016a): Naturethik. Grundtexte der gegenwärtigen tier- und ökoethischen Diskussion. Frankfurt (Main): Suhrkamp.

Krebs, Angelika (2016b): Naturethik im Überblick. In: Krebs, A. (Hrsg.): Naturethik. Grundtexte der gegenwärtigen tier- und ökoethischen Diskussion. Frankfurt (Main): Suhrkamp, S. 337-379.

Krebs, Angelika (2017): „Das heilige Grün“. Natur und Ethik. In: Nida-Rümelin, J./Spiegel, I./Tiedemann, M. (Hrsg.): Handbuch Philosophie und Ethik. Band 2: Disziplinen und Themen. Paderborn: Ferdinand Schöningh, S. 282-288.

Kropotkin, Peter (2018): Gegenseitige Hilfe in der Tier- und Menschenwelt. Berlin: Henricus.

Kropp, Cordula (2002): „Natur“. Soziologische Konzepte, politische Konsequenzen. Wiesbaden: VS Verlag für Sozialwissenschaften.

Krumm, Thomas (2015): Föderale Staaten im Vergleich. Eine Einführung. Wiesbaden: Springer VS.

Kückens, Mathis/Anthropocene Learning Lab (o. J.): Geschichte der Erde. Der Weg zur Menschenzeit. https://www.bpb.de/gesellschaft/umwelt/anthropozaen/2567 81/animation-geschichte-der-erde [Zugriff: 04.10.2020].

Kunstreich, Timm (2005): Sozialgenossenschaften. Ein Versuch, eine kooperative Vergesellschaftung im kapitalistischen Sozialstaat zu denken. In: Widersprüche Redaktion (Hrsg.): Politik des Sozialen - Alternativen zur Sozialpolitik. Umrisse einer Sozialen Infrastruktur. Heft 97. Bielefeld: Kleine Verlag, S. 105-122.

Kunstreich, Timm (2006a): Klientin — Kundin — Nutzerin — Genossin?! In: Böllert, K./Hansbauer, P./Hasenjürgen, B./Langenohl, S. (Hrsg.): Die Produktivität des Sozialen - den sozialen Staat aktivieren. Sechster Bundeskongress Soziale Arbeit. Wiesbaden: VS Verlag für Sozialwissenschaften | GWV Fachverlage GmbH Wiesbaden, S. 241-259.

Kunstreich, Timm (2006b): MARKT MACHT MORAL. Zur moralischen Ökonomie der Sozialen Arbeit. In: Widersprüche Redaktion (Hrsg.): Politik des Sozialen - 
Verhandlungen über Lebensweisen. Moralische Ökonomien heute. Heft 99. Bielefeld: Kleine, S. 7-21.

Kunstreich, Timm (2014): Grundkurs Soziale Arbeit. Sieben Blicke auf Geschichte und Gegenwart Sozialer Arbeit. Band II: Blicke auf die Jahre 1955, 1970 und 1995. Bielefeld: Kleine.

Kunstreich, Timm (2015): „Meine Stimme geb ich nicht ab - ich brauche sie noch!“. Commons als lokal- und sozialpolitisches Projekt. In: Widersprüche Redaktion (Hrsg.): Das Kommune. Kämpfe um das Gemeinsame ; von Commons, Gemeingütern und sozialer Infrastruktur. Widersprüche, Band 137. Münster: Westfälisches Dampfboot, S. 77-95.

Kunstreich, Timm (2018): Commons als Sozialgenossenschaften in der Sozialen Arbeit. In: Stehr, J./Anhorn, R./Rathgeb, K. (Hrsg.): Konflikt als Verhältnis Konflikt als Verhalten - Konflikt als Widerstand. Widersprüche der Gestaltung Sozialer Arbeit zwischen Alltag und Institution. Wiesbaden: Springer VS, S. 265277.

Kunstreich, Timm/May, Michael (1999): Soziale Arbeit als Bildung des Sozialen und Bildung am Sozialen. In: Widersprüche Redaktion (Hrsg.): Transversale Bildung - wider die Unbilden der Lerngesellschaft. Heft 73. Widersprüche. Bielefeld: Kleine, S. 35-52.

Kunstreich, Timm/May, Michael (2020): Partizipation als Arbeitsprinzip - zur Praxis gemeinsamer Aufgabenbewältigung. In: Widersprüche. Zeitschrift für sozialistische Politik im Bildungs-, Gesundheits- und Sozialbereich, Heft 155, S. 49-60.

Kutschera, Franz von (1972a): Wissenschaftstheorie I. Grundzüge der allgemeinen Methodologie der empirischen Wissenschaften. München: Fink.

Kutschera, Franz von (1972b): Wissenschaftstheorie II. Grundzüge der allgemeinen Methodologie der empirischen Wissenschaften. München: Fink.

Langemeyer, Ines (2009): Antonio Gramsci. Hegemonie, Politik des Kulturellen, geschichtlicher Block. In: Hepp, A./Krotz, F./Thomas, T. (Hrsg.): Schlüsselwerke der Cultural Studies. Wiesbaden: VS Verlag für Sozialwissenschaften, S. 7282.

Latour, Bruno (2010a): Das Parlament der Dinge. Für eine politische Ökologie. Frankfurt (Main): Suhrkamp.

Latour, Bruno (2010b): Ein Versuch, das „Kompositionistische Manifest“ zu schreiben. https:/www.heise.de/tp/features/Ein-Versuch-das-KompositionistischeManifest-zu-schreiben-3384467.html [Zugriff: 11.07.2020].

Latour, Bruno (2017): Kampf um Gaia. Acht Vorträge über das neue Klimaregime. Berlin: Suhrkamp.

Latour, Bruno (2018): Das terrestrische Manifest. Berlin: Suhrkamp.

Laurent, Éloi (2012): Demokratisch, gerecht, nachhaltig. Die Perspektive der SozialÖkologie. Zürich: Rotpunktverlag.

Laux, Henning (2014): Soziologie der Existenzweisen: Bruno Latour. In: Lamla, J./Laux, H./Rosa, H./Strecker, D. (Hrsg.): Handbuch der Soziologie. Konstanz: UVK-Verlags-Gesellschaft, S. 261-279.

Lefebvre, Henri (1939): Nietzsche. Paris: Editions sociales internationales.

Lefebvre, Henri (1971a): Der Dialektische Materialismus. Frankfurt (Main): Suhrkamp.

Lefebvre, Henri (1971b): Probleme des Marxismus, heute. Frankfurt (Main): Suhrkamp. 
Lefebvre, Henri (1972): Das Alltagsleben in der modernen Welt. Frankfurt (Main): Suhrkamp.

Lefebvre, Henri (1974): Die Zukunft des Kapitalismus. Die Reproduktion der Produktionsverhältnisse. München: List.

Lefebvre, Henri (1975a): Der Marxismus. München: Beck.

Lefebvre, Henri (1975b): Die Stadt im marxistischen Denken. Ravensburg: Maier.

Lefebvre, Henri (1975c): Metaphilosophie. Prolegomena. Frankfurt (Main): Suhrkamp.

Lefebvre, Henri (1977): DIe Produktion des städtischen Raumes. In: Arch+, Heft 37.

Lefebvre, Henri (1978): Einführung in die Modernität. Zwölf Präludien. Frankfurt (Main): Suhrkamp.

Lefebvre, Henri (1987): Kritik des Alltagslebens. Grundrisse einer Soziologie der Altäglichkeit. Mit einem Vorwort zur deutschen Ausgabe. Mit einem Nachwort zu dieser Ausgabe von Bernd Dewe, Wilfried Ferchhoff und Heinz Sünker. Frankfurt (Main): Fischer.

Lefebvre, Henri (2002): Die Produktion des städtischen Raumes. Aufbereitet und Kommentiert von Gottdiener, M. und Elden, S. In: AnArchitektur.

Lefebvre, Henri (2006): Die Produktion des Raums (1974). In: Dünne, J./Günzel, S. (Hrsg.): Raumtheorie. Grundlagentexte aus Philosophie und Kulturwissenschaften. Frankfurt (Main): Suhrkamp, S. 330-342.

Lefebvre, Henri (2014): Die Revolution der Städte. Hamburg: CEP Europäische Verlagsanstalt.

Lefebvre, Henri (2016): Das Recht auf Stadt. Hamburg: Edition Nautilus.

Lefebvre, Henri/Régulier, Catherine (1979): Die Revolution ist auch nicht mehr, was sie mal war. München: Hanser.

Leggewie, Claus (2015): Der Mensch entscheidet im Anthropozän. In: Herrmann, B. (Hrsg.): Sind Umweltkrisen Krisen der Natur oder der Kultur? Berlin, Heidelberg: Springer, S. 63-78.

Leinfelder, Reinhold (2015): Der Menschenplanet. Aufbruch ins Anthropozän. Zeitalter der Verantwortung. Broschüre zur Ausstellung „Willkommen im Anthropozän“, S. 8-13.

Leinfelder, Reinhold (2017): Das Zeitalter des Anrhopozäns und die Notwendigkeit der großen Transformation. Welche Rollen spielen Umweltpolitik und Umweltrecht? Heft 5/2017. In: Zeitschrift für Umweltrecht (ZUR), Heft 5.

Lemke, Thomas (2007): Die Natur in der Soziologie. Versuch einer Positionsbestimmung. In: Leviathan 35, Heft 2, S. 248-255.

Lesch, Harald/Kamphausen, Klaus (2016): Die Menschheit schafft sich ab. Die Erde im Griff des Anthropozän. München: Komplett-Media.

Liedholz, Yannick (2021): Berührungspunkte von Sozialer Arbeit und Klimawandel. Perspektiven und Handlungsspielräume. Leverkusen-Opladen: Budrich Barbara.

Limbrunner, Alfons (2013): Boden unter den Füßen. Wie sich Sozialarbeit und Landbau verbündeten und wie daraus ein zukunftsfähiger Arbeits-, Lebens- und Kulturimpuls entstehen könnte. In: Limbrunner, A./van Elsen, T. (Hrsg.): Boden unter den Füßen. Grüne Sozialarbeit; Soziale Landwirtschaft; Social Farming. Weinheim: Beltz Juventa, S. 18-32.

Limbrunner, Alfons/van Elsen, Thomas (Hrsg.) (2013): Boden unter den Füßen. Grüne Sozialarbeit; Soziale Landwirtschaft; Social Farming. Weinheim: Beltz Juventa. 
Lindenberg, Michael (Hrsg.) (2004): Die gelebte Hoffnung der Gemeinwesenökonomie. Bielefeld: Kleine.

Lindner, Urs (2008): Materialismus der Praxis und historische Sozialwissenschaft. Zur doppelten wissenschaftlichen Bedeutung von Karl Marx. In: Lindner, U. (Hrsg.): Philosophieren unter anderen. Beiträge zum Palaver der Menschheit. Frieder Otto Wolf zum 65. Geburtstag. Münster: Westfälisches Dampfboot, S. 26-53.

Lindner, Urs (2021): Kausalität und Kritik. Der Critical Realism als Metatheorie für die Soziale Arbeit. In: Spatscheck, C./Borrmann, S. (Hrsg.): Architekturen des Wissens. Wissenschaftstheoretische Grundpositionen im Theoriediskurs der Sozialen Arbeit. Weinheim: Beltz Juventa, S. 41-57.

Löhr, Dirk (2015): Die beste von allen schlechten Steuern. Bodenwertsteuer: Eine vergessene Geschichte. https://www.heise.de/tp/features/Die-beste-von-allenschlechten-Steuern-3376067.html [Zugriff: 28.07.2020].

Losee, John (1977): Wissenschaftstheorie. Eine historische Einführung. München: Beck.

Lovelock, James (1992): Gaia. Die Erde ist ein Lebewesen. Bern: Scherz Verlag.

Löwy, Michael (2005): Destruktiver Fortschritt. Marx, Engels und die Ökologie. In: UTOPIE kreativ, Heft 174, S. 306-315.

Löwy, Michael (2016): Ökosozialismus. Die radikale Alternative zur ökologischen und kapitalistischen Katastrophe. Hamburg: LAIKA Verlag.

Lüdtke, Alf (2015): Eigen-Sinn. Fabrikalltag, Arbeitererfahrungen und Politik vom Kaiserreich bis in den Faschismus. Münster: Westfälisches Dampfboot.

Lumer, Christoph (2011): Der Primat der Leidensminimierung. Von neminem laede zum Prioritarismus. In: Lumer, C./Meyer, U. (Hrsg.): Geist und Moral. Analytische Reflexionen für Wolfgang Lenzen. Paderborn: Mentis, S. 177-196.

Lutz, Tilman (2012): Verordnete Beteiligung im aktivierenden Staat - Bearbeitungsweisen und Deutungen von Professionellen. In: Widersprüche Redaktion (Hrsg.): Einspruch! Partizipation und Rechtsansprüche in Politik, Gesellschaft und Sozialer Arbeit. Widersprüche, Heft 123. Münster: Westfälisches Dampfboot, S. 5768.

Lux, Alexandra/Janowicz, Cedric/Hummel, Diana (2006): Versorgungssysteme. In: Becker, E./Jahn, T. (Hrsg.): Soziale Ökologie. Grundzüge einer Wissenschaft von den gesellschaftlichen Naturverhältnissen. Frankfurt (Main): Campus Verlag, S. 423-433.

Mader, Dimitri/Lindner, Urs/Pühretmayer, Hans (2017): Einleitung. Critical Realism als Philosophie der Sozialwissenschaften. In: Lindner, U./Mader, D./Urs Lindner, Dimitri Mader (Hg.) (Hrsg.): Critical realism meets kritische Sozialtheorie. Ontologie, Erklärung und Kritik in den Sozialwissenschaften. Bielefeld: Transcript, S. 7-73.

Magg, Rosaly (2006): Die Ganze Welt im Sucher: Einzoomen und ausblenden. In: Holzbrecher, A./Oomen-Welke, I./Schmolling, J. (Hrsg.): Foto + Text. Handbuch für die Bildungsarbeit. Wiesbaden: VS Verlag für Sozialwissenschaften, S. 433446.

Maiwald, Klaus (2006): Fotografie und Deutschunterricht. In: Holzbrecher, A./Oomen-Welke, I./Schmolling, J. (Hrsg.): Foto + Text. Handbuch für die Bildungsarbeit. Wiesbaden: VS Verlag für Sozialwissenschaften, S. 115-126. 
Marcuse, Herbert (1970): Der eindimensionale Mensch. Studien zur Ideologie der fortgeschrittenen Industriegesellschaft. Neuwied: Luchterhand.

Marcuse, Herbert (2009): Ökologie und Gesellschaftskritik. Nachgelassende Schriften 6. Lüneburg: zu Klampen.

Marquard, Odo (2013): Der Einzelne. Vorlesungen zur Existenzphilosophie. Stuttgart: Reclam.

Marx, Karl (1960a): Der achtzehnte Brumaire des Luis Bonaparte. In: Institut für Marxismus-Leninismus beim ZK der SED (Hrsg.): MEW 8. Berlin: Dietz Verlag, S. 111-207.

Marx, Karl (1960b): Die künftigen Ergebnisse der britischen Herrschaft in Indien. In: Institut für Marxismus-Leninismus beim ZK der SED (Hrsg.): MEW 9. Berlin: Dietz Verlag, S. 220-226.

Marx, Karl (1962a): Das Kapital. Kritik der politischen Ökonomie. Erster Band: Der Produktionsprozess des Kapitals. In: Institut für Marxismus-Leninismus beim ZK der SED (Hrsg.): MEW 23. Berlin: Dietz Verlag.

Marx, Karl (1962b): Der Bürgerkrieg in Frankreich. Adresse des Generalrats der Internationalen Arbeiterassoziation. In: Institut für Marxismus-Leninismus beim ZK der SED (Hrsg.): MEW 17. Berlin: Dietz Verl., S. 313-365.

Marx, Karl (1964): Das Kapital. Kritik der politischen Ökonomie. Dritter Band: Der Gesamtprozess der kapitalistischen Produktion. In: Institut für MarxismusLeninismus beim ZK der SED (Hrsg.): MEW 25. Berlin: Dietz Verlag.

Marx, Karl (1968a): Differenz der demokritischen und epikureischen Naturphilosophie nebst einem Anhange. In: Institut für Marxismus-Leninismus beim ZK der SED (Hrsg.): MEW 40. Ergänzungsband. Schriften bis 1844. Erster Teil. Berlin: Dietz Verlag, S. 257-373.

Marx, Karl (1968b): Ökonomisch-philosophischen Manuskripte aus dem Jahre 19844. In: Institut für Marxismus-Leninismus beim ZK der SED (Hrsg.): MEW 40. Ergänzungsband. Schriften bis 1844. Erster Teil. Berlin: Dietz Verlag, S. 465-588.

Marx, Karl (1978a): Thesen über Feuerbach (Revidierte Fassung von 1888). In: Institut für Marxismus-Leninismus beim ZK der SED (Hrsg.): MEW 3. Berlin: Dietz Verlag, S. 533-536.

Marx, Karl (1978b): Thesen über Feuerbach von 1845. In: Institut für MarxismusLeninismus beim ZK der SED (Hrsg.): MEW 3. Berlin: Dietz Verlag, S. 5-7.

Marx, Karl (1981a): Der leitende Artikel in Nr. 179 der „Kölnischen Zeitung“. In: Institut für Marxismus-Leninismus beim ZK der SED (Hrsg.): MEW 1. Berlin: Dietz Verlag, 86-104.

Marx, Karl (1981b): Kritische Randglossen. In: Institut für Marxismus-Leninismus beim ZK der SED (Hrsg.): MEW 1. Berlin: Dietz Verlag, S. 392-409.

Marx, Karl (1981c): Zur Judenfrage. In: Institut für Marxismus-Leninismus beim ZK der SED (Hrsg.): MEW 1. Berlin: Dietz Verlag, S. 347-377.

Marx, Karl (1981d): Zur Kritik der hegelschen Rechtsphilosophie. Einleitung. In: Institut für Marxismus-Leninismus beim ZK der SED (Hrsg.): MEW 1. Berlin: Dietz Verlag, S. 201-391.

Marx, Karl (1983): Grundrisse der Kritik der politischen Ökonomie. In: Institut für Marxismus-Leninismus beim ZK der SED (Hrsg.): MEW 42. Berlin: Dietz Verlag, S. 47-875.

Marx, Karl (1987): Kritik des Gothaer Programms. In: Institut für MarxismusLeninismus beim ZK der SED (Hrsg.): MEW 19. Berlin: Dietz Verlag, S. 11-32. 
Marx, Karl/Engels, Friedrich (1962): Die heilige Familie oder Kritik der kritischen Kritik. Gegen Bruno Bauer und Konsorten. In: Institut für MarxismusLeninismus beim ZK der SED (Hrsg.): MEW 2. Berlin: Dietz Verlag, S. 3-223.

Marx, Karl/Engels, Friedrich (1977): Manifest der Kommunistischen Partei. In: Institut für Marxismus-Leninismus beim ZK der SED (Hrsg.): MEW 4. Berlin: Dietz Verlag, S. 459-493.

Marx, Karl/Engels, Friedrich (1978): Die Deutsche Ideologie. Kritik der neuesten deutschen Philosophie in ihren Repräsentanten Feuerbach, B. Bauer und Stirner, und des deutschen Sozialismus in seinen verschiedenen Propheten. In: Institut für Marxismus-Leninismus beim ZK der SED (Hrsg.): MEW 3. Berlin: Dietz Verlag, S. 9-546.

Mathis, Franz (1992): Die deutsche Wirtschaft im 16. Jahrhundert. München: Oldenbourg.

May, Michael (1997a): Gemeinwesenarbeit als Organizing nicht nur von Gegenmacht, sondern auch von Erfahrung und Interessen. In: Widersprüche Redaktion (Hrsg.): Zur politischen Produktivität von Gemeinwesenarbeit. Widersprüche, Heft 65. Bielefeld: Kleine.

May, Michael (1997b): Perspektiven einer ProduzentInnen-Sozialpolitik. In: Widersprüche Redaktion (Hrsg.): Gesellschaft ohne Klassen? Politik des Sozialen wider Ausgrenzung und Repression. Bielefeld: Kleine.

May, Michael (2001): Gemeinwesenarbeit. Beitrag im Historisch-kritischen Wörterbuch des Marxismus. Band 5, Spalten 201-209. http://www.inkrit.de/e inkritpedia/e_maincode/doku.php?id=g:gemeinwesenarbeit [Zugriff: 26.02.2019].

May, Michael (2004): Selbstregulierung. Eine neue Sicht auf die Sozialisation. Gießen: Psychosozial-Verlag.

May, Michael (2005): Wie in der Sozialen Arbeit etwas zum Problem wird. Versuch einer pädagogisch gehaltvollen Theorie sozialer Probleme. Münster: Lit-Verlag.

May, Michael (2009): Menschliche Verwirklichung. In: Widersprüche. Zeitschrift für sozialistische Politik im Bildungs-, Gesundheits- und Sozialbereich, Heft 112, S. 43-63.

May, Michael (2010): Aktuelle Theoriediskurse Sozialer Arbeit. Eine Einführung. Wiesbaden: VS Verlag für Sozialwissenschaften.

May, Michael (2013a): Reflexivität und Eigensinn. In: Bareis, E./Kolbe, C./Ott, M./Rathgeb, K./Schütte-Bäumner, C. (Hrsg.): Episoden sozialer Ausschließung. Definitionskämpfe und widerständige Praktiken; Festschrift zum 65. Geburtstag von Helga Cremer-Schäfer. Münster: Westfälisches Dampfboot, S. 30-53.

May, Michael (2013b): Soziale Infrastruktur und Politik des Sozialen. In: Hirsch, J./Brüchert, O./Krampe, E.-M. (Hrsg.): Sozialpolitik anders gedacht. Soziale Infrastruktur. Hamburg: VSA-Verlag, S. 185-191.

May, Michael (2016): Marx - Bildung als Verwirklichung menschlichen Gemeinwesens. In: Paul-Siewert, B./Pfützner, R./Winkler, M. (Hrsg.): Sozialistische Pädagogik. Eine kommentierte Anthologie. Baltmannsweiler: Schneider Verlag Hohengehren GmbH, S. 187-194.

May, Michael (2017a): Ansätze migrantischer Sozialpolitik der Produzierenden und Dilemmata sie unterstützender Sozialer Arbeit. In: Braches-Chyrek, R./Sünker, H. (Hrsg.): Soziale Arbeit in gesellschaftlichen Konflikten und Kämpfen. Wiesbaden: VS Verlag für Sozialwissenschaften, S. 139-158. 
May, Michael (2017b): Soziale Arbeit als Arbeit am Gemeinwesen. Ein theoretischer Begründungsrahmen. Opladen: Verlag Barbara Budrich.

May, Michael (2018a): Partizipative Sozialraumforschung im Kontext sozialpädagogischen Ortshandelns: Zur Weiterentwicklung der Methode der Autfotografie im Anschluss an Paolo Freires Prinzip von Kodierung/Dekodierung. https:// www.sozialraum.de/partizipative-sozialraumforschung-im-kontextsozialpaedagogischen-ortshandelns.php [Zugriff: 02.11.2019].

May, Michael (2018b): Transdisziplinäre Professionalität. Die Artikulation historischer Problemkonstellationen als Grenzsituationen. In: Bütow, B./Patry, J.L./Astleitner, H. (Hrsg.): Grenzanalysen - erziehungswissenschaftliche Perspektiven zu einer aktuellen Denkfigur. Weinheim: Beltz Juventa, S. 182-208.

May, Michael (2019): Zur Weiterentwicklung von Paulo Freires Prinzip von Kodierung/Dekodierung in der partizipativen Sozialraumforschung. Das Beispiel der Analyse jugendlicher Raumaneignung eines Stadtteilzentrums. In: ÖZS - Österreichische Zeitschrift für Soziologie 44, Heft 3, S. 27-44.

May, Michael/Herzog, Christian (2017): Partizipative Sozialraumforschung und das Prinzip Kodierung/Dekodierung: Ein Beispiel aus der offenen Jugendarbeit. In: Alisch, M./May, M. (Hrsg.): Methoden der Praxisforschung im Sozialraum. Opladen: Budrich Barbara, S. 55-72.

May, Michael/Schmidt, Marcel (2021): Zur Bedeutung des dialektischen Materialismus für Wissenschaft und Praxis Sozialer Arbeit. In: Spatscheck, C./Borrmann, S. (Hrsg.): Architekturen des Wissens. Wissenschaftstheoretische Grundpositionen im Theoriediskurs der Sozialen Arbeit. Weinheim: Beltz Juventa, S. 142156.

May, Michael/Stock, Lothar (2019): Das uneingelöste Erbe der gemeinwesenarbeiterischen Arbeitsprinzipien Dieter Oelschlägels. https://www.sozialraum.de/dasuneingeloeste-erbe-der-gemeinwesenarbeiterischen-arbeitsprinzipien-dieteroelschlaegels.php [Zugriff: 18.02.2020].

MCC - Mercator Research Institute on Global Commons an Climate Change (2020): MCC erstellt umfassende Landkarte der Klimaforschung. https://www.mccberlin.net/de/news/meldungen/meldungen-detail/article/mcc-erstellt-umfassendelandkarte-der-klimaforschung.html [Zugriff: 11.03.2020].

Meadows, Dennis L. (1987): Die Grenzen des Wachstums. Bericht des Club of Rome zur Lage der Menschheit. Stuttgart: Deutsche Verlags-Anstalt.

Meier, Christian (1983): Die Entstehung des Politischen bei den Griechen. Frankfurt (Main): Suhrkamp.

Meister, Klaus (2010): „Aller Dinge Maß ist der Mensch“. Die Lehren der Sophisten. München: Fink.

Menze, Clemens (1965): Wilheilm von Humboldts Lehre und Bild vom Menschen. Ratingen: A. Henn Verlag.

Menzl, Marcus (2014): Nimby-Proteste - Ausdruck neu erwachten Partizipationsinteresses oder eines zerfallenden Gemeinwesens? In: Gestring, N./Ruhne, R./Wehrheim, J. (Hrsg.): Stadt und soziale Bewegungen. Wiesbaden: Springer VS, S. 65-81.

Meyer, Kurt (1973): Henri Lefebvre. Ein romantischer Revolutionär. Wien: Europaverlag.

Michel, Boris/Roskamm, Nikolai (2013a): Die postpolitische stadt? In: sublurban zeitschrift für kritische stadtforschung, Heft 2. 
Michel, Boris/Roskamm, Nikolai (2013b): Einführung. Die ,postpolitischen Stadt'. In: sub $\backslash \mathrm{u} \mathrm{r}$ b a n zeitschrift für kritische stadtforschung, Heft 2, S. 9-16.

Mittelstraß, Jürgen (2005): Methodische Trandisziplinarität. In: Technikfolgenabschätzung Theorie und Praxis, Heft 2, S. 18-23.

Moog, Willy (1930): Hegel und die Hegelsche Schule. München: Ernst Reinhardt Verlag.

Moore, Jason W. (2013): Anthropocene or Capialocene? https://jasonwmoore.word press.com/2013/05/13/anthropocene-or-capitalocene/ [Zugriff: 19.03.2020].

Moore, Jason W. (2016): Über die Ursprünge unserer ökologischen Krise. In: PROKLA. Zeitschrift für kritische Sozialwissenschaft, Heft 185, S. 599-620.

Mössner, Samuel (2016): Quariersmanagement in der post-politischen Stadt. In: Oehler, P./Thomas, N./Drilling, M. (Hrsg.): Soziale Arbeit in der unternehmerischen Stadt. Kontexte, Programmatiken, Ausblicke. Wiesbaden: Springer VS, S. 131-142.

Mührel, Eric (2020): Sozialpädagogik - eine Reformulierung. Transgenerative Ethik, das Parlament der Dinge und transformative Bildung als Grundlage für eine humane und nachhaltige Entwicklung. In: Birgmeier, B./Mührel, E./Winkler, M. (Hrsg.): Sozialpädagogische SeitenSprünge. Einsichten von außen, Aussichten von innen: Befunde und Visionen zur Sozialpädagogik. Weinheim: Beltz Juventa, 166-173.

Mührel, Eric/Birgmeier, Bernd (Hrsg.) (2009): Theorien der Sozialpädagogik - ein Theorie-Dilemma? Wiesbaden: VS Verlag für Sozialwissenschaften.

Mührel, Eric/Birgmeier, Bernd (Hrsg.) (2011): Theoriebildung in der Sozialen Arbeit. Entwicklungen in der Sozialpädagogik und der Sozialarbeitswissenschaft. Wiesbaden: VS Verlag für Sozialwissenschaften.

Müller, Carsten (2013): Zur Geschichte und Theorie der Sozialpädagogik - vom politischen zum pädagogischen Mandat. In: Mührel, E./Birgmeier, B. (Hrsg.): Menschenrechte und Demokratie. Perspektiven für die Entwicklung der Sozialen Arbeit als Profession und wissenschaftliche Disziplin. Wiesbaden: Springer VS, S. 205-218.

Müller, Enrico (2019a): Nietzsche-Lexikon. Paderborn: Schöningh.

Müller, Horst (2019b): Neosozialismus: 8 Thesen und Antithesen zur System- und Transformationsdebatte. aus: Infobrief Nr. 37 der Praxisphilosophischen Initiative. https://www.praxisphilosophie.de/neosozialismus_thesen_und_antithesen.pdf [Zugriff: 25.07.2020].

Müller, Werner (1991): Indianische Welterfahrung. Stuttgart: Klett-Cotta.

Müller-Schöll, Ulrich (2001): Zur Staatskritik von Henri Lefebvre. In: Ernst-BlochAssoziation (Hrsg.): Der Staat als Retter der Utopie? Zur Kritik des Politischen im Zeitalter der „Globalisierung“. VorSchein, 20/21.2001. Berlin, Wien: Philo Verlagsgesellschaft mbH, S. 199-214.

Mullis, Daniel/Schipper, Sebastian (2013): Die postdemokratische Stadt zwischen Politisierung und Kontinuität. Oder ist die Stadt jemals demokratisch gewesen? In: sub $\backslash \mathrm{u}$ r b a n zeitschrift für kritischen stadtforschung, Heft 2, S. 79-100.

Nassehi, Armin (2008): Die Zeit der Gesellschaft. Auf dem Weg zu einer soziologischen Theorie der Zeit. Neuauflage mit einem Beitrag „Gegenwarten“. Wiesbaden: VS Verlag für Sozialwissenschaften.

Natorp, Paul (1922): Sozial-Idealismus. Neue Richtlinien sozialer Erziehung. Berlin: Verlag Julius Springer. 
Negt, Oskar (1977): Nicht nach Köpfen, sondern nach Interessen organisieren! Aktuelle Fragen der Organisation. 1972. In: Keine Demokratie ohne Sozialismus. Über den Zusammenhang von Politik, Geschichte und Moral. Frankfurt (Main): Suhrkamp, S. 300-312.

Negt, Oskar/Kluge, Alexander (1981): Geschichte und Eigensinn. Frankfurt (Main): Verlag Zweitausendeins.

Niemann, Hans-Joachim (2010): Arthur Schopenhauer und sein nicht preisgekröntes Meisterwerk der Ethik. In: Aufklärung und Kritik. Zeitschrift für freies Denken und humanistische Philosphie, Heft 4/2010, S. 27-42.

Nietzsche, Friedrich (1954a): Also sprach Zarathustra. Ein Buch für Alle und Keinen. In: Nietzsche, F. (Hrsg.): Werke. In drei Bänden. Band 2. München: Hanser.

Nietzsche, Friedrich (1954b): Die Fröhliche Wissenschaft. In: Nietzsche, F. (Hrsg.): Werke. In drei Bänden. Band 2. München: Hanser.

Nietzsche, Friedrich (1954c): Jenseits von Gut und Böse. Vorspiel einer Philosophie der Zukunft. In: Nietzsche, F. (Hrsg.): Werke. In drei Bänden. Band 2. München: Hanser.

Nietzsche, Friedrich (1954d): Menschliches, Allzumenschliches. In: Nietzsche, F. (Hrsg.): Werke. In Drei Bänden. Band 1. München: Hanser.

Nietzsche, Friedrich (1954e): Zur Genealogie der Moral. In: Nietzsche, F. (Hrsg.): Werke. In drei Bänden. Band 2. München: Hanser.

Nietzsche, Friedrich (1988): Nachgelassene Fragmente. 1875-1879. KSA 8. München: Deutscher Taschenbuch-Verlag.

Obrecht, Werner (2005): Umrisse einer biopsychosoziokulturellen Theorie menschlicher Bedürfnisse. Geschichte, Probleme, Struktur, Funktion. Skript zur gleichnamigen Lehrveranstaltung. http://www.freies-institut-tpsa.com/documents/ Obrecht, \%20Werner\%20A.\%20-

$\%$ 20Umrisse \%20einer\%20biopsychosoziokulturellen\%20Theorie\%20menschlich er\%20Bed\%C3\%BCrfnisse.pdf [Zugriff: 09.06.2019].

Oehler, Patrick/Käser, Nadine/Drilling, Matthias/Guhl, Jutta/Thomas, Nicola (Hrsg.) (2017): Emanzipation, Soziale Arbeit und Stadtentwicklung. Eine programmatische und methodische Herausforderung. Opladen: Budrich UniPress Ltd.

Oehler, Patrick/Thomas, Nicola/Drilling, Matthias (Hrsg.) (2016): Soziale Arbeit in der unternehmerischen Stadt. Kontexte, Programmatiken, Ausblicke. Wiesbaden: Springer VS.

Oelschlägel, Dieter (2013a): Die Soziale Arbeitsgemeinschaft Berlin-Ost: Friedrich Siegmund-Schultze. In: Stövesand, S./Stoik, C./Troxler, U. (Hrsg.): Handbuch Gemeinwesenarbeit. Traditionen und Positionen, Konzepte und Methoden. Deutschland - Schweiz - Österreich. Opladen: Barbara Budrich, S. 44-47.

Oelschlägel, Dieter (2013b): Geschichte der Gemeinwesenarbeit in der Bunderepublik Deutschland. In: Stövesand, S./Stoik, C./Troxler, U. (Hrsg.): Handbuch Gemeinwesenarbeit. Traditionen und Positionen, Konzepte und Methoden. Deutschland Schweiz - Österreich. Opladen: Barbara Budrich, S. 181-202.

Ökosozialistisches Netzwerk (2017): Ökosozialistische Erklärung. In: die internationale - Magazin der Internationalen Sozialistischen Organisation, Heft 4/2017, S. $12-18$.

Olk, Thomas (1986): Die professionelle Zukunft Sozialer Arbeit. Zur Veränderung des beruflichen Selbstverständnisses in einem schwierigen Arbeitsfeld. In: Oppl, H./Tomaschek, A. (Hrsg.): Soziale Arbeit 2000. Band 2. Modernisierungskrise 
und soziale Dienste. Chancen für gesellschaftlichen Stellenwert, Profession und Ausbildung. Freiburg im Breisgau: Lambertus, S. 107-136.

Oschmann, Wolfgang (2003): Vier Milliarden Jahre Klimageschichte im Überblick. In: Deutscher Wetterdienst (Hrsg.): Klimastatusbericht 2003. Der Hitzesommer 2003 - Vier Milliarden Jahre Klimageschichte im Überblick - Aktuelle Ergebnisse des Klimamonitorings. Offenbach: Deutscher Wetterdienst, S. 7-24.

Ott, Konrad/Dierks, Jan/Voget-Kleschin, Lieske (Hrsg.) (2016): Handbuch Umweltethik. Stuttgart: J.B. Metzler.

Owen, Robert (1988): Das Soziale System. In: Opitz, H./Gerlach, H.-M. (Hrsg.): Philosophen-Lesebuch. Band 2. Berlin: Dietz Verlag, S. 685-696.

Owen, Robert (2016): Parerga und Paralopomena. In: Paul-Siewert, B./Pfützner, R./Winkler, M. (Hrsg.): Sozialistische Pädagogik. Eine kommentierte Anthologie. Baltmannsweiler: Schneider Verlag Hohengehren GmbH, S. 197-206.

Paech, Niko (2014): Befreiung vom Überfluss. Auf dem Weg in die Postwachstumsökonomie. München: oekom verlag.

Paech, Niko (2017): Postwachstumsökonomik. Wachstumskritische Alternativen zu Marx. In: APuZ, Heft 19-20, S. 41-46.

Paech, Niko (2018): Postwachstumsökonomik. In: Kümmel, R./Lindenberger, D./Paech, N. (Hrsg.): Energie, Entropie, Kreativität. Was das Wirtschaftswachstum treibt und bremst. Wiesbaden: Springer Spektrum, S. 101-135.

Park, Robert Ezra/Burgess, Ernest Watson/McKenzie, Roderick D. (1967 [1925]): The City. Suggestions for investigation of human behavior in the urban environment. [Nachdr. von 1925]. Chicago: University of Chicago Press.

Pehnt, Wolfgang (2015): Der Prophet der ,strahlenden Stadt“. Vorwort zum Reprinz 2015. Anlässlich des 50. Todestages von Le Corbusier. In: Le Corbusier (Hrsg.): Städtebau. Reprint. München: Deutsche Verlags-Anstalt.

PIK - Potsdam-Institut Für Klimafolgenforschung (o. J.): Kippelemente - Achillesfersen im Erdsystem. https:/www.pik-potsdam.de/services/infothek/kippelemente/ kippelemente [Zugriff: 17.03.2020].

Platon (1940): Phaidros. In: Sämtliche Werke. Band 2. Berlin: Lambert Schneider.

Polt, Richard (2013): »Beiträge zur Philosophie (Vom Ereignis)«. Ein Sprung in die Wesung des Seyns. In: Thomä, D./Grosser, F./Meyer, K./Schmid, H. B. (Hrsg.): Heidegger-Handbuch. Leben - Werk - Wirkung. Stuttgart, Weimar: Verlag J.B. Metzler, S. 153-162.

Pongratz, Hans J./Voß, Günter G. (1998): Der Arbeitskraftunternehmer. Eine neue Grundform der Ware Arbeitskraft. In: KZfSS - Kölner Zeitschrift für Soziologie und Sozialpsychologie, Heft 1, S. 131-158.

Popper, Karl R. (1973): Objektive Erkenntnis. Ein evolutionärer Entwurf. Hamburg: Hoffman \& Campe.

Rahmstorf, Stefan/Schellnhuber, Hans-Joachim (2007): Der Klimawandel. Diagnose, Prognose, Therapie. München: Verlag C. H. Beck.

Rawls, John (1998): Politischer Liberalismus. Frankfurt (Main): Suhrkamp.

Rawls, John (2012): Eine Theorie der Gerechtigkeit. Frankfurt (Main): Suhrkamp.

Reden, Sitta von (2015): Antike Wirtschaft. Berlin: de Gruyter Oldenbourg.

Redepenning, Marc (2013): Varianten raumbezogener sozialer Gerechtigkeit. Ein sozialgeographischer Versuch über das Verhältnis von Raum und Gerechtigkeit und ein Nachdenken über die Frage ,Was soll wo sein?“. In: ethik und gesellschaft. ökumenische zeitschrift für sozialethik, Heft 1/2013, S. 1-29. 
Rehmann, Jan (2019): Ideologiekritik. In: Bittlingmayer, U. H./Demirovic, A./Freytag, T. (Hrsg.): Handbuch Kritische Theorie. Wiesbaden: Springer VS, S. 663700.

Reichardt, Tobias (2008): Aporien der soziologischen Erkenntnistheorie Alfred SohnRethels. In: Wissenschaftliche Mitteilungen, Heft 6, S. 242-267.

Reichertz, Jo (2013): Objektive Hermeneutik und hermeneutische Wissensoziologie. In: Flick, U./Kardorff, E. v./Steinke, I. (Hrsg.): Qualitative Forschung. Ein Handbuch. Reinbeck: Rowohlt, S. 514-524.

Resch, Christine/Steinert, Heinz (2011): Kapitalismus. Porträt einer Produktionsweise. Münster: Westfälisches Dampfboot.

Richter, Helmut (1998): Sozialpädagogik - Pädagogik des Sozialen. Grundlegungen, Institutionen, Perspektiven der Jugendbildung. Frankfurt (Main): Lang.

Richter, Helmut (2001): Kommunalpädagogik. Studien zur interkulturellen Bildung. Frankfurt am Main: Lang.

Richter, Helmut (2008): Kommunalpädagogik. In: Coelen, T./Otto, H.-U. (Hrsg.): Grundbegriffe Ganztagsbildung. Das Handbuch. Wiesbaden: VS Verlag für Sozialwissenschaften, S. 868-877.

Richter, Helmut (2009): Kommunalpädagogik. In: Mührel, E./Birgmeier, B. (Hrsg.): Theorien der Sozialpädagogik - ein Theorie-Dilemma? Wiesbaden: VS Verlag für Sozialwissenschaften, S. 273-286.

Richter, Helmut (2015): Demokratie. In: Otto, H.-U./Thiersch, H. (Hrsg.): Handbuch Soziale Arbeit. Grundlagen der Sozialarbeit und Sozialpädagogik. München, Basel: Ernst Reinhardt Verlag, S. 272-281.

Richter, Helmut (2016): Pädagogik des Sozialen. Bildungsbündnisse in Demokratiebildung. In: Widersprüche Redaktion (Hrsg.): Pädagogik des Sozialen - ein Schritt zu Demokratie als Lebensform, Heft 142. Münster: Westfälisches Dampfboot, S. 47-59.

Richter, Helmut (2019a): Demokratie und Identitätsbildung als strukturierendes Element des Sozialraums. In: Kessl, F./Reutlinger, C. (Hrsg.): Handbuch Sozialraum. Grundlagen für den Bildungs- und Sozialbereich. Wiesbaden: Springer VS, S. 341-358.

Richter, Helmut (2019b): Sozialpädagogik - Pädagogik des Sozialen. Grundlegungen, Institutionen und Perspektiven der Jugendbildung. 2. Auflage. Wiesbaden: VS Verlag für Sozialwissenschaften.

Ritsert, Jürgen (2005): Dimensionen des Vernunftbegriffs in der »Dialektik der Aufklärung«. Vortrag im Colloquium mit Heinz Steinert. http://ritsert-online.de/ materialien.htm [Zugriff: 15.08.2018].

Ritsert, Jürgen (2007): Anerkennung als Prinzip der Gesellschaftkritik. Über die Wurzeln bei Kant, Fichte und Hegel,. Seminarmaterialien 20. http://ritsertonline.de/materialien.htm [Zugriff: 15.08.2018].

Rohr, Jascha (2012): Kollaborative Demokratie - konzeptionelle Grundlagen. https:// www.partizipativ-gestalten.de/kollaborative-demokratie-konzeptionellegrundlagen/ [Zugriff: 18.06.2020].

Rohr, Jascha (2013): In unserer Macht. Aufbruch in die kollaborative Demokratie. Lassan, Vorpommern: thinkOya.

Rohr, Jascha/Ehlert, Hanna/Möller, Benjamin/Hörster, Sonja/Hoppe, Marie (2017): Impulse zur Bürgerbeteiligung vor allem unter Inklusionsaspekten - empirische Befragungen, dialogische Auswertungen, Synthese praxistauglicher Empfehlun- 
gen $\mathrm{zu}$ Beteiligungsprozessen. https:/www.umweltbundesamt.de/sites/default/ files/medien/1410/publikationen/2017-05-08_texte_36-2017_impulse-buerger beteiligung_0.pdf [Zugriff: 18.06.2020].

Ronneberger, Klaus (2014): Die Revolution der Städte wieder lesen. Vorwort zur Neuauflage. In: Die Revolution der Städte. Hamburg: CEP Europäische Verlagsanstalt, S. I-XXI.

Rosa, Hartmut (2019): Analyse, Diagnose, Therapie? Versuch einer kritischen Neubestimmung der spätmodernen Sozialformation. In: Bittlingmayer, U. H./Demirovic, A./Freytag, T. (Hrsg.): Handbuch Kritische Theorie. Wiesbaden: Springer VS, 1351-1373.

Rousseau, Jean-Jacques (1978): Abhandlung über den Ursprung und die Grundlagen der Ungleichheit unter den Menschen (1755). Schriften. Band 1. München.

Rousseau, Jean-Jacques (2006): Der Gesellschaftsvertrag oder Prinzipien des Staatsrechts. Wiesbaden: Marix.

Rudnicka, J. (2020): Megacities: Anzahl der Einwohner der größten Städte weltweit im Jahr 2018. https://de.statista.com/statistik/daten/studie/881664/umfrage/ megacities-einwohnerzahl-der-groessten-staedte-weltweit/ [Zugriff: 24.08.2020].

Ruoff, Michael (2009): Foucault-Lexikon. Entwicklung, Kernbegriffe, Zusammenhänge. Paderborn: Fink.

Russell, Bertrand (2009): Philosophie des Abendlandes. Ihr Zusammenhang mit der politischen und sozialen Entwicklung. Zürich: Europa.

Russo, Manfred (2016): Projekt Stadt. Eine Geschichte der Urbanität. Basel: Birkhäuser.

Schadewaldt, Wolfgang (1978): Die Anfänge der Philosophie bei den Griechen. Die Vorsokratiker und ihre Voraussetzungen. Tübinger Vorlesungen Band I. Frankfurt (Main): Suhrkamp.

Scherr, Albert (2019): Systemtheoretische Differenztheorie als kritische Gesellschaftstheorie. In: Bittlingmayer, U. H./Demirovic, A./Freytag, T. (Hrsg.): Handbuch Kritische Theorie. Wiesbaden: Springer VS, S. 559-583.

Schipper, Sebastian (2018): Neoliberale Stadt. In: Rink, D./Haase, A. (Hrsg.): Handbuch Stadtkonzepte. Analysen, Diagnosen, Kritiken und Visionen. Wien: UTB $\mathrm{GmbH}$, S. 259-278.

Schipper, Sebastian/Latocha, Tabea (2018): Wie lässt sich Verdrängung verhindern? Die Rent-Gap-Theorie und ihre Gültigkeitsbedingungen am Beispiel des Frankfurter Gallus. In: sub $\backslash \mathrm{u} r \mathrm{~b}$ a $\mathrm{n}$ zeitschrift für kritischen stadtforschung, Heft 1, S. 51-76.

Schmale, Ingrid/Ravensburg, Nicole Göler von (2017): Sozialgenossenschaften als Akteure des sozialen Wandels und genossenschaftliche Beiträge zu einer nachhaltigen Sozial- und Daseinsvorsorge. In: Theuvsen, L./Andeßner, R. C./Gmür, M./Greiling, D. (Hrsg.): Nonprofit-Organisationen und Nachhaltigkeit. Wiesbaden: Springer Gabler, S. 439-448.

Schmalstieg, Catharina (2010): Intervention als emanzipatorische Praxis. Erfahrung von SUbalternität und kollektives Handeln. In: Dege, M./Grallert, T./Dege, C./Chimiri, N. (Hrsg.): Können Marginalisierte (wieder)sprechen? Zum politischen Potenzial der Sozialwissenschaften. Gießen: Psychosozial-Verlag, S. 173200.

Schmelzer, Matthias/Vetter, Andrea (2019): Degrowth/Postwachstum zur Einführung. Hamburg: Junius. 
Schmidt, Alfred (1988a): Emanzipatorische Sinnlichkeit. Ludwig Feuerbachs anthropologischer Materialismus. München: Piper.

Schmidt, Alfred (1988b): Idee und Weltwille. Schopenhauer als Kritiker Hegels. München: Hanser.

Schmidt, Alfred (2016): Der Begriff der Natur in der Lehre von Marx. Hamburg: CEP Europäische Verlagsanstalt.

Schmidt, Alfred (2018a): Der Wissenschaftsbegriff von Marx in der gegenwärtigen Diskussion (1970/71). In: Görlich, B./Jeske, M. (Hrsg.): Marx als Philosoph. Studien in der Perspektive kritischer Theorie. Springe: zu Klampen, S. 64-88.

Schmidt, Alfred (2018b): Für einen ökologischen Materialismus. In: Görlich, B./Jeske, M. (Hrsg.): Marx als Philosoph. Studien in der Perspektive kritischer Theorie. Springe: zu Klampen, S. 159-178.

Schmidt, Alfred (2018c): Materialismus und Subjektivität. Aspekte ihres Verhältnisses in der gegenwärtigen Diskussion. Alfred Schmidt und Bernhard Görlich im Gespräch. In: Görlich, B./Jeske, M. (Hrsg.): Marx als Philosoph. Studien in der Perspektive kritischer Theorie. Springe: zu Klampen, S. 99-150.

Schmidt, Marcel (2017): Für ein Gemeinwesen von unten! Rezension vom 06.11.2017 zu: Michael May: Soziale Arbeit als Arbeit am Gemeinwesen. Ein theoretischer Begründungsrahmen. Verlag Barbara Budrich GmbH (Opladen, Berlin, Toronto) 2017. https://www.socialnet.de/rezensionen/23569.php [Zugriff: 26.02.2019].

Schmidt, Marcel (2019): Metaphilosophische Soziale Arbeit als solidarisches Mandat für Residuen. In: Widersprüche. Zeitschrift für sozialistische Politik im Bildungs, Gesundheits- und Sozialbereich, Heft 144, S. 33-48.

Schmidt, Marcel (2020): Zur Entstehung und Bedeutung des „Recht auf Stadt“ im Werk Lefebvres. https://www.sozialraum.de/zur-entstehung-und-bedeutung-desrecht-auf-stadt-im-werk-lefebvres.php [Zugriff: 01.10.2020].

Schmidt, Marcel (2021a [i.E.]): Bildung im Anthropozän oder für ein Anthropozän? Rezension zu Christoph Wulf (2020): Bildung als Wissen vom Menschen im Anthropozän. In: Sozialwissenschaftliche Literatur Rundschau - Zeitschrift für Sozialrabeit, Sozialpädagogik, Sozialpolitik und Gesundheitspolitk, Heft 1/2021.

Schmidt, Marcel (2021b [i.E.]): Wohnen als Begriff sozial-ökologischer Subjektbildung? In: Alisch, M./May, M. (Hrsg.): Ein Dach über dem Kopf. Wohnen als Herausforderung von Sozialraumentwicklung. Leverkusen-Opladen: Budrich Barbara.

Schmied-Kowarzik, Wolfdietrich (2018): Zur Aktualität der Praxisphilosophie von Karl Marx. In: Novkovic, D./Akel, A. (Hrsg.): Karl Marx - Philosophie, Pädagogik, Gesellschaftstheorie und Politik. Aktualität und Perspektiven der Marxschen Praxisphilosophie. Kassel: kassel university press, S. 21-38.

Schmolling, Jan (2006): Fotografie als Lebenszeichen. Der Deutsche Jugendfotopreis als Forum für authentische Sichtweisen. In: Holzbrecher, A./Oomen-Welke, I./Schmolling, J. (Hrsg.): Foto + Text. Handbuch für die Bildungsarbeit. Wiesbaden: VS Verlag für Sozialwissenschaften, S. 59-72.

Schneidewind, Uwe (2014): Von der nachhaltigen zur transformativen Hochschule. Perspektiven einer „True University Sustainability“. In: uwf - UmweltWirtschaftsForum 22, 4, S. 221-225.

Schopenhauer, Arthur (1989): Philosophie in Briefen. Frankfurt (Main): Insel-Verlag. Schopenhauer, Arthur (1998): Die Welt als Wille und Vorstellung. Gesamtausgabe. München: Deutscher Taschenbuch-Verlag. 
Schoppek, Dorothea E. (2019): How Far is Degrowth a Really Revolutionary Counter Movement to Neoliberalism? In: Environmental Values, Heft 2, S. 131-151.

Schoppek, Dorothea Elena (2018): Mitschwimmen oder untergehen? In: Forschungsjournal Soziale Bewegungen 31, Heft 4, S. 44-51.

Schott, Dieter (2014): Europäische Urbanisierung (1000 - 2000). Eine umwelthistorische Einführung. Köln: Böhlau.

Schramm, Alfred (1998): Vermutungswissen: Keine Lösung des Induktionsproblems. In: Gadenne, V. (Hrsg.): Kritischer Rationalismus und Pragmatismus. Amsterdam: Rodopi, S. 77-88.

Schröder, Carolan/Walk, Heike (2014a): Chancen und Grenzen von Genossenschaften als Akteure einer sozial-ökologischen Transformation. In: Schröder, C./Walk, H. (Hrsg.): Genossenschaften und Klimaschutz. Akteure für zukunftsfähige, solidarische Städte. Wiesbaden: Springer Fachmedien Wiesbaden, S. 299-306.

Schröder, Carolin/Walk, Heike (Hrsg.) (2014b): Genossenschaften und Klimaschutz. Akteure für zukunftsfähige, solidarische Städte. Wiesbaden: Springer Fachmedien Wiesbaden.

Schubert, Axel H. (2017): Planen vor der Herausforderung gelingender Partizipation, Rechtsstaatlichkeit und Emanzipation. In: Oehler, P./Käser, N./Drilling, M./Guhl, J./Thomas, N. (Hrsg.): Emanzipation, Soziale Arbeit und Stadtentwicklung. Eine programmatische und methodische Herausforderung. Opladen: Budrich UniPress Ltd, S. 51-77.

Schultz, Irmgard/Götz, Konrad (2006): Konsum. In: Becker, E./Jahn, T. (Hrsg.): Soziale Ökologie. Grundzüge einer Wissenschaft von den gesellschaftlichen Naturverhältnissen. Frankfurt (Main): Campus Verlag, S. 360-370.

Schultz, Irmgard/Hayn, Doris/Lux, Alexandra (2006): Gender \& Envorinment. In: Becker, E./Jahn, T. (Hrsg.): Soziale Ökologie. Grundzüge einer Wissenschaft von den gesellschaftlichen Naturverhältnissen. Frankfurt (Main): Campus Verlag, S. 434-446.

Schulz-Nieswandt, Frank (2017): Genossenschaftliche Selbsthilfe in anthropologischer Perspektive. In: Schmale, I./Blome-Drees, J. (Hrsg.): Genossenschaft innovativ. Wiesbaden: Springer Fachmedien Wiesbaden, S. 345-362.

Seiffert, Helmut (1980): Einführung in die Wissenschaftstheorie. Sprachanalyse, Deduktion, Induktion in Natur- und Sozialwissenschaften. München: Beck.

Selle, Klaus (2013): Über Bürgerbeteiligung hinaus. Stadtentwicklung als Gemeinschaftsaufgabe? Analysen und Konzepte. Lemgo: Verlag Dorothea Rohn.

Sohn-Rethel, Alfred (1989): Geistige und körperliche Arbeit. Zur Epistemologie der abendländischen Geschichte. Revidierte und ergänzte Neuauflage. Weinheim: VCH Acta Humaniora.

Sohn-Rethel, Alfred (1990): Das Geld, die bare Münze des Apriori. Berlin: Wagenbach.

Sommer, Michael (2012): Narren im Purpur. Lebensbilder aus der Antike. Darmstadt: Philipp von Zabern Verlag.

Sommer, Michael (2013): Wirtschaftsgeschichte der Antike. München: Beck.

Spivak, Gayatari Chakravorty (2008a): Can subaltern speak? In: Spivak, G. C. (Hrsg.): Can the subaltern speak? Postkolonialität und subalterne Artikulation. Wien: Turia + Kant, S. 17-118. 
Spivak, Gayatari Chakravorty (2008b): Ein Gespräch über Subalternität. In: Spivak, G. C. (Hrsg.): Can the subaltern speak? Postkolonialität und subalterne Artikulation. Wien: Turia + Kant, S. 119-148.

Stache, Christian (2017): Kapitalismus und Naturzerstörung. Zur kritischen Theorie des gesellschaftlichen Naturverhältnisses. Berlin: Budrich UniPress Ltd.

Stamm, Ingo (2021): Ökologisch-kritische Soziale Arbeit. Geschichte, aktuelle Positionen und Handlungsfelder. Leverkusen-Opladen: Budrich Barbara.

Staub-Bernasconi, Silvia (2007): Vom beruflichen Doppelmandat zum professionellen Tripelmandat. Wissenschaft und Menschenrechte als Begündungsbasis der Profession Sozialer Arbeit. In: Zeitschrift für Sozialarbeit in Österreich, JuniHeft, S. 8-17.

Staub-Bernasconi, Silvia (2013): Integrale soziale Demokratie als gemeinwesenbezogener Lernprozess und soziale Vision: Jane Addams. In: Stövesand, S./Stoik, C./Troxler, U. (Hrsg.): Handbuch Gemeinwesenarbeit. Traditionen und Positionen, Konzepte und Methoden. Deutschland - Schweiz - Österreich. Opladen: Barbara Budrich, S. 37-43.

Stein-Hölkeskamp, Elke (2015): Das archaische Griechenland. Die Stadt und das Meer. München: Beck.

Steyerl, Hito (2008): Die Gegenwart der Subalternen. In: Spivak, G. C. (Hrsg.): Can the subaltern speak? Postkolonialität und subalterne Artikulation. Wien: Turia + Kant, S. 5-16.

Stieß, Immanuel/Deffner, Jutta/Janowicz, Cedric (2006): Bauen und Wohnen. In: Becker, E./Jahn, T. (Hrsg.): Soziale Ökologie. Grundzüge einer Wissenschaft von den gesellschaftlichen Naturverhältnissen. Frankfurt (Main): Campus Verlag, S. 394-408.

Stoik, Christoph (2013): Von der Gemeinwesenarbeit zur „sozialraumorientierten Verwaltungsmodernisierung": Wolfgang Hinte. In: Stövesand, S./Stoik, C./Troxler, U. (Hrsg.): Handbuch Gemeinwesenarbeit. Traditionen und Positionen, Konzepte und Methoden. Deutschland - Schweiz - Österreich. Opladen: Barbara Budrich, S. 79-84.

Stövesand, Sabine (2013): Communitiy Organization als Soziale Aktion: Saul D. Alinsky und Co. In: Stövesand, S./Stoik, C./Troxler, U. (Hrsg.): Handbuch Gemeinwesenarbeit. Traditionen und Positionen, Konzepte und Methoden. Deutschland - Schweiz - Österreich. Opladen: Barbara Budrich, S. 48-52.

Sünker, Heinz (1989): Bildung, Alltag und Subjektivität. Elemente zu einer Theorie der Sozialpädagogik. Weinheim: Deutscher Studien Verlag.

Sünker, Heinz (2012): Soziale Arbeit und Bildung. In: Thole, W. (Hrsg.): Grundriss Soziale Arbeit. Wiesbaden: VS Verlag für Sozialwissenschaften, S. 249-266.

Sünker, Heinz (2014): Bildung - Theoriebildung oder Gemengelage. In: Erwägen Wissen - Ethik. Forum für Erwägungskultur, Heft 2, S. 334-336.

Sünker, Heinz (2017): Demokratie, Kapitalismus, Soziale Gerechtigkeit. Gesellschaftliche und politische Perspektiven heute. In: Neue Praxis -Zeitschrift für Sozialarbeit, Sozialpädagogik und Sozialpolitik, Heft 6/2017, S. 438-456.

Sünker, Heinz/Braches-Chyrek, Rita (2010): Disziplin- und Professionsentwicklungen in der Sozialen Arbeit: Transformationen. In: Wilken, U./Thole, W. (Hrsg.): Kulturen Sozialer Arbeit. Wiesbaden: VS Verlag für Sozialwissenschaften, S. 61-73.

Swyngedouw, Eric (2013): Die postpolitische Stadt. In: Sublurban zeitschrift für kritische stadtforschung, Heft 2, S. 141-158. 
Theweleit, Klaus (1982a): Männerphantasien, Teil 1. Frauen, Fluten, Körper, Geschichte. Frankfurt (Main): Rowohlt.

Theweleit, Klaus (1982b): Männerphantasien, Teil 2. Männerkörper, zur Psychoanalyse des weissen Terrors. Frankfurt (Main): Rowohlt.

Thürling, Marleen (2017): Sozialgenossenschaftliche Unternehmen in Deutschland. Begriff, aktuelle Entwicklungen und Forschungsbedarf. In: Theuvsen, L./Andeßner, R. C./Gmür, M./Greiling, D. (Hrsg.): Nonprofit-Organisationen und Nachhaltigkeit. Wiesbaden: Springer Gabler, S. 459-468.

Thürling, Marleen (2018): Gemeinwohl liegt im Trend. In: Magazin enormweconomy, Genossenschaften, Heft 22, S. 22-27.

Töppner, Sandra (2016): Charles Fourier - Utopist einer allgemeinen Utopie. In: PaulSiewert, B./Pfützner, R./Winkler, M. (Hrsg.): Sozialistische Pädagogik. Eine kommentierte Anthologie. Baltmannsweiler: Schneider Verlag Hohengehren GmbH, S. 101-111.

Trebbin, Anja (2007): Michel Foucaults Weg in die Antike. Zur Bedeutung der Selbsttechniken für den Widerstand gegen die moderne Macht. Berlin: LogosVerlag.

Tricarico, Antonio/Löschmann, Heike (2012): Finanzialisierung — ein Hebel zur Einhegung der Commons. In: Helfrich, S./Heinrich-Böll-Stiftung (Hrsg.): Commons. Für eine neue Politik jenseits von Markt und Staat. Bielefeld: Transcript, S. 184-195.

UBA - Umweltbundesamt (2019): Monitoringbericht 2019 zur Deutschen Anpassungsstrategie an den Klimawandel. Bericht der Interministeriellen Arbeitsgruppe Anpassungsstrategie der Bundesregierung. Kempten: AZ Druck und Datentechnik GmbH.

Uekötter, Frank (2019): Kleine Geschichte der Klimadebatte. In: APuZ - Aus Politik und Zeitgeschichte, Heft 47-48, S. 10-15.

UN-Habitat (2010): The Right to the City: Bridging the urban divide. Report of the fifth session of the World Urban Forum Rio de Janeiro, Brazil. 22-26 March, 2010. Rio de Jainero: UN Habitat.

UN-Habitat III (2017): The Right to the City and City for all. Quito, Ecuador: United Nations.

van Vogt, Alfred Elton (1982): Welt der Null-A. München: Heyne.

Vereinte Nationen (1992): Rio-Erklärung über Umwelt und Entwicklung. Abschlusspapier der Tagung vom 3. bis 14. Juni 1992. www.un.org/Depts/german/conf/ agenda21/rio.pdf [Zugriff: 16.08.2019].

Vereinte Nationen (2015a): Resolution der Generalversammlung, verabschiedet am 25. September 2015. Transformation unserer Welt: die Agenda 2030 für nachhaltige Entwicklung.

Vereinte Nationen (2015b): Übereinkommen von Paris.

Vereinte Nationen (2019): Ziele für nachhaltige Entwicklung. Bericht 2019. New York: o. A.

Vester, Frederic (1986): Neuland des Denkens. Vom technokratischen zum kybernetischen Zeitalter. München: Deutscher Taschenbuch-Verlag.

Völker, Wolfgang (2013): Bedingunsgloses Grudneinkommen und Soziale Infrastruktur. In: Hirsch, J./Brüchert, O./Krampe, E.-M. (Hrsg.): Sozialpolitik anders gedacht. Soziale Infrastruktur. Hamburg: VSA-Verlag, S. 75-94. 
Vollmer, Lisa (2017): Keine Angst vor Alternativen. Ein neuer Munizipalismus. Über den Kongress „FearlessCities“, Barcelona 10./11. Juni 2017. In: sublurban. zeitschrift für kritische stadtforschung 5, Heft 3, S. 147-156.

Wagner, Felix (2017): Reallabore als kreative Arenen der Transformation zu einer Kultur der Nachhaltigkeit. In: Reinermann, J.-L./Behr, F. (Hrsg.): Die Experimentalstadt. Wiesbaden: Springer Fachmedien Wiesbaden, S. 79-94.

Walkenhorst, Oliver (2008): Klimapolitik. In: Haug, W. F./Haug, F./Jehle, P. (Hrsg.): Historisch-kritisches Wörterbuch des Marxismus. Bd. 7/I. Kaderpartei bis Klonen. Hamburg: Argument-Verlalg, S. 1035-1056.

Walther, Manfred (2009): Kommunalismus und Vertragstheorie. Althusius - Hobbes Spinoza - Rousseau oder Tradition und Gestaltwandel einer politischen Erfahrung. In: Blickle, P./Müller-Luckner, E. (Hrsg.): Theorien kommunaler Ordnung in Europa. München: Oldenbourg, S. 127-162.

Walther, Uwe-Jens/Günther, Simon (2007): Soziale Stadtpolitik in Deutschland: das Programm ,Soziale Stadt“. In: Baum, D. (Hrsg.): Die Stadt in der Sozialen Arbeit. Ein Handbuch für soziale und planende Berufe. Wiesbaden: VS Verlag für Sozialwissenschaften, S. 289-400.

Wark, McKenzie (2017): Molekulares Rot. Theorie für das Anthropozän. Berlin: Matthes \& Seitz Berlin Verlag.

WBGU (2011a): Ein Gesellschaftsvertrag für die Transformation. Factsheet Nr. $1 / 2011$. Berlin.

WBGU (2011b): Globale Megatrends. Factsheet Nr. 3/2011. Berlin.

WBGU (2011c): Welt im Wandel. Gesellschaftsvertrag für eine Große Transformation. Hauptgutachten. Berlin.

WBGU (2014a): Klimaschutz als Weltbürgerbewegung. Sondergutachten. Berlin.

WBGU (2014b): Zivilisatorischer Fortschritt innerhalb planetarischer Leitplanken. Ein Beitrag zur SDG-Debatte. Berlin.

WBGU (2016a): Der Umzug der Menschheit. Die transformative Kraft der Städte. Zusammenfassung. Berlin.

WBGU (2016b): Der Umzug der Menschheit. Die transformative Kraft der Städte. Hauptgutachten. Berlin.

WBGU (2016c): Entwicklung und Gerechtigkeit durch Transformation: die vier großen I. Sondergutachten. Berlin.

WBGU (2018): Zeit-gerechte Klimapolitik. Vier Initiativen für Fairness. Berlin.

Weber, Andreas (2018a): Indigenialität. Berlin: Nicolai Publishing \& Intelligence $\mathrm{GmbH}$.

Weber, Joachim (2018b): Warum die sozialpädagogische Sorge um die Kindeswohlgefährdung die Kindeswürde gefährdet. Einige Gedanken im Anschluss an Janusz Korczak. In: Widersprüche. Zeitschrift für sozialistische Politik im Bildungs-, Gesundheits- und Sozialbereich, Heft149, S. 89-100.

Weizsäcker, Carl Friedrich von (1989): Das philosophische Problem der Kybernetik. In: Die Einheit der Natur. Studien. München: dtv, S. 280-291.

Wendt, Wolf Rainer (2018): Wirtlich handeln in Sozialer Arbeit. Die ökosoziale Theorie in Revision. Opladen: Verlag Barbara Budrich.

Wex, Corell (2001): Logistik der Macht. Zur Staatstheorie Henri Lefebvres. In: ErnstBloch-Assoziation (Hrsg.): Der Staat als Retter der Utopie? Zur Kritik des Politischen im Zeitalter der „Globalisierung“. VorSchein, 20/21.2001. Berlin, Wien: Philo Verlagsgesellschaft mbH, S. 184-198. 
Widersprüche (Hrsg.) (2020): Dialogisches Handeln und Forschen. Mit Freire die neoliberalen Verwüstungen überwinden. Widersprüche. Zeitschrift für sozialistische Politik im Bildungs-, Gesundheits- und Sozialbereich, Heft 155. Münster: Westfälisches Dampfboot.

Widersprüche Redaktion (Hrsg.) (1983): Ökologische Sozialpolitik? Eine Auseinandersetzung, Heft 8. Offenbach: Verlag 2000.

Widersprüche Redaktion (1984): Verteidigen, kritisieren und überwinden zugleich! Alternative Sozialpolitik - Gegen Resignation und „Wende“. Ein Strategiepapier. In: Widersprüche. Zeitschrift für sozialistische Politik im Bildungs-, Gesundheits- und Sozialbereich, Heft 11.

Widersprüche Redaktion (1985): „Mindesteinkommen“ als soziale Garantien. In: Widersprüche. Zeitschrift für sozialistische Politik im Bildungs-, Gesundheitsund Sozialbereich, Heft 15.

Widersprüche Redaktion (Hrsg.) (1997): Gesellschaft ohne Klassen? Politik des Sozialen wider Ausgrenzung und Repression. Bielefeld: Kleine.

Widersprüche Redaktion (Hrsg.) (2005): Politik des Sozialen - Alternativen zur Sozialpolitik. Umrisse einer Sozialen Infrastruktur. Heft 97. Bielefeld: Kleine Verlag.

Widersprüche Redaktion (Hrsg.) (2006): Politik des Sozialen - Verhandlungen über Lebensweisen. Moralische Ökonomien heute. Heft 99. Bielefeld: Kleine.

Widersprüche Redaktion (Hrsg.) (2012): Einfach anders!? Ambivalente Alternativen der Vergesellschaftung, Heft 124. Münster: Westfälisches Dampfboot.

Wiener, Norbert (1977): Kybernetik. In: Bernsdorf, W. (Hrsg.): Wörterbuch der Soziologie. Band 2. Frankfurt (Main): Fischer, S. 490-492.

Winker, Gabriele (2015): Care Revolution. Schritte in eine solidarische Gesellschaft. Bielefeld: transcript Verlag.

Winkler, Michael (1988): Eine Theorie der Sozialpädagogik. Über Erziehung als Rekonstruktion der Subjektivität. Stuttgart: Klett-Cotta.

Winkler, Michael (2006): Kleine Skizze einer revidierten Theorie der Sozialpädagogik. In: Badawia, T./Luckas, H./Müller, H. (Hrsg.): Das Soziale gestalten. Über Mögliches und Unmögliches der Sozialpädagogik. Wiesbaden: VS Verlag für Sozialwissenschaften, S. 55-80.

Winkler, Michael (2014): Bildung als Lebensform. In: Erwägen - Wissen - Ethik. Forum für Erwägungskultur 25, Heft 2/2014, S. 344-346.

Winkler, Michael (2017): Not such politics, please! Verstreute Überlegungen. In: Braches-Chyrek, R./Sünker, H. (Hrsg.): Soziale Arbeit in gesellschaftlichen Konflikten und Kämpfen. Wiesbaden: VS Verlag für Sozialwissenschaften, S. 43-66.

Winkler, Michael (2018): Stationen der Diskussion: Eine historisch-systematische Betrachtung der Vielfalt und Wandelbarkeit von Theorien der Sozialen Arbeit. In: May, M./Schäfer, A. (Hrsg.): Theorien für die Soziale Arbeit. Baden-Baden: Nomos, S. 31-56.

Wissenschaftliche Dienste des Deutschen Bundestags (2019): Aktueller Begriff. Die Enteignung nach Art. 14 Abs. 3 GG und die Vergesellschaftung nach Art. 15 GG. Nr. 05/19. https:/www.bundestag.de/resource/blob/640256/7039208bc770dc8 73cecee22b17e06d3/Enteignung-nach-Art-14-data.pdf [Zugriff: 02.12.2019].

Wolf, Frieder Otto (2009): Den Green New Deal nicht ablehnen, sondern Instandbesetzen! Für eine sozial-ökologische Transformation. In: Zeitschrift LuXemburg, Heft 01/2009, S. 154-159. 
Wright, Erik Olin (2017): Reale Utopien. Wege aus dem Kapitalismus. Frankfurt (Main): Suhrkamp.

Wulf, Christoph (1989): Mimesis. In: Gebauer, G. (Hrsg.): Historische Anthropologie. Zum Problem der Humanwissenschaften heute oder Versuche einer Neubegründung. Reinbek: Rowohlt, S. 84-125.

Wulf, Christoph (1994): Mimesis in der Erziehung. In: Wulf, C. (Hrsg.): Einführung in die pädagogische Anthropologie. Weinheim: Beltz, S. 22-44.

Wulf, Christoph (1997): Mimesis. In: Wulf, C. (Hrsg.): Vom Menschen. Handbuch historische Anthropologie. Weinheim: Beltz, S. 1015-1029.

Wulf, Christoph (2014): Mimesis. In: Wulf, C./Zirfas, J. (Hrsg.): Handbuch pädagogische Anthropologie. Wiesbaden: Springer VS, S. 247-257.

Wulf, Christoph (2020): Bildung als Wissen vom Menschen im Anthropozän. Weinheim: Beltz Juventa.

Zelený, Jindrich (1972): Zum Wissenschaftsbegriff des dialektischen Materialismus. In: Schmidt, A. (Hrsg.): Beiträge zur marxistischen Erkenntnistheorie. Aufsätze von György Márkus, Jindrich Zelený, E. W. Iljenkow, Hans-Georg Backhaus, Henri Lefebvre, Alfred Schmidt. Frankfurt (Main): Suhrkamp, S. 73-86. 
Stefanie Debie

Fabian Lamp

Kristin Escher

Claudia Spindler (Hrsg:)

\section{Fachdidaktik}

Soziale Arbeit

Fachwissenschaftliche

und lehrpraktische Zugänge

Stefanie Debiel | Fabian Lamp

Kristin Escher | Claudia Spindler (Hrsg.)

\section{Fachdidaktik Soziale Arbeit}

Fachwissenschaftliche und lehrpraktische Zugänge

Theorie, Forschung und Praxis der Sozialen Arbeit, Band 20

2020. 295 Seiten $\cdot$ Kart. $\cdot 34,00 €(D) \cdot 35,00 €(A)$

ISBN 978-3-8474-2402-4 • eISBN 978-3-8474-1526-8

Das Thema Didaktik findet zunehmend Beachtung in der Hochschullehre. Welche fachdidaktischen Herausforderungen sehen sich Disziplin und Profession der Sozialen Arbeit gegenüber? Im Zentrum des Buches stehen Lehrkonzepte zur Vermittlung von fachbezogenen Theorien und zur Reflexion von Praxisphasen. Das Buch vermittelt den Leser*innen theoretische Kenntnisse, bietet darüber hinaus aber auch methodisch-didaktische Konzepte zur Gestaltung konkreter Lehrveranstaltungen. 
Julia Franz

Ursula Unterkofler (Hrsg.)

Forschungsethik

in der Sozialen Arbeit

Prinzipien und Erfahrungen

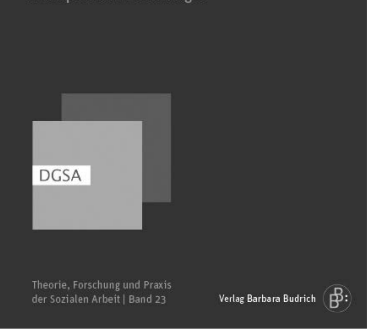

Julia Franz

Ursula Unterkofler (Hrsg.)

Forschungsethik in der Sozialen Arbeit

Prinzipien und Erfahrungen

$2021 \cdot 285$ Seiten $\cdot$ Kart. $\cdot 28,00 €(D) \cdot 28,80 €(A)$

ISBN 978-3-8474-2493-2 • eISBN 978-3-8474-1637-1

Theorie, Forschung und Praxis der Sozialen Arbeit, Band 23

Zum Kern der empirischen Forschung Sozialer Arbeit gehören die Methoden der Befragung und Beobachtung von Menschen. Dabei sind ethische Kriterien anzulegen, die vielfältige Fragen und Dilemmata in der Planung und Umsetzung von Forschung sowie im Umgang mit Forschungsergebnissen aufwerfen.

Der Sammelband legt einen Schwerpunkt auf forschungspraktische ethische Herausforderungen. In den Beiträgen wird der Forschungsethikkodex der DGSA präsentiert und kommentiert, disziplinär eingeordnet und ethisch reflektiert. 


\section{Gesellschaft und Nachhaltigkeit,}

Bettina Stoll I Heike Herrmann (Hrsg.)

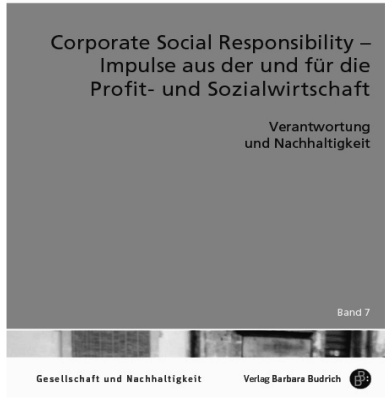

Bettina Stoll

Heike Herrmann (Hrsg.)

Corporate Social

Responsibility -

Impulse aus der und

für die Profit- und

Sozialwirtschaft

Band 7. 2020. Ca. 140 Seiten • Kart. • Ca. 22,00€(D) •22,70€(A)

ISBN 978-3-8474-2400-0 • auch als eBook

Unternehmen in Profit- und Sozialwirtschaft tragen ökonomische, ökologische und soziale Verantwortung, auch als Corporate Social Responsibility bezeichnet. Um dieser - ggf. auch durch Kooperationen - entsprechen zu können, bedarf es Aushandlungsprozesse, kluger Wirtschafts- und Sozialkonzepte, Unternehmenskonzepte und Wege zur Verankerung des nachhaltigen Leitbilds in den Institutionen. Der Band setzt dazu Impulse für die Profit- und Sozialwirtschaft. 
Während Begriffe wie Klimawandel und sozial-ökologische Transformation zum festen Bestandteil der fachlichen wie alltäglichen Kommunikation geworden sind, ist es weder der Disziplin noch der Profession Sozialer Arbeit bislang gelungen, sich fachlich und öffentlichkeitswirksam an dieser Diskussion zu beteiligen. Der Autor geht auf theoretischer Ebene der Frage nach, wie sich daran etwas ändern ließe und womit sich Soziale Arbeit in der Diskussion positionieren könnte.

Der Autor:

Dr. phil. Marcel Schmidt, Vertretungsprofessor

für Theorien Sozialer Arbeit, Fachbereich Sozialwesen, Hochschule RheinMain, Wiesbaden

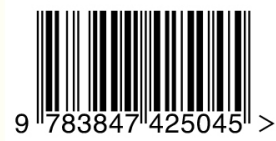

www.budrich.de 